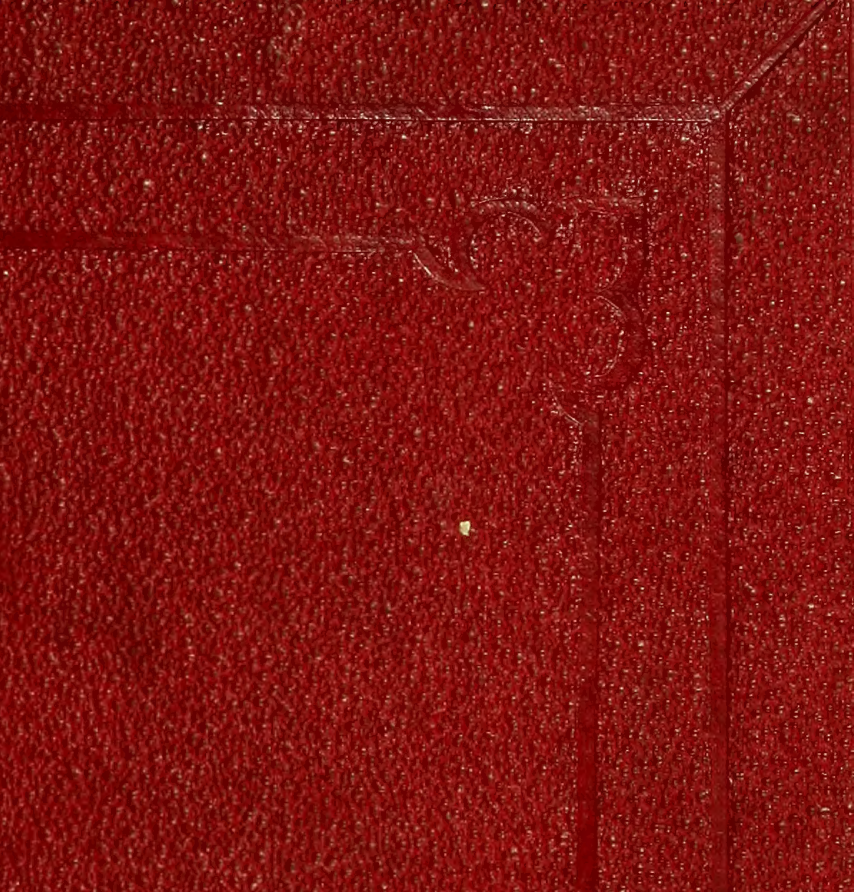


689.1 
Digitized by the Internet Archive in 2015 


LE MONDE

DE LA MER 




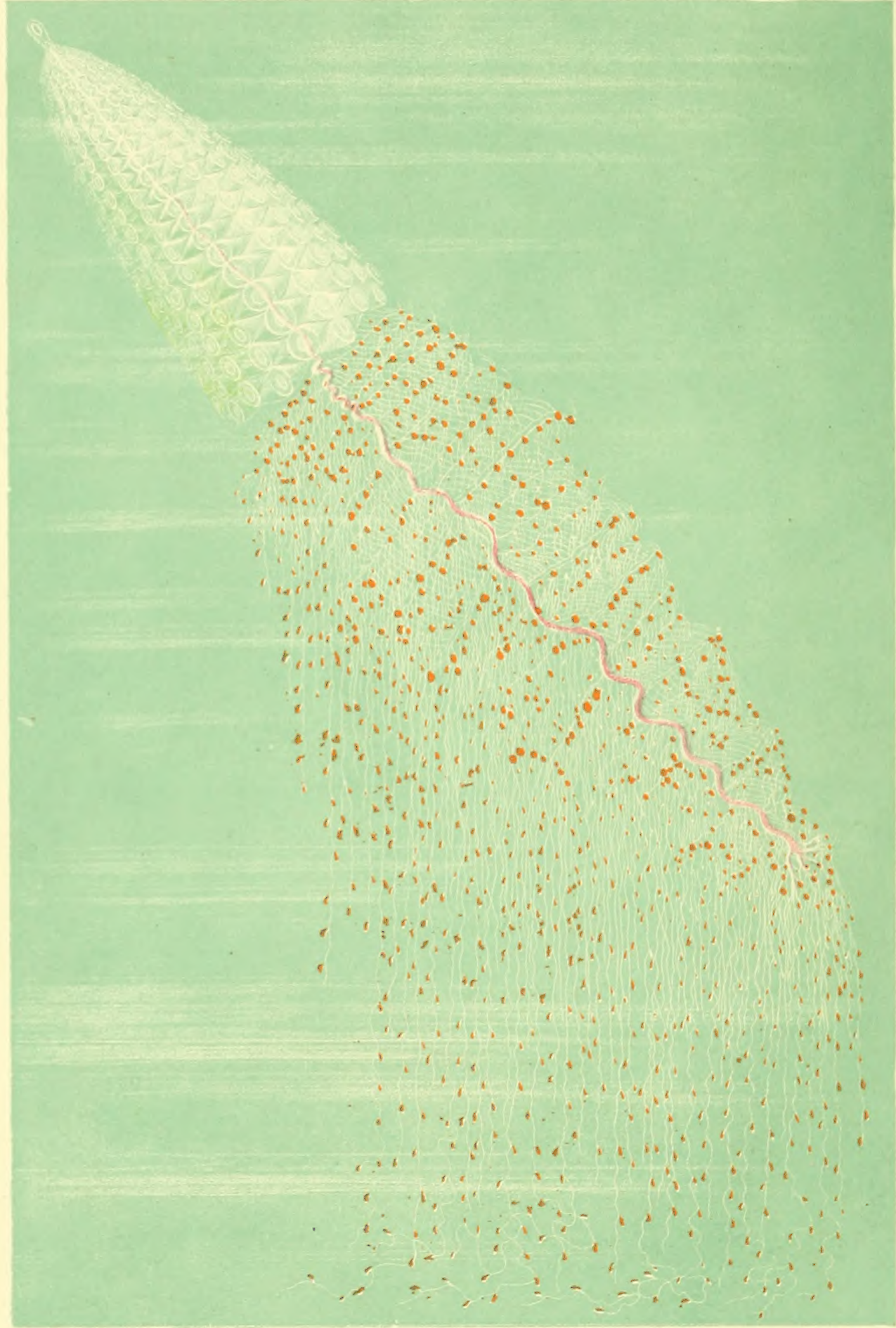

P Lackerbauer Chr.Lith. d'apres C.Vog t. 



\title{
LE NONDE
}

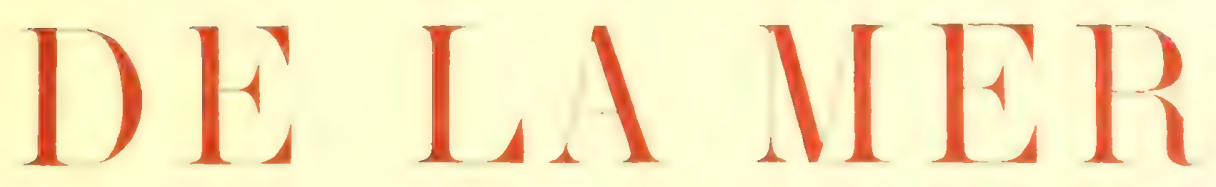

$P \wedge R$

\section{ALFRED FREDOI.}

\author{
IIE 2? PLANGHES TIREES EN COULEUR

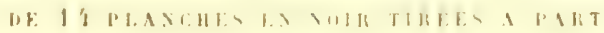

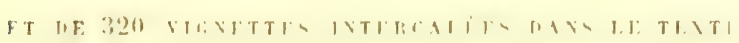

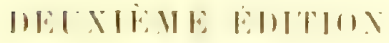

\section{PARIS}

1.11:1111111. 111. 1. 1114.111:111 1.11

BOULEVARI SAINT-GERMAIN, NO 77

1866 



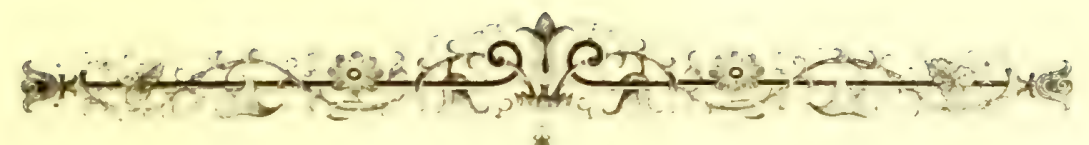

\section{PREFICE}

IIE I.I PREMIIRE IMTIU.

Le Momele de ln mer est l'neuvre posthime d'un savant dont la carriere a ble comsarerere anx phos sérieuses spéculations de la science.

Lamteur sest proposé, commer délassement a des

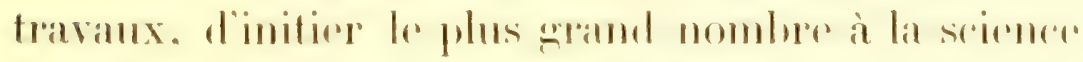
quil coltivait avere amone of qui fut la gramde passion de sa vir. Il a rassemblete, dams une histoire naluredle

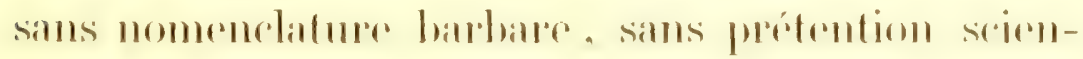
lificfur, sans anatomice propoussante, an nombere considerable de faits interessants of daperens nonveaux.

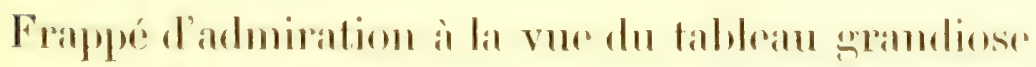

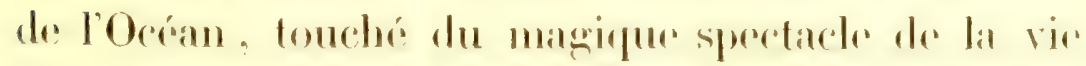


des eaux, l'auteur peint le monde de la mer dans son luxe et ses agitations.

Il décrit les êtres avec originalité et poésie; il expose leurs développements et leurs métamorphoses, leurs ruses et leurs industries, leurs combats et leurs amours; il insiste sur les produits de la mer, sur l'abondance de ses fruits, sur l'utilité de sa culture; parfois il descend dans la description des organismes, et fait «admirer, et la magnificence de l'Exécution, et la simplicité du Dessin ».

La mort a surpris l'anteur alors que ce livre était presque terminé. Sa famille s'est fait un pieux devoir de le publier tel qu'il l'a laissé, et de respecter, à tous égards, ses dernières volontés. Le Nonde de la mer a paru sous le pseudonyme d'A. FrénoL, l'auteur du Noyer de Maguelome, des Jujubes de Monto pellier, ete.

Des savants distingués, des amis, ont obligeamment contribué au Monde de la mer. MM. C. Vogt, de Genève; Is. Geoffroy Saint-Hilaire, Coste, de Quatrefages, E. Blanchard, Deshayes, Lacaze-Duthiers; P. H. Gosse, d'Angleterre; Sabin Berthelot, des îles Canaries; Aug. Duméril, Gerbe, Lespés, AuziasTurenne....., ont communiqué des notes curieuses 
ou importantes, et des dessins inédits d'animaux parfois inconnus.

M. Gudin et M. Biard ont bien voulu permettre la reproduction de leurs tableaux de la Mer calme, de la Mer agitée et de la Chasse aux Morses.

Que ces savants et ces artistes recoivent l'expression d'une gratitude que l'auteur eût été heureux de leur témoigner lui-même.

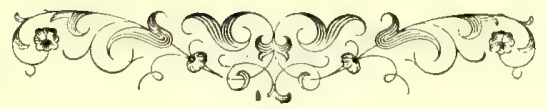





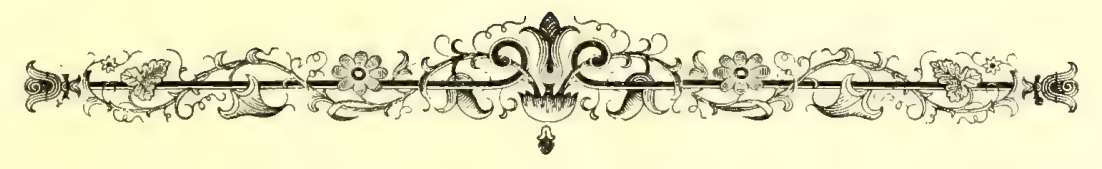

\section{AVERTISSENENT}

DL LA DEUXIEME ÉDITION

L'accueil fait au Monde de la mer nous engage à publier aujourd'hui cette seconde édition, que nous avons cru devoir enrichir des conquêtes nouvelles de la science et des progrès récents de la culture des eaux.

Un long séjour sur les bords de la mer, dans les laboratoires de Concarneau, nous a permis d'ajouter des observations nouvelles, et de donner, d'après nature, un plus grand nombre de dessins.

L'ouvrage est en outre augmenté d'un aperçu du développement des ètres; on peut suivre dans une série de planches les phases successives de leur formation. 
Les savants et les amis qui s'étaient intéressés à la première édition du Monde de la mer ont bien voulu continuer leur précieux concours.

Nous devons surtout des remerciments à MM. Coste, Milne Edwards, Gratiolet, Lacaze-Duthiers, Charles Robin, Gerbe, Lespés, L. Hautefeuille, Sabin Berthelot, Balestrier, qui nous ont aidé de leur science et de leurs découvertes, et ont mis à notre disposition des dessins originaux.

Puisse le lecteur retrouver dans ce tableau de la vie des eaux un peu du coloris du Modèle!

\section{OLIVIER FRÉDOL.}

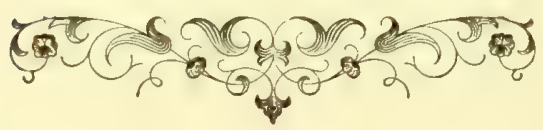




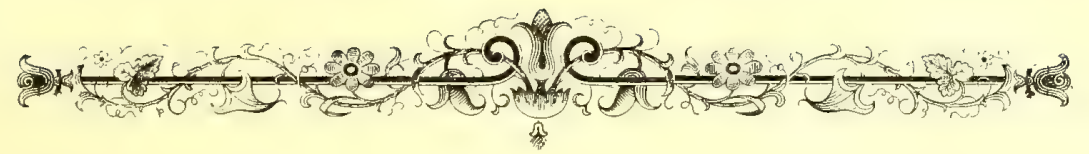

\section{CHAPITRE PREMIER}

\section{GONSIDERATIONS GENÉRALES.}

"Il nomma aussi l'amas des eiux, neers; et Dieu vit que cela étoit bon."

(Genèse.)

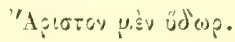

(PIndare.)

Tout le monde sait que la mer couvre à peu près les deux tiers de la surface de la terre. Voici le calcul exact donné par les savants. La surface de la terre est évaluée à こ̌ 098857 myriamètres carrés. La partie occupée par les eaux est de 3832558 myriamètres carrés environ, et celle qui compose les continents et les îles, de 1266 299. D'où il suit que la surface baignée est à la surface non baignée comme 3,8 est à 1,2. Par conséquent, l'eau recouvre un peu plus des sept dixièmes ou un peu moins des trois quarts de la surface entière.

A la surface du globe, l'eau est la généralité, la terre est l'exception. (Michelet.)

Ce volume d'eau est divisé par les géographes en cinq grands océans: le Glacial arclique, l'Atlantique, l'Indien, le Pacifique et le Glacial antarclique. 
L'océan Giacial aretique s'étend depuis le pòle jusqu'au cercle polaire; il est situé entre l'Asie, l'Europe et l'Amérique.

L'océan Atlantique conmence au cercle polaire aretique et arrive jusqu'au cap llorn. Il est situé entre l'Amérique, l'knrope et l'Afrique. Il présente une longueur d'environ 9000 milles, sur une lirgenr moyenne de 2700. 11 couve une surface de 2.5 millions de milles carrés. Il est situé entre l'ancien et le nouveau monde. Au dela do cap des Tempètes, il n'est plus séparé que par une ligne imaginaire des vastes mer's du Sud, immenses plaines où prennent naissance les ondes qui sont la principale source des marées, et qui se propagent en gramdes vagues à travers l'Atlantique. (Maury.)

L'océan Indien est borné au nord par l'Asie, à l'ouest par l'Afripue, et à lest par la presifu'ile de Malacea, les iles de la Sonde et l'Australie.

L'océan Pacifinge, on griand Ocram, sétend du nord au sud, depuis le cercle polaire aretique jusqu'au cerele polare antaretirue. Il est borné d'un còté par l'Asie, les îles de la Somle et l'Australie, et de l'autre par l'Amérique. Cet océan contraste d'une maniere frappante arec l'Atlantique. L'un a sa plus grande dimension nord et sud; l'autre, est et onest. Les conrants du premier sont larges et lents; ceux du second, étroits et rapides. Les marées de celui-ci sont trèsbasses; celles de celui-là, tris-hautes. Si l'on représente le volume des eaux pluviales qui tombent dans le Pacifique par J, celui que recoit l'Itlantique sera représenté par un cimquième. L'océan Pacifique est la plus tranquille des mer's; l'océan Atlantique est la plus orageuse.

L'océan Gilacial antaretique s'étend depuis le cercle polaire antaretique jusqu'au pòle austral.

Il est remarquable qu'une moitié du globe soit entière- 


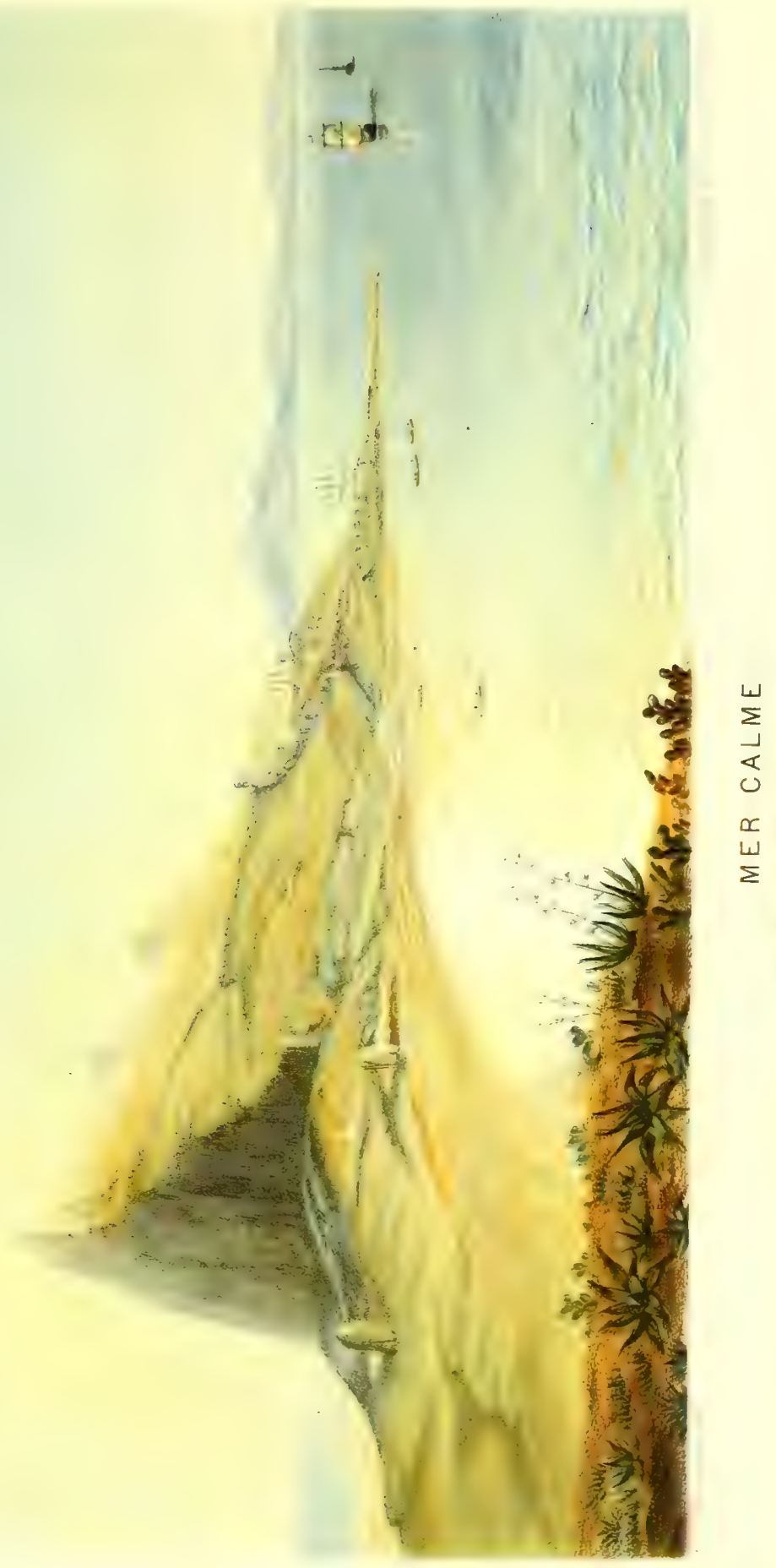



ment couverte d'eau, tandis que l'autre contient inoins d'eau que de terre. De plus, la distribution des mers et des terres est encore très-inégale, si, en faisant abstraction de la forme des bassins océaniques, on compare les hémisphères séparés par l'équateur, et les moitiés boréale et australe du globe.

Les océans communiquent avec les continents et les îles par des côtes, lesquelles sont dites escarpées, quand un sol

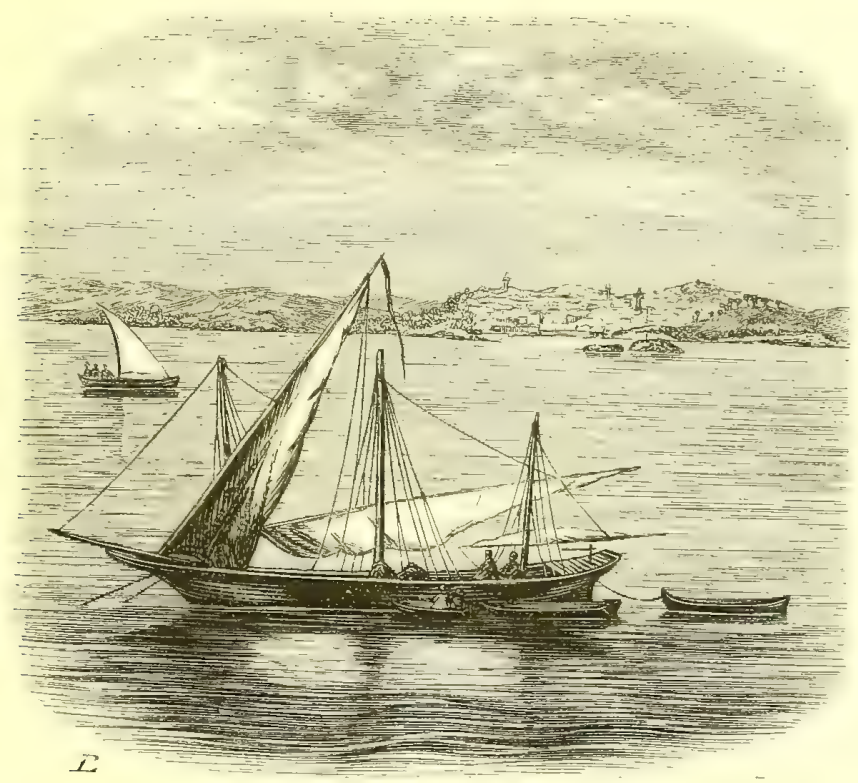

de roche s'étend et arrive brusquement jusqu'aux rivages, comme en Bretague, en Norvége et en Écosse. Dans ce genre de còtes, certaines sont dentelées, c'est-à-dire ceintes de rochers, soit au-dessus, soit au-dessous de l'eau, formant souvent des labyrinthes d'iles. D'autres s'enfoncent tout d'un coup, laissent la mer libre, et produisent des falaises : telles sont les còtes de la Manche. Les côtes sont dites basses, quand elles sont formées par des terrains argileux 
ef mous yui s'abaissent en pentes douces. On eu distingue de deux sortes, celles par collines et celles par dunes.

\section{II}

Quelle est la profondeur de la mer? Il est bien difficile de répondre exactement à cette question, à cause des grandes difficultés ‘fu'on rencontre dans les sondages, déterminées par les déviations des courants sous-marins.

Laplace a trouvé, par des considérations astronomiques, ¿que la profondeur moyenne de l'Océan ne peut pas dépasser 3000 mètres. Ilumboldt admet le même chiffre. Le docteur Young attribue à l'océan Atlantique une profondeur moyenne d'environ 1000 mètres, et à l'océan Pacifique une profondeur de 4000.

Dupetit-Thouars, pendant son voyage scientifique sur la frégate la Vénus, a exécuté deux sondages très-remarquables. L'un, dans le grand Océan méridional, n’a pas domné de fond à 2411 brasses, c'est-à-dire à un peu moins de 1000 mètres; le second, daus le grand Océan équinoxial, a indiqué un fond à 3790 .

Dans la dernière expédition à la recherche d'un passage au pôle nord-ouest, le capitaine Ross n'a pu, par $76^{\circ}$ et $77^{\circ}$ de latitude nord, rencontrer le fond ì une profondeur de 9143 mètres.

Le lieutenant américain Walsh a trouvé, non loin des côtes des États-Unis, une profondeur de 10 424 mètres: c'est la plus grande tre l'on connaisse; elle est supérieure ì la hauteur des sommets les plus élevés de l'Inde et de l'Amérique.

La profondeur de la Méditerranée n'est pas considérable. Entre Gibraltar et Ceuta, le capitaine Smith a compté 1710 mètres, et seulement de 915 à 293 dans les parties 
les plus resserrées du détroit. Près de Nice, Saussure a rencontré le fond à 990 mètres. On dit que ce fond est moins bas dans la mer Adriatique, et qu'il n'arrive qu'à 44 mètres entre les côtes de la Dalmatie et l'embouchure du Pô.

La mer Baltique est une des mers les moins profondes du globe. Son maximum ne dépasse pas 200 mètres.

Le fond de la mer parait avoir des inégalités semblables à celles qu'on observe à la surface des continents. Il y a des montagnes et des vallées, des collines et des plaines.

\section{III}

Quelques auteurs ont calculé que toutes les eaux de la mer réunies formeraient une sphère de 50 à 60 lieues de diamètre, et, en supposant la surface du globe parfaitement unie, ces eaux la submergeraient d'environ 200 mètres.

En admettant que la profondeur moyenne de la mer soit de 4000 mètres, on a calculé que l'Océan doit contenir à peu près deux milliards deux cent cinquante millions de milles cubes d'eau. On croit que si la mer était mise à sec, tous les fleuves de la terre devraient verser leurs eaux pendant 40000 ans pour en combler de nouveau le bassin.

\section{IV}

Si nous imaginons le globe entier divisé en 1786 parties égales en poids, nous trouverons approximativement que le poids total des eaux de l'Océan est équivalent à une de ces parties. (J. Herschel.)

Le poids spécifique de l'eau de la mer est un peu au-dessus de celui de l'eau douce. Tandis que celle-ci pèse un kilogramme par litre, ou 1000 kilogrammes par mètre cube, l'eau de la mer pèse 1027. 
La mer Morte, ne recevant pas assez d'eau donce pour se maintenir au niveau des mers voisines, acquiert un degré de salure plus considérable, et pèse 1228 kilogrammes au lieu de 102\%.

Le poids spécifique de l'eau de la mer est à peu près celui du lait de femme.

A une grande distance du rivage, l'Océan parait bleu et le plus souvent d'une belle couleur d'azur (caruleum mare). Cette teinte s'arloucit insensiblement jusqu'à ce qu'elle se confonde avec le ciel. Tout près de la côte, elle devient d'un vert plus ou moins glauque ef plus ou moins brillant. II y a des jours où l'Océan se montre un peu livide, et d'autres jours où il est d'un vert assez pur. Mise dans un vase, l'eau de la mer paraît transparente et sans couleur. D'après Scoresby, les régions polaires sont d'une teinte bleu d'outremer. Suivant Costaz, la Méditerranće est bleu céleste. Suirant Tuckey, l'Atlantique équinoxial est d'un bleu vif.

Phusieurs causes locales influent sur la couleur des eaux marines. L'eau semble blanche dans le golfe de Guinée, jaunâtre près du Japon, verdâtre à l'ouest des Canaries, et noire antour des îles Maldives. La Méditerranée, vers l'Archipel, devient quelquefois plus ou moins rouge. La mer Vermeille, près de la Califor'nie, présente une teinte analogue.

Les noms de mer Blanche et de mer Noire paraissent provenir senlement des glaces de la première de ces deux mers et des tempêtes de la seconde.

Près des côtes où de fortes marées agitent un fond vaseux ou sablonneux, la teinte de la mer devient plus ou moins grisâtre; mais, quand dans les eaux les plus pures et les plus calmes, la couleur jaunâtre du fond se laisse voir ì 
travers l'azur du liquide, il en résulte une teinte verte que les rayons du soleil nuancent quelquefois de reflets brillants, comme les feux de l'émeraude et du saphir.

Quand on descend dans l'Océan, on voit s'évanouir peu à peu les teintes azurées. A l'éclat du jour succède une lumière douce et uniforme; bientôt, on entre dans un crépuscule rougeàtre et terne; les couleurs se fondent, s'assombrissent, et l'on arrive par degrés à une nuit profonde.

\section{VI}

La mer présente une salure particulière, légèrement âcre, mèlée à une amertume un peu nauséabonde. Elle a une odeur sui generis. Elle est faiblement visqueuse.

On sait que l'eau pure est le produit de la combinaison de 1 volume d'oxygène et de 2 volumes d'hydrogène. Ce qui fait, en poids, 100 oxygène et 12,30 hydrogène. L'eau de la mer est composée de même; mais on y trouve, en sus, d'autres éléments dont les chimistes nous ont révélé la présence. Sur 100 grammes d'eau de l'océan Atlantique, l'analyse a montré :

\begin{tabular}{|c|c|}
\hline 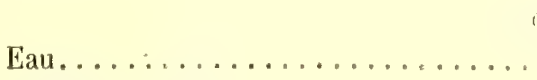 & $\begin{array}{l}\text { rammes. } \\
96,470\end{array}$ \\
\hline Chlorure de sodium............. & 2,700 \\
\hline Chlorure de magnésium........... & 0,360 \\
\hline Chlorure de potassium.... & 0,070 \\
\hline Bromure de magnésium. ........... & 0,002 \\
\hline Sulfate de magnésie............. & 0,230 \\
\hline Sulfate de chaux.......... & 0,140 \\
\hline Carbonate de chaux..... & 0,003 \\
\hline Résidu. . . . . . . . . . & 0,025 \\
\hline
\end{tabular}

Outre ces substances, on a découvert encore, dans l'eau de la mer, en quantité minime il est vrai, de l'iode, du soufre, de la silice, de l'ammoniaque, du fer et du cuivre. 
En examinant, à Valparaiso, des feuilles de cuivre retirées de la carène d'un bàtiment depuis longtemps submergé, on y a constaté des traces d'argent déposées par la mer.

Enfin, on trouve encore, en dissolution dans les eaux de l'Océan, une mucosité particulière, qui semble de nature végéto-animale, matière organique provenant de la décomposition successive des innombrables générations qui ont paru et disparu depuis l'origine du monde vivant. Cetle matière a été parfaitement décrite par lo comte Marsigli, qui la désigne tantòt sous le nom de glu, tantôt sous celui d'oncluosité.

Les sels nombreux qui existent dans l'Océan ne peuvent ni se déposer dans son lit, ni être enlevés par les vapeurs pour être restitués au sol par les pluies. Des agents particuliers les retiennent, les trausforment et les empêchent de s'accumuler. De cette manière, les eaux possèdent toujours le même degré de salure et d'amertume, et l'Océan d'aujourd'hui présente les mêmes caractères chimiques ou physiques que l'Océan d'autrefois.

D’après les calculs du professeur Schafhäutl, de Munich, le total des sels contenus en dissolution dans la mer donnerait une masse de 4 millions et demi de lieves cubes. Le sel commun en compose, à lui seul, dans cette masse, 30.31312 , ce qui fait un corps d'un tiers plus petit que l'Himalaya et cinq fois aussi considérable que les Alpes.

La salure de la Méditerranée est plus forte que celle de l'Océan, probablement parce que cette mer perd, par l'évaporation, plus d'eau qu'elle n'en reçoit de ses fleuves. Par' une raison contraire, la mer Noire et la mer Caspienne sont moins chargées de sel. La mer Morte renferme une quantité de sel si considérable, qu'un homme reste en suspension à sa surface comme un morceau de liége sur l'eau douce.

La salure de la mer semble en général moindre vers les 
pôles que sous l'équateur. Cependant il y a des exceptions pour certains pays.

Dans la mer d'Irlande, près du Cumberland, l'eau contient, eu sel, le $40^{\mathrm{e}}$ de son poids; sur les còtes de la France, le $32^{\circ}$; dans la mer Baltique, le $30^{\circ}$; sur les côtes de Ténériffe, le $28^{\circ}$, et sur celles de l'Espagne, le $16^{\mathrm{e}}$.

En plusieurs endroits la mer est moins salée à la superficie qu'au fond.

Dans le détroit de Constantinople, la proportion est de 72 à 62; dans la Méditerranée, de 32 à 29 . On prétend qu’en augmentant de salure, à une certaine profondeur, la mer diminue d'amertume. A l'embouchure des grands fleuves, il est à peine besoin de le dire, la mer est toujours moins salée que sur les côtes qui ne reçoivent aucun cours d'eau donce.

\section{VII}

L'Océan est sans cesse agité. Son immense surface se soulève et s'abaisse, comme si elle était donée d'une douce respiration (Schleiden). Ses mouvements, faibles on puissants, lents ou brusques, sont déterminés d'abord par des différences de température.

La chaleur change le volume, et par suite le poids de l'eau, qui se dilate ou se resserre.

A mesure qu’i] se refroidit, le liquide devient plus lourd et descend dans les profondeurs, jusqu à ce qu'il soit arrivé à 4․,25, température qu'il conserve sous toutes les latitudes, à 1000 mètres de profondeur. (D'Urville.)

Si l'eau continue à se refroidir et si elle arrive à zéro, elle devient plus légère qu'elle n'était à 10,20 , et elle remonte; de sorte que la congélation, par suite d'une admirable prévoyance de la nature, ne peut avoir lieu qu'à la surface. 
Tant que la température est au-dessus de $4^{\circ}, 25$, l'ean chaude et légère se transporte à la surface, et l'eau froide descend dans le fond. A partir de $4^{\circ}$, 25 et au-dessous, l'opposé a lieu : les couches froides montent, et les chaudes descendent à leur tour. Le premier phénomène se passe surtout sous les tropiques, et le second près des pồles; d'où résultent, d'une part, le refroidissement, et, de l'autre, la persistance d'une température moins basse dans les profondeurs des mers les plus chaudes ou les plus froides.

De l'élévation des couches chaudes provient l'évaporation qui forme les nuages, et les pertes que les mers éprouvent, par cela même, sont sans cesse compensées par les courants d'eau froide venus des pôles.

I'un antre còté, les pluies produites par les nuages condensés sout plus chaudes ou plus froides que les couches supérieures de la mer. Daus le premier cas, l'eau tombéc reste à leur surface; dans le second, elle descend.

Les eaux des fleures agissent aussi par leur température, par leur légèreté spécilique et par leur impulsion.

Les mouvements de l'air, les vents et les ouragans exercent encore mue influence manifeste sur les agitations de l'eau.

Enfin, les attractions combinées de la lune et du soleil entrainent, chaque jour, autour du globe, deux ondes immenses qui, ver's les nouvelles et les pleines lunes, s'élivent a leur plus grande hauteur, et baignent les parties du rivage ordinairement découvertes. Ces grands mouvements sont désignés sous le nom de marées. Durant une moitié de l'année, les plus hautes marées ont lien pendant le jour, et durant l'autre moitié, pendant la nuit.

Les marées, en plein Océan, ne s'élèvent qu'à une hauteur de 65 centimètres à un mètre. Mais, à la rencontre des continents, qui leur font obstacle, elles envahissent le 

littoral avec la vitesse d'un torrent, et montent à mo hauteur qui varie depuis 3 mètres jusqu’à 20. Ces courants quotidiens balayent et purifient nos rivages, nos rades, nos ports, les embouchures de nos fleuves, répandent partout me fraicheur vivifiante et salutaire. Soumis aux influences des corps célestes que des millions de lieues séparent de nous, ils n'en ont pas moins, dans leurs retours périodiques, toute la régularité mathématique du mouvement de ces

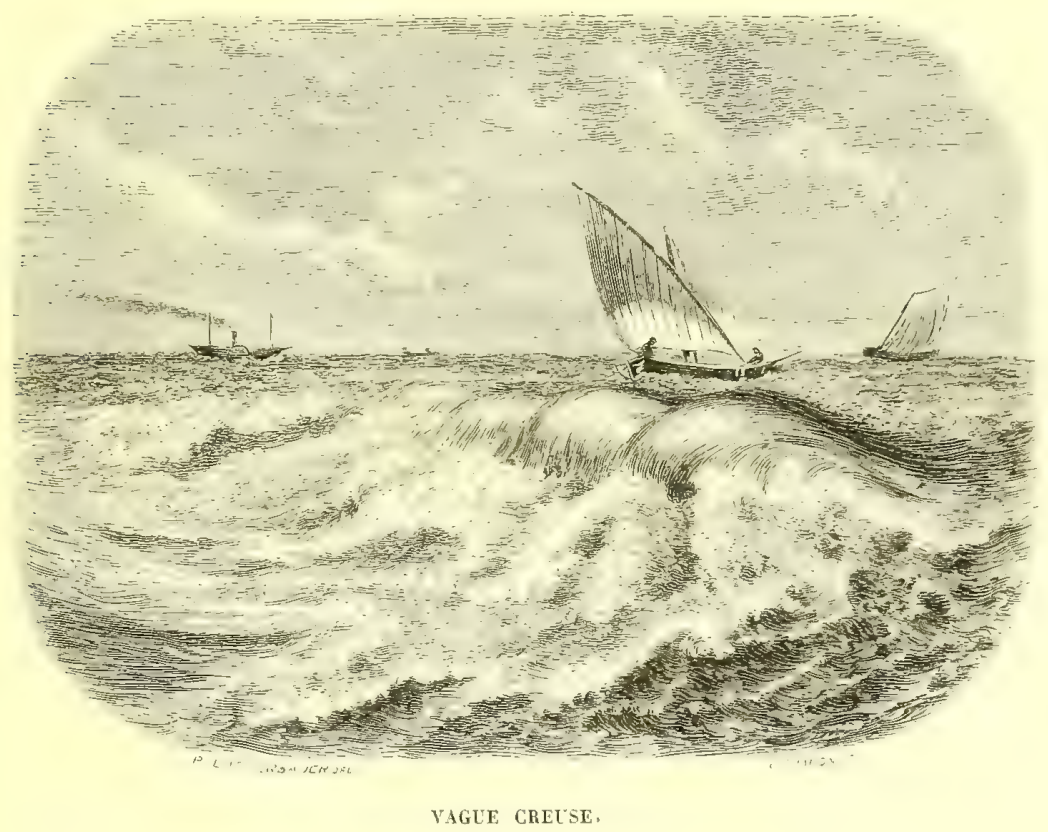

corps. L'énorme volume d'eau qu'ils soulèvent, et qui renverserait les plus formidables barrières, s'arrète doucement au moment prévu, sans dépasser la limite qui lui est tracée. (Maury.)

Parmi les beaux spectacles de la mer, il faut placer les vagues, avec leur marchẹ incessante et régulic̀re, leur mugissement continu et monotone, et leur écume impatiente et fugitive, qui monte, descend, remonte, et vient mourir sur 
le rivage. Quelquefois la lame est lancée dans les falaises; mais, à la marée basse, elle retourne dans son lit, en formant mille cascades, mille ruisseaux, mille petites veines sinueuses.

Le volume et la puissance des vagues augmentent avec l'épaisseur de l'eau. On peut mème, connaissant leur grandeur et leur vitesse, dans une région donnée, en déduire jusqu'à un certain point la profondeur de l'eau dans cette région. (Airy.)

La hauteur des vagues ordinaires peut aller jusqu'à 11 mètres. Leur force vient à bout des roches les plus dures; elle use leurs débris et finit par les arrondir; elle ballotte les galets, les froisse, les polit, les atténue et les réduit en sable fin, qui s'accumule dans les abìmes de la mer ou se dépose sur ses rives.

Les vagues les plus fortes heurtent les escarpements sousmarins et tendent à s'élancer en fusées; mais, arrêtés et déviés par les couches d'eau qui les couvrent, ces courants ascendants se changent en flots de fond, lesquels se meuvent avec une effrayante vitesse et déferlent contre la plage avee une puissance irrésistible. Pendant la tempète de 1822, dans la baie de Biscaye, les vagues, parties des rochers d'Arta, avaient jusqu'à 100 mètres d'amplitude, et par' conséquent parcouraient 20 mètres par seconde. Elles marchaient donc deux fois plus vite qu'une locomotive faisant dix lieues à l'heure. (Quatrefages.)

D'après le colonel Emy, les flots de fond agissent par une profondeur de 130 mètres, et peuvent élever, au-dessus du niveau de la mer, des colonnes d'eau de plus de 50 mètres de hauteur, de 2 à 3000 mètres cubes de volume, et pesant de 2 à 3 millions de kilogrammes. Ces flots de fond jouent un rôle considérable dans la plupart des phénomènes de l'Océan. On les rencontre dans toutes les mers. Ce sont eux, 
et non les ondulations de la surface, qui poussent jusqu'au rivage les galets, les sables, les débris des coquillages et tous les objets submergés. Ce sont eux encore qui, sur les bancs sous-marins, produisent ces brisants si redoutés des matelots, qui rendent quelquefois impraticables, même par les temps les plus calmes, la passe de certaines baies. (Emy).

C'est par les flots de fond qu'on a expliqué le singulier phénomène qui a lieu à l'embouchure des grands fleuves, appelé la barre par les mariniers de la Seine, mascarel par ceux de la Dordogne, et pororoca par les riverains de l'Amazone.

A la terminaison de ce dernier fleuve, lors des grandes marées des pleines et des nouvelles lumes, la mer, au lieu d'employer six heures à monter, atteint sa plus grande hauteur en deux ou trois minutes. Un flot de 4 à 5 mètres d'élévation s'étend sur toute la largeur du fleuve. Il est bientòt suivi de deux ou trois autres semblables, et tous remontent le courant avec un bruit effroyable et une rapidité telle, qu’ils brisent tout ce qui résiste, déracinent les arbres, et emportent de vastes étendues de terrain. Le pororoca se fait sentir jusqu'à 200 lieues dans l'intérieur des terres. (Adalbert.)

Un autre terrible tourbillon de la mer a été désigné sous le nom de mäström ou mälström : c'est une espèce de trombe permanente et éternelle qui se fait remarquer dans lesmers du Nord, entre Mosken et le cap sud de l'archipel de Lofoden, en Norvége. Lorsque les tempêtes de l'ouest poussent du large une mer houleuse, et que souffle une belle brise de terre, de grandes vagues, hautes comme des collines, accourent de tous les points de l'horizon, et se précipitent les unes sur les autres avec une fureur inouie, pour disparaître comme englouties dans un abìme. Le mäström attire les vaisseaux à une grande distance, et dès qu'on sent l'influence de son courant, on est irrévocablement perdu. II 
était très-redouté des anciens, qui le nommaient nombril de la mer ${ }^{1}$.

Les tremblements de terre donnent quelquefois naissance à des vagues gigantescues. Le 23 décembre $18 \%$, à neuf heures quarante-cinq minutes du matin, la frégate russe Diana, qui était à l'ancre dans la baie de Simoda, près de lédo (Japon), ressentit les premières atteintes d'un tremblement de terre. Quelques minutes après, une vague immense pénétra dans la baie, le niveau de l'eau s'éleva subitement, et la ville parut engloutic. Une seconde vague suivit la prenière, et quand toutes deux se furent retirées, il ne restait plus une maison debout. La frégate elle-même, qui avait talonnó plusieurs fois, finit par s'échouer sur le rivage. Or, le même jour, quel ques heures plus tard, sur la côte de Californie, à plus de 8000 kilomètres du Japon, les échelles de maréc conservèrent les marques de plusieurs vagues d'une hauteur excessive. Il est à croire que c'étaient les mèmes vagues qui avaient causé l'échouage de la Diana, lesquelles (on en a fait le calcul) devaient avoir une lar-

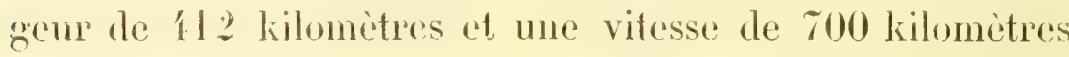
a l'heure. (Manry.)

Il existe dans les mers trois grands courants, qui prennent naissance, l'un dans le grand Océan, l'autre dans l'océan Itlantique, et le troisième dans la mer des Indes. Ces courants sont des espèces de fleuves marins immenses, qui déterminent des différences très-notables dans la température de beaucoup de régions.

Le premier a recu le nom de courant de Humboldt. Parti du pôle sud, il longe les côtes du Chili et du Pérou. Ce courant est froid.

1 En temps calme, le mälström est un fort courant ordinaire où les étrangers se promènent en bateau. 
Le courant de l'océan Atlantique atteint l'extrémité australe de l'Afrique, où il se partage en deux. La partie méridionale se détache de la côte et la contourne à distance. La branche nord suit la côte occidentale de l'Afrique, du sud au nord. Dans la région équatoriale, elle change de direction, traverse l'océan Atlantique dans sa plus grande largeur, de l'est à l'onest, et remonte la côte du Brésil, où elle se partage en deux. Ce courant est appelé courant équinoxial. Le courant nord suit les côtes du Brésil, de la Guyane, entre dans la mer des Antilles, se dirige vers la baie de Honduras, traverse le golfe du Mexique, et prend alors le nom de Gulfstream. Il sort par le canal de Bahama, et court, en s'élargissant et avec une grande rapidité, au nord-est. Sa vitesse est plus grande que celle du Mississippi ou de l'Amazone. On dit qu'il fait cing milles à l'heure. Il n'existe pas sur la terre un cours d'eau phs majestueux. Le Gulf-stream se jette dans l'océan Arctique. Ses dernières branches vont se perdre sur les côtes occidentales du Spitzberg. Ce courant est chaud. En longeant adroitement, avec sa barque, le bord de ce fleuve marin, un matelot pourrait tremper en mème temps l'une de ses mains dans l'eau chaude et l'autre dans l'eau froide.

On a vu le Gulf-stream amener jusque sur les còtes de l'Écosse les débris d'un vaisseau de guerre anglais, le Tilbury, qui fut détruit par un incendie dans le voisinage de la Jamaïque. (Schleiden.)

Le courant de la mer des Indes se dirige à l'est, et rencontre la côte occidentale de la Nouvelle-Hollande. Une partie de ses caux longe le sud de ce continent, et retombe dans le compant circulaire lu grand Océan. L'autre partie remonte au nord, suit l'équateur, de l'est à l'onest, descend au sud, en passant entre l'Afrique et Madagascar, contoume la pointe sud de l'Afrique, et va se jeter dans le courant de l'océan Atlantique. 
“L'eau, dans son mouvement, n'est pas seulement le principal, mais aussi le plus fort et le plus terrible des éléments. » (Pindare.)

\section{VIII}

La mer se congèle vers les pôles, et revêt alors un caractère tout particulier. Ce phénomène semble naître à mesure que la salure diminue et que le mouvement de rotation devient moins rapide. On rencontre déjà, vers le $40^{\circ}$ degré de latitude, de gros morceaux de glace flottant sur la mer. Ces morceaux ont été détachés de quelque région plus septentrionale et entrainés par les courants qui vont du pôle à l'équateur. A $50^{\circ}$, il est assez ordinaire de voir les bords de la mer se couvrir de glace. A $60^{\circ}$, les golfes et les mers intérieures se gèlent souvent sur toute leur surface. A $70^{\circ}$, les glaçons flottants deviennent très-nombreux et très-gros. Ils forment quelquefois de véritables îles, lesquelles penvent offrir jusqu'à une demi-lieue de diamètre. Enfin, vers le $80^{\circ}$ degré, on trouve génératement des glaces fixes, c'està-dire accumulées, arrêtées et soudées.

Les glaces polaires sont teintes des couleurs les plus vives: on dirait des blocs de pierres précieuses. On y trouve I'éclat du diamant et les nuances éblonissantes du saphir et de l'émeraude. Ces amas d'eau solide forment tantôt de vastes champs, tantôt des montagnes élevées.

Les champs de glace composent souvent des bancs immenses. Ces champs sont quelquefois parfaitement unis, sans fissure, ni creux, ni monticules. Scoresby en a vu un flottant, sur lequel une voiture aurait pu parcourir trentecinq lieues en ligne droite, sans le moindre empêchement. Cook en a trouvé un autre, étroit, qui joignait l'Asie à l’Amérique septentrionale. 


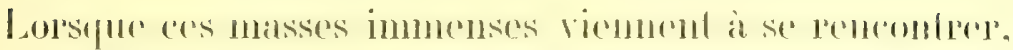
il en résulte des chocs épouvantables dont le fracas est semblable a colui du tonnerpe.

Les montagnes de glace sont produites par les îles. Ces

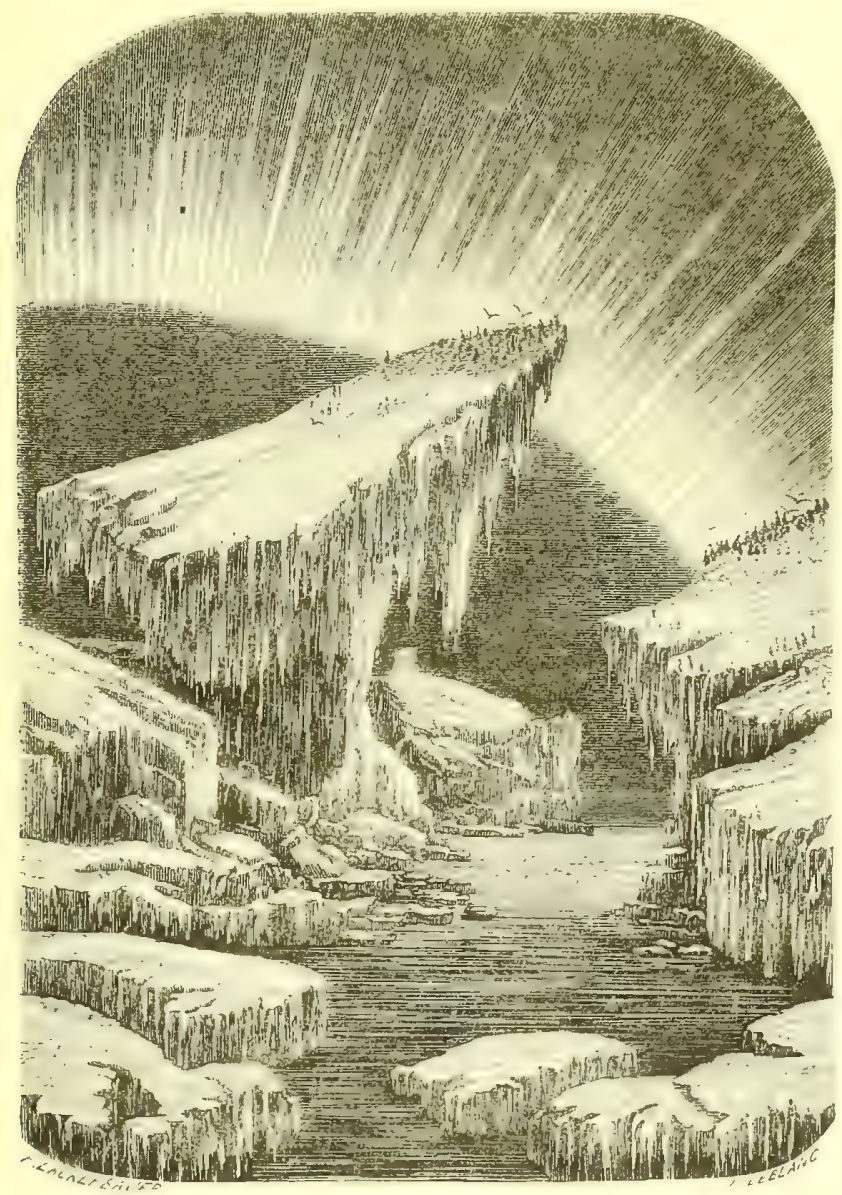

dernières, glissant les unes sur les autres, finissent par former des accumulations gigantesques qui s'élèvent jusqu'à 10 mètres. Ces masses flottantes, sans cesse minées par la

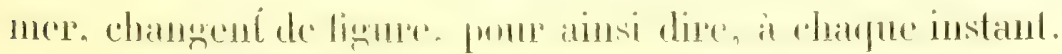


Elles se heurtent, se poussent, se brisent ou se soudent. Les montagnes de glace ont communément une surface carrée taillée à pic du côté de l'Océan. De loin, elles représentent de gigantesfues découpures blanches qui entament la voùte lileue du ciel. Vues de près, elles offrent une surface unie ou hérissée de mamelons. On dirait des pyramides de cristal ou de diamant, des colonnes élancées, des aiguilles pointues, ou bien des édifices bizarres et majestucux, avec des areades, des frontons, des chapiteaux. Mais bientòt ces pyramides se fendent et s'éeroulent, une colonne s’affaisse et s'arrondit, une aiguille se transforme en escalier, un édifice se change en champignon.... Spectacle toujours imposant, où l'inconstance des formes jivalise avec leur variété, et la grandeur des blocs avec leur bizarrerie.

Scoresby s'est souvent amusé à plonger ses matelots dans la stupéfaction, en allumant sa pipe avee un glaçon taillé. Il dégrossissait le morceau ì la hache, le raclait avee un couteau, et le polissait avec la chaleur de la main, en le soutemant aree un gant de laine. Un jour, il se procura de la sorte une lentille merveilleusement tramsparente, de $3 \ddot{3}$ centimètres de diamètre.

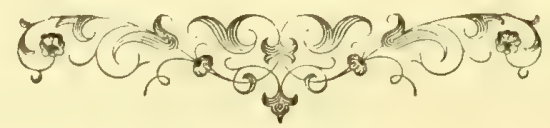




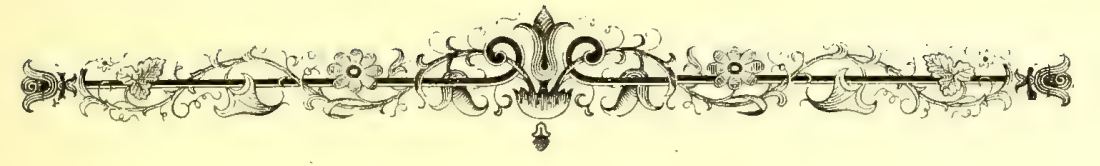

\section{GHAPITRE II}

\section{LA VIE DANS LA MER.}

\footnotetext{
"Quc les eaux produisent en toute abons dance des animaux qui aient vie et qui se neuvent!n

(Genese.)
}

\section{I}

A l'aspect de la haute mer, libre de tout rivage, celui qui aime à créer en lui-même un monde à part où puisse s'exercer librement l'activité spontanée de son âme, celui-là se sent rempli de l'idée sublime de l'infini. Son regard cherche surtout l'horizon lointain. Il y voit le ciel et l'eau qui s'unissent en un contour vaporeux où les astres montent et descendent, paraissent et disparaissent tour à tour. Mais bientôt cette éternelle vicissitude de la nature réveille en lui le vague sentiment de tristesse qui est au fond de toutes les joies de notre cour. (Humboldt.)

Des émotions d'un autre genre, et tout aussi sérieuses, sont produites par la contemplation et par l'étude des innombrables êtres organisés qui peuplent l'Océan.

En effet, cette immense masse d'eau qu'on appelle la mer n'est pas un vaste désert liquide. La vie habite dans son sein, comme clle habite sur la terre. Elle y règne en souveraine, avec ses épanouissements, son luxe et ses agitations. 
La vie plait à Dieu. C'est la plus belle, la plus brillante, la plus noble et la plus incompréhensible de ses manilestations.

On l'a dit il y a bien longtemps, la vie est partout, et le monde n'est rien que par la vie. Les ètres qui en jouissent la transmettent fidèlement à d'autres êtres, leurs enfants et leurs successeurs, qui en seront comme eux les dépositaires ou les usufruitiers. Le merveilleux héritage traverse ainsi les années et les siècles, sans ètre dénaturé ni amoindri, et le globe possède toujours la même quantité de vie qui lai a été si libéralement distribuée.

On sait ce que produit la vie, mais on ignore ce qu' elle est (Lamartine), et cette ignorance est peut-être l'aiguillon puissant qui excite notre curiosité et provoque nos études.

$\mathrm{Au}$ sein de toute chose animée, il se livre un combat ncessant et muct, entre la vie, yui assimile, et la mort, qui désagrége. La première est d'ahord la plus pruissante, elle maîtrise la matière. Cependant son règue est limite; elle s'affaiblit graduellement avec l'àge, et finit par s'éteindre avec le temps : alors les lois physiques et chimiques reprennent le dessus et détruisent l'organisation. Mais les éléments de cette dernière, d'abord incrtes, sont bientòt ressaisis el remis en ceuvre par une nouvelle vie. Ainsi, chaque plante. chaque animal se lie avec le passé et se confond avec l'avenir; car toute génération qui surgit n'est que le corollaire de celle qui expire et le prélude d'une autre qui va naitre. La vie est le séminaire de la mort. La mort est la nourrice de la vie.

\section{II}

La vie ne s'est pas manifestée sur le globe au moment même où il a ćté formé. Elle a paru tard; elle n'est venue 
qu'après les autres phénomènes naturels. Pour la recevoir, il fallait un sol convenablement préparé et un ensemble déterminé de conditions physiques et chimiques.

L'apparition et la diffusion des êtres vivants n'ont pas marché au hasard, elles ont suivi un ordre rigoureux. La connaissance des débris fossiles a jeté le plus grand jour sur ce développement régulier et progressif de l'organisation. L'évolution des ètres vivants a commencé par les plus rudimentaires. Les couches très-anciennes de la terre ne recèlent rien qui ait vécu; les traces des corps organisés n'existent que dans des terrains de formation relativement récente. Les végétaux se montrent les premiers, et, parmi ces végétaux, ce sont d'abord les plus inférieurs. Paraissent ensuite les animaux, et en première ligne ceux qui se rapprochent le plus du règne végétal, et qui appartiennent, par conséquent, aux tribus les moins parfaites. Ainsi, les combinaisons de la vie, d'abord simples, sont devenues de plus en plus compliquées, jusqu'au moment de la création de l'homme, cet admirable chef-d'œuvre de l'organisation.

Si l'on met au printemps, dans une soucoupe exposée à l'air et à la lumière, une certaine quantité d'eau pure, on voit bientôt se produire des nuages légèrement jaunâtres ou verdàtres. Ces nuages, examinés au microscope, présentent des milliers de végétaux agglomérés. Bientôt naissent des animaleules qui nagent an milieu de ces nuages vivants et se nourrissent de leur substance; puis se forment d'autres animalcules qui poursuivent et dévorent les premiers.

En résumé, la vie transforme la matıère brute en matière organisée. Les végétanx apparaissent tout d'abord; puis viennent les animaux herbivores, puis les animaux carnassiers. La vie entretient la vie. La mort des uns alimente le développement des autres. Car tout s'enchaîne, tout s'entr'aide, tout se métamorphose dans le monde organisé 
comme dans le monde minéral, et il en résulte une harmonie générale toujours profonde, toujours la mème et tonjours digne de notre admiration. Dien seul est permanent, tout le reste est transition.

\section{[II}

Les eaux ont beancoup plus d'habitants que les parties solides de la terre ${ }^{4}$. Sur une surface moins variée que celle des continents, la mer renferme dans son sein une exubérance de vic dont aucune autro région du globe ne pourrait donner l'idée (Humboldt).

La vie s'épanouit au nord comme an midi, à l'est comme à l'ouest. Partout les mers sont peuplées; partout, au sein de l'abìme, s'agitent et s'ébattent des créatures qui se cor" respondent et s'harmonisent; partout le naturaliste trouve it suinstruire et le philosophe à méditer; et ces changements mêmes ne font qu'imprimer davantage dans notre tume un sentiment de reconnaissance pour l'Auteur de l'univers. (J. Franklin.)

Oni, les rives de l'Océan et ses profondenrs, ses plaines et ses montagnes, ses vallées et ses précipices, même ses ruines, sout animés et embellis par d'imnombrables êtres organisés. Ce sont d'abord des plantes solitaires ou sociales, dressées ou pendantes, étalées en prairies, groupées en oasis ou rassemblées en immenses forêts. Ces plantes protégent et nourrissent des millions d'animaux qui rampent, qui courent, qui nagent, qui volent, qui s'enfoncent dans le sable, s'attachent à des rochers, se logent dans des erevasses 
ou se construisent des abris; qui se recherchent ou se fuient, se poursuivent ou se battent, se caressent avec amour ou se dévorent sans pitié.

Charles Darwin remarque, avec raison, que nos forêts terrestres n'entretiennent pas, à beaucoup près, autant d'animaux que celles de la mer.

L'Océan, qui est pour l'homme l'élément de l'asphyxie et de la mort, est, pour des milliards d'animaux, un élément de vie et de santé. Il y a de la joie dans ses flots; il y a du bonheur sur ses rives; il y a du bleu partout!

\section{IV}

La mer influe sur ses nombreux habitants, végétaux ou animaux, par sa température, par sa densité, par sa salure, par son amertume, par l'agitation de ses flots et par la rapidité de ses courants.

On a vu, dans le chapitre qui précède, que les eaux marines ne se congèlent qu’à la surface, et qu’à 1000 mètres de profondeur, il existe une température permanente, la même sous toutes les latitudes. D'un autre côté, on a recomnu que l'effet des agitations les plus puissantes et celui des ouragans les plus forts s'étendent tout au plus à 23 mètres de profondeur (Bergmann). D'où il résulte que les végétanx et les animaux, en descendant plus ou moins, suivant le froid ou les mouvements qui les dérangent, peuvent toujours avoir un milieu qui leur convienne.

Les hôtes de la mer se distinguent par une mollesse particulière. Certaines plantes pélagiques ne présentent qu’une faible, une très-faible consistance; nu grand nombre se transforment, par l'ébullition dans l'eau, en une sorte de gelée. Les animaux marins offent nne chair plus on moins 


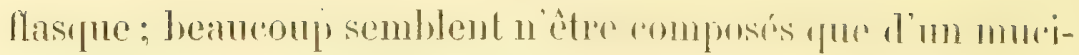
lage diaphane. Ie stuclette des esprees les plus parfaites ost plus ou moins flexible et plus ou moins cartilagineux; il ressemble raremeut, quant au poids et it la consistance, an os des vertébrés terrestres. Cependant les corjuilles et les

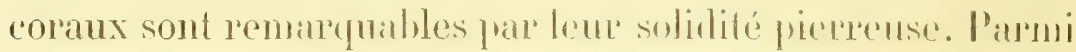
les corps organisés marins, se tronvent done à la fois, et les plus mous, et les plus durs!

La répartition des itres organisés nomris par locrim ost soumise à des lois fixes. On ne trouve pas, sur les côtes, les

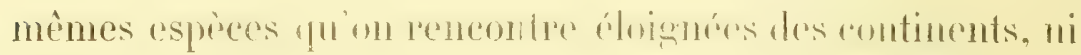
à la surface celles qui se cachent dans les profondeurs.

Quelle immense variété de tailles, de formes et de cou-

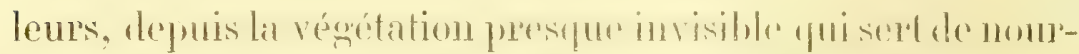

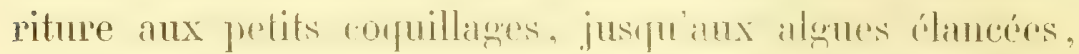

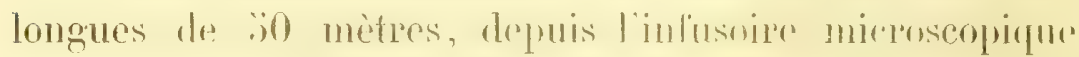
jusqu'à la baleine gigantesque!

On trouve dans la mer animée de l'unité et de la diversité,

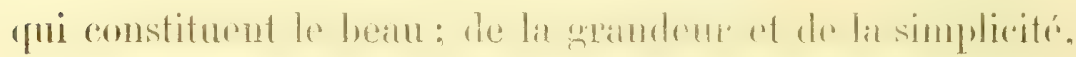
qui forment le sublime; de la puissance et de l'immensité, qui commandent le respect. (Lacépède.)

On a décrit et figuré bien des plantes et bien des animaux. Mais combien en reste-t-il encore à figurer et à

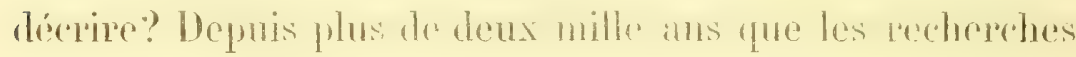
so multipliont ef se sucredent sans intermption, combien la science ne laisse-t-elle pas encore à désirer, même pour

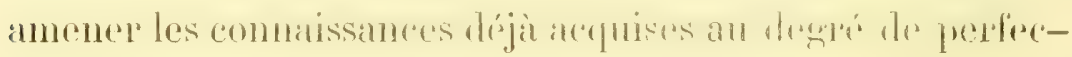
tion dont elles sont susceptibles! (Lamarck.)

Lorsque la marée se retire des bords de l'0céan, la mer

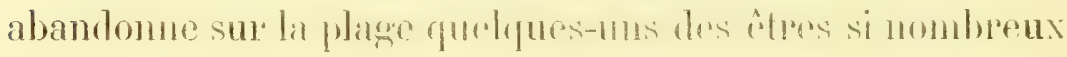


qu'elle abrite dans son sein. Le naturaliste et l'amateur peuvent, dans les premiers moments, recueillir une foule de végétaux et d'animanx avec tous leurs caractères, tontes leurs couleurs et toutes leurs propriétés.

Les populations riveraines y trouvent les éléments de leur' nourriture, de leur commerce ou de leur industrie. Aussi s'empressent-elles d'accourir à la marée basse. Les villages et les hameaux les plus rapprochés y envoient tout leur contingent. Hommes et femmes, vieux et jeunes, chacun est

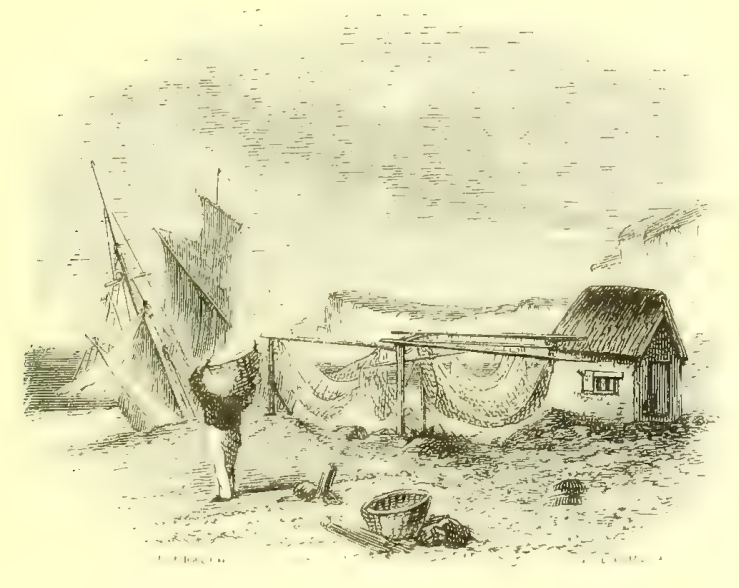

FIIIT, Hi HitII.

propre à la récolte, suivant ses forces et son activité. On s'arme de bâtons, de perches et de pioches; on apporte des corbeilles, des paniers, des sacs, même des filets. On amène des bronettes et des chariots.

Des pêcheurs ramassent les Zostères rubanées, les Ulves membraneuses, les Fucus rembrunis, et en font des chargements considérables. D'autres recueillent les petits coquillages disséminés sur la grève. Les jemnes gareons enlèvent adroitement sur les rochers, des Rans ou Buccins, des Vignelles on Turhos, ot des Oreilles de mer on Ormiers. Ils 
détachent aussi des Bénicles ou Patelles. Les jeunes filles font la chasse aux Mactres, aux Cythérées et aux Bucardes. Des femmes entrent dans l'eau jusqu'à mi-jambes, et vont arracher des quantités considérables de Modioles et de Moules.

On retourne les pierres, ou bien on sonde les crevasses avec un crochet attaché au bout d'une latte. On y surprend des Poulpes, des Sèches et des Calmars, quelquefois même des Anguilles de mer ou Congres, qui s'y sont réfugiés.

On explore les petites mares que la mer a formées en se retiraut. On y plonge une pochette longuement emmanchée; on y promène un filet à mailles très-petites, et l'on s'empare ainsi des animaux qui s'y sont attardés, mollusques, crustacés ou poissons.

Des hommes creusent le sable, et mettent à nu des Oursins, des Donaces et des Manches de couleau.

\section{I}

Dans la Méditerranée et dans les petites mers, la marée est nulle ou presque nulle, au grand détriment des populations du voisinage. 11 existe, d'ailleurs, un grand nombre de végétaux et d'animaux, appartenant à la haute mer, que les flots ou les courants n'amènent presque jamais sur la plage. Il en est d'autres tellement fugaces ou si fortement collés à leurs rochers, qu'on ne peut bien les étudier que dans les endroits mêmes qu'ils habitent. Il faut aller les surprendre flottant à la surface des eaux ou retirés dans leurs mystérieux asiles. Voilà pourquoi les naturalistes sérieux doivent étudier beaucoup de productions vivantes de l'eau salée au sein même de la mer, et non sur les rivages.

La plupart des explorateurs emploient dans ce but la 
drague, la sonde et d'autres engins propres à racler et à briser les rochers les plus durs.

Dans son voyage sur les côtes de la Sicile, M. Milne Edwards a eu l'excellente idée de se servir de l'appareil inventé par le colonel Paulin, ancien commandant des ponpiers de Paris. Cet appareil consiste en un casque métallique pourvu d'une visière de veire, et par conséquent transparente, qui se fixe au cou à l'aide d'un tablier de

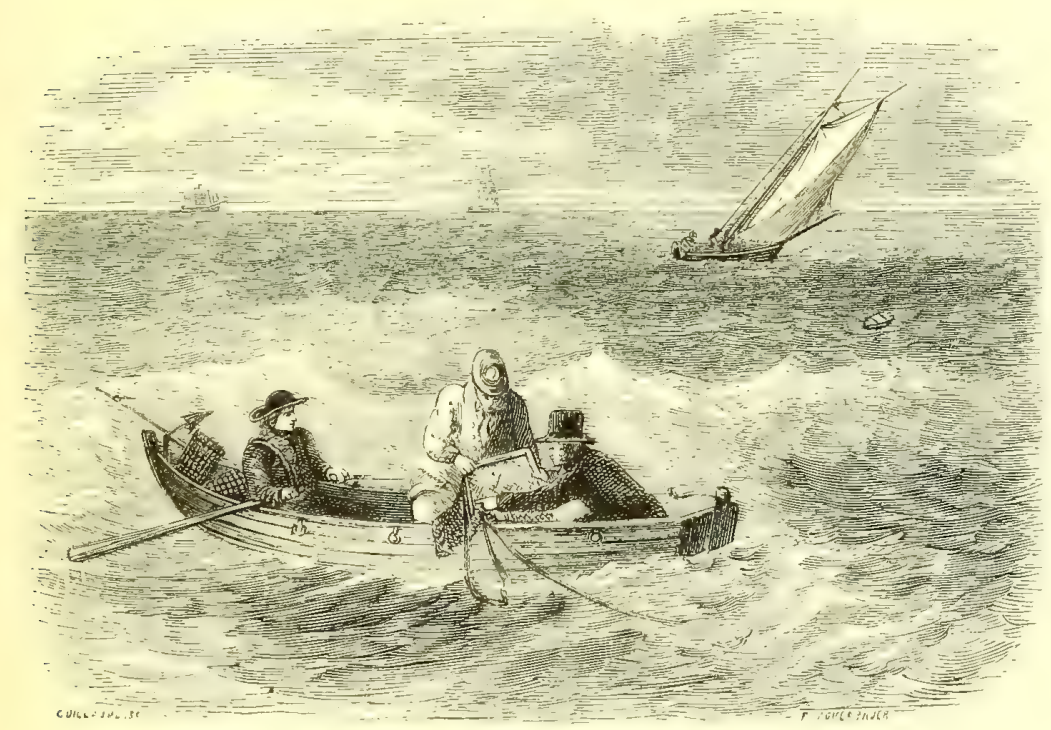

HHSTELTI HS.

cuir maintenu par un collier rembourré. Ce casque est une véritable cloche à plongeur en miniature. Il communique avec une pompe foulante au noyen d'un tube flexible. Quatre hommes sont employés au service de cette pompe : deux la mettent en exercice, pendant que les deux autres se reposent. D'autres hommes tiennent l'extrémité d'une corde (qui passe dans une poulie attachée à une certaine élévation), laquelle permet de hisser rapidement le plongeur. Un observatem vigilant tient dans la main lo 
petit cordon destiné aux signaux. L'immersion du plongeur est facilitée par de lourdes semelles de plomb, lesquelles favorisent en même temps la station verticale au fond de la mer. Il faut près de deux minutes pour retirer un homme de l'eau et pour le débnrrasser de son casque. M. Milne Edwards se faisait descendre, avee cet appareil, jusqu'à 8 ou 9 mitres de profondenr. Ses recherches ont été conronnées du succès le plus complet. Dans ses excursions sous-marines, ce savant naturaliste a pu étulier sur place, daus leurs retraites les plus cachées et en apparence les moins accessibles, des animaux rayomnés, des mollusques, des crustacés, des ammélides, surtont des larves et des neufs, et a contribue puissamment à faire comnaitre les développements, les fonctions et les mours d'un rertain nombre d'habitants de la mer, que leur séjour et lem maniore de vire semblaient soustraire pour tonjours ì nos investigations.

On a proposé, dans ces derniers temps, pour tous les travanx qui exigent un séjonr phus ou moins long au sein des eaux, le bateau plongeur te MV. Lamiral et Payerne. Ce bateau est un réservoir d'air atmosphérique comprimó, ¡r'on descend à différentes profondeurs. Il fournit les éléments de la respiration, sans communication extérieure; il favorise le contact direct avec les objets submergés of per'met facilement la locomotion sous l'eau.

\section{III}

On peut encore étudier les êtres vivants abrités par la mer, en les conservant dans des vases convenables. C'est à M. Charles des Moulins (de Borleaux) qu'on doit la possibilité de ces éducations à domicile (1830). 
Quand on place dans un bocal rempli d'cau donce, des mollusques, des crustacés ou des poissons, on voit, au bout de quelques jours, le liquide perdre sa transparence et sa pureté, et se corrompre peu à peu. Il faut nécessairement changer ce dernier de temps à autre, changement qui dérange, fait souffrir et mème périr les animaux. L'eau nouvelle, d'ailleurs, n'offre jas toujours la mème composition, ni la même aération, ni la même température que l'eau remplacée. II. Charles des Noulius a proposé de mettre dans le vase un certain nombre de plantes aquatiques, flottantes ou submergées, par exemple des lentilles d'eau, des volants d'eau, des potamogets. Ces plantes agissent sur le liquide en sens inverse des animaux qui l'habitent. On sait que ies végétaux assimilent le carbone, en clécomposant l'acide carbonique, produit de la respiration des animaux, et dégagent l'oxygène indispensable à ces dexniers. De cette manière, on n'a plus besoin de changer le liquide, ni mème de l'agiter, et l'on ne trouble pas ses habitants.

M. Dujardin, en 1838, M. Thysme, en 1846 , et 11 . Warrington, en 1849, ont eu l'heureuse idée de faire pour l'eau salée ce que M. Ch. des Moulins avait conseillé pour l'eau douce. Il va sans dire que les plantes dont ils se servent sont des ulves et des fucus. Enfin, M. Philippe Henri Gosse et $\mathbf{M}$. Bowerbank ont imaginé des réservoirs sur une plus graude échelle, espèces de bassins transparents auxquels ils ont donné le nom d'aquariums.

Les aquariums sont pour les populations aquatiques co que les volières sont pour les viseaux. Seulement, au lieu de cages de fer, ce sont des cages de verre, et au lieu d'air, c'est de l'eau. (Millet.)

Les aquariums de cabinet affectent généralement une forme rectangulaire. Qu'on se représente des bassins dont le lond est une lable d'ardoise ou une lame de zince. Guatre 
colomnettes de fonte ou de fer soutiennent quatre glaces verticales, surmontées par un encadrement de métal. Ce sont des maisons de verre qui dévoilent, avec tous leurs secrets, les mouvements, les mours, les habitudes du monde aquatique.

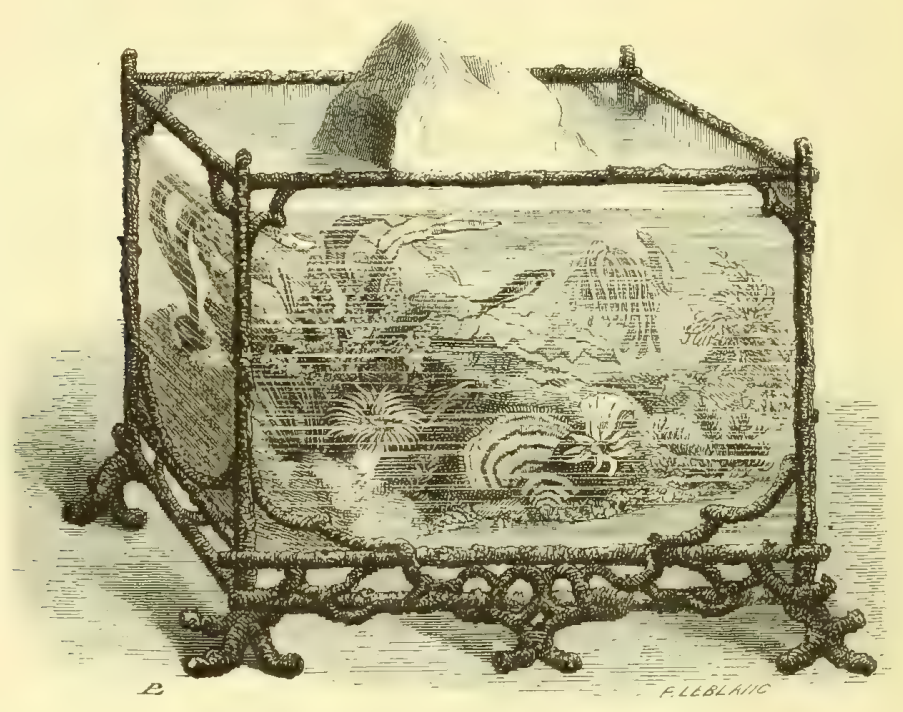

IUISTIL M.

Afin d'élever un plus grand nombre d'animaux, et pour imiter jusqu'à un certain point l'agitation des caux et leur incessante aération, on a imaginé de renouveler le liquide petit à petit et d'une manière continue, à l'aide d'un appareil spécial. On fait arriver l'eau, soit en un filet plus ou moins grêle, soit seulement goutte à goutte. Le liquide s'échappe par un trop-plein.

On a soin de placer, dans le réservoir, des picres creuses, des tuyaux, pour offrir des abris aux animaux rqui fuient la lumière. On peut aussi former des écrans, soit avec une planche ou une lame de carton, soit avee une pièce d'étoffe ou un verre dépoli. On ménage sur l'écran quelques petites 
ouvertures qui permettent d'observer sans être vu. De cette manière on ne dérange en aucune façon les fonctions des animaux, et l'on saisit tous les détails de leur vie intérieure. C'est en réalité la maison de verre des sages de l'antiquité (Millet).

Il est bon d'appliquer un couverele sur l'aquarium, pour arrêter les animaux qui pourraient en sortir, soit en sautant, soit en rampant, et pour empècher la poussière de tomber sur l'eau, de s'y accumuler et de pénétrer dans sa masse.

En 1853, 11. Mitchell, secrétaire de la Société zoologique de Londres, construisit dans le jardin de Regent's Park un aquarium avec des dimensions qu'on n'avait pas encore employées. Le succès de ce petit musée vivant de la mer excita en Angleterre de véritables transports d'admiration (Rufz de Lavison).

Le plus grand, le plus beau et le plus complet des aquariums établis jusqu'à ce jour, est celui du Jardin zoologique du bois de Boulogne, à Paris, inauguré le 3 octobre 1861 .

Qu'on se figure un bâtiment, solidement construit en pierre, de 40 mètres de long sur 10 de large, offrant une rangée de quatorze réservoirs, d'ardoise d'Angers, alignés du côté du nord. Ces réservoirs sont à peu près cubiques, et offrent des devants de forte glace de Saint-Gobain, qui permettent de voir l'intérieur. Ils sont éclairés par le haut : il en résulte un demi-jour verdâtre, uniforme, mystérieux, qui donne une idée exacte des faibles clartés sous-marines. Chaque réservoir contient environ 900 litres d'eau; il est garni de rochers disposés un peu en amphithéâtre et d'unc manière pittoresque. Sur ces rochers s'étalent ou s'élèvent diverses espèces de plantes aquatiques. Les réservoirs ont dans le fond une couche de galets, de gravier et de sable, pour donner à certains animaux des retraites suffisantes.

Dix de ces réservoirs sont destinés aux animaux marins. 
La quantité d'eau employée est d'environ 2:2700 litres. Cette eau n'est jamais changée, mais clle est sans cesse en mouvement, elle circule. Ce mouvement est produit de la manice suivante. On profite d'un courant d'can amenć par le grand tuyau de la eoncession qui alimente le bois de Boulogne. Cette eau, soumise à une forte pression, comprime une certaine masse d'air. Cet air, dès qu'on hir permet d'agir sur une partie de l'eau de mer contenue dans un cylindre fermé qui se trouve au-dessons du niveau de l'aquarium, la fait monter et entrer avec une grande force dans charque réservoir', où clle s'introduit par un petit jet. L'eau de mer', pressée, absorbe beaucoup d'air, qu'elle entraine avec elle dans les réservoirs. Un tuyau placé dans un coin de ces der-

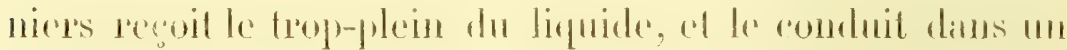
liltre de charbon très-serré, d'où il passe dans un grand réservoir souterrain, de fonte, doublé de gutta-pereha. De là, l'eau revient au cylindre fermé, y subit encore la pression de l'air, et remonte de nouveau daus l'aufuarium. Les cylindres étant sous terre, on y maintient facilement une température égale de 16 degrés centigrades environ : ce qui est à peu près la température uniforme de l'eau dans l'Océan. Pement l'hiver, le batiment de l'anuarium est chanffé antificiellement. (Lloyd.)

A l'aide d'une disposition très-simple, on peut, dans chaque réservoir, diminuer la quantité de l'eau, et imiter le flux et le reflux de la mel'. On peut même, en baissant considérablement le liquide, exposer périodiquement certains animaux à l'air atmosphérique.

Dans cette circulation et cette agitation de l'enu, sa masse tend à diminuer par l'évaporation. Les matières qu'elle contient restant dans le liquide, ce dernier finirait par devenir trop salé. Pour remédier à cet inconvénient, on y ajoute de l'eau pure. A l'aide d'un appareil spécial, on l'ait 
entrer de temps en temps, dans le grand réservoir, une certaine quantité d'eau pluviale qui vient dn toit du bâtiment. Un hydromètre indique le moment où cette addition d'eau douce est devenue nécessaire.

“La lengua no basia para decir, ni la mano para escribir todas las maravillas del mar! '(Christophe Colomb.)

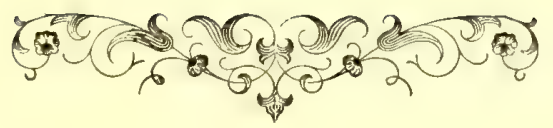





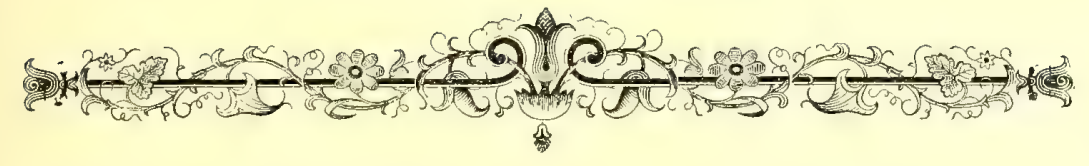

\section{CHAPITRE III}

\section{LA PHOSPHORESGENGE DE LA MER.}

Lumière sans feu, mais pas sans vie.

Les Infusoires sont une des principales causes de ce beau phénomène que présente la mer dans les pays chauds, surtout pendant l'été; nous voulons parler de la phosphorescence.

Dès que le soleil a disparu de l'horizon, des essaims innombrables d'animalcules lumineux sont attirés à la surface du liquide par certaines circonstances météorologiques (Ilumboldt). Une nouvelle clarté surgit du sein des flots. On dirait que l'Océan essaye de rendre pendant la nuit les torrents de lumière qu'il a reçus pendant le jour. Mais cette lumière étrange n'éclaire pas uniformément le milieu dans lequel elle se produit; elle naît çà et là par une foule de points qui tout à coup s'allument et scintillent.

Quand la mer est bien tranquille, on croit voir à sa surface des millions de vives étincelles qui flottent et se balancent, et, au milieu d'elles, de capricieux feux follets qui se poursuivent et se croisent. Ces soudaines apparitions se réunissent, se séparent, se rejoignent, et finissent par former une vaste nappe de phosphorescence bleuâtre ou 
blanchàtre, pàle et vacillante, au sein de laquelle se font distinguer encore, d'espace en espace, de petits soleils éblouissants qui conservent leur éclat.

Quand la mer est très-agitée, les flots semblent s'embraser. Ils s'élèvent, roulent, bouillonnent, et se brisent en flocons d'écume qui brillent et disparaissent comme les bluettes d'un immense foyer. En déferlant sur les rochers du rivage, les vagues les ceignent d'une bordure lumineuse : le moindre écueil a son cercle de feu. (Quatrefages.)

Rien n'est gracieux comme une troupe de Dauphins qui se jouent au milieu de la nuit, frappant, divisant, éparpillant, pulvérisant cette onde merveilleuse. (Humboldt.)

Chaque coup de rame fait jaillir de l'Océan des jets de lumière : ici faibles, peu mobiles et presque contigus; là resplendissants, vagabouds et dispersés comme un semis de perles chatoyantes.

Les roues des bateaux à vapeur agitent, soulèvent et précipitent des gerbes enflammées. Quand un vaisseau fend les ondes, il pousse devant lui deux vagues de phosphore liquide; il trace en inême temps, derrière sa poupe, un long sillon de feu qui s'efface avec lenteur, comme la queue d'une comète!

Quel beau sujet d'études pour les savants, et quelle admirable source d'inspirations pour les poëtes!

Lorsque la Vénus mit à l'ancre à Simon's-town, la mer exhalait une phosphorescence si abondante, que la chambre des naturalistes de l'expédition semblait éclairée par une torche.

L'eau brillante, puisée dans un seau, présente en coulant l'aspect du plomb fondu (Quatrefages). Quand on y plonge la main, on la retire converte de corpuscules lumineux et dégouttante de diamants vivants.

Certains animalcules, doués d'une phosphorescence pen 


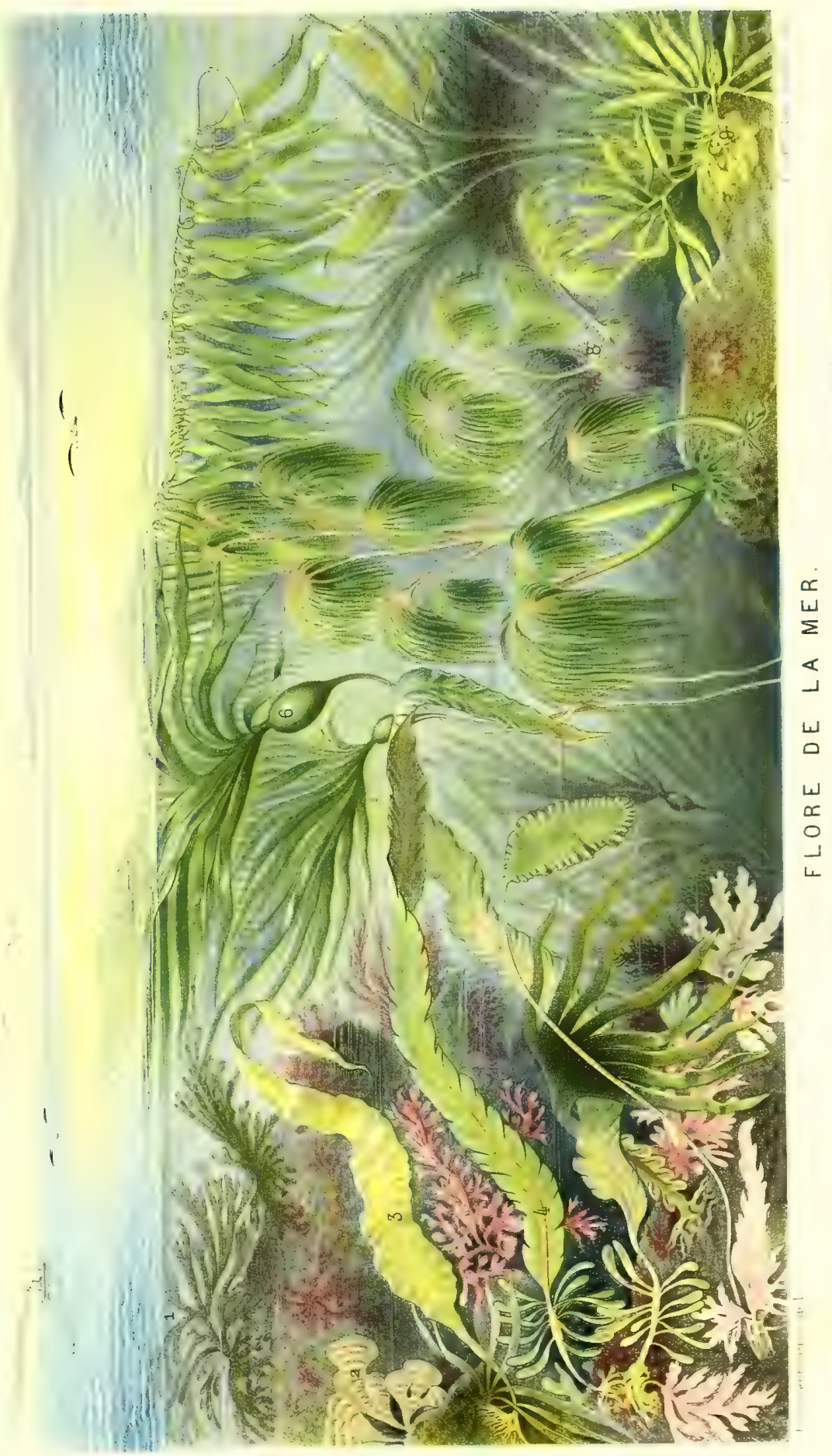



marquée, peuvent, lorsqu'ils sont très-nombreux, rendre les eaux tout à fait blanches. Ce phénomène est désigné par les marins hollandais sous le nom de mer de lait ou mer de neige. Les bestioles dont il s'agit, offrent à peine un ou deux dixièmes de millimètre de longueur et l'épaisseur d'un cheveu. Ce sont des géants parmi les Infusoires! Elles adhèrent les unes aux autres par les extrémités, et forment de longues files quelquefois extrêmement nombreuses.

En 1834, dans le golfe du Bengale, le capitaine Kingmann navigua pendant trente milles au milieu d'une énorme tache blanche : c'était une mer de lait.

Dans la nuit dı 20 au 21 août 1860, M. Trébuchet, commandant la frégate la Capricieuse, en rade d'Amboine, fut témoin d'un magnifique spectacle de même genre, qui dura jusqu'au lever du jour. L'Océan ressemblait à certaines plaines de terrain crayeux fortement éclairées par la lune.

La Noctiluque miliaire est un des Infusnires pélagiens

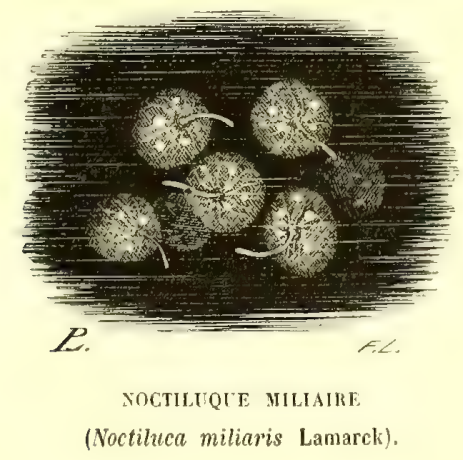

qui contribuent le plus ì la phosphorescence de la mer (Rigant, Suriray). Cet animalcule, oublié par Cuvier dans son Règne animal, a été rapproché par les naturalistes, 
tantôt des Anémones ${ }^{1}$, et tantôt des Méduses² et des Foraminifères ${ }^{3}$. Dans 30 ceutimètres cubes d'eau, il peut en exister 25000 !...

La Noctiluque parait, au premier abord, comme un globule de gelée transparente ${ }^{4}$. Avee un grossissement un peu fort, on distingue sa forme sphérique plus ou moins régulière, un peu déprimée et légèrement ombiliquée en dessous. An centre de l'ombilic se trouve la bouche, qui communique avec un cesophage en forme d'entomoir. II en sort un tentacule filiforme, tris-grêle, mobile, qui nait dans ret endroit, comme li quene dans une pomme. Ce tentacule semble tubuleux. Blainville suppose quil est terminé par un suçoir : ce serait alors une espèce de trompe.

Dans certaines contractions, le corps devient réniforme; dans d'autres, il perd son tentacule.

La Noctiluque offre gà et là, dans son intérieur, des granules, probablement des germes, et des points lumineux. Ceux-ci paraissent et disparaissent avec rapidité : la moindre agitation détermine leur bolat. Ces points forment tout au plus la vingt-cinquième ou la trentième partie du grand diamètre du globule. Les Noctiluques émaillent la surface de l'ean comme de petites constellations tombées du firmament.

\section{III}

Les Infusoires, on le sait aujourd'hui, ne sont pas les seuls animaux producteurs de la phosphorescence. Cet état brillant de la mer est encore déterminé par des Méduses,

1 Voyez le chapitre XII.

${ }^{2}$ Voyez le chapitre XIII.

3 Voyez le chapitre VI.

${ }^{4}$ Ce globule présente de $1 / 5^{\circ}$ à $1 / 3$ de millimètre de diamitre. 
des Astéries, des Mollusques, des Néréides, des Crustacés et même des Poissons '..... Ces animaux engendrent la lumière comme la Torpille engendre l'électricité. Ils multiplient et diversifient les effets du phénomène. La lumière qu'ils produisent passe tantôt au verdâtre, tantôt au rougeâtre. A certains moments, on croit voir, dans le sombre royaume, des disques rayounants, des plumets étoilés, des franges flamboyantes. Plusieurs animaux paraissent de loin comme des masses métallirues rougies à blanc, ou comme des bouquets de feu lançant des étincelles. Il y a des festons de verres de couleur comparables aux guirlandes de nos illuminations publiques, et des météores incandescents, allongés on globuleux, qui se poursuivent à travers les vagues, montent, descendent, s'atteignent, se groupent, se confondent, se disjoignent, déerivent mille courbes capricieuses, et s'éteignent pour se rallumer et se poursuire de nouveau.

Spallanzani a fait $u$ grand nombre d'expériences sur la lumière des Méduses ${ }^{2}$, particulièrement sur celle de l'Aurélie phosphorique ${ }^{3}$. Il a reconnu que cette remarquable propriété réside dans les grands bras ou tentacules, dans la zone musculaire du corps et dans la cavité de l'estomac. Le reste de l'animal ne brille que par réverbération. La source de la phosphorescence est due à la sécrétion d'un liquide visqueux qui suinte à la surface des organes. Si l'on mêle cette humeur à d'autres liquides, ceux-ci deviennent

1 Viviani a trouvé (seulement dans les parages de Gênes) quatorze espèces d'animaux phosphoriques. MM. Van Beneden et de Quatrefages en signalent une soixantaine.

${ }^{2}$ Voyez le chapitre XIII.

${ }^{3}$ Aurelia phosphorica Péron ef I.esueur. 
plus ou moins lumineux. Une seule Aurélie, pressée dans 850 grammes de lait de vache, rendit ce lait si brillant, qu'on put lire une lettre à un mètre de distance.

Pline savait que les Pholades dattes ', petits mollusques à deux valves dont nous parlerons bientòt, présentent aussi une clarté phosphorescente, qui se répand sur les lèvres des personnes qui mangent ces pauvres bètes. Il nous apprend que cette même lueur brille sur les habits, lorsqu'ils sont mouillés par quelques gouttes du fluide phosphorescent échappé de l'animal.

Réaumur, après aroir manié quelque temps une Pholade, se lava les mains dans un vase d'eau. Ayant porté cette eau dans l'obscurité, elle répandit une lueur d'un blänc bleuâtre.

M. Milne Edwards ayant mis dans l'alcool des Pholades vivantes, la maticre lumineuse qui suinta du corps de ces mollusques descendit dans le fond du bocal, et y forma une couche d'un éclat aussi vif qu'au contact de l'air.

\section{V}

La plupart des animaux lumineux paraissent maitres de leur phosphorescence, comme les Vers luisants de leur petit fanal; car plusieurs d'entre eux en augmentent ou en diminuent l'intensité, suivant les circonstances, et peuvent même l'éteindre tout à fait. C'est principalement à l'époque de la reproduction... ou des amours, que la merveilleuse clarté se manifeste avec toute sa splendeur et toute son animation, triomphe impatient d'une vie exubérante et généreuse qui veut s'épandre et se donner.

1 Pholas dactylus Linné. 


\section{I}

Les plantes contribuent aussi au resplendissant météore de la mer. Meyen a décrit une Oscillatoire qui donne des lueurs assez éclatantes.

Tous les marins savent que, pendant les fortes chaleurs, quand on retire certaines Algues du sein de l'eau, qu'on les

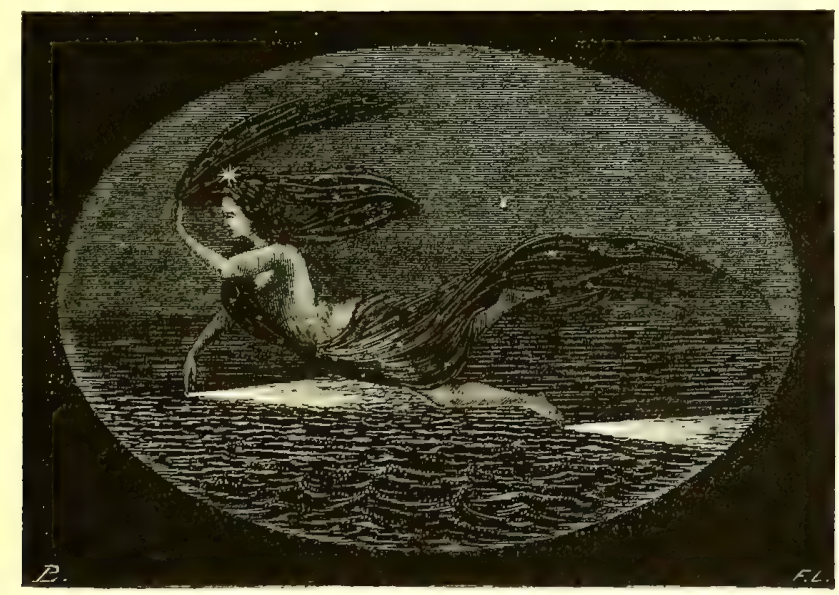

PHOSPIORESCEXCE.

agite ou qu'on les frotte, elles deviennent plus ou moins phosphorescentes.

Beaucoup de naturalistes et de physiciens admettent que ce magnifique phénomène peut résulter encore de diverses matières animales ou végétales tenues en suspension dans la mer, et surtout de la décomposition de ces maticres.

Les anciens l'attribuaient faussement à la salure de l'Océan ou à l'Esprit salé.

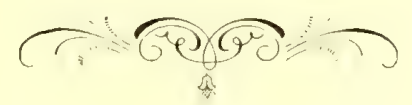





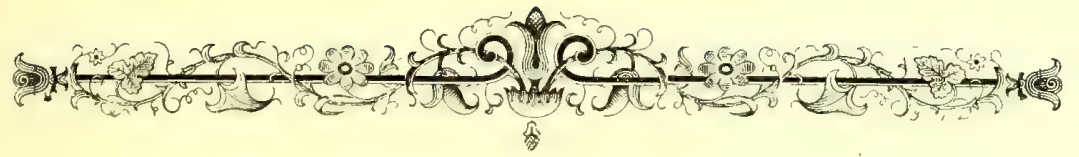

\section{CHAPITRE IV}

\section{LES PLANTES DE LA MER.}

Plasén jandi, plus qu'autre jos lo cè.

(A. Crisa, 1471.)

La flore de l'Océan mérite sous tous les rapports l'attention du botaniste, du philosophe et de l'artiste; car il existe, au milieu des eaux comme sur la terre, dans l'eau salée comme dans l'eau douce, des plantes curieuses, utiles et pittoresques.

Ces plantes offrent une diversité de formes telle, qu'un paysage au fond de la mer n'est ni moins intéressant, ni moins varié que celui d'une contrée à laquelle le soleil a imprimé le cachet de la végétation si riche des tropiques. (Schleiden.)

Cependant, disons-le tout d'abord, la vie végétale est moins largement représentée dans les mers que sur les continents (Humboldi). La masse des végétaux terrestres est incomparablement plus grande que celle des végétaux majins. Mais la nature a compensé cette différence au sein de l'Océan, ainsi que nous le montrerons ailleurs, en créant les Polypiers, e'est-à-dire des animalcules réunis en sociétés nombreuses plus ou moins arborisées, qui composent une flore d'un autre genre, plus compliquée, plus animée, plus étonnante : ce sont, pour ainsi dire, des animaux dans des plantes et des minéraux dans des animaux. 
La flore océanique appartient presque exclusivement à une seule classe de végétaux, celle des Algues.

Linné n'a signalé qu'une cinquantaine de ces plantes; on en connaît aujourd'hui plus de 2000. Dans les eaux de l'Angleterre seulement, on compte 105 genres et 370 espèces!

La flore marine est assez nombreuse et assez brillante dans la zone tempérée; elle diminue graduellement de richesse vers l'équatem et vers les pôles. (Schleiden.)

Les plantes de la mer ont souvent une taille tout à fait microscopique. Freycinct et Turrel, à bord de la corvette la Créole, ont observé, dans le voisinage de Tajo (île de Luçon), une étendue d'eau de 60 millions de mètres carrés colorée en rouge écarlate. Ciette teinte provenait de la présence d'une chétive plantule, dont il faut 40000 individus pour occuper l'espace d'un millimètre carré! Comme cette coloration s'étendait à une profondeur assez considérable, il serait impossible d'évaluer, même d'une manière approximative, le nombre de tous ces ìtres vivants. (Schleiden.)

La mer Rouge présente aussi, dans certaines circonstances, me coloration analogue qui lui a valu son nom. Cette coloration est due également à une Algue microscopique. "Le 10 décembre, dit M. Ehrenberg, je vis à Tor, près du mont Sinaï, toute la baie qui forme le port de cette ville, rouge de sang. La haute mer, en dehors de l'enceinte des coraux, conservait sa couleur ordinaire. De courtes vagues apportaient sur le rivage, pendant la chaleur du jour, une matière mucilagineuse pourpre, et la déposaient sur le sable; en sorte que, dans l'espace d'une demi-heure, toute la baie, à marée basse, fut entourée d'une ceinture 
rouge.... Je puisai de l'eau avec des verres, que j'emportai dans ma tente. Il fut facile de reconnaitre que cette coloration était due à de petits flocons à peine visibles, souvent verdâtres, quelquefois d'un vert intense, mais pour la plupart d'un rouge foncé. Toutefois l'eau dans laquelle ils nageaient était parfaitement incolore. J'observai cette matière au microscope. Les flocons étaient formés de faisceaux de filaments. Ces faisceaux avaient rarement plus de 2 millimètres de longueur; ils étaient fusiformes et contenus dans une sorte de gaîne mucilagineuse. Durant le jour ils se maintenaient à la surface de l'eau, mais pendant la nuit ils gagnaient le fond du verre; quelque temps après, ils remontaient. "Cette Algue a été désignée sous le nom de Trichodesmie rouge ${ }^{4}$.

M. Évenot Dupont, avocat distingué de l'ỉle Maurice, raconte, de son côté, que le 13 juillet 1843 , il vit la même mer teinte en rouge aussi loin que l'œil pouvait s'étendre. Sa surface était partout couverte d'une matière fine d'un rouge de brique un peu orangé. La sciure du bois d'acajou produirait à peu près le même effet. M. Dupont fit recueillir, à l'aide d'un seau attaché au bout d'une corde, une certaine quantité de cette substance; puis, avec une cuiller, il en remplit un flacon. Le lendemain, elle était devenue d'un violet foncé, et l'eau avait pris une jolie teinte rose. Le contenu fut vidé sur un linge de coton; l'eau passa au travers, et la substance adhéra au tissu : en se séchant, elle devint verte.

M. Montagne a étudié cette matière, et constaté que c'était une petite Algue du même genre que la précédente. Il l'a nommée Trichodesmie d'Ehrenberg ${ }^{2}$. Cette Algue est com-

I Trichodesmium erythroum Ehrenberg.

2 Trichodesmium Ehrenbergii Montagne. Il en existe encore une autre espìce, appelée par les savants Trichodesmium Hindsii. 
posée de filaments articulés et juxtaposés, variant entre un dixième et un vingtième de millimètre. Le microscope y fait découvrir des cellules régulièrement soudées bout à bout, fortement pressées et un peu quadrilatères.

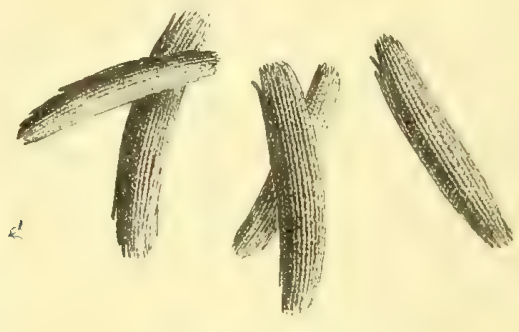

THCHODESME D'EHRENBERG

(Trichodesmiun Lhrenbergii Muntagne).

D'autres plantes marines présentent au contraire une taille gigantesque. Humboldt a vu pêcher un Fucus qui avait plus de 500 mètres de longueur!

\section{I I}

Les plantes de l'Océan ne ressemblent pas beaucoup ì celles qui ornent nos bois et nos vallons. D'abord elles n'ont pas de racines.

Celles qui flottent sont globuleuses ou ovoïdes, tubulées ou membraneuses, sans apparence aucune de corps radiculaire.

Celles qui adhèrent sont fixées par une sorte d'empatement superficiel plus ou moins lobé ou divisé. La terre n'est pour rien dans leur développement, car leur point d'origine 
est toujours extérieur. Tout se passe dans l'eau; tout virnt d'elle, et tout retourne à elle (Quatrefages).

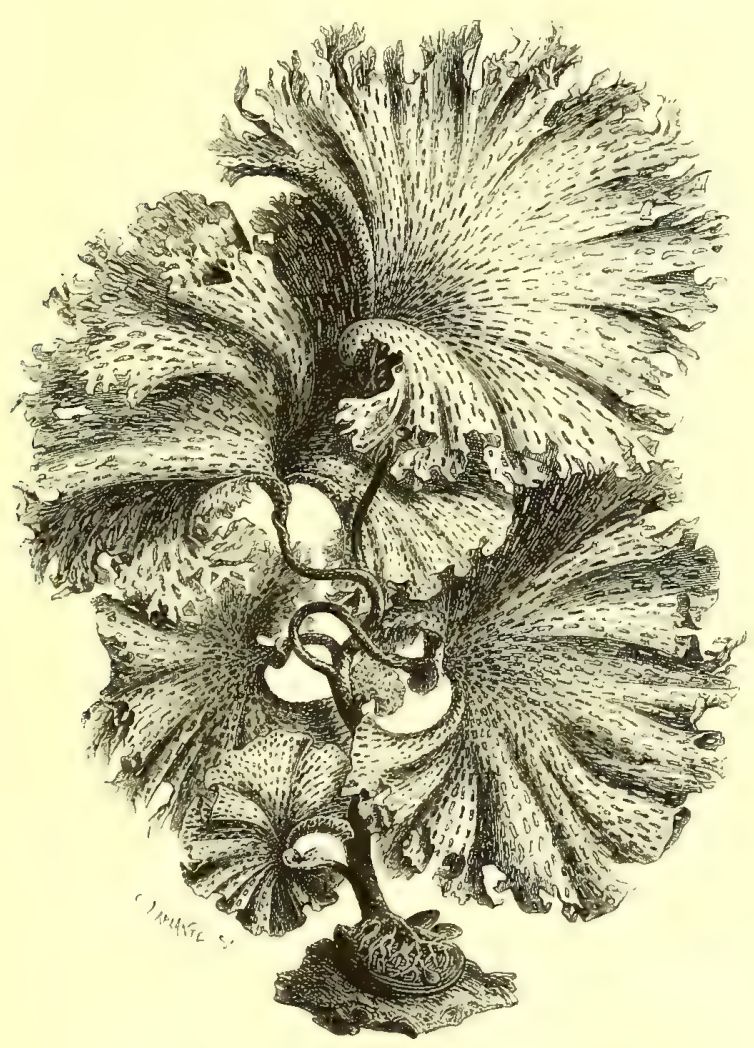

TILALASSIOPIYLLUM PERFOKE

(Thalassiophyllum clathrus Montagne).

Les plantes terrestres choisissent tel ou tel terrain; elles ne prospèrent bien que dans un sol déterminé. Les plantes marines sont indifférentes au rocher qui les supporte. Qu'il soit calcaire ou granitique, elles n'en profitent pas; aussi croissent-elles indistinctement partout, même sur des coraux ou des coquilles.

Ces hydrophytes ne possident ni vraies tiges, ni vraies feuilles; elles se dilatent souvent en lames ou lamelles 
larges ou étroites, d'une seule ou de plusieurs pièces, qui tiennent lieu de ces organes. Elles ressemblent tantòt à des lanières onduleuses, tantôt à des filaments crispés; celles-ci épaisses et coriaces, celles-là minces et membraneuses. Il y en a qu'on prendrait pour de petits ballons transparents, pour des étoffes régulièrement gaufrées, pour des lambeaux de gelée tremblante, pour des rubans de corne blonde, pour des baudriers de peau tannée, ou pour
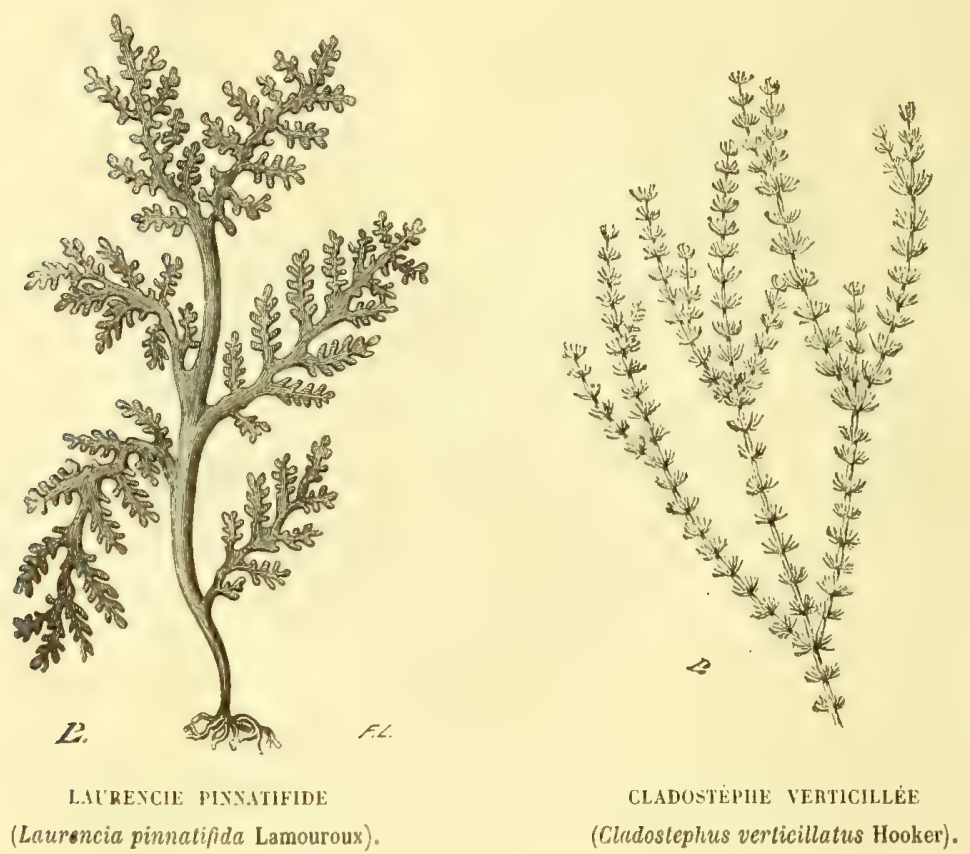

des éventails de papier vert! Leur surface est tantôt lisse, polie, même luisante, tantôt couverte de papilles, de verrues ou de véritables poils. On y trouve un enduit visqueux, une poussière saline, une efflorescence sucrée, et quelquefois un répôt crétacé. Leur couleur est olivâtre, fauve, jaunâtre, d'un brun plus ou moins obscur, d'un vert plus ou moins gai, d'un rose plus ou moins tendre, ou d'un carmin plus ou moins vif. 
Quelques auteurs les ont divisées d'après leurs teintes dominantes en trois grandes sections : les brunes ou noires

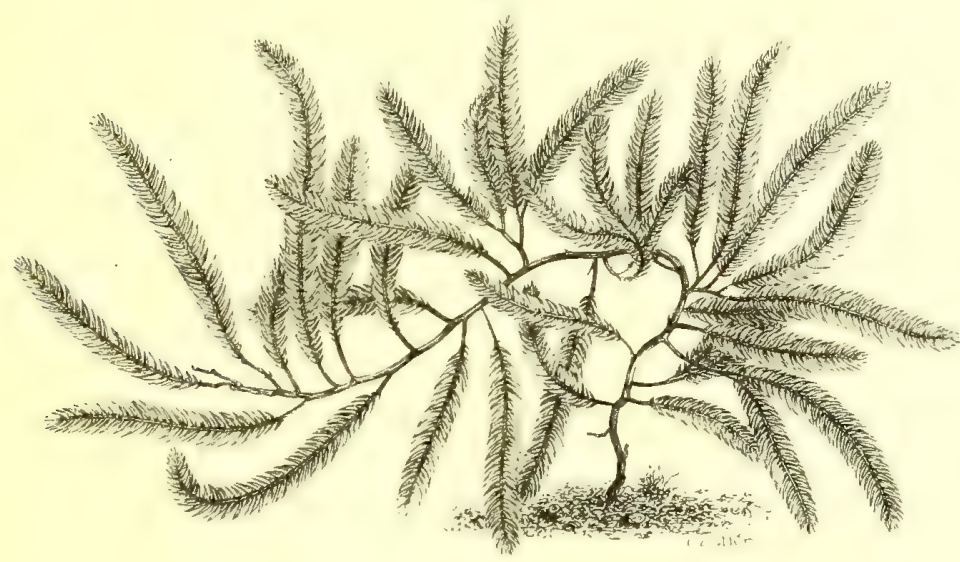

CALLERPE A TEUILIES D'H $\left(\frac{1}{4}\right)$

(Caulerpa taxiolia Agardh).

(Mélanospermées), les verles (Chlorospermées), et les rouges (Rhodospermées). Les premicres sont de beaucoup les plus

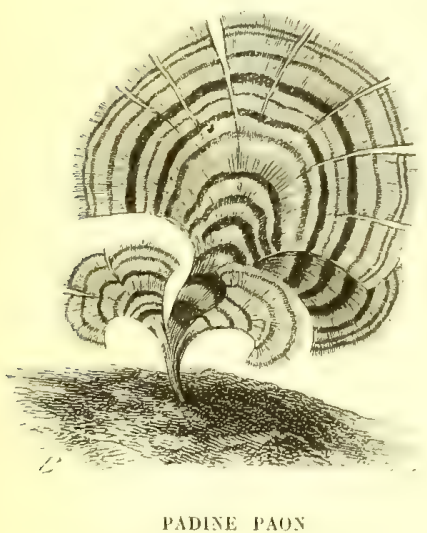

(Padina pivonia Lamouroux).

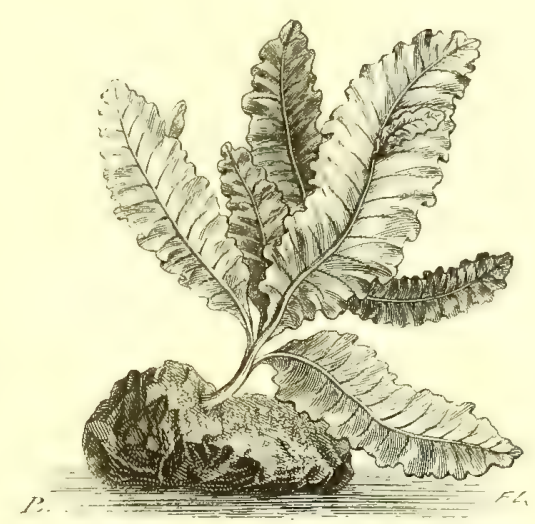

DELESSERIE ROLGE

(Delesseria sanguinea Lamouroux).

nombreuses. Elles s'enfoncent phus ou moins, et semblent occuper dans l'océan trois régions plus ou moins distinctes; 
elles constituent la plus grande partie des forêts sous-marines. Les vertes sont superficielles et souvent flottantes.

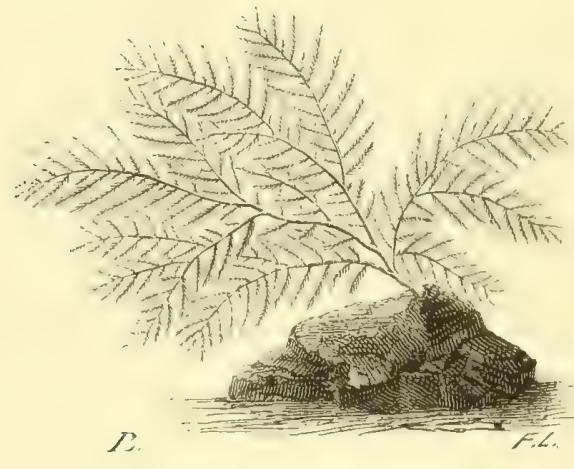

PIOCANSE PLITIEST

(locamium plumosum Lanoujous).

Les rouges se rencontrent habituellement à de faibles profondeurs et sur les rochers peu éloignés des rivages ${ }^{1}$.

Si du fond de la mer un volcan soulève tout à coup audessus des flots un rocher incrte couvert de scories, la force organique est prête à faire naître la vie à sa surface (Ilumboldt). A peine l'air a-t-il touché la pierre nue, qu'il s'y forme de toutes petites plantes adhérentes qui la rongent et la détruisent peu à peu. Ce sont d'abord des taches jaunâtres ou grisâtres, puis bleuâtres ou verdâtres, simples ou doubles, bordées par des lignes saillantes ou traversées par des sillons entrecroisés. A mesure que ces taches vieillissent, leur couleur devient un peu plus foncée, et leur épaisseur un peu plus grande. Au bout d'un certain temps, elles se trans-

1 Voyez la planche IV. 


forment en filets de velours. Mais bientòt ceux-ci se décomposent, et, du milieu de leurs dépouilles, surgissent d'autres plantules à taille un peu plus haute, à végétation moins chétive et à caractères plus tranchés.

Les plantes de l'Océan qui végètent à sa surface, sans adhérence, s'entrelacent souvent et forment des îles herbacées, lesquelles sont poussées par les courants et vont échouer vers quelque plage inconnue, ou bien sont dispersées par les orages.

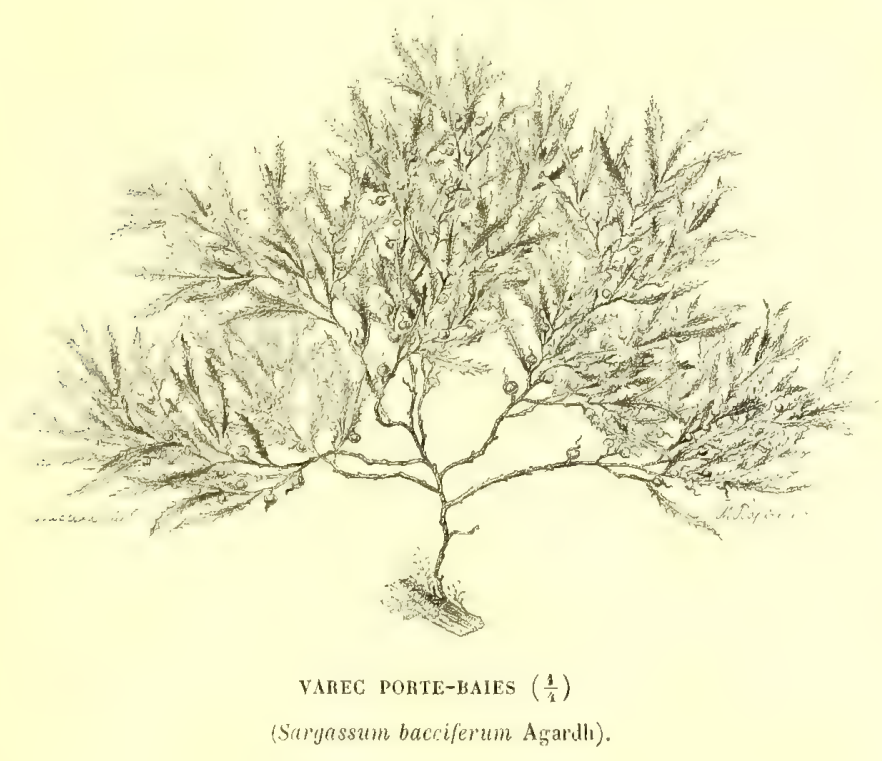

Au sud-est de Terre-Neuve, non loin des Açores, on rencontre un immense bane de plantes pélagiennes, composé du Varec nageur ou porte-baies ", l'un des plus répandus parmi les Fucus de l'Océan. On appelle ce banc, la mer des

${ }^{1}$ Sargassum bacciferum Agardh. 
Sargasses (mar de Sargasso). C'est cette masse gigantesque qui frappa si vivement l'imagination de Christophe Colomb, et qui est nommée par Oviédo, la prairie des Varecs (praderias de Yerva). (Humboldt.)

Ces lits d'herbes flottantes se rassemblent quelquefois autour des vaisseaux d'une manière très-serrée. Les premiers navigateurs les regardaient comme la limite

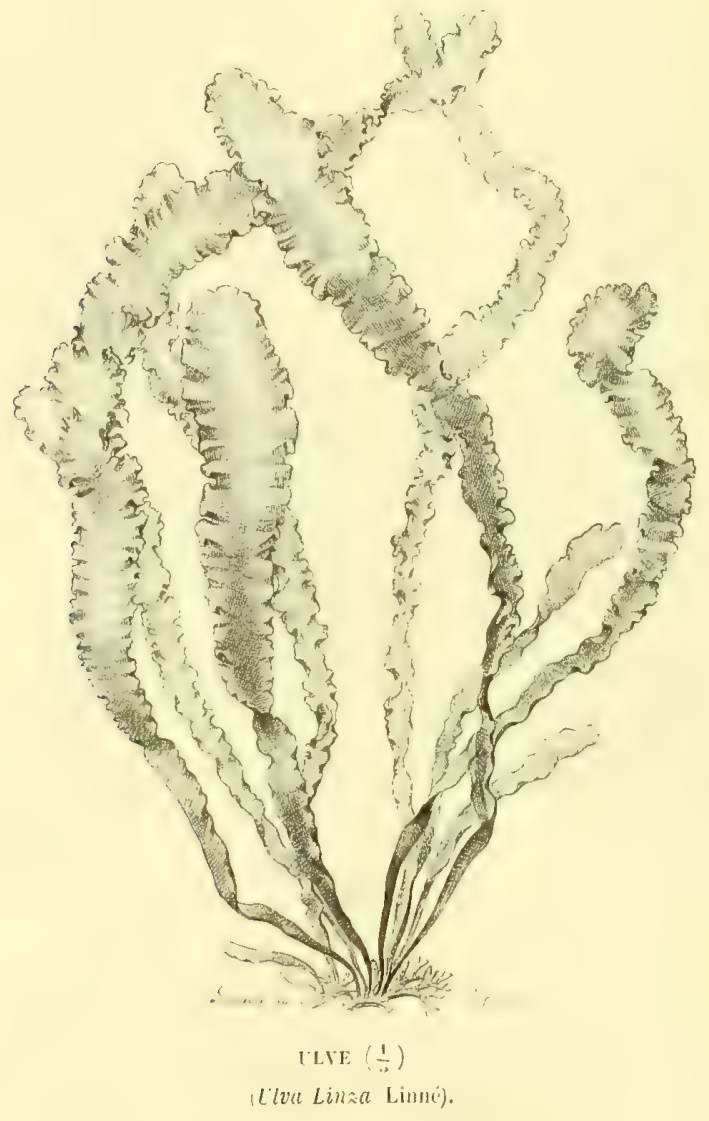

de l'Océan navigable. On assure que Colomb employa trois mortelles semaines à franchir la prairie des Sargasses.

Beaucoup dautres Algues flottent aussi à la surface de 
la mer, tantôt réunies, tantôt en petit nombre, et composant d'étroites plates-bandes ou de petites oasis. Parmi res plantes, nous devons citer surtout les Laitues de mer (Ulves), avec leur ample et mince feuillage, d'un vert tendre ou d'un violet obscur. Une espèce ressemble à un long tube comprimé; une autre, à un fil mince tortueux.

A ces Algues viennent s'entremêler différentes herbes marines, qui s'étaient développées dans les bas-fonds, yue les vagues ont détachées, et dont les rameaux déliés ont été soulevés jusqu'à la surface par leurs cellules gonflées d'air (Humboldt). I. de Martius croit que beaucoup de ces Algues flottantes ont été arrachées par les Baleines.

Une fois arrivés à la surface de la mer, les Fucus poussent des branches et des lobes dans toutes les directions, qui s'enlacent et s'entortillent de toutes les manières.

Ces plantes de la surface de la mer ont une exubérance de végétation si fongueuse, si l'on pent parler ainsi, qu'elle dépasse le développement de l'Anacharis du Canada'. Cette plante d'eau donce, transportée accidentellement, il y a quelques années, dans les eaux de la Tamise, menace aujourd'hui d'encombrer ce fleuve et d'arrèter la navigation!

Un des caractères des prairies de Varecs, c'est la simplicité de leur composition. Dans une prairie terrestre, on olserve un assez grand nombre d'espèces végétales; dans une prairie marine, on n'en compte que deux ou trois, et souvent même qu'une seule.

Mais les prairies flottantes sont bien moins nombreuses et moins remarquables que les prairies sous-marines. 
On voit an fond de l'Océan de riches pelouses ćtalées sur le sol, à plantes serrées et comme confondues, semblables à des tapis de moquette.

On y découvre des buissons et des bosquets, des jardins et des bois. Il existe un petit nombre de forêts vierges sur la terre; on en rencontre presque partout sous les ondes, car la végétation des mers est mieux défendue et mieux respectée que la végétation des continents. L’homme mutile, exploite, arrache, incendie les bois de l'Amérique, mais il n'aborde que tris-timidement, avec beancoup de précautions, et seulement pour quelepes minutes, les bois de l'Océan.

Les hydrophytes submergées confondent leurs feuillages d'une manière très-liche ou très-compracte, et composent des berceanx arrondis, des galeries mystérieuses, ou des fourrés impénétralßles... Il y a dans les harmonies végétales de la mer comme une splendide répétition des magnificences de la terre.

Quelques-unes de ces plantes sous-marines sont ì peine couvertes d'eau, d'autres se cachent plus on moins profondément.

Dans les parages des îles Canaries, Humboldt et Bonpland ont retiré d'une profondenr de 6 i metres me Canlerpe à feuilles de Vigne. Elle offrait une admirable conleur verte.

Entre l'ile de France et les îles Mascareignes, Bory de Saint-Vincent a recueilli une touffe de Varec turbiné ${ }^{\prime}$ à une profondeur d'environ 200 mètres.

Les Céramies se font remarquer, entre toutes les plantes de la mer, par la merveilleuse délicatesse de leur organi-

1 Sargassum turbinatum Agardh. 
sation, par l'élégance de leur branchage et par leurs belles teintes écarlates ou violettes.

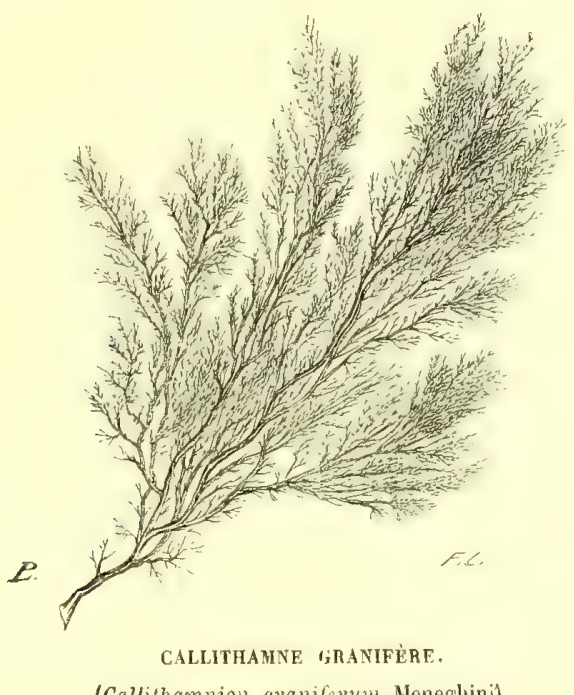

(Callithamnion granifemm Meneghini).

Les Laminaires s'allongent comme d'immenses courroies

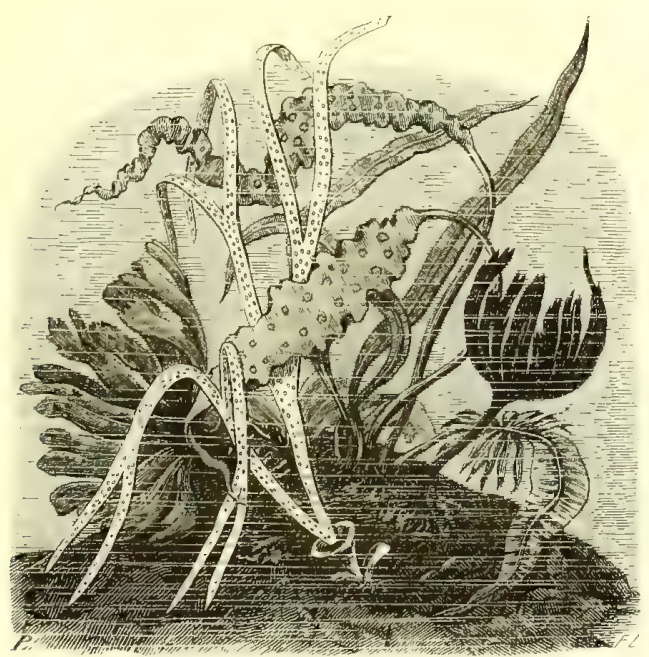

T.MMYMARES.

souvent frangées et plissées, qui flottent au gré des courants et se tordent aux vents des tempêtes. 
Les Agares étalent leurs languettes onduleuses ou leurs larges éventails à bords crispés ou découpés.

Les Alariées s'élancent dans le liquide avec leur support grêle et roide, surmonté d'une délicieuse collerette de ru-

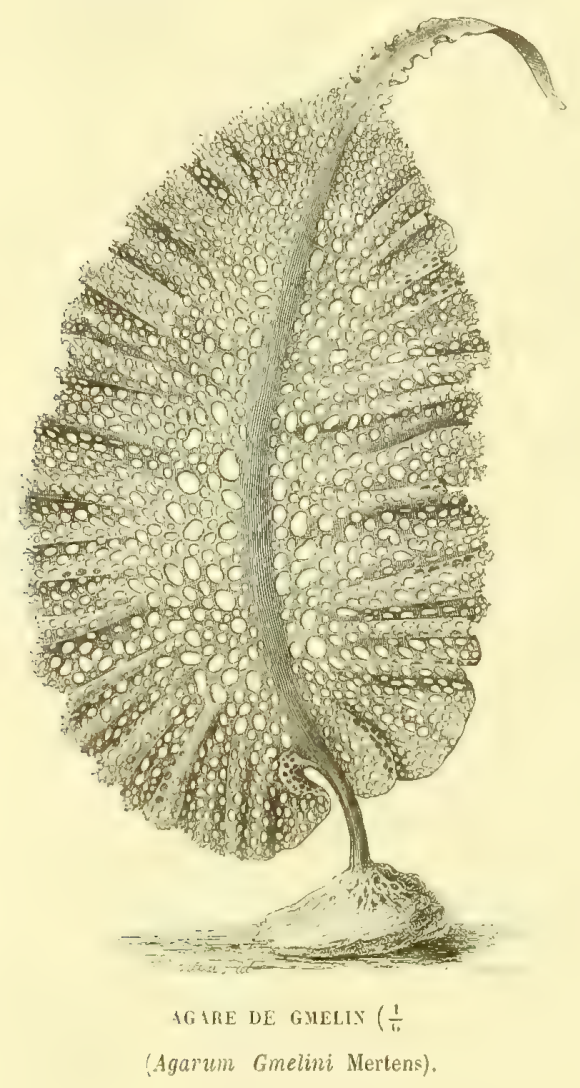

bans étroits et sinueux, du milieu de laquelle s'élève une lanière longue de plus de 1 ğ mètres, d'abord ćtroite, puis égale, puis graduellement rétrécie.

Le Varec porte-poire 'de la Terre de Feu compose de larges buissons ramifiés, dont chaque branche est terminée par un renflement creux, espèce de vessie natatoire gonflée

1 Macrocystis pyrifera Agardh. 
d'air, qu'on serait tenté de prendre pour un fruit. Ce Fucus peut atteindre jusqu'à une hauteur de 300 mètres (Cook, G. Forster); il dépasse, par conséquent, celle de nos arbres verts les plus élevés.

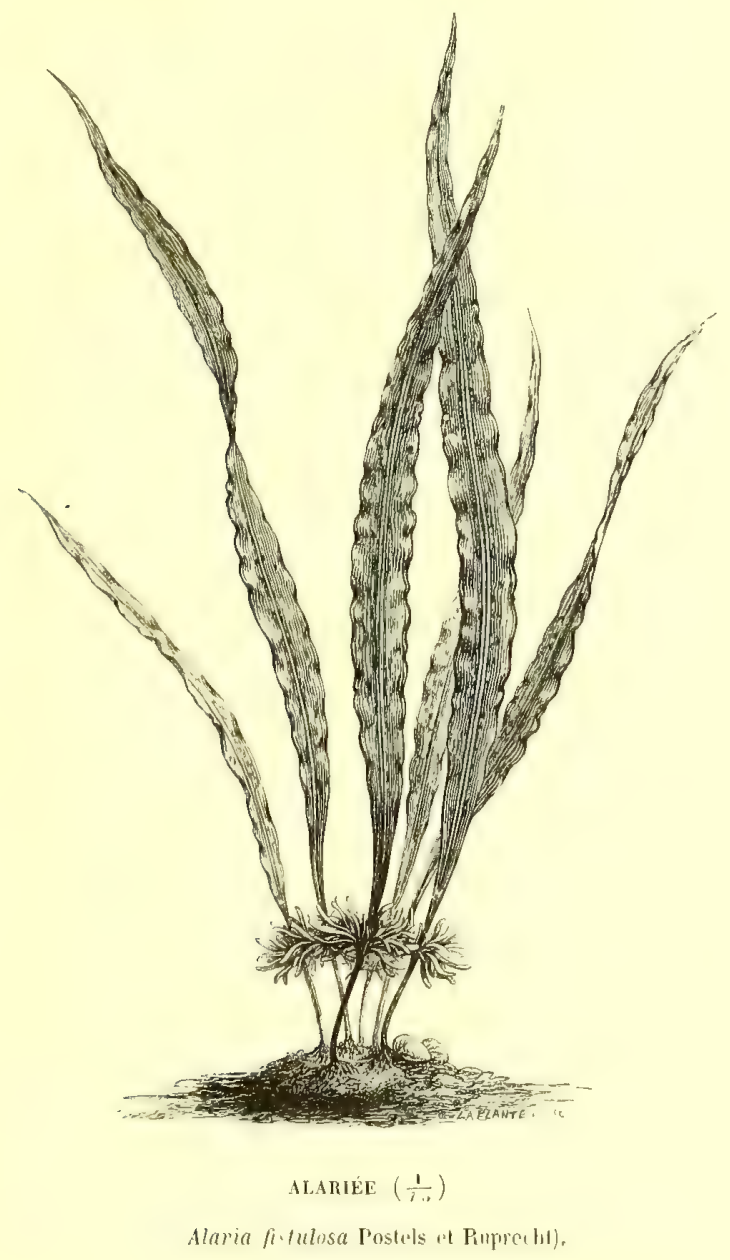

Les Néréocyslées ont une fansse tige filiforme, flexueuse, haute de 20 ì 30 mètres, grossissant légèrement vers l'extrémité, où elle se dilate brusquement en une petite poire, de l'ceil de laquelle s'échappe une touffe d'appendices dicho- 
tomes longs de 10 à 12 mètres, étroits et flexueux, composant un immense bouquet.

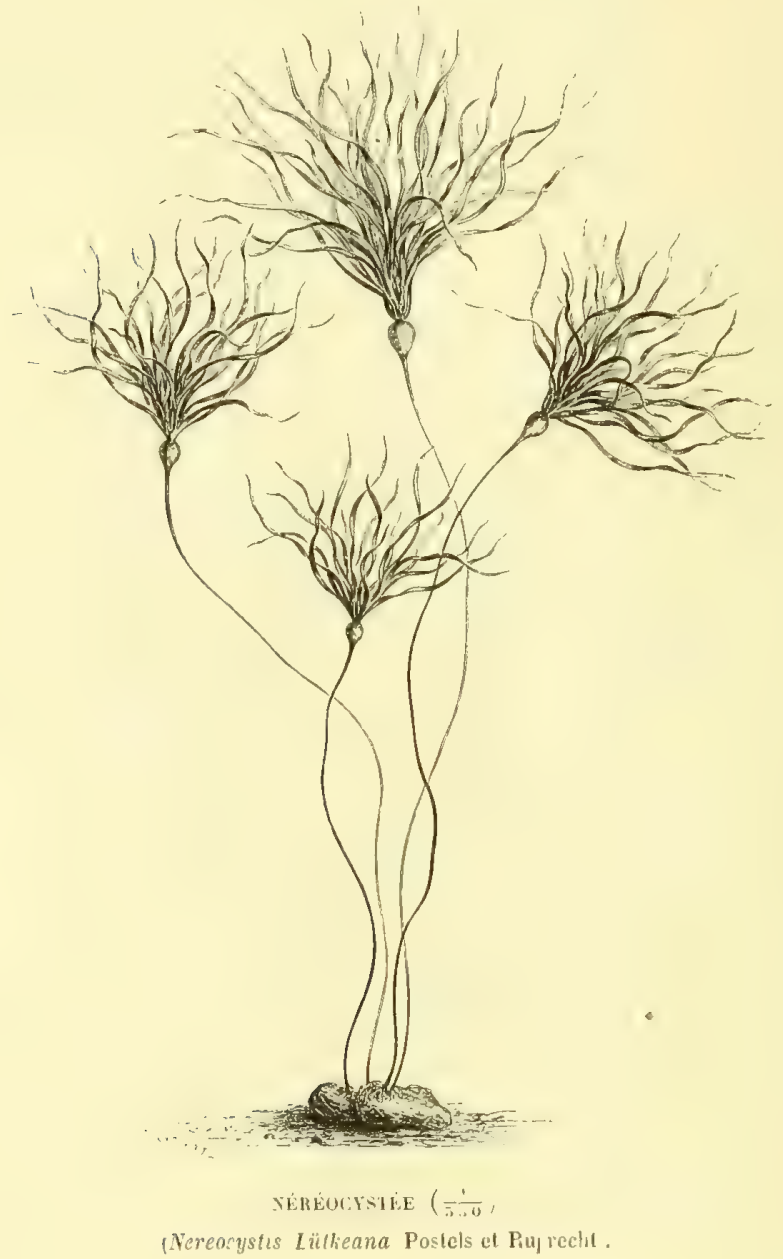

N'oublions pas de mentionner les Acétabules, organisations gracienses, longtemps mal connues, regardées par Tournefort comme des Algues ', et par Linné comme des Polypices?

I C'est aussi l'opinion de Donati, de Cavolini, d'Agardh, de Delile, de Link, de Kützing, de Zanardini, de Nägeli, de Woronine.

2 C'était aussi l'opinion de Cuvier, de Lamarck, de Blainville. 
Ce sont de petits plateaux orbiculaires, minces, en forme de parasols très-déprimés, striés en rayons, et plus ou moins semblables au chapeau de certains champignons, par exemple celui de l'Agaric androsacé'.

Au centre de l'ombelle, en dessous, se voit une tige trèsgrêle, longue et fistuleuse, qui sert de support. Les rayons sont creux, et leur tube communique avec la grande cavité du chapeau. Le végétal tout entier ne forme qu'une seule cellule. (Nägeli.)

La peau de la plante contient de la chaux carbonatée, grenue, disposée par couches concentriques.

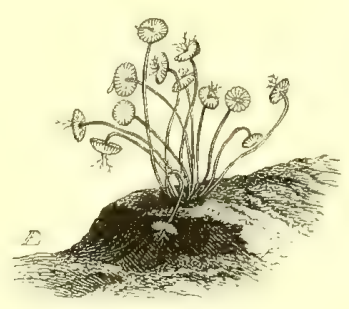

ACERABILE MARINE

(Acelabulum mediterianeum Lamarck).

Delile a laissé parmi ses papiers une monographie inédite de ce bizarre végétal. M. Woronine vient de publier une excellente étude sur son organisation.

“ Les tiges grandissent par le sommet, et produisent plusieurs verticilles successifs de rameanx confervoïdes. Les inférieurs périssent, étant caducs, et leurs points d'attache s'obliterent. De nouveanx verticilles supérieurs continuent de croître. Il arrive un degré auquel il semble qu'une soudure de tubes verticillés forme un bouton circulaire, véritable disque ou plateau celluleux à compartiments rayon-

' Agaricus androsaceus Iinné. 
nants. Ce plateau, d'abord demi-transparent, s'élargit jusqu’à maturité. Les verticilles confervoïdes inférieurs subsistent quelquefois par fragments, ou laissent des traces annulaires, tandis qu'me houppe de ramifications flottantes s'allonge au milieu du plateau. ") (Delile.)

Quelquefois on rencontre deux chapeaux l'un au-dessus de l'autre. (Woronine.)

\section{II}

Les plantes pélagiennes ne produisent ni calice, ni corolle; elles n'ont ni vraies étamines, ni vrais pistils: mais, par une merveilleuse compensation, ainsi qu'on le verra dans les chapitres suivants, beaucoup d'animaux de la mer sont organisés et quelquefois groupés comme de véritables fleurs !.... Bizarre élément, oì le règne animal fleurit, et où le règne végétal ne fleurit pas!

Pondant longtemps les botanistes ont ignoré le mode générateur des végétanx de l'Océan. Ils les rangeaient jarmi les plantes à noces cachées (Cryptogames). On sait aujourdhui que les Algues se reproduisent par le moyen de corpuscules, les uns mâles, les antres femelles, souvent doués d'une molilité singulière. Si les animaux marins ont emprunté anx végétaux terrestres la forme de leurs fleurs. les végétaux marins, à leur tour, ont pris aux animaux une partie de leur locomotion!

Ln 1793, Girod-Chantrans signala, le premier, mais sans bien s'en rendre compte, une sorte de mouvement spontané dans la matière granuleuse verte de certaines Algues. Il considérait mal à propos cette matière comme une agglomération d'animalcules analogues à ceux des Polypiers'.

I Voyez le chapitre VII. 
En 1817, Bory de Saint-Vincent découvrit d'me manière certaine, et démontra de la façon la plus évidente, la faculté locomotile des granulations dont il s'agit. Ses observations furent confirmées par Gaillon, à Paris, et par Agardh, à Stockholm. Les études plus récentes de MM. Derbès et Solier, et surtout de MII. Thuret et Pringsheim, ont jeté le plus grand jour sur la propagation des végétaux marins.

Les Algues rouges se reproduisent par des spores de deux espèces. Les premières, ou tétraspores, se développent au nombre de quatre dans des cellules appartenant à des frondes spéciales; elles paraissent ressembler à des bulbilles, et portent en elles-mèmes la raison de leur germination. Les spores proprement dites maissent dans des capsules, ou polyspores; l'action des anthéridies semble nécessaire à leur entier développement : ce sont de véritables graines.

Les anthéridies sont de formes très-variables, et finissent par se diviser en nombreuses cellules. Ces cellules deviennent libres; elles ne germent pas, mais il est probable que leur action sur les polyspores est analogue à ce que nous offrent celles des Algues vertes.

Le plus souvent chacun de ces organes appartient à une plante distincte, de telle sorte que l'espèce comprend trois formes d'individus; ce qui est encore plus compliqué que chez le Dattier, où il y a seulement des pieds mâles et des pieds femelles.

Les Algues vertes se propagent principalement par des zoospores et par des spores.

Les zoospores sont des corpuseules microscopiques d'euviron un ou deux centièmes de millimètre de longueur, de forme ovoïde ou turbinée, et remplis aux deux tiers d'une matière verte (chlorophylle). L'extrémité antérieure, ou 
rostre, est atténuéc en pointe et surmontée le plus souvent par deux ou quatre cils plus longs que le corpuscule tout entier. Dans certaines Algues (Phéosporées), les cils sont inégaux, le plus long dirigé en avant, le plus court trainant par derrière comme unc sorte de gouvernail. Vers la naissance du rostre, on observe fréquemment un point rou-

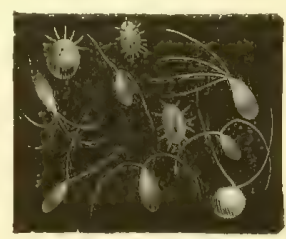

ZOKSPOKES.

geatre, qui subsiste encope quelefue temps après que la germination est commencée.

Le Myrionema, parasite qui forme sur la surface des autres Algues de petites tames lomes ayant à peine quelques lignes de large, et l'Ilaligenia, dont la fronde étalée atteint jusqu à douze pieds de diamètre, se reproduisent par des zoospores semblables, présentant la même petitesse et la mème simplicité d'organisation. L'analogic nous conduit de même à supposer que les immenses Lessonia arjorescents de l'océan Austral se propagent aussi par des zoospores dont la longueur ne dépasse guère un centième de millimètre. (Thuret.)

Certaines Algues jonissent dims toutes les parties de leur tissu de la faculté de produire des zoospores; dans d'autres espèces, au contraire, leur formation est plus ou moins localisée dans quelques parties de la fronde.

Ces corpuscules semblent toujours produits par une sorte de coagulation de la matière contenue dans les cellules. Cette matière s'agglomère en masses plus ou moins nom- 
breuses, d'abord confuses et mal limitées (fig. 1), plus tard nettement circonscrites (fig. 2), et constituant alors autant de zoospores distinctes (fig. 3).

L'émission des zoospores a presque toujours lieu avec une sorte de violence, déterminée par la pression exercéc sur les parois de la cellule par le liquide mucilagineux

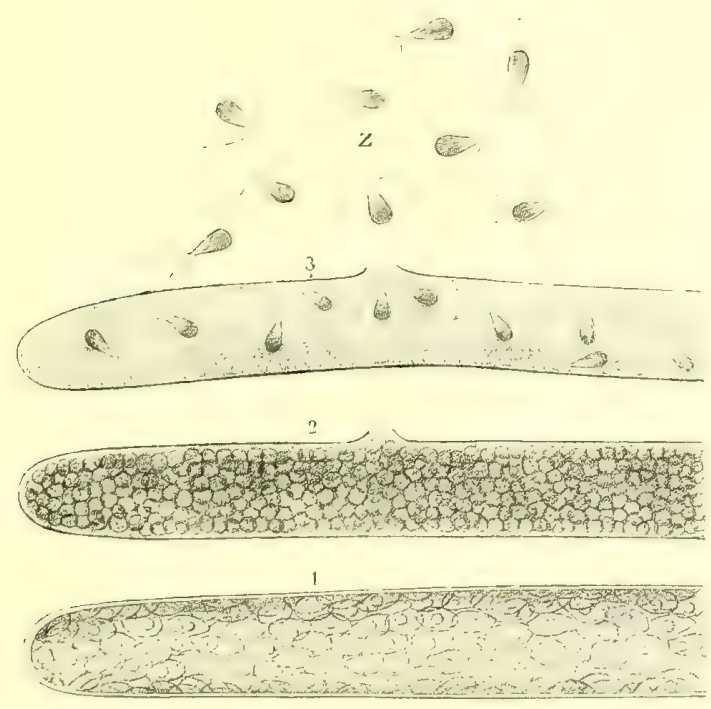

FORMATIOY ET ÉMISSION DLS ZOOSPORES (

(Bryopsis hynoides Lamarck).

qui en remplit la cavité. Ce liquide augmente peu à peu de volume par endosmose, et finit par en déterminer la rupture.

Aussitôt libres (fig. Z), les zoospores s'agitent dans tous les sens, présentant presque toujours leur rostre en avant. Leurs mouvements sont vifs et capricieux; quelquefois elles reviennent subitement en arrière; souvent on les voit pirouetter sur leur grand axe. Si le vase qui les contient est placé dans le voisinage d'une fenêtre, elles se dirigent le plus souvent vers la lumière. (Thuret.) 
Après s'être ainsi démenées pendant plusieurs heures ou plusieurs jours, suivant les espèces, les zoospores (fig. Z) se fixent par leur rostre au moyen d'une sécrétion mucilagineuse; leur corps s'arrondit; les cils, décomposés ou détachés, disparaissent; en même temps l'extrémité opposée

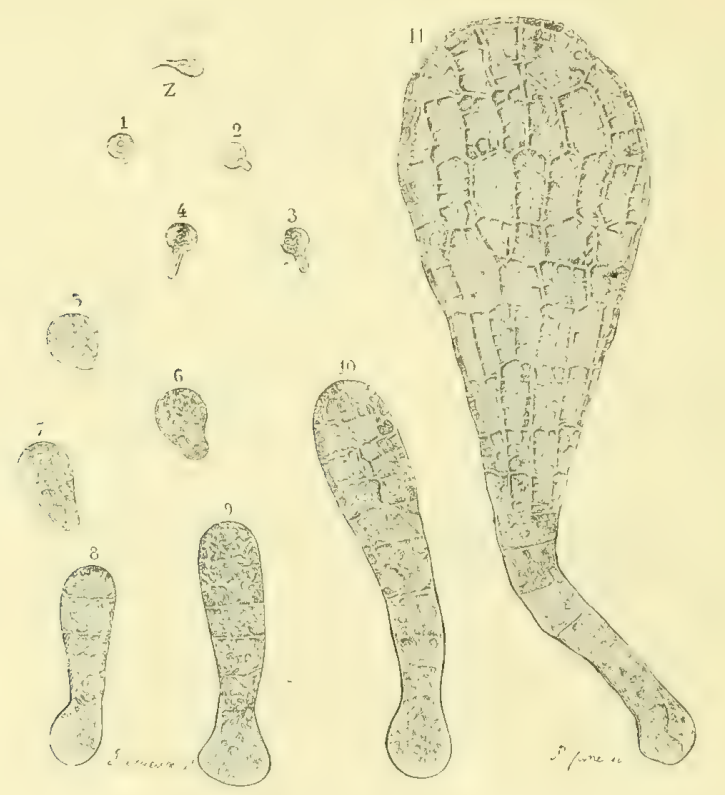

DEVELOPPEMEXT DE LA ZUOSPURE ET FuRMATIOA DE LA JELSE PLAYTE $\left(\frac{5 !}{\mathbf{1}}\right)$

(Haligenia bulbosa Decaisne).

grossit et s'allonge en un tube qui ne tarde pas à se cloisomner. Souvent même ce développement est si rapide, qu’il suffit de quelques jours pour voir se former une jeune fronde (fig. 11). (Thuret.)

I a spore est une petite masse ronde remplie d'une substance olivâtre, et qui reçoit, de corpuscules ciliés (anthérozoïdes), la propriété de reproduire un individu semblable à celui qui lui a donné naissance. Elle est contenue dans un sac (sporange) fixé par un court pédicule aux parois d'une cavité (conceptacle) qui s'ouvre à l'exté- 
rieur par un petit orifice (ostiole). Le sporange con-

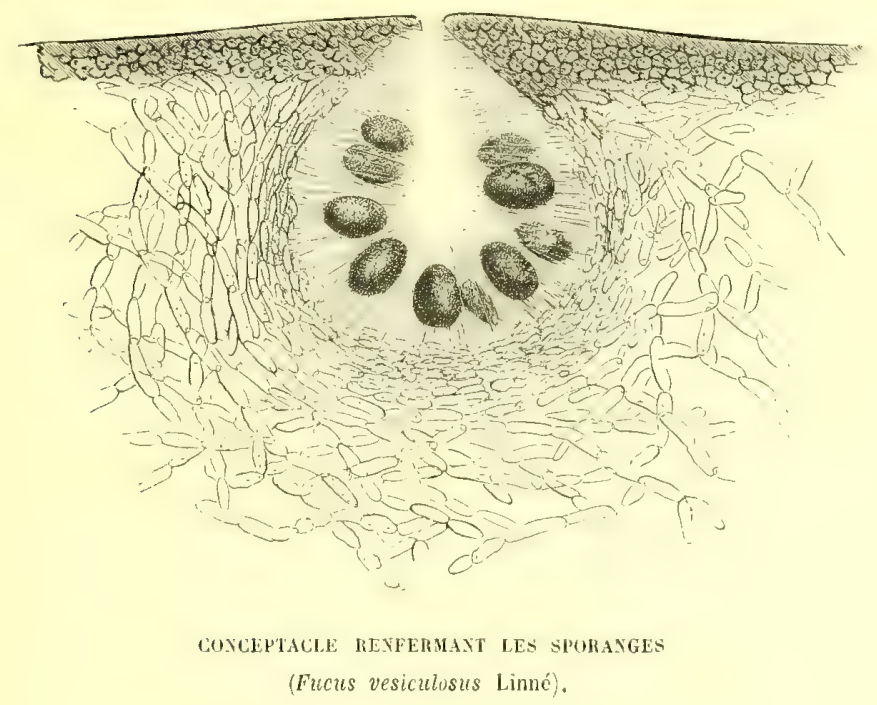

tient, suivant les espèces, une ou plusieurs spores.

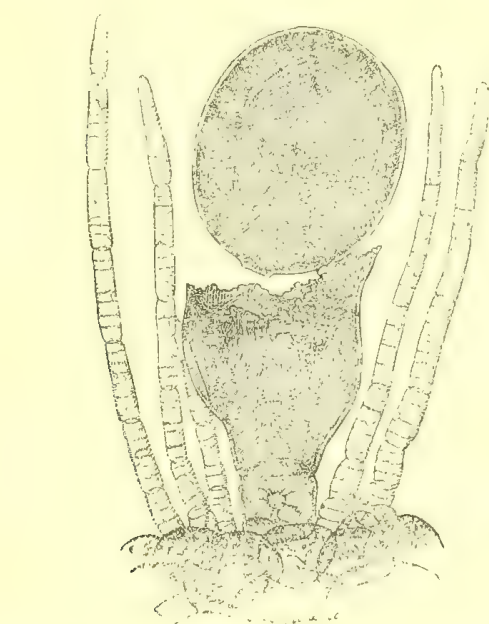

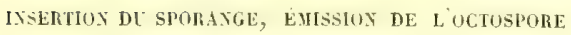
(Fucus vesiculosus Linné).

Les anthérozoïdes consistent en des corpuscules microscopiques d'un ou deux centic̀mes de millimètre de longueur 
environ, renfermant un granule coloré qui semble faire saillic à la surface, et muni de deux cils locomoteurs trèsténus. Ils sont en grand nombre dans un petit sac ovoïde

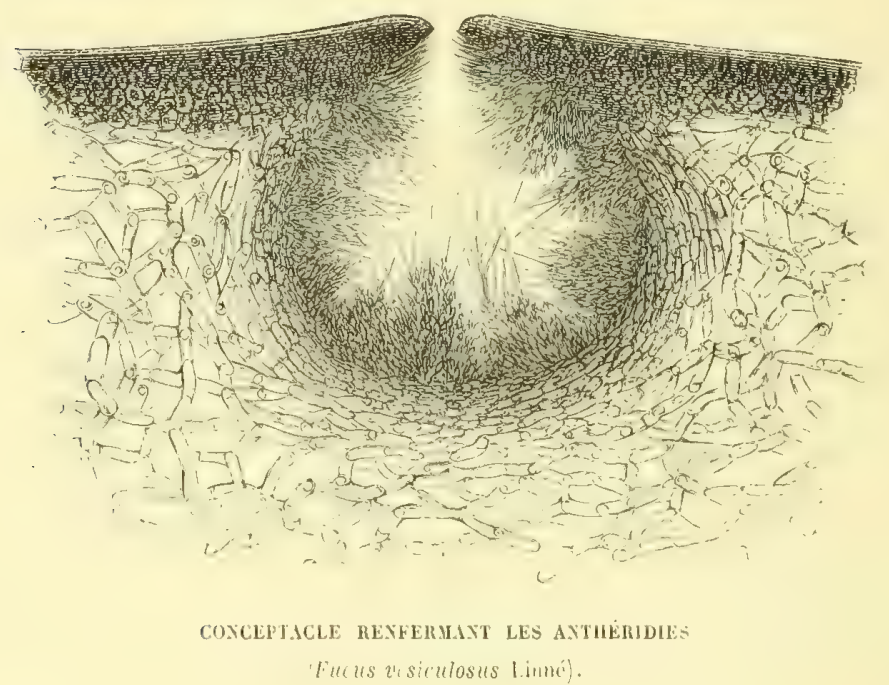

transparent (anthéridie) inséré par sa base sur des poils ramenx et articulés. Ces poils naissent des parois d'un con-
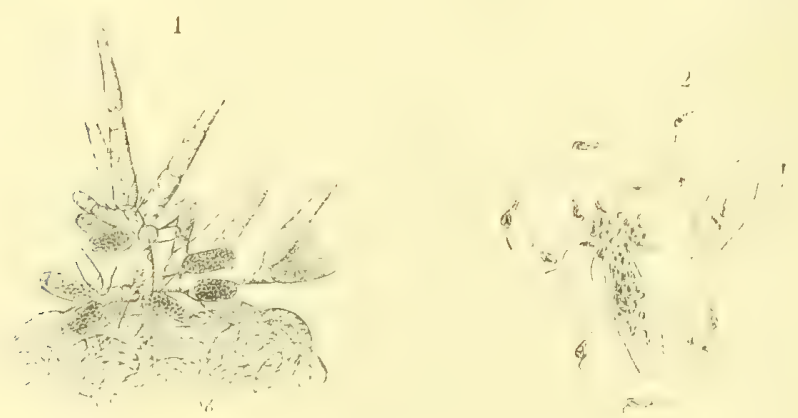

1. Nasertion DES ANTIÉRIDIES, - 2. ÉMISSION DES AYTHÉROZOİDES (Fucus vesiculosus Linné).

ceptacle, ef convergent ver's l'ostiole, comme pour guider les anthérozoïdes à la sortie de leur cavité. 
Les sporanges et les anthéridies peuvent être, selon les espèces, réunis dans un mème conceptacle, ou séparés dans des individus différents et dans des conceptacles distincts.

Voici, d'après les beaux travaux de M. Thuret, la suite des phénomènes auxquels donne lieu ce mode de reproduction dans le Fucus vésiculeux ${ }^{1}$ :

Les sporanges tirent leur origine des cellules de la cavité conceptaculaire. Quelques-unes d'entre ces cellules forment au-dessus des autres une petite protubérance qui se dédouble au moyen d'une cloison transversale: l'inférieure cesse de grossir, et forme dès lors le pédicule; la supérieure continue de s'accroitre, se remplit d'unc matière olivâtre et s'organise en sporange. Bientôt cette matière se segmente en huit parties qui constitueront autant de spores; leur réunion est l'octospore. Ce corps se présente sous la forme d'une masse oparpue et brunàtre entourée de deux membranes transparentes. La membrane extérieure (périspore) appartient au sporange, et reste fixée au pédicule quand celui-ci crève. La membrane interne (épispore) reste adhérente à la masse commune, et retient les spores fortement serrées entre elles. Une fois sorties des sporanges, les octospores glissent jusqu'à l'orifice du conceptacle et se dispersent dans l'eau.

Bientôt elles angmentent de volunc; en nême temps la membranc enveloppante (épispore) commence à se dissoudro à la partie supérieure, et l'on s'aperçoit alors (fig. 1) que les spores sont encore revêtues d'une troisième membrane extrèmement délicate. La portion inférieure de l'épispoé, qui ne s'est pas dissoute, se replie sur elle-même pour livrer

' Voyez les figures de la planche V, dont les éléments nous ont été libéralement communiqués par M. Thuret. 
passage aux spores (fig. 2), s'en sépare complétement et ne tient plus que par sa base à la membrane interne (fig. 3); enfin, cette dernic̀re se brise et laisse échapper les spores (fig. 4). Tous ces phénomènes s'accomplissent en moins d'une heure. Les spores libres sont parfaitement rondes, d'uu jaune olivâtre, absolument dépourvues de tégument; c'est à ce moment que l'action des anthérozoïdes (fig. A) devra intervenir pour féconder la spore dégagée de ses enveloppes. Il suffit pour cela que quelques anthéridies soient mélangées à l'eau qui contient les corps reproducteurs. Sous l'influence de l'hmmidité, les anthérozoïdes se dégagent de leur anthéridie (fig. a), entourent la spore, s'attachent à sa surface (fig. b), et, an moyen de leurs cils locomoteurs, lui communiquent un mouvement de rotation très-vif. Peu à peu ce mouvement se ralentit, et au bout d'une demi-heure il a entièrement cessé. Quelques heures après, la spore se revêt d'une membrane; plus tard encore une cloison apparaît, qui la divise en deux cellules (fig. (i). En mème temps (fig. 7) se montre un petit épaississement qui continue à s'allonger, et finit par se convertir en un filament transparent, défourvu de matière verte, et ne renfermant que quelques grains jaunâtres à son extrémité. Bientôt plusieurs de ces radicules naissent à la base de la spore, et servent à fixer la jeune fronde (fig. 7, 8, 9, 10). Celle-ci, dont les cellules ont continué à se multiplier par la production de nouvclles cloisons dans les cellules déjà existantes, s'allonge peu à peu en une petite expansion de forme obovale et de couleur brune (fig. 1 1, 12). La jeune fronde est maintenant formée; elle présente déjà, en plus petit, il est vrai, les organes fondamentaux de la plante mère. Encore quelques jours, elle aura acquis son entier développement, et sera capable à son tour de reproduire des individus semblables à elle-mème. 


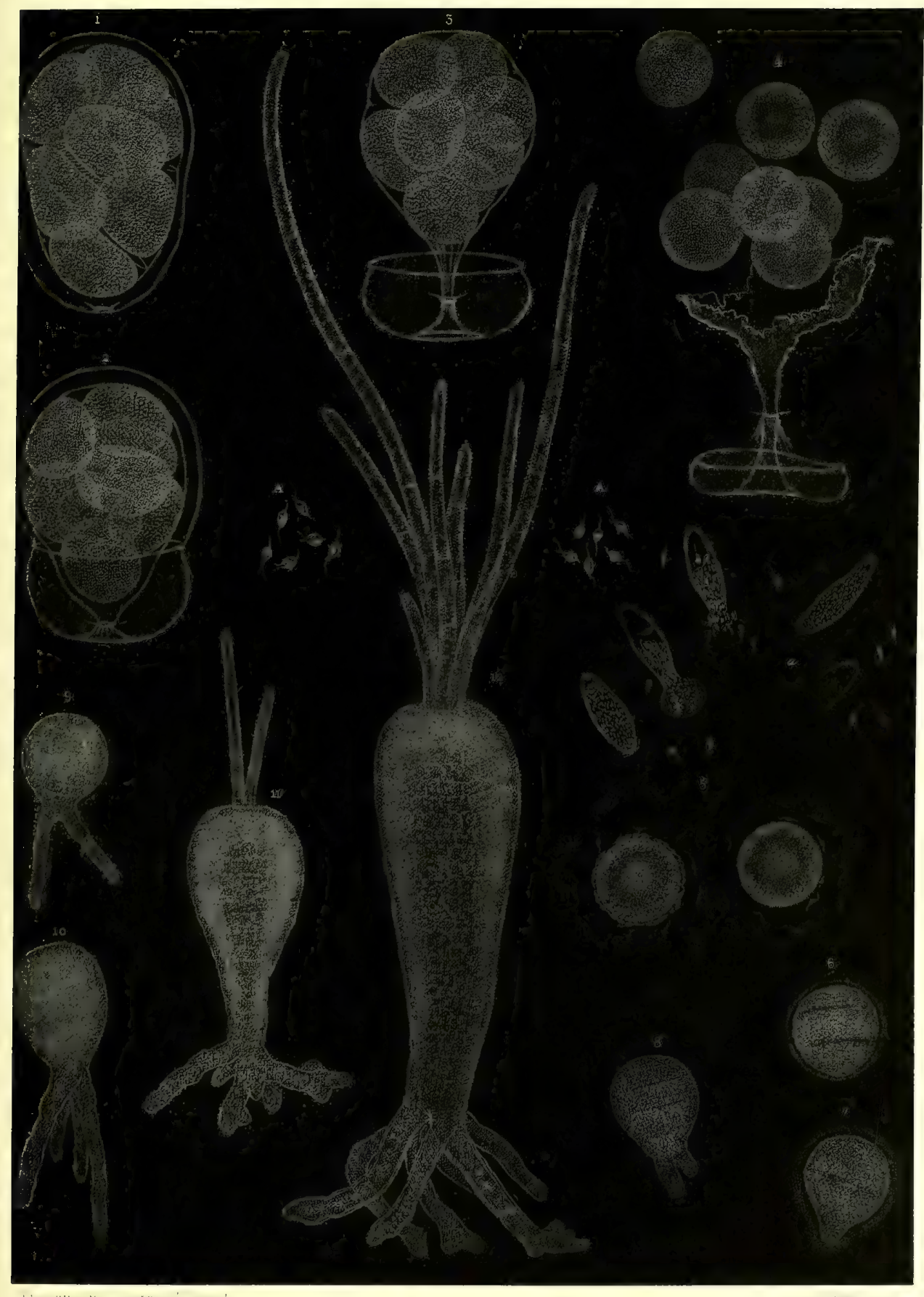

REPROLUCIION ET GERMINATION D'UNE ALGUE. 



\section{VII}

Chaque marée, et surtout chaque ouragan accumule sur les côtes occidentales de l'Europe d'énormes monceaux de Varees ou Goëmons. On les recueille et on les transporte dans les champs pour y servir d'engrais. Les pauvres gens les font sécher, e'est là leur combustible. D'autres fois on

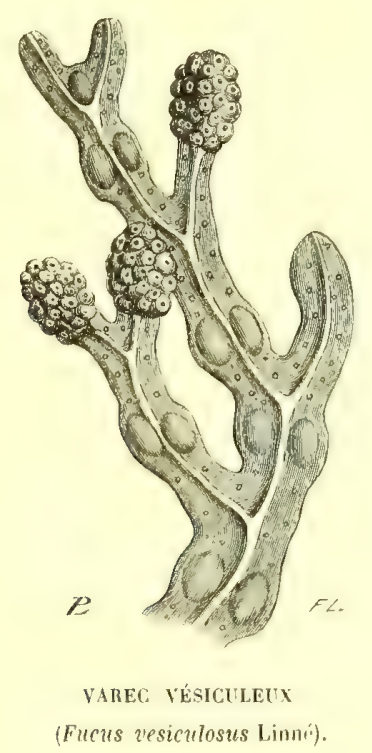

prépare avec ces plantes marines la soude de Varec, on soude naturelle. Les Goëmons couvrent la plage et les rochers submergés. Ils forment sur le sable de longues trainées flexuenses indiquant la limite atteinte par la vague. Les principaux sont le Vraigin, on Varec à nœuds ', renflé d'espace en espace de vésicules pleines d'air; le Craquel, on Varec vésiculenx, caractérisí anssi par de petites outres

1 Fucus modosus Iinné. 
semblables à des pois; et le Vraiplat, ou Varec dentelé ', dont les lanières ont les bords découpés en scie et la surface parsemée de petits enfoncements. On exploite aussi le Varec à siliques ${ }^{2}$, qui porte des capsules allongées et comprimées, marquées de cloisons transversales, comme les fruits des choux et des navets.

Dans certaines baies il y a jusqu’à 30000 personnes qui accourent sur la grive pour ramasser les fö̈mons que la mer a jetés, ou pour couper ceux qui végètent sur les rochers. Comme dans cette sorte de récolte... on de pillage, les phus riches, qui disposent de nombreux attelages et de beancoup de bras, seraient toujours les mieux partagés, les prêtres catholiques du moyen âge avaient établi me contume aussi ingénieuse que noble. C'était de n'admettre, le premier jour, à la récolte du Varec, que les habitants pou aisés de lat paroisse. Cenx-ci empruntaient a leurs voisins des charrettes et des chevaux, et parvenaient ainsi it finire une honne récolte. Dans le Finistère, où les mœurs antiques sont en partic conservées, cet usage se retrouve "meore : le premicr jour de la coupe du Goümon s'y appelle lo gour du paure. Le prêtre vient à la grève dìs le matin, et si un riche se présente pour récolter : - c Laissez les pauvres gens ramasser leur pain », dit le recteur. Et le riche se retire. (Mag. pitlor.)

Les ouvriers qui se livrent à la fabrication de la soude de Varec sont appelés barilleurs on soudiers, aux environs de Brest et de Cherbourg.

Les barilleurs se rendent dans les lieux les plus favorables par groupes de six hommes, et construisent au centre de l'espace qu'ils veulent exploiter une sorte de

1 Fucus serratus Linné.

2 Furus siliquosue Iinno. 
cabane dans laquelle ils se retirent pour passer la nuit. Quand la mer est basse, les ouvriers se dispersent sur les rochers, arrachent les Varecs et en forment de grands tas. Ils transportent ceux-ci vers un endroit déterminé du rivage, soit en les faisant flotter, soit avec des civières, soit tout simplement sur leur dos. Ils les étalent sur la grève, au soleil. Quand la dessiccation est suffisante, ils les empilent dans des fours formés de quatre pierres plates disposées en rectangle, et y mettent le feu. La combustion s'opère lentement en répandant une fumée abondante des plus désagréables. Les Goëmons, constamment remués avec une barre de fer, développent une forte chaleur; les cendres subissent une sorte de vitrification, et se premment en masse : c'est cette matière qui constitue la soude de Varec.

Anciennement, dans les seules îles Orkneys, 20000 hommes étaient occupés toute l'année à ramasser des Fucus et à les brùler. Aujourd'hui, dans ces mêmes îles, l'industrie de la soude a été remplacée par celle de l'iode, laquelle est bien loin de donner les mèmes avantages. (L. Wraxall.)

Un autre produit de la mer, exploité sur les bords de l'Océan, c'est la Zostère marine ', plante remarquable par' ses longues feuilles rubanées, d'un vert sombre. Cette plante n'est pas une Algue; clle appartient à la famille des Zostéracées. Elle a des racines très-grêles qui l'attachent aux sables mouvants; elle possède de véritables fleurs, à la vérité bien petites et bien modestes. La Zostère est cmployée, dans beancomp d'endroits, pour les matelas, les coussins, et surtout pour les emballages. En Ilollande, ì l'entrée du Zuyderzée, on s'en sert, sous le nom de Wier, pour la construction des digues. (De Candolle.) 
On est vraiment saisi d'admiration, quand on réfléchit sur les énormes masses de végétaux marius que charue marée ou chaque tempête rejette et accumule sur les plages tous les ans, tous les mors, même tous les jours, sans que jamais leur quantité paraisse s'amoindrir.

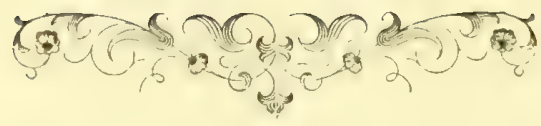




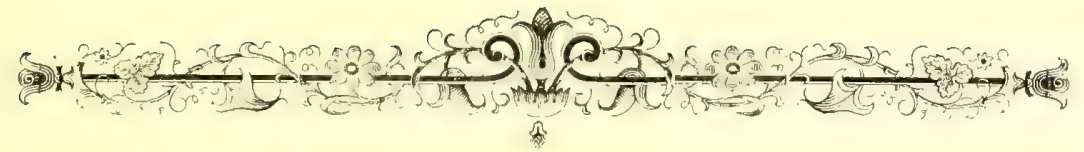

\section{CHAPITRE V}

\section{LES ANIMAUX INFUSOIRES.}

"Natura nusquim magis quim in minimis totn est.") (PLine.)

।

La Providence a distribué avec une grande profusion les espèces et les individus inféricurs de l'animalité. Dieu semble avoir voulu consoler (et même égayer) les abîmes de la mer en y répandant par millions et par milliards les représentants les plus mobiles de la vie.

L'Océan est done penplé de légions innombrables d'infi-

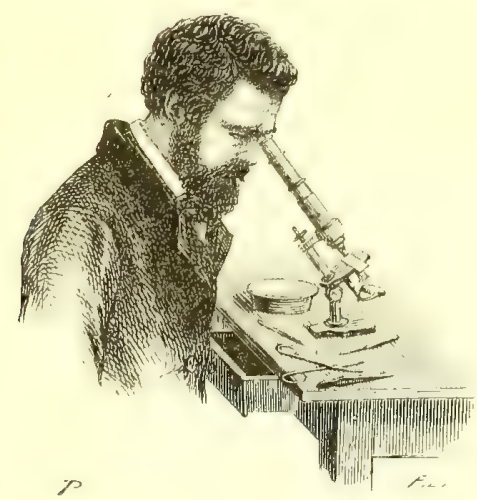

MICROSCOPE.

niment petits... Ces infiniment petits échapperaient encore à nos regards, si nous ne possédions pas le microscope, re sixieme sens dr l'homme, comme l'appelle M. Michelet. 
Le microscope! merveilleux instrument qui a fait pour J'organisation ce que le télescope a fait pour les étoiles ${ }^{1}$ !

La connaissance des Infusoires est, sans contredit, une des plus belles conquètes de l'optique. C'est un monde entièrement nouveau que nous a révélé la précicuse lunette, et l'une des sources les plus fécondes de notre admiration pour la puissance créatrice.

“ Il n’y a chose, en ce monde, tant soit elle estimée "petite et lesgicre, qui ne nous soit tesmoignage de la s grandenr de nostre supernatmel et plus que nompareil »Ouvrier. »(Belon.)

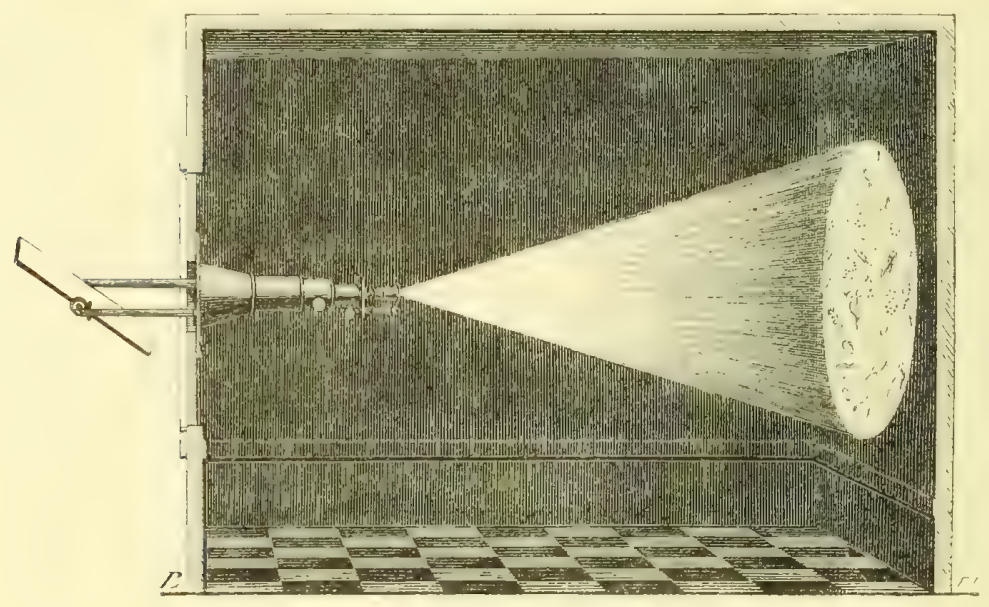

MLROSCOPE SOLAIRE.

Les animalumes infusoires sont tellement petits, qu'une gouttelette de liquide en contient plusieurs millions.

Toutes les eaux en présentent, les douces comme les salées, les froides comme les chaudes. Les grands fleuves en charrient constamment des quantités énormes dans la mer.

1 " Le microscope précise les caractères des infiniment pelits, comme le télescope rapproche les infiniment grands. » (Leibnitz.) 
Le Gange en transporte, dans l'espace d'une année, une masse égale à six ou huit fois le volume de la plus grande pyramide d'Égypte. Parmi ces animalcules, on a compté soixante et onze espèces différentes. (Ehrenberg.)

L'eau et la vase recueillies entre les îles Philippines et les îles Mariannes, à une profondeur de 6600 mètres, on ont donné cent seize espèces.

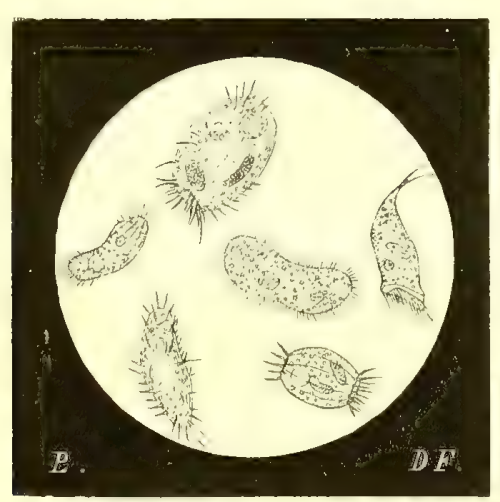

IFUSOURE, DIVERS

Près des denx pôles, là où de grands organismes ne pourraient pas exister, on rencontre encore des myriades d'Infusoires. Ceux qu'on a observés dans les mers du pôle austral, pendant le voyage du capitaine James Ross, offraient une richesse toute particuliere d'organisations inconnues jusqu'ici et souvent d'une élégance remarquable. Dans les résidus de la fonte des glaces qui flottent en bloes arrondis, par $70^{\circ} 10^{\prime}$ de latitude, on a trouvé près de cinquante espèces différentes. (Ehrenberg.)

A des profondeurs de la mer qui dépassent les hauteurs des plus puissantes montagnes, chaque couche d'eau est animée par des phalanges innombrables d'imperceptibles habitants. (Humboldt.)

Les Infusoires sont done it ha fois les animaux les plus 
petits et les plus nombreux de la nature. Ces êtres microscopiques constituent, anssi bien que l'espèce humaine, un des rouages de la machine si compliquée de notre globe. Ils sont à leur rang et à leur échelon : ainsi l'a voulu la grande Pensée premiere! Supprimez ces microscopiques bestiolettes, et le monde sera incomplet! On l'a dit il y a longtemps, il n'est rien de si petit à la vue qui ne devienne grand par la réflexion!

\section{II}

Les Infusoires sont tous plus on moins translucides. Ils n'ont pas assez de substance pour arriver à l'opacité!

Lem corps est plus ou moins globuleux on ovoide, yuel-

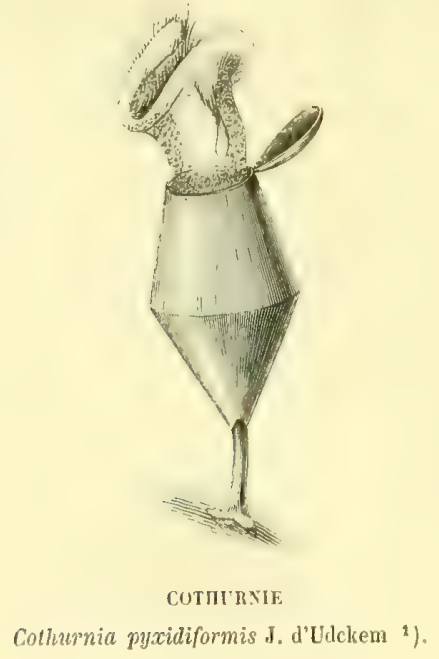

quefois façomé en navette on comló en croissant, enflé comme une ampoule, aplati comme un disque, aminci

1 Infusoire d'eau douce des environs de Lille, réduit d'après un dessin communiqué par M. Lacaze-Duthiers. 
comme une feuille.... Certains ressemblent à un tètard, à un dé, à une clochette, à un sabot, à un bouton de rose, à une fleur, à une graine...

Les Monades ${ }^{1}$, ces petits des petits, semblent n'ètre que des molécules de substance absorbante, des atomes agités,

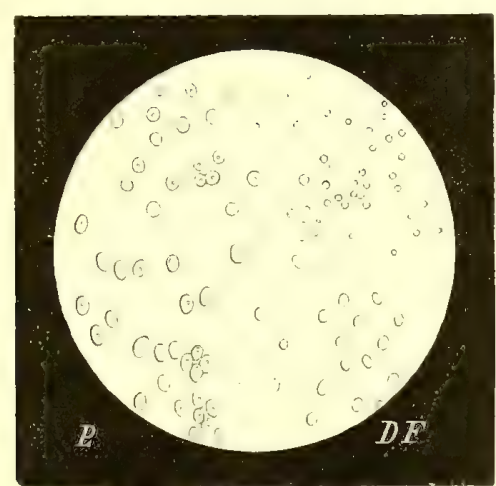

MONADES.

des points qui se meuvent. Ces délicates créatures n’ont environ qu'un trois-millième de millimitre de grand diamètre!...

\section{1}

On a regardé d’abord les Infusoires comme privés de toute espèce d'organisation. On a сти qu'ils se nourrissaient par absorption, uniruement par absorption. Mais on a fini par découvrir que certaines espèces étaient assez compliquées. Il en est (polygastriques) qui n'ont pas moins de quatre estomacs (vacuoles) bien distincts. Les mammifères ruminants n'en présentent pas davantage. M. Ehrenbergr

\footnotetext{
'Monas termo Müller.
} 
assure avoir vu des Infusoires pourvus de deux cents estomacs!... L'appétit de ces animaux est-il en rapport avec ce luxe stomacal?

Pour étudier les organes de ces imperceptibles vies, il faut colorer avec du carmin ou de l'indigo le liquide dans lequel elles s'agitent. Puis, plaçant une goutte de cette liqueur colorée sur un morceau de verre, auprès d'une goutte d'eau pure, on fait communiquer les deux gouttes

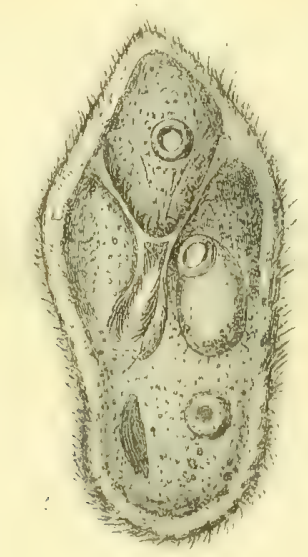

IXFUSOIRE GROSSI

(Paramecium bursaria Pritchard).

fal $u$ point, avee une aiguille. Les animaleules arrivent de la goutte colorée dans la goutte incolore, et viennent s'offrir à l'observateur avec les estomacs of le canal alimentaire remplis de carmin ou d'indigo.

Les difficultés que présente l'exanen des Infusoires et l'imagination des observateurs ont été prendant longtemps des obstacles sérieux à la connaissance de ces infimiment petits. Lenwenhoeck, si habile à se servir des microscopes qu’il fabriquait lui-mème, apporta dans leur étude une préoccupation qui lui fit toujours supposer des faits au delà 
de ceux qu'il voyait réellement. Il s'extasiait devant la complexité et la perfection de ces êtres microscopiques, et voulait admettre, jusque dans lemr filament caudal, des vaisseaux, des museles et des nerfs (Dujardin). Joblot allait plus loin : il voyait, parmi eux, des cornemuses vivantes, des poules huppées, des poissons d'or et d'argent!... On sait aujourd'hui que les Infusoires ne sont, ni aussi compli-

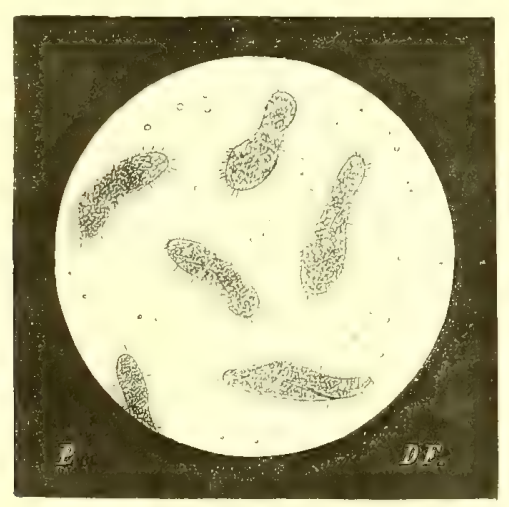

PIRAMECIES.

qués que l'ont écrit certains auteurs, ni aussi simples que l'ont voulu plusieurs autres. C'est au savant professeur Ehrenbero, et plus tard à MM. de Siebold, Claparède, Lachmann, Lieberkühn et Balliani, que nous devons les travaux les plus complets et les plus intéressants que possède la science sur ces jolis petits nains de l'animalité.

Les Infusoires sont pourvus, en avant ou tout autour du corps, d'un certain nombre de cils plus ou moins fins, égaux ou inégaux, toujours en mouvement, lesquels produisent des tourbillons et des comrants qui attirent dans la bouche de la plus petite bête (quand elle en a une) les parcelles organiques qui doivent la nourrir. Les cils dont il s'agit, servent non-seulement à l'alimentation de l'animalcule, mais encore à sa respiration et à ses mouvements. 
Les Infusoires ne possèdent pas de membres proprement dits. Quelques-uns ont une queue plus ou moins longue.

Ces miniatures animales nagent comme des Poissons, rampent comme des Serpents, ou se tortillent comme des Lombrics. Les Volvoces ${ }^{1}$ roulent et tournoient constamment sur eux-mêmes, semblables à des boules abandonnées sur un plan incliné.

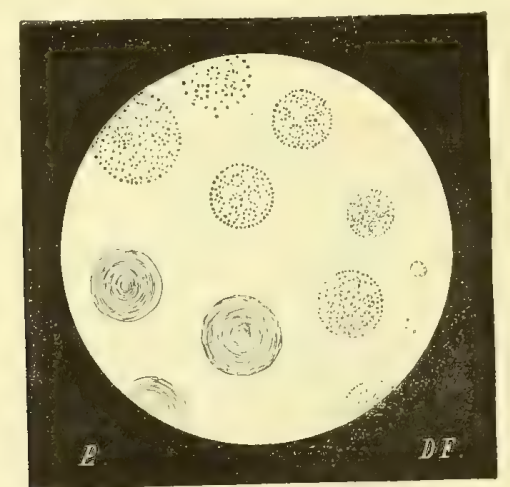

VOLYOCES.

La plus petite bète qui remue, comme la plus petite fleur qui éclôt, éveille dans notre coeur un sentiment profond qui nous surprend et nous réjouit, nous émeut et nous fait rêver!....

\section{IV}

Les Infusoires se propagent de diverses manières. D'abord par division spontance (scissiparité) : ils se partagent en deux parties égales qui deviennent chacune exactement semblables à l'individu primitif; de telle sorte que, littéralement, le fils est la moitié de sa mère, et le petit-fils le quart de son aieule. D'autres se perpétuent

1 Volvox globator Linné. 
par émission de bourgeons (gemmiparité). Comme on le pense bien, ces sortes d'œufs doivent être d'une excessive petitesse.

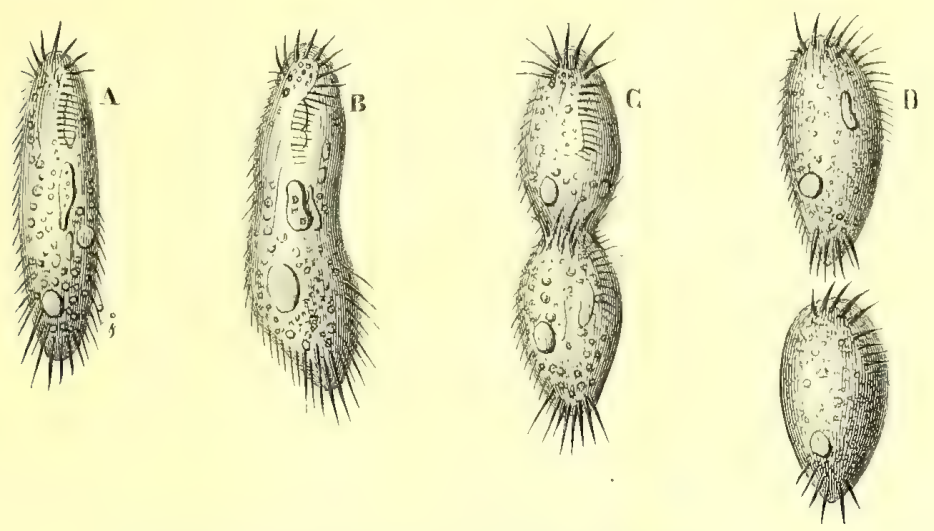

PROPAGATION D'UN INFUSOIRE PAR DIYISION SPOYTAYEE.

Dans l'espace de quelques jours, on voit naitre, dans un verre d'eau de mer, soit par division, soit par germes, plusieurs millions d'individus.

Tout récemment on a découvert, chez plusieurs espèces, des individus mâles et des individus femelles ${ }^{1}$.

Deux Infusoires se rencontrent dans leurs courses vagabondes, se réunissent, se greffent par leur partie antérieure (fig. 1), se fusionnent (fig. 2, 3, 4, 5), et ne forment plus qu'une masse homogène (fig. 6). Celle-ci s'entoure d'une enveloppe transparente, et laisse voir dans son intérieur quatre points nébuleux (fig. 7) qui s'étendent et se transforment en quatre corps oviformes (fig. 8). Bientôt l'enveloppe se déchire et laisse échapper les corps oviformes (fig. 9), lesquels, comme certaines graines, attendront peut-ètre des années avant de trouver les circonstances nécessaires à leur dévelopjement. Alor's la semence

' b'après M. Balbiani, les Infusoires seraient des hermuphrodites complets dans le genre des Limaçons. (Voyez le chapitre XXIII et la planche V bis, communiquée par M. Gerbe.) 
germe (fig. 10, 11), l'Infusoire se dessine (tig. 12), grossit rapidement (fig. 13, 14), et, devenu adulte (fig. 15), reprend sa course capricieuse à la recherche do quelque autre Infusoire de son espèce, auquel il unira sa destinée.

Il peut done y avoir de l'amour et des caresses dans une goutte d'eau! O Jéhovah!

La vie est répandue dans la Nature avec une telle abondance, que de très-petits Infusoires s'établissent en parasites

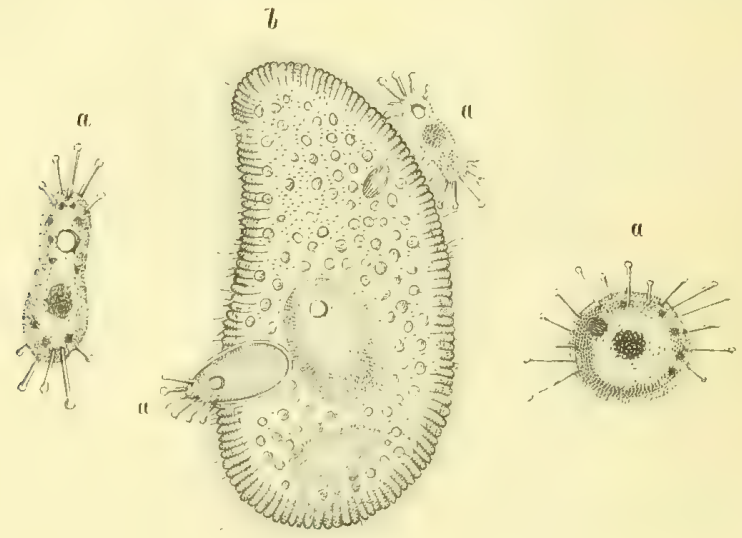

UN INFUSOIRE ET SES PARASITES.

sur d'autres Infusoires un peu plus grands, et servent à leur tour de demeure et de pâture à d'autres animalcules encore plus petits. (Humboldt.)

Les parasites de la Paramécie Aurélie ${ }^{1}$ sont tantôt sous la forme de massettes cylindriques, pourvues de quelques suçoirs assez courts et revètues de cils natatoires; tantôt sphériques et dépouillées de leur revêtement ciliaire, mais conservant leurs suçoirs. Les premiers nagent librement

1 Paramecium Aurelia Müller. 


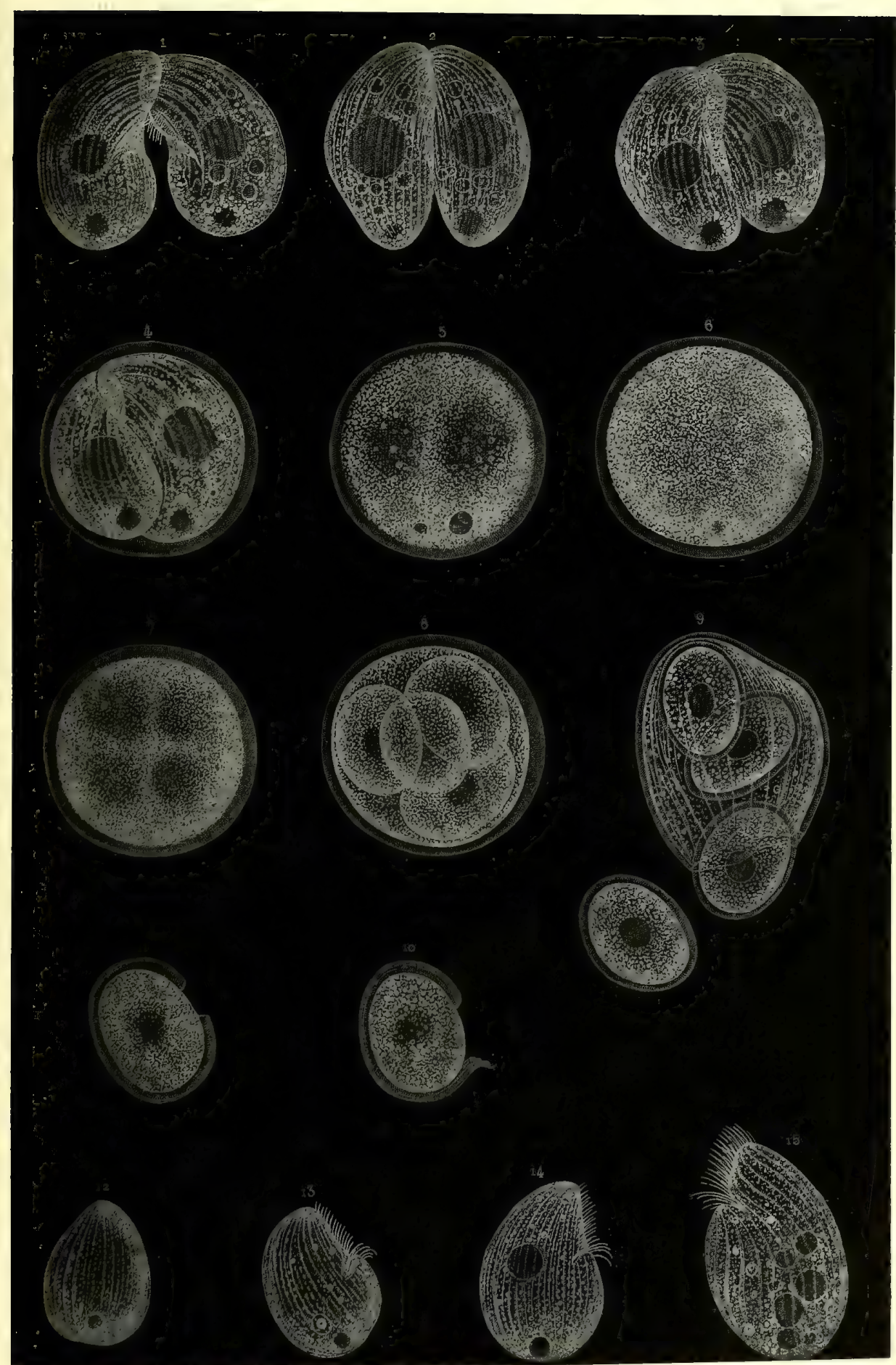

REPRODUCTION ET DÉVELOPPEMENT D'UN INFUSOIRE. 

dans l'ean et vont à la chasse des Paramécies. Les seconds attendent dans une immobilité complète qu'un Infusoire vienne les effleurer en passant : ils sont à l'affìt. Ils s'attachent à leur victime et se laissent emporter par elle. Bientôt ils s'enfoncent dans sa chair, où ils se multiplient avec une telle rapidité, qu'il y en a quelquefois jusqu'à cinquante dans un seul individu.

\section{I}

Un des phénomènes les plus surprenants qu'on rencontre dans l'étude des Infusoires, c'est leur désorganisation par diffuence. Cette décomposition arrive entièrement ou partiellement. Müller a vu une Kolpode pintade ${ }^{1}$ se résoudre en molécules jusqu'à la sixième partie du corps; puis le reste se mettre à nager, comme si de rien n'élail!

Les Infusoires offrent encore un autre genre de décomposition. Si l'ou approche de la goutte d'eau dans laquelle ils nagent une barbe de plume trempée dans de l'ammoniaque, l'animaleule s'arrête, mais continue à mouvoir rapidement ses cils. Tout à coup, sur un point de son contour, il se fait une échancrure qui s'agrandit peu à peu, jusqu'à ce que l'animal entier soit dissons. Si l'on ajoute une gontte d'eau pure, la décomposition est brusquement enrayée, et ce qui resle de l'animalcule recommence à se mouvoir et à nager (Dujardin), toujours comme si de rien n'élail!

1 Kolpoda meleayris Mäller.

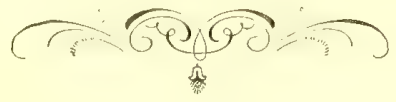





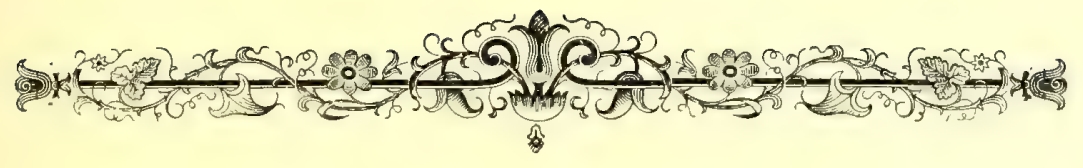

\section{CHAPITRE VI}

\section{LES FORAMINIFÈRES.}

Siès pichoto, ségur, maï qué dé souveni !

(Aubanel.)

Lorsqu'on examine au microscope le sable de la mer, on y distingue un grand nombre de corpuscules solides, réguliers, souvent géométriques.

Beccaria parait être le premier qui ait fait attention à ces petits grains, à peine visibles à cause de leur taille; il les découvrit dans le sable de Ravenne. On crut mal à propos, pendant longtemps, que ces productions microscopiques n'existaient que sur les bords de la mer Adriatique. On en recueillit plus tard en France, en Angleterre, en Allemagne, et enfin sur les rivages de toutes les mers.

Des recherches d'une patience infinie, entreprises par Bianchi, Soldani, Walker, Fichtel et Moll, et surtout par Alcide d'Orbigny, ont fait comnaitre un grand nombre de ces petits corps.

Ces granulations ne sont autre chose que la charpente solide ou la coquille d'une foule d'animalcules marins, lesquels constituent un ordre tont entier des plus curieux 
parmi les habitants de l'eau salée. La grève en est tellement remplie, dans certains endroits, qu'elles forment presque la moitié de sa composition. Bianchi en a trouví 6000 dans 30 grammes de sable de la mer Adriatique. D'Orbigny en a compté 3 millions 840000 dans une quantité semblable recueillie dans les Antilles. Par conséquent, un mètre cube de ce dernier sable en renferme un nombre qui dépasse tout ce qu'on peut imaginer!

Ces petites coquilles varient beaucoup dans leurs figures. Les micrographes y ont coustaté plus de deux mille organisations différentes, symétriques ou non symétriques, souvent remarquables par leur bizarrerie et presque toujours par leur élégance. Il y en a de globulaires, de discoides, d'étoilées, de festonnées, de contoumées en limaçon, d'allongées en massue, de façonnées en amphore.... Les unes ont une ouverture très-bilargie, les autres un orifice trèsétroit.

Elles sont divisées générulement en plusieurs chambrettes (polythalames), lesquelles communiquent entre elles par de petits trous; elles offrent aussi des pores qui s'ouvrent à l'extérieur. De là le nom de Foraminifères, c'està-dire porte-trous, donné par d'Orbigny aux animalcules auxquels appartiennent ces dépouilles.

On a mis à profit la forme générale de ces coquilles, le nombre et la disposition de leur's chambrettes, pour les grouper en familles. La classification de d'Orbigny est assez heurense et méritait d'être adoptée, quoique ses dénominations ne brillent pas par l'euphonie. Ce savant naturaliste (qui peut ètre regardé comme le grand historiographe de ces infiniment petits) distingue cing familles de Foraminifères, lesquelles comprennent environ soixante genres.

Les cellules sont quelquefois simples et comme enfilées 
sur un axe droit ou peu courbé (Stichostègues), ou bien disposées eu deux séries alternatives (Énallostègues), ou bien encore rassemblées en petit nombre et ramassées comme en peloton (Agathistègues).

D’autres fois elles sont groupées en spirale (Hélicoslègues), et dans ce cas les tours de la spire s'enveloppent ou ne

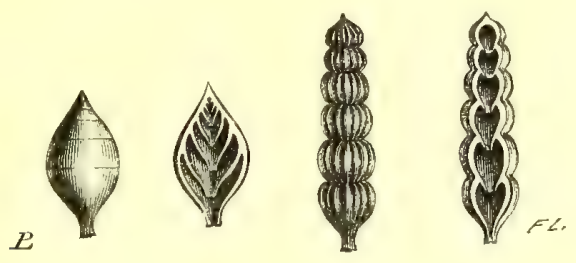

STICHOSTEGUES.

se recouvrent pas, ou bien s'élèvent les uns au-dessus des autres.

Dans certaines espèces, les cavités ne sont plus simples comme dans les familles précédentes, mais subdivisées par

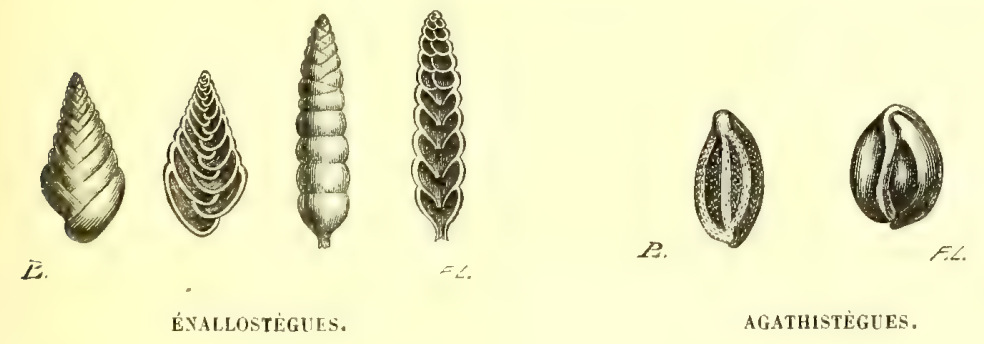

des cloisons transversales, de manière que la coupe de la coquille représente une sorte de treillis (Entomostègues). Que de géométrie, que de mécanique, que d'harmonie daus les plus chétives des organisations!

La ressemblance de ces petits tests avec les coquilles polythalames des Nautiles fit croire d'abord qu'ils étaient produits par des animaux semblables ou analogues à ces 
derniers, mais extrêmement petits. C'est pourquoi les naturalistes proposèrent de rapprocher les Foraminiferes des Mollusques céphalopodes'. Ils les regardèrent comme des

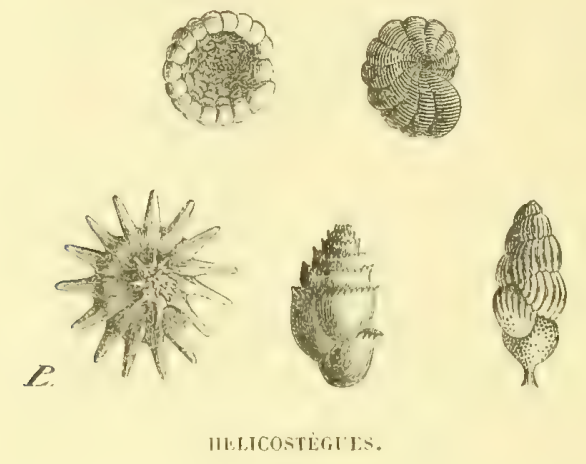

Nautiles microscopiques et dégradés. Mais la découverte de quelques espèces vivantes, et un examen attentif de leurs caractìres, apprirent bientìt que ces animalcules

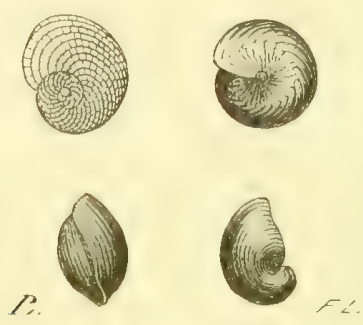

FVTOMOSTIGIF-

constituaient une tribu beaucoup plus simple en organisation que celle de ces derniers Mollusques. Dujardin les a considérés comme des Infusoires ${ }^{2}$. D'autres ont conseillé de les placer dans le voisinage des Méduses ${ }^{3}$.

\footnotetext{
1 Voyez le chapitre XXV.

2 Voyez le chapitre $V$.

3 Voyez le chapitre XIII.
} 
Cuvier se borne à dire, sur les habitants de ces coquilles, qu'ils ont le corps oblong, couronné par des tentacules nombreux et rouges.... Les observateurs modernes ont reconnu qu'ils sont formés d'une gelée transparente qui remplit les chambrettes dont nous avons parlé, et que les différentes parties de la petite bète communiquent entro elles par les pores des cloisons. Les trous extérieurs de la coquille laissent sortir des filaments capillaires (pseudopodies) très-longs, flexueux, de forme indéterminée, incessamment variables, diaphanes, semblables à du verre filé, lesquels s'éteudent en rayonnant autour de l'animal. Dans
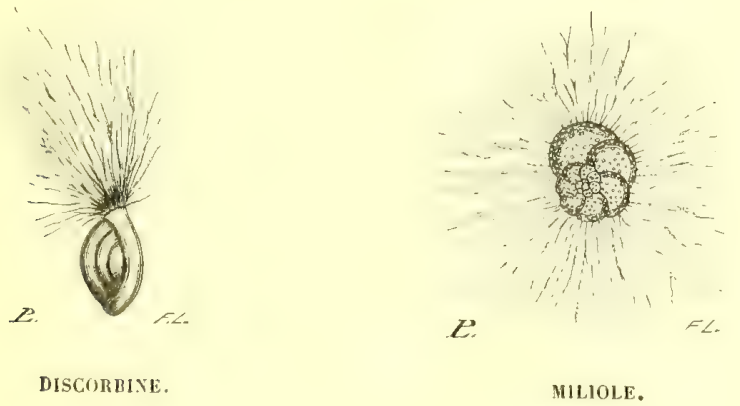

certaines espèces, on en compte seulement huit ou dix; dans d'autres, il y en a un plus grand nombre. Ces filaments se meuvent en divers sens et avec assez de vivacité. Ce sont à la fois des pieds et des liras, mais d'une ténuité excessive. L'animal s'en sert pour ramper et pour saisir sa proie. Ces fils paraissent avoir quelque chose de venimeux. Le docteur Schultze (de Greifswalde) a remarqué ì plusieurs reprises que des Infusoires vivants étaient privés tout à coup et tout à fait de leurs mouvements par le simple contact de ces bras. C'est probablement ainsi que le Foraminifère réussit à pêcher ses petits aliments....

N'est-il pas digne de remarque que des ètres si petits 
soient, malgrıé leur taille exiguë, des carnassiers impitoyables! Ainsi, avec une dose homœopathique de venin, la bestiole la plus faible et la plus microscopique peut devenir un redoutable destructeur!

Dujardin a constaté dans les Milioles, que lorsqu'un individu veut grimper sur les parois d'un vase, il compose à l'instant, aux dépens de sa substance, une sorte de pied provisoire, qui s'allonge et qui fonctionne comme in membre permanent. Puis, le besoin satisfait, ce pied temporaire rentre dans la masse commune el se confond avec le corps.

La volonté d'une fonction à remplir a done le pouvoir de créer un organe? Et dire que l'llomme, malgré la perfection de son intelligence, n'a pas le privilége de faire naitre un tout petit cheveu! Comme e'est humiliant!

Il parait que les filaments de toutes les espèces peurent aussi se rétracter complétement, et se confondre avec le reste de la substance. () Nature! que tes combinaisons sont admirables!

Les Foraminifères nont pas d'estomac proprement dit, mais la Vature leur a donné ce tissu particulier, glaireux et contractile, essentiellement assimilatem (sarcode), que Dujardin a découvert chez les animalcules infusoires.

\section{II}

Les pseudopodies ne se rencontrent pas seulement dans les Foraminifères; ces sortes de fils pèchenrs sont le caractère important de toute une classe d'animalcules. Comme ces organes ressemblent au chevelu des racines, on désigne ces animaux sous le nom collectif de Rhizopodes (piedsracines). 
Les Rhizopodes comprennent, avec les Foraminifères, dont le test est calcaire, des animaux dépourvus de toute espèce de coquille, comme les Amoebinées, et d'autres dont le test est siliceux : ces derniers sont les Radiolaires.

Les Amœbinées sont des Infusoires à fils pècheurs, des Infusoires rhizopodes; elles peuvent ètre regardées comme

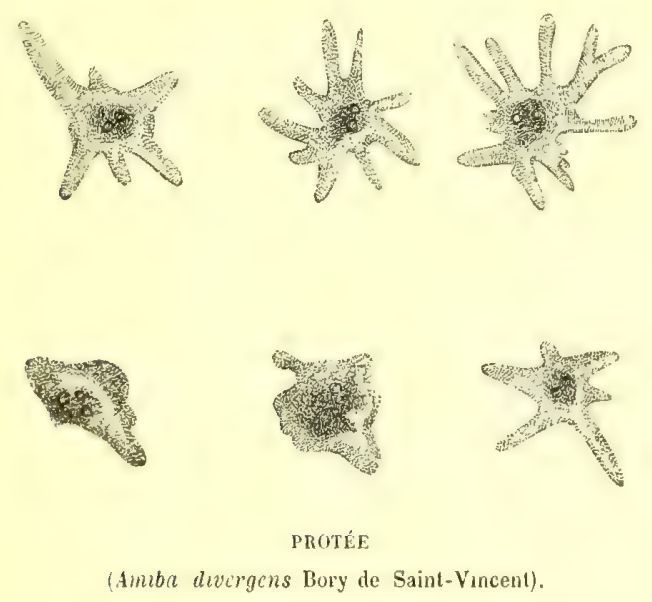

des animaux non encore asservis à un plan d'organisation nettement déterminé. Ce sont des masses microscopiques informes, mais susceptibles d'expansion et de contraction. Comme exemple, nous citerons les $d$ mibes ${ }^{~}$. Imaginez-vous une gouttelette de matiure demi-solide, demi-transparente, demi-gélatineuse, homogène, donée de mouvement volontaire. Elle s'agite dans divers sens, se dilate ou se resserre, adopte les figures les plus irrégulieres et les plus inattendues. Quand on place l'animalcule sur le porte-objet d'un microscope, il glisse comme une gouttelette d'huile, se déforme et se reforme. Véritable Protée, il est, suivant les moments, circulaire, oblong, échancré, sinueux, lobé, étoilé et même tout à fait ranneux.....

1 Amiba divergens Bory de Saint-Vincent. 
La Lieberkuhnia de Wagener est aussi une Amœbinée; elle présente un nombre considérable de pseudopodies, qui roulent dans tous les sens, se soudent ou se séparent, s'allongent ou se raccourcissent, paraissent ou disparaissent.

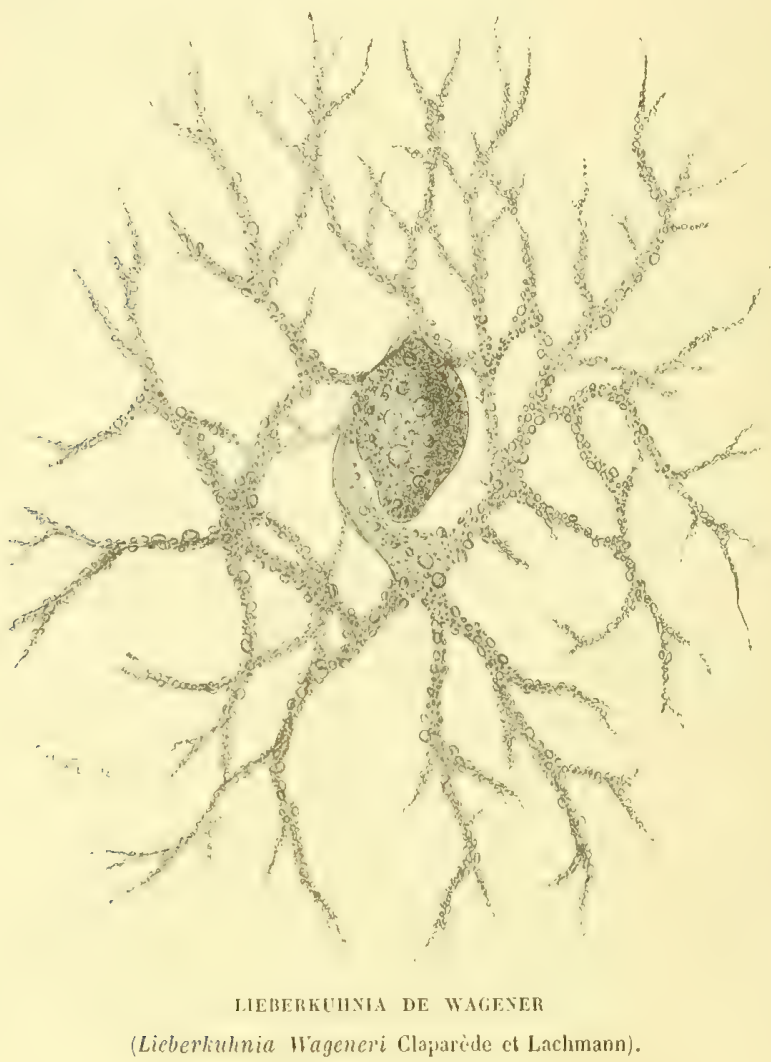

Les Rondiolaires flottent en abondance à la surface de la mer. Sous le bean ciel de Messine, on les voit parcourir les eaux blenes, aussi profondément que l'œil peut les distinguer, sous l'aspect d'une masse de gelée molle, diaphane, incolore, en apparence immobile. Leur taille varie d'une ligne à un point, rarement plus, souvent moins. Leur forme est sphérique on elliptique, ou cylindrique, parfois contournée en couronne. Si l'on essaye de les saisir avec une pince, elles se déchirent; si l'on tente de les pêcher au 
filet, elles restent collées aux mailles : on les mutile quand on essaye de les détacher. On ne peut les avoir intactes

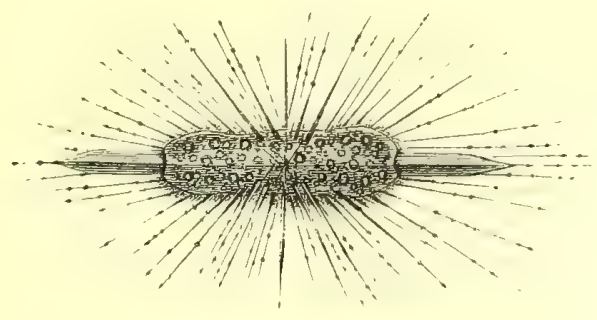

MADIOLAIRE MUYUZUA

(Amphilonche heteracantha Hackel).

qu'en les recueillant avec un vase de verre où elles puissent flotter librement.

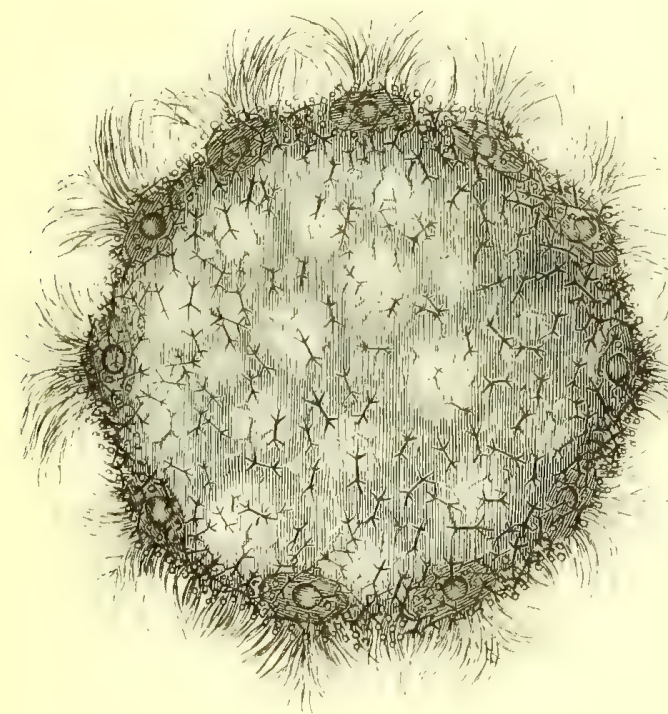

MALIUALRE PULYUA

(Spharo:oum avolimare Haccked.

Vues alors à la lumière, ces gelées ne tranchent sur l'eau par aucun contour déterminé, et l'œil aperçoit à peine à leur surface quelques points clairs ou sombres. Sous un 
fort grossissement, ces bestioles montrent toute la délicatesse et la beauté de leur organisation. On pent voir, dans le magnifique ouvrage de M. Ilacckel, la rariété de forme, la bizarrerie des contours de ces légions innombrables d'infiniment petits.

II. Haeckel a distingué les Radiolaires qui vivent isolées, et qu'il appelle Monozoa, de celles qui forment des associations, sortes de colonies flottantes qui sont emportées par les courants : ces dernières sont les Polyzoa.

Les Monozoa sont très-nombrenx ef forment vingt-neuf genres ${ }^{1}$.

Les Polyzoa ne comprennent que quatre genres ${ }^{2}$.

Les recherches de d'Orbigny, relativement à ces organisations microserpiques, teudent à prouver que les débris des Foraminifères constituent en grande partie les banes sous-masins qui, par leur accumulation, avec les Polypiers ${ }^{3}$, interrompent les comrses des navigateurs, comblent les ports, ferment les haies ef les détroils, et domnent naissance à ces récifs et à ces îles qui s'élèvent dans les régions chaudes de l'océan Pacifique.

Ces créatures, en apparence si frêles et si imparfaites, se retrouvent sous toutes les latitudes et à toutes les profondeurs. Que sont en comparaison les nécropoles des

1 loyez planche 11, tig. 1, 2, 3, 4, 5, 7.

2 Voyez planche VI, fig. 6.

3 Voyez le chapitre VIII. 


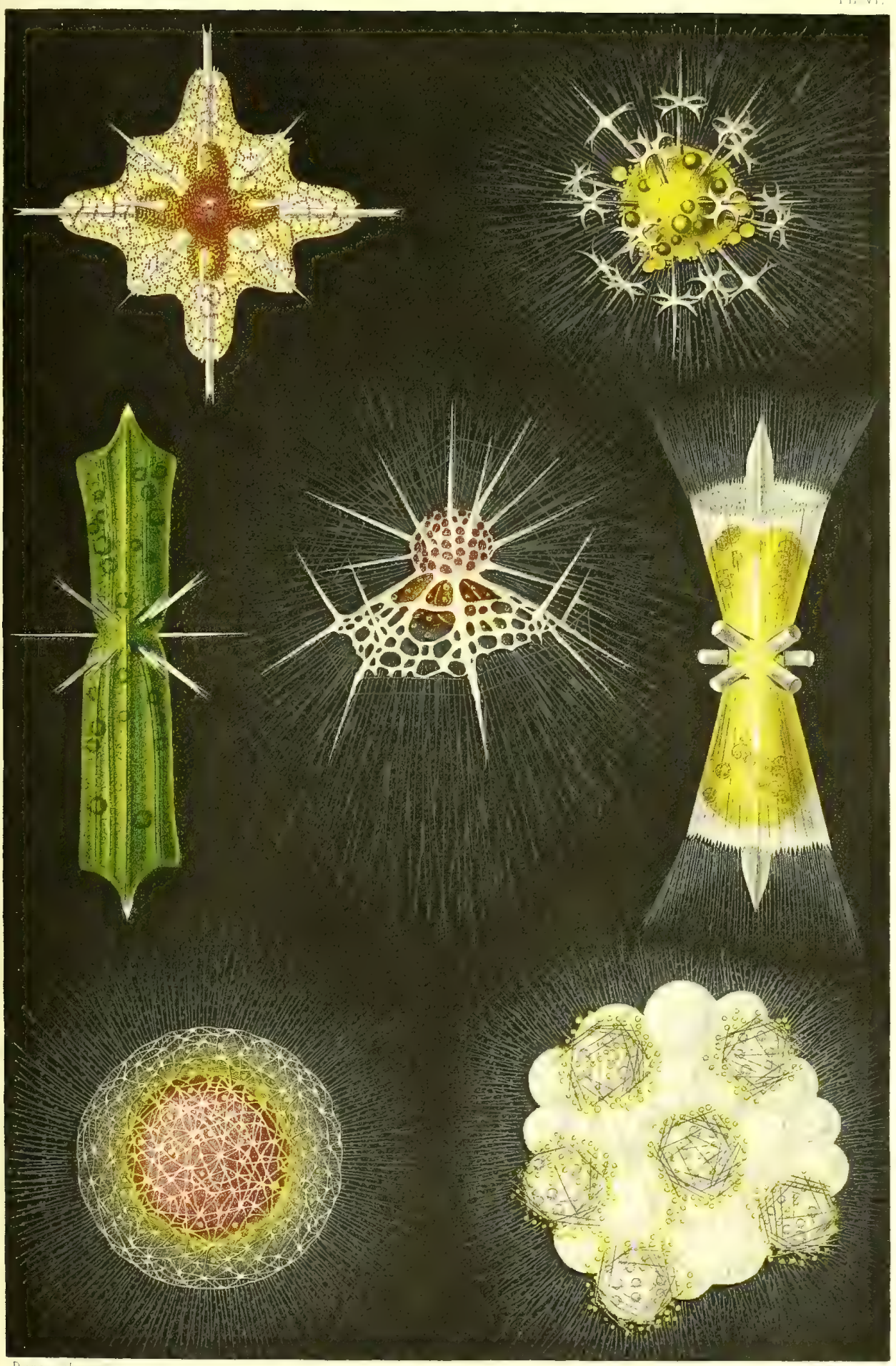

ANIMAUX RADIÉS 

Éléphants et des Baleines? Ne semble-t-il pas que plus l'animalcule est petit, plus sa dépouille occupe de place dans l'univers? (Blerzy.)

Les coquilles des Foraminifères se rencontrent très-souvent, et plus souvent qu'on ne le pense, à l'état fossile Elles forment à elles seules des chaînes entières de collines élevées et des bancs immenses de pierre à bâtir.

Le calcaire grossier des environs de Paris est, dans certains endroits, tellement rempli de ces déponilles, qu'un centimètre cube des carrières de Gentilly, carrières par couches d'une grande épaisseur, en renferme au moins 20000 ; ce qui fait, par mètre cube, le chiffre énorme de 20000000000.

Quand nous passons près d'une maison en démolition ou d'un édifice que l'on construit, et que nous sommes enveloppés par un nuage de poussière qui pénètre dans notre gosier, nous avalons souvent, sans nous en douter, des centaines de ces infiniment petits.

Comme tous les édifices de Paris et une grande partie des maisons des départements voisins sont bâtis avec des pierres extraites des carrières des environs, il est évident que, sans exagération, la capitale de la France, et beaucoup de villages et de villes tout autour, sont construits avec des carcasses de Foraminifères.

La pierre dite de Laon est formée, assure-t-on, d'un amas considérable de Camérines, charmante espèce de forme 1 laire, à cellules très-nombreuses disposées en spirale. ass cette espèce n'est pas microscopique.

Les , framides d'Égypte sont construites avec des 
pierres analogues et fondées sur des rochers de même genre.

Les Foraminifères ont done sécrété une partic du sol sur lequel nous marchons, des maisons qui nous abritent et des édifices que nous léguons à la postérité. Chaque animalcule a fourni son grain solide, chaque race a déposé sa couche imperceptible, et Dieu, qui préside à ce mystérieux travail, a rassemblé ces grains et ces couches dans la durée des siècles, et en a composé des masses imposantes!

Les espèces qui vivent aujourd'hui préparent en silence, au sein de l'Océan, des pierres de taille pour les constructions des générations futures!

“C'est sans raison que l'on mépriserait ces animaux, dont le grand Ouvrier de la nature a pris soin de relever la petitesse en les douant d'industrie et de force. Il a montré par la cue la grandeur ponvait se trouver dans les petites choses aussi bien que la force dans la faiblesse. Apprenons done à respecter le Créateur jusque daus les ouvrages qui nous paraissent les plus vils. » (Tertullien.)

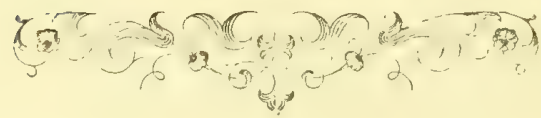




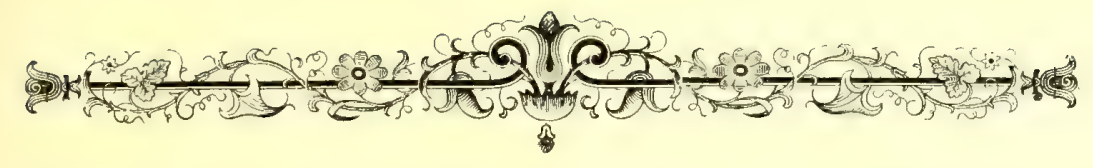

\title{
CHAPITRE VII
}

\section{LES ÉPONGES.}

\begin{abstract}
Heureux qui, salisfait de son humble fortüne, Vit dans l'état obscur où les dieux l'ont placé.
\end{abstract}

(RACINE.)

Le sein de l'Océan est rempli de mystères. Parmi les associations animales qu'il renferme et qu'il nourrit, une des moins conmues est peut-être celle qu'on désigne communément sous le nom d'É Eonge.

Cette association apparait comme une masse de tissu léger, résistant, élastique, lacuneux, de forme très-variée, et d'un fauve brun ou blond tirant un peu sur le rougeâtre.

Les opinions les plus diverses ont régné tour à tour dans la science sur la nature des Éponges. Parmi les anciens, les uns les regardaient comme des plantes, les autres comme des animaux; certains faisaient du juste-milieu, ils les prenaient pour une espèce de nid feutré de nature végétale, servant d'habitation à des Polypes. Ces animalcules n'étaient pas attachés à leurs petites loges, ils pouvaient en sortir et y rentrer à volonté. Les Polypes du Corail ne sont pas aussi heureux!... 
Pline, Dioscoride et leurs commentateurs ont prétendu que les Éponges étaicnt sensibles, qu'elles adhéraient aux rocher's par une force particulière, et qu'elles fuyaient la main qui voulait les saisir... Ils les ont même distinguées en mâles et en femelles.

Les premiers naturalistes, pour le rappeler en passant, vovaicut des màles et des femelles partout. L'Homme a toujours voulu trouver quelque chose ì sa ressemblance, même dans les corps organisés les plus obscurs.

Lrasme, critifuant les assertions de Pline, conclut qu'il fant passer l'éponge sur tout ce qu'il a écrit à ce sujet.

Nieremberg, et plus tard Peyssomel et Trembley, ont soutenu avec raison l'animalité des Éponges. Leur manière de voir a été adoptée par Linné, par Guettard, par Donati, par Ellis et par Lamouroux...

Les liponges habitent dans presque toutes les mers, principalement dans la Méditerranée, dans la mer Rouge, et daus le golle du Mexinue. Elles aiment les caux chaudes ou tempérées, et les lieux les moins exposés aux vagues et aux courants.

Ces colonies vivent dans les fonds marins de cing à vingtciny brasses, parmi les excavations et les anfractuosités des ruchers, et sont toujours adhérentes. Elles se développent non-seulement sur les corjs inorganiques, mais encore sur les végétaux et sur les animaux.

Elles sont étalées, dressées ou pendantes, suivant les endroits où elles croissent, suivant les corps qui les supportent et suivant leur propre forme.

C'est un caractère bien singulier que la fixation de certaines espèces animales. Les personues du monde s'imaginent que tous les animaux jouissent de la faculté de se transporter d'un endroit dans un autre; en un mot, qu'ils sont locomoliles, pour nous servir d'un mot consacré par la 
science. Cependant il n'en est pas ainsi; il existe des tribus entières et nombreuses qui sont adhérentes, qui vivent et

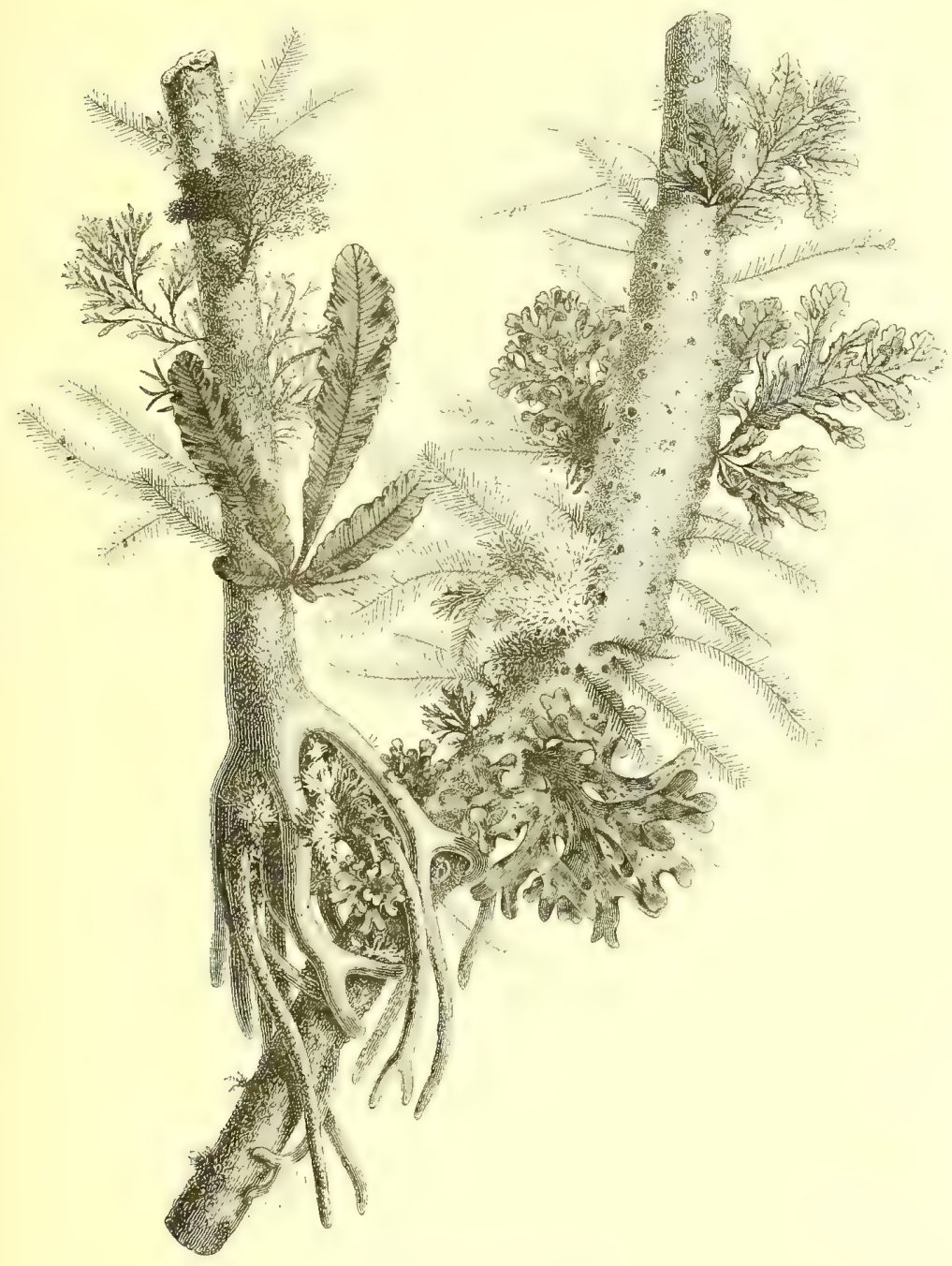

EPONGE SUR UNE ALGUE.

(Pechée prar soixante brasses de profondenr. - Dessin de Riocreux.)

meurent attachées an même point. Tels sont les Polypiers, telles sont les Éponges.....

Il résulte de l'adhérence des corps organisés, qu'ils sont plus soumis à la puissance des agents extérieurs et plus 
influencés par eux que les animaux locomotiles, lesquels ne manquent pas de se soustraire à ces mêmes agents par leurs fréquents changements de place, quelquefois même par des migrations périodiques. De là de graudes différences dans les fonctions, dans les mœurs, dans les caractères, entre les animaux fixés et les animaux non fixés.

\section{I}

On connait plus de trois cents espèces d'Éponges. 11 y en a de pédiculées et de non pédiculées, de foliacées, de globuleuses, de concaves, de fistuleuses, de digitées. Cette variété de formes nous explique les noms plus ou moins singuliers qui leur ont été donnés par les marins : la Plume, l'Éventail, la Cloche, la Corbeille, le Calice, la Lyre, la Trompette, la Quenouille, la Corne d'élan, le Pied de lion, la Patte d'oie, la Queue de paon, le Gant de Neptune...

La Nature a mis autant de soin à organiser les plus humbles habitants des eaux que les êtres qui appartiennent aux ordres les plus élevés de la création.

L'Éponge usuelle est une masse irrégulièrement arrondie, souvent un peu concave en dessus. Quand on examine à la loupe son tissu, on le trouve composé de fibres fines, flexibles, entrelacées, formant un grand nombre d'orifices, les uns très-petits (pores), et répandus en grand nombre sur tonte la surface de l'Éponge, les autres beaucoup plus grands (oscules), et généralement situés à la partie supérieure.

Dans l'intérieur, des conduits irréguliers de toutes les dimensious s'abouchent les uns dans les autres, et font communiquer les pores et les ostioles. 
Le tissu est comme feutré de corps durs, appelés spicules, calcaires ou siliceux, effilés comme des navettes étroites, simples ou divisées en deux ou trois branches.

A l'état vivant, cette masse est recouverte d'une coucbe muqueuse, qui coule gluante quand on retire le Polypier de l'eau.

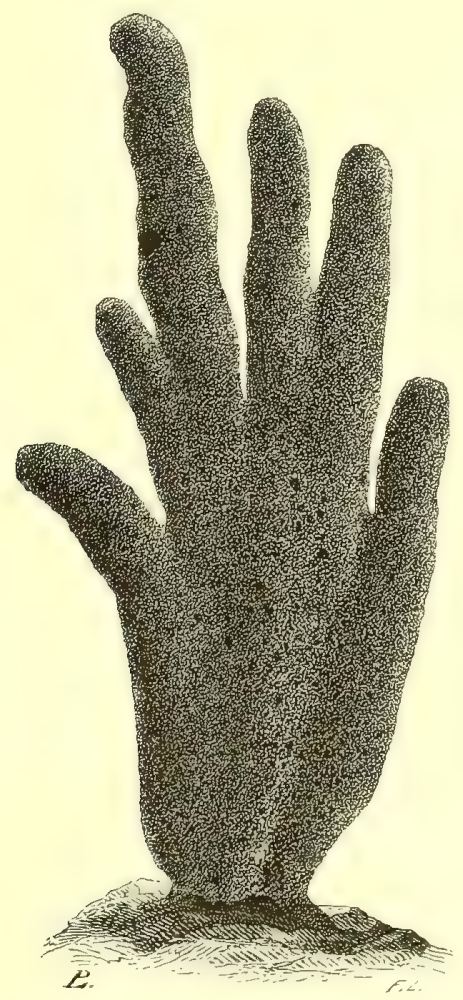

GANT DE NEPTINE.

Pendant la vie de l'Éponge, on voit sortir de chaque cellule ou de chaque Polype un torrent d'eau impétueux, sorte de fontaine vivante qui semble ne s'arrêter jamais. Pauvres petites bètes qui reçoivent leur nourriture du flot qui les baigne, qui aspirent et expirent l'onde amère toute leur vie, et qui ne savent pas ce qui se passe à 2 millimètres de leur bouche! 
Dans les mois d'avril et de mai, ces animalcules engendrent des germes arrondis jaunâtres ou blanchâtres, d'où naissent des embryons ovoïdes, granuleux, munis vers le

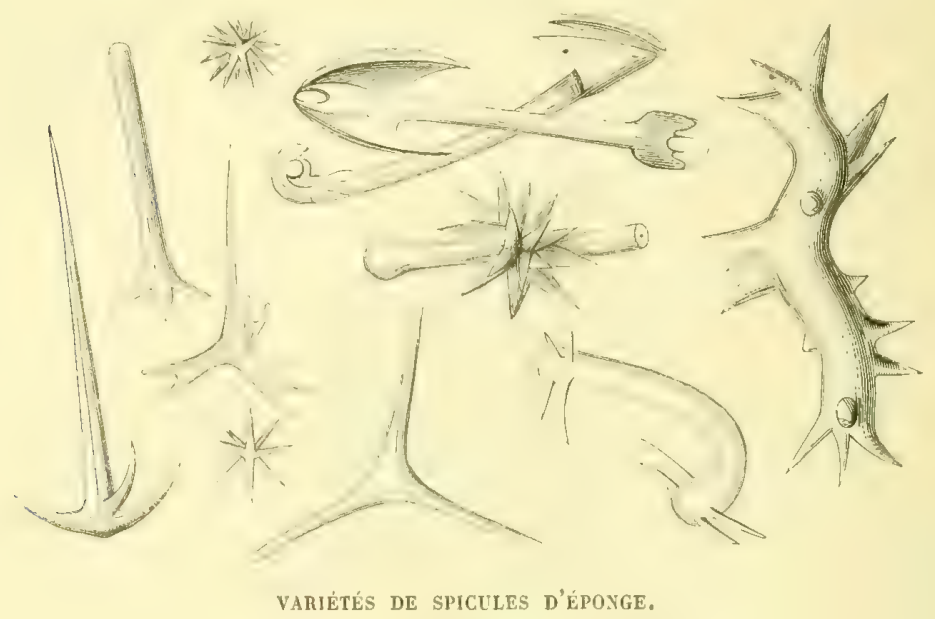

gros bout de potits cils vibratiles. Ces embryous sont rejetés par le courant qui sort de l'estomae, et forment des essaims

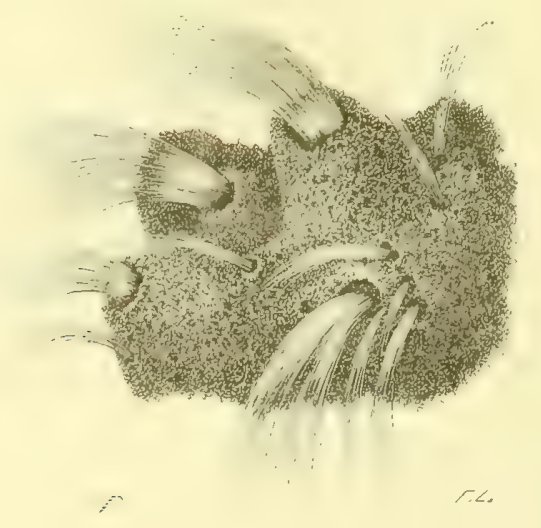

FRAGMENT D'ÉPONGE USUELLE, TRLS-GROSEI.

de larves antour du Polypier. Ces larves nagent, la partie la plus dilatée en avant, comme les larves du Corail, par des mouvements doux et réguliers qui ressemblent à un glisse- 
ment onduleux. Quand elles sont restées quelque temps dans l'eau, elles viennent ordinairement à la surface, mais elles sont souvent entrainées par les courants. Pendant deux ou trois jours, elles semblent chercher un endroit convenable pour se fixer. Une fois fixée, la larve perd les cils vibratiles, s'étale, et prend la forme d'un disque gélatineux très-aplati.

Dans l'intérieur s'organisent des cellules contractiles et de nombreux spicules.

On ne sait pas exactement combien de temps les Éponges mettent à se développer. On pense que, dès la troisième année, on peut revenir dans les lieux précédemment épuisés.

\section{III}

La pêche des Éponges est principalement exploitée par les Grees et par les Syriens, depuis Beyrouth jusqu'à Alexandrie. Les Grees commencent à pècher en mai et finissent en août; les Syriens continuent jusqu'à la fin de septembre.

Les embarcations portent quatre ou cinq hommes.

Chaque plongeur est armé d'un couteau à forte lame, ou bien d'un trident à branches tranchantes, recourbées et garnies d'une poche faite de filet.

Les bateaux arrivent sur les còtes rocheuses habitées par les Éponges. Lorsque la mer est très-calme, on aperçoit assez distinctement ces Polypiers, et l'on commence à plonger ou à draguer.

Ce dernier genre de récolte offre l'inconvénient de déchirer le tissu; aussi les Ćponges obtenues de cette manière se vendent-elles 30 pour 100 de moins que les Éponges dites plongées. (Lamiral.) 
Dans le golfe du Mexique, où ces Polypiers croissent à de faibles profondeurs, les marins enfoncent dans l'eau une longue perche amarrée près du bateau, se laissent glisser sur les Liponges et les arrachent avec facilité. (Lamiral.)

Après la pèche, on nettoie les Éponges, on les débarrasse de la matière animale, des spicules et des corps étrangers qu'elles contiennent.

Une fois préparé, le tissu prend une teinte roussâtre plus ou moins dorée. Son élasticité, sa perméabilité et sa résistance à la macération sont connues de tout le monde. Certaines espèces, habituellement très-colorées, perdent leurs nuances cn se séchant, et deviennent plus ou moins blanches.

M. Lamiral a publié un excellent mémoire sur les moyens d'acclimater et de multiplier les Éponges dans les eaux françaises de la Méditerranée, et sur la nécessité de réglementer leur pêche. Il insiste sur l'introduction, dans nos parages, de l'Eponge fine de Syrie, appelée chimousse. La Société zoologique d'acclimatation a résolu d'essayer cette introduction; elle a donné (avril 1862) une mission spéciale à II. Lamiral pour aller chercher dans l'Orient des Éponges pleines d'aufs. Le succès n'a pas couronné cette première expérience.

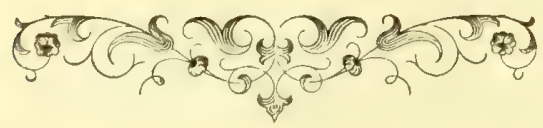




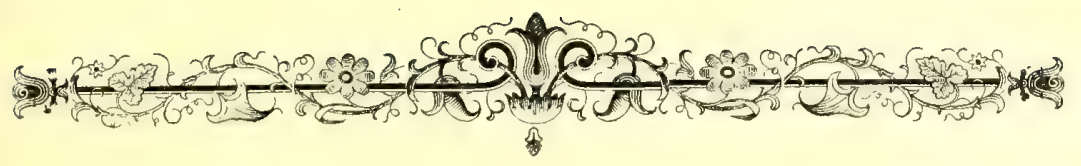

\title{
CHAPITRE VIII
}

\author{
LES POLYPES.
}

Disiser, cest dnne multipicicr

Les Polypes sont de grands personnages. Plusieurs peuvent atteindre jusqu'à un centimètre de hauteur!

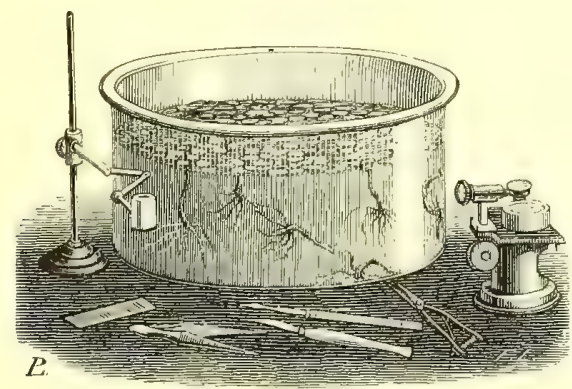

POIXYPE.

Ces animaux ne sont pas rares. Les savants ont beaucoup écrit sur leur organisation et sur leurs mœurs. On en parle très-souvent; ils sont presque populaires !... Toutes les fois que, dans une conversation (ou dans un livre), on veut comparer un animal bien simple à notre propre espèce, 
le nom de Polype se présente aussitôt. Dans combien de circonstances n'avons-nous pas répété ce membre de phrase devenu presque banal : Depuis le Polype jusqu'ci l'Homme?

Eh bien! demandez à une personne quelconque ce que c'est qu'un Polype, si e'est un animal marin ou fluviatile; s'il est écailleux ou velu, s'il a une tète ou une queue? Vous verrez ce que l'on vous répondra... La quasi-popularité de notre curieux animal se rédnit le plus habituellement à la connaissance de son nom.

Rien n'est plus commun que le nom....

C'est pourquoi nous allons consacrer un chapitre spécial à l'étude du Polype.

Le Polype par excellence est le Polype d'eau douce, ou IIydre verle'. Qu'on se représentẽ un petit sac étroit, tubuleux, diaphane, vert ou verdâtre, ouvert à une seule extrémité, faconné comme un cornet de trictrac ou comme un tube sinueux, et portant autour de l'ouverture six appendices (rarement huit ou dix) grêles, filiformes, flexueux, disposés en couronne. Voila tout l'animal : le sac est son corps, l'ouverture sa bouche, et la cavité son estomac; les appendices sont ses bras.

Si l'on compare cette modeste organisation, nous ne dirons pas à l'llomme, mais à un quadrupède quelconque, on la regardera comme imparfaile. Et l'on aura bien tort! car un animal qui possède toutes les parties dont il a besoin pour subsister, est en réalité un animal parfait dans son genre. La privation des organes qui sont absolument néces-

Iydra viridis Linné. 
saires à un autre, n'est point en lui une imperfection. En effet, la perfection d'un composé ne consiste pas dans l'abondance de ses parties, mais uniquement dans leur proportion et dans leur aptitude à faire les fonctions auxquelles elles sont destinées (Lessep). Chaque Polype est done aussi parfait, dans son espèce, qu'un quadrupède dans la sienne; et il serait aussi absurde de lui contester cette qualité qu'il y aurait d'extravagance à soutenir qu'il n'y a point d'Éléphant achevé sans ailes et point de Cheval accompli saus nageoires.

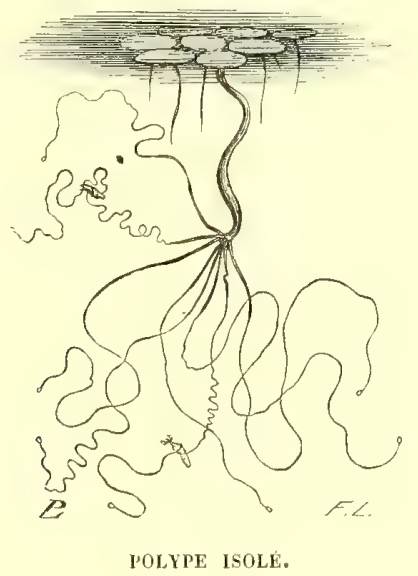

En histoire naturelle, les savants emploient souvent l'adjectif imparfait, mais seulement comme terme relatif, et pour dire d'un senl mot, que telle espèce présente une organisation beancoup moins compliquée que telle autre. Nous suivrons l'exemple des savants.

Le Polype recherche la lumière; il est sensible au moindre bruit. Il s'attache aux plantes aquatiques, et aux autres corps solides submergés, par l'extrémité aveugle de son sac. Il s'y amarre comme à une rive. Trembley a vu une longue planche qui en était si exactement bordée, qu'elle paraissait comme garnie d'une frange toujours en 
mouvement. Presque tous les Limaçons fluviatiles en portent quelques-uns sur leur coquille. Le mollusque leur sert de voiture, et quoiqu'il nage ou marche avec lenteur, il leur fait parcourir cependant, en quelques minutes, plus de chemin qu'ils n'en pourraient faire seuls dans tout un jour. D'autres Polypes vont encore plus vite : ce sont cenx qui s'établissent sur les fourreaux des Friganes, jolies larves aquatiques, légères et très-vives, qui s'agitent et serpentent dans les lits des bassins et des ruisseaux. (Trembley.)

Les Polypes se balancent mollement et gracieusement sur leur point d'appui, étendant leurs membres capillaires dans tous les sens. Ces organes sont aussi longs ou plus longs que le corps lui-même, et recouverts de cils vibratiles microscopiques qui exécutent jusqu’à trois cent cinquante mouvements par minute!

Quand une malheureuse bestiole aquatique vient à passer près du Polype et à toucher un de ses bras, celui-ci la saisit et l'entraine dans sa bouche; aussitôt le ravisseur rapproche ses tentacules, contracte son sac, et digère en repos. Quand il a fini, il se débarrasse du caput mortuum de son repas, par une sorte de vomissement. Il en est de même, du reste, de tous les animaux chez lesquels la Nature, dans la constitution du tube digestif, a voulu économiser une ouverture.

Lorsque beaucoup de Polypes sont agglomérés dans un endroit, si l'on jette un Ver au milieu d'eux, il est enlacé, garrotté en peu de temps, et de mille manières, par un nombre prodigieux de bras. Quelque mêlés que soient ces derniers, ils se séparent ensuite sans confusion, et cette multitude de fils déliés qui se touchaient presque, s'allongent, se raccourcissent et se tordent sans aucune espèce d'embarras. (Trembley.)

Un Polype avale quelquefois un volume d'aliments trois 
ou quatre fois plus considérable que son corps. Il peut enfermer dans son long estomac jusqu'à une douzaine de Pucerons à la file les uns des autres. Son corps tubuleux offre alors autant de renflements qu'il y a d'insectes avalés.

Quand un Polype a trop mangé, il se laisse tomber au fond de l'eau. Il u'en peut plus. Parfois il vomit une partic de son trop-plein : excellente détermination qui lui permet de digérer le reste! La voracité des Polypes fait voir, pour le noter en passant, que saint François de Sales a été un peu trop loin, lorsque, voulant présenter aux hommes les vertus des bêtes comme exemples à suivre, il dit qu'elles sont sobres, tempérantes, et ne mangent jamais au delà de leur appétil!....

On a prétendu que les animaux dont les dents sont molles ont les mœurs douces. Les Polypes, qui ne possèdent pas de dents ni même de mâchoires, et dont tout le corps est assez mon, devraient ètre des types de douceur! Fiez-vous done aux apparences!

- Les petits Vers avalés par les Polypes cherchent souvent à s'échapper, ce qui est fort naturel. Le ravisseur les retient alors avec un de ses bras plongé dans sa cavilé digestive. Chose admirable! cette cavité digère les Vers et respecte le bras.

Quand on coupe la partie postérieure d'un Polype, et qu'on ouvre ainsi le fond de son estomac, le petit ogre ne discontinue pas de saisir des animalcules et de les avaler; il mange, mange toujours... Mais ces animalcules, entrés par la bouche, sortent immédiatement par l'ouverture qu'on a faite. Le Polype devient alor's insaliable. C'est le tonneau des Danaïdes; c'est le cheval de M. de Crac!...

La nourriture des Polypes influe momentanément sur la couleur de leur corps. Les Naïs les rendent rouges, les 
Pucerons, verts, et les Têtards, noirs. Figurez-vous un homme qui deviendrait ronge après avoir mangé des cerises, ou vert après avoir mangé des petits pois!

A la surface extérieure du sac digestif, on voit bourgeonner de temps en temps des tubercules (gemmes), qui grossissent, s'allongent, se creusent et se transforment en miniatures de Polypes, en Polypules, lesquels se séparent et s'en vont dès qu'ils sont en état de pourvoir à leurs besoins.

Les bourgeons qui naissent en automne se détachent,

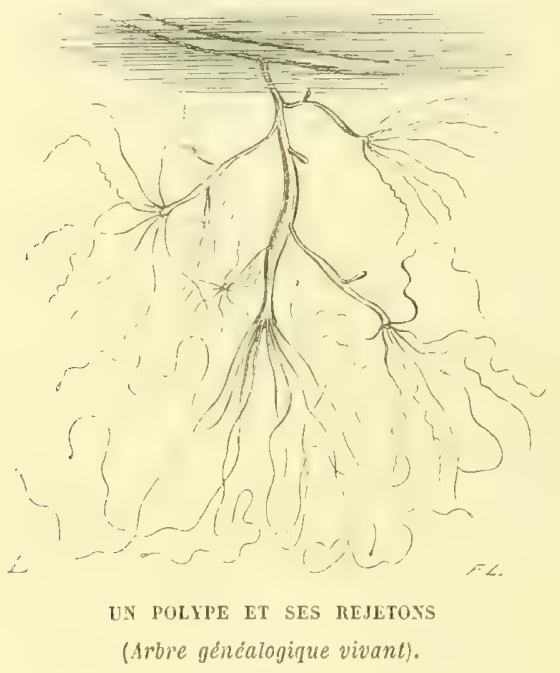

sans se développer, comme des cufs; ils tombent et se conservent dans l'eau pendant l'hiver.

Pendant qu'm jeune Polype est encore adhérent à sa mère, il pousse sonvent, sur son propre corps, un nouveau petit, qui lui-même en donne un troisième, et ce dernier un quatrième; de telle sorte que la maman porte à la fois son fils, son petit-fils et son arrière-petit-fils! Le Polype, ainsi chargé de sa postérité, compose avec elle une sorte d'arbre généalogique vivanl, suivant l'heureuse expression de Charles Bonuet. 


\section{III}

Si l'on divise un Polype en sept on huit fragments, au bout de deux jours chaque fragment deviendra un Polype tout entier.

Røesel assure avoir vu des bras coupés par petits morceaux donner naissance à des Polypes complets! Un seul individu pourrait donc se créer toute une famille avec un bras!

Et notez bien que, après l'opération, il lui repousserail un autre bras!!

Si l'on hache un de ces animaux, chaque parcelle formera bientôt un individu pareil à l'individu haché (Trembley). Une armée de Polypes taillée en pièces serait loin d'ètre anéantie !...

Autre singularité : on peut retourner un Polype comme on retourne un doigt de gant. L'animal continue de vivre (Trembley); mais alors sa peau intérieure respire et sa peau extérieure digère. Respiration et digestion à l'envers.

Un Polype qu'on retourne porte souvent des petits naissants à la surface de son corps. Après l'opération, ces petits se trouvent enfermés dans l'estomac. Ceux qui ont déjà pris assez d'accroissement, se développent et grandissent dans la cavité digestive; ils sortent ensuite par la bonche : ils sont vomis. Ceux, au contraire, qui sont peu avancés, se relournent d'eux-mémes, et surgissent à l'extérieur du sac maternel, à la surface duquel ils achèvent de pousser. (Trembley.)

Un Polype retourné plusieurs fois ne cesse point de s'acquitter de toutes ses fonctions. Il y a plus, le mème individu peut être successivement coupé, retourné, recoupé 
et reretourné, sans que son économie en paraisse bien malade. (Trembley.)

Il faut avouer cependant que cette pauvre bête n'aime pas à demeurer retournée. (Ce doit être un singulier malaise que celui d'avoir ses organes à l'envers!) Le Polype s'efforce de se remettre dans son premier état; il se dérelourne en tout ou en partie. On l'empêche d'y réussir en le transperçant près de la bouche avec une soie de sanglier. Cette espèce de transpercement, naturellement peu agréable, ne porte en définitive aucun obstacle bien sérieux aux fonctions de l'animal.

Les premières expériences sur les Polypes surprirent grandement tous les naturalistes. Ils ne connaissaient rien d'analogue dans le règne animal. "Nous ne jugeons des choses que par comparaison, disait Charles Bonnet; nous avions pris nos idées d'animalité chez les grands animaux, et un auimal qu'on coupe, qu'on retourne, qu'on recoupe, et qui se porte bien, nous choque singulièrement. Combien de faits, encore ignorés et qui viendront un jour déranger nos idées sur des sujets que nous croyons connaitre! Nous en savons au moins assez pour que nous ne devions être surpris de rien. La surprise sied peu à un philosoplie; ce qui lui sied est d'observer, de se souvenir de son ignorance et de s'attendre à tout. »)

\section{IV}

11 y a vraiment de quoi être confondu, quand on réfléchit sur tout ce que présente l'histoire des Polypes! Personne ne regarde ce qui est à ses pieds, et bien souvent il s'y passe de curieux phénomènes qui renferment de grands enseignements! 
Les Polypes, on l'a vu plus hant, n'ont ni cœur, ni poumon, ni foie, ni intestin. Ils manquent de tête et de cerveau. Six filaments très-grêles et très-simples remplissent les fonctions de pieds, de bras, de lèvres et de tous les organes des sens... Et cependant ces animaux guettent une proie, l'aperçoivent, la saisissent, la dévorent... Ils ne se trompent jamais sur sa nature et sur sa taille, et manquent rarement leur coup. Ils se battent entre eux, se repoussent ou se recherchent. Ils savent se sauver et se mettre à l'abri, quand un danger les menace. Ils élèvent leurs petits (à leur manière).... Comment peuvent-ils accomplir tous ces actes variés? La Providence leur a donné une impulsion vitale particulière, appelée instinct, impulsion indépendante de la prévoyance, de l'expérience, de l'éducation, et peut-être même de la réflexion, qui leur tient lieu d'intelligence. Le mot instinct vient du verbe latin instinguere, qui veut dire pousser, exciter... L'instinct et l'intelligence sont deux facultés qui se compensent, et dont l'une supplée à l'autre, comme, à d'autres égards, la fécondité supplée à la force ou à la longévité (Cuvier). L'instinct est l'intelligence des animaux inférieurs.

\section{V}

Les Polypes de la mer ressemblent beaucoup aux Polypes des eaux douces. L'animal est toujours composé d'un corps, d'une ouverture, d'une poche et de plusieurs bras. Le corps peut être long ou court, quelquefois étroit comme un tuyau de plume, d'autres fois arrondi comme une bourse, plus rarement façonné en entonnoir. L'ouverture est plus ou moins large, et sert toujours à l'entrée de l'aliment et à la sortie de l'excrément. La poche tend à se compliquer; elle 
offre souvent un tube distinct, entouré de canaux verticaux où viemnent aboutir des organes bizarres en forme d'intestins. Les bras sont en nombre variable. On en trouve quelquefois jusqu'à douze; mais généralement il y ell a huit. Ils ressemblent à des cils, à des vrilles, à des rubans, à des pétales. Leur's bords sont souvent granuleux ou barbelés.

Avec cette organisation de l'Hydre verte et avec des modifications très-légères, mais très-variées, la Nature a composé la plus grande partie des animaux dits imparfaits qui peuplent l'Océan.

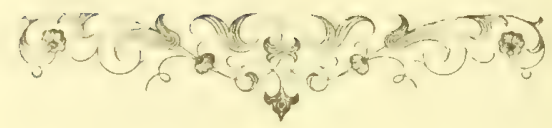





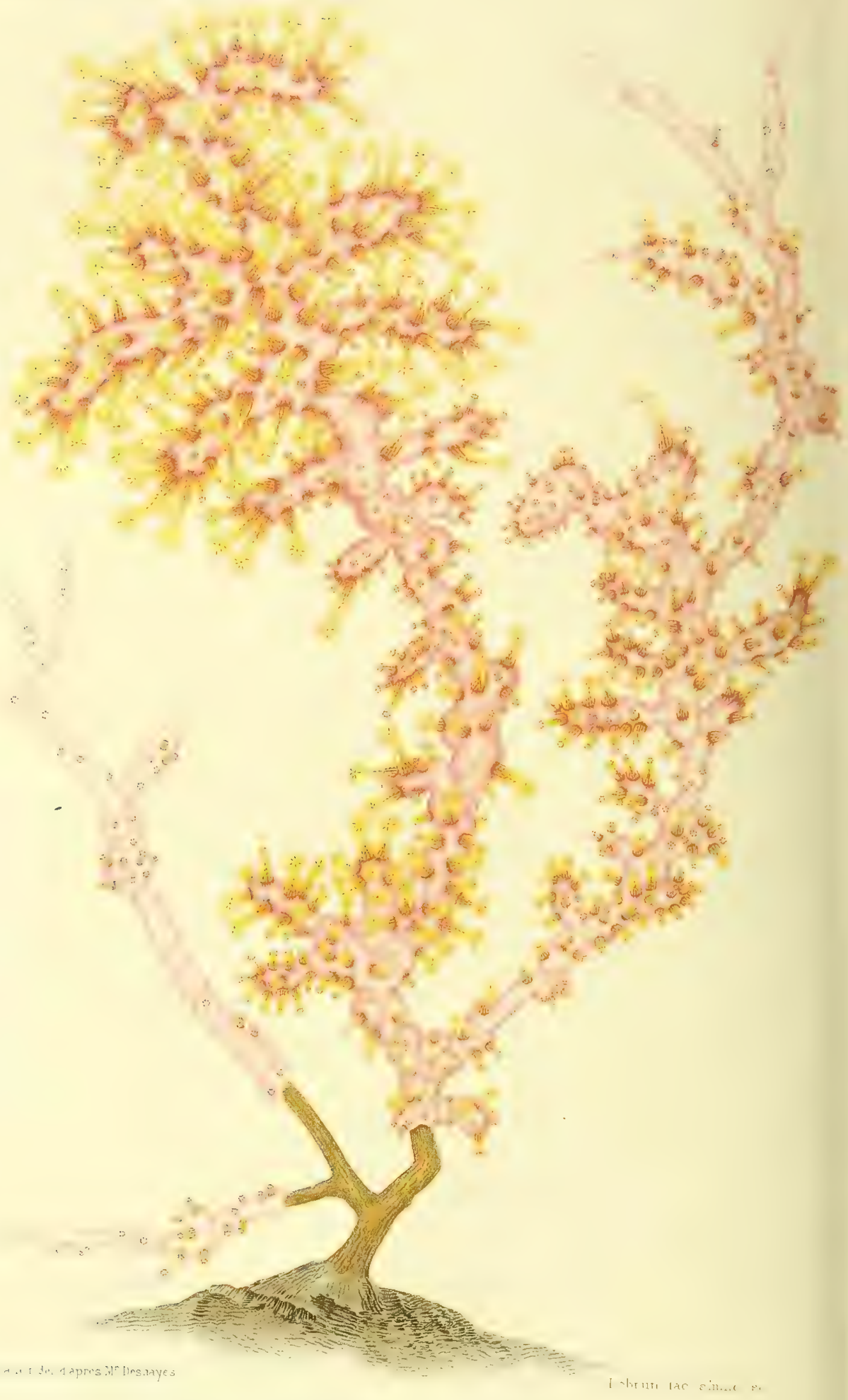

ANTHOZOANTHE PARASITE

'Poyprer des cotes de I Alóerio 


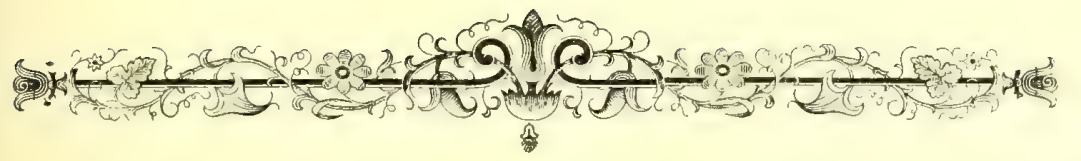

\section{CHAPITRE IX}

\section{LES POLYPIERS.}

"Le travail en commun centuple le produit."

(UN SAINT-SIMONIEN.)

Les Polypes ne vivent pas toujours à l'état d'isolement, ils sont le plus souvent agrégés.... L’arbre généalogique temporaire est devenu permanent! La famille a reçu le nom de Polypier.

Linné appelle ces associations animaux composés (animalia composita).

Ces habitants d'une mème agrégation vivent dans une harmonie parfaite. Ils constituent un peuple de frères unis physiquement d'une manière très-intime. Ils occupent la même maison; chacun y tient une cellule, mais il lui est défendu d'en sortir tout à fait, et par conséquent de visiter, de déranger ou de tourmenter son voisin. Attachés à leur chambrette, ces demi-reclus altendent du hasard, ou, pour mieux dire, de la Providence, des aliments qui ne manquent jamais; et ce qui est mangé par chaque bouche profite à la communauté. Poussés par un admirable instinct, les Polypes travaillent ensemble au même ouvrage : isolés, ils seraient faibles; réunis, ils deviennent forts. Ils ont une vie d'ensemble et des vies particulières. Mêmes besoins, mêmes goûts, mêmes ilées (et Dieu sait quelles idées!). Ils par 
tagent leurs peines et leurs jouissances, quelque bornées et quelque confuses qu'elles soient; et, s'il est vrai que les chagrins s'adoucissent quand ils sont épanchés, et que les

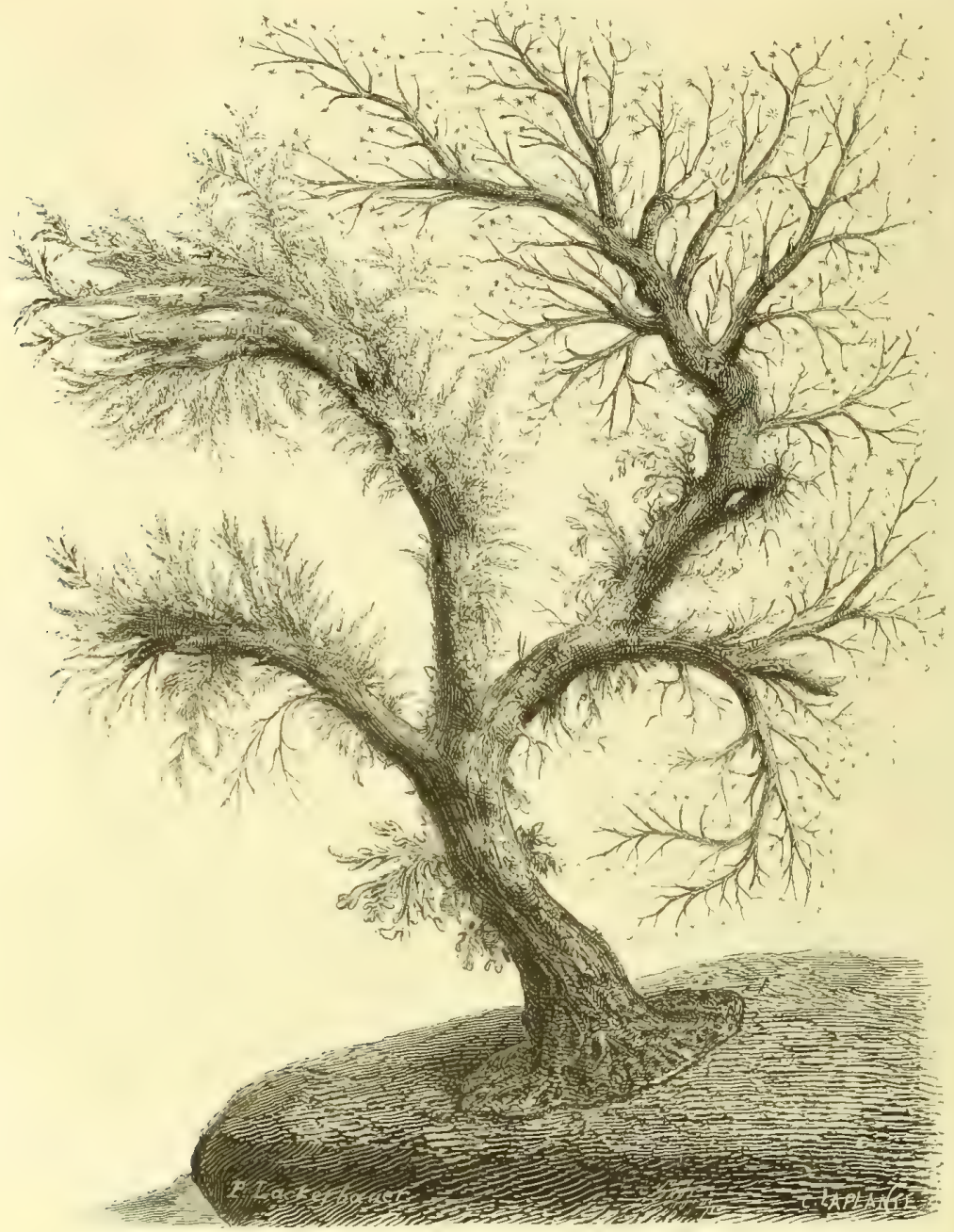

POLYPIER IYDRAIRE

Serlularia ramea, d'après Dalyeli).

plaisirs augmentent quand ils sont goûtés en commun, les Polypes doivent être des animalcules fort heureux!

Les Polypiers ont été mal connus pendant longtemps. Ce u'est qu'à l'aide du microscope et par l'étude des individus 
vivants qu'on est parvenu à connaître leur organisation et leur genre de vie, et qu'on a mis un certain ordre dans la classification des espèces et de leurs variétés. M. Lacaze-

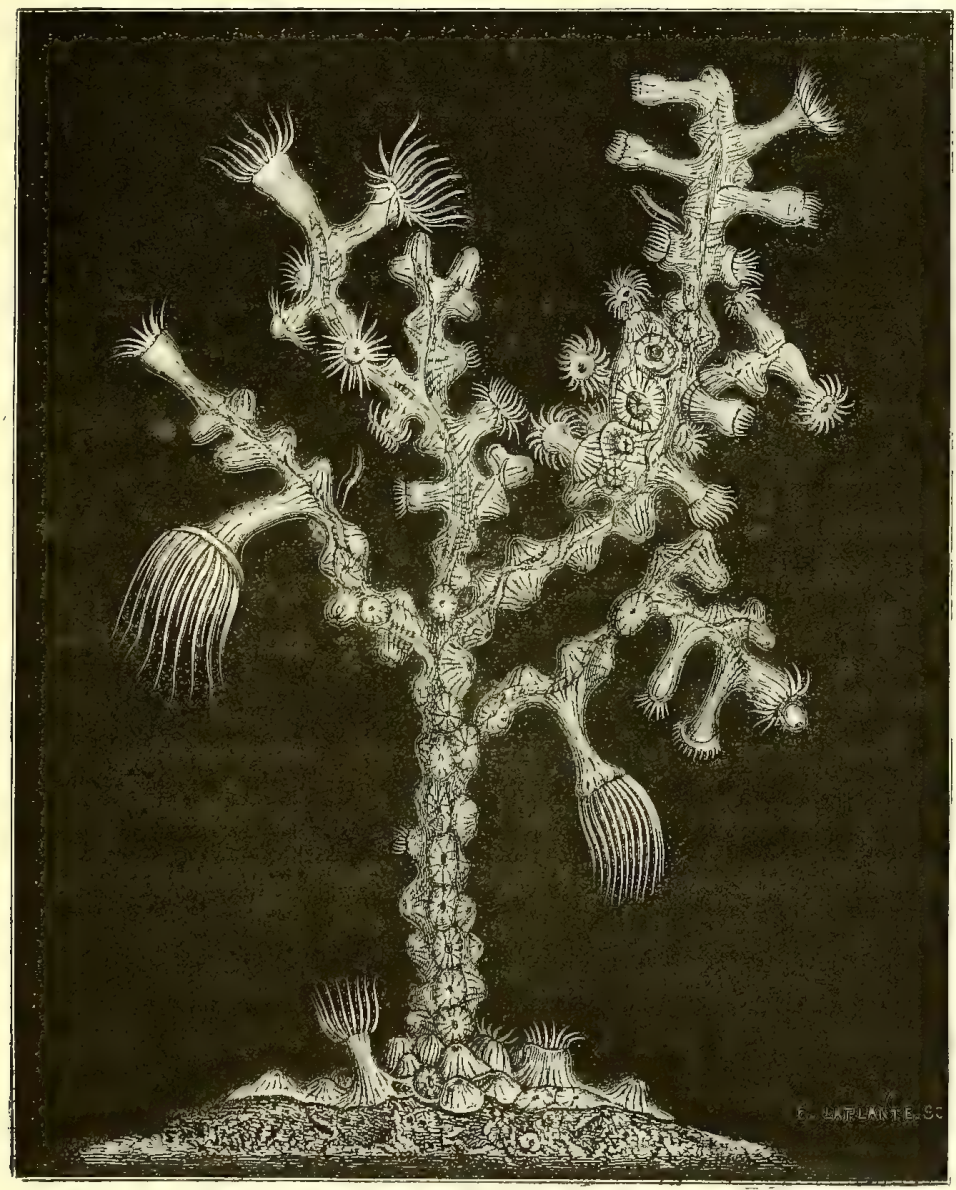

POLYPIER ACTIVIAIRE

(Gerardic Lamarckii, d'après Lacaze-Duthiers).

Duthiers a ainsi démontré que l'Antipathes glaberrima et le Gorgonia tuberculata de Lamarck, le Leiopathes glaberrima de Gray et le Leiopathes Lamarckii de J. Haime, n'étaient qu'un seul et même Polypier, la Gérardie de Lamarck.

On a reconnu aujourd'hui que, sous la dénomination générale de Polypiers, étaient groupés des animaux dis- 
tincts. Les uns étaient construits sur le type de l'llydre, les autres sur le type de l'Ietinie; d'autres, enfin, comme les Plumulaires, sur un plan d'organisation totalement différent. Les premiers sont les Polypiers Hydraires; les seconds, les Polypiers Acliniaires; les dernicrs appartiennent à plusieurs classes d'animaux.

Les Polypiers IIydraires sont de faux Polypiers. Des travaux modernes ont appris que ees arborisations sont, pour la plupart, une forme dégradée ct transitoire des Méduses. La Méduse fait le Polypier; le Polypier fera la Méduse.

Les Polypiers Ilydraires sont très-aboudants sur nos côtes. Ils appartiennent au groupe des Tubulaires, des Campanulaires, des Sertulaires...

I a Tubulaire chalumean est un P'olypier des plus curieux. Ses tiges, nombrenses, sont comées, jaunes et marquées drespace en espace do nouds inéganx; elles ressemblent à des brins de paille. Leur partie inférieure est torfucuse of tris-allorente aux corpsétrangers; la partie supérieure est ì peu près droite, ou mieux, légèrement flexueuse. L'ensemble représente un végétal fleuri, sans feuilles ni rameaux.

Iu sommet de chaque tige, se développe une double corolle écarlate de quinze à trente-cinq pétales par rangée, les cxtériemes étalés, les intérieurs relevés en houppe. Un peu au-dessous paraissent les ovaires, qui pendent, quand ils sont mûrs, comme des grappes orangées. Au bout d'un certain temps, les corolles se flétrissent, tombent et meurent. Un bouton les remplace, lequel produit un nouveau Polype; et ainsi de suite. Cette succession détermine l'allongement des tiges, chaque prétendue fleur élevant un 
peu le tube qu'elle termine, et chaque addition ajoutant un nœud de plus à l'axe qu'elle allonge.

La Tubulaire rameuse est une des productions animales

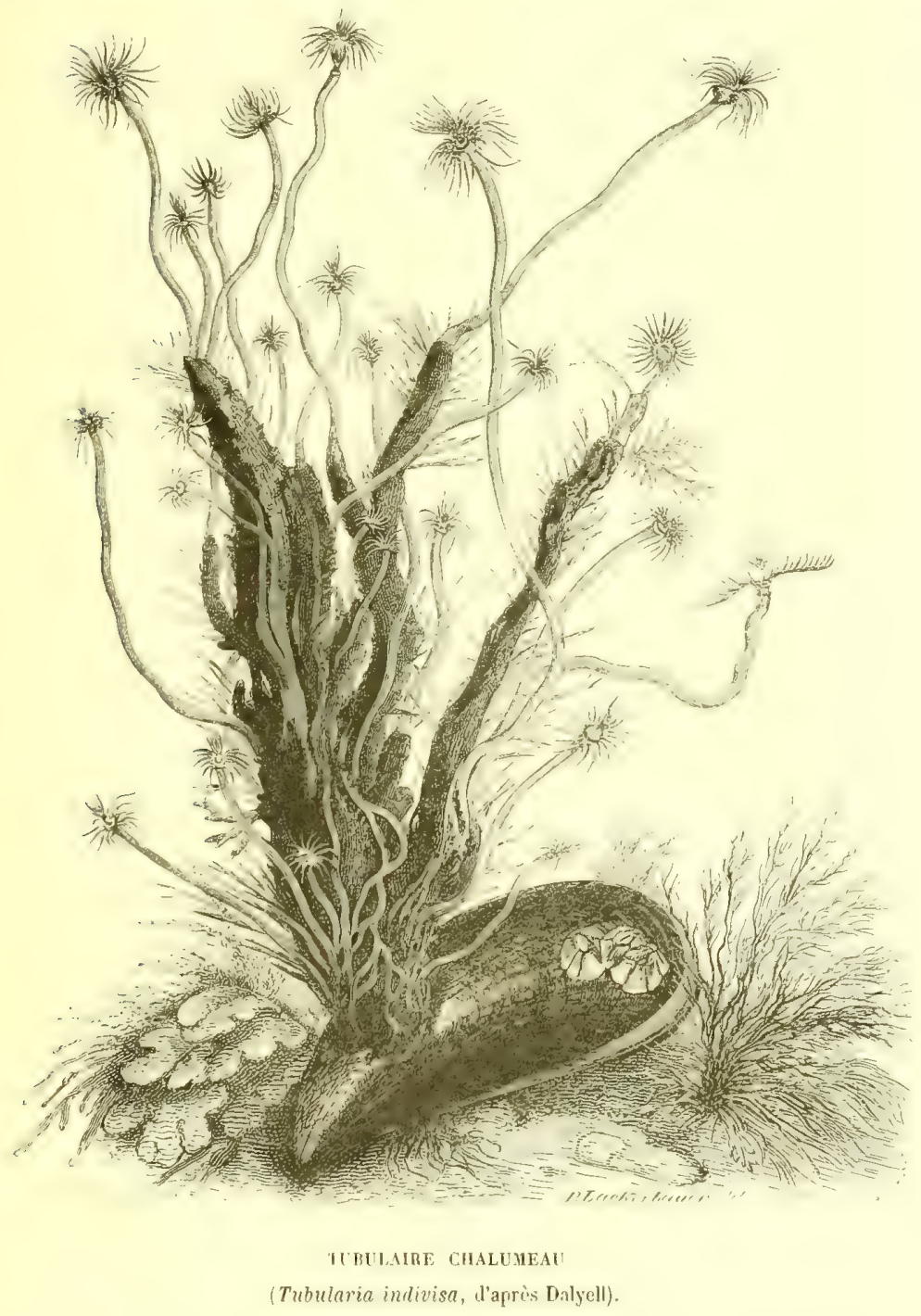

les plus singulières et les plus intéressantes. Parfois elle ressemble àun vieil arbre ruinć par le temps; d'autres fois elle appelle un vigoureux arbrisseau en miniature, tout fleuri, d́levant au-dessus d'unc tige brum foncé un grand nombre 
de branches et de rameaux touffus, que terminent autant de petites Hydres d'un beau jaune ou d'un rouge éclatant. Les Campanulaires diffèrent davantage. Les bouts de

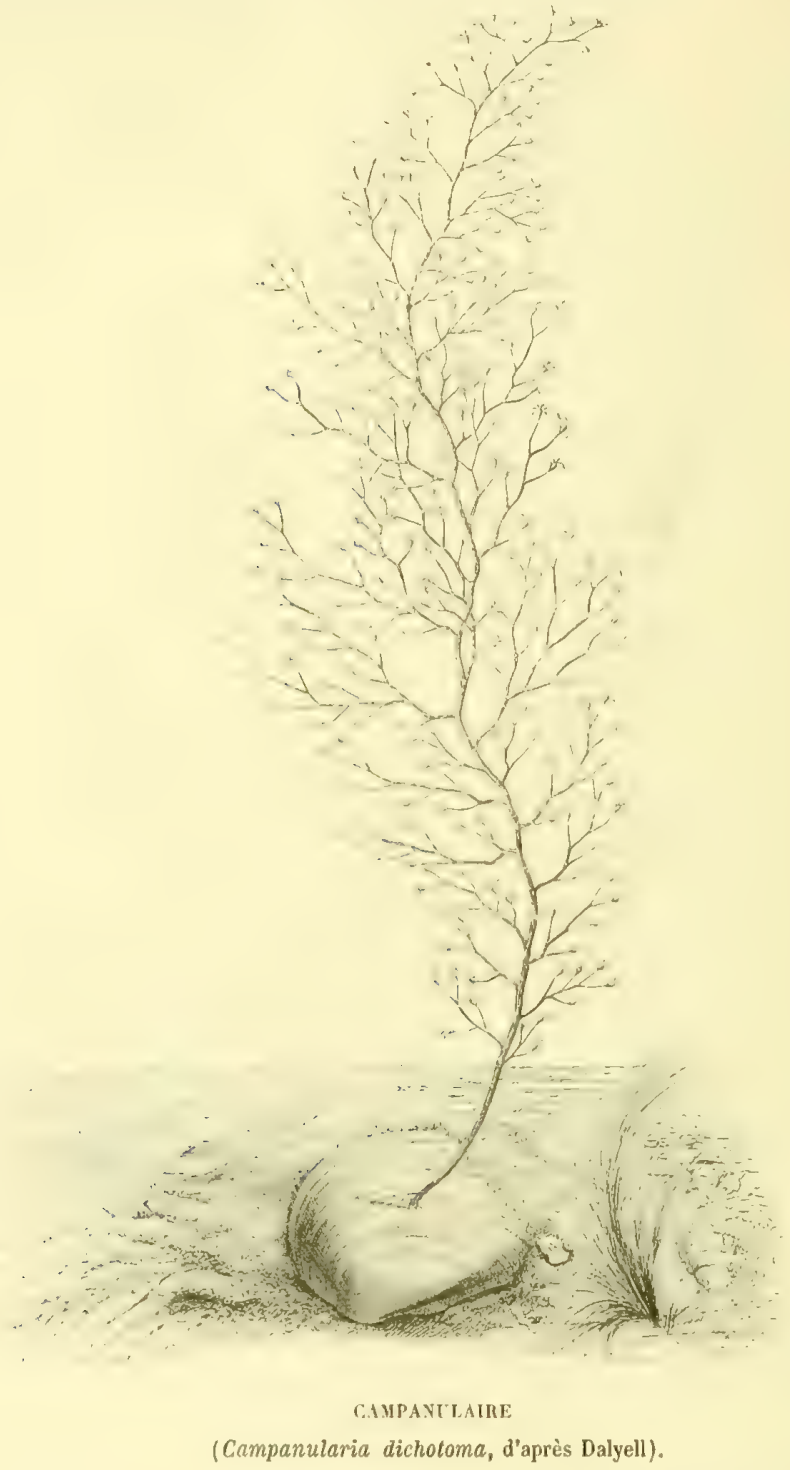

leurs branches par où sortent les Polypes sont élargis en forme de clochettes.

L'espice appelée dichotome est une des plus délicates 
et des plus élégantes. Elle offre une tige mince comme un fil de soie, résistante, élastique et brune. Les Polypes sont assez nombreux. Sur une arborisation haute de 20 centimètres, il en existe peut-être douze cents.

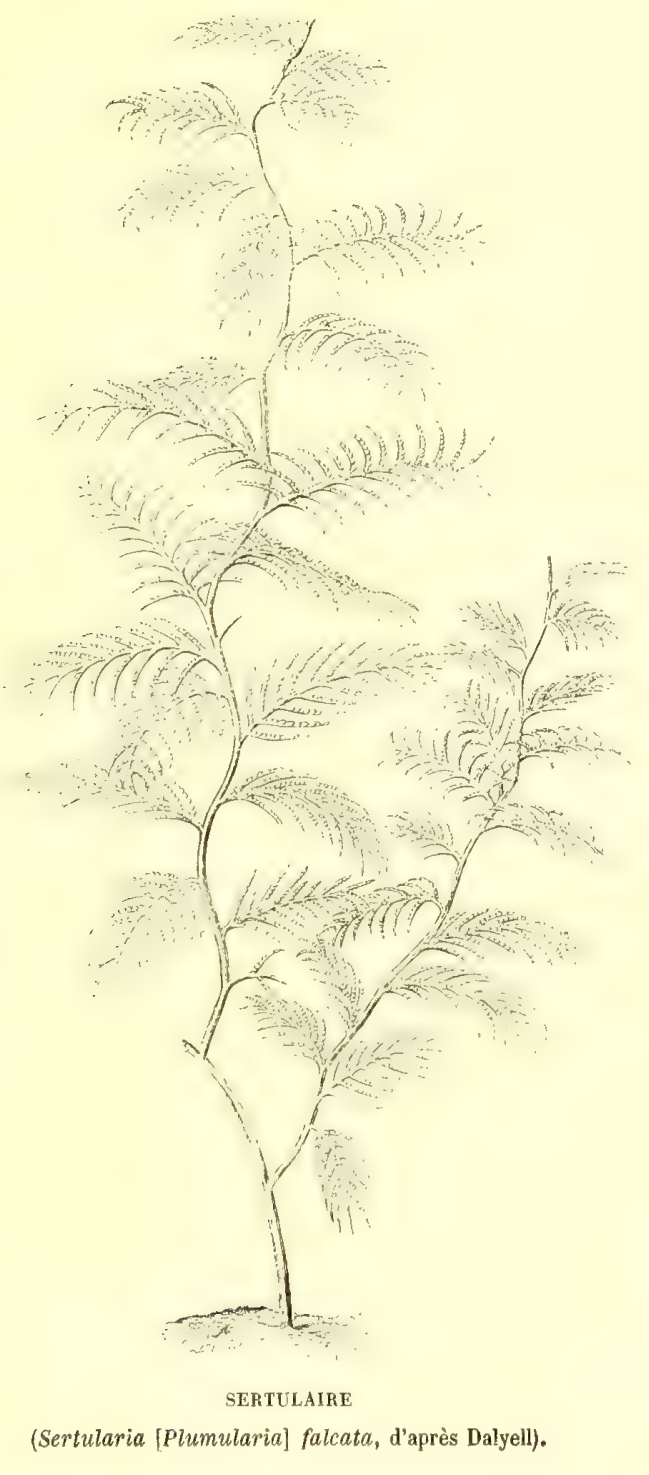

Les Sertulaires sont encore des Polypiers Hydraires. Ceux-ci ont une tige cornée, tantôt simple, tantôt rameuse : 
on les prendrait pour de petites plantes. Leur nom est dérivé du latin serfum (bouquet). On peut les comparer à

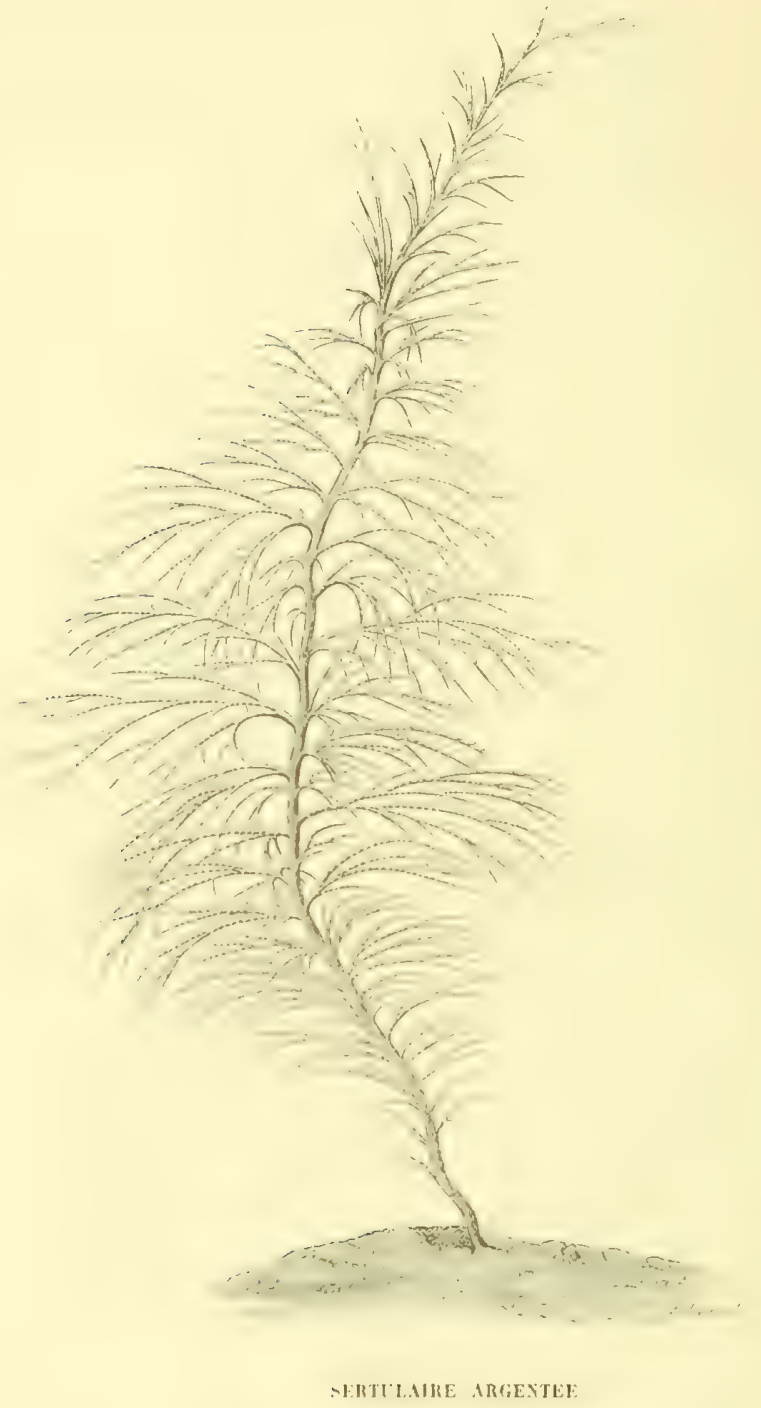

(Scmtularia argenten, d'après [balyell),

des arbustes en miniature, ì branches flexibles, demitransparentes et jaunâtres.

Dans chaque Sertulaire, il y a sept, huit, douze, vingt 
petits panaches, contemant chacun cinq cents animalcules, ce qui fait jusqu'à dix mille Polypes par association. On assure que, dans un pied de Sertulaire argentée, il existe au moins cent mille individus.

Le Serhularia falcata rappelle, par l'élégance de son port et la délicatesse de ses rameaux, les plus belles Mimoses. Ce Polypier fait partie aujourd'hui des Polypiers Bryozoaires.

Les petites cellules qui logent les Polypes ne sont pas toujours distribnées de la mème manière. Il y en a tantôt des deux côtés, tantòt d'un seul. Quelquefois elles se groupent comme de petits tuyaux d'orgue; d'autres fois elles s'enroulent en spirale autour de la tige, ou forment çà et là des anneaux horizontaux.

Parmi les Polypiers Actiniaires, on a formé denx tribus d'après le nombre des tentacules de leurs animaux. Tantôt ces tentacules sont au nombre de six ou de ses multiples: ce sont les Zoanthaires; tantôt an nombre de huit: ce sont les Alcyonaires.

Les Zoanthaires comprennent les Actinies, les Zoanthes proprement dits, les Antipathes et les Madrépores.

On regarde comme intermédiaires entre les Polypiers et les Anémones de mer, dont nous traiterons plus loin ${ }^{1}$, des Zoophytes élégants, désignés sous le nom de Zoanthes. Ces animaux sont réunis en nombre souvent considérable sur une base commune. Cette base est tantôt dilatéc en large surface, tantôt vermiculée comme une racine rampante. 
Le Zoanthe des Moluques ${ }^{1}$ compose de larges tonffes gazonnantes sur les rochers de Corail. Ses animalcules sont assez rapprochés, et imitent, à faire illusion, un amas de fleurs épanouies. Ils sont portés par de fausses racines d'un blane pur enlacées les unes dans les autres. Leur corps est fusiforme, rétréci et comme pédiculé à la base, tronqué au sommet, d'un rouge brun marqué de stries longitudinales plus colorées; sa consistance est ferme et parcheminée. De ce corps sort un tube étroit, musculaire, con-

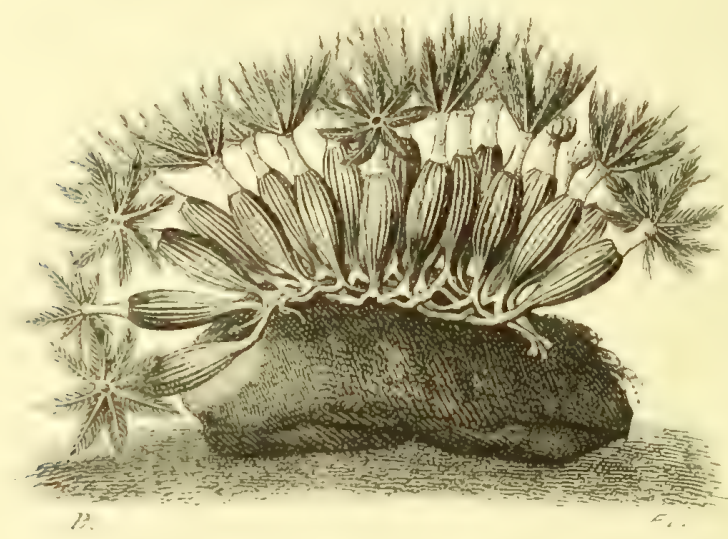

ZOAYTHE DES MOLIOLE:

(Zoantha thalassanthos Lesson).

tractile, rougeâtre, terminé par huit bras allongés, d'un jaune pur an sommet et traversés par une nervure de la même couleur. Sur les côtés de ces bras naissent des pinnules fines, parallèles, d'une couleur marron clair, semblables aux barbes d'une plume.

Les bras de ce Zoanthe sont sans cesse en mouvement; ils forment dans l'eau divers petits courants, dans l'oscil- 
lation desquels sont précipités, comme dans un torrent, les animalcules dont le Polype se nourrit. Au moindre mouvement, le Zoophyte replie ses bras. (Lesson.)

Les Antipathes ont un polypier toujours fragile, et

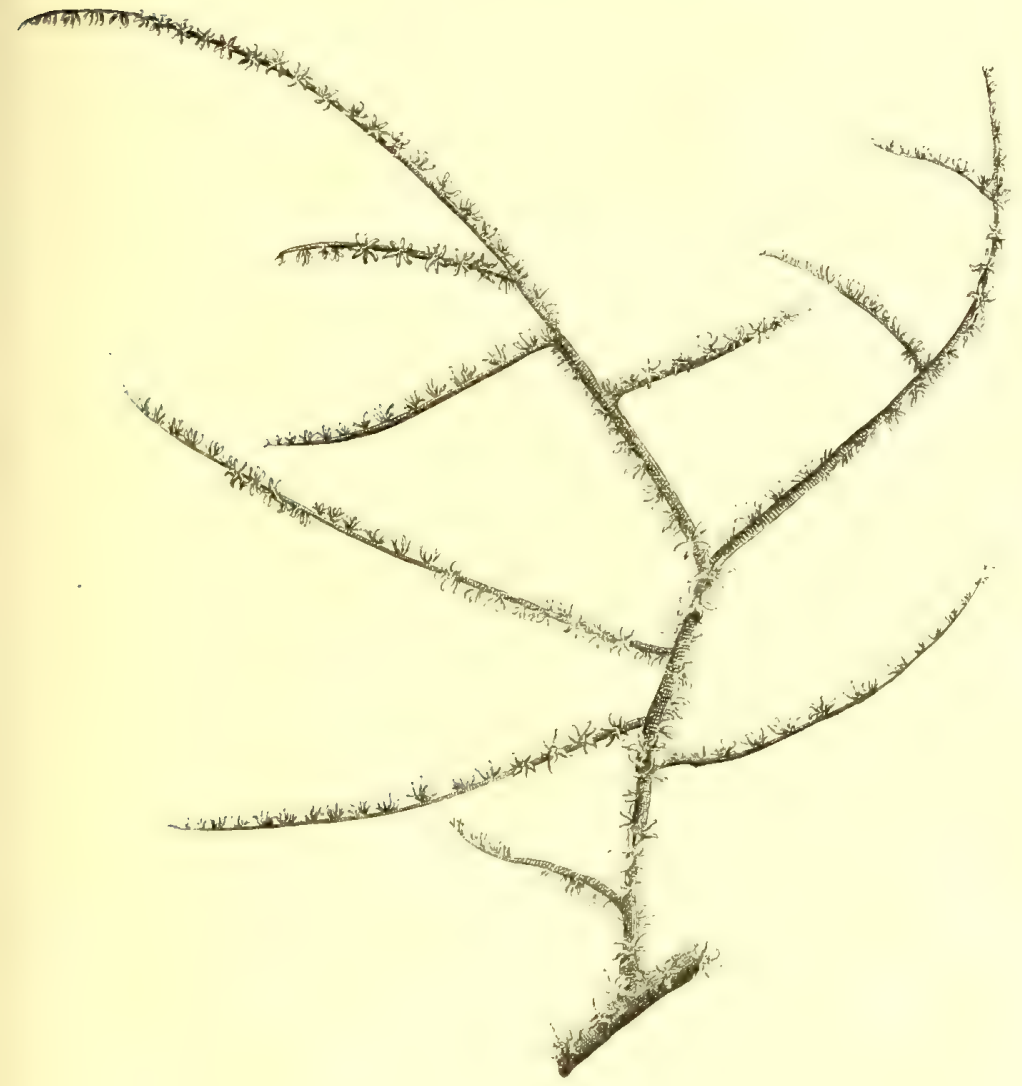

AYIIPATHE

(.Mlipathes arborea Dana).

cassant, quand il est desséché; les ramifications, toujours grêles, déliées, ressemblent aux barbules délicates d'une plume. La couleur est noirâtre foncé, ou plutôt bistre et terre de Sienne. Au microscope ou à une forte loupe, les extrémités des branches apparaissent hérissées de petites pointes (spinules), et le tronc est formé de couches ovales 
concentriques et inégales: ce sont les zones de la croissance. Sa consistance est assez lerme pour qu'il soit travaillé

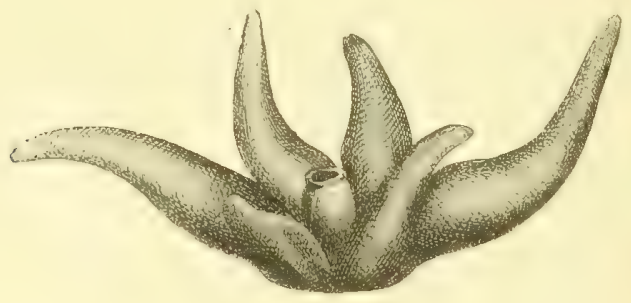

POLYTE GROSSI D'AYTHATHE

(Antipathes arborea Dana).

et converti en chapolets de perles et autres bijoux, connus dans le commerce sous le nom de Corail noir.

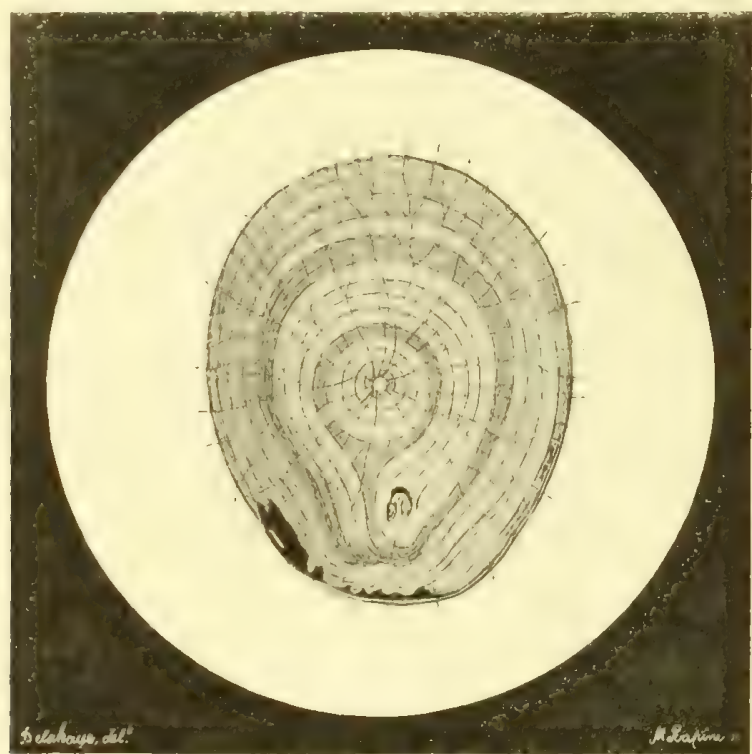

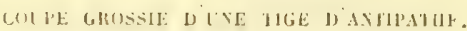

(D'après une préparation de M. Potteau.)

L'écorce est molle, dépourvue de grains calcaires ou siliceux, et se détruit après la mort. Elle reçoit des 
Polypes de forme allongée, et le plus souvent de couleur jaune.

La Gérardie pêchée par M. Lacaze-Duthiers dans les

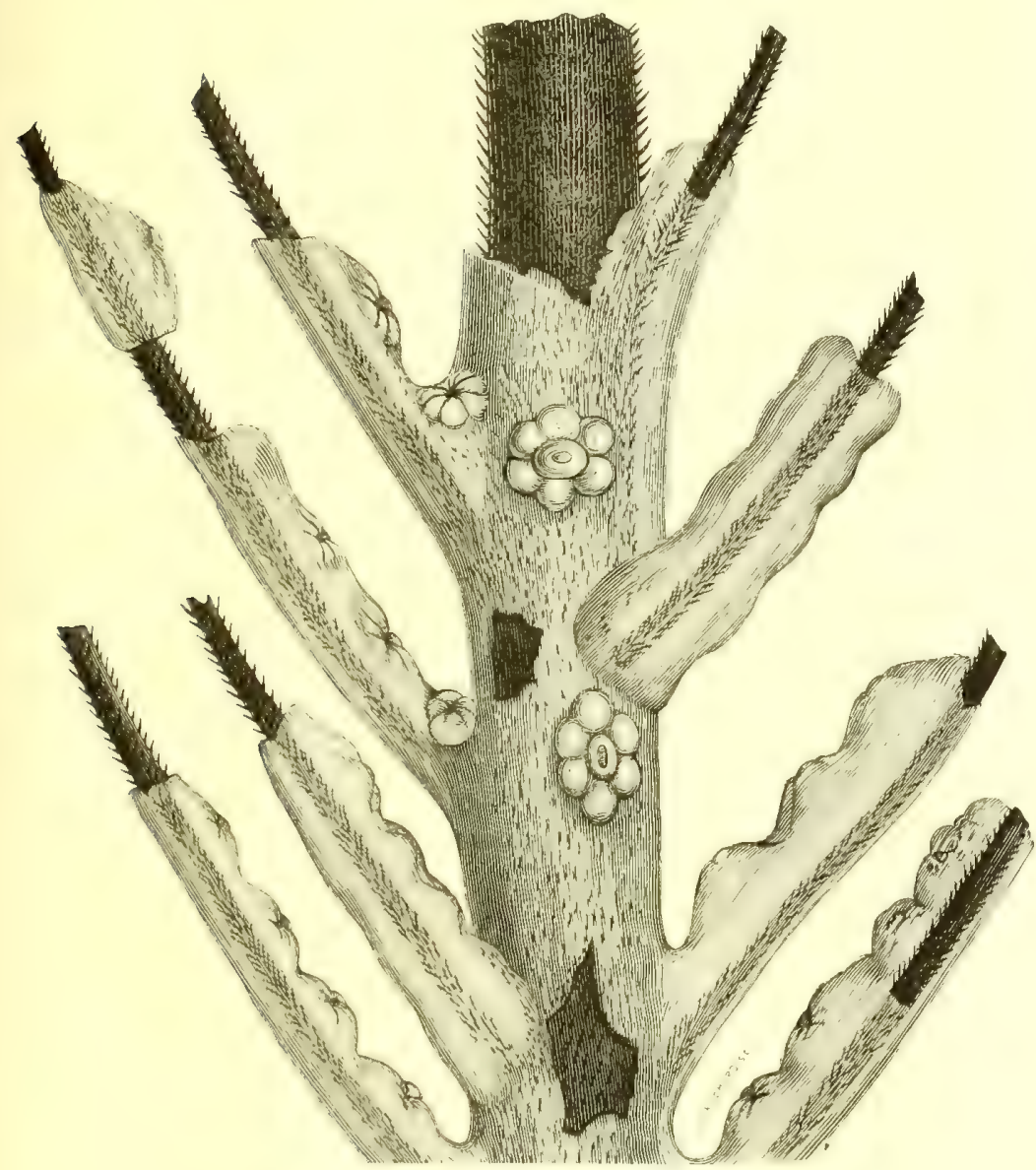

ANTIPATHE GROSSI POCR MONTRER LES SPINULES

(Antipathes subpinnita, d’après Lacaze-Duthiers).

eaux de l'Algérie est un genre voisin très-curieux que ce savant naturaliste a fait connaitre dans une suite de beaux mémoires dont il a bien voulu nous communiquer les dessins originaux. 
La Gérardie vivante est couverte de fleurs jaunâtres ou orangées à vingt-quatre pétales souvent très-allongés et pendants.

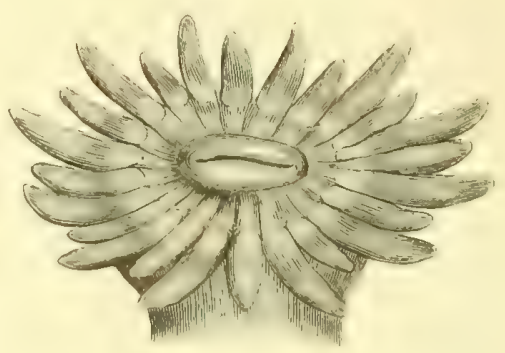

PULAPE DE LA GERARDIE.

L'intérieur du Polype présente autant de cloisons que de tentacules. Le polypier est très-lameux et très-élancé

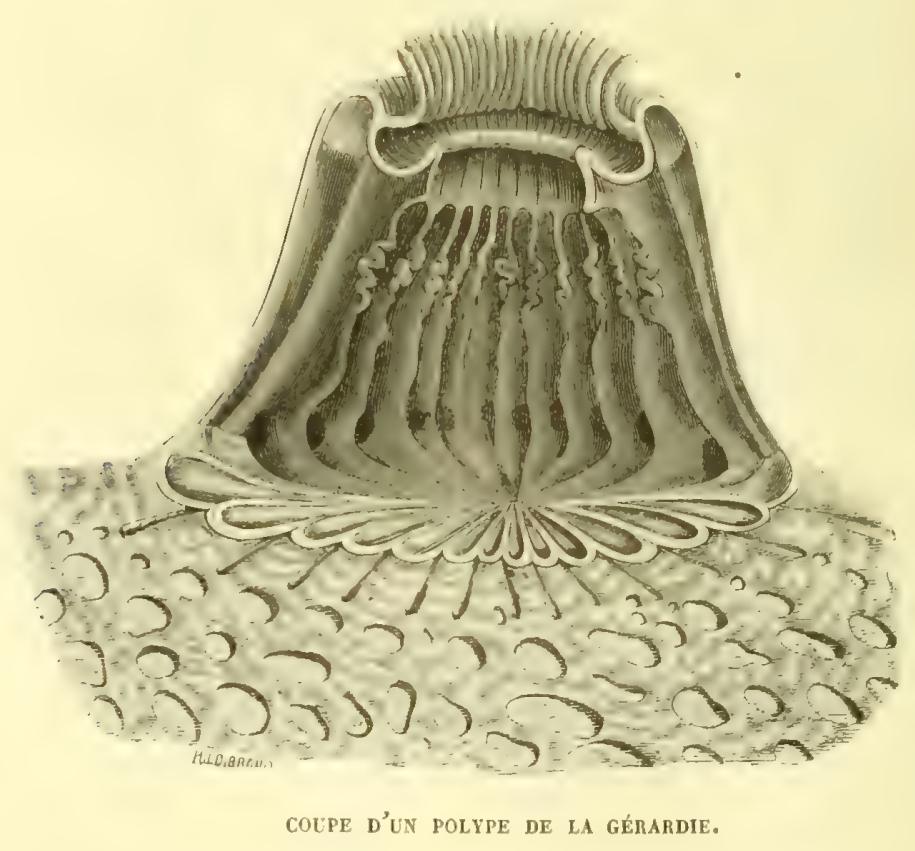

quand il est adulte. Dans le jeune âge, l'écorce se développe plus rapidement que le support; aussi la Gérardie se 
greffe-t-elle à tous les corps à sa portée. Malheur à la Gorgone qu'elle cnvahit, elle ne tarde pas à l'étouffer sous sa végétation exubérante. De là, souvent, cet aspect gorgonien que présentent les jeunes Polypiers. M. Lacaze-Duthiers a tronvé une de ces colonies, qui s'était développéc sur un øuf de Squale.

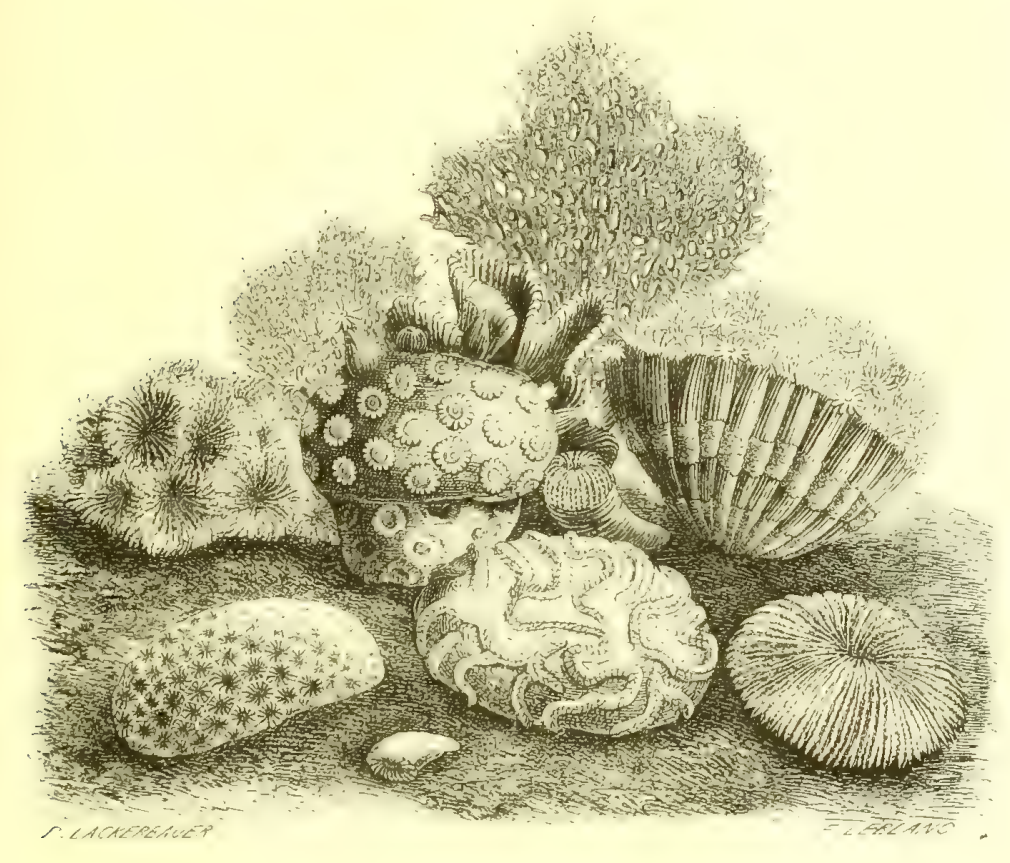

MADKEPORAIRES.

Les Madréporaires sont tres-nombrenx; ils forment le: groupe le plus important des Polypiers letiniaires. Tous sont pierreux : ce sont cux surtont qui constituent les récifs ef les îles à coraux. On connaît peu leurs Polypes.

Parmi les plus curieux, on doit citer les Caryophyllies, les Madrépores proprement dits, les Astrées, les Méandrines et les Poritides...

Les Caryophyllies présentent des cellules tubuleuses en partie isolées les unes des autres, ce qui domne à la masse 
un aspect comme raneux. Chatpue branche est oceupée par un Polype.

Une des plus belles est la Caryophyllie de Smith', avee sa

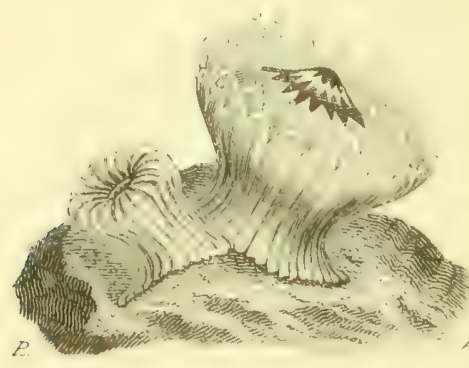

C.MYYOPIYLLIE DE SMITH

(C'aryophyllia Smithii Stokes et WV. P. Broderiph.

pobe jaunàtre, plus paile it la base of all sommet, ornéc de lignes longitudinales d'un blane léger! Son disfue, d'abord

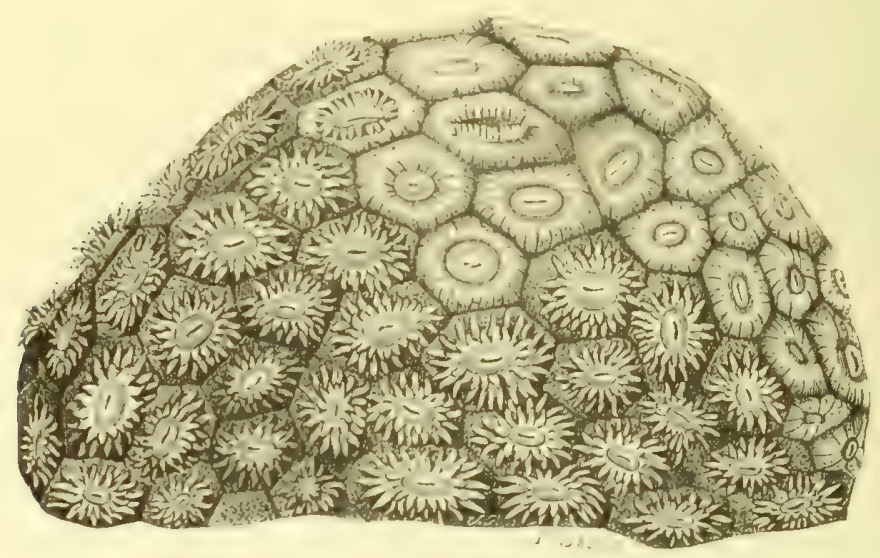

A.TIÉE

I. Istrue fiallida Dana).

brun, devient blanc ef puis rert; ses tentacules, à peu près triangulaires, sont presque transparents. Ils ressemblent

1 Voyez figure 1 , planche $X$. 
à des festons de dentelle finement bordés d'un ourlet blanchàtre et terminés chacun par un pois blanc.

Les Madrépores proprement dits sont des associations bizarres des plus variées et des plus intéressantes. Qu'on se rappelle un gâteau de cire sorti d'une ruche, avec des larves d'Abeilles dans charne cellule; 'fu'on suppose ce gàteau de picre et non de cire, et charue larve remplacée

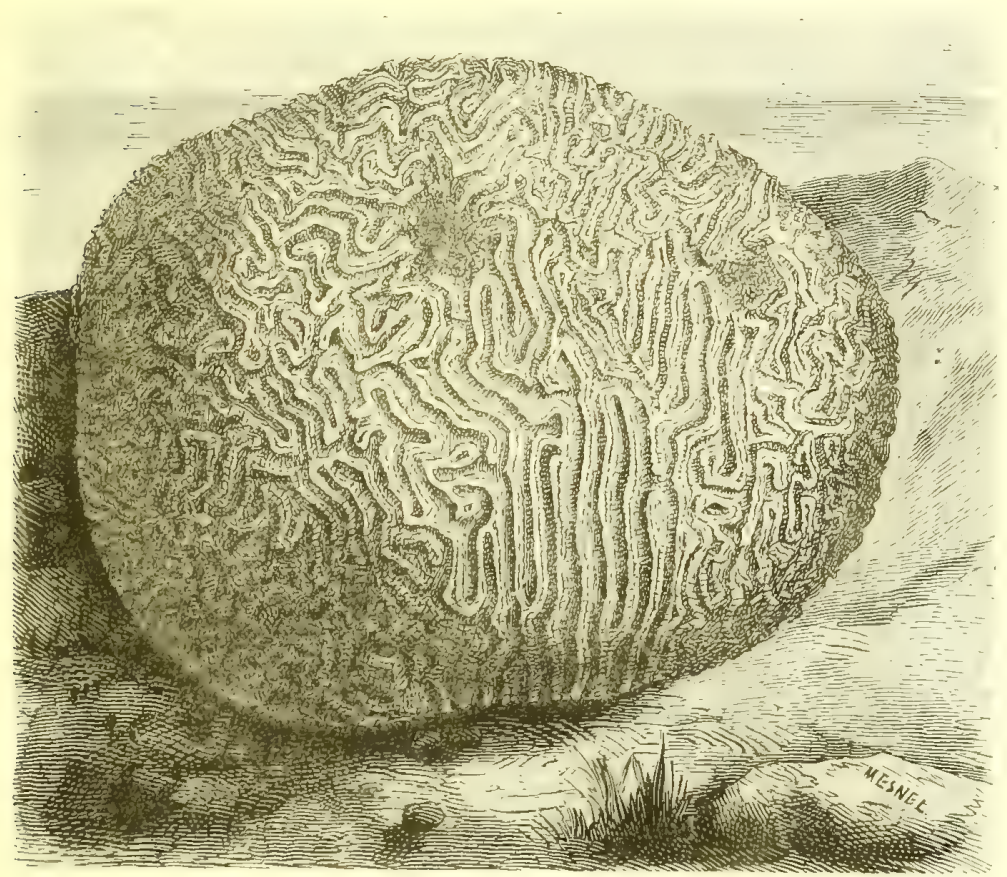

MISTHIXE

(Mcandrina cerebriformis Lamarck).

par un Polype, et l'on aura le Madrépore désigné sous le nom d'Astrée : e'est un des plus connus.

Les Méandrines different des Astrées par une surface creusée de lignes allongées et tortucuses, sillonnées en traver's. Leur's cellules sont placécs régulièrement dans les vallons. 
Les Poritides ont des branches qui s'élèvent peu, généralement dichotomes, il lobes obtus. Leurs Polypes sont des

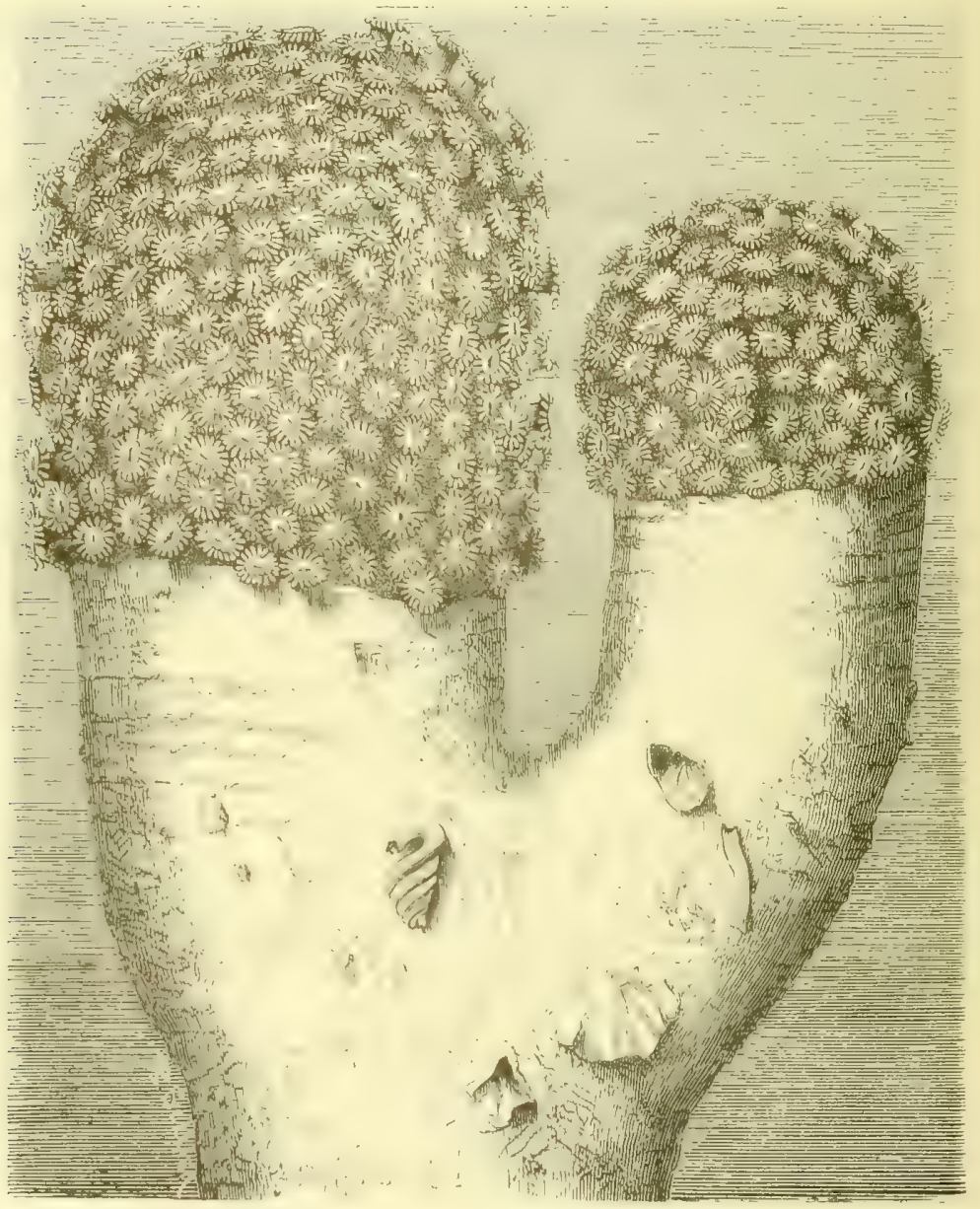

PORITIDE AYEC SES POLYPES EPAYOLIS

(Goniopora columna Dana).

mintatures dincimones, portant antour de leur bouche douze tentarules raliés. Lenr polypier est pierreux, fixé, rameux ou lobé, ¿̀ surface libre, présentant un grand nombre d'étoiles régulieres. superficielles ou excavées, à bords imparfaits ou nuls. Ces étoiles sont caractéris- 
tiques; on ne saurait les confondre avec celles d'une Astrée on d'un Madrépore.

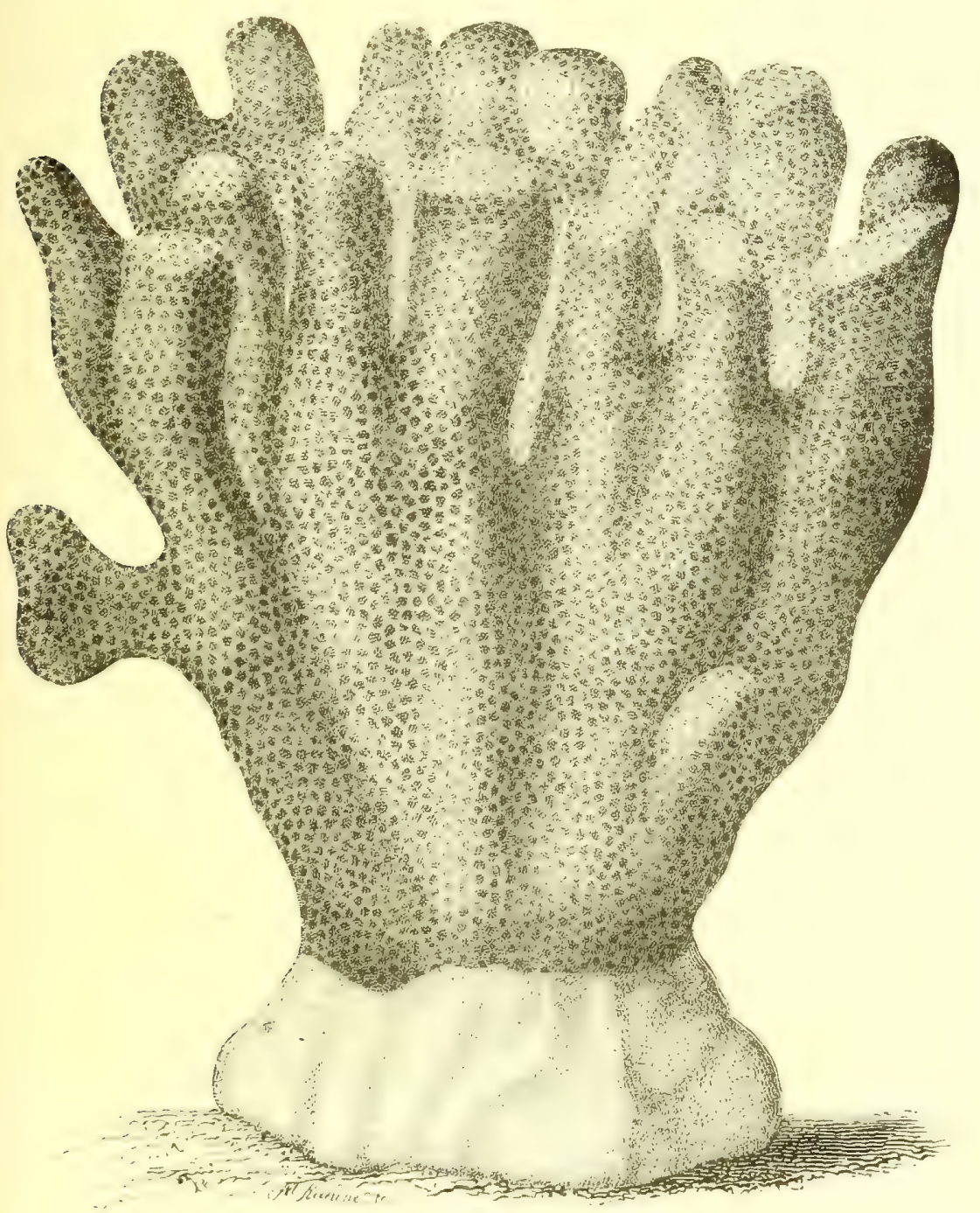

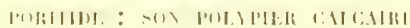

(Porites mordax Dana).

Les Polypiers Alcyonaires réunissent les Aleyonides, les Tubiporides, les Corgomides of les Pematulides, dont nons traiterons dans mn chapitre spécial. 
Les Alcyonides sont très-communs; on en trouve souvent sur les coquilles de Saint-Jacyues, sous lit forme de masses charnues mrondies, a lobes irréguliors et de couleur rouge : cette masse nst toute une colonic. Placée dans de l'eau de mer pure et fraiche, on ne tarde pas à voir apparaître des points opalins ou jinmâtres, qui se gouflent

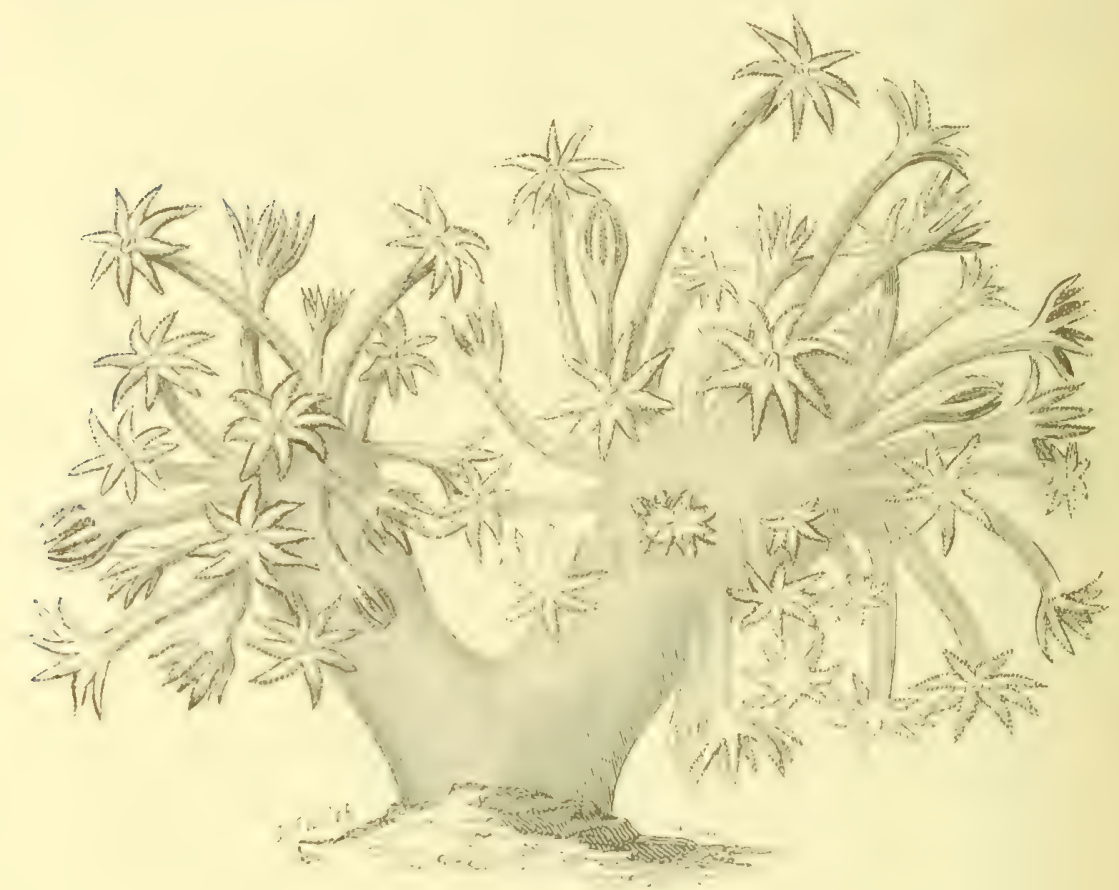

M.1:(1)

(Tenia elongata Dana).

peu ì pen, font saillie, ot s'épanonissent an uno corolle transparente at animée. Charenn de res Polypes a huit pétales dentelés: an rentre. ast la frouche. Le rorps du

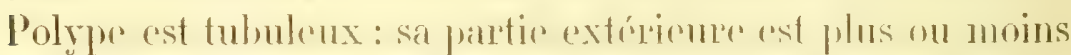
longue; sa partio intérieure travorse au dedans, jusqu’a la

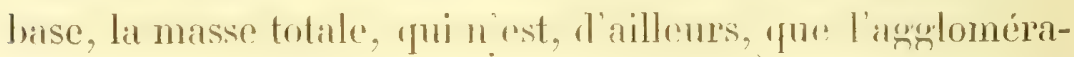
tion de tous les individus de l'assocjation rámis pald un tissu 
cornmun, criblé de spicules rouges et sillonné de vaisseaux.

La Bebryce tendre 1 est un Alcyonide. Ce Polypier, incomplet comme tous les Alcyons, ne possède qu'une écorce qui contient les Polypes. L'axe qui lui sert de soutien est un support d'emprunt.

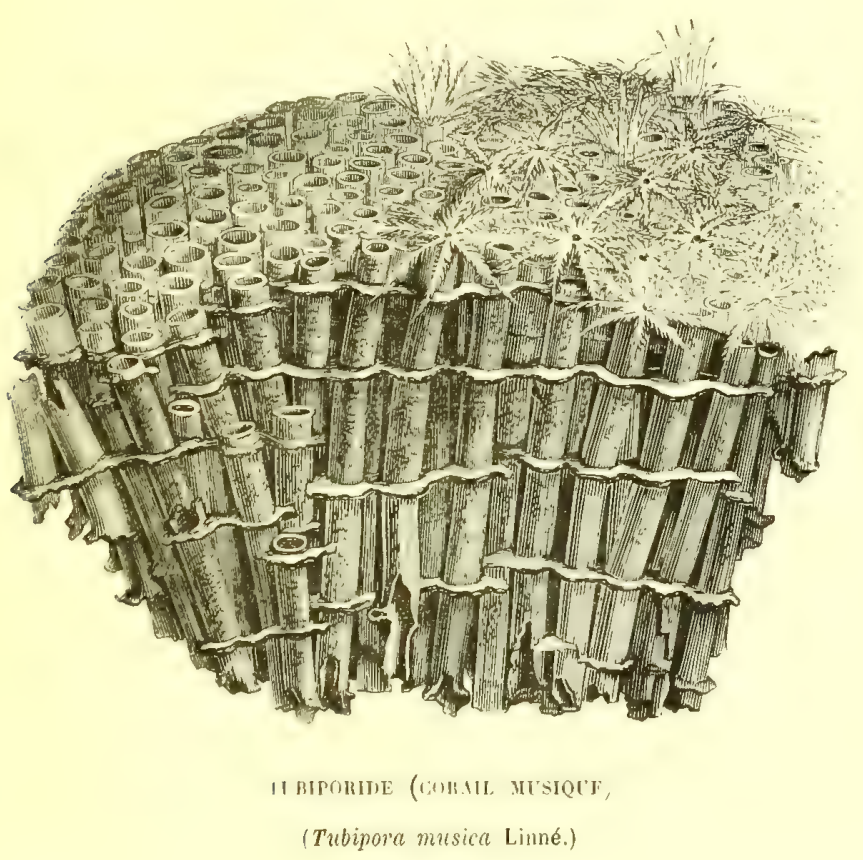

Parmi les Tubiporides, se trouve le Corail musique, de l'archipel des Indes, caractérisé par ses tubes pierreux, simples, nombrenx, rapprochés, droits ou flexueux, parallèles et un peu rayommants, l'un beau louge pourpre, unis ensemble de distance en distance prar des lames transversales. On a comparé leur ensemble à un amas de tuyaux d'orgue.

Ses Polypes sont d'un vert d'herbe brillant (Péron); ils

1 Voyez la planche VIII. 
ont des tentacules garnis de charue coté de deux ou trois rangées de papilles gramulenses charnues, an nombre de soixante à quatre-vingts (Lesson).

Les Gorgonides ont une écorce tellement pénétrée de grains raleaires ou siliceux (spicules), gu'elle forme une

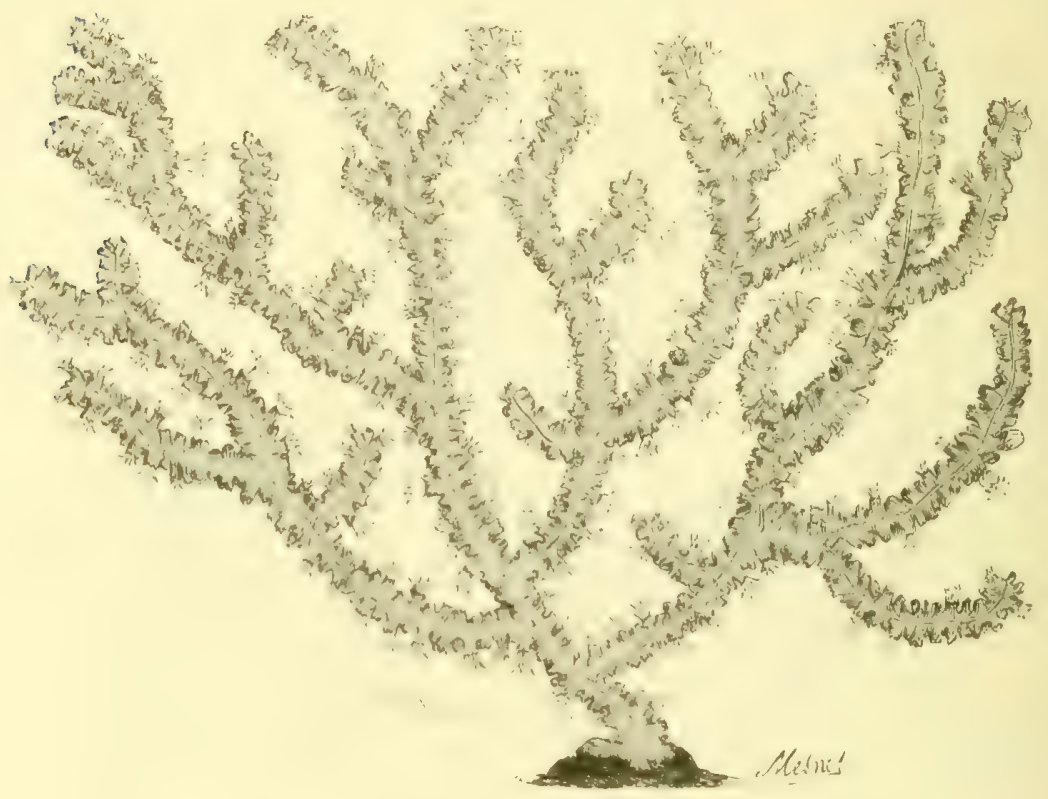

Gohgosid.

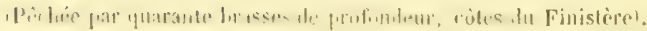

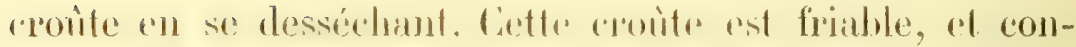
serve sonvent les andeu's phos on moins brillantes qui la caractérisent. Laur's rellules sont creusées tautôt daus une surface plane, tantiol daus des mamelons saillants; eenx-ci sont lisses, hépissés on renillens. quelquefois pendants les uns sur les autres.

C'est à ce groupe qu appmiticment les Isis et le Corail, lont l'étude nous occuprera dans le chapitre snivant, et toutes ces arborisations noires, lisses et flexibles, que l'on

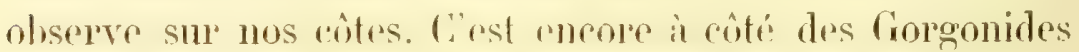


que M. Deshayes a placé le beau Polypier pêché à la Calle, l'Anthozoanthe parasite ${ }^{1}$, magnifique arbrisseau redressé et non pendant, avec des axes d'un brun foncé, une écorce d'un rose vif, et des Polypes d'un jaune d'or.

\section{IV}

Les Polypiers sont fixés aux corps solides. Quelquefois ils s'attachent les uns aux autres, se greffent dans tous les sens ou s'enlacent dans toutes les directions.

Il y en a de blanchitres, de tout ì fait blanes, de jaunâtres, de vert-pomme. Leurs nuances passent du brun olivâtre an bleu foncé, du vermillon an violet, et du jaume pâle au gris de perle.

Chaque tuyan ou cellule contient un individu. Les loges sont plus ou moins profondes, suivant les espèces. Les animalcules sont composés généralement d'une partie cachée plus ou moins tubuleuse, et d'une partie étoiléc plus ou moins apparente. Cette dernière présente de huit à douze harbillons lisses ou granuleux, susceptibles de sépanouir comme les pétales d'une fleur. Quand ces appendices sont étalés, ils atteignent souvent le double de la hauteur du corps; ils sont alors presque transparents, excepté vers l'extrémité.

Les Polypes étendent ou resserrent leurs barbillons, dilatent ou contractent leur bouche, suivant les besoins: mais leur tube digestif est sondé à leur cellule, ot les axes qui portent les cellules sont condamnés à l'immobilité. Singulière combinaison! des arbustes moitié animés et croissant an fond de l'ean; des animalcules moitié empri-

1 Vovez la planche VII, communiquée par M. Deshayes. 
sommés et rivés à leur prison; des estomaes dans me écorce, des bras sur une branche, of le mouvement sur le repos!

Les animalcules des Polypiers se reproduisent par de petites larves romies par l'animal et par des bourgeons développés dans leur écorce.
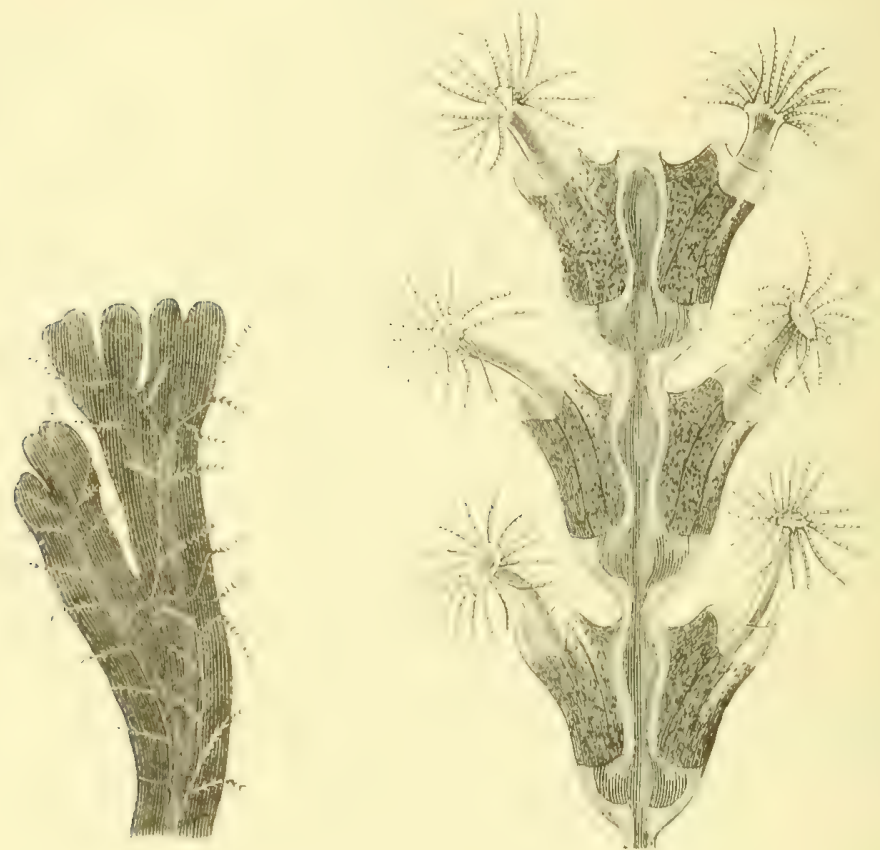

POLYPES EPAYOTIS SORTIS DE IEUR I.OGT

(Sertularia pumila liuné).

Dans les Polypiers llyilmires, les aufs sont souvent contomus dans des capsules comóes spériales, qui se brisent Iors de la maturation. Leurs formes sont tres-rariées, suivant les espèces.

Qu'on imagine un ellipsoïde transparent comme du cristal, dont les parois sont décorées de rampes à créneaux disposées en spirale, interrompues à charpue tour, et lais- 
sant voir par transparence cinq ou six ceufs ronds, d'un jaune safrané, et l'on anra la capsule ovigère d'un Polypier Bryozoaire, la Plumulaire plume.
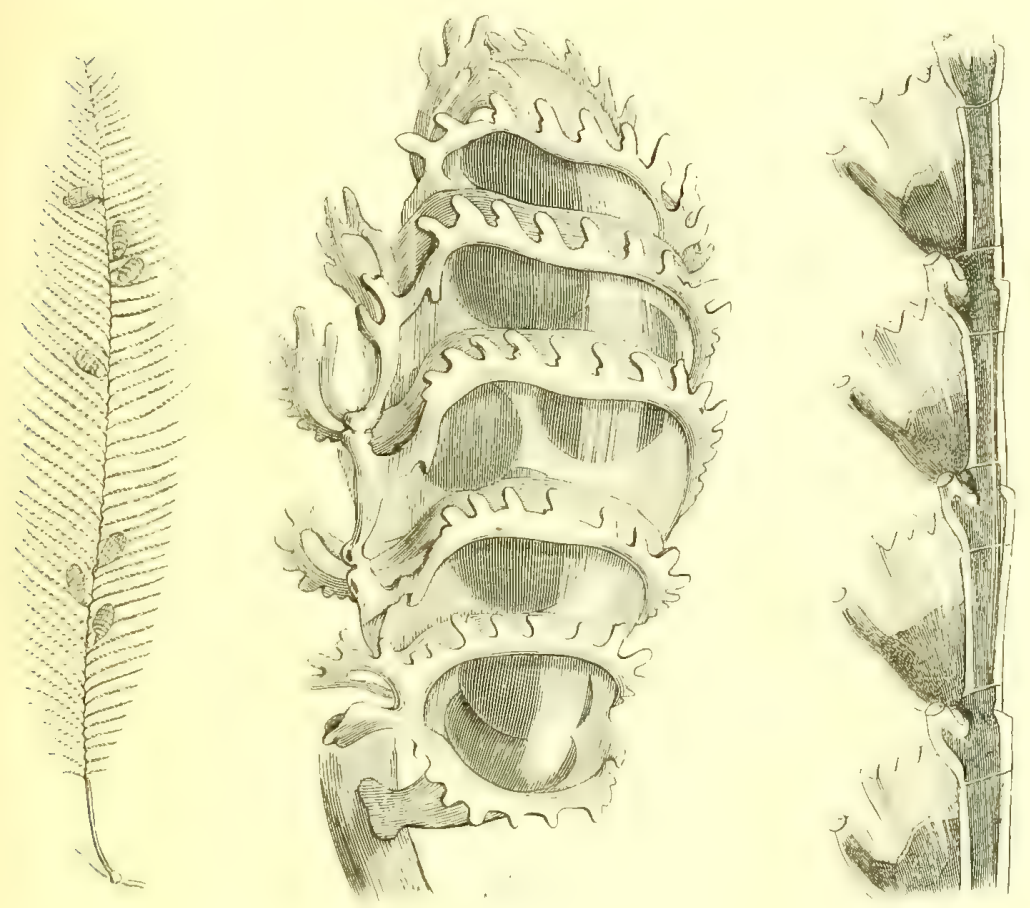

POIYPIER GRYOZOAIRE: SON SAG A OELFS ET SES LOGES A POLYPES, GROSSIS

(Plumularia pluma Linné).

Chez les Campanulaires, il existe des branches mâles et des branches femelles: les unes chargées de loges dans lesquelles se développent les aufí; les autres portant des capsules mâles surmontées chicune d'un bourquet d'élégants tentacules.

Mais un des phénomènes les plus curieux que présente l'étude des Polypiers Ilydraires, est celui que les savants ont désigné sous le nom de génération médusipare. A une cèrtaine époque de l'année, apparait, chez les Campamulaires, les Syncorines, etc., une sorte de hernie extériemre, 
au centre de laquelle tourbillonne le liquide nourricier. C'est mu bourgeon qui, peu à peu, se revêt d'un bourrelet de sulsstance transparente, grandit rapidement, et ne tarde pas à montrer des traces d'organisation intériemre. On voit
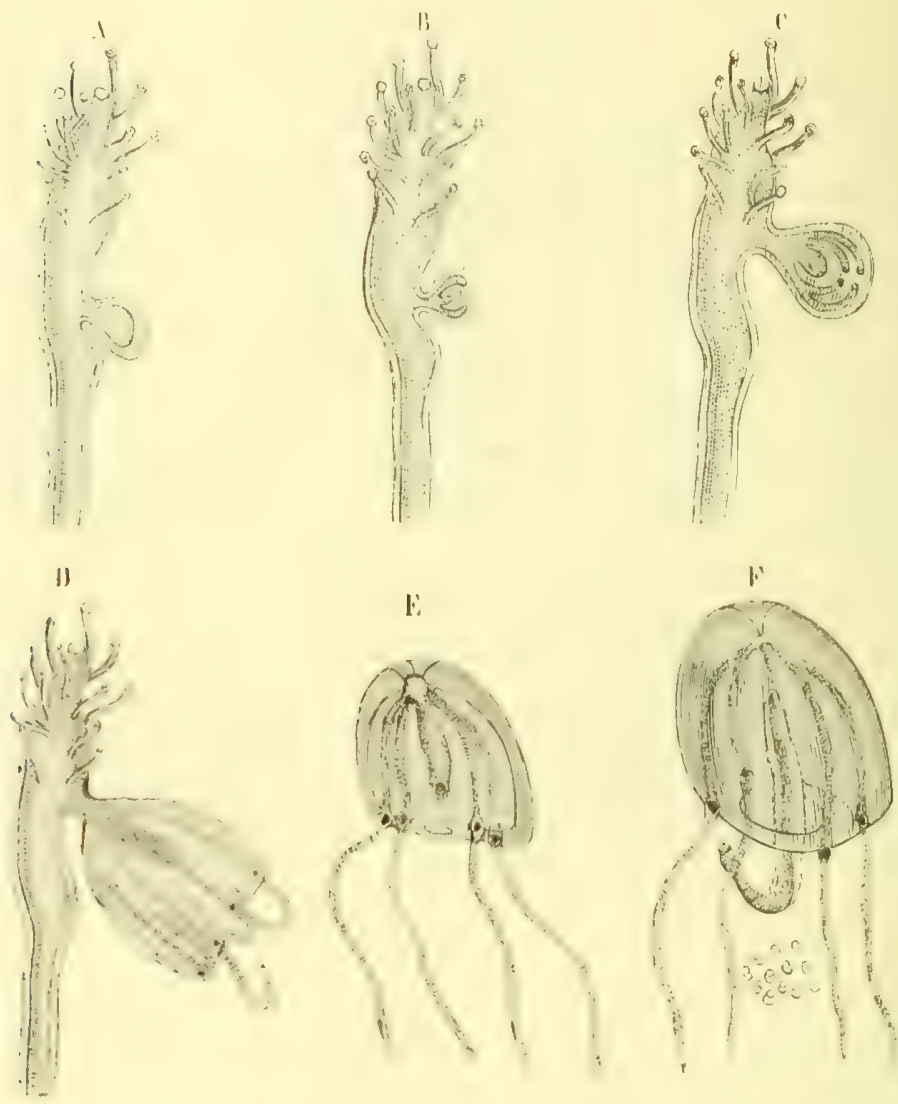

POIYPIER HYDRAINE PRODUISAYT TNE MÉDLSE

alors le lipuide nourricier circuler dans quatre canaux; fuatre points noirs se dessinent au sommet du bourgeon, à l'extrémité des quatre canaux : ce sont les yeux. Insensiblement le bourgeon prend un aspect plus campanuliforme; son extrémité se dilate, les yeux s'écartent, et dans leur voisinage naissent quatre tentacules. Le réservoir central 
augmente de capacité, se limite par une membrane distincte, et forme l'estomac. L'animal est développé : c'est une vraie Méduse. Dans peu de temps, elle rompra son pédicule par de violentes contractions, et prendra son essor vers la haute mer.

La jeune Méduse, aussitôt libre, atteint en peu de jours le double de son volume. La déchirure de son pédicule se cicatrise, les tentacules s'allongent; l'estomac acquiert une bouche. Quelques semaines encore, et l'intestin de chacune de ces petites Méduses présentera un contour onduleux, comme mamelonné : ce sont des cufs qui se forment, grossissent, se développent, et se détacheront par un mécanisme semblable (Desor).

Les Polypes sont de petits ouvriers silencieux, actifs, infatigables, qui sécrètent et organisent les gâteaux ou les axes qui les portent et les logent. Eclatante industrie, qui sera sans cesse un objet d'admiration! Population modeste, digne des plus grands éloges, réservéc dans ce qu'elle consomme, magnifique dans ce qu'elle produit !

Les Polypes aiment les régions chaudes de l'Océan, et prospèrent mal dans les pays froids.

Les uns forment des pelouses de vie sous-marines qui tapissent les rochers; les autres composent des stalactites animées, de grands arbrisseaux, de petits arbres ou d'immenses forêts. Le câble électrique qui relie la Sardaigne au fort Génois était incrusté d'un si grand nombre de Polypiers et de Bryozoaires, que certaines parties retirées de l'eau avaient le volume d'un baril. (Lacaze-Duthiers.)

Les Polypiers occupent quelquefois des espaces immenses 
„ui grandissent sous les flots, s'élevent en récif's, entourent les iles, les joignent entre olles, les unissent aux continents, et comblent ainsi la profondeur des mers.

En 1702, un royageur anglais, Strachan, observa que les Polypiers étaient capables de former de grandes masses de rochers. En 1780, Forster, savant compagnon du capitaine Cook, ćtablit d'une maniere positive que la plupart des îles de la mer du Sud doivent leur existence à la multiplication excessive of i l'agolomération compacte des l'olypier's. Cette manière de voir a été confirmée par un grand nombre de marins, do zoologistes et de géologues.

Ces Zoophytes sont rémis au fond de l'eau par masses innombrables. Ils absorbent les sels calcaires contenus dans locian, of en composent leurs rellules et leurs axes; ils froduisent ainsi des associations sonvent colossales.

Lemes germes tombent antom d'eux, et doment naissance it de nonveaux gaiteanx. Les dernicrs vemus s'élancent lont anton des premiers ot anteressus d'eux, of les chouflent; coux-ci latissent apres leur mort leurs cellules de propre greflées les unes sur les autres. Ces conches de matiòe devenue inerte servent de fondement à de nourolles génépations qui se superposent régulièrement comme les assises dans me macomnerie. Il résulte de ces agglomébations gigantespues des rocher's immenses qui atteignent jusqu'à deux ou trois cents lieues de longueur!

Cus inchers śélivent peu ì peu du fond de la mer, sans trouthe, sans offort, sans réaction. In bout d'un certain temps, ils composent des ilus: ces îles forment de vastes terres. Il faut des siecles, il ast vai, ponl que ce travail s'accomplisse, mais le temps ne manque jamais à la Nature!

Les auteurs de ces constructions séculaires sont des animaleules gélatineux, fragiles, chétifs, presque toujour's microscopiques; mais ils sont extrêmement nombreux... 
il $\mathrm{y}$ en a des milliards. Ils peuvent done produire, par l'entassement de leur's squelettes, des maçonneries dont le genre humain tout entier, travaillât-il cent mille ans, n'enfanterait qu'une bien faible partie!

Une fois arrivés à la surface de l'eau, les Polypiers cessent de croître, parce que leurs animalcules sont des êtres essentiellement aquatiques. Enfants de la mer, ils doivent

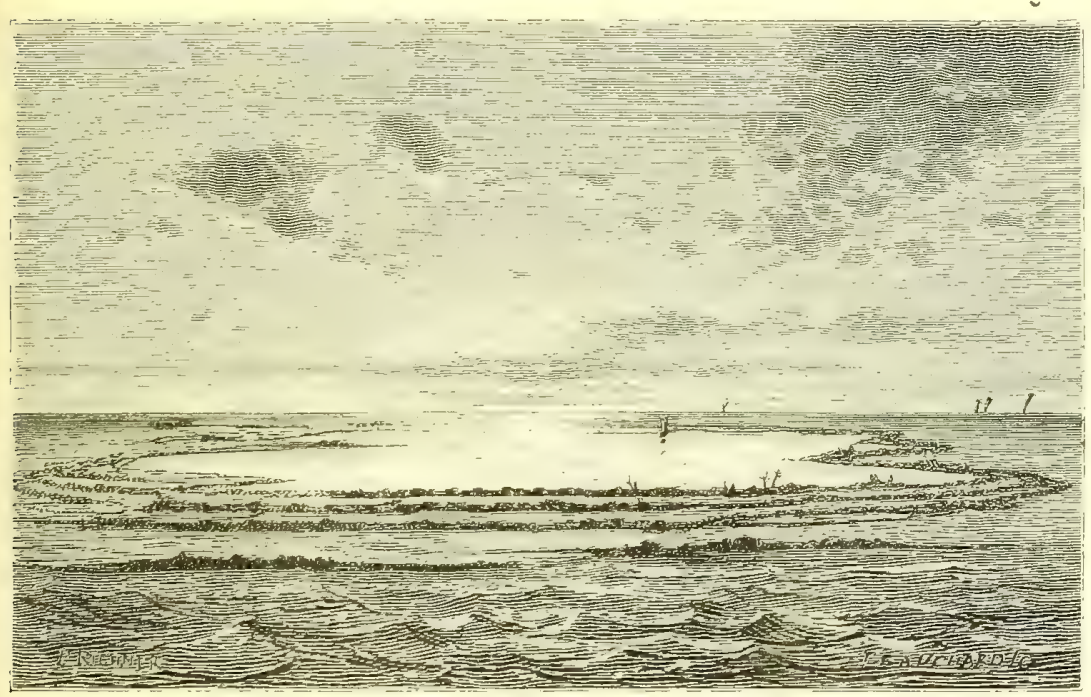

VLE GÉNÉRALE D İLES A CORAUX.

(Ile de Clermont-Tonnerre, archipel Pomotou.)

vivre dans la mer; ils meurent à l'air et au soleil. Voilà pourquoi les couches les plus élevées de ces gigantesques édifices sont toujours privées de vie.

Les vagues qui se brisent contre ces îles ou ces rochers en détachent des quartiers, les ronlent, les ballottent et les réduisent en poussière. Il en résulte d'abord un gravier blanchâtre parsemé de quelques blocs arrondis, puis un sable plus ou moins fin et plus ou moins grisâtre. l.es flots apportent des restes de végétaux, de Mollusifues, de Crustacés, de Poissous.... Ces restes se décomposent et se mêlent 
aux débris madréporiques : la terre végćtale commence ì se former. C'est ainsi que la Providence a fait surgir de l'Océan des espaces de terrain considérables.

L' massif, monté au niveau de la mer, est bientòt envahi par la végétation et embelli par l'animalité. L Les vagues y abandonnent quelques graines; celles-ci se développent. Les végétaux prennent pied dans le terrain, et l'ile est bientòt converte de verdure. Des trones d'arbres arrachés par la mer sur les cotes voisines, et poussés par les conlants, abordent su' sa plage. Des Vars, des coquillages, des lusectes ef d'autres petits animaux apportés avec ces frones se hatent de gagner la terre; ils y pullulent et en constituent la première population. Les Tortues de mer accourent ver's l'ile naissante, et viennent y déposer leurs reufs. Les (tiseanx, attirés de loin par la verdure, arrivent pour s' reposer et pour y construire lems nids. Ėnlin, les habitants des îles roisines, chassés par quelque coup de vent on séduits par la beauté du site et par l'abondance de ses finuts, sy lendent avee leu's pirogues, y batissent des cabanes, y fondent une tribu; et l'industric de l'Homne complète et vivifie l'industrie des Polypiers!

Les actions si puissantes des animalcules les plus petits et les plus faibles sont empreintes, dans la Nalure, d'un chame et diue philosophic que ne domneront jamais dans nos musées les formes les plus élégantes de leurs cadavres soigneuscment conservés et savamment classés.

les Infusoires, les foraminifères et les Polypes existent dans la mer par milliards de milliards... Ciest l'intini vivant!

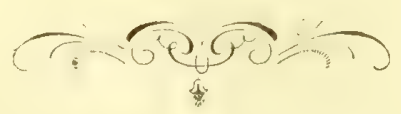







CORAIL

Portion de Macciotta péchée à 80 brasses de profondeur. 


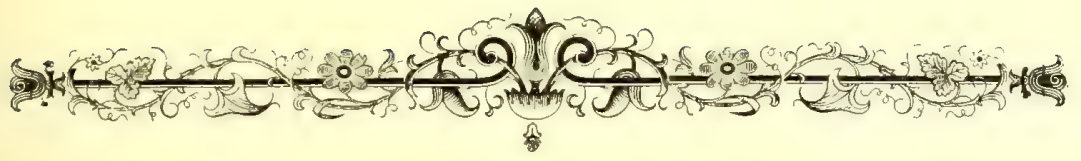

\section{CHAPITRE X}

\section{LE CORAIL.}

“ Curaliea decus liquidi.

(Prisciev.)

\section{I}

Dans certaines régions de la mer’, au milieu des rochers les plus accidentés, s'étendent de petites forêts purpurines. Ces forêts aquatiques sont composées par le Corail rouge, un des plus brillants et des plus célèbres parmi les Polypiers. Curalium decus liquidi!

Pendant longtemps, le Corail a été pris pour une plante marine. Les anciens Grees appelaient cette prétendue plante, fille de la mer ${ }^{4}$. Le comte Marsigli lui-même considérait cette curieuse production comme faisant partie du règne végétal.

Peyssonnel, chirurgien de la marine, recomnut le prenier la véritable nature de l'arbrisseau Corail. Il fit part de sa découverte au célèbre Réaumur, qui hésita quelque temps à la transmettre à l'Académie royale des sciences. Ce ne fut qu'en 1727 qu'il se décida à la communiquer à l'illustre compagnie, mais sans l'adopter encore lui-même.

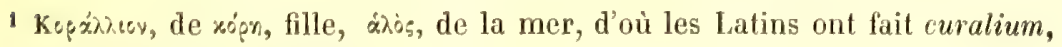
puis corallium ou coralium. 
Les observations de Peyssonnel furent contestées jusqu'au moment où Trembley (de Genève) eût publié ses belles expériences sur le Polype d'eau douce, et que les savants eussent constaté la grande ressemblance qui existe entre la nature de ce curieux Invertébré et les animalcules du Corail.

Guettard (d'Etampes) of Bermand de Jussieu firent exprès un voyage sur nos cotes pour vérifier les assertions de Peyssonnel.

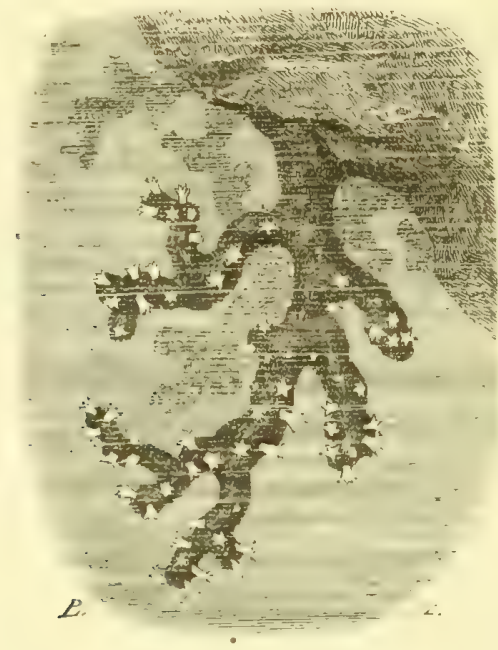

CORAIL ROLGE

(Corallium rubrim Lanarck)

Aujourd'hui, pour tous les naturalistes, le Corail est une famille de Polypes vivant ensemble et composant un Polypier.

Ce Polypier habite surtout dans la Méditerranée et dans la mer Rouge. Il se trouve à diverses profondeurs. Cependant il n'est jamais à moins de 3 mètres, ni à plus de 300 .

Observé sur place, le Corail est mêlé avec d'autres Polypiers et avec d'autres animaux marins. Il en résulte un 
assemblage lâche ou compacte, quelquefois inextricable, qui a reçu le nom de macciolla ${ }^{1}$.

Chaque pied de Corail ressemble à un joli sous-arbrisseau rouge, sans feuilles, portant de délicates petites fleurs étoilées à rayons blanes.

Les axes de ce sous-arbrisseau sont les parties communes à l'association; les fleurettes sont les Polypes.

Les arborisations dont il s'agit se dirigent ordinairement
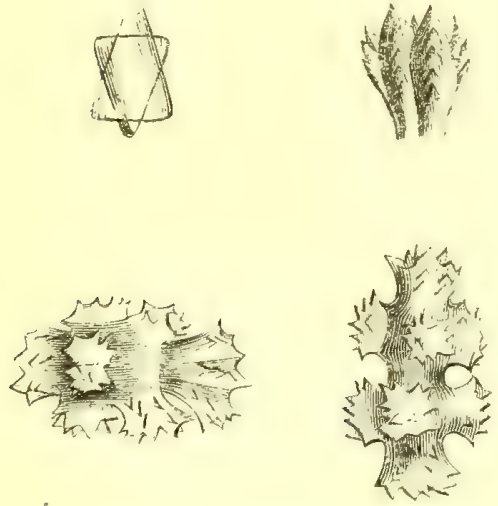

SPICILT: IH: GOHALL
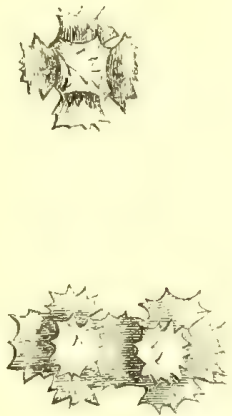

(U'apres les dessins communiqués prar M. Lacaze-Lulliess.)

de haut en bas, et non de bas en haut, comme celles des plantes. Elles forment des buissons, des taillis, et, comme nous l'avons dit plus haut, de véritables forêts. Ces axes offrent une écorce molle, comme réticuléc, pénétrée d'un suc laiteux, et creusée de petites cavités, qui sont les loges des Polypes. De petits corps durs (spicules) sont contenus en grand nombre dans son épaisseur. Au-dessous de l'écorce, se tronve le Corail proprement dit, qui égale le

1 La planche VIII représente une portion de maccioltu retirée de quatrevingts brasses de profondeur, dans les eaux de la Calle, dessinée et coloriée par M. Lacaze-Duthiers (juillet 1862). 
marbre en dureté, et qui est remarequable par sa surface striée, par sa belle couleur rouge, par son extrème dureté et par le poli brillant dont il est susceptible. Les anciens

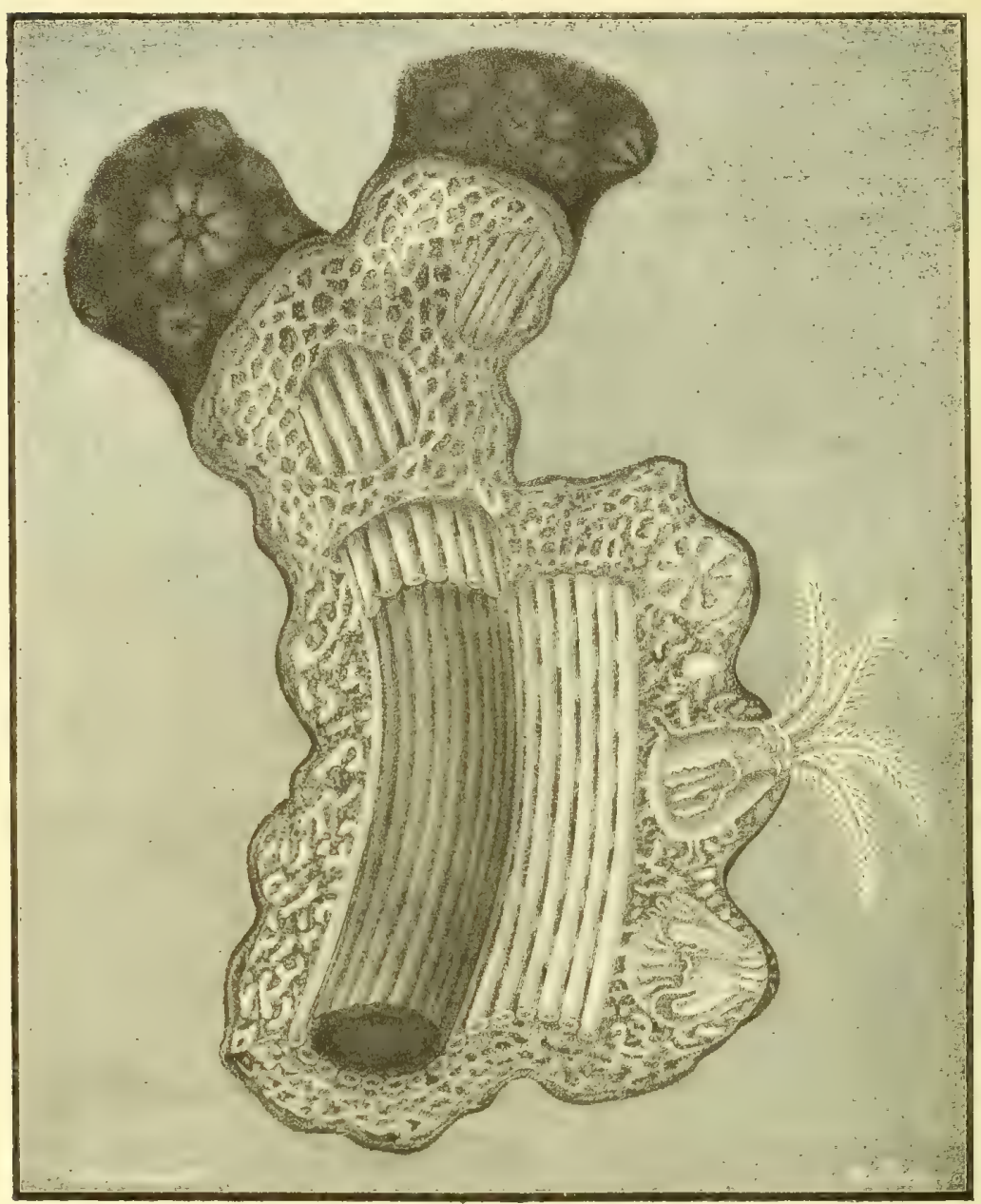

COUPE GROSSIE DE LA TIGE DU CORAIL.

(D'aprés Jes dessins communiqués te M. Lacaze-Duthiers.)

croyaient que sal substance était molle dans l'ean, et ne prenait de la consistance qu'au contact de l'air ${ }^{1}$.

1 Sic et coralium, quo primum contigit auras

Tempore, durescit.... (Ovinj:) 
Les Polypes sont composés, comme ceux de la plupart des Polypiers, d'une partie sacciforme enfermée dans la loge corticale, et d'une partie extérieure cylindrique, entourée de huit petits barbillons qui divergent comme les pétales d'un OEillet. Ces barbillons sont aplatis, larges, pointus et garnis sur les bords de barbules courtes et creuses. Quand ils sont épanouis, l'ensemble représente une charmante fleurette blanchâtre et diaphane, à huit pétales découpés, placés sur un mamelon rose, renflé parfois en forme d'urne. Le comte Marsigli avait très-bien vu les

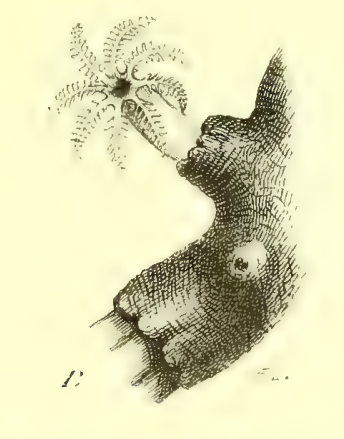

IY POLYPE DI CORAIL ROUGE.

Polypes du Corail. "Ce sont des fleurs, dit-il, qui rentrent dans leurs tubules dès que la plante est retirée de l'eau. Ces fleurs adoptent en mourant une teinte jaune safranée. ')

Le Corail est done, comme on l'a dit avec justesse, animal (ou animaux) en dehors et rocher en dedans.

M. Lacaze-Duthiers a étudié tout récemment la reproduction du Corail. Il est arrivé à des résultats extrêmement intéressants. Suivant ce savant zoologiste, les individus de la colonie sont tantôt mâles, tantôt femelles, tantôt hermaphrodites. Ordinairement les Polypes d'un sexe l'emportent en nombre, dans une même branche, sur ceux d'un autre sexe. Ainsi, tel rameau présente presque exclusivement 
des máles, et tel autre des femelles. Quant aux hermaphrodites, ils semblent les moins nombreux.

On trouve dans le règne végétal des plantes dites polygames, qui offrent dans la distribution de leurs fleurs màles, femelles ou hermaphrodites, un arrangement analogue : l'Épinard d'Espagne est dans ce cas. Qui aurait pu soupconner un rapport physiologique quelconque entre le Corail et l'Épinard?

Les aenfs du Corail ont des pédienles longs et grèles; ils font saillic a l'exterieur des liunes minces qui se trouvent dans le sac digestif. Ils sont sphériques, opaques et d'un blane de lait. Ils se détachent par la rupture de leur support, et tombent dans la cavité générale, cavité qui sert tout à la fois d'estomate ot de poche incubatrice, dans l'intérieur de larpuelle deux matières bien différentes peuvent, à coté l'me de l'autre, la première se dissoudre et servir à l'entretion de limimal, la seconde se développer et produire un être nouveau! (Lacaze-Duthiers.)

Les aufs sallongent of seretent de cils vibratiles. Des qu'ils sont pondus (ou, pour mieux dire, vomis), ils se creusent d'une cavité qui s'ouvre au dehors par un pore destimé a derenir la bourhe. Alors ils prennent la forme d'um netit vel blunchatere of demi-transparent; ces larves nagent en tous sens avec une assez grande agilité, en se détonrnant quand elles se rencontrent. Elles montent et descendent dans les vases qui les contiennent, portant toujours en avaut leur grosse extrémité on leur base, tandis que lem bonche est en imière. De là vient, lorsqu'elles trourent des obstades, qu'elles buttent contre eux. Elles ont une tendance à s'accoler, puis à adhérer, et cela d'autant plus, que leur genre de progression favorise leur contact en les poussant contre les objets. Ainsi, ce sont les mourements mêmes qui semblent destines it faire resser 

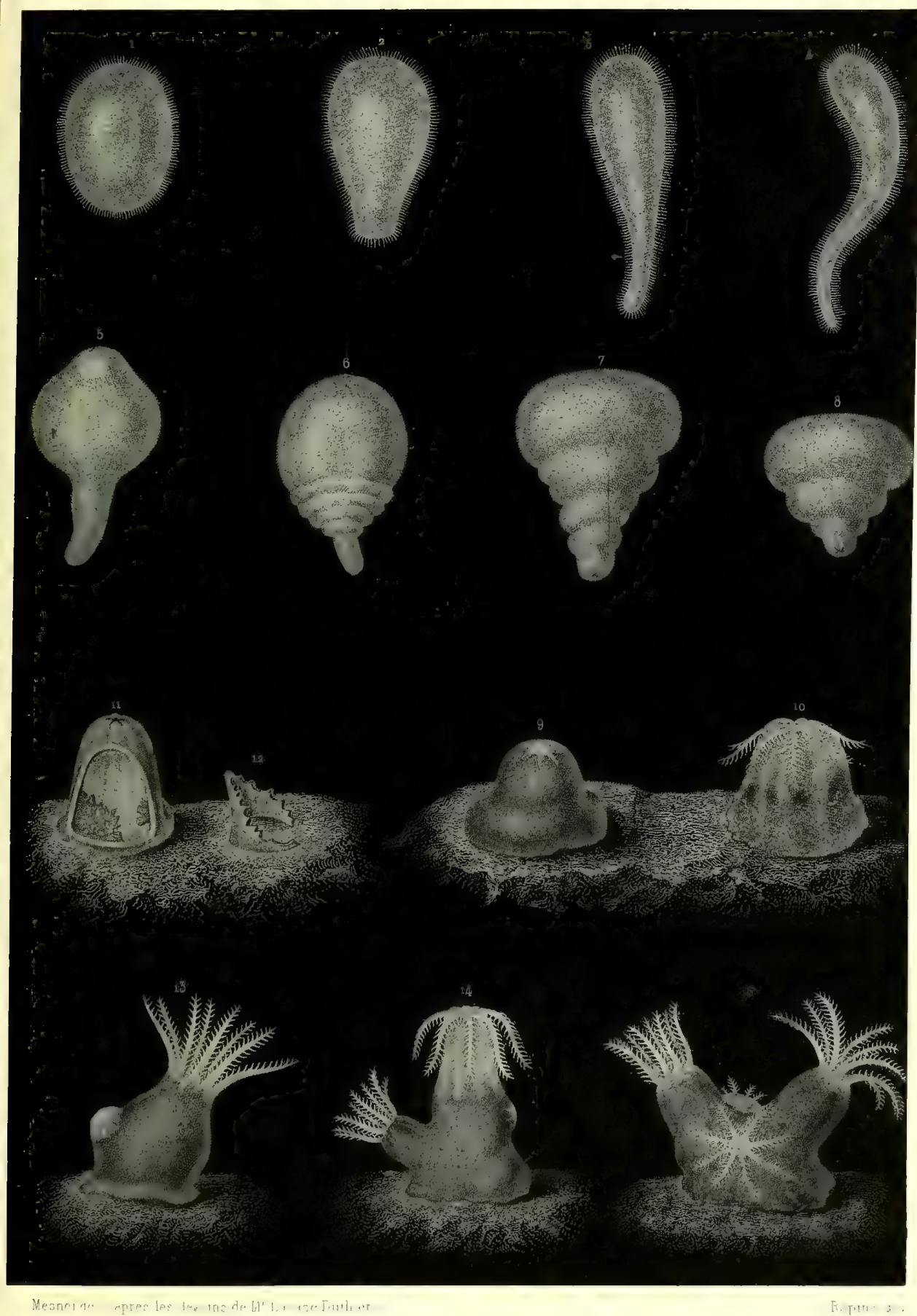

F. T.1T: $:$

\section{DÉVELOPPEMENT DU CORAIL.}



cette période de liberté, en facilitant l'adhérence de la partie du corps qui répondra plus tard à la base du Polype. (Lacaze-Duthiers.)

Arrive bientòt le moment où les larves vont se fixer. L'animal abandonne sa forme de ver; il s'étale, pour ainsi dire, et perd en hauteur ce qu'il gagne en largeur : il se raccourcit et devient comme discoïde. L'extrémité la plus cffilée, celle qui porte la bouche, rentre dans le tissu, et, en s'enfonçant au milieu du disque, elle s'entoure d'un bourrelet circulaire (Lacaze-Duthiers). Sur ce bourrelet, naissent les rudiments des huit tentacules, qui se couvrent bientôt de festons latéraux.

Ce premier Polype fixé devient le fondateur d'une grande colonie arborisée. Des gemmes ou bourgeons se forment sur ses axes, et produisent, en se développant, tout un petit peuple de Coraux ${ }^{4}$.

Chez les animaux adhérents, les larves sont mobiles. C'est une loi générale! Les jeunes Polypes, au sortir de l'œuf, diffèrent presque en tout de leurs parents. Ils doivent subir des métamorphoses pour arriver à l'état parfait, mais des métamorphoses inverses, à certains égards, de celles des Insectes. Chez ces derniers, la chrysalide, qui est immobile, se change en Papillon qui vole. Chez les Coraux, la larve, qui nage, se transforme en Polype qui adhère !... Il n'y a pent-ètre pas dans la Nature une loi qui, renversée, ne devienne une autre loi.

On a distingué des vrais Coraux les Mélites et les Isis, dont les ramifications sont articulées, et dont les Polypes

' Voyez la planche IX, dont les éléments nous ont été communiqués par M. Iacaze-Duthiers. 
possèdent six tentacules au lieu de huit; ces tentacules sont entiers et non frangés.

Dans le premier genre, les axes sont noueux d'espace en

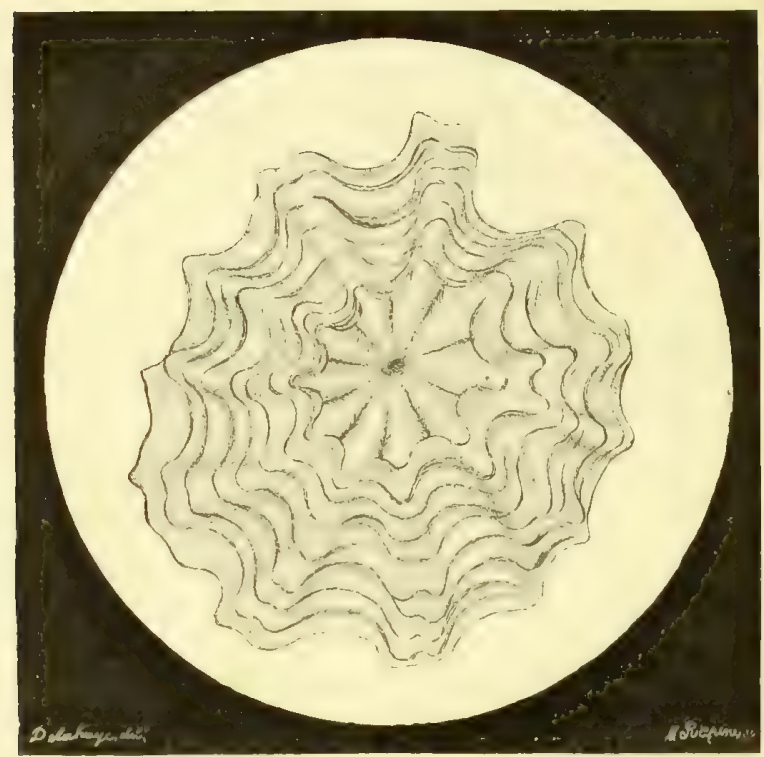

COUPE GROSSIE DE LA TIGE D'ISIS.

(D'après une préparation de M. Poteau.)

espace, et recouverts d'un encroîtement adhérent et persistant; dans le second, ils sont étranglés et revêtus d'un encroûtement libre et caduc.

Le tissu des Mélites est pierreux et homogène, celui des Isis est composé de deux substances distinctes; leurs étranglements sont cornés et noirâtres, leurs articulations sont calcaires et striées.

On emploie souvent, dans le commerce, la tige des Isis pour du Corail blanc; la structure des deux espèces de tiges est si différente, qu'il suffit d'une loupe pour les distinguer. Les deux figures ci-dessus montrent la grossièreté de la fraude. 
Chaque Corail, vrai ou faux, est un atelier distinct de petits travailleurs, habiles, toujours nombreux, toujours actifs; atelier merveilleux où se fabriquent à la fois la

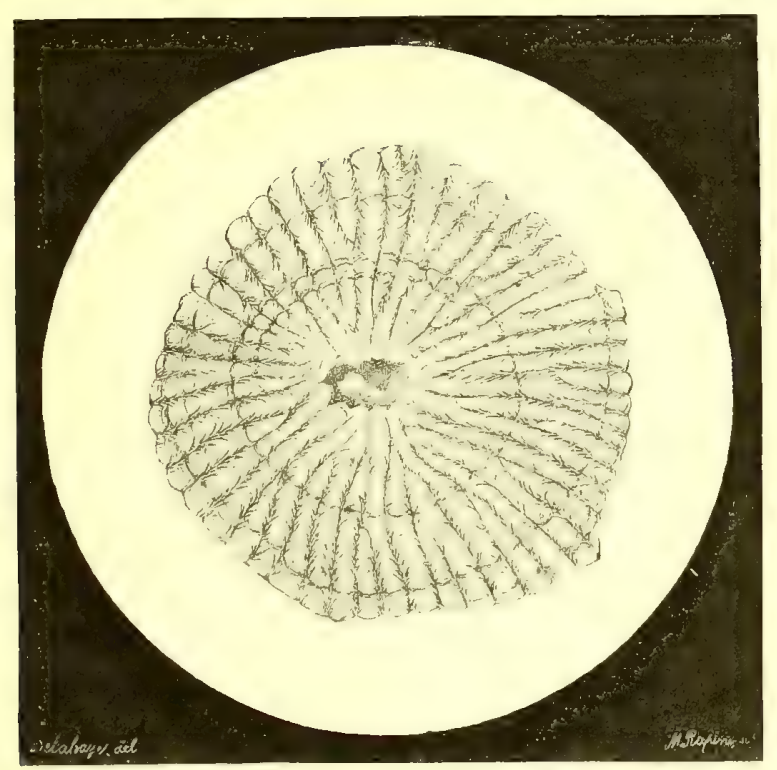

COTPE gROSSIE DE LA TIGE DU CORAIL ROTGE.

(D'aprés une préparation de II. Poleau.)

matière première, corne ou marbre, qui lui est indispensable, et les ouvrages élégants, tiges ou branches, qui lui sont particuliers.

\section{III}

D'après ce que l'on vient de voir sur la nature des Coraux, on peut en conclure que ces Polypiers ressemblent plus à des plantes qu'à les animaux. C'est à cause de cela qu'on les a souvent désignés sous le nom de Zoophytes, c'est-à-dire animaux-plantes, dénomination appliquée plus tard, par extension, à un grand nombre d'Invertébrés marins. 
Cette structure remarquable établit entre les deux règnes organiques les rapports les plus curieux. Nous trouvons dans ces animaux, comme dans les végétaux, une tige, des branches et des rameaux recouverts d'une véritable écorce. Leurs axes sont comés ou calcaires; dans les végétaux, ils sont herbacés ou ligneux. Des deux còtés, le tissu est plus ou moins solide, strié, cannelé, tordu et composé de couches concentriques. De plus, l'écorce animale est spongieuse et plus ou moins tendre, comme l'écorce végétale.

Les gemmes représentent les bourgeons; les Polypes représentent les fleurs. Les barbillons s'étalent en rosettes comme des pétales; ils forment une corolle animée qui s'épanoûit et se ferme alternativement.

Dans le Polypier, de mème que dans le végétal, les individus élémentaires sont aux extrémités des axes ou sur les côtés, ou bien tout à la fois terminaux et latéraux.

Enfin, une dernière ressemblance se rencontre dans leur reproduction. Le Corail ef le régétal doment des individus isolés, ceufs ou graines, qui se détachent de la collection, se développent of produisent me colonie dont les membres demement adhérents, of par suite d'autres Coranx et d'antes végétanx. coest-it-dire d'antres ètres collectifs. C'est la syuthese qui engendre l'amalyse, et l'analyse qui reconstitue la synthese!

Tont en s'arborisant, le Polype se minéralise. Ne dirait-on pas que le rigne animal, le règne par excellence, abandonne sa suprématie. et "hroche à so confondre avec les autres règnes"?

On fait la pèche du Corail principalement à l'entrée de la mer Adriatique, nux environs de Bone et de la Calle, et 
dans le détroit de Bonifacio. Cette pèche donne naissance à une industrie considérable, qu'il serait important d'encourager et de régulariser.

Sur les côtes de la Sicile, la pêche est extrêmement simple. Trois ou quatre pêcheurs, placés sur une barque, plongent dans la mer une sorte de croix de bois horizontale, à branches égales, portant à chaque extrémité un filet de forme conoïde, tissé avec de l'étoupe. Au centre de l'appareil est ajustée en dessous une grosse pierre, qui l'entraine rapidement au fond de l'eau. La croix est attachée à une corde; on la descend à une profondeur de 60 à 100 mètres. Un pècheur élève et abaisse alternativement cet appareil; en même temps les autres rament lentement, de manière à balayer la surface d'un certain nombre de rochers. Les mailles làches des quatre filets promenés sur les Coraux accrochent leurs branches, les cassent, ou arrachent les Polypiers tout entiers. Quand on suppose que la prise est suffisante, on retire l'appareil; on détache la récolte, et on la dépose dans le bateau.

A la place de l'instrument que nous venons de décrire, on emploie quelquefois un autre engin, composé d'un cercle de fer de 30 centimètres de diamètre, qui forme l'onverture d'une petite poche destinée à recevoir les branches qu' on brise. A droite et a gauche sont suspendus deux filets. Le cercle est situć à l'extrémité d'une grande pontre, quelquefois plus longue que la barque. Cette poutre est portée par deux cordes, et, tout près du cercle de fer, on a fixé une pierre. On introduit cet instrument dans des cavités où le premier n'a pas pu pénétrer.

Dans d'autres localités, on se sert de bâtons garnis d'étoupes, que l'on traine au fond de la mer avec un boulet. Derrière se trouve un filet à larges mailles, où tombe le Corail à mesure qu'il est détaché. 
Le Corail ainsi obtenu est toujours mêlé à d'autres Polypiers, à divers animaux, et même à des plantes marines.

Anciennement, on pêchait ce Zoophyte avec de grandes cloches dans lesquelles un homme était placé. Par ce moyen, on obtenait le Corail pur et non brisé.

En 18:3, M. Focillon a fait ressortir la possibilité d'employer le bateau plongeur de MM. Lamiral et Payerne pour la récolte du Corail, et les avantages qu'offrirait l'application de cet appareil.

Dans certains pays, les pêcheurs plongent à des profondeurs plus on moins considérables, et récoltent le Corail à la main.

Malgré les efforts du gouvernement français, et malgré les bénéfices de l’industrie coraillère, nos pêcheries dans le détroit de Bonifacio et sum le littoral africain ne sont guère fréquentées que par des marins étrangers.

En 18:32, les corailleurs qui exploitèrent le détroit de Bonifacio étaient tous des Italiens. Le produit de la campagne ne domna qu'une quarantaine de mille franes.

En 18:33, sur 211 lateanx pêcheurs qui se rendirent sur les cotes d'Ifrique, il n'y en avait que 19 français; la plupart étaicnt napolitains. La même chose a lieu presque tous les ans.

D'après les documents publiés par le ministère de la guerre, les côtes de Bone et de la Calle ont fourni, en 1833, 33800 kilogrammes de Corail, lesquels, vendus en majeure partic aux fabricants de Naples, à raison de 60 francs le kilogramme, ont représenté une valeur brute de 2148000 franes. Beaucoup de bateaux, la plupart napolitains, dont les frais ne dépassaient pas au maximum 8000 franes, ont emporté 4 à 500 kilogrammes de Corail, et ont eu par consérquent un bénéfice de 16 à 22000 franes. 
Sur la côte ouest, la pêche 'a été exploitée, la même année, par des corailleurs espagnols, qui avaient pris leurs patentes dans les ports de Mers-el-Kébir, Tenez et Arzew. Chaque embarcation a recueilli en moyenne de 350 à 400 kilogrammes de Corail.

\section{V}

Les anciens regardaient le Corail comme une matière d'un grand prix, et lui attribuaient des vertus merveilleuses. Les Gaulois en décoraient leurs casques, leurs boucliers et leurs autres instruments de guerre. Les Romains en portaient des fragments ou des grains comme amulettes et comme ornements agréables aux dienx. Ils en fabriquaient des colliers pour préserver leurs nouveau-nés des maladies contagieuses. Dans beancoup de circonstances, ils croyaient les préparations de Corail excellentes pour conjurer les malheurs.

Il n'y a pas longtemps que les médecins français considéraient le Corail comme une des ressources de la thérapeutique. Lémery le croyait propre à réjouir le cour. Ce qui n'est pas aussi certain que sa vertu pour nettoyer les dents, bien que cette dernière se réduise à une simple action physique.

Le Corail est plus estimé aujourd'hui comme ornement que comme remède. On fabrique des bijoux recherchés non-seulement en Europe, mais aussi en Afrique et en Asie, surtont au Japon.

Le Corail des côtes de France, mieux choisi peut-être que celui des autres pays, passe pour avoir la couleur la plus vive et la plus éclatante. Celui d'Italie rivalise eu 
beauté avec le nôtre; celui de Barbarie est le plus gros et le moins brillant.

Dans le commerce, on distingue cinq variétés de Corail, auxquelles on donne des noms assez bizarres : 10 l'écume de sang, $2^{\circ}$ la fleur de sang, $3^{\circ}$ le premier sang, $4^{\circ}$ le second sung.

Le Corail rose est très-rare et très-cher. Le Corail travaillé par les Napolitains donne des bijoux quelquefois un peu grosciers. Celui de Marseille, façonné par d'habiles artistes, produit des résultats supérieurs. On a vu, à l'exposition de 1830. des ornements dont la taille. le poli et le bon goǹt étaient à l'abri de toute critique. On y remarpuait particulierement un jen d'échees, représenlant l'armóe des Sinrasins of relle des croisés, qui valait $1000(1)$ lames.

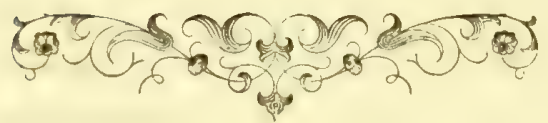




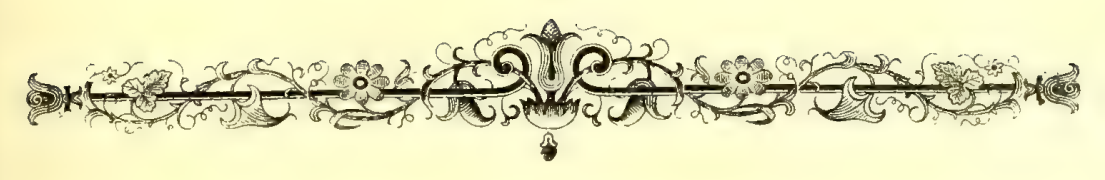

\section{CHAPITRE XI}

\section{LA PLUME DE MER.}

Quantes fois, lor aue sur les ondes

Ce nouvan miracle flottoit....

MaLmeril.

La contemplation des animaux qui habitent dans un milieu différent dı nôtre, et qui cependant accomplissent sans gêne les diverses phases de la vic avec des mœurs particulières, avec leurs joies et leurs souffrances, n'est-elle pas faite pour nous plonger dans une sorte de ravissement!

Tous les Zoophytes marins, sans exception, peuvent être le sujet de nos études et de notre enthousiasme. Mais parmi ces animaux, un des plus merveilleux est bien certainement la Plume de mer ou Pennalule.

Ce Polypier habite loin des rivages, il aime la haute mer; aussi n'est-il pas adhérent, mais libre. Son organisation complexe ressemble grossièrement à une plume.

Cette agglomération animale offre un axe ou partie commune, et des espèces de barbes sur lesquelles sont établis des Polypes.

L'axe est composé de deux parties, une antérieure, qui 
porte les barbes, ct une postérieure, qui est nue. La première est plus ou moins étroite et déprimée; la seconde ressemble à un coeur allongé. Son extrémité est obtuse et percée d'un trou avengle, "fuc certains naturalistes ont pris mal à propos pour une bouche.

Dans l'intérieur de l'axe, an milieu d'un tissu charnu et contractile. se troure une baguette dure, aplatie, grisattre,

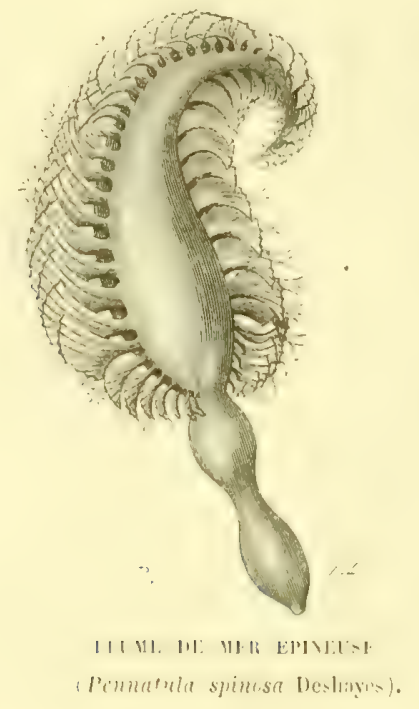

de nature calcaire. Cefte bagnette offie en dessus et en dessous drux painures, whe à droite ef l'antre à gauche. Elle est enferméc dams une membrane très-mince.

On observe encore, dans l'épaisseur de la Plume, trois ravités, dont une moyenne et supérine et deux latérales. Lat caviti moremne, qui est assez grande, dimimue vers l'extrémité antérieure, où l'on roit un véritable orifice. Des deux cotés de cette mème cavité se trouvent des brides formant des loges celluleuses qui semblent communiquer avec les barbes.

I certains moments, l'agrégation aspire de l'eau et se gonfle, puis elle rejette le liquide et s'amoindrit. 
Les barbes sont plus grandes au milieu de la tige qu'à l'extrémité. Leur ensemble forme des espèces d'ailerons aux deux còtés de l'axe. Leur bord postérieur est subdivisé en lames qui présentent inférieurement de petites aiguilles calcaires, dures, blanches et cassantes. Ces lames soutiennent les Polypes.

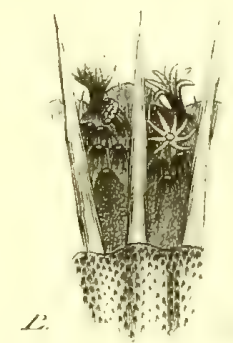

POLYLS DE LA PLEME DL MLU EIISLOL.

Ceux-ci sont rapprochés et alignés, implantés obliquement et répartis avec inégalité. Ils ont la forme d'une bourse divisée en deux portions: une de ces dernières offre la bouche bordée de lunit tentacules; l'autre comprend les organes de la digestion et les sacs des oufs.

En définitive, ces Polypes, comme la plupart des animanx inférieurs, ressemblent toujours plus ou moins à des fleurs vivantes, mais à des fleurs vivantes qui frémissent d'une sensibilité encore bien incomplète et qui jouissent d'une volonté encope bien limitée!

Les Plumes de mer sont épineuses. On en commait une d'un rouge-cannelle', et une autre d'un gris sale ${ }^{2}$. Le soir, la première devient phosphorescente, et balance mollement ses lueurs à la surface de la mer.

Ces Polypiers peuvent contracter la partie postérieure et renflée de leur axe, de mème que leurs ailerons. Ces der-

1 Iesmatula phosphorea linnc.

2 Pennalula grisea Esper. 
niers semblent leur servir de nageoners ou de rames. Mais les Peunatules ne réussissent qu'à produre des monvements très-imparfaits. Les eaux les poussent dans mu sens ou dans un autre, et les courants ne tardent pas à les entrainer.

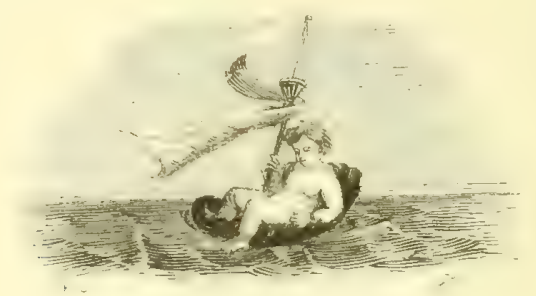

Flollant sims volonté, do moins apprareste, an gré des vagues et des vents, elles vont partout, et partout elles rencontrent 'e qu'il linut ponr lenr nomriture, ce qui convient à leur bien-être et ce qui est nécessaire à leur reproduction!

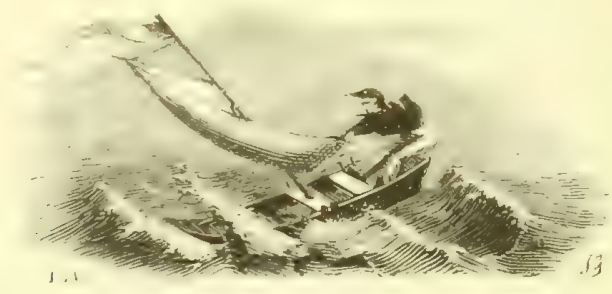

I) apres les observations rénentes de M. Lacaze-l)uthiers, ces Polypes des Pennatules sont tous mâles ou tous femelles. exchusivement; de maniere que chaque communauté ne présente qu'un seul sexe. On sait qu'il existe des végétaux organisés d'une maniere analogue, c'est-ì-dire à fleur's mailes ot a fleur's fornelles sciparées sur des pieds différents (diö̈ques) : par exemple, les l'istachiers, les Dattiers, les Epinards.... 


\section{1}

L'Ombellulaire, qu'on ne reucontre que sur les côtes du Groenland, et les Virgulaires de Lamarck, sont des Pennatulides.

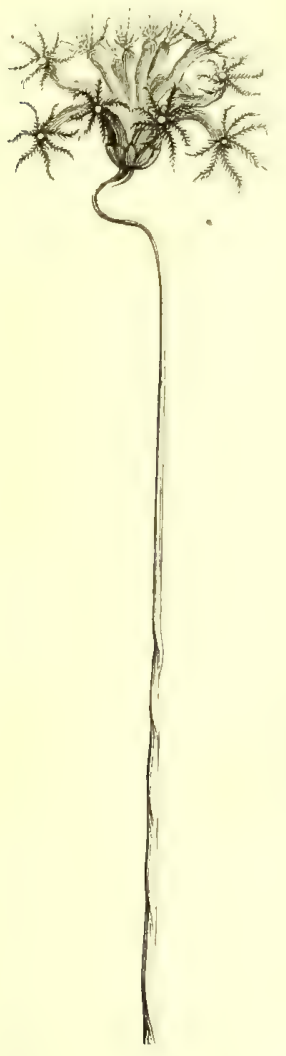

(I) ULLLC LAIEE DL GRUEYLATD

(Umbellularia groenlandica Lamarck).

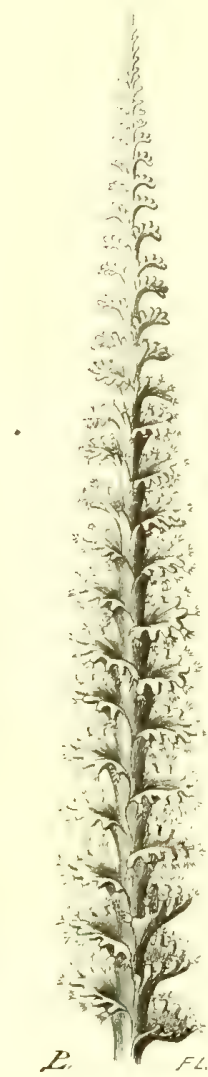

VIRGCLARE IDWHABLL

(Virgularia mirabilis Lamarck).

La Virgulaire admirable est un des plus beanx Polypiers de l'Océan.

Deux séries d'ailes en demi-lune, obliquement horizontales, sont placées avec symétrie autour d'un axe étroit et 
léger, qu'elles embrassent alternativement. (In dirait deux larges rubans enroulés en sens inverse, de manière à produire deux rampes opposées. Ces ailes sont un peu onduleuses, découpées et frangées sur le bord libre, ef d'un jaune assez brillant. Les dentelures de leurs franges scrvent de logement ì de jolis petits Polypes, yui montrent de temps co temps leur bouche béante et leurs barbillons étalés. Cies Polypes sout blanchatees et demi-transpanents. Quand ils epanouissent leurs rayous, ils ajoutent a la marge de chaque aile une bordure d'étoiles argentées.

Chez lat phupat des Polypier's, les individus élémenlaines, malgré leur adhépence entre eux, possedent une activité vitale propre, et, à certains égards, indépendante. Ils ont des volontes particulaires qu'il len serait difficile de rémnir, de confondre en une volonté générale. C'est probablement à cause de cette difficulté insumontable, que la Vature a rendu ces corporations fixées et sédentaires. Ville a cmpèché leurs Polypes de prendre aucune détermination collective, et de mouvoir leur ensemble comme un seul individu.

Il 11 en est pas ainsi chez les Plumes de mer; lenr assuriation constitue un Polypier non alhérent. Ce Polypier se remue, obscurément à la vérité, mais entin il se remue. I yuoi cela tient-il? I re que les parties communes qu'il présente, an lieu d'itre cornées ou calcaires, c'est-à-dire complétement inertes, sont cbarmues et contractiles, c'est-à-dire manifestement animées. Par conséquent, les Polypes d'unc Plume de ner sont moins indépendants les uns des autres 
que les Polypes d'un Corail. Ils ont un organe central irritable, peut-être même sensible, qui appartient à tous, qui les relie plus intimement les uns anx autres, et qui donne plus d'unité à leur ensemble. Le Corail n'a pas de volonté, la Plume de mer en a une.

Les Polypiers fluviatiles (ou Polypes à panache de Trembley), véritables miniatures des Polypiers marins, ne sont pas tous fixés. Il en existe aussi de libres, tels que les $\boldsymbol{C r i s -}$ tatelles. L'Auteur de la Nature a placé cà et là, dans les bassins ef les ruisseanx, de petites créatures imperceptibles, analognes aux grands Zoophytes vagabonds que les ondes nourrissent et ballottent dans l'immensité de l'océan!...

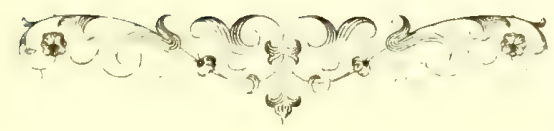





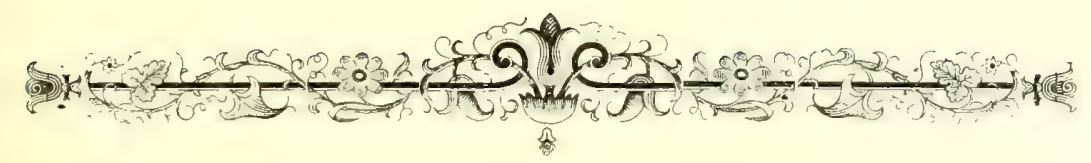

\section{CHAPITRE XII}

\section{LES ANEMONES DE MER.}

..... Living flowers,

Which like a hud comparted,

Their purple lips contracted;

Ind nou in open lossoms spread,

Stretched like green anthers many a seeking head.

(SOTTHEY.

Qu'on suppose mu Polype bien grand of hien trapu, possédant, au lieu de six modestes barbillons, un grand nombre de brillants appendices disposés comme une riche collerette, et l'on aura une Anémome de mer.

Le Polype d'eau donce semble l'ébauche de l'Anémone de mer.

Ce nom d'Anémone est admirablement choisi; car ce Polype perfectionné ressemble beaucoup plus à une fleur qu'à une bête. On dirait, en effet, une gracieuse Anémone ou une jolie corolle de Cactus.

Les poëtes ont regardé ces fleurs vivantes comme les Roses du monde des Zoophytes.

On a donné encore à ces charmantes créatures le nom d'Actinies (Brown), pour indiquer lemr conformation radiér. ou étoilée. 
Les Anémones de mer sont des animaux charnus, plus ou moins coriaces, ordinairement fixés par la base, offrant un corps ou colonne en forme de bourse, avec un aplatissement terminal ou disque bordé de tentacules, an centre duquel est percée la bouche.

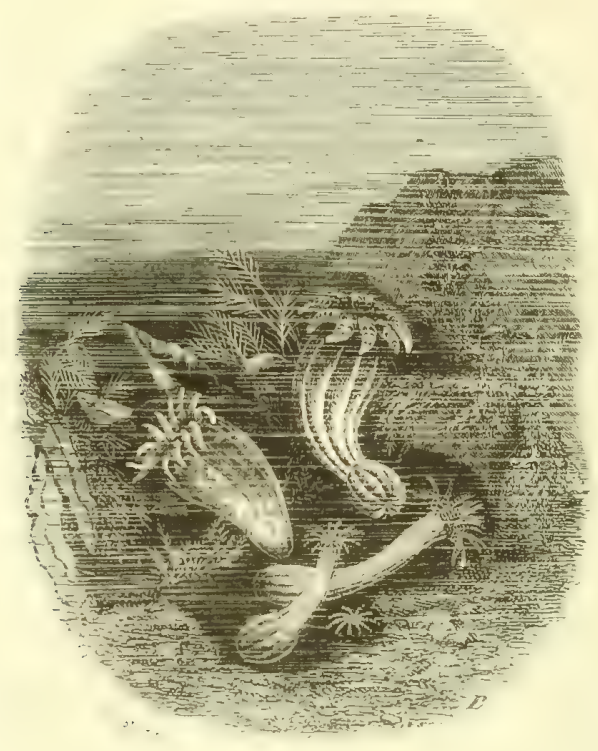

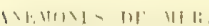

La base des Anémones est, en général, une surface plane, au moyen de laquelle l'animal adhère aux corps solides sous-marins (rochers ou plantes). Dans quelques espèces, elle se dilate plus ou moins, et peut même produire comme deux ailerons demi-circulaires; dans d'autres, an contraire, elle se rétrécit considérablement, au point de ne plus pouvoir remplir sa fonction. L'animal n'adhère plus.

La colonne est raccourcie le plus souvent; mais, dans rertains cas, olle devieut cylindrique et allongée comme ume tige. Celle-ri est lisse, verruqueuse on sillonnée. 

Le disque varie en étendue.

Les tentacules sont des cônes creux disposés circulairement sur un ou plusieurs rangs horizontaux et concentriques. Ils sont très-longs ou très-courts, filiformes ou pétaloides, renflés ou aplatis, souvent pointus, quelquefois ciliés ou frangés, d'autres fois ramifiés. Il y en a qui ressemblent à de gros Vers cylindriques, demi-transparents et demi-laiteux.

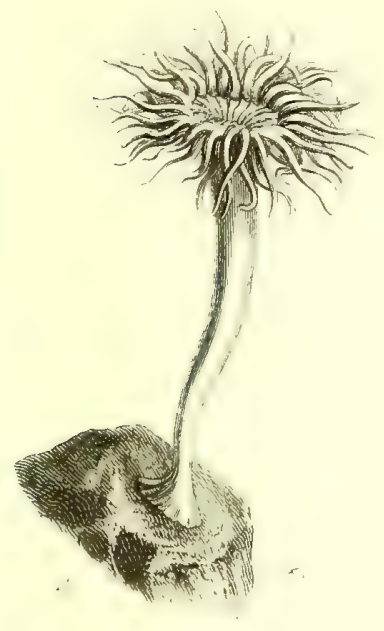

ANËMONE DE COUCH

(Aiptasia Couchii Gosse).

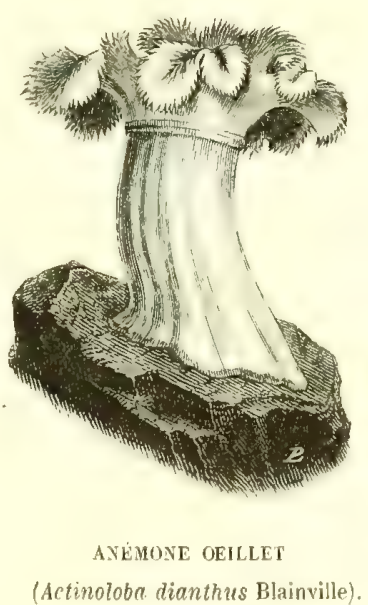

(Actinoloba dianthus Blainville).

Charles Bonmet a compté dans une espèce cent cinquante tentacules, alignés sm trois rangs. De ces jolis appendices s'élançaient de temps en temps de petits jets d'eau.

La bouche est presque toujours très-large. Elle présente une lèvre circulaire généralement épaisse, tantôt déprimée. tantôt élevée sur une sorte de saillie.

Limué n’a mentionné ame cinq espèces d'Actinies. Papl' en a caractérisé vingt-trois, el Lamarek vingt-cing. Aujomd'hui on en connait plus de cront. 
Ces brillants Zoophytes sont blanes, gris, roses, ronges, pourpres, fauves, jamnes, nankins, orangés, lilas, azurés, verts....

Regardez cette charmante espèce à barbillons violets finement pointillés de blane, et cette antre à tentacules rouges légèrement maculés de gris. Examinez celle-ci qui les étale verts, terminćs par ume pointe d'un blane mat, et celle-là qui les agite d'un blanc de lait, avec une belle écharpe rose!...

Le corps, le disque et les tentacules n'ont pas toujours la mime conleur; ce qui contribue puissamment à varier la parure de ces corolles animées. Voici une Anémone à corps faure ot à disque couleur d'abricot, entomé de tentacules d'un blane mat. En voilà me seconde dont le centre est rouge, avec des tentacules gris, et une troisième où il est vert, avec des tentacules fauves.

Comme la Nature est féconde et diversifiée dans ses nombreuses créations! Que de variations et de surprises avec le mene thime!

Les Anémones de mer se tiennent parmi les rochers, souvent dans des crevasses ou des fentes. Il y en a qui logent leme corps dims quelque vieille corpuille abandonnére épanouissant leur collerette antour de son ouverture.

Les individus laissés à découvert par les flots rapprochent leurs tentacules et se dessèchent. Quamd la mer revient, ils se gonflent, s'ouvrent et rayonnent de nouveal.

Quoique ces animanx soient très-adhérents, ils peuvent copembunt se mouvoir, mais ils le font avec lenteur, par des contrictions ot des relachements successifs. Guand ils wan- 
gent de place, ils étendent par une action imperceptiblo un des bords de leur base, et retirent le bord opposé. Ils se trainent quelquefois à l'aide de leurs tentacules, qui leur servent alors comme de pieds.

Le professeur Forbes avait une Actinie qui se promenait sur les parois d'un bocal, adhérant alternativement par sa base et par son disque, à la manière des Sangsues (Rymer Jones). Il y a done, dans la Nature, des fleurs qui se promènent!

A l'approche de l'hiver, les Anémones de nos côtes détachent leur bourse, se laissent emporter par les flots, et vont chercher une température plus douce dans des eaux plus profondes. L'instinct de ces délicieuses bêtes, si différentes des animaux terrestres, est plus assuré, dans ses inspirations, que ne le sont souvent, dans leurs conséquences, les raisonnements suivis des Vertébrés supérieurs. La connaissance de l'instinct chez les animaux est bien certainement une des plus grandes et des plus nobles parties de l'historre naturelle. Cette partie devrait être étudiée beaucoup phus qu'on ne le fait habituellement.

Lorsqu'une vive lumière éclaire une Anémone, elle épanonit ses tentacules comme un capitule de Pâquerette qui étale ses demi-fleurons. Ces organes s'allongent ef se rarcourcissent, vont et viennent, se balancent et se tordent autour de sa bonche dilatée. Touchez l'animal avee le bout d'une baguette, ou bien agitez l'eau qui l'environne, et soudain tout se rapproche, se ferme, se contracte of s'amoindrit.

Pendant que l'Anémone étale sa brillante collerette, si un petit ver, un jeune crustacé, un poisson nouvellement éclos, viemnent s'y heurter étourdiment, anssitit, par un brusque mouvement, l'animal vorace pousse l'imprudente victime vers sa gneule béante, et la précipite dans sa 
bourse, c'est-à-dire dans son estomac... el consummatum est! La vie des Anémones est un affuit continuel!

Les tentacules filamenteux de certaines espèces semblent itre de véritables armes offensives. M. Gosse a surpris un de ces filaments au moment où il s'attachait à un petit poisson. La pauvre bète fit quelques efforts pour fuir, et ne tarda pas à succomber. M. Hollard a vu de jeunes Maquereamx se coucher sur le flane ef mourir au simple contart d'une Actinie.

Quand on touche ces tentacules, dit M. Rymei Jones, ils occasionnent une cuisson assez vive. Pendant plus d'une heure, la main demeure rouge, enflammée ef douloureuse. si l'on mord un de ees organes, et qu'on applique la langue sur la partie mordue, on éprouve une sensation brûlante et corrosive.

La propriété toxirue des tentacules réside dans de petits urganes qui s'étendent sur toute leur peau, et consistent 'n des rapsules imnombrables, visibles seulement au microscope, lesquelles contiennent un gros fil entortillé. An moindre contact, ces capsules semblent se crever et lancer leur fil au dehors. Celui-ci s'attache aux corps étrangers, comme certains fruits épineux (Rymer Jones). Ce fil est ordinairement entouré d'une ou de plusieurs bandes en spirale, dont chacune porte une sépie de petites barbes. L'appareil tout entier sert à l'émission d'un fluide trèsvenimeux (Gosse).

Les Anémones sont voraces et vigoureuses. Rien ne peut ŕchapper à leur gloutonnerie : tous les animanx qui s'approchent sont saisis, précipités et dévorés.

Malgré la puissance de leur bouche, ces estomacs insatiables ne retiennent pas toujours la proie qu'ils ont avalée. Dans certaines eirconstances, celle-ci réussit à s'échapper: dans d'autres, elle est arlroitement enlevée par quelque 
maraudeur du voisinage, plus rusé et plus actil que l'Anémone.

On voit quelquefois, dans les aquariums, des Cirevettes, qui ont senti de loin la proie mangée, se précipiter sur le ravisseur, lui prendre audacieusement sa nourriture et la dévorer à sa place, au grand désappointement de celui-ci. Bien plus, lorsque le morceau savoureux a été complétement englouti, la Crevette, redoublant d'efforts, réussit à s'en emparer an milieu mème de l'estomac. Elle fond en plein sur le disque étendu de l'Anémone; avee ses petits pieds, elle l'empèche de rapprocher ses tentacules; elle introduit en mème temps ses pinces daus la cavité digestive, et saisit l'aliment. L'Anémone essaye en vain de contracter ses barbillons et de fermer sa bouche... Parfois le conflit devient très-grave entre le Zoophyte sédentaire et le Crustacé vagabond... Quand le premier est un peu robuste, l'agression est repoussée, et la Crevette court le risque de former un supplément au repas de l'Anémone....

Pendant leur digestion, les Actinies semblent dormir; elles entrent en torpemr. Elles tiennent alors leurs tentacules appliqués les uns contre les autres, formant un dòme pointu au-dessus de leur bouche. linsi resserrées, elles figurent assez bien un bouton de plante radiée, par exemple celui d'une Marguerite ou d'un Souci.

La cavité viscérale de ces animaux parait grande et régulièrement divisée en loges rayonnantes.

Il est remarquable que les papien's réactifs plongés dans eet organe, soit chez l'animal à jeun, soit pendant sa digestion, ne domnent ancum signe, ni d'acidité, ni d'alcalinité. (Hollard.)

Comme les Polypes d'eau douce, les Anémones premnent souvent une quantité de nourriture hor's de proportion avec leur cavité stomacale. Eu moins d'une heure elles peuvent 
vider la coquille d'une Moule ou réduire un Crabe à ses parties dures, qu'elles ne tardent pas à rejeter, ch renversant leur poche digestive. (Hollard.)

Le docteur Johnson rapporte qu'il troura une Anémone crassicorne ${ }^{1}$ qui avait aralé une valve de Pèlerine géante, ladpuelle était entrée en traver's et divisait l'estomac en deux compartiments, l'un supérieur et l'autre inférieur. Ce dernier ne communiquait plus avec la bouche; le corps, fortement distendu, était devenu d'une minceur extrême. Lne nouvelle bouche, pourvue de deux raugées de tentacules, s'était formée du còté de la base et desservait l'estomac inférienr. L'animal mangeail ainsi par en haut et par en bas!... Un accident qui aurait été funeste à un animal vertébré arait doublé les jouissances de l'Anémone crassicorne!...

Les tetinies supportent des jeines prolongés. Cela devait ètre chez des organismes adhérents, qui sont forcés d'attendre patiemment la nourriture, et par conséquent exposés à ce qu'elle n'arrive pas toujours à point nommé. Quand nos bètes ne mangent pas, leur corps diminue graduellement de volune; il s'atrophic, et peut se réduire au dixième de sa masse. Mais quand l'abondance revient, il regrossit aree rapidité, et reprend bicutot son premier embonpoint. Un assure qu'une Anémone peut vivre deux ans, mème trois, sans nourriture.

Quand on irrite l'Anémone rousse ${ }^{2}$, elle lance arec force lean contenue daus sa bourse stomacale. Cette singulière habitude, bien connue des pècheurs provencaux, lui a fait donner le sobriquet peu honnête de pissuso.

Les Anémones ont les sens très-obtus. Elles ne paraissent

\footnotetext{
1 Tealia crassicornis Gosse.

- Actinia mesembrianthemum Ellis.
} 
pas se douter du voisinage de leurs proies; elles ne les sentent pas ì la plus faible distance; elles ne font rien non plus pour éloigner d'elles un danger. Chose étrange! si l'ean qui les baigne s'évapore, elles n'ont jamais l'idée de s'approcher d'une flaque voisine, quand bien mème leurs tentacules pourraient y atteindre sans changer de place (Rymer Jones). Cependant on a vu plus haut que dans certaines circonstances, conseillées par leur instinct, elles savent à propos se détacher de leur rocher et se laisser emporter par le flot.

L'abbé Dicquemare croit avoir reconnu qu'elles sentent les moindres variations atmosphériques. Est-il vrai qu'elles montent et descendent dans les bocaux, suivant le vent qui domine? (Hollard.)

Les Actinies vivent longtemps en domesticité. Une Anćmone rousse a été couservée chez sir John Dalyell l'espace de vingt ans; elle devait avoir au moins dix ans lorsqu' elle fut prise dans la mer. Une autre est restée chez le même observateur treize ou quatorze ans. Ces deux patriarches étaient pleins de vigueur à l'époque où l'on a parlé de leur longévité, et semblaient devoir vivre encore de longues années.

\section{I}

A certaines époques, on remarque, dans les tentacules des Anémones, des germes et des embryons; les premiers en repos, les autres en mouvement. Le meilleur moyen pour étudier ces corps, c'est de couper les tentacules avec un instrument tranchant.

Sir J. Dalyell, ayant opéré vers la fin d'octobre sur une Inémone rousse, il tomba de la blessure deux corpuscules. Le premier resta immobile; mais le second déploya une 
sorte de donble mouvement rotatoire, tournant sur luimème avec beaucoup d'activité. L'un était un ouf, et l'autre une larve.

Ces animaux portent done leurs aufs et leurs petits, non pas sur leurs bras, mais dans leurs bras?

Généralement, les larves passent des tentacules dans la

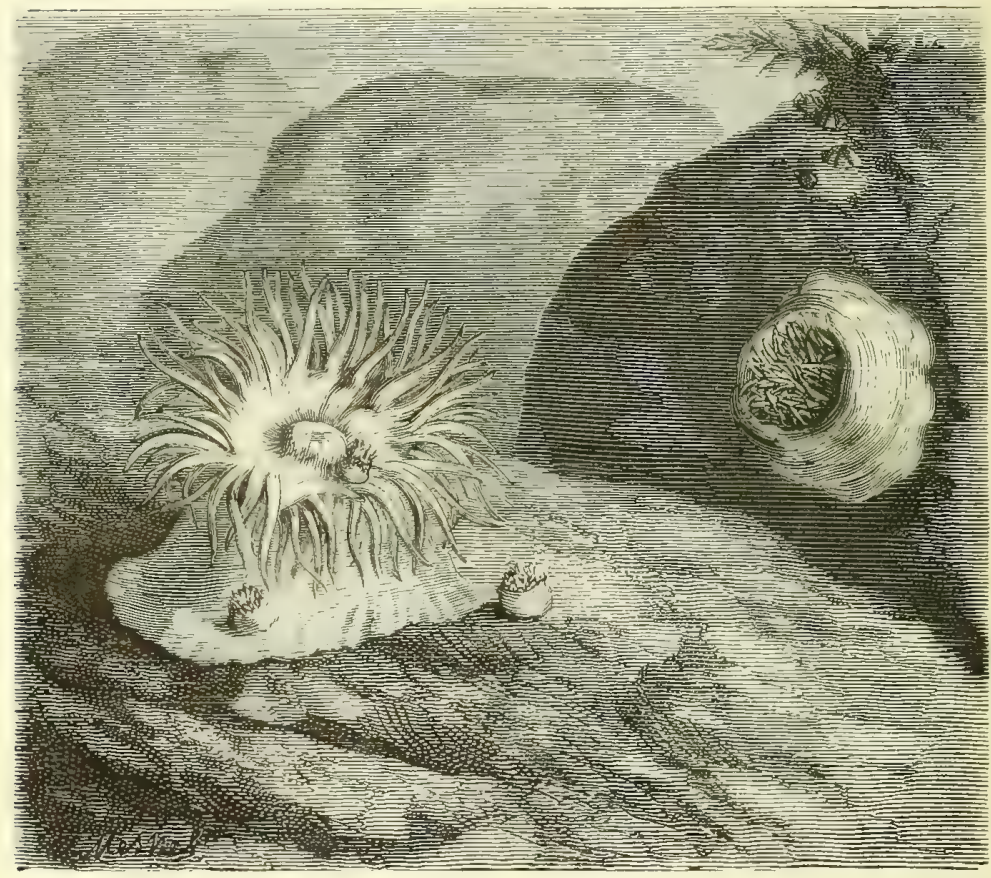

IASSAMCE D ATEWUIL

(Actinia eq̨uina Linné).

cavité stomacale, et sont ensuite rejetées par la bonche, en mème temps que le résidu de l'alimentation. Voilà unc bouche qui cumule, en dehors de ses fonctions habituelles, deux emplois bien singuliers!

Les Anémones paquerettes " du Jardin zoologique de Paris ont vomi plusieurs fois de jolis petits embryons, lesquels se 
sont éparpillés et fixés dans divers endroits de l'aquarium, et ont produit des miniatures d'Anémones exactement semblables à leur mère.

Une Actinie qui avait pris un repas trop copieux, rendit, au bout de vingt-quatre heures, une portion de ses aliments, au milieu de laquelle se trouvèrent trente-huit jeunes individus (Dalyell). C'était un accouchement dans une indigestion!

Les animaux des classes inférieures ont en général, comme fondement de leur organisation, un sac avec une seule ouverture. Cette ouverture remplit (ainsi qu'on l'a vu) des usages très-divers; elle recoit et rejette, elle avale et vomit. Le vomissement, devenu nécessaire, babituel, normal, ne doit plus être douloureux... Peut-ètre même s'exécutet-il avec quelque plaisir; car ce n'est plus une maladie, c'est une fonction, et mème une fonction multiple. Chez les Anémones, il expulse l'excrément et pond les oufs; chez d’autres, il sert encore à la respiration. Nos animaux-fleurs jouissent done d'un vomissement perfectionné et régularisé.

Chez quelques especes, les petits se forment et naissent à la base de la bourse, en dehors. Par exemple, daus l'Anémone déchirée ${ }^{1}$, la partie inférieure du corjs devient rugueuse, surtout pendant les mois d'août et de septembre. On apercoit bientôt, aux bords de cette base, des espèces de bourgeons ou gemmes, lesquels se transforment eu embryons, et se séparent de la mère pour coustituer autant de nouvelles Actinies. (Dalyell.)

II. Rymer Jones a vu une Anémone déchirée donner vingt petites larves dans un mois, et soixante et dix dans une année.

Parlons maintenant d'un autre mode reproducteur, 
bien phus extraordinaire. Lne Anémone sillet ${ }^{1}$, de l'aquarium de .I. J. Hogg, adhérait si fortement à la paroi du réservoir, qu'au lieu de se détacher sous l'influence d'efforts très-violents, elle se déchira inférieurement, et laissa contre le verre six petits fragments du bord extérieur de sa base. Ces morceaux, solidement collés, ne servirent, pendant plusieurs jours, qu'à indiquer l'endroit où l'Anémone avait vécu. Au bout d'une semaine, II. Hogg, essayant de les enlever avec une baguette, découvrit, à sa grande surprise, que lesdits fragments se contractaient lorsqu'ils étaient touchés. Peu de jours après, il distingua une rangée de tentacules poussant sur la partie supérieure de chacun d'eux. Bientôt il y eut autant d'Anémones parfaitement formées qu'il y avait de petits morceaux !...

De son còté, la mère s'était guérie de sa perte de substance, et se trouvait aussi complète, aussi bien portante qu'avant la déchirure. (Rymer Jones.)

Les Anémones jouissent, comme les Polypes d'ean douce, de l'admirable faculté de reproduire les morceanx qu'on leur enlève. Si on leur ampute les tentacules, ces organes repoussent arec rapidité, ct l'on peut répéter l'expérience, pour ainsi dire, à l'infini....

Si l'on coupe la bête transversalement par le milieu, la moitié inférieure du corps produit une comronne de tentacules et se complète. Quant à la moitié supérieure, elle continue à saisir des proies et à lés engloutir comme par le 
passé, sans faire attention que la nourriture sort immédiatement par l'ouverture inférieure. Mais bientôt l'Anémone se ravise, et apprend à retenir son repas; et voici ce qui arrive. Tantòt cette seconde ouverture se resserre, se ferme, et il s'organise une nouvelle base; tantôt il naît des tentacules à son pourtour, et il se forme une seconde bouche, opposée à la première; eu sorte que l'animal saisit des proies et les avale par en haut et par en bas. Plus tard, il s'opère un étranglement vers le milieu du corps, d'abord faible, et graduellement plus fort. Il en résulte deux Anémones altachées base à base ou dos à dos : Rilta-ChrisinaAnémone! A cet étranglement succède une rupture, et l'on a des animaux parfaitement indépendants. Ritta et Christiua se sont émancipées.

Si l'on divise un de ces Zoophytes daus le sens vertical, de manière à partager sa bourse en deux parties égales, en peu de jours les bords se soudent dans chaque demi-bète, et l'on obtient deux Anémones complètes, mais un peu plus étroites que dans l'état babituel.

Trembley a rendu célèbres les Polypes d'eau douce; l'abbé Dicquemare a illustré les Anémones. Il a fait de nombreuses expériences sur ces curieux animaux, plus remarquables encore par leur ténacité à la vie que par la vivacité de leurs couleurs. Il les a mutilés de toutes les manières; il a toujours vu les fragments isolés supporter vaillamment les douleurs de la vivisection, et sortir tout à fait triomphants de cette rude épreuve.

“ On m'accusera peut-ètre de cruauté, dit cet excellent homme; mais je crois que, vu le résultat de mes expériences, ces animaux auraient plutòt lien de se féliciler d'en avoir été l'objet. Car, non-seulement j'augmentais la durée de leur vie, mais encore je les rajeunissais. ” 


\section{V}

Les Anémones sont bonnes à manger.

En Provence, on recherche la rousse et l'Anthée. Du temps de Rondelet, la crassicorne se vendait à Bordeaux à un bon prix. L'abbé Dicquemare regarde cette dernière comme la meilleure pour la table. Lorsqu'elle a bouilli dans l'eau de mer, elle devient ferme et très-appétissante: elle a l'odeur de l'Écrevisse. Le mème auteur assure que l'OEillet est anssi très-estimé. Plancus a conseillé de l'apprêter à la manière des Huitres.

\section{1}

Les Lucernaires, très-voisines des Anémones, en diffèrent par un tissu plus mou et par leur partie supérieure dilatée comme un parasol renversé. Leur corps est porté par un pédicule. Leurs tentacules sont réunis en faisceaux; ils entourent quatre espèces de cornes qui partent de la cavité digestive, et contiennent me matière grenue de couleur rouge.

Elles s'attachent aux Varees et aux autres corps marins.

La Campanule est probablement la plus jolie espèce du genre. Son nom de fleur lui convient à merveille. Figurezvous une corolle en forme de cloche, haute d'environ 25 millimètres, d'un brun foncé uniforme, attachée par un pédicule mince et court. Sa gorge est fermée par une lame transversale un peu concave, au milieu de laquelle s'ouvre une petite bouche carrée, placée sur un mamelon. Les bords de la corolle sont régulièrement découpés en huit 
lobes, portant chacun un bouquet de tentacules microseopiques terminés par un bouton glandulaire d'un rose vif. Quand on regarde cette charmante bestiole de côté, les huit touffes de tentacules ressemblent aux étamines polyarlehphes de certaines Myrtacées (Mélaleuques).

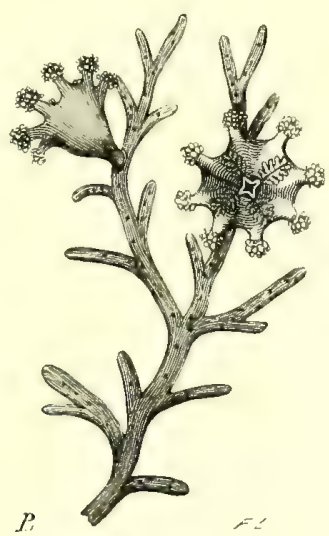

DEIT IICERYARES CAMPAXILES SIR Y YE AIGIT

(Lacernaria actoradiata Limarch).

Nous aurions bien des choses à dire encore sur les Anémones et sur les animaux qui leur ressemblent, et cependant, malgré la belle monographie de II. P. II. Gosse, ces Zoophytes sont encore très-mal connus. "L'histoire natırelle est un vaste pays dont nous connaissons à peine les frontières, et cependant nous voulons en dresser la carte! ” (Ch. Bonnet.) L'Homme est toujours pressé, il no sait pas attendre. Eratosthène et Hipparque ont rédigé la géographie du globe avant Christophe Colomb et Vaseo de Gama.

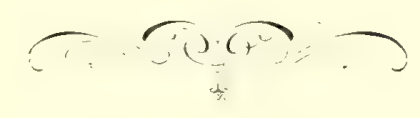





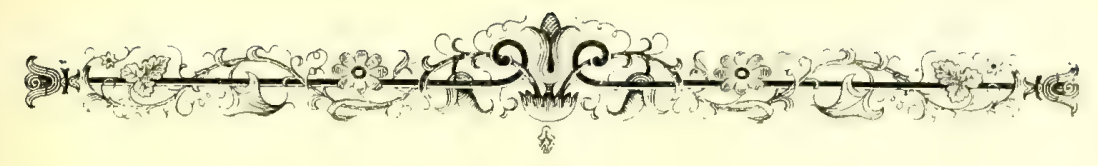

\section{CHAPITRE XIII}

\section{LES MÉDUSES.}

"Le Polypier fit la Méduse; la Méduse fait
le Polypier.
(Michelet.)

Voyez ces cloches demi-transparentes qui flottent gracieusement dans la mer! Ce sont des Méduses, organisa-

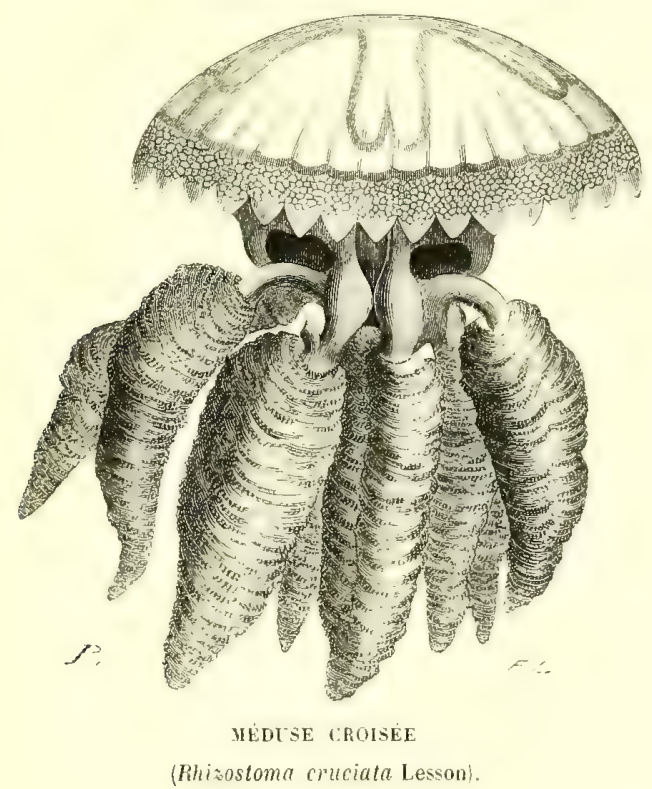

tions extraordinaires qui constituent une grande classe d'animaux fragiles et vagabonds, désignés par Cuvier 
sous le nom d'Acalèphes. Nous dirons plus loin pourcpuoi ce nom.

Les Méduses ressemblent à des calottes, à des ombrelles, on micux peut-être à des Champignons élégants et délicats, dont le pédicule serait remplacé par un corps également central, mais profondément divisé en lobes divergents. Ces

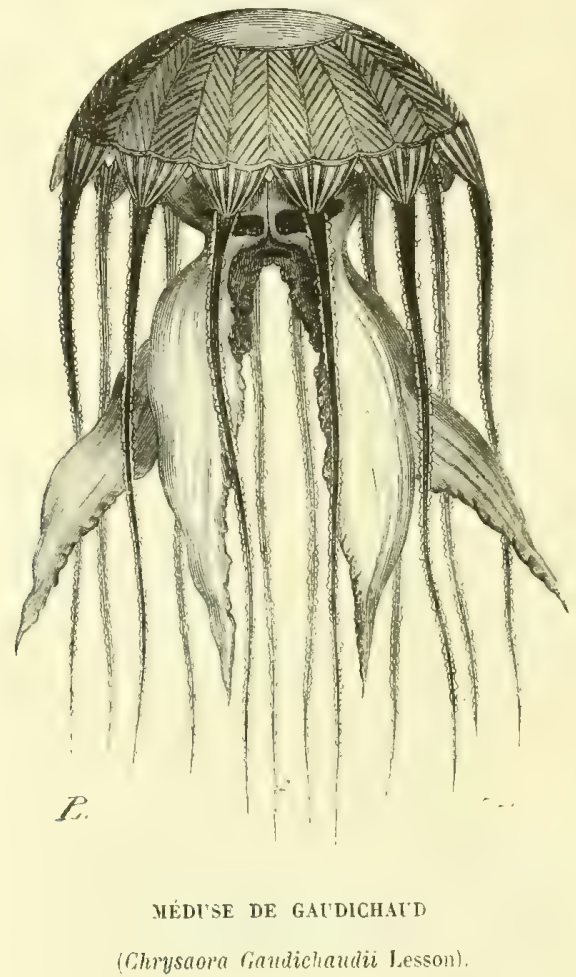

lobes sout simneux, tordus, crispés, frangés.... Au premier abord, on 'serait tenté de les prendre pour' des espèces de racines.

Les bords de l'ombrelle sont entiers ou denticulés, quelquefois découpés, souvent ciliés, ou bien pourvus de longs appendices filiformes qui descendent verticalement dans l'ean. 
Tantòt l'animal est incolore et d'une limpidité prestur égale à celle du cristal; tantôt il parait légèrement opalin, d'un bleu tendre ou d'un rose affaibli. D'autres fois il présente les teintes les plus vives et les reflets les plus brillants.

Dans certaines espèces, les parties centrales seulement

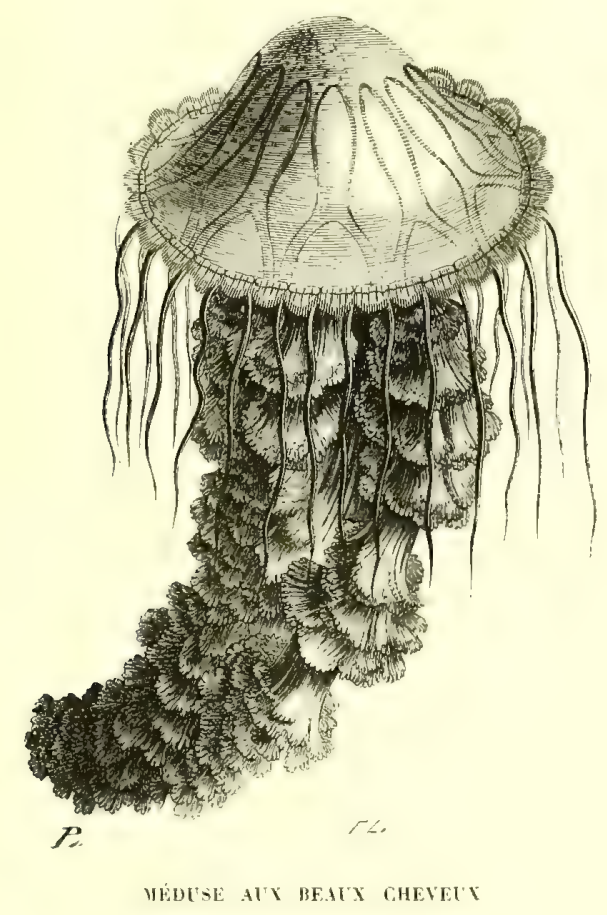

Cryanea euplocamia Lesson'.

sont colorées; elles se montrent rouges ou jamnes, blenes on violettes. Le reste est sans couleur.

Dans d'autres, la masse centrale semble vètue d'un voile extrêmement mince, diaphane et irisé, semblable à la lame légère et fugace d'une bulle de savon, ou bien à la cloche transparente qui recouvre un bouquet de fleurs artilirielles.

Les tealepples sont des andmanx soms comsistance, prémé- 
trés de beancoup d'ean. On a de la peine à comprendre comment leur trame délicate peut résister à l'agitation des flots et à la force des courants. La vague les balance sans les meurtrir; la tempête les disperse sans les tuer. Quand on retire de la mer ces favoris de la Nature et qu'on les jette sur la plage, leur substance se dissout; l'animal se décompose, il se réduit à presque rien. Si le soleil est bien ardent, cette désorganisation s'opère en un clin d'œil.

Les vagues, en se retirant, déposent souvent sur la grève des amas de pauvres lléduses, qui s'y fondent comme des glaçons.

On dit que certaines espèces très-grandes, du poids de 马े à 6 kilogrammes, ne contiennent que 10 à 12 grammes de matière solide.

M. Telfair vit, en 1819, sur le rivage de Bombay, une Méduse énorme abandonnée; elle pesait plusieurs tonneaux. Trois jours après, l'animal commençait à se putréfier. M. Telfair fit surveiller cette décomposition par les pècheurs $d u$ voisinage, afin de recueillir les os ou les cartilages de cette grosse bete, si par hasard elle en avait. Mais elle se pourrit tout entière et ne laissa aucun reste. Il fallut pourtant neuf mois pour qu'elle dispar'ut complétement.

Les Acalèphes de nos côtes sont loin d'avoir une taille anssi monstrueuse; beaucoup peuvent passer pour de petits animaux. Un des plus délicats est la Turris négligée ${ }^{\text {, }}$ qu'on a décrite comme une clochette de verre rouge ornée de quatre raies transversales et de quatre appendices blanes disposés en croix. Aux bords de la clochette règne une frange neigense du plus joli effet.

Les Acalèphes sont quelquefois réunis en nombre con- 
sidérable. Les barques qui traversent l'étang de Than rencontrent, à certaines époques de l'année, des colonies nombreuses d'une espèce de la taille d'un petit melon, presque transparente, blanchâtre comme de l'eau troublée par un nuage d'anisette. On serait tenté de prendre ces



LIZZIA DE KüLLAKER (TRÉS-gROSSAH:)

(Lizzia Kœllikeri Gegenbauer).

animaux pour une collection flottante de bonnets grees de mousseline.

La Lizzia de Köllitier est si petite, qu'on la distingue à peine dans la transparence de l'eau.

Sur les côtes du Groenland, on remarque sonvent de grands espaces colorés en brun foncé par la jolie Méduse brune tachelée. Un centimètre cube d'eau en contient, 
dit-on, plus de 3000, of un de leurs banes, qui présente une étendue insignifiante par rapport à l'Océan, se compose au moins de 1600 milliards de ces animalcules (Schleiden). Quelle source de réflexions philosophiques et de poétiques rêveries!

Les Méduses étant flottantes et légères, les courants et les autres monvements de la mer les entrainent souvent i de très-grandes distances de leur pays natal. Les myriades d'individus que mangent les Baleines sont transportés des côtes du Mexique jusqu'amx îles Hébrides, l'me les principales stations de ces énormes Cétacés.

Pendant longtemps, les Acalèphes ont été négligés par les naturalistes, qui les prenaient, comme l'avait fait Réanmur, pour des masses de gelée ou pour une eau gélalinée. On ignorait que c'étaient de véritables animaux. Constant Duméril eut l'idée d'injecter leurs cavités avec du lait. Il vit ce liquide se distribuer dans des canaux nombreux, d'une grande régularité. On découvrit bientôt les organes de la digestion et ceux de la circulation.... II. Ehrenberg montra, dans une espèce d'Aurélie, une complication des plus inattendues. Enfin, la science réussit ¿̀ pénétrer tont à fait dans les mystères de leur structure intérieure.....

Quoi qu’il en soit de ces études de plus en plus merveilleuses, les gélatines vivantes dont il s'agit sont toujours des ébauches de la vie, et, comme on l'a dit très-justement, elles fondent et refondent des millions de fois avant que la Nature ćlabore avec leur substance une portion qualrompur dim amimal solidement ronstiture! 


\section{III}

Les Méduses se nourrissent de petits animaux marins, principalement de Vers et de Mollusques. Leur bouche est placée au milieu de leur pédicule; quelques-unes possèdent plusieurs bouches.

Ces singulières bètes sont très-gloutonnes et avalent leur proie sans la màcher, voire mème sans la diviser. Quand celle-ci résiste, l'Acalèphe tient bon, jusqu'à ce que la malheureuse victime soit épuisée de fatigue. On a vu unc Méduse ne pas lâcher un animal qu'elle avait saisi par la tète, quoique celui-ci, par ses efforts énergiques, lui ent complétement tourné l'estomac à l'envers.

Des Méduses emprisonnées dans un vase avec des Crustacés ou des Poissons de petite taille les dévorent fréquemment. Et cependant ces derniers, plus compliqués en organisation, sont doués d'une intelligence plus que suffisante pour apercevoir le danger. Apparemment, dit II. Forbes, les Méduses trouvent des jouissances toules démocratiques dans la destruction des animaux des classes élevées! O rivalité des castes et des conditions! II y a donc partout de la démocratie et de l'aristocratie!

\section{IV}

Le corps des Méduses se dilate et se contracte alternativement. Ce double mouvement est un des principaux éléments de leur progression. Il avait été observé par les anciens, et comparé par eux à ceux de la poitrine humaine pendant la respiration. C'est pourquoi ils appelaient nos animaux, Poumons de mer. 
Quand les léduses voyagent, leur partie convexe est toujours en avant, de manière que la petite calotte devient 111 pen oblique. Si, pendant qu'elles naviguent, on les touche, mème légèrement, elles replient leurs tentacules, contractent leur ombrelle, et s'enfoncent dans la mer.

Une étude attentive des parties marginales des Acalèphes a fait découvrir, chez un certain nombre, des organes visuels et auditifs. M. Kölliker avait constaté l'existence des premiers dans une Océanie. M. Gegenbauer les a retrouvés dans plusieurs autres genres (Rhizostomes, Pélagies); il a reconnu en même temps la présence des seconds. Les yeux consistent en de petites masses hémisphériques, celluleuses, colorées, dans lesquelles sont enfoncés à moitié de petits cristallins globuleux, dont la partie libre est parfaitement à nu.

Les appareils auditifs se trouvent accolés à ces organes; ce sont de petites vésicules remplies de liquide. Il existe done des yeux sans paupières et sans cornée, et des oreilles sans ouverture et sans pavillon!...

\section{V}

Mais c'est la reproduction de ces êtres fugitifs, parfaitement étudiée de nos jours, qui a présenté de merveilleux phénomènes.

A une époque de l'année, les Méduses sont chargées d'œufs ornés des couleurs les plus vives, suspendus en larges festons à leurs corps flottants. Ces œufs sont trèspetits.

Dans certaines espèces, ils se développent greffés au corps de la Néduse, et ne se détachent qu'après leur complet développement. 
Dans d'autres, les larves qu'ils produisent ne ressemblent mullement à leur mère. Elles sont allongées, vermiformes, un peu élargies à leur extrémité : on dirait des Sangsues microscopiques. Elles possèdent des cils vibratiles à peine perceptibles, qui exécutent des mouvements assez

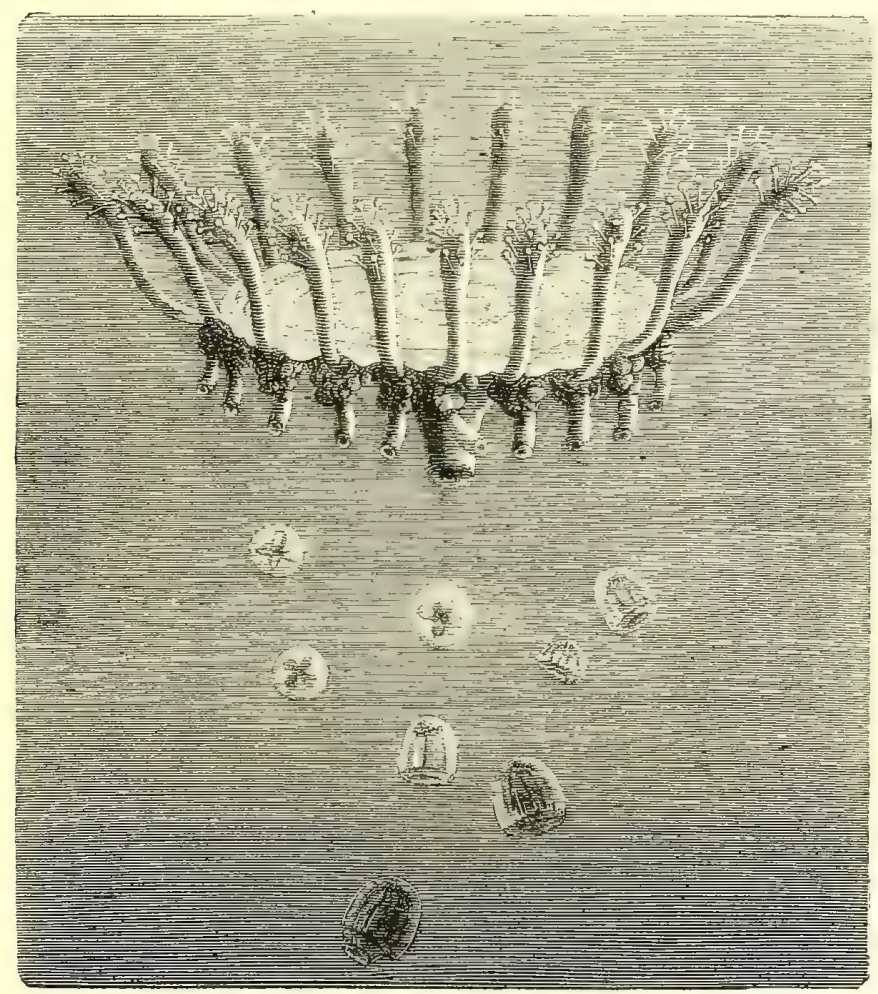

IMSSATCE DI, MEULCL

[D'apues un tessin de M. Lacaze-Duthiers]

vifs. Au bout d'un certain temps, elles se transforment en Polypes pourvus de huit tentacules.

Cette sorte d'animal préparatoire, créature vraiment surprenante, jouit de la faculté de se reproduire par des tubercules ou bourgeons, qui naissent à la surface de son corps, et aussi par des filaments qui en surgissent gà et là. 
Un seul individu peut devenin ainsi la source d'une nombreuse colonie.

Ce Polype subit une transformation des plus remarquables. Sa structure se complique; son corjes s'articule, et parait composé d'une douzaine de disques empilés les uns sur les autres, comme les rondelles d'une pile de Volta.

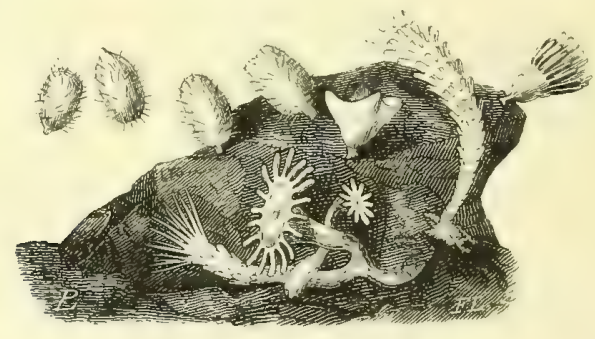

LARVES DE MEDLSES.

Le disque supérieur est bombé; il se sépare de la colonne après des efforts convulsifs : il devient libre. Il en résulte une Méduse excessivement petite, assez semblable à une étoile ${ }^{1}$.

Tous les disques, c'est-d̀-dire tous les individus, s'isolent les uns après les autres et de la même manière.

Ainsi, des Zoophytes sexués se propagent suivant les lois ordinaires; mais ils engendrent des enfants qui ne leur ressemblent pas, et qui sont neutres, e'est-à-dire non sexués (agames). Ceux-ci produisent, par bourgeonnement et par fissiparité, des individus semblables à eux. Ils peuvent donner aussi des individus sexués; mais, avant l'apparition de ceux-ci, l'animal, qui était simple, se transforme en animal composé, et c'est de la désagrégation des éléments de ce dernier que naissent des individus pourvus de sexe, c'est-à-dire les animaux les plus complets. 


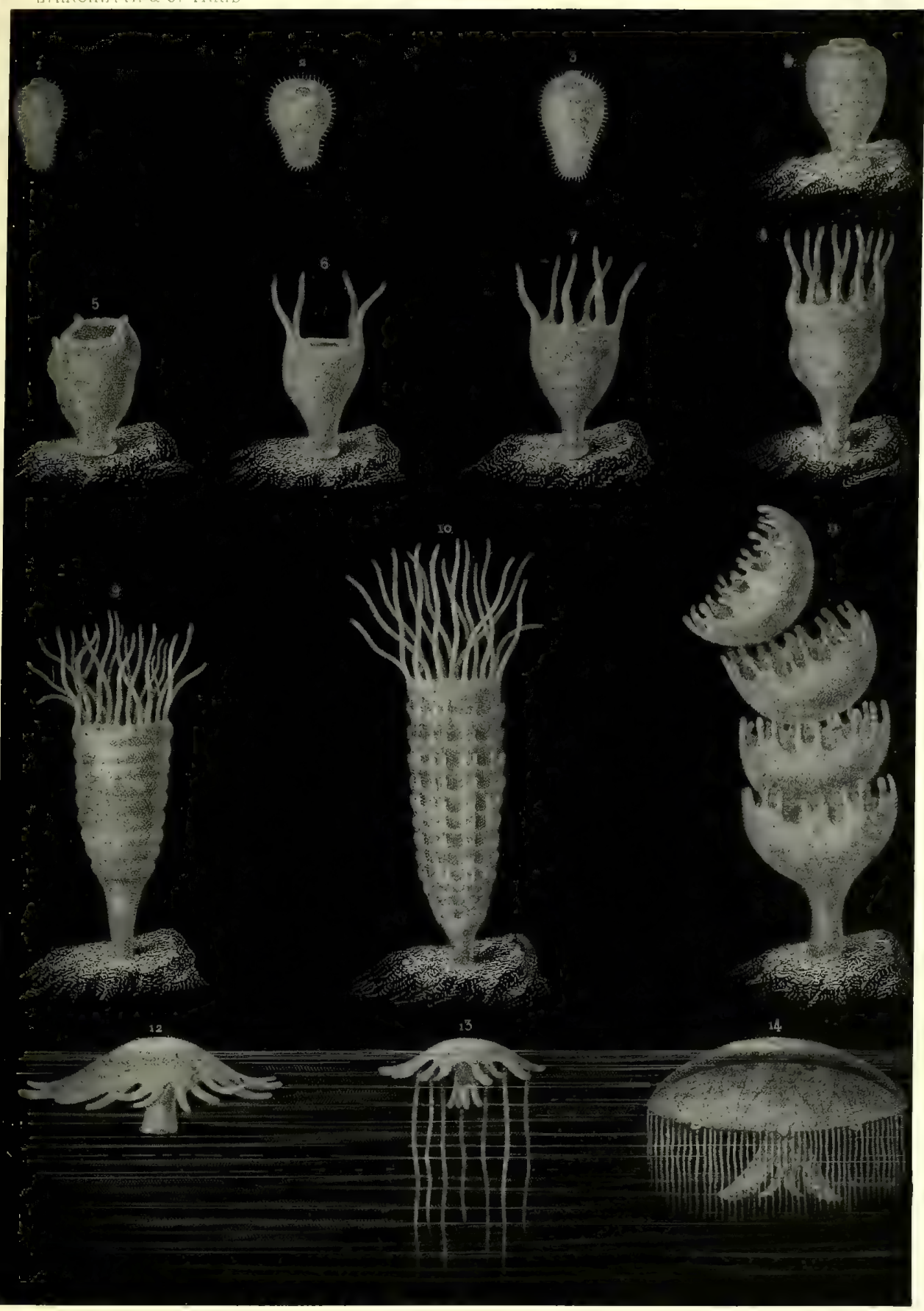

DÉVELOPPEMENT D'UNE MÉ.DUSE 

Ces deux modes de propagation si différents (la sexuelle et la non sexuelle) se succèdent d'une manière régulière. lls constituent ainsi une combinaison qui a reçu le nom de génération alternante, génération dans laquelle, ainsi que nous venons de le dire, les enfants ne ressemblent jamais à leur mère, mais bien à leur grand'mère.

On appelle nourrices (dénomination assez mal choisie) les individus neutres qui produisent les individus sexués.

Ces transformations successives qui ont lieu dans le mème animal paraissent, au premier abord, bien extraordinaires. Cependant il se passe autour de nous, et chaque jour, des phénomènes analogues auxquels nous n'accordons qu'une assez mince attention, probablement parce qu'ils sont très-communs et que nous y sommes très-habitués. Par exemple, les Papillons les plus brillants et les plus vagabonds pondent des oufs immobiles, arrondis et saus aucune espèce d'élégance. Ces cufs produisent des chenilles destinées à ramper avec peine, vêtues le plus souvent avec simplicité. Ces chenilles, à leur tour, se changent en chrysalides condamnées à un repos léthargique, ovoïdes, couleur de corne, et ressemblant à des momies. Enfin, celles-ci se transforment en riches, légers et pétulants Papillons. Supposons ces insectes excessivement rares et cachés dans les profondeurs de l'Océan, n'est-il pas vrai qu'il aurait fallu beaucoup de temps pour reconnaitre que l'œuf', la chenille, la chrysalide et le Papillon ne sout qu'un mème animal? Si cet insecte avait une organisation moins compliquée, il est probable que sa chenille ou sa chrysalide (et peut-être même son cuf!) pourraient se reproduire gemmiparement ou fissiparement, c'est-à-dire par bourgeons et par scissions, et nous aurions des phénomènes exactement semblables à ceux qui se présentent dans l'évolution d'une Méduse. 
Tous les médecins savent aujourd'hui que les Témas, vers parasites rubanés et articulés, ont des larves (Cysticerques) très-différentes de l'état parfait, qui possèdent la faculté de produire d'autres larves. Chose étonnante! ces curieux animanx sont simples à une époque de leur vie, composés à une seconde époque, et redeviennent simples à une troisième.

Nous ne samious trop le répéter, tout change et rechange dans la Nature. Dieu seul ne change pas!

Ce qui est digne de remarque chez les Papillons, e'est cette alternance de vitalité exaltée et de vitalité latente, de mouvement et de repos, qu'on observe dans la succession de leurs métamorphoses. L'œuf est immobile, la chenille rampe, la chrysalide dort, et le Papillon s'élance dans les airs. Chaque temps d'évolution est précédé par un temps d'arrêt. Ciest là une des grandes lois de la physiologie. Voyez le modeste Ver à soie : toutes les fois qu'il se dispose à changer de vètement, il demeure quelque temps dans une sorte de torpeui. Il se prépare, par un simulacre de la mort, aux mouvements d'une nouvelle vie.

" La tendance aux métamorphoses, dans le règne anımal, considérée dans son ensemble, devient de plus en plus prononcée, à mesure qu'on s'éloigne davantage des types les plus élevés de l'organisation. ” (Quatrefages.)

\section{VI}

Quelques Méduses donnent naissance, quand on les touche, à une sensation brûlante qui rappelle celle des Orties. De là les noms d'Orties de mer et d'Acalèphes sous lesquels on a désigné ces animaux.

Une des plus redoutables, parmi ces espèces remar- 
quables, c'est la Méduse chevelue ${ }^{1}$, la terreur des baigneurs et des baigneuses. L'animal représente me jolie ombrelle brune, découpée et festonnée, avec un gros pédicule et des bras nombreux, longs et rubanés, qui forment après elle une chevelure flottante, d'autant plus dangereuse qu'elle est presque diaphane. Quand on s'embarrasse imprudemment au milieu de ces filaments empoisonnés, on sent bientôt des donleurs aiguës insupportables. La Méduse, en fuyant, abandonne souvent ses cheveux, qui se détachent. Ces derniers, quoique isolés, agissent toujours, comme si l'animal était présent et comme s'il voulait se venger de leur séparation.

Les organes urlicants des Méduses sont des coques très-petites disséminées dans leur peau, sur laquelle elles forment des saillies plus ou moins tuberculeuses. On les observe surtout à l'extrémité ou le long des tentacules. Ces coques sont dures, diaphanes et doublées d'une membrane mince et flexible. Au fond de leur cavité se trouve un fil long et ténu, enroulé sur lui-même pendant le repos. Ce fil peut sortir de la bourse, et l'on voit alors à sa base une ou plusieurs pointes aiguës en forme de dards. Ces poignards microscopiques, probablement creusés d'un petit canal, sont portés par une glande qui sécrète une sorte de venin. C'est avec ces petits appareils que les Méduses, dont le tissu est si faible, si délicat, et l'intelligence si obtuse, si bornée, penvent se défendre et même attaquer. La sensation brulante qu'elles déterminent, quand on a l'imprudence de les toucher, est si forte, qu'elle peut produire l'effet d'un vésicatoire, et donner naissance à une affection qui dure quelques jours.

La Méduse d'Aldrovande ${ }^{2}$, qui vit dans la Méditcranée,

1 Cyancea capillata Eschscholtz.

${ }^{2}$ Rhizostoma Aldrovandi Péron. 
et la Méduse de Cuvier ${ }^{1}$, qui se trouve daus la Mauche, sécrètent une bave qui offre des propriétés assez irritantes. On assure qu'une seule goutte sulfit pour déterminer une inflammation de la conjonctive et mème des paupières. Cette bave fait naitre sur la main de très-petites élevures. accompagnées d'une vive démangeaison.

\section{1}

C'est dans la classe des Acalèphes que les naturalistes ont placé les Béroés et les Vélelles.

Les Béroés ont un corps ovoïde ou globuleux, garui de

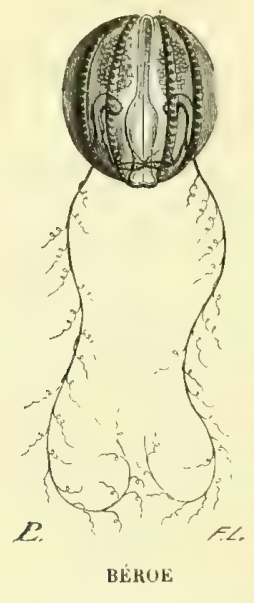

(Berne pileus Gmelin!.

còtes phus ou moins saillantes ornées de dentelles et hérisscies de filameuts. Ces còtes forment quelquefois des sortes d'ailes. Certains Béroés ressemblent à de petits barils saus fond: leurs couleurs sont éclatantes: on dirait des émaux vivants.

L'espèce des còtes de l'Irlande, appelée pomiforme ${ }^{2}$, est une petite sphère du plus pur cristal, nuancée des couleurs

1 Rhizostoma Cuvierii Péron.

2 Cydippe pomiformia Patterson. 
de l'iris. Quand elle mange, on distingue sa proie à travers son tissu. Ses côtes sont frangées; on y remarque des cils diaphanes très-mobiles, à l'aide desquels le délicienx ballon glisse et avance dans les eaux, comme un petit météore. Les mouvements des cils ont lieu avec alternance, e'est-à-dire que ceux d'une rangée s'agitent avec vivacité pendant que ceux de la rangée voisine se reposent, et que ces derniers, à leur tour, se mettent en mouvement quand les premiers sont en repos. Ce Béroé semble capricieux dans ses évolutions : quelquefois il monte à la surface de la mer, lentement, comme une bulle qui s'élève, et redescend avec la mème lenteur; d'autres fois il opère une ascension d'une excessive rapidité et une descente comme la chute d'une pierre. D'autres fois encore, sans s'élever ni descendre, il pirouette sur son axe vertical, et décrit une suite de cercles transversaux, comme un gracieux valseur. (Rymer Jones.)

Cette jolie espèce possède deux tentacules six fois plus longs que son corps, très-fins, très-délicats, composés d'un axe capillaire flexueux, donnant des branches latérales courtes et arborisées. Ces tentacules descendent en divergeant de la partie inférieure du corps; ils sont très-onduleux et ressemblent à des fils d'Araignée. On assure que leur surface est couverte de vésicules microscopiques étroites et piquantes, qui servent probablement à étourdir ou à tuer la proie (Strethill Wright). L'organe le plus faible a toujours quelque moyen de perfection; il peut même devenir, comme on voit, un instrument très-dangereux.

On connait un Béroé phosphorescent ${ }^{1}$. Quand il tourbillonne, il produit l'effet d'un petit corps lumineux en forme

1 On a signalé plusieurs autres Acalèphes avec une propriété analogue, par exemple la Diancea cyanella de Lamarck, et l'Oceania phosphorica de Péron et Lesueur. 
de colonne torse, qui change constamment de place en tournant sur lui-même.

Les Vélelles ont un cartilage intérieur, ovale et transparent, qui sontient la substance gélatineuse de leur corps. Celui-ci est une ombrelle d'un bleu foncé, garnie en des-

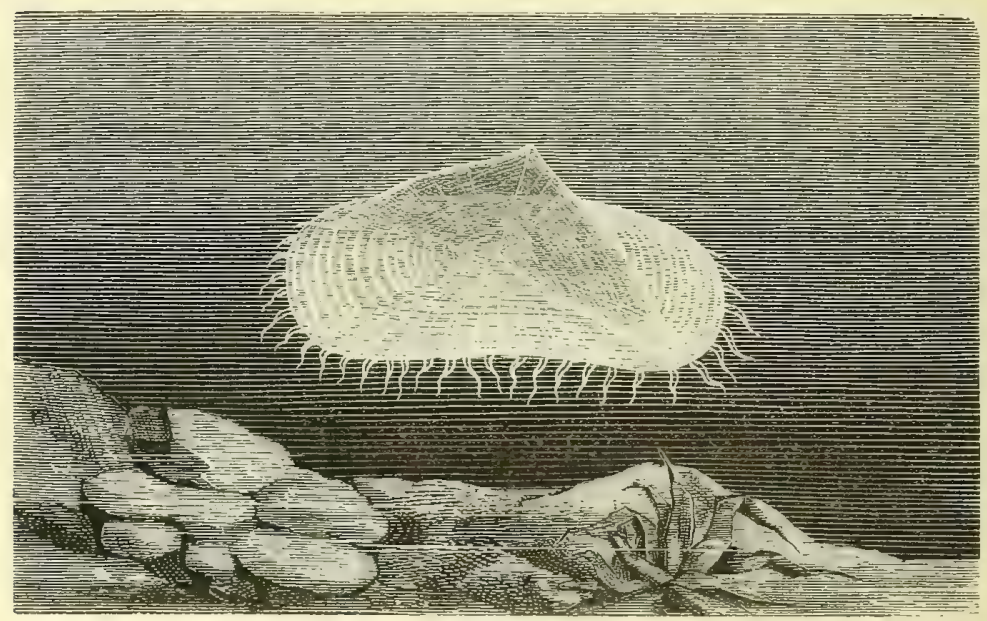

VÉLELLE

(Velella limbosa Lamarck).

sous de nombreux suçoirs. Une crête verticale, en forme de voile, est implantée sur son cartilage et croise obliquement son dos.

Les Vélelles flottent sourent en grand nombre à la surface des vagues, maintenues à fleur d'eau par l'air qui les leste et poussées par le zéphyr qui frappe sur leur voile.

\section{VIII}

On a nommé Hydrostatiques ou Hydroméduses, les aninaux de la même classe, essentiellement nageurs, qui possident une ou plusieurs vessies ordinairement remplies d'air, on bien des cloches natatoires de forme variée. Ces ćlégants 
animaux flottent souvent sur les ondes, au milieu des phus grandes agitations de la mer, comme de faibles nacelles

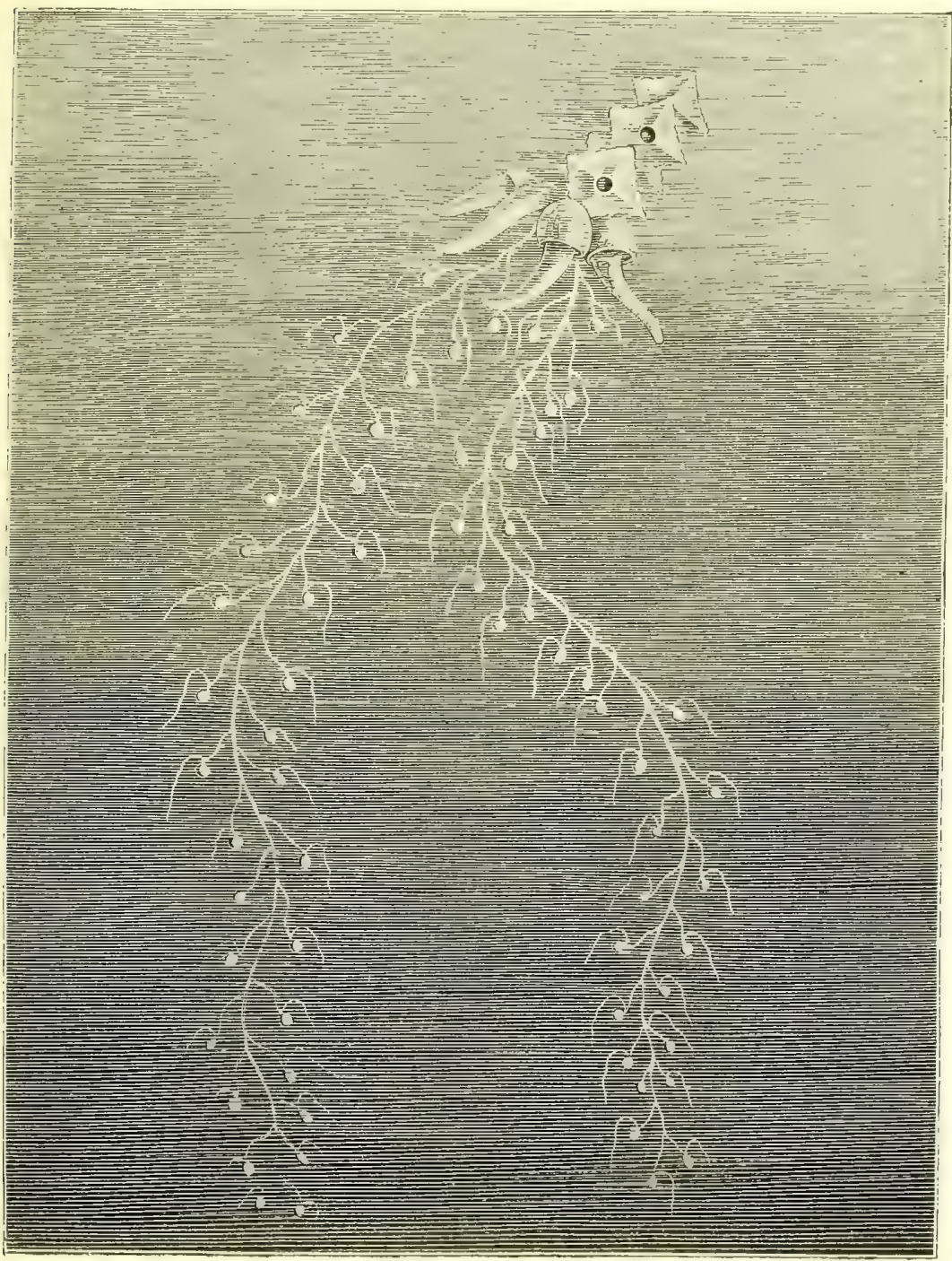

HYDRONEDI'SE

(logliul).

surprises par la tempête; mais ils sont insulmersibles, et, quoi qu'il arrive, ils restent toujours à la surface. 
Ces autres Acalèphes présentent généralement des tentacules grêles ou fils pécheurs, plus ou moins longs, souvent nombreux et de la plus grande délicatesse.

Leurs vessies ou leurs cloches les soutiennent dans la mer; leurs tentacules les dirigent dans leur marche, et leurs fils pêcheurs leur servent à la fois d'organes de défense, d'organes de préhension et d'organes de succion.

Les Hydroméduses sont des animaux composés, des sortes de Polypiers voyageurs. Leurs colonies forment des franges, des guirlandes, des grappes d'une légèreté remarquable. Ces colonies peuvent offrir trois sortes d'animalcules élémentaires : des individus nourriciers stériles, des individus prolifères sans bouche, et des individus à la fois nourriciers et fertiles. Les premiers ne manquent à aucun genre; les seconds et les troisièmes n'existent pas toujours. On rencontre encore, chez les IIydroméduses, des bourgeons reproducteurs, soit isolés, soit agglomérés. (C. Vogt.)

Ces curieux animaux présentent, ou bien une grande ampoule qui domine toute leur organisation, ou bien des cloches natatoires égales ou inégales, simplement rapprochées ou diversement emboîtées.

Les organes natatoires sont passifs dans les Physahes.

Voyez, sur la mer calme, cette grande vessie oblongue, relevée en dessus d'une crête saillante, oblique et ridée, qui ressemble à une petite voile de pourpre et d'azur tendue sur une nacelle de nacre. Ce brillant Zoophyte est désigné par les marins sous les noms de Vessie de mer, de pelite Galère, de Vaisseau de guerre porlugais.... Les savants l'appellent Physalie pélagique ${ }^{1}$. En dessous de la vessie, naissent un grand nombre de tentacules charnus, 
cylindriques, tordus, rayés, qui descendent perpendiculairement comme des sondes de soie bleue. Ceux du milieu portent des groupes de petits filaments; les latéraux se. divisent en deux branches grêles, souvent très-inégales. Ces longs filaments sont semés de gouttelettes chatoyantes on de

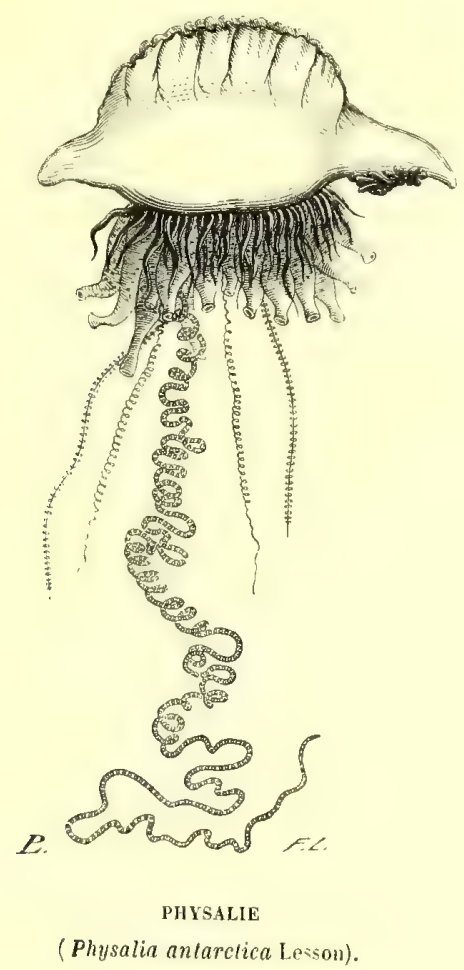

perles étoilées couleur indigo, qui dessinent des bordures, des zigzags ou des spirales d'une élégance peu commune.

“Les Galères, dit Lesson, cheminent parées des plus riches couleurs. La partie vésiculeuse et la crête, remplies d'air, sont d'un blane nacré argentin, auquel s'unissent les teintes les mieux fondues de bleu, de violet et de pourpre. Un carmin vif colore les bouillonnements du biseau de la crète, et le bleu d'outremer le plus suave teint les divers tentacules. » 
Gardez-vous de toucher à ce petit vaisseau vivant : une cuisson plus brîlante que celle de la piqûre des Orties punirait la main téméraire qui oserait le saisir. Cette sensation est prodnite par un liquide corrosif bleu, de consistance légèrement sirupeuse (Lesson). Le mal dure assez longtemps. Il entraine quelquefois une tendance syncopale (Dutertre, Leblond). Mais, en général, il ne s'étend pas au delà de la main.

“La Vessie de mer, dit le père Feuillée, m’occasionna, en la touchant, des douleurs si vives, que j'en eus des convulsions. 》

Le père Dutertre, étant aux Antilles, dans une petite embarcation, vit un jour une Galère; il essaya de la saisir :

“ Je ne l'eus pas plutôt prise, que toutes ses fibres m'en» gluèrent la main, et à peine en eus-je senti la fraischeur ") (car elles sont froides au toucher), qu'il me sembla avoir "plongé mon bras, jusqu'à l'épaule, dans une chaudière nd'huile bouillante, et cela avec de si estranges douleurs, " que quelque violence que je pusse faire pour me contenir, "de peur qu'on ne se moquast de moy, je ne pus m'em" pescher de crier par plusieurs fois à pleine teste : Miséri» corde, mon Dieu! je brusle! je brusle!... »

Leblond, dans son Voyage aux Antilles, donne une figure de la Physalie pélagique, et dit : “Un jour, je me baignais avec quelques amis dans une grande anse, devant mon habitation. Pendant qu'on pêchait de la Sardine pour le déjeuner, je m’amusais à plonger à la manière des Carähes, dans la lame près de se déployer... Cette prouesse faillit me coûter la vie. Une Galère (il y en avait plusienrs d'échouées sur le sable) se fixa sur mon épaule gauche, au moment où la mer me rapportait à terre; je la détachai promptement, mais plusieurs de ses filaments restèrent collés à ma pean, jusqu'au bras. Bientôt je sentis à l'aisselle une douleur si 
vive, que, près de m'évanouir, je saisis un flacon d'huile qui était là, et j'en avalai la moitić pendant qu'on me frottait avec l'autre; mais la douleur s'étendant au ceur, j'eus un évanouissement. Revenu à moi, je me sentis assez bien pour retourner à la maison, où deux heures de repos me rétablirent, à la cuisson près, qui se dissipa dans la nuit. "

Meyen, pendant le premier voyage de la PrincesseLouise autour du monde, remarqua une magnifique Physalie qui passait près du navire. Un jeune matelot, hardi et courageux, sauta nu dans la mer pour s'emparer de l'animal, nagea vers lui et le saisit. Celui-ci entoura son ravisseur avec ses nombreux filaments (ils avaient près d'un mètre de longueur); le jeune homme, épouvanté et sentant une douleur brủlante, cria au secours... Il eut à peine la force d'atteindre le vaisseau et de se faire hisser à bord; mais la douleur et l'inflammation furent si violentes, qu'une fièvre cérébrale se déclara, et l'on fut trèsinquiet sur sa santé.

Les organes matatoires sont actifs dans les Diphyes de Cuvier, les Physophores de Forskäl, les Apolémies do Lesson.

Chez les Diphyes, deux cloches inégales ou deux individus différents sont toujours ensemble, mais bien autrement unis que Philémon et Baucis. Un des individus s'emboite dans une cavité de l'autre. L'emboitant produit me sorte de chapelet qui traverse un demi-canal de l'emboité!

Ces animaux sont gélatineux, pyramidaux, ovoïdes, quelquefois en forme de Campanule ou de sabot. On peut les séparer sans mutilation, et les conserver vivants. Mais quand un individu est isolé, on reconnait sans peine qu'il s'ennuie, qu’il souffre, qu’il dépérit.... Il lui manque quelque chose!

Quelques auteurs regardent charue paire d'individus 


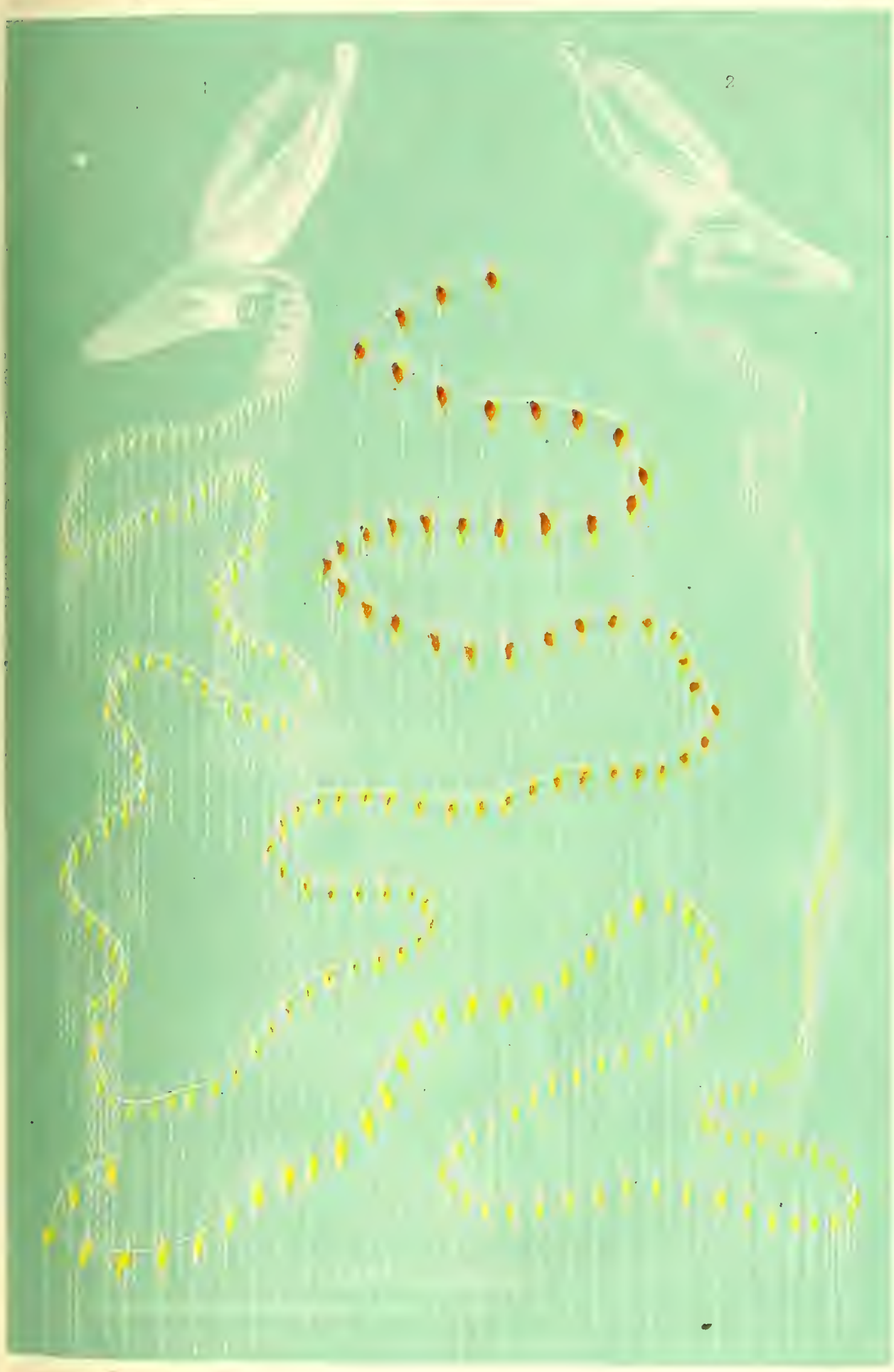

GALEOLARE ORANGEE. 

aux individus, et destinées à les soutenir dans l'eau. C'eux-ci sont les corps piriformes dont nous venous de parler. II y

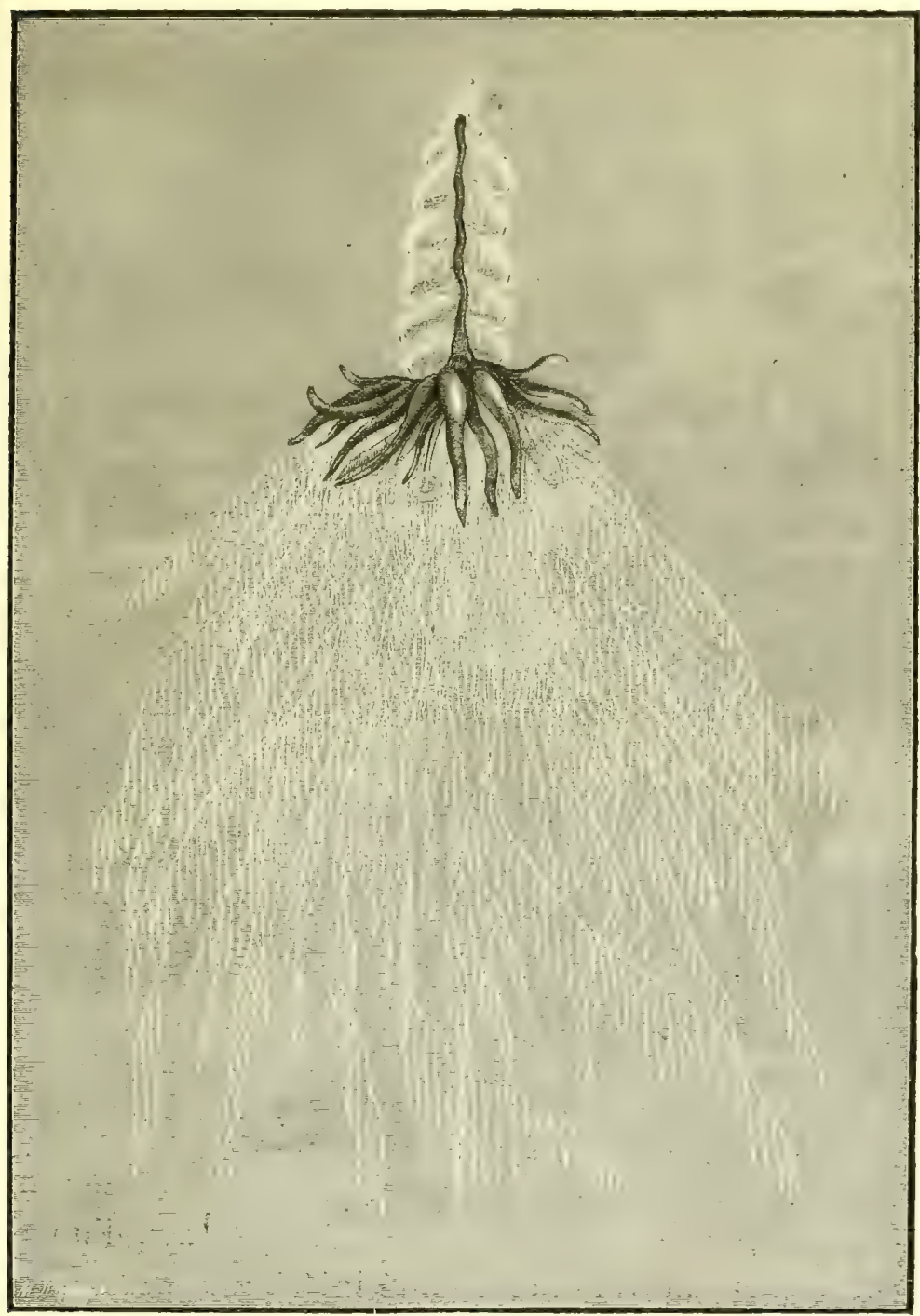

PHSSOPUOR:

(l'hysophora hydrostutica [rorskit).

en a de mảles et de femelles, les premiers orangés, et les seconds jamaatres; ils ne vivent pas ensemble, ils forment 
des associations unisexućes. Il est probable que plusieurs Diphyes sont des animaux mutilés, e'est-à-dire privés de leurs filaments, et par conséquent incomplets.

Les Physophores, ou Porte-vessies, ont des cloches nombreuses.

La Physophore distique est une des espèces les plus délicates et les plus jolies de ce groupe. I l'extrémité supérieure d'un axe grêle et flexueux s'élève une petite ressie oblongue et transparente, mamelonnée en dessus. A droite

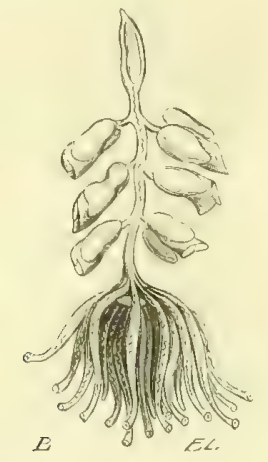

PUYSORHURE DISTHQTL

(Physophora disticha Lesson).

et à gauche de cet axe naissent trois appendices opposés, d'un jaune de soufre, trilobés, c'est-à-dire composés d'une sorte de clochette courte, pourvue de chaque côté d'une ampoule oroïde. En dessous, l'axe supporte une trentaine de tentacules composant un bouquet renversé, cylindriques, atténués à leur naissance et à leur terminaison, par conséquent légèrement fusiformes, demi-transparents, d'un rose pourpre, plus pâle vers l'extrémité inférieure, se terminant chacun par un petit suçoir. Ils sont traversés par un filament capillaire d'un pourpre vif, tordu en zigzag. Cette association est-elle complète? N'avait-elle pas des filaments capillaires, comme la Galéolaire dont nous venous de parler? 
Dans les Apolémies, les cloches sont encore plus nombreuses.

La contournée ${ }^{1}$ réunit la forme la plus gracieuse à une délicatesse de tissu et une transparence étonnantes (Vogt). Elle ressemble, en nageant, à un plumet formé de petites floques très-déliées, d'une couleur ronge ardente. Cette charmante espèce a été décrite avec une rare exactitude par MM. Milne Edwards et C. Vogt. Ce dernier savant en a publié une excellente figure que nous reproduisons.

Les cloches natatoires de cette espèce composent une masse ayant la forme d'un øuf allongé, coupé par le milieu, au sommet duquel s'élève une vésicule aérienne très-petite, portée par un col court. Dans cette masse, on compte une douzaine de séries verticales de cloches de cristal, emboitées mutuellement par les bords et attachées symétriquement à un axe commun, tordu en spirale. Chacune d'elles présente une tache jaune. L'axe commun est un ruban rose garni dans toute sa longueur d'aspérités creuses. Les longs filaments capillaires qui en naissent sont onduleux, transparents et à peine visibles à l'œil nu; ils portent de petits corps oblongs, suspendus comme des boucles d'oreilles.

Les individus nourriciers sont très-petits et remarquables au premier coup d'œil par la teinte pourpre de leur cavité digestive. lls sont fixés sur le trone commun, à des distances assez égales, et presque toujours en quinconce, au moyen de pédicules allongés.

La partie antérieure de l'animalcule est armée de capsules urticantes. Sur sa partie moyenne existent douze bourrelets longitudinaux (cellules biliaires) qu'on est tenté de prendre pour des ovules. A la base de la tige nait le fil

1 Apolemia contorta C. Vogt (voy. planche XIII). 
pècheur, yui est extrêmement délié et garni d'une multitude de vrilles urticantes rouges attachées à des fils secondaires dépendant du fil pècheur. Les organes urticants sont de deux sortes : de petits sabres serrés verticalement les uns contre les autres, et des fèves, un peu plus grandes, posées sur les bords du cordon rouge. La vrille se termine par un fil incolore tordu en spirale et couvert de lentilles urticantes. (C. Vogt.)

Les individus reproducteurs sont placés entre les individus nourriciers. On les a comparés à des boyaux allongés et dilatables; ils n'ont pas de bouche et sont toujours disposés par paire sur un pédoncule bifide. A leur base se voit souvent un fil pêcheur rabougri, court, hérissé sur toute sa surface de capsules urticantes. (C. Vogt.)

Quelle complication, quelle variété et quel développement dans ces petits appareils d'attaque et de défense! Mais aussi les élégantes Apolémies, si légères et si fragiles, n'ont guère plus de consistance qu'un amas de bulles de savon.

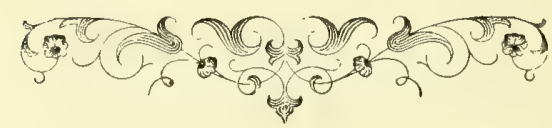




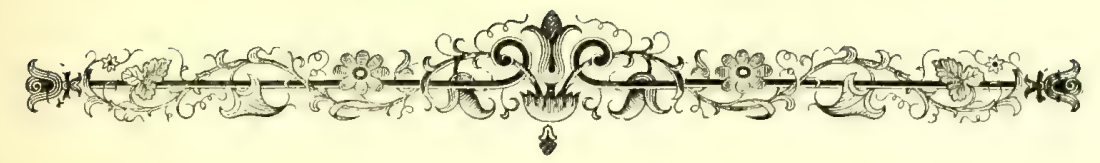

\section{CHAPITRE XIV}

\section{LES ÉTOILES DE MER.}

Vos etz l'Estèla dé la mar'.

(R. Stairem, 1468.)

\section{1}

Que de formes variées daus les populations aquatiques! Nature se plaît en diversité ${ }^{1}$, disait avec raison un ancien

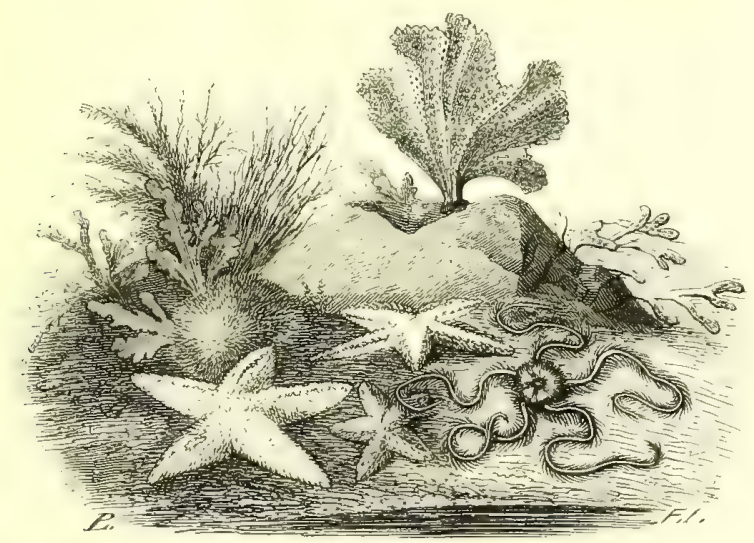

ÉTOILES DE MER.

roi de France. Voici des animaux dont la charpente parait dessinée par quelque géomètre : on les appelle Étoiles de mer ou Astéries.

1 "Ludens polymorpha natura." (LiNvé.) 
Leur ressemblance avec la figure bien commue que nous nommons étoile a frappé depuis longtemps tous les naturalistes et tous les amateurs. Cependant l'organisation de nos bètes marines est loin d'ètre rigoureusement régulière; car la puissance créatrice, dans la construction des animaux, emploie bien rarement les lignes parfaitement droites : elle préfère les cercles ou les ares, elle ondule!

Les Étoiles de mer sont des animaux sans vertèbres, le plus souvent déprimés, pentagonaux, à branches à peu

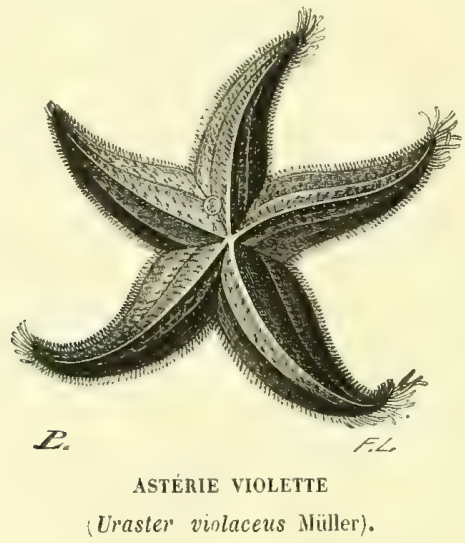

près égales entre elles et disposées comme des rayons. Ces rayons sont plus ou moins triangulaires. L'animal en offre habituellement cing : il a cinq branches, comme une croix d'honneur.

Les Étoiles de mer jonchent le sol des forêts sousmarines.

Les sondages récemment faits par le capitaine Mac Clintock, pour explorer le trajet du télégraphe nordatlantique, ont fait découvrir, à une profondeur de plus de 500 mètres, des Astéries vivantes, qui appartiennent à des espèces dont on a retrouvé les traces dans les couches de terrain les plus anciennes, et qui prospèrent, sous cette 
énorme pression, dans une région presque inaccessible i la lumière du soleil.

Il n'existe rien dans les eaux douces qui ressemble aux Astéries. Ce sont par conséfuent des animaux essentiellement marins.

Certaines espèces sont extrèmement nombreuses, à te point qu'on en charge des tombereaux pour les transporter dans les champs et pour en fumer les terres.

Edward Forbes a observé, dans les Luidies, une singulière faculté. L'animal peut se détruire en quelque sorte de lui-mème, en détachant et abandonnant d'abord ses bras, qui se rompent, et en se divisant ensuite par morceaux. Ne pouvant pas se défendre tout entier, il se tue en détail. C'est un suicide partiel!

Les Etoiles de mer offrent les couleurs les plus variées : il y en a d'un gris jaunâtre, d'un jaune orangé, d'un rouge grenat, d'un violet enfumé, d'un roux obseur....

Leur corps est soutenu par une enveloppe calcaire composée de pièces juxtaposées réunies par des fibres tendineuses, et armé de tubercules et de piquants.

M. Gaudry a évalué à plus de 11000 les pièces solides "qui se trouvent daus l'Étoile de mer rougeâtre', une des espèces les plus communes de l'Europe.

Les Astéries ont la bouche au centre de la surface inférieure. De cette bouche partent autant de gouttières ou sillons qu'il y a d'appendices brachiaux. Ces gouttières domnent passage aux organes du mouvement. 
Ceux-ci forment une double ou quadruple rangée. Ils consistent en des cylindres charnus, grêles, tubuleux, terminés, dans le plus grand nomlne, par une petite vésicule globuleuse remplie d'un liquide aqueux. Ils sont très-

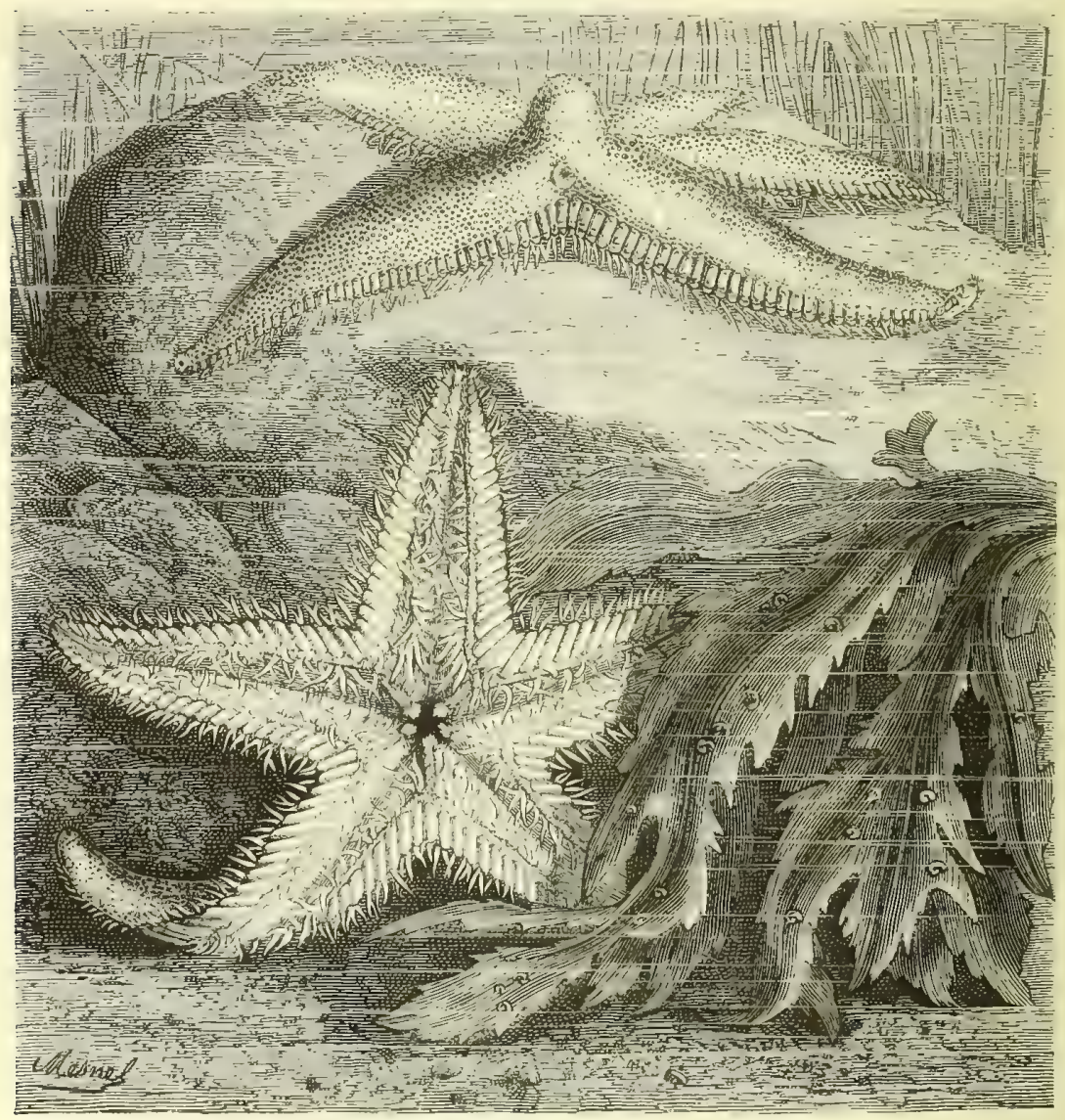

ASILRIE VIE L.Y DESSI'S LI LY DESSUC'S

(Astropecten spinulosus Müller et Troschel).

extensibles. Quand les pieds sortent, la vessie contractée pousse l'eau dans le tube, qui se roidit. Quand les pieds rentrent, leur pean musculaire renvoie leur contenu dans la vessie. L'Litoile s'accroche aux corps étrangers au moyen 
de ces organes, et réussit à exécuter les faibles mouvements qui constituent sa progression.

Malgré ce prodigieux attirail de jambes, l'animal ne va guère plus vite que beaucoup d'habitants de l'eau salée qui n'en ont qu'une seule ou qui n'en possèdent pas.

Si l'on renverse une Astérie sur le dos, elle reste d'abord immobile, les pieds enfermés. Bientôt elle fait sortir ces derniers, semblables à autant de petits Vers; elle les porte en avant et en arrière, comme pour reconnaitre le terrain ;

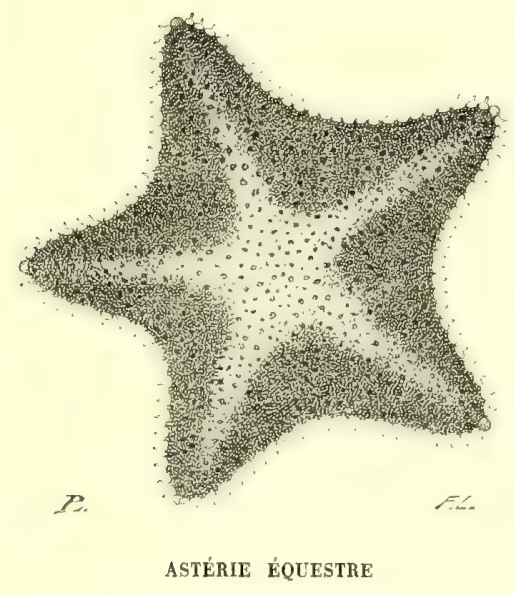

(Goniaster equestris Gmelin).

elle les incline vers le fond du vase, et les fixe les uns après les autres. Quand il y en a un nombre suffisant d'attachés, l'animal se retourne.

On croit que ces organes jouent en même temps un rôle important dans la respiration. Par moments, mème pendant le repos, ils sont traversés par des courants intérieurs de corpuscules.

La bouche des Astéries se rend presque immédiatement dans l'estomac. Celui-ci forme un grand sae qui envoie un long prolongement dans l'intérieur de chaque bras. Ces 
prolongements sont des espèces d'intestins... Des intestins dans des bras!

Ces animaux sont très-voraces : ils engloutissent leur proie vivante d'un senl morceau. Quand la victime est trop grosse pour la bouche, l'estomac se porte au-devant d'elle.

Chez la plupart des animaux, les lèvres sont les pourvoyeuses de la cavité digestive. Ici cette dernière se passe des lèvres, elle se pourvoit toute seule!

Les Étoiles de mer peuvent manger jusqu'à des Huîtres. Est-ce bien vrai? Leur bouche est étroite et non dilatable, et une Huître est un morceau assez volumineux! Voici comment procèdent les Astéries, suivant M. Rymer Jones. Elles saisissent l'Huitre entre leurs rayons, et la maintiennent sous leur bouche au moyen de leurs sucoirs; elles retournent leur estomac, qui enveloppe de ses replis le malheureux mollusque, et distille peut-être sur son corps un liquide stupéfiant (?). Bientòt la pauvre victime écarte les volets de sa coquille, livre ses organes à merci, et devient la proie du ravisseur étoilé.

Les Astéries jouent un rôle important dans la police et l'hygiène de la mer. Elles aiment les viandes mortes de toute nature, et déploient une activité merveilleuse à rechercher, à dévorer, à faire disparaître les diverses matières animales corrompues. Cet important travail de propreté et de salubrité est accompli sur une immense échelle, silencieusement, tranquillement et continuellement... Gloire à Dieu!

C'est M. Ehrenberg qui a découvert les yeux des Astéries. Ils sont placés à l'extrémité inférieure, au bout de chaque bras. (L'œil dans la main, co̊mme Figaro!) Ce sont des globules d'un rouge vif, entourés d'un rempart de cils épineux. Pour s'en servir, l'animal est obligé de les ramener en dessous en relevant son rayon. Du reste, ces 
organes doivent ètre bien imparfaits, puisque, malgré les recherches les plus minutieuses, on n'a pu y trouver un cristallin (Valentin). Cependant Edward Forbes raconte avec beaucoup d'esprit l'histoire d'une Étoile de mer de la Méditerranée, la Luidie ciliaire ${ }^{1}$, qui, après lui avoir échappé, en sacrifiant ses bras, ouvrait et fermait sa paupière épineuse, et le regardait avec un air moqueur!

\section{III}

Le frai des Étoiles de mer passe pour un poison violent.

Leurs œufs sont en nombre très-considérable. La mère les porte dans une cavité formée par la courbure du corps et des rayons. Ils sont logés de manière que l'animal est obligé de fermer sa cavité digestive et de se passer de nourriture pendant tout le temps de sa gestation. On a vu une Astérie rester ainsi onze jours sans aliments. Les femelles de presque tous les animaux mangent double, quand elles sont dans une situation intéressante!

Les œufs sont jaunâtres on rougeâtres; ils produisent des petits ovoïdes et sans rayons, mais pourvus de cils vibratiles qui leur donnent l'aspect des Infusoires. Ils nagent avec vivacité.

Au bout de quelques jours, des appendices bourgeonnent sur la partie antérieure du corps, et forment comme quatre petits bras, à l'aide desquels la larve se fixe sur sa mère. Ce ne sont encore que des membres provisoires. Le corps s'aplatit ensuite graduellement, et se transforme en un disque d'abord arrondi, sur une des faces duquel, vers le milieu, surgissent, sous forme de protubérances globulaires,

1 Luidia ciliaris Dujardin. 
les rudiments des suçoirs. Il y en a dix rangées concentriques. Enfin, le corps devient pentagonal et plus on moins semblable à une étoile. Les rayons sortent des angles, et l'animal est complet.

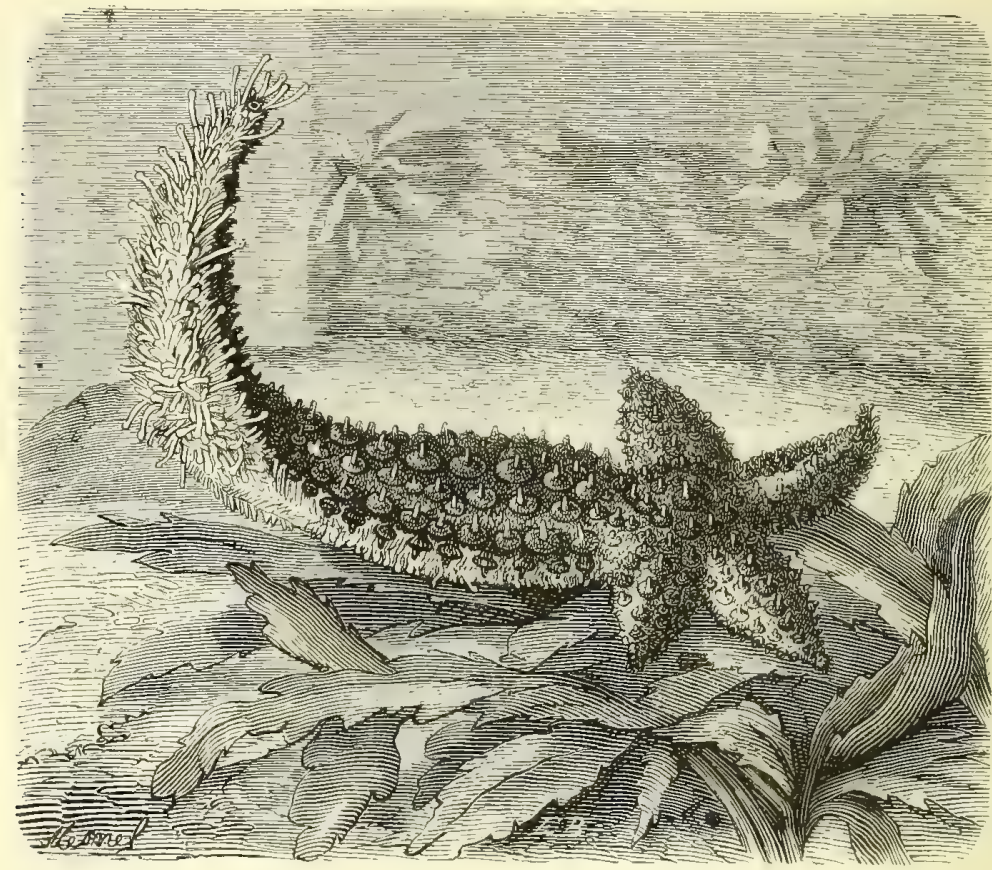

ASTÉRIE EN PLEINE REPRODUCTION DE SES RAYONS

Dessinée d'après le vivant (Concarneau).

Les Étoiles de mer jouissent à un haut degré du phénomène vital de la rédintégration; elles reproduisent avec une facilité étonnante des parties qui leur ont été enlevées. Les individus qui perdent par accident un ou plusieurs bras, les remplacent plus tard par des bras exactement semblables. Ces nouveaux membres en voie de développement sont d'abord très-petits, d'où il résulte nécessairement une aberration dans la figure étoilée de l'Astérie. 
Il existe une espèce de l'océan Indien ${ }^{4}$, qui offre souvent quatre bras, sur cinq, nouvellement reproduits, et par conséquent phus petits que le cinquième. L'étoile a pris l'aspect d'une comète.

Sir John Dalyell recueillit, le 10 juin, un rayon isolé d'une Astérie. Ce rayon ne donnait aucun signe de reproduction. Mais, le 15, parurent les rudiments de quatre nonveaux rayons, indiqués par de petites proéminences. Vers le soir, un de ces rudiments avait grossi du double; les autres se trouvaient moins avancés. Un orifice, e'est-à-dire une bouche, commençait à se former au centre du nouveau groupe. Le travail reproducteur fut alors en pleine activité, et, trois jours plus tard, l'animal possédait cinq rayons, dont quatre lilliputiens, comparés au rayon primitif. An bout d'un mois, ce dernier tomba par morceaux, laissant l'Étoile nouvelle composée de quatre petites branches symétriques. Le vieux rayon était remplacé par un jeune animal complet. (Rymer Jones.)

\section{IV}

Les Astéries sont tourmentées par des parasites. Il n'est peut-être pas d'animal, marin on non marin, qui ne serve de retraite et de nourriture à un autre animal ou à plusieurs autres animaux. Vivre anx dépens d'autrui, est une des grandes lois de la physiologie. Généralement, les parasites appartiennent à un groupe moins élevé en organisation que la victime qu'ils exploitent. Le contraire arrive rarement. En voici un exemple : e'est un petit Poisson qui passe sa vie dans la cavité intestinale d'une Astérie.

\footnotetext{
1 Ophidiaster miliaris Müller et Troschel.
} 
Ce petit poisson s'appelle Oxybale de Brandes'; l'Astérie se nomme Culcite discoïde? ${ }^{2}$ Un Vertébré vivant dans un Invertébré ${ }^{3}$ !

Certaines Etoiles de mer ont un corps en forme de petit disque plus ou moins rond, d'où partent des rayons soutenus par une série d'osselets : ce sont les Ophiures, ainsi appelées à cause de la ressemblance grossière qui existe entre leurs bras et la queue d'un Serpent. Ces bras sont allongés, grêles, flexibles, onduleux, quelquefois garnis sur les côtés d'épines ou de soies.

Chez plusieurs espèces, dites Astrophytes, ils se bifurquent vers leur origine, puis se subdivisent en deux ou trois rameaux qui émettent des ramuscules phus ou moins nombreux, très-fins et très-contournés. Dans un individu, on a compté 81920 ramifications.

Les rayons élégants des Ophiures s'agitent et se tordent suivant les besoins; ils saisissent les proies qui sont à leur portée, et les dirigent vers la bouche, placée toujours audessous et au centre de l'Étoile.

Chez les Astrophytes, l'ensemble des bras forme comme un filet pour prendre les victimes, et même comme un panier pour les tenir en réserve.

La cavité viscérale est absolument limitée au centre de la bète, et ne se prolonge pas dans les bras, comme chez les Astéries.

1 Oxybates Brandesii Bleker.

2 Culcita discoidea Agassiz.

3 Un autre petit Poisson, le Fierasfer Fontanesii de Risso, habite en parasite dans le gros intestin de l'Holothurie royale de Curier. 
Quand on met une Ophiure dans une eau malpropre, ses rayons tombent les uns après les autres, morceau par morceau, jusqu'à ce qu'il ne reste plus que le disque. Figurez-vous une roue réduite à son moyeu. Cependant l'animal vit encore et mange toujours avec avidité. (Rymer' Jones.)

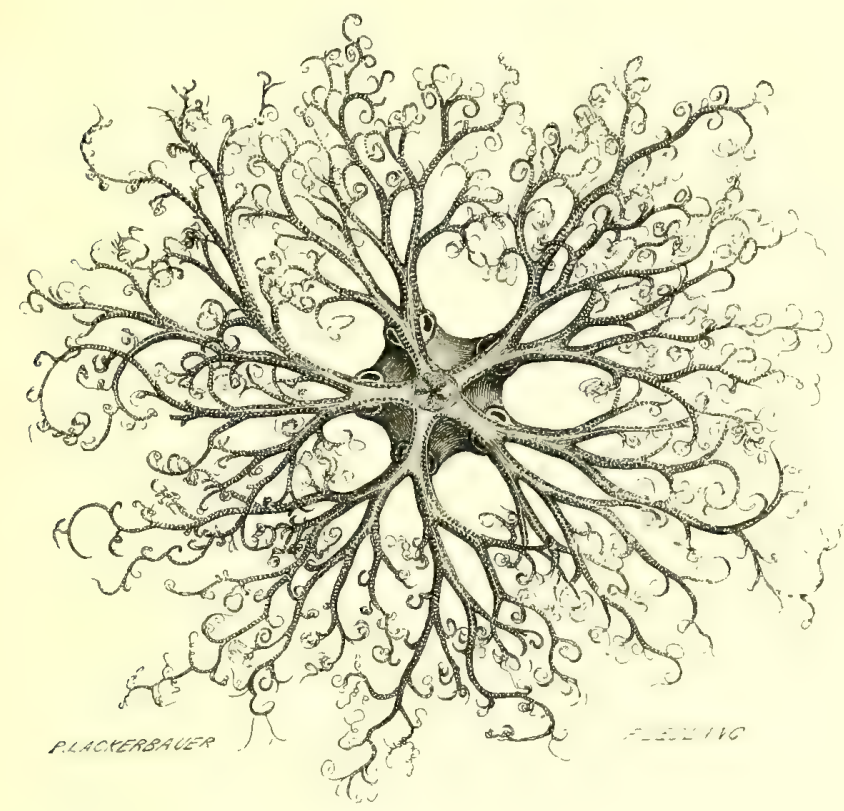

ASTROPHYTE VERRLQIETX

(Astrophyton verrucosum Niiller el Troseled).

Vers le commencement d'avril, les bords du disque se gonflent; l'espace intermédiaire entre les rayons est envahi par le frai. Les œufs sont ovoïdes et d'un rouge brillant.

Vers les mois d'août et de septembre, paraissent les petits. Au moment de leur naissance, ils sont presque microscopiques, transparents et légèrement verdâtres; ils présentent une forme très-bizarre. On les a comparés an chevalet d'un peintre. La partie supérieure du corps semble 
conoïde; la partie inférieure est divisée en huit prolongements de diverses dimensions, disposés en deux groupes divergents. Ces prolongements offrent des cils, et sont

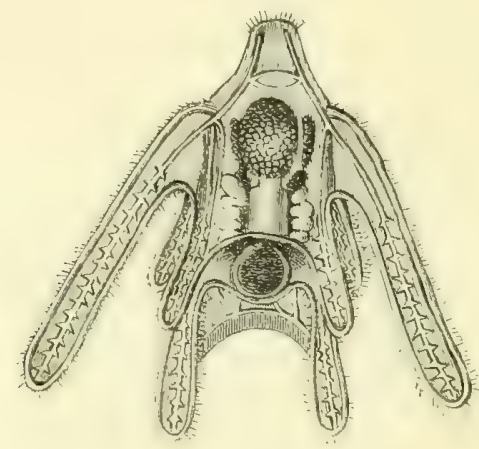

LARYE GROSSIE D'ÉCHIYODERME

(Pluteus paradoxus J. Niiller).

légèrement orangés vers leur extrémité. Chacun est soutenu par un petit support calcaire intérieur. Ces larves singulières ont été décrites sous le nom de Pluteus paradoxus.

\section{I}

En terminant ce chapitre, nous devons dire un mot de la Téle de Méduse ${ }^{1}$ l'une des productions les plus extraordinaires de la mer.

Cet animal est très-rare. Il a été pêché plusieurs fois, à de grandes profondeurs, dans la mer des Antilles. On l'a désigné d'abord sous le nom de Palmier marin.

Son corps est pédiculé et revêtu d'un test calcaire (calice) semblable à une fleur. Cette enveloppe a des plaques polygonales et des rayons élégauts.

1 Pentacrinus caput Medusce Müller. 
La Tête de Méduse est une Astérie adhérente (nous allions dire une étoile fixe!), et par conséquent imparfaite.

Elle n'a pas de bouche, et son appareil digestif parait

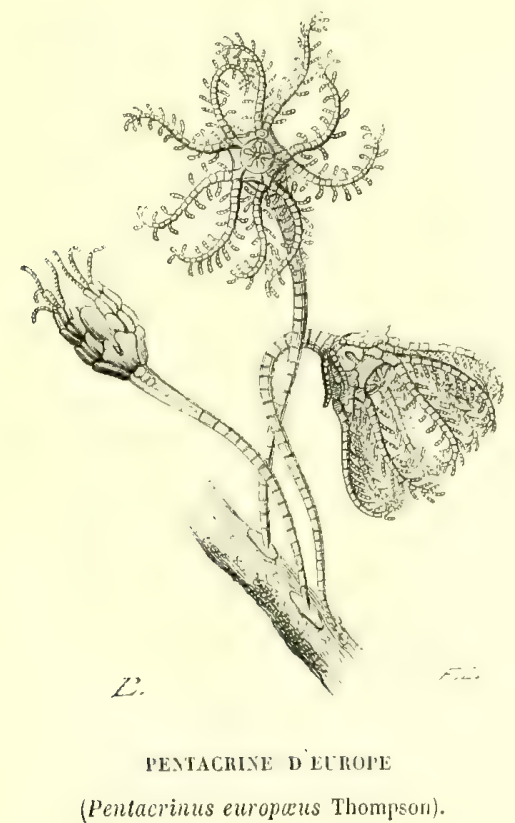

très-rudimentaire. Son pédicule est grêle, anguleux et articulé; il permet à'l'animal de se balancer dans tous les sens, et semble jouir d'une sorte de sensibilité.

Entre les animaux qui ne changent pas de place et les animaux qui se meuvent, il faut mettre, comme intermédiaires, les animaux fixés qui se balancent. Toujours des transitions!

En 1823, M. Thompson a découvert une seconde espèce de Tête de Méduse, dans les mers d'Europe.

La Pentacrine d'Europe est très-petite. Ses rayons sont profondément divisés en deux parties; l'animal semble en 
avoir dix. Ils sont ornés de cils tentaculaires disposés arec régularité. Le pédicule de cette espèce est grêle comme un fil.

Que dorganisations encore inconnues renfermées dans les profondeurs de l'océan!

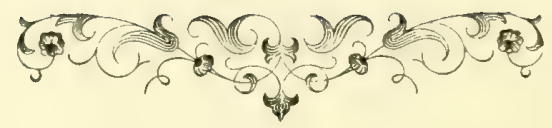




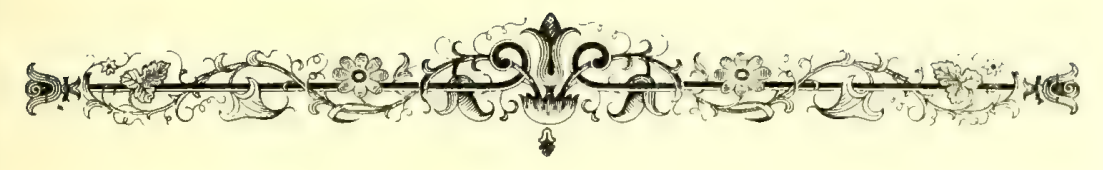

\section{CHAPITRE XV}

\section{LES OURSINS.}

Atra magis pisces et Eurinos aquora celent.

(HORACE.)

\section{I}

Les Astéries ressemblent à des étoiles, les Oursms ressemblent à des melons. Tous appartiemnent pourtant à la mème classe : ce sont des Échinodermes.

Les Oursins sont vètus d'une tunique calcaire souvent globuleuse ou ovoïde, quelquefois déprimée, composée de plaques (assules) hexagonales ou polygonales soudées intimement entre elles, formant vingt rangées symétriques distribuées par paires. Les rangées les plus larges portent des piquants mobiles (baguettes), qui sont à la fois des organes de protection et des organes de mouvement; les autres sont percées de pores en séries longitudinales régulières comme les allées d'un jardin (ambulacres), lesquels domnent issue à des filaments (tenlacules) dont l'animal se sert pour respirer et pour marcher.

Dans l'Oursin comestible', la coquille est composée d'au moins 10000 pièces distinctes, admirablement assemblées

I Spherechinus esculentus Desor. 
et si solidement unies, que l'ensemble parait former un seul corps.

Les piquants sont souvent très-nombreux; ils recouvrent et protégent l'enveloppe. De là le nom de Hérissons de mer qu'on a souvent donné à ces animaux. Les mots Oursin, Echinus, Echinoderme, indiquent aussi cette armure

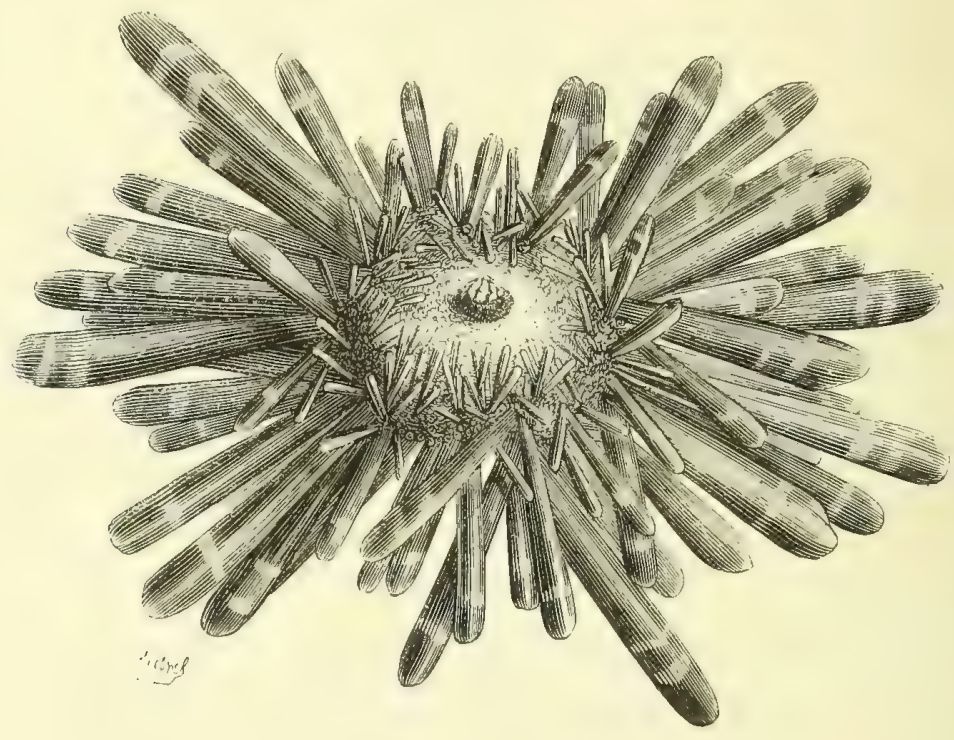

UURSIN MAHELONE

(Echinus mamillatus Lamarck).

épineuse. Dans une espèce, on a compté jusqu'à 2000 piquants; dans l'Oursin comestible, il y en a au moins 3000. Ces appendices cachent tout à fait la tunicue calcaire qui les porte, comme les perles nombreuses qui couvraient lo fameux halit du due de Saint-Simon. L'étoffe était de soie, mais on ne la voyait pas!

Les piquants des Oursins offrent à la base une petite tête lisse, séparée par un étranglement. La face inférieure de cette tête est creusée d'une facette concave qui s'articule 
avec un tubercule de la coque. Chaque piquant est mis en mouvement par un appareil spécial.

Ces épines présentent une structure poreuse. Elles sont souvent sillonnées longitudinalement ou formées de lamelles rayonnantes partant de leur axe, toutes criblées de trous et réunies entre elles par des prolongements transverses; de telle sorte qu'on ne voit à l'extérieur que les bords de ces lames revêtus d'une membrane garnie de cils vibratiles.

Les dimensions et les formes des piquants sont extrêmement variables. Des Oursins ont des épines trois ou quatre fois plus longues que le diamètre de leur enveloppe testacée; tandis que d'autres en ont de trois ou quatre fois plus courtes. Dans quelques-uns, ces organes sont réduits à de petites soies couchées sur la coque protectrice.

Les appendices dont il s'agit paraissent ordinairement subulés et pointus, ou cylindriques et obtus. Certaines espèces en offrent d'aplatis, même de tranchants sur les bords.

Dans les Oursins fossiles, on trouve des piquants tantôt creusés en entonnoir, tantôt dilatés en olive. On donnait autrefois à ces derniers, très-communs dans le terrain jurassique, le nom de pierres judaïques.

Chez une espèce ${ }^{1}$ qui vit à la Nouvelle-Hollande, M. Hupé a trouvé un Mollusque gastéropode du genre Stylifer, enfermé dans un de ses piquants, creusé et profondément modifié, quant à sa forme et quant à sa structure, par la présence de ce petit parasite!

De tous les tableaux que nous offre la Nature, il en est peu qui aient plus de charmes que ceux dans lesquels nous voyons les créatures se donner les unes aux autres abri,

1 Leiocidaris imperialis Desor. 
nourriture et protection.... volontairement ou involontairement. L'instinct du Stylifer n'est-il pas merveilleux? La Nature protége un animal en hérissant son corps d'une armure de poignards. Arrive un autre animal qui se met en sureté dans un de ces poignards!

Quand les piquants sont tombés, les Oursins de nos còtes

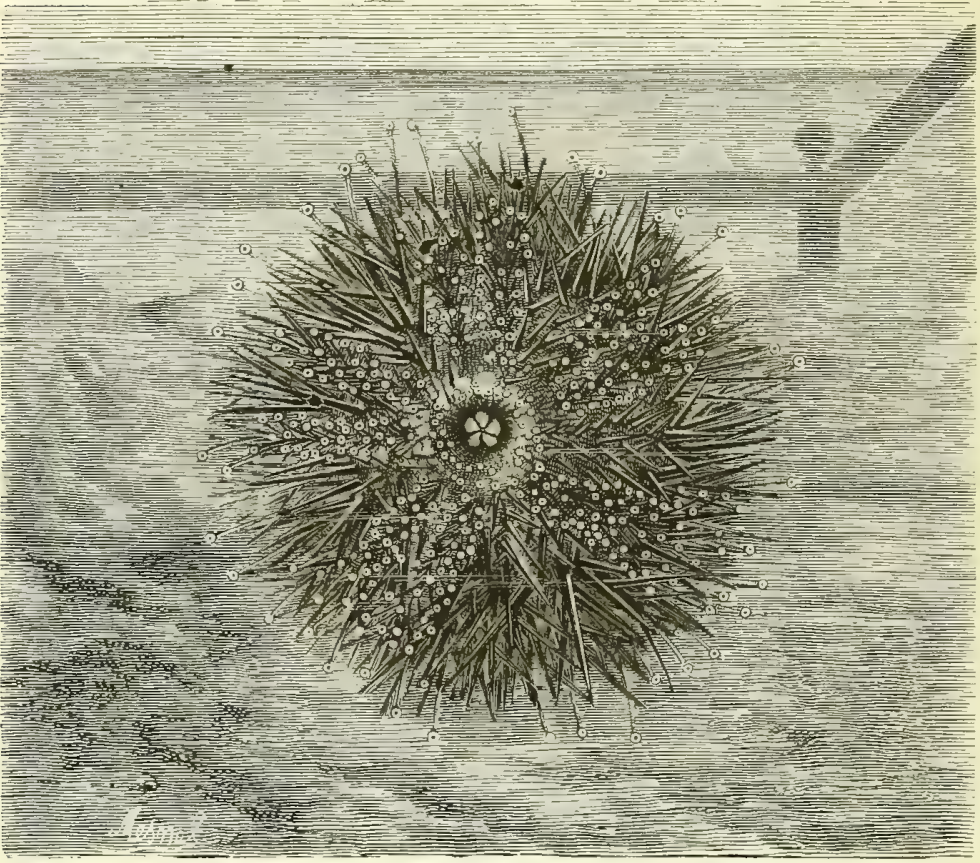

OERSIN GRMTAYT COYTRE LA PAROI D'UN AQUARIUM.

(Dessiné d'après le viıant, à Concarneau.)

prennent la pliysionomie de petits fruits globuleux ornés de còtes et de tubercules symétriquement distribués. Leur forme arrondie, et plus encore leur substance calcaire, leur ont fait domner, dans certaines localités, le nom d'oufs de mer.

Les espèces déprimées ou tout a fait aplaties ressemblent beaucoup plus à des galettes qu'à des œufs. 
Les filaments tentaculaires des Oursins sont tubuleux, très-extensibles et terminés par une petite ampoule. Ils peuvent se gonfler et se roidir; ils dépassent alor's la longueur des piquants, et vont se fixer aux corps étrangers.

Ces organes sont très-nombreux daus l'Oursin ordinaire, il y en a au moins 1400 , et dans l'Oursin melon environ 4300. (Caillaud.)

Les Oursins se meuvent avee leurs filaments et leurs épines. Edward Forbes en a vu grimper sur les parois verticales d'un vase très-lisse.

Pour comprendre la manière dont ces animaux se servent de leurs organes, supposons un individu au repos. Tous ses piquants sont immobiles et tous ses filaments retirés dans la coque. Quelques-uns de ces derniers commencent à sortir, ils s'allongent et tatent le terrain tout autour; d'autres les suivent. L'animal les fixe solidement. S'il veut changer de place, les filaments antérieurs se contractent, pendant que ceux de derrière làchent prise, et la coquille est portée en avant. L'Oursin marche ainsi avec aisance, et même avec rapidité. Pendant sa progression, les suçoirs ne sont que très-faiblement aidés par les piquants; ceux-ci ne servent que de points d'appui sur lesquels roule l'animal.

Les Oursins peuvent voyager sur le dos comme sur le ventre. Quelle que soit leur posture, il y a toujours un certain nombre de piquants qui les portent et de sucoirs qui les fixent. Dans certaines circonstances, l'animal marche en tournant sur lui-mème, comme une roue en mouvement. 


\section{II}

La bouche des Oursins est situéc alu-dessous du corps, ordinairement vers le milieu.

Autour de cet orifice existent des tentacules charnus, palmés, peu ou point rétractiles. Ce sont les organes de la préhension alimentaire.

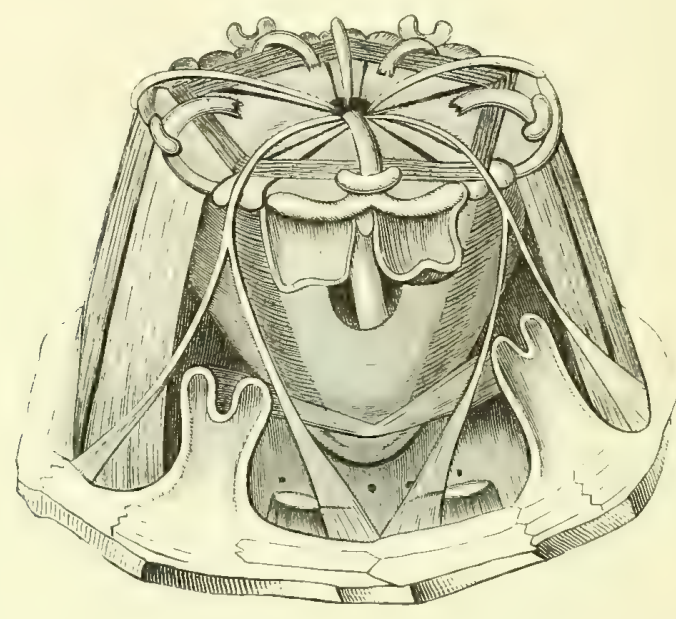

APPAREUL BUCCAL GROSSI D'UN OURST

(Lanterne d'Aristote).

Le système digestif présente un appareil ossenx trèscompliqué, de forme bizarre, connu depuis longtemps sous le nom de lanterne d'Aristote. Cet appareil se compose de einq sortes de parties : les dents, les plumules, les pyramides, les faux, les compas. Les dents sont au nombre de cinq; elles ont une base prolongée et dilatée qui constitue la plumule; elles sont contenues dans une gouttière résultant de l'assemblage des pyramides. Celles-ci, au nombre de dix, sont réunies par deux; leur partie 
inférieure est consolidée par les cinq fanx et par les cinq compas. Ce qui fait que, en résumé, l’appareil dentaire présente trente pièces ${ }^{1}$. Il faut beaucoup de bonne volonté pour lui trouver le moindre rapport avec une lanterne!

Les dents sont longues, aiguës, arquées et très-dures. Leur tranchant est parfaitement organisé pour couper les substances les plus résistantes. Cependant, malgré sa dureté pierreuse, il serait bien vite limé par le travail; mais la Nature y a sagement pourvu. Les dents croissent par la base, à mesure qu'elles s'usent par la pointe, comme les incisives des Lièvres et des Souris; de telle sorte qu'elles se maintiennent toujours aiguisées et toujours en bon état.

Les Oursins mangent des Varees, des Vers, des Mollusques et mème des Poissons.

M. Rymer Jones a vu un individu s'empares d'un Crabe vivant, lequel parut comme paralysé et ne tenta aucume résistance.

Un autre Oursin enlaça une Galatée striée ${ }^{2}$ arec ses appendices buccaux; mais rette dernière, heureusement pour elle, ouvrit une de ses pinces, conpa les appendices, et se délivra de la fatale étreinte.

\section{III}

Plusieurs Oursins, ne se trouvant pas suffisamment protégés et par leur coque calcaire ef par leurs piquants pointus, se taillent une demeure dans les roches les plus dures,

' D'après M. Caillaud, il existe quarante pièces dans l'appareil de l'Oursin livide, réduites à vingt par soudure.

2 Galatea strigosa Latreille. 
dans le grès et le granit : cette demeure semble faite avec un emporte-pièce. L'animal s'y loge et s'y retranche merveilleusement. Il en défend l'entrée avec une partie de ses épines.

Des observations très-suivies et très-intéressantes ont été publiées par MI. Caillaud, Robert et Lory, sur la propriété perforante des Oursins. Les jeunes individus, alors qu'ils sont à peine gros comme des pois, creusent des trous en rapport avec leur taille. Ils se fixent d'abord au corps solide à l'aide de leurs filaments tentaculaires, entament

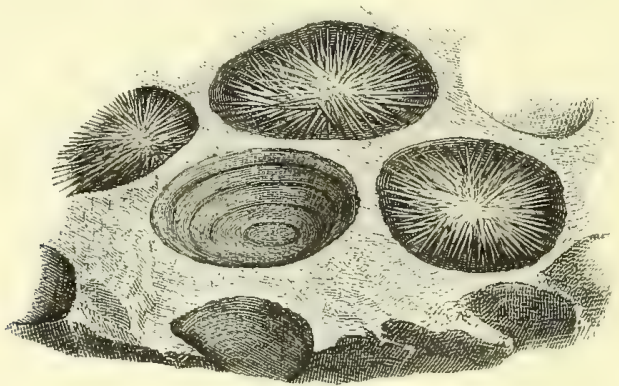

(1) HSISS DAVS LE ROC.,

ce corps avec leurs fortes dents et le rongent peu à peu. Ils enlèvent au fur et à mesure, avec leurs épines, les détritus qu'ils ont ainsi détachés.

Pauvres petits piqueurs de pierres! passer une partie de leur vie à travailler le granit avec les dents!

Lorsqu'un Oursin s'est aventuré un peu trop vers le rivage, et que la marée l'abandonne sur la côte, il s'enterre dans le sable, qu'il creuse avec ses appendices épineux. Sa cachette est reconnaissable au trou en entomnoir qui reste béant au-dessus. Les pêcheurs prétendent prévoir les oragres d'après la profondeur plus ou moins grande où se tient le Hérisson de mer (Rymer Jones). 


\section{IV}

Linné n'a mentionné que dix-sept espèces d'Oursins. Gmelin en a signalé cent sept. Aujourd'hui, on en connaît plusieurs centaines, et ce petit groupe d'animaux (Echinus) est devenu le type d'une classe tout entière (Échinodermes).

Dans beaucoup de pays, on mange les Oursins crus. Les ovaires de la plupart des espèces sont d'un rouge orangé et d'un goût agréable.

On estime en Provence le comestible, le granuleux ${ }^{1}$ et le livide ${ }^{2}$. Cette dernière espèce est recherchée à Naples et sur les côtes de la Manche. On sert sur les tables, en Corse et en Algérie, l'Oursin melon ${ }^{3}$.

\footnotetext{
1 Toxopneustes granularis Agassiz.

2 Toxopneustes lividus Agassiz.

3 Echinus melo Lamarck.
}

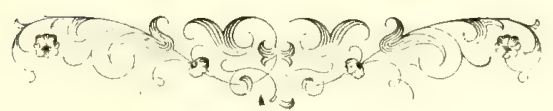





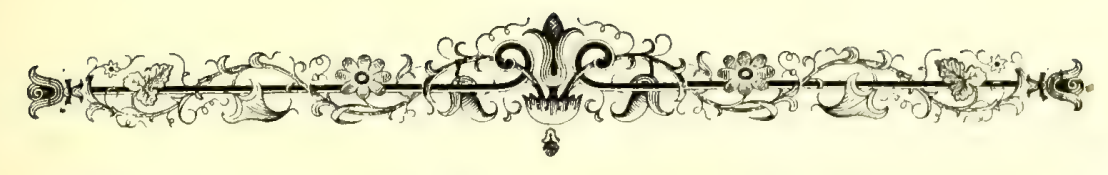

\section{CHAPITRE XVI}

\section{LES HOLOTHURIES.}

Pourquoi des animaux faits comme des corni-

chons? - Et pourquoi des comichons?

\section{I}

Les savants comprennent dans la même famille que les Oursins de modestes animaux appelés Holothuries, ou plus vulgairement, Cornichons de mer.

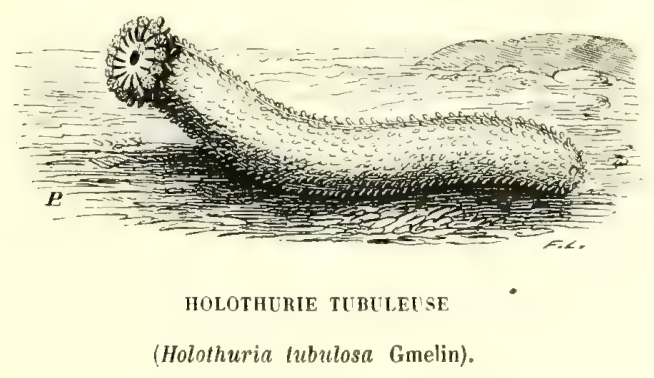

Ces animaux sont allongés, tantòt cylindriques, tantôt pentagonaux, droits ou arqués, quelquefois sans forme déterminée. Plusieurs ressemblent à de gros Vers disgracieux....

Leur longueur varie de quelques centimètres à un mètre. Les plus petits sont les moins rares. 
Les Cornichous de mer ont une peau coriace, opaque ou transparente, souvent raboteuse ou granuleuse, farcie (c'est bien le mot) de parties calcaires. A travers cette enveloppe, sortent habituellement des filaments (pieds tentaculaires), creux, extensibles, épars ou symétriques, terminés, comme les pieds des Oursins, par une ventouse en niniature.

La bouche est placée à l'un des bouts du cylindre. On voit autour des appendices lobés, pinnés ou ramifiés. Cette

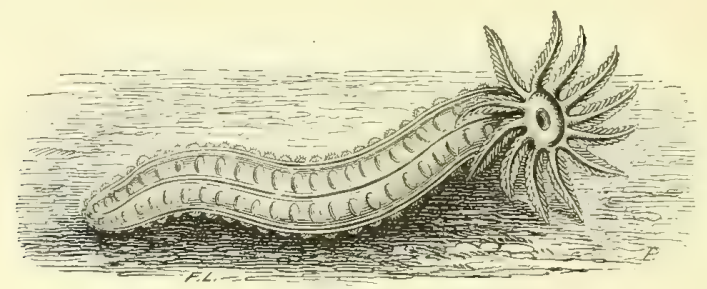

HOLOTHURIE ÉLÉGANTE

(Holothuria elegans $0 . \mathrm{F}$. Mü̈ller).

bouche offre en dedans un anneau osseux, de dix à douze pièces calcaires. C'est un rudiment de la lanterne d'Aristole. A l'extrémité postérieure, se trouve un autre orifice par où jaillit de temps en temps un courant d'eau semblable à une petite fontaine.

Les Holothuries habitent généralement à de grandes profondeurs. Leurs mouvements sont assez bornés. Elles exécutent une sorte de reptation au moyen des ondulations plus ou moins fortes de leur corps, ou bien à l'aide des contractions plus ou moins nombreuses de leurs pieds.

Toujours baisent la terre et rampent tristement.....

Leurs pieds sont tantôt vers le milieu du ventre, dans un endroit qui forme comme un disque (sur lequel rampe l'animal à la manière des Limaces); tantôt disposés en 
séries nombreuses tout le long du corps. Chez l'Holothurie frondeuse ${ }^{4}$, des mers du Nord, ils forment cinq rangées longitudinales.

Certaines espèces sont arméés de petits organes en forme d'hamecons ou d'ancres, qui leur permettent de s'amarrer aux roches sous-marines. Lorsque ces crochets agissent sur la peau des mains, ils peuvent causer une sensation cuisante de brûlure.

Une Ilolothurie de la baie de Matavaï, dans l'île d'Otaïti ${ }^{2}$, décrite par Lesson, longue d'un mètre et très-contractile (au point de se réduire à 33 centimètres), est lubrifiée par un liquide acre et corrosif qui fait naitre un prurit intolérable sur les doigts, lorsqu'on la touche sans précantion. Aussi les naturels de la mer du Sud témoignent-ils la plus grande répugnance à sa vue. (Lesson.)

Beaucoup de Cornichons de mer, quand on les irrite, rejettent volontairement et brusquement leurs viscères, et ne tardent pas à périr. Ce phénomène est bien une des choses les plus étonnantes et les plus inexplicables qui existent dans les mœurs des animaux!

" Il est bon de comprendre clairement, dit le père Malebranche, qu'il est des choses qui sont absolument incompréhensibles. »

Le docteur Johnston raconte qu'il avait oublié une pauvre Holothurie, pendant deux ou trois jours, dans de l'eau non renouvelée. L'infortunée devint triste et malade (on le serait à moins). Bientôt elle vomit tout à la fois ses tentacules, son appareil buccal, son tube digestif et une partie de ses ovaires.... Ces organes tombèrent çà et là au fond du vase. L'effort musculaire avait été sans doute bien

1 Cucumaria frondosa Blainville.

${ }^{2}$ Holothuria (Intestinaria) oceanica Lesson. 
terrible, pour déterminer un pareil effet, et cependant la vie de la malheureuse n'était pas éteinte; car sa pean vide se contractait au moindre attonchement, ot prouvait, par ses contorsions, qu'elle n'avait presque rien perdu de son irritabilité.

Mais ce qui est plus extraordinaire encore que ce vomissement et cette contraction, c'est que l'animal, privé de ses anciens viscères, en reproduisit de nouveaux au bout de trois ou quatre mois, et recommenca, tout joyeux, son train de vie habituel. (J. Dalyell.)

La division spontance de certaines llolothuries, qui se partagent en deux morceaux, n'est pas moins digne de remarque que le rejet et la restauration de leurs organes. L'individu demeure quelque temps stationnaire; chacune de ses extrémités s'élargit et s'aplatit. En mème temps, sa partie moyenne devient graduellement étroite, et finit par se réduire à un fil très-mince. Ce fil se rompt. On a alors deux demi-Holothuries de grosseur égale ou inégale. Plus tard, chaque portion se complete, et il en résulte deux animaux exactement semblables an premier. (Rymer Jone

\section{II}

Les Chinois mangent les Ilolothuries, ils estiment surtout le Trépang. Cet animal est chez emx l'oljet d'un commerce considérable. Des milliers de jonques malaises sont équipées, tous les ans, pour la pếche de ce Zoophyte, et même des navires anglais et anglo-américains se livrent à la vente de cette denrée.

La récolte du Trépang exige beaucoup de patience et d'adresse. Le pêcheur malais se tient penché sur le bord 
de son embarcation, ayant dans les mains une longue perche formée de plusieurs bambous attachés bout à bout, et terminée par un crochet acéré. Sous le beau ciel de ce pays, son eil exercé apercoit à une profondeur souvent considérable l'Holothurie qui rampe sur les fonds de sable ou de roche. Alors le Malais descend doucement le harpon, et, d'un coup prompt et sûr, il accroche l'animal.

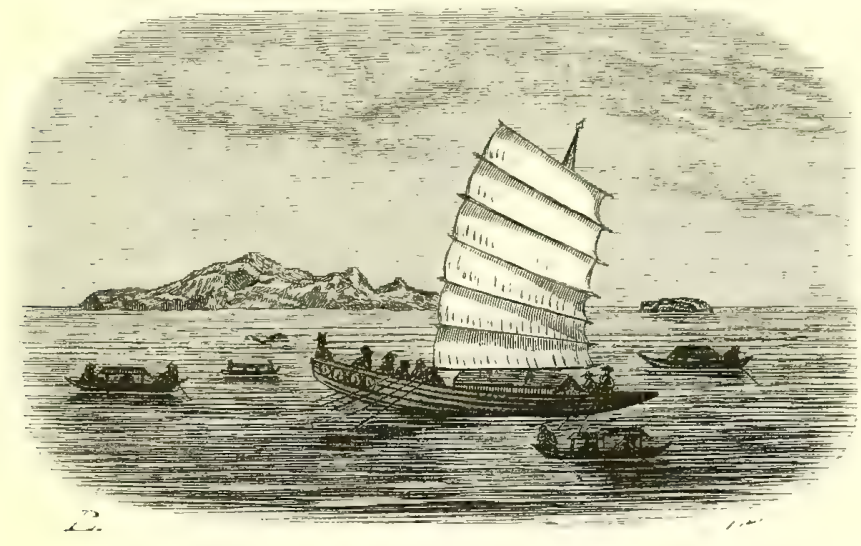

P'LCCIL MALAISE DUT TRLPPAMG

(Trepang edulis Jäger).

On fait ensuite dégorger les Trépangs dans de la chaux de corail, et on les dessèche à la fumée (Lesson). La plus grande partie est expédiée en Chine. La tonne se vend jusqu'à 1800 franes.

Coupés en filaments, on en fait des potages qui rappellent, par leur délicatesse, la soupe à la Tortue.

La pêche a dépouillé les localités où ces animaux étaient autrefois très-abondants. Il serait à désirer qu'elle fùt soumise à une réglementation.

Aux îles Marianmes, on recherche le Guam ${ }^{1}$, et à Naples, la tubuleuse.

1 Mulleria guamensis Jäger. 


\section{III}

Il est des animanx analogues aux Holothuries qui méritent notre attention : ce sont les Synaptes.

Ces animaux sont dépourvus de pieds tentaculaires; leur

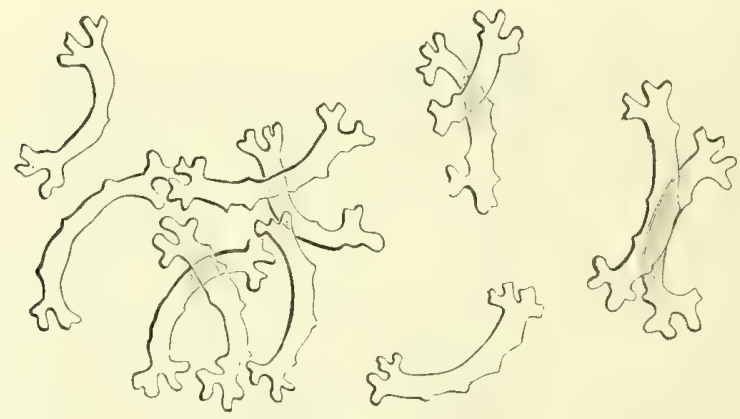

SPICULES DES TENTACULES DE SYYAPTE,

peau est transparente et laisse voir leur intérieur. Le microscope montre dans leur tissu des spicules nombreux qui occupent une disposition particulière dans les tentacules.

Les Synaptes vivent dans le sable tourbeux; elles se nourrissent des matières organiques qu'elles y rencontrent.

L'une des espèces les plus curieuses est la Synapte de Duvernoy ${ }^{1}$, découverte aux îles de Chausey par M. de Quatrefages.

Figurez-vous un cylindre de cristal, d'un rose tendre un peu lilas, ayant quelquefois jusqu'à cinquante centimètres de longueur, parcourn dans toute son étendne par cinq petites bandelettes de soie blanche opaque, et surmonté d'une fleur vivante à douze pétales étroits et pinnatifides, d'un blane mat, garnis de petites ventouses qui se recour-

1 Synapta Duverncea Quatrefages (voy. planche XIV). 


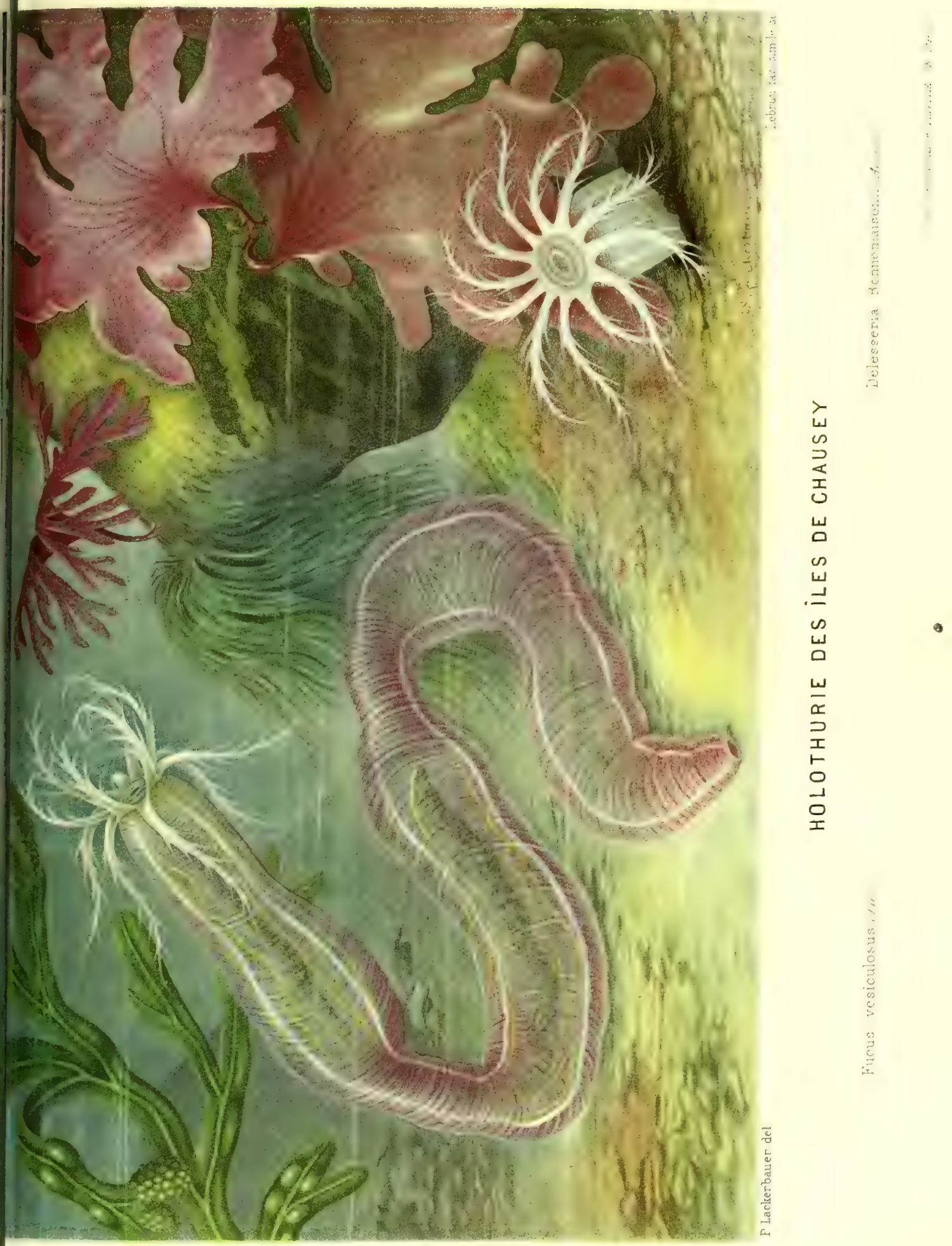



bent gracieusement en arrière. Au milieu de ces tissus dont la délicatesse semble défier les produits les plus raffinés de notre industrie, placez un intestin de la gaze la plus ténue, gorgé d'un bout à l'autre de corpuscules de granit dont l'œil distingue parfaitement les pointes vives et les arètes tranchantes. Les parois du corps ont à peine un demi-millimètre d'épaisseur, et cependant on peut y compter sept couches plus ou moins distinctes, une peau, des muscles, des membranes.... L'animal est protégé par une espèce de mosaïque composée de petits boucliers calcaires, hérissés de doubles hameçons dont les pointes sont dentelées comme des flèches de Caraïbe. (Quatrefages.)

Lorsque l'on conserve pendant quelque temps les Synaptes vivantes dans un vase d'eau de mer, on les voit se morceler d'elles-mêmes. Il se forme un étranglement dans une partie du corps, et la séparation s'opère brusquement. On dirait que l'animal, sentant qu'il ne peut se nourrir tout entier, supprime successivement les parties dont l'entretien coûterait trop à l'ensemble, à peu près comme on chasse les bouches inutiles d'une ville assiégée. Singulier moyen de combattre la famine, et qu'il emploie jusqu'au dernier moment! Car, au bout de quelques jours, il ne reste souvent qu'un petit ballon sphérique couronné de tentacules. La Synapte, pour conserver la vie à sa tète, s’est à peu près retranché tout le corps! (Quatrefages.)

Que de merveilles dans la vie et dans les mœurs des animaux de l'Océan!

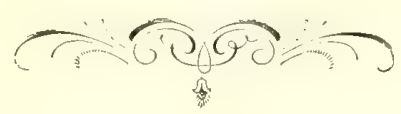





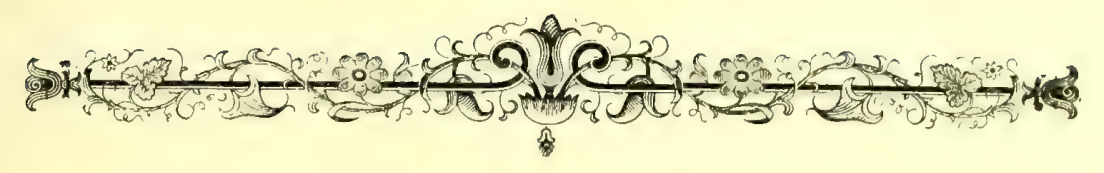

\title{
CHAPITRE XVII
}

\author{
LES BRYOZOAIRES.
}

"Sigillutim mortules, cunctim perpetui. .

(AHCLE.)

Les plantes marines sont quelquefois recouvertes d'une matière abondante, veloutéc, parasite, qui ressemble à un tapis de mousse. Cette matière, étudiće au microseope, paraît comme une agrégation d'animalcules à cellules charnues, cornées ou calcaires, le plus souvent transparentes. Ces animalcules sont des Bryozoaires ou Animaux-mousse.

Chaque cellule loge une bestiole délicate, laquelle, à certains moments, fait sortir de nombreux petits bras; les étale, les agite, les balance, pour guetter, attirer et saisir sa proie. Cette proie doit ètre bien mignonne!

Au moindre danger, au plus léger frôlement, les Bryozoaires se contractent et se retirent dans leur logette d'écaille ou de cristal.

Cette cellule n'est pas inerte conme celle de la plupart des Polypiers; elle jouit de la faculté de se mouvoir, surtout quand elle est bien éclairée. Lorsqu'on l'excite, elle 
s'incline vivement, comme un lameau de Sensitive qu'on touche avec le doigt. Elle tombe sur une de ses voisines; celle-ci se précipite sur une autre, celle-là sur une quatrième, et, au bout d'nne seconde, toute la communauté est mise en mourement. Nais bientòt la tranquillité se rétablit, et les bras, (fui s'étaient repliés et retirés, reparaissent et s'étalent de nouveau. (Rymer Jones.)

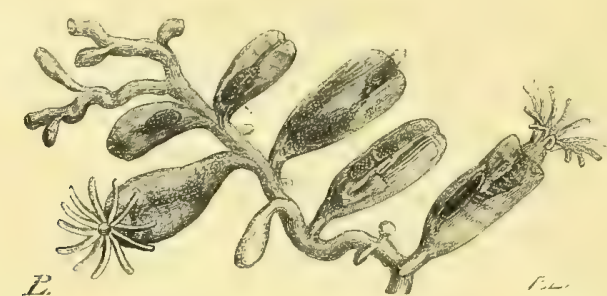

LAGUYCLLE R.IMPAYTE

(Laguncula repens Farrc).

Les Animanx-mousse ont été bien étudiés par MII. Ehrenberg et J. W. Thompson, qui ont fait commaitre les différences qui les éloignent des Polypiers ordinaires.

On les regarde comme des Mollusques dégradés'.

La petite loge de charue animalcule est formée par une sorte de couvercle membraneux, qui se retourne comme le doigt d'un gant toutes les fois que le Hollusque veut sortir. Cette loge est plutôt une boite qu'une maison.

Quand le Bryozoaire se déploie, un cercle de soies microscopiques, d'une ténuité excessive, se montre tout d'abord, s'élevant au-dessus du sommet de la cellule. II est suivi de son support, lequel est plus ou moins flexible. Les tentacules passent ensuite cutre les soies, et les poussent de còté.

1 Voyez les chapitres suivants. 


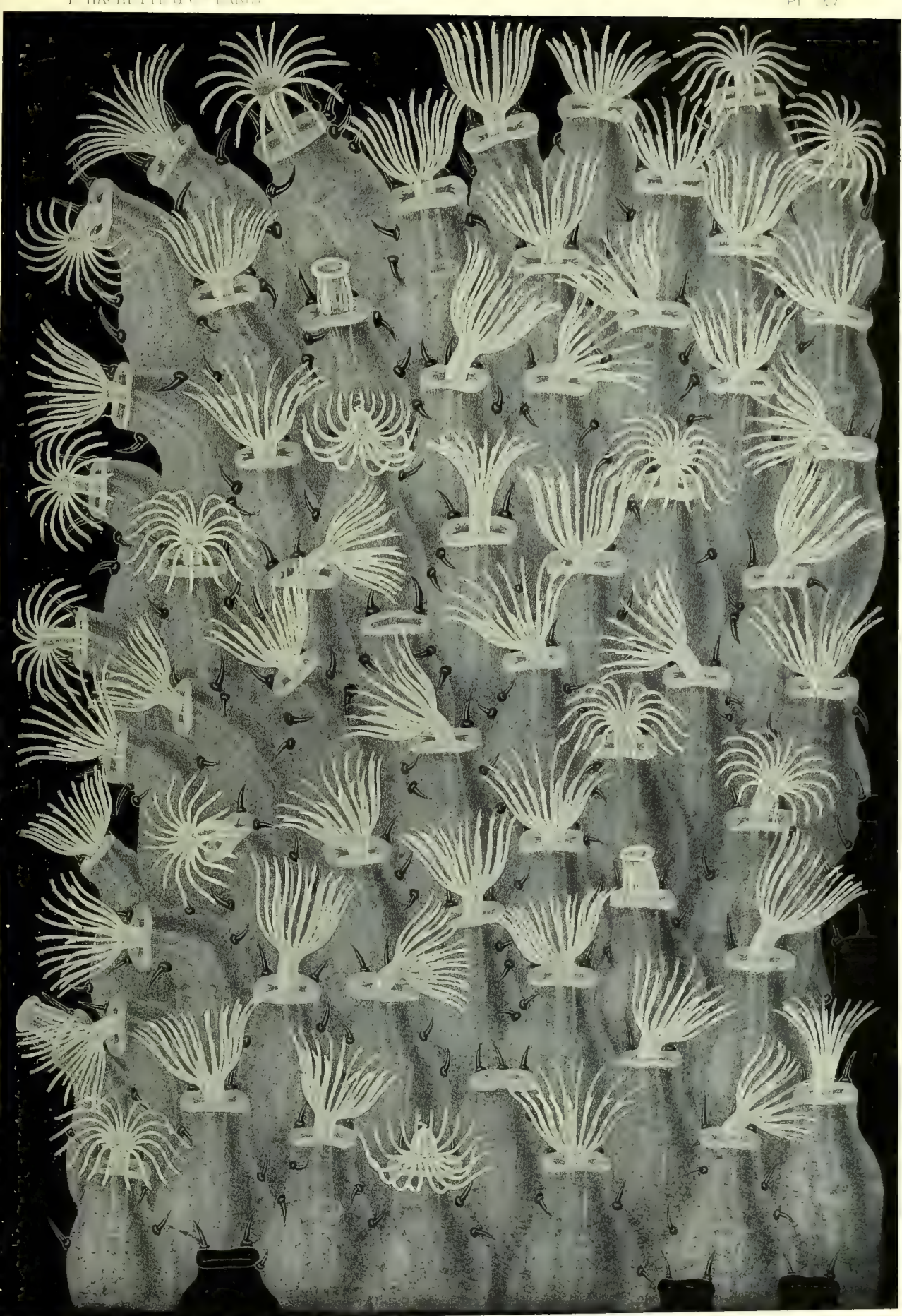

ANIMAUX MOUSSE 

Ces tentacules sont armés, sur le dos, d'une douzainr. d'appendices semblables à des cheveux tris-fius, attachés presque à angle droit. Ils ont de plus, de charque côté, un nombre très-considérable de cils vibratiles.

Les cils vibratiles jouent un rôle très-important chez la plupart des animaux microseopiques. Il n'est peut-être pas d'organes plus répandus et plus simples, chargés de fonctions aussi utiles et aussi variées....

Au moment où les tentacules paraissent à l'extéricur, la tumique de l'animalcule se déroule peu à peu.

Bientôt, le Bryozoaire étale ses jolis petits bras. Les appendices et les cils de ces derniers commencent leurs rapides vibrations. L'œil, trompé par la vivacité et par la régularité des mouvements qu'ils exécutent, croit voir des chapelets de gouttelettes de rosée balancés, tordus, nonés et dénoués!

Les corpuseules qui flottent autour de l'animal sont violemment agités, comme s'ils étaient sous l'influence de quelque toubillon. Nalheur, dans ce moment, aux infortunés Infusoires que le hasard amène dans ce cercle fatal! (Rymer Jones.)

Dans plusieurs espèces, les observateurs ont décourert un organe particulier, le vibracule, sur lequel nous arrèterons quelques moments notre attention. C'est un filament creux, situé à l'angle supérieur et extérieur de chaque cellule, rempli d'une substance comme fibreuse et contractile, qui lui permet d'exécuter des mouvements très-remarquables. Ces mourements ont lieu à des intervalles réguliers, ordinairement très-courts. D'abord, le filament se porte rers le bas, frémit, oscille et semble balayer; puis il revient sur lui-mème, et descend daus la direction opposée, où il répète le même jeu, avec le même ordre et dans le même temps. Ces fonctions sont-elles, comme on l'a dit, 
indépendantes, jusqu'à un certain point, de la volonté du Bryozoaire? Quel est leur but? On pense que cet organe sert à nettoyer et surtout à fortifier l'entrée de la cellule. Il s'agite encore quelque temps après qu'on a mutilé ou tuć le petit animal. La pauvre bestiole malade ou morte est encore défendue par son vibracule protecteur!

\section{II}

D’après ce qui précède, on voit que les animalcules des Bryozoaires sont plus compliqués que ceux des Polypiers. L'étude de leur anatomie confirme pleinement cette conclusion. Ainsi leur appareil digestif n'est pas réduit à un simple sac arec un seul orifice. Il présente une bouche, un pharynx, un resophage, un gésier, un estomac membraneux, et des intestins avec une ouverture spéciale.... On a décrit des espèces dans lesquelles le gésier semble pourvu d'un certain nombre de dents intérieures, formant un merveilleux pavé, mu moulin vivant, destiné à broyer la nourriture avant son entrée dans le second estomac.

L'organisme de la plus petite bête révèle à nos yeux ćtonnés une combinaison savante, 11 art admirable qui dépasse infiniment tout ce que l'industrie humaine pourrait offrir de plus parfait!

\section{III}

Les savants s'accordent aujourd'hui à placer parmi les Bryozoaires un certain nombre de faux Polypiers, dont les animalcules étaient restés pendant longtemps mal étudiés et mal connus : par exemple, les Flustres et les Eschares. 
Les Flustres' ont de petites loges plus ou moins cornées, groupées symétriquement comme les alvéoles des Abeilles. Tantôt elles composent des croùtes qui recouvrent les Algues et les autres corps marins, tantôt elles forment des feuilles minces ou des tiges rubanées. Dans certaines espèces, il n'existe de cellules que d'un seul côté; dans d'autres, il y en a sur les deux. Leurs orifices sont extrêmement petits et défendus par des épines microscopiques.

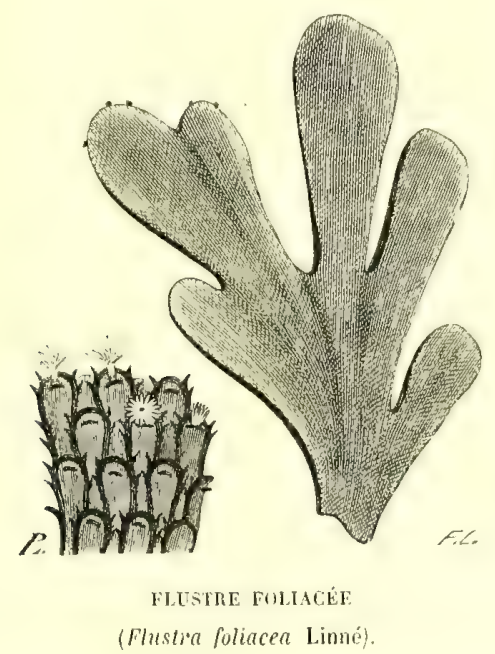

Leurs tentacules sont converts de eils vibratiles (torjours des cils vibratiles!) disposés en séries droites, qui produisent, dans leurs mouvements, l'effet d'une rangée de perles animées qui rouleraient de la base à la pointe de l'organe.

Les Eschares forment des expansions comme foliacées. L'entrée de leurs cellules possède anssi son épine protectrice.

Les expansions représentent encore des ruches microsco-

'Voyez planche XT. 
piques, dont les citoyens jouissent ì la fois d'ume existence commune et d'une existence indépendante. Comme chez les Polypiers, chacum mange pour le compte de l'association et pour son propre compte. Travail et mutrition pour la république; travail et nutrition pour soi!

Très-probablement il règne, entre tous les habitants d'un même groupe, des sentiments de fraternité d'une nature particulière, dont nous n'avons aucune idée. Puisque ce qui est digéré par un membre de la famille Jrofite jusqu'à un certain point à tous les autres, ne doit-il pas y avoir entre tous les divers indiridus, surtout entre les plus rapprochés, un lien physiologinue plus ou moins étroit. lequel entraine peut-ître... un lien moral plus ou moins fort? Et, s'il en était ainsi, les animalcules d'une Flustre ou d'une Eschare ne devraient pas connaître le sentiment de l'égoïsme?....

Que de combinaisons organiques et que de vitalités étranges sous le brillant azur de l'Océan!

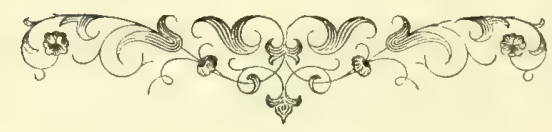




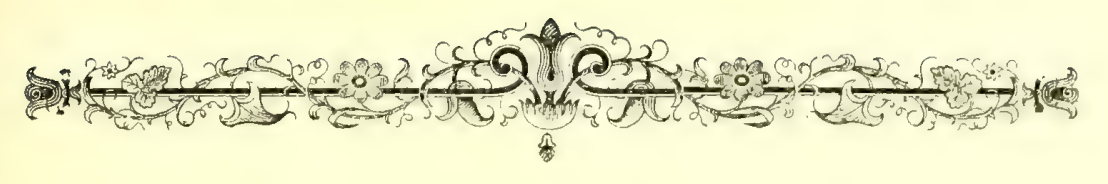

\section{CHAPITRE XVIII}

\section{LES MOLLUSQUES AGRÉGES.}

(Gorneilie, )

Comme leur nom l'indique, les Mollusques sont des animaux essentiellement mous ou mollasses, comme disait Cuvier. Ils offrent pour caractère constant de n'être jamais articulés.

Leur chair est froide, humide, visqueuse, souvent grisâtre. Leur peau présente généralement un repli plus ou moins ample, souple, qui cède et qui résiste, désigné sous le nom de manteau.

Quelques-uns sont nus, c'est-à-dire sans organe solide de défense, du moins apparent, semblables aux Limaces de nos jardins. Ils ont alors, ou une peau épaisse et coriace, un véritable cuir protecteur, ou une enveloppe mince et délicate, dans layuelle s'épanouit au-dessus du cœur et du poumon une lame cornée ou crétacée (Limacelle), plus on moins épaisse et plus ou moins dure, sorte de bou- 
clier rudimentaire destiné à garantir les viscères les plus nobles.

Mais ordinairement ces animaux sont protégés, contre les flots et contre leurs ennemis, par une véritable cuirasse calcaire (coquille), double ou simple, dans laquelle ils s'enferment plus ou moins complétement, quand un danger les menace. On les appelle alors testacés, ou plus vulgairement, coquillages.

Chez les Vertébrés, ce sont les parties molles qui recouvrent la charpente calcaire. Chez les Mollusques, c'est la charpente calcaire qui recouvre les parties molles. L’idéc de considérer le test comme un squelelte extérieur est loin d'être nouvelle. Charles Bonnet disait, il y a longtemps : "On pourrait regarder la coquille comme l'os de l'animal qui l'occupe. "

Pour les gens du monde, la distinction des Mollusques en nus et en testacés est une distinction parfaite. Pour les naturalistes, l'absence ou la présence de la coquille est un caractère à peu près sans valeur. En effet, on troure dans la mer tontes les nuances intermédiaires possibles entre les Mollusques nus et les Mollusques testacés. La nature ne passe jamais brusquement d'une forme ì une autre.

Il existe des Mollusques, de vrais Mollusques, avec me demi-coquille, d'autres avec un quart de coquille, d'antres avec un cinquième, un dixième, un vingtième de coquille....

On a même constaté que beaucoup d'espèces, tout à fait nues, sont couvertes, dans la première période de leur vie, par une coquille parfaitement caractérisée, quelquefois même pourvue d'un couvercle, qui disparait pendant leur accroissement. (Sars.)

Pour quiconque aime à surprendre les secrets de l'orga- 
nisme, l'étude de la formation et du développement de la coquille est une source très-féconde d'instruction.

Les Mollusques sont Agrégés ou solitaires. Nous parlerons d'abord des premiers, dont la constitution est la plus simple, et qui sont les plus rapprochés des Polypiers et des Bryozoaires.

Les Mollusques Agrégés sont agglomérés, comme les grappes de certains fruits, on enchaînés, comme les grains d'un chapelet.

Les Mollusques agglomérés présentent des associations assez curieuses. Les principaux sont peut-être les Ascidies dites sociales, masses de gelée translucide, tantôt d'une

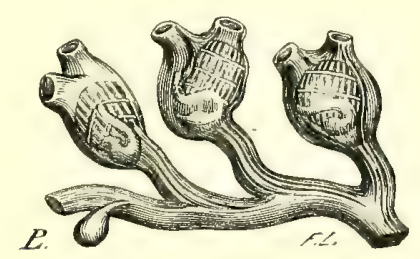

AsCIDIES SOCIAILS

(Perophora Listeri Wiegmann).

teinte uniforme, verte, brune, rouge, violacée, souvent trèspâle; tantòt, au contraire, multicolores et splendidement pointillées, rayées ou panachées.

Les Mollusques agglomérés sont attachés aux rochers, étalés à leur surface, comme des plaques de Lichens, ou suspendus à leurs arêtes, comme des groupes de glaçons. Les Varecs à larges feuilles abandonnés sur le sable après une tempête paraissent presque toujours couverts de ces 
animaux bizarres, protégés par leur manteau glaireux. Ces ensembles figurent quelquefois une pléiade de gracieuses étoiles, un bouquet, wue rosette. Leurs individus élémentaires sont allongés on arrondis, et souvent anguleux on découpés.

Lorsqu' on introduit une de ces masses dans un aquarium, elle a l'air aussi apathique qu'une Éponge, et ne dome d'autre signe de vie apparent qu'un léger resserrement au pourtour des orifices. Mais, en l'examinant de près, on découvre qu'elle n'est pas aussi inanimée qu'on l'avait d'abord supposé, et que, par les mêmes ouvertures, entrent et sortent des courants d'ean extrèmement rapides, faisant parfois l'effet de tourbillons. (Rymer Jones.)

Les larves de ces animaux multiples sont isolées et libres. Alternance continuelle d'esclavage et de liberté!

A une époque de leur vie, ces larves se fixent. Quand l'animal a perdu la faculté de se mouvoir et qu'il a suffisamment grandi, on voit naitre ì la surface de son corps mn certain nombre de petits tubercules qui s'allongent, se creusent et forment autant de nouveaux individus. Ceux-ci restent adhérents au corps de la mère, laquelle devient l' fondateur d'une nouvelle colonie.

Il existe une très-grande diversité dans l'arrangement des membres de chaque association. Mais tous ces arrangements, quels qu'ils soient, présentent toujours un ordre rigoureux et une régularité géométrique.

Les habitants de ces brillantes compagnies sont plus on moins nombreux, suivant les espèces; ils reçoivent en famille les mêmes rayons du soleil, les mêmes caresses de la vague, les mêmes coups de la tempête!... Tous remplissent leurs devoirs particuliers avec exactitude et zile, sans trouble et sans humenr. L'aceord le plus parfait règne 
entre eux, comme entre les animalcules des Polypiers of des Bryozoaires. Admirables communautés, dont les citoyens sont plus intimes et plus unis que beaucoup d'autres! N'est-ce pas là le beau idéal de l'association répulılicaine? E pluribus unum.

\section{III}

Un des genres les plus intéressants, parmi ces animaux, a été désigné sous le nom de Botrylle.

Les individus de charque corporation sont au nombre de

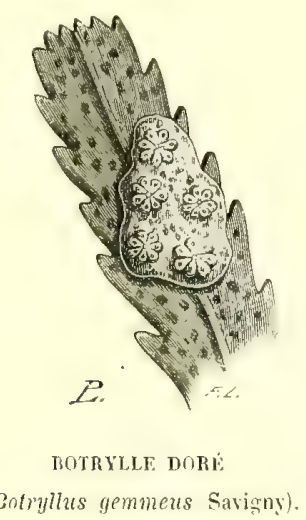

dix, de quinze, de vingt, ovoïdes, oblongs ou piriformes, et disposés comme les rayons symétriques d'une roue.

Quand on irrite une des branches de l'ensemble, un seul Mollusque se contracte. Guand on toumente le centre. ils se contractent tous. (Cuvier.)

Les orifices buccaux se trouvent anx extrémités extérieures des rayons; mais les terminaisons intestinales aboutissent à une cavité commune, qui est au moyeu de la rotie. 
Voilà donc des animaux qui mangent séparément et qui remplissent ensemble une singulière fonction! Ce genre d'union et de communauté nous rappelle ce qui se passait dans Ritta-Christina. Mais, chez nos Mollusques, au lieu de deux individus soudés, nous en avons une quinzaine!

On pent considérer l'étoile entière comme une seule bète à plusieurs bouches! Mais alors il y a, chez elle, luxe d'organes pour la fonction intelligente, qui cherche et qui choisit, et parcimonie pour la fonetion stupide, qui ne cherche pas et qui ne choisit pas!

Chez les Pyrosomes, la colonie n'est plus adhérente. Eille constitue une masse brillamment coloréc, cylindrique, creuse, ouverte à une extrémité, fermée à l'autre. Cette masse flotte et se balance sur les eaux comme la Plume de mer.

L'espèce surnommée allantique ${ }^{4}$ varie singulièrement dans ses nuances. Elle passe avec rapidití du rouge vif à l'aurore, à l'orangé, au verdâtre, au bleu d'azur, d'une manière vraiment udmirable (Lamarck). Elle est, de plus, phosphorescente.

Le nom de Pyrosome signifie littéralement corps de feu. Humboldt a vu une troupe de ces splendides Mollusques côtoyer son vaisseau comme une bande de globes enflammés vivants, projetant des cercles de lumière de cinquante centimètres de diamètre, qui lui faisaient apercevoir à une profondeur de einq mètres, et pendant plusieurs semaines, des Thons et d'autres poissons qui suivaient le navire.

Bibra, dans son voyage au Brésil, prit une fois sept ou huit Pyrosomes atlantiques et les portá dans sa cabine.

1 Pyrosoma atlantica Lamarck. 
A l'aide de leur lumière, il put lire, à l'un de ses amis, liı description qu'il en avait faite sur son carnet ${ }^{1}$.

\section{IV}

Les Salpes ou Biphores offrent un groupement qui ressemble beaucoup moins à celui des Polypiers. Ces animaux

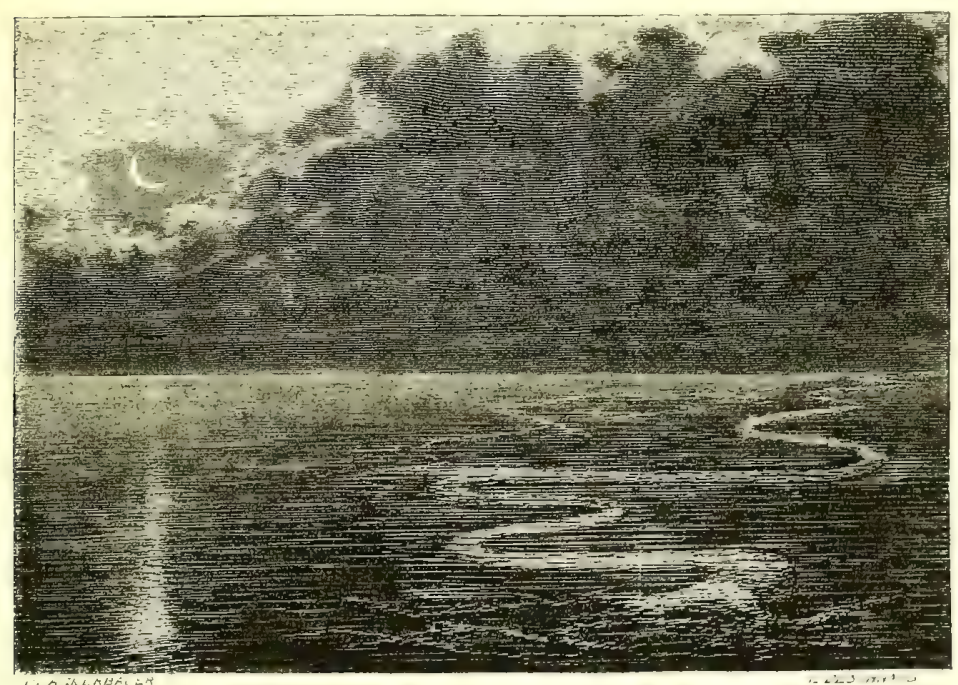

CILAiYes DE SALPES PIIOSPIORESCEYTES ENTRAiNeES PAR LES COLTAYTS.

ne sont plus agglomérés, mais disposés en séries. Ils font le passage des Mollusques que nous venons d'étudier aux Mollusques solitaires.

On trouve les Salpes réunies en longues files transparentes, d'une grande délicatesse de tissu : cordons composés d'individus placés côte à côte et greffés transv ersalement; rubans dans lesquels chaque bestiole est greffée bout à bout avec ses sœurs; doubles chaines parallèles de

1 Voyez le chapitre III. 
créatures sociales, tantôt alternes, tantôt opposées.... Merveilleuse symétric qui ne déroge jamais aux lois qui la régissent! Chapelets vivants dont chaque perle est 1 !n individu!

Ces sociétés voyageuses occupent jusqu'à 30 ou fill milles d'étendue....

Leurs Mollusques élémentaires ont 11 corps oblong, à pen près cylindrique; irrégulier, contractile, souvent irisé, quelquefois phosphorescent, ouvert à chaque extrémité; d'une transparence cristalline, avec une teinte rosée ou rougeâtre à l'intérieur.

Les colonnes de Salpes glissent daus les eaux tranefuilles par des ondulations régulières. Les petites nageuses de chaque file se contractent et se dilatent simultanément. Elles mancuvrent de concert comme me compagnie de soldats bien disciplinés; chaque sćrie ne semble offrir qu'un seul individu qui flotte en serpentant. Les matelots ont donné à la chaîme le nom de Serpent de mer. (Rymer Jones.)

Ces animaux nagent habituellement le dos en bas : ils font la planche. Ils se meuvent surtout en aspirant une certaine quantité d'eau par l'ouverture postérieure (qui est munic d'une valvule) et en la rejetant par l'orifice antérieur. En sorte que leur corps est toujours poussé en arrière, et qu'il chemine à reculons (Cuvier). Bizarre locomotion, qui ne ressemble en rien à celle des autres animaux!

Lorsqu'on retire de l'eau ces chaînes animées, leurs amneaux se séparent, et leurs individus se désagrégent. La compagnie est licenciée. Les Salpes perdent la faculté d'adhérer ensemble; les soldats ne peuvent plus s'aligner.....

On rencontre quelquefois, dans la mer, des Salpes solitaires. On serait tenté de les regarder comme d'un genre 
différent, si de récentes découvertes n'avaicut prouvé que ce sont les mères ou les filles des Salpes enchainées. On a constaté, en effet, que ces petites Salpes solitaires s'unissent ensemble en longs rubans à une époque de leur vic, et que ceux-ci engendrent des Salpes isolées. En un mot, les Salpes enchainées ne produisent pas des Salpes enchañées, mais des Salpes solitaires, et celles-ci, à leur tour, domnent nais-

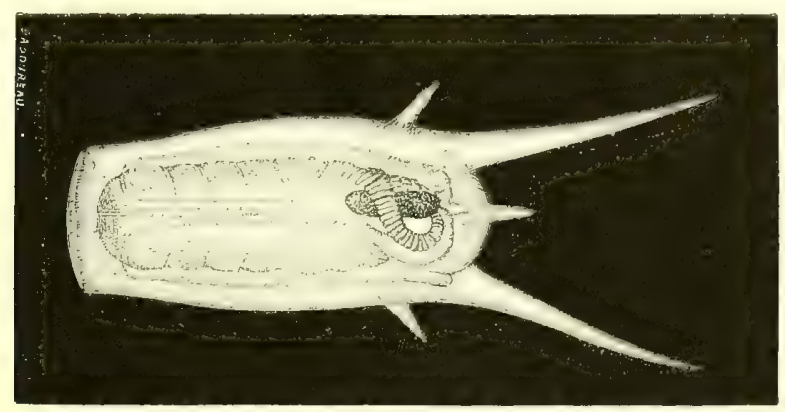

SIIPE SOLITARE

(Sulpa democratica Hor:hill).

sance non à des individus distincts comme elles, mais à des Salpes enchainées. P'ar conséquent, une Salpe n'est pas organisée comme sa mère, ni comme sa fille, mais elle ressemble à sa socur, à sa grand'mère ct à sa petite-fille. (Chamisso, Krohu, Milne Edwards.)

Que de recherches ne faut-il pas, que de patience et que de temps, pour arracher à la nature un admirable secret, que l'on apprend souvent en trois minutes!

Malgré leur organisation si limitée et leurs fonctions si réduites, les Salpes vivent et se reproduisent aussi certainement et aussi heureusement que les autres animaux. Elles s'élancent après leur proic ou l'attendent à l'affrùt. Elles ont des appétits, des instincts, peut-être mème des caprices.... Véritables sybarites, elles passent leur vie à 
manger et à dormir; elles se promènent toujours en compagnie, sans trouble et sans fatigue; elles sont balancées constamment, doucement et mollement.... Ces associations enrégimentées ne révèlent-elles pas tout un monde nouveau de conditions particulières, de phénomènes collectifs et de sentiments confondus?

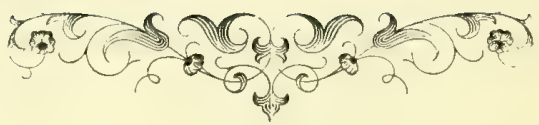




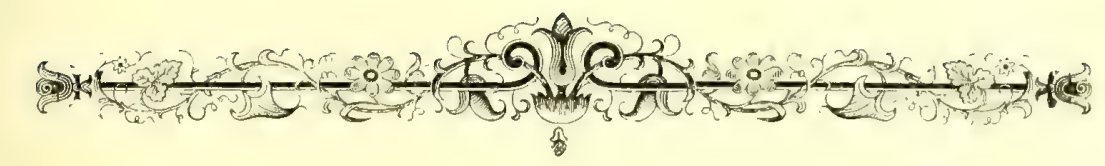

\section{CHAPITRE XIX}

\section{LES IOLLUSQUES ACÉPHALES.}

Les Mollusques solitaires sont les vrais Mollusques. Il en existe un très-grand nombre. On peut les ranger tous sous deux types généraux. Les uns sans tête, e'est-à-dire à strueture plus ou moins simple : on les appelle Acéphales. Les autres pourvus d'une tête, c'est-à-dire à structure plus ou moins compliquée : on les nomme Céphalés.

Occupons-nous d'abord des Acéphales.

Ces Mollusques sont tantòt nus, et tautót cnlermés daus une coquille (testacés).

Les Acéphales nus rampent sur les rochers, sur les Fucus et sur les animax. Il y en a qui flottent en peuplades innombrables à la surface de la mer. Quelques-uns, collés contre les corps solides, ne paraissent avoir aucun mode de progression bien caractérisé.

Parmi ces Mlollusques, mentionnons d'abord les Ascidies 
solitaires. Paurres Ascidies! Figurez-vous des animaux en forme de sac irrégulier, qui adhèrent par une extrémité à quelque pierre ou à quelque coquille, et qui sont condamnés à vivre, à se reproduire et à mourir, sans changer de position. On en pêche fréquemment, à Cette, une espèce bien connue, de très-vilaine forme, et qu'on appelle Bichus'. On la déponille de sa peau coriace, épaisse, ridée, d'un gris brunâtre'; on isole ses viscères, qui sont d'un jaune pâle, et on les mange. Ils ont un goût d'abord salé, puis douceâtre, puis un peu piquant et comme poivré.

Ces Mollusques présentent deux orifices, à marge quelquefois ciliée, par lesquels, à la moindre pression, ils projettent avec beaucoup de force une certaine quantité d'eau ${ }^{2}$ ?

Les Ascidies n'ont pas de mains, ui de lèvres pour saisil leur proie. Leur bouche est placée très-défavorablement; elle se trouve au fond du sac, et non à l'une de ses extrémités. Mais la nature n'a pas oublié qu'un animal, avant tout, doit se nourrir. La surface interne de la poche viscérale est couverte d'une multitude de cils vibratiles trèsserrés, qui produisent dans l'eau de forts courants, tous dirigés vers l'orifice buccal. Vus au microseope, les cils dont il s'agit, font l'effet de roues ovales délicatement dentelées, toumant continuellement de gauche à droite. Ce mouvement engendre de toutes petites vagues; celles-ci cntrainent les substances alimentaires virantes ou inanimées, qui entrent dans le sac avec l'eau de la respiration, et les conduisent jusqu'à la bouche. Ainsi, chez ces curieux animaux (comme du reste chez beaucoup d'autres),

1 Cette Ascidie se vend, au marché, 2 centimes et demi la pièce (15 mars 18633).

2 "Ascidice exspunt aquam tanquam e siphone." (INNÉ.) 
manger et respirer sont deux fonctions qui se confondent! La Providence est économe d'organes, quand il faut!

Quelques auteurs attribuent des yeux anx Aseidies. Ils regardent comme tels six ou huit taches rouges (dans les organisations inférieures, les yeux sont souvent rouges) disposées en cercle autour des orifices de la peau. Il est difficile de comprendre à froi serviraient des yeux chez des animaux privés de la faculté de se mouvoir et dont la structure est si légradée. Nais qui sait, dit un savant naturaliste, de quelles nonchalantes jouissances les Ascidies peuvent ètre susceptibles? (Rymer Jones.)

Les larves des Ascidies ne sont pas adhérentes comme leur mère. Elles se transportent librement d'un endroit dans un antre; elles nagent. Leur corps est rougeâtre. Elles ont une grosse tête presque opaque, avec une tache noire antérieure, et une petite quene aplatic qui constitue leur principal instrument de natation. Elles ressemblent à un têtard de Grenouille ou de Crapaud.

A l'époque où ces larves doivent se fixer, voici ce qui arrive. Elles appuient leur tête contre un corps solide, et restent là, la queue en l'air. Représentez-vous des baladins qui feraient l'homme droit. En mème temps, leur face s'élargit et semble se creuser. L'animal sort alors de sou calme habituel; il témoigne, par de violentes commotions, que ce n'est pas volontairement qu'il est retenu. L'amour de la liberté semble plus fort chez lui que le besoin de la transformation. Il fait tous ses eflorts pour se dégager. Les vibrations de sa queue deviennent si rapides, qu'on ne pent presque plus la distinguer. Hélas! la paure bète est collée, solidement collée et pour toujours collée! Enfin cette agitation s'apaise. Une matière sort des bords do la tète, s'étale sur le corps solide, ct la larve demenre irré- 
rocablement fixée. La quene disparait; clle n'était plus boune à rien. Une tunique résistante s'organise autour de l'animal, et, sur les marges de la partie adhérente, surgissent de nombrenses saillies radiculaires qui assurent si fixation (J. Dalyell.)

L'Ascidic adulte et immobile se lappelle-t-elle les courses vagabondes de son premier àge? Le Papillon se souvient-il du ramper de la chenille?

L'Ascidie laineuse', contrairement anx habitudes de ses congénères, est libre. Iei l'adulte a conservé les prérogatives de l'enfant. Cette espèce habite dans les eaux profondes, parmi le sable. Son sac est arrondi et d'un brun rougeatre, avec l'intérieur des orifices écarlate. On ignore sil'extrémité inférieure du Mollusque est ou non cufoncér daus le sol; mais, en captivité, l'Ascidie reste couchée horizontalement, sans finire le moindre effort pour descendre plus bas ou pour changer de position. (Rymer Jones.)

Les lecphales testaces sont plus nombreme que les Acéphales nus.

On les appelle bivalves, parce qu'ils possèdent une coquille à deux battauts (valves). Ils sont abrités dans cette double carapace comme un livre dans sa couverture.

Quoiqu'ils manquent de tête, ils se nourrissent, ils sentent et ils se reproduisent. Ils ont des amitiés et des inimitiés, peut-ìtre mène des passions.... Toutefois ces dernières ne doivent pas être bien vives; car la plupart de ces animaux ont de la peine à changer de place, même à faire lo

1 .Iscidia ampulle Bruguicise. 
moindre mouvement. Plusieurs demeurent fixés an rocher qui les a vus naitre. Or, les sentiments tumultueux ne sont guère compatibles avec l'immobilité....

Les bivalves sont répandus dans toutes les mers. On trouve partout des Vénus, des Tellines et des Arches. Quelques espèces semblent cantonnées dans ceptrines régions: les Pandores n'appartiemnent qu'aux mer's du Nord; les Cames ne prospèrent, au contraire, que dans la zone nustrale. Les Tridacnes n'ont été encore trouvées que dans les eaux situées entre l'Inde et l'Australie....

Les bivalves habitent dans le sable ou dans la vase, sur des rochers et au milieu des plantes nquatiques. Ils peuvent vivre à de très-grandes profondeurs. La sonde a retiré, de 2800 mètres, une Huitre et mo Pèlerine pleines de vie et de santé (A. Edwards).

Les bivalves ont une coquille ovoïle, globuleuse, trigone, en forme de cœur, allongée comme une gousse ou aplatie comme une feuille. Cette coquille est une sorte d'étui à charnières, composé de battants égaux ou inégaux. Parfois l'un de ces battants est bombé et l'autre plat. Leur' partic antérieure ressemble à la postérienre, ou 'n differe d'une manière plus ou moins tranchée.

Les deux valves peuvent offrir plusieurs pièces accessoires; de la le nom de multivalves que les anciens avaient donné aux coquilles ainsi organisées.

- Les bivalves, un peu locomotiles, changent de place à l'aide d'un pied charnu extensible, qui ressemble moins à min véritable pied qu'à une grosse langue. Cet organe varie beaucoup quant à sa forme. C'est tour à tour me hache, une ventouse, une perche, une alène, un doigt, une sorte de fouet, une espèce de ressort. Ce pied est simple, fourchu ou frangé. Chez quelques espees, son tissu parait spongienx et capable de recevoir une quantité d'eau considérable. 
Alors l'organe se gonfle, s'allonge et se roidit. Puis, expmlsant brusquement tout le liquide qu’il contient, il redevient petit et flasque, et peut rentrer dans la coquille.

Les Mollusques se servent de leur pied très-habilement.

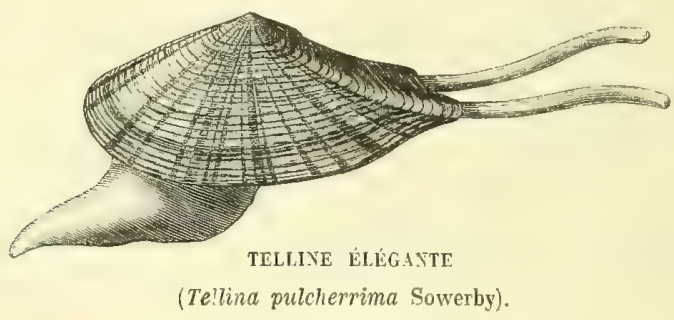

Ils l'étendent, le fixent par l'extrémité, le contractent sur son point d’appui, et se portent en avant. Réaumur a comparé la progression de ces animaux à celle d'un homme placé sur le ventre, qui allonge un bras, saisit un objet

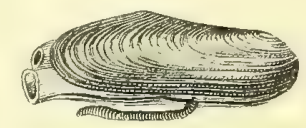

MODIOLE LITHOPIIAGE (Modiola lilhophaga Lamarch).

solide et entraine son corps vers cet objet. Il y a cette seule différence que, chez le Mollusque, le membre se contracte tout entier.

Dans quelques cas rares, le bivalve agit exactement en sens inverse : il appuie fortement son pied contre le sable, le roidit, et fait reculer son corps, à peu près comme le batelier qui dirige sa nacelle en pressant avec sa rame contre le fond de la rivière.

Certains Acéphales exécutent de petits bonds et même de véritables sauts, mais e'est par un autre mécanisme: 


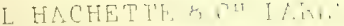

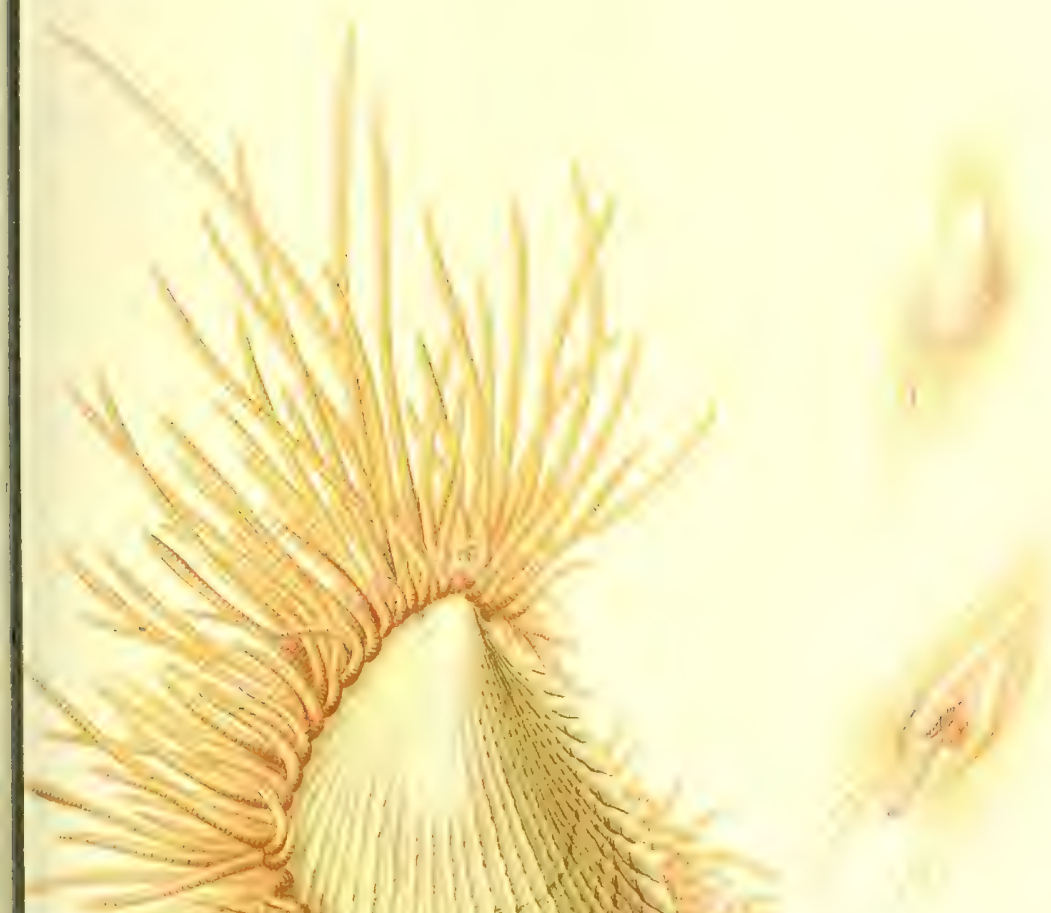

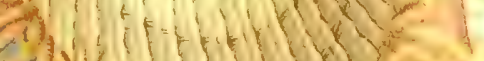

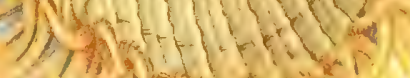

log h the

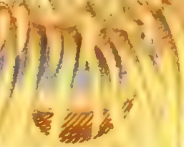

LIMA TENERA 

c'est en ouvrant et fermant leurs valves à plusieurs reprises et brusquement. Les Pèlerines s'élancent quelquefois ì travers les ondes pour éviter un danger. Les Limes ${ }^{1}$ voltigent dans l'eau comme les papillons dans l'air, avec la mème légèreté et la même étourderic. Leur locomotion est favorisée par une centaine de tentacules allongés, grêles, cylindriques, très-contractiles et très-mobiles, placés sur les bords du manteau, et composés de nombreux petits articles qui rentrent, au besoin, les uns dans les autres. (Deshayes.)

\section{III}

Les Manches de couteau, on Solens, s'enfoncent verticalement et profondément daus le sable. Leur's places sont indiquées par des trous qui correspondent au siphon de l'animal. Quand le Mollusque est alarmé, il rejette hors de son trou une certaine quantité de liquide, qu'il lance comme un petit jet d'eau. Ces Mollusques s'enterrent avec leur énorme pied conique, qu’ils allongent outre mesure; ils en font une dague naturelle qui s'aplatit, se fait pointue et perfore admirablement le terrain, puis qui redevient cylindrique, se renfle à l'extrémité et tire le coquillage de haut en bas. Il faut très-peu de temps pour qu'un Nanche de couteau ait pénétré à une profondeur de 50 centimètres.

Les Dattes' de mer, les Pétricoles, les Saxicaves et les Pholades se pratiquent une résidence daus le bois et dans les pierres. Leur cellule semble faite avec un emportepièce. Les Mollusques y sont logés étroitement, comme dans un étui, à pli de corps.

1 Voyez la planche XVl, de lo Lima tenera, que nous devons a lobligeane de II. Deshayes. 
Comment ces animaux parvienment-ils à creuser les matières les plus dures? Aldrovande croyait qu'ils naissaient dans le sein même de la roche, pendant qu'elle était encore molle. Réaumur pensait qu'ils y entraient à cette même époque. Mais comment naissaient-ils ou s'introduisaient-ils dans le bois? D'antres ont supposé que le courant d'eau déterminé par leur respiration entamait

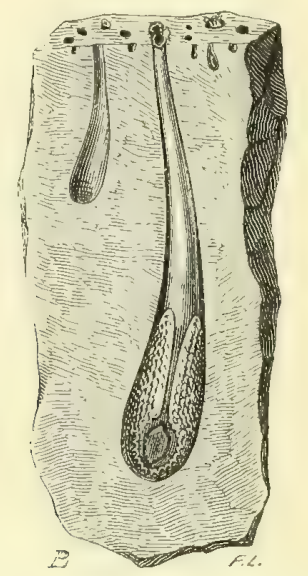

PHOLADE DANS LA PIERRE

(Pholas dactylus Linné).

à la longue les solides, comme la goutte d'eau use le granit. Mais la loge d'une Pholade est creusée en quelques mois! Suivant quelques-rus, le pied et le bord du manteau, pénétrés de particules siliceuses, frottent le roc comme du papier de verre, et râpent peu à peu le calcaire ou le silex. Suivant d'autres, le Mollusque est pourvu d'un liquide dissolvant qui attaque la substance dans laquelle il veut entrer. Enfin, un grand nombre soutiennent que l'animal perfore par un mouvement rotatoire de sa coquille, laquelle agit comme une sorte de tarière. Ces denx dernières opinions paraissent les seules vraies. Les 
bivalves qui se logent dans les calcaires tendres y entrent. les uns à l'aide d'une sécrétion acide, les autres par un moyen mécanique. Les bivalves qui creusent le gneiss, le grès, le bois, se servent du moyen mécanique seulement (Caillaud). Tous ces Mollusques pénètrent de plus en plus profondément, et rendent leur demeure de plus en plus spacieuse à mesure qu'ils grossissent.

La perforation des bivalves est en définitive $n$ combat

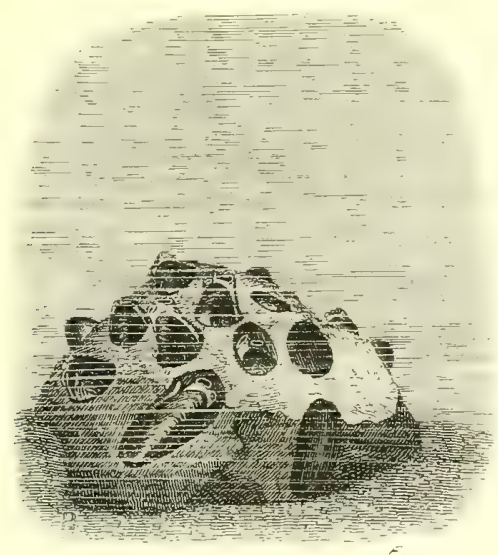

MODIOLES LITHOPIAGES DAYS LE RUCHER,

entre un corps dur et un corps mou, singulier combal dans lequel le corps mou a le dessus. Pourquoi triomphe-t-il? Paree que la vie domine et dominera toujours la matière. Le corps mou est animé, et le corps dur est inerte!

Il est des bivalves qui produisent une soie résistante, brune ou dorée, dont ils forment des câbles (byssus) qui les amarrent solidement aux rochers. Chez les Moules, le byssus est court et rude; chez les Pinnes, il est long. et soyeux. On a essayé de filer et de tisser ce dernier. Les habitants de Tarente en font des gants et des bas. On en fabrique anssi des draps d'un brun fauve assez brillant, 
recherchés pour leur finesse et leur moelleux. On en a vu de très-beaux, à Paris, à l'exposition de l'an IX et à celle de 1855. M. J. Cloquet a offert, l'année dernière, à la Société zoologique d'acclimatation, une paire de mitaines faites de byssus de Pinne.

Chez quelques espèces, le byssus sert au Mollusque, mon-seulement à s'attacher aux divers corps, mais encore à réunir ensemble de petites pierres, des morceaux de corail, des fragments de corfuilles et d'autres matières solides, dont l'ensemble compose un manteau raboteux, dans lequel elles attendent leur proie, patiemment et à l'abri (Draparnaud). En construisant cette enveloppe, le Mollusque, par un artifice singulier, file et tisse la matière de son byssus, la tapisse intérieurement d'une couche plus fine et plus unie, et la renforce extérieurement avec les petits corps durs dont il vient d'être question, qu'il associe avec adresse et maconne avec solidité. Son travail est done en même temps, celui du tisserand, celui dı tapissier et celui du maçon!

Ainsi vètus d'un habillement calcaire ou d'un mantean feutré, enfoncés dans une roche ou attachés par un câble, les bivalves, animanx très-mous et très-délicats, peuvent vivre sans avaries et sans trouble, au milieu d'un élément toujours agité, quelquefois turbulent, souvent terrible!...

\section{IV}

Les plus petits bivalves ont à peine mu demi-millimètre de longueur.

L'espèce la plus grande, la Tridacne gigantesque', peul

Tridacna gigas Lamarck. 
dépasser un mètre. On l'appolle vulgairement Bénitier, parce qu'on se sert de ses valves, dans les églises, comme réservoirs d'eau bénite. Il en existe un bel échantillon à Montpellier, dans l'église de Sainte-Eulalie. Il y en a deux autres encore plus grands, à Paris, dans l'église de SaintSulpice. Ces derniers avaient été envoyés en présent à François Ier, par la république de Venise. Le curé Langnet se les fit donner par Louis XIV. On dit que l'animal de ce bivalve, isolé, peut atteindre le poids de 1 bilogrammes, et que chaque valve peut dépasser celui de 300 !

Le manteau des Acéphales est une sorte de tunique membraneuse très-grande, à deux pans, épaissie et mêmo frangée sur les bords. Ce manteau les protége, et il est luimème protégé par les deux volets de la coquille.

L'animal possède quelquefois des yeux et des oreilles; mais, comme il n'a pas de tète pour les porter, ses yeux sont placés à la marge du manteau, et ses oreilles dans le ventre!....

Les Tellines, les Pinnes, les Arches, les Péloncles, ont des organes oculaires assez distincts, mais très-petits. Ces animaux sont, du reste, très-myopes, et le grand jour les ćblouit.....

Les oreilles sont de petites ampoules qui contiennent un caillou microseopirque suspendu dans une gontte d'eau....

Lorsque l'on compare entre eux les organes des diverses espèces animales, on reconnaît bientòt qu'ils passent de l'état le plus simple à l'état le plus compliqué par des nuances infinies. Mais les parties de ces mèmes organes n'arrivent pas toutes à la mème perfection d'un pas égal. Il en est même qui s'arrêtent en route, pendant que d'autres accomplissent leur évolution.

Ce qui a lieu entre les éléments d'un même organe s'effectne de la même manière entre les organes d'un même 
appareil ou entre les appareils d'un mime organisme'. II semble mème exister une harmonie compensatrice qui préside à ces inégalités de développement, souvent si prononcées, accordant à certaines parties ce qu'elle refuse à d'antres, de telle sorte que le budget de la nature se maintient toujours dans un équilibre parfait. (Gœthe.)

\section{1}

C'est parmi les Mollusques Acéphales que se trouvent les redoutables animanx marins connus sous le nom de Tarets.

Ces Vandales d'un nouveau genre attaquent tous les bois submergés, à peu près comme les larves de certains insectes attaquent les bois exposés à l'air. En quelques mois, en quelques semaines, des planches épaisses, des poutres de sapin, des madriers de chène, sont vermoulus de manière à n'offrir aucune résistance et à céder au moindre choe. On a vu des navires s'ouvrir en pleine mer sous les pieds des marins, que rien n'avait avertis du danger.

Limné appelait les Tarets, la calamité des navires (calamitas navium).

Dans le commencement du siècle dernier, la moitié de la Hollande faillit périr sous les flots, paree que les pilotis de toutes ses grandes digues avaient été minés par les Tarets. Il en coûta des millions pour résister aux désordres produits par un chétif animal!

Les Tarets ont le corps allongé, vermiforme, mou, demi-

1 Voyez le chapitre $\mathrm{xx}$. 
fransparent, d'un blanc légerenent grisatre, terminé à une extrémité prar une partic arrondic, improperement appelér léte, et à l'autre par une sorte de quene bifurpuée.

Ils peuvent atteindre jusqu'à 3 :̈ centimetres de longuenr.

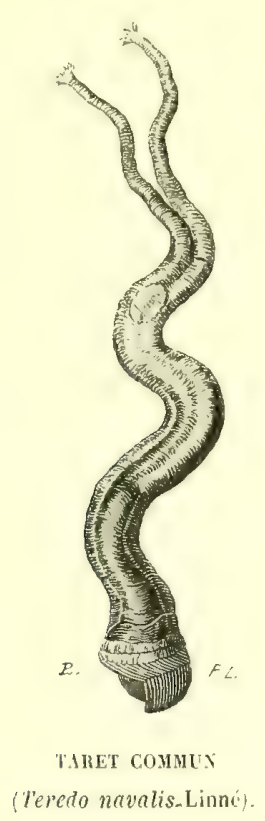

Ils sont enfouis dans un long étui creusé aux dépens du bois, la partie céphalique an fond et la queue bifide en haut. Les parois de l'étui sont revêtues d'un enduit mucosocalcaire blanchâtre, très-fin, qui en rend les murs à la lois plus unis et plus solides.

La partie arrondie ou céphalique du Mollusque offre deux petites valves très-minces et très-fragiles, semblables à deux demi-coques de noisette. Ces valves sont immobiles ct ne protégent qu'une très-faible portion de l'animal.

Les Tarets forment en quelque sorte le passage entre les Acéphales nus et les Acéphales bivalves.

Leur manteau constitue une espèce de fourreau charnu; 
il se divise en deux tubes que le Mollusque allonge et raccourcit à volonté. L'un de ces tubes sert à introduire l'eau aérée, qui va baigner les organes de la respiration et apporter jusque dans la bouche les molécules organiques dont le bivalve se nourrit. L'autre rejette au dehors cette eau épuisée, ainsi que les résidus de la digestion qu' elle entraîne en passant.

Les organes du Taret, au lieu d'être placés à còtéles uns des autres, sont disposés les uns derrière les autres, à cause de la forme étroite et allongée de l'animal.

Quand on réfléchit à la mollesse des Tarets, on a peine à comprendre comment ils peuvent entamer et détruire les bois les plus durs.

La larve de ce Mollusque est pourvue d'une couronne de cils natatoires. Elle nage aree facilité, monte et descend, cherehant le bois dans lequel elle doit pénétres. Quand elle a rencontré une pièce à sa convenance, elle se promène quelque temps à sa surface, à la manière des chenilles arpenteuses. Elle y exerce une pression en se mouvant de droite à gauche et de gauche à droite, ct pratique d'abord un tout petit godet dans lequel elle loge la moitié de son corps. Le jeune Taret se recouvre alors d'une couche de substance muqueuse qui se condense, brunit un peu, et offre au centre un et quelquefois deux petits trous pour le passage des siphons. Cette première couche, qui le lendemain, et surtont le troisième jour, devient calcaire, est l'origine du tube de l'animal. On ne pent voir ce qui se passe au-dessous, à cause de son opacité. Mais en sacrifiant et en détachant du bois quelques jeunes individus, on recomnait que l'animal sécrète avec une très-grande promptitude une nouvelle coquille blanche, tont à fait semblable à celle de l'adulte, parsemée, comme cette dernière, de stries à dentelures très-fines. 
L'apparition de la nouvelle coquille coincide si exactement avec la térébration du bois et la formation rapide d'un trou relativement profond, qu'on doit la considérer évidemment comme l'instrument principal de lit perforation.

Le jeune Taret mange les molécules du bois râpé. (L. Laurent.)

On protége les bois contre les ravages des Tarets en enfonçaut dans leur tissu des clons à grosse tète. Ces clous se rouillent par l'action de l'eau salée, et le bois se trouve bientòt couvert d'une épaisse cuirasse d'oxyde de fer. Les Tarets éprouvent une forte antipathice contre la rouille et respectent le bois qui en est imprégné. On pourrait encore empoisomer le tissu ligneux avec le procédé bien comuu du doeteur Boucherie. On garantit les mavires en les doublant de cuivre.

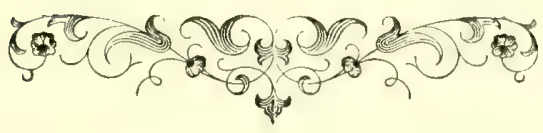





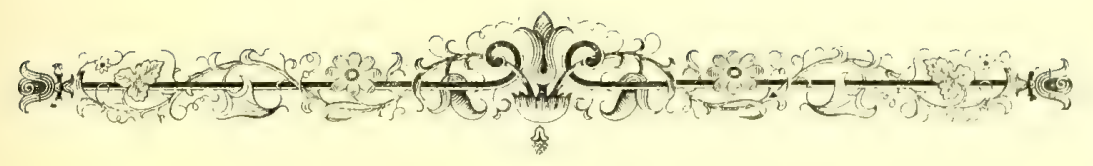

\section{CHAPITRE XX}

\section{L'HUITRE.}

"Mensarum palma et gloria!"

(PLIYL)

\section{l}

Les sociétés protectrices des animaux accordent des récompenses aux personnes sensibles qui ont entouré do soins affectucux la vieillesse des chiens et des chevaux; elles recommandent les bons traitements et la douceur envers tous les quadrupèdes, voire même envers les oiseaux, et blàment sévèrement les hommes endurcis qui les frappent, les blessent, les torturent ${ }^{1}$. Dans leur excès de zèle, clles voudraient nème décider l'autorité à défendre aux professeurs, dans les écoles vétérinaires et dans les facultés, de faire des opérations et des expériences sur les animaux vivants.

On sait que le fidèle ami de l'homme était déjà, du temps

1 "Malheur à l'homme qui ne sait pas compatir aux souffrances des animaux, les allćger dans leurs peines, leur accorder des soins qui assurent leur force et la durée de leurs services! Halheur à celui qui les traite avec violence!" (Buffon.) 
de Limmé, une des principales victimes des expérimentateurs (anatomicorum victima!).

D'un autre côté, la loi Gramont punit les charretiers et les cochers qui traitent leurs solipèdes un peu trop brutalement.

Eh bien! les sociétés protectrices et la loi Gramont n’ont jamais rien dit sur la conduite barbare des hommes.... envers les pauvres Huîtres!

Essayons de combler cette lacune.

On commence par pêcher les Huitres, c'est-à-dire par les tirer de leur élément. On les place ensuite dans des pares d'eau plus ou moins saumâtre, malpropre, remplie d'une vilaine matière verte, qui s'introduit peu à peu dans leur appareil respiratoire, l'imprègne, l'obstrue et le colore. L'Huitre se gonfle, engraisse, et arrive bientòt à un état d'obésité voisine de la maladie.

Quand la misérable n'en peut plus et que son séjour dans un pareil milieu l'a rendue d'un vert livide, on la pèche unc seconde fois. Hélas! elle ne doit plus revoir ni la mer, ni son pare, ni son rocher natal! Elle n'aura d'autre eau à sa disposition que la petite quantité de liquide retenue entre ses deux coquilles, quantité à peine suffisante pour l'empècher d'ètre asphyxiée.

Bientôt les Huitres sont enfermées dans une bourriche étroite et obseure (prison ignoble, sans porte ni fenêtre!). On oublie que ce sont des animaux; on les empile comme une marchandise inerte, on les entasse comme des parés...

La bourriche est emportée et secouée par un chemin de fer. Fille s'arrête devant un restaurant.

Nous voici au moment le plus critique pour les malheureuses bêtes. Une femme sans pitié les saisit l'une appès l'autre; avec un gros couteau ébréché, elle ampute brutalement la partic de leur corps adhérente a la coquille plate, 
et détache violemment cette coquille, apres aroir rompu la charnière'.

Cette cruelle opération terminée, l'animal est exposé aux courants d'air, sans aucune précaution. On l'apporte tout souffrant sur uue table. Là un gastronome impitoyable jette du poivre pulvérisé ou du jus de citron (c'est-à-dire des acides citrique et malique) sur le corps de l'infortunée et sur la blessure encore saiguante. Eheu! Puis avec un petit couteau d'argent, qui ne coupe jamais, on incise une seconde fois la reine des Mollusques, ou, pour mieux dire, on la scie, on la déchire, on l'arrache de son battant concave. On la saisit avec deux crocs pointus qu'on enfonce dans son foie et dans son estomac, et on la précipite dans la bouche. Les dents la pressent, lécrasent, la broient toute vivante et toute palpitante, réduisant a une masse informe ses orgaues d'abord meurtris, puis triturés, imbibés de son sang, de sa graisse et de sa bile!!!

On dira pent-itre que les lluitres n'ont ni tête, ni jambes, ni bras; qu'elles sont saus yeux, sans oreilles et sans nez; qu'elles ne bougent pas, qu'elles ne crient pas!.....

D'accord! parfaitement d'accord! mais tous ces caractères négatif́s ne les empêchent pas d'être sensibles. Deux célèbres Allcmands, MM. Brandt et liatzehuro, ont montré qu'elles possèdent un système nerveux assez développé. Or, si elles sont sensibles, elles peuvent souffir. Ce qu'il fallait démontrer"

Hâtons-nous toutefois de tranquilliser les pêcheurs, les éducateurs, les vendeurs, les ouvreuses et les consomma-

${ }^{1}$ Les anciens ouvraient les Huîtres sur la table même. Sénèque le dit trèsexpressément.

2 "L'animal a-t-il des nerfs pour être impassible? Qu on ne suppose pas cette impertinente contradiction dans la nature. " (Volt.sIRE.) 
teurs! On excuse l’indifférence des sociétés protectrices et le mutisme de la loi Gramont, par l'énorme différence qui existe entre ces Mollusques imparfaits et les animaux supérieurs, différence si grande, que leur physionomie ne rappelle pas l'idée que les gens du monde se font d'uu animal. Ce sont des citoyens d'un autre élément que le nôtre, vivant dans un milieu où nous ne vivons pas, offrant une structure dégradée, une vitalité obscure, des mouvements indécis et des møurs insaisissables.... On peut done les voir mutiler', les mutiler soi-même, les màcher et les avaler sans émotion et sans remords!

Un savant des bords de la mer se fit un jour apporter une douzaine d'Huitres. Il voulait étudier leur organisation. II les tourna, les retourna, examina leurs diverses parties en dehors et en dedans, les dessina et les décrivit. Après son travail, ces intéressants Mollusques n'avaient rien perdu de leurs excellentes qualités, et leur étude ne porta aucun préjudice à la consommation.

Cette histoire nous paraît apocryphe; parce que généralement, quand on a disséqué une bète, bien ou mal, on n'est guère tenté de la manger. 11 y a plus : les zoologistes, qui conmaissent ex professo l'organisation des Huitres, cherchent ordinairement à ne pas penser à leurs dissections passées, ou à s'étourdir sur leur savoir, quand ils veulent savourer sans répugnance ces très-estimables animaux.

C'est pourquoi nous avons hésité quelque temps à placer dans cet ouvrage un exposé plus ou moins anatomique de ce qu'on a écrit sur les organes de nos illustres et malheureux bivalves....

Du reste, nous supplions le lecteur, s'il est au moment de dújeuner avec des Huîtres, de ne pas lire les détails que nous allous domner. Nous ne voulons dégoûter persomne. 


\section{II}

Supposons devant nos yeux une Huitre bien grasse, bien fraiche, bien ouverte, bien épanouie dans son battant concave.

Nous voyons d'abord un animal très-aplati, compacte, mou, demi-transparent, grisâtre ou gris verdâtre. Sa figure ressemble grossièrement à celle d'un ovale dont on aurait tronqué le petit bout. La partie tronquée répond à la charnière des battants et représente le sommet du coquillage. La ligne courbe qui nait à gauche forme sa partie antérieure; celle qui nait à droite, et qui est moins arrondie, représente sa région postérieure ou son dos, et le gros bout de l'ovale représente sa partie inférieure. Au sommet de l'animal; on apercoit un corjs semblable à un petit coussin irrégulièrement quadrilatère et légèrement renflé.

L’Iluitre est revêtue d'un manteau très-ample, mince, lisse, contractile, plié sur lui-même, offrant deux lobes séparés dans la plus grande partie de sa circonférence, c'est-à-dire en avant, au gros bout de l'ovale, ct en arrière, vers la partie inférieure. Ce manteau peut ètre comparé à une sorte de capuchon fortement comprimé, dont le sommet serait tomrné vers la charnière. Les bords de cette tunique sont légèrement épaissis; on y remarque une multitude de petits corps ciliés, disposés sur un rang du côté intérieur, qui est comme frangé, et sur trois ou quatre rangs du còté extérieur, qui est comme plissé et festonné. Ces corps paraissent donés d'une sensibilité assez vive. L'animal peut les allonger et les raccourcir à volonté.

Si l'on écarte les lobes du manteau en avant, on observe 
à l'endroit de leur réunion, dans l'intérieur du repli, quatre pièces irrégulièrement triangulaires, plates, appliquées les unes contre les autres. Ce sont les parties de l'animal chargées de choisir sa nourriture et de l'introduire dans la bouche. On les appelle tentacules ou palpes labiaux. La bouche est située au milieu; elle paraît grande et dilatable; elle s'ouvre immédiatement dans l'estomac. Celui-ci a la forme d'une poche cylindrique; il est caché dans l'intérieur du coussinet quadrilatère. De la partie postérieure do l'estomac part un intestin grêle, sinueux, qui se dirige obliquement vers le côté antérieur, descend un peu, puis remonte, passe derrière la cavité stomacale, se boncle en haut d'arrière en avant, descend vers le dos, et se termine ì sa partic moyenne par un canal flottant, dont l'extrémití est à peu près en forme d'entonnoir. Là on trouve l'ouverture par où sont expulsés les excréments.

L'estomac et l'intestin sont entourés de tous côtés et pressés par une matière épaisse, noirâtre, abondante, pénétrée d'une liqueur d'un jaune foncé. Cette matière n'est autre chose que le foie; la liqueur jaune, e'est la bile.

Ainsi, en résumant, on peut dire que les Huîtres ont l'estomac et l'iutestin dans le foie, l'ouverture de lả bouche sur l'estomac et l'ouverture de l'intestin dans le dos.

Depuis longtemps, les gastronomes ont constaté que le coussinet quadrilatìre était, dans nos coquillages, la partie la plus savoureuse et la plus excitante. Aussi, aux environs de Cette, où les Huîtres sont fort grandes, certains amateurs, très-distingués, adoptent et proclament le principe de diviser transversalement le corps du Mollusque et de manger seulement le coussinet. L'histoire naturelle a expliqué cette petite découverte de la gastronomie. Elle a reconnu que c’est la bile sécrétée par le foic et contenue 
dans sa substance, qui active, qui effrite chez nous la surface gustative de la langue et du palais, et qui vient encore en aide aux fonctions de l'estomac.

Au-dessous du foie parait le cour (car les lluitres ont un cœur), composé de deux cavités distinctes, unc oreillelle et un ventricule : la première presque carrée, à parois épaisses et d'un brun noir; la seconde en forme de petite poire, à parois minces et comme grise. Les deux angles antérieurs de l'oreillette reçoivent chacun un gros vaisseau, dans lequel s'ouvrent trois autres conduits formés par la réunion de plusieurs veines déliées. La pointe du ventricule donne naissance à un canal qui se sépare, à sa sortie, en trois branches divergentes: l'une qui se dirige vers la bouche et les tentacules; la seconde, qui se rend au foie; la troisième, qui fournit aux parties inférieures et postérieures du Mollusque.

Le cœur entoure étroitement, embrasse, si l'on veut, la partie terminale de l'intestin, le recum; de telle sorte que celui-ci semble passer sans façon au milieu du noble organe, pour arriver plus vite à sa porte de sortie. Quand le cœur se contracte, il pousse le sang, mais il pousse aussi bien autre chose!... O bizarrerie des bizarreries!

Le sang est incolore. Il arrive vivifié dans la cavité de l'oreillette. Celle-ci se contracte et le verse dans le ventricule. Cette poche se contracte à son tour, le précipite dans le gros vaisseau qui en nait, et le répand dans tout le corps.

Les Huîtres respirent au sein de l'eau. La nature leur a donné des organes pour séparer de ce liquide la petite quantité d'air qui s'y trouve mêlée. C'est l'oxygène de cet air qui vivifie le sang et qui le renouvelle. Les parties respiratoires sont deux paires de feuillets, ou branchies, courbes comme des ares, formés d'une double série de 
canaux très-fins et très-serrés, attachés transversalement et disposés avec beaucoup de symétrie : on dirait les dents d'un joli peigne. Ils sont cachés sous les bords libres du manteau. Ils naissent près des tentacules, et se terminent vers le milieu de la partic postérieure. Les externes sont plus courts que les internes.

Les Huîtres, étant sans tête, ne devaient pas offrir de cerveau. Il est remplacé par un petit corps blanchâtre, bilobé, situé près de la bouche. De ce corps naissent deux nerfs déliés qui embrassent le foie et l'estomac, et vont aboutir à un autre renflement, de même nature et de même forme, placé au-dessous de ces organes.

Le premier renflement fournit des nerfs à la bouche et aux tentacules; le second en dome aux feuillets de la respiration.

Les Huîtres n'ont point d'organes pour voir, ni pour entendre, ni pour flairer. Le toucher réside, chez elles, dans les quatre tentacules de la bouche. Le goût a son siége autour de ce dernier orifice, et peut-être à la surface interne des tentacules intérieurs. 11 semble fort obscur.

Les Huîtres sont peut-être, de tous les coquillages, ceux dont les facultés paraissent le plus bornées. En les rendant à peu près immobiles dans leur station, en les emprisomnant à perpétuité dans leur coquille, et en leur refusant des sexes séparés, ainsi qu'on le verra plus loin, la Providence ne pouvait guère leur donner des besoins et des désirs bien nombreux, bien variés et surtout bien ardents; elle en fait des animaux presque apathiques, vivant et digérant dans une donce quiétude voisine de l'indifférence. Toutefois, comme ces Mollusques sont essentiellement sociaux et composent ordinairement des agglomérations extrèmement considérables, il ne serait pas impossible que, malgré leur faible intelligence, il n'y ait chez les 
Huîtres des sympathies et des répulsions.... nous n'osons pas dire des rivalités et des tracasseries!

Il n'existe, chez nos bivalves, qu'un appareil très-simple et très-imparfait pour la locomotion. Il ne faut pas s'étonner si ces coquillages demeurent à pen près toute leur vie sur le rocher où ils ont pris naissance. L'organe des mouvements est immédiatement au-dessous du cœur. C'est mn corps charnu, épais, moitié grisâtre, moitié blane, qui traverse le manteau des deux côtés et va s'attacher vers le milieu des valves. L'écaillire conpe en travers ce

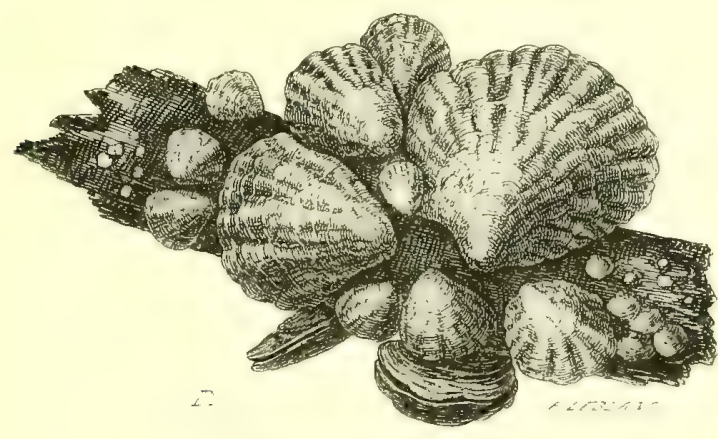

GROUPE D'II ITRES.

corps charnu, quand elle veut ouvrir une Huitre et la dépouiller d'un battant. Nous incisons ce muscle une seconde fois, quind nous voulons manger le malheureux Mollusque.

C'est en contractant fortement le corps dont il s'agit, que l'Ituitre se tient hermétiquement enfermée dans son habitation. Lorsqu'elle relàche son muscle, mn ligament élastique, placé à la charnière, agit sur les volets et les écarte l'un de l'autre. On assmre qu'en ouvrant et en fermant plusieurs fois et brusquenent ces deux battants, l'animal réussit à changer sa position, et parvient même à se traînes un peu sur son rocher; mais je n'ose y croire. 
Voltaire écrivait en 1767 : « Je suis toujours embarrassé de savoir comment les IIuitres font l'amour ${ }^{1}$. »

Les Iluitıes possèdent les deux sexes. Elles remplissent done à la fois les rôles paternel et maternel. Ce qui paraîtra tout aussi singulier, e'est que les organes de la fécondité n'apparaissent, chez nos Mollusupues, comme les fleurs dans les végétaux, qu'à l'époque déterminée où leur fonction doit s'accomplir. Passé ce temps, ils se flétrissent et disparaissent.

Les aufs sont logés entre les lobes du manteau et entre les feuillets respiratoires. Leur nombre est très-considérable. Suivant Baster, un seul individu peut en porter 100 000. Suivant Poli, il en produirait jusquà 1 million 200000 , et suivant Leuwenhoeck, jusqu’à 10 millions. D'après les naturalistes moderues, le nombre est d'environ 2 millions. Ce qui parait très-raisonnable.

Ces œufs sont jaunâtres.

Ils éclosent dans le sein du Mollusque, qui met au monde ses petits en respirant.

Les jeunes Huitres forment un nuage blanchâtre vivant, plus ou moins épais, qui trouble un moment la transparence du liquide, s'éloigne du foyer dont il émane, et que les mouvements de l'eau dispersent. (Coste.)

Ces larves sont pourvues d'un appareil transitoire de natation qui leur permet de se répandre au loin, et d'aller à la recherche d'un corps solide où elles puissent s'attacher. Cet appareil se compose d'une sorte de bourrelet sinueux, couvert de cils nombreux et serrés; il sort des valves et y rentre à volonté. Il est muni de muscles puissants destinés à le mouvoir (Davaine).

A l'aide de cet appareil, les jeunes Huitres peuvent nager

1 Voyez le chapitro XXII, \$6. 
avec facilité. Quand elles ont quitté leur mère, elles flottent autour de celle-ci. On assure que dans les commencements, au moindre danger, elles se réfugient entre les valves maternelles.
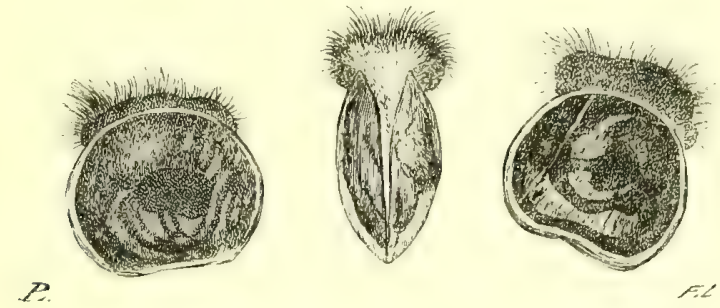

JELYES HLITRES AYEC IJURS CHS MATATOIRES.

Bientôt les larves se fixent à quelque corps résistant. Elles s'y accroissent, y prospèrent et arrivent à l'état adulte. Il faut environ trois ans pour que le Mollusque ait acquis une taille ordinaire. (Coste.)

\section{III}

Les Huitres aiment à vivre sur les côtes, à une faible profondeur et dans une eau peu agitée. Elles se développent quelquefois en masses considérables. C'est ce qu'on appelle bancs d'Huîtres.

Il est de ces banes qui ont plusieurs kilomètres d'étendne et qui semblent inépuisables. On en découvrit un, en 1819, près d'une des îles de la Zélande, qui alimenta les PaysBas pendant un an en si grande abondance, que le prix de ces Mollusques était tombé à un franc le cent. Mais, comme ce bane était placé presque au niveau de la basse mer, l'hiver étant rigoureux, il fut entièrement détruit. (Deshayes.) 
Les espèces d'Huîtres qu'on mange en France sont :

Sur les còtes de l'Océan, l'Huitre commune ${ }^{1}$ et le Piedde-cheval ${ }^{2}$.

Sur les còtes de la Méditerranéc, l'Huître rosacée ${ }^{3}$ et le Pelocestiou ${ }^{4}$.

Et en Corse, l'Huître lamelleuse ${ }^{5}$.

On trouve encore dans la Méditerranée, l'Huître en crête ${ }^{6}$ et l'Huîlre plissée ${ }^{7}$. Mais ces dernières sont petites et peu recherchées.

Dans les ports de mer, on distingue ces Mollusques suivant les endroits de la mer où ils ont été récoltés. Il y a les Huitres arrachées des lits profonds (ce sont les moins estimées), celles des bancs rapprochés de la còte et celles des pares artificiels.

L'Huître commune présente en France deux variétés principales, qui diffèrent par la taille et par la délicatesse. Ce sont l'Huitre de Cancale et l'Huitre d'Ostende. Quand la première a séjourné quelque temps dans un pare, et qu'elle a pris une couleur verditre, on la désigne sous le nom d'Huître de Marennes. Nous parlerons tout à l'heure de la nature et de la source de sa coloration.

\section{IV}

L'Huître ordinaire est la palme et la gloire de la table. "Elle peut être considérée comme l'aliment digestible par excellence; c'est la base de toutes les substances capables

1 Ostren edulis Liuné.

- Ostrea hippopus Linné.

${ }^{3}$ Ostrea rusacea Favanne.

Ostrea lacleola Moquin.
5 Ostrea lamellosa Brocchi.

- Ostrea cristata Born.

7 Ostrea plicata Chemnitz. 
de nourrir et de guérir sans eflort l'estomac; c'est le premier degré de l'échelle des plaisirs de la table réscrvés par la Providence aux estomacs délicats, aux malades et aux convalescents ${ }^{1}$.

“ L'expérience, d'ailleurs, a si bien démontré ces vérités gastronomiques, qu'il n'est pas de festin, de repas digne des connaisseurs, où l'Huitre ne figure honorablement ef en première ligne. C'est elle, en effet, qui ouvre les voies, qui les excite doncement, qui semble commander à l'estomac à se préparee anx sublimes fonctions de la digestion; en un mot, l'Huitre est la clef de ce paradis qu'on nomme l'appétit. "

“ Il n'est point de substance alimentaire, sans même en excepter le pain, qui ne produise des indigestions dans une circonstance donnée; les Huîtres, jamais! C'est un hommage qui leur est dù. On peut en manger aujourd'hui, demain, toujours, en manger à profusion, l'indigestion n'est point à redouter. » (Reveillé-Parise.)

On a vu des personnes engloutir sans inconvénient des quantités énormes de ces Mollusques. On assure que le docteur Gastaldi (il fut frappé d'apoplexie à table, devant un pàté de foie gras) avalait impunément trente à quarante douzaines d'Huitres. Tout un banc y aurait passé ${ }^{2}$.

Montaigne a dit : "Etre sujet à la colique ou se priver de manger des lluitres, ce sout deux maux pour un; puisqu'il faut choisir entre les deux, hasardons quelque chose à la suite du plaisir. ”

D'après M. Payen, scize donzaines d'lluîtres représentent

1 Adolphe Pasquier, Sainte-Harie.

2 Vitellius, disent les historiens, eu mangeait quatre fois par jour, of douze cents à chaque repas. Ce qui fait quatre mille huit cents! Est-ce possible! 
les 315 grammes de substance azotéc sèche nécessaires à la nourriture journalière d'un homme de moyenne taille. Par conséquent, pour alimenter cent persomnes pendant un jour, miquement arec ces Mollusques, il en faudrait dixneuf mille deux cents!

\section{1}

On pêche les Huitres de différentes manières. Autour de Minorque, des plongeurs intrépides, armés d'un martean attaché à leur main droite, descendent jusqu'à douze brasses de profondeur, et chargent leur bras gauche d'un certain nombre de bivalves. Deux marins s'associent d'ordinaire pour cette récolte. Ils plongent alternativement et remplissent souvent leur bateau.

Sur les côtes de France et sur les côtes d'Angleterre, la pêche dont il s'agit s'effectue avec la drague. Chaque cmbarcation est montée par deux hommes et pourvue de deux engins pesant 9 kilogrammes en moyenne. Ces dragues sont attachées au bout d'une corde. On les descend dans la mer; elles sillonnent les fonds, raclent, détachent et ramassent les Huitres qui s'y trouvent.

On divise les banes naturels en plusieurs zones qu'on exploite successivement et qu'on laisse reposer pendant un temps déterminé, de manière que les zones puissent se repeupler facilement et régulièrement.

Sur la côte de Campêche, au Mexique, les Huitres s'établissent entre les racines submergées des Mangliers, et s'y développent en quantités considérables. Les Indicns coupent les branches radicales de ces arbres, sans en détacher les grappes de bivalves, et portent au marché de véritables régimes d'Huitres. (Jourdanet.) 
A différentes époques on a eu l'idée de culliver les Ituitres. Sergius Orata, suivant Pline, est le premicr qui imagina de les parquer dans les environs de Baies, au temps de l'orateur L. Crassus, avant la guerre des Marses. Ce fut le même Sergius qui fit la réputation des Huittres du lac Lucrin, en leur attribuant le premier une saveur exquise. Alors, comme aujourd'hui, remarque Reveillé-Parise, les industriels spéculaient sur les faiblesses et sur la gourmandise humaines.....

Sergius avait réellement créé une industrie, dont les pratiques sont encore suivies à quelques milles du lieu où il l'avait exercée, ainsi que M. Coste l'a démontré tout récemment. Pour exprimer le degré de perfection où Sergius avait porté cette industrie, ses contemporains disaient de lui, par allusion aux bancs suspendus dont il était l'inventeur, que si on l'empêchait d'élever des Huitres dans le lac Luerin, il saurait en faire pousser sur les toits.

Qu'est devenu ce fameux lac? Hélas! il n'existe plus; tout a disparu. Le président des Brosses, ce spirituel et malin voyageur, gourmand achevé, voulut voir ce lac célèbre. Voici ce qu'il en dit : « Ce n'est plus qu'un mauvais margouillis bourbeux. Ces Huîtres précieuses du grandpère de Catilina, qui adoucissent à nos yeux l'horreur des forfaits de son petit-fils, sont métamoxphosées en malheureuses anguilles qui sautent dans la vase. Une vilaine montagne de cendres, de charbon et de pierres ponces, qui, en 1538, s'avisa de sortir de terre, tout en une nuit, comme un champignon, a réduit ce panve lac dans le triste état que je vous raconte. " 
Rondelet parle d'un pêcheur qui connaissait l'art de semer les Huitres.

On sait aujourd'hui que le terrible Achéron des poëtes, le lac Fusaro des Napolitains, est une grande, une trèsgrande huîlrière, où l'industrie-aide la nature daus la multiplication de ses produits.

Son pourtour est occupé par des fragments de rochers en forme de blocs arrondis. Sur ces blocs on apporte des

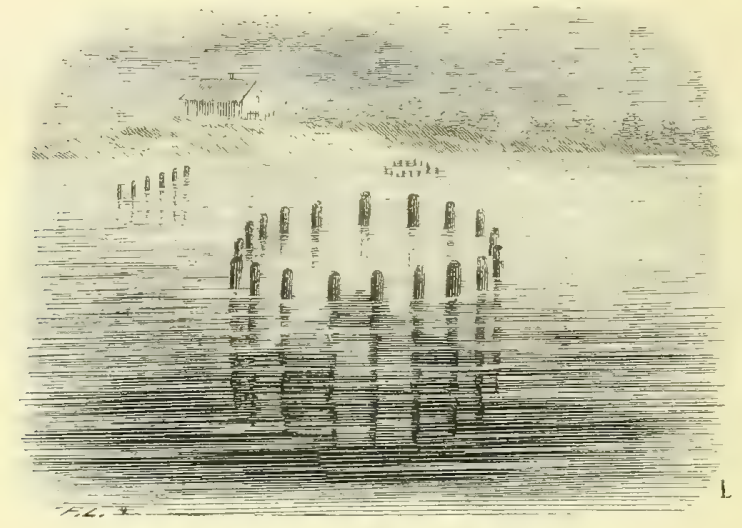

B.IYC D'HUitres ARTHFLCL EXTUURE DE SES PIELX.

Huitres de Tarente, et l'on transforme chacun d'cux en un petit banc artificiel; on place, tout autour, des pieux enfoncés et rapprochés. Ces pieux s'élèvent un peu audessus de la surface de l'eau, afin qu'on puisse facilement les saisir avee la main et les òter, quand cela devient utile. D'autres pieux, disposés par rangées, sont unis ensemble avec des cordes, d'où pendent d'autres cordes portant des parquets de fascines plongées dans l'eau. Ces dernières ont pour but de recueillir la poussière (larves microscopiques) répandue, chaque annéc, dans la nocr. A une éporfue déterminée, on enlève les fascines et l'on récolte les Huitres. (Coste.) 
Dans le siècle dernier, le marquis de Pombal, ayant fait jeter quelques cargaisons d'Huitres sur les côtes de son pays, 'qui n'en produisait pas, ces Mollusques s'y multiplièrent tellement, qu'ils y sont aujourd'hui très-communs.

Vers la mème époque, en Angleterre, un propriétaire, II. de Carnarvon, ayant disséminé une certaine quantité de ces Mollusques dans le détroit de Menai, ils s'y propagèrent rapidement, et furent pour lui, pendant longtemps, une source considérable de revenu. Excité par cet exemple,

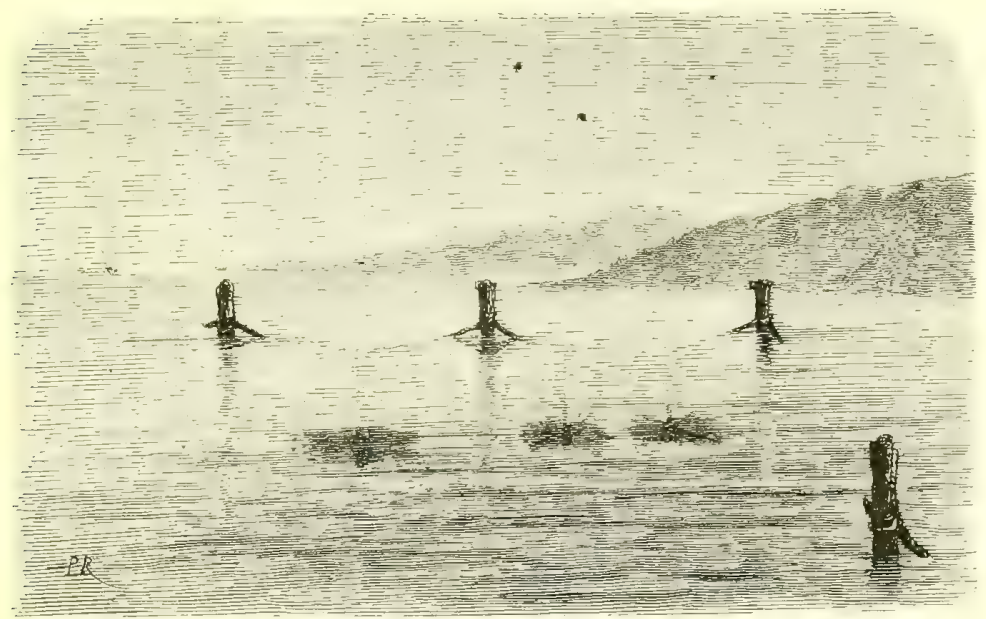

FASCIXES SUSPEXDUES POUR RECEYOIR LES JELYES ILITRES.

le gouvernement anglais fit porter des chargements d'lluîtres sur divers points des côtes de l'Angleterre, où elles prospérèrent également.

La création des bancs artificiels d'Huitres a multiplié et régularisé la production de ces Mollusques. Sur les côtes des comtés d'Essex et de Kent, l'ostréiculture est pratiquée avec méthode. Ce qui se fait dans le lac Fusaro a servi d'exemple dans beaucoup de pays.

En France, l'ostréiculture n'a pas été négligée. Mais 
c'est surtout depuis quelques années que, gràce à l'impulsion donnée par M. Coste, cette industrie produit des résultats de plus en plus satisfaisants.

Sur toutes nos côtes, des industriels se sont mis à l'ouvre. La marine a fourni ses navires et ses matelots, et des huitrières artificielles ont surgi sur un grand nombre de points.

Les premières tentatives sérieuses ont été faites dans la baie de Saint-Brieuc, pendant les mois de mars et d'avril 18:38, à la suite d'un rapport de M. Coste à Sa Majesté l'Empereur. On opéra, à de grandes profondeurs, une sorte de semis d'Huitres près de pondre (environ 3 millions), autour et au-dessus desquelles furent déposés, comme collecteurs des nourrissons qu'elles allaient émettre, des fascines, des tuiles, des fragments de poteries, des valves de coquillages... Au bout de huit mois, on vérifia le degré de développement de l'huitrière. La drague, promenée pendant quelques minutes, amena chaque fois plus de deux mille Huitres comestibles; et trois fascines prises an hasard en contenaient près de 20000 du diamètre de 3 à mètres. Deux de ces faseines, exposées à Binic et à Portrieux, ont excité pendant plusieurs jours l'étonnement de toutes les populations du littoral. Ces fascines ressemblaient à des branches très-rameuses dont chaque feuille était un coquillage vivant.

Des savants distingués, parmi lesquels on doit citer II. Van Beneden, professeur à Louvain, et M. Eschricht, professeur à Copenhague, envoyés par leurs gouvernements respectifs, sont venus étudier le procédé d'ostréiculture mis en usage dans nos mers, pour en faire l'application sur les còtes de la Belgique et du Danemark.

M. Coste a montré, de plus, que l'industrie huitrière pouvait être fixće sur les terrains à marée basse. Par 
suite de ses conseils, le bassin d'Areachon est aujourd'hui transformé en un vaste champ de production qui s'accroît chaque jour, et fait présager des récoltes trèsabondantes.

Déjà cent douze capitalistes, associés à cent douze marins, y exploitent une surface de 400 hectares de terrains émergents. Pour donner l'exemple, l'Etat y a organisé denx fermes modèles, destinées à faire l'essai des divers appareils propres à fixer la semence et à favoriser la récolte.

Des toits collecteurs formés par des tuiles adossées on imbriquées, des planchers mobiles, les uns servant de convert à des fascines, les autres ayant une de leurs faces enduite d'une couche de mastic hérissée de Bucardes, y sonl alignés sur des chemins d'exploitation, comme les maisons d'une rue. En dehors des appareils, de vastes surfaces de terrain ont été recouvertes de coquilles d'Huitres et de Bucardes, afin de recevoir les très-jeunes individus non fixés. Ces diver's corps étrangers sont tellement chargés de petites Huitres, que sur une tuile on en a compté jusqu'à 1000.

Ce genre d'éducation à marée basse permet de voir régulièrement l'état des coyuillages, et de soigner l'huítrière comme on soigne les fruits dans un espalier, si l'on veut permettre cette comparaison.

Dans le rapport (octobre 1865) de M. Chaumel, commandant le garde-péche d' Areachon, on trouve les chiffres suivants pour le parc de 4 hectares de Lahillon, établi sur une plage détestable.

Les frais du pare, tout garni, installé et entretenu, ont été de 28500 franes, ainsi répartis :

Défrichement, 2800 franes; achat d'outils, 200 francs; achat d'IJuitres, 20000 franes; achat de ponton, 1000 franes; 
gardiennage, 2600 franes; corvées, 1500 franes; achat de tuiles, 400 franes.

Aujourd'hui, la population actuclle du pare est évaluée à 1299248 jemes Huitres fixées aux tuiles, 2680000 jeunes Huitres attachées aux Iluîtres mères, 1246000 jeunes Huitres collées aux coquillages et aux pieux collecteurs: soit un total de 3 18.5248. Leur valeur en argent peut

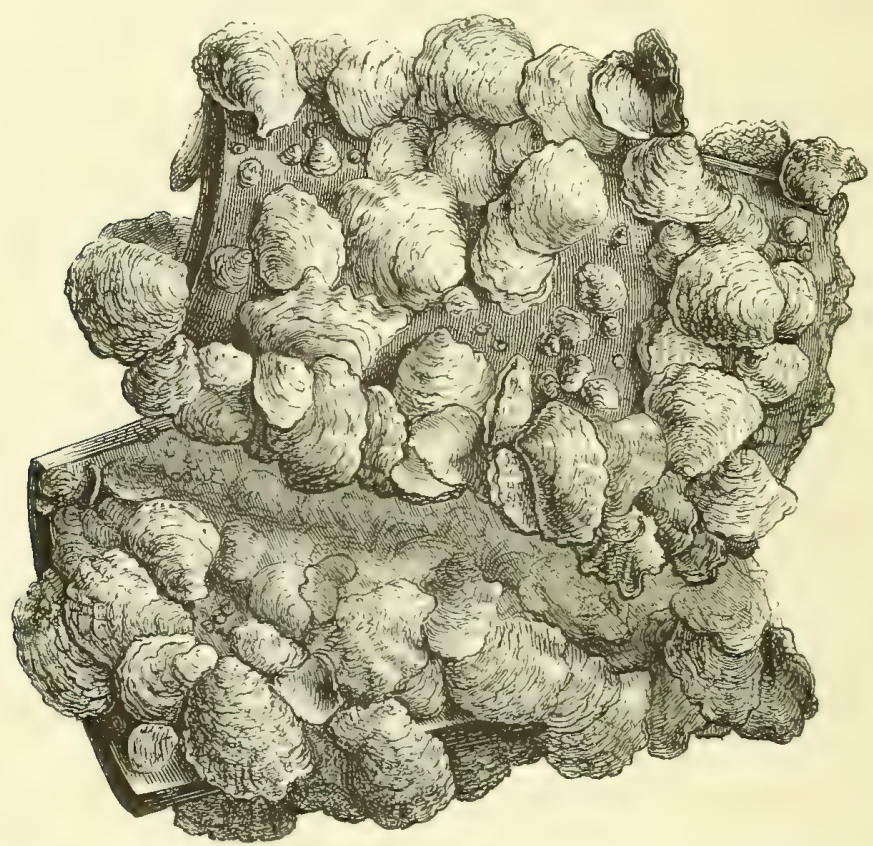

HUITRES D'EXYIROX DIX-HUIT MOIS SUR UNE TULE RLCOUYERTE DE CIMEST (BAIE DE I.A FORÉT).

itre estimée, au plus bas, à 2000000 franes. Si l'on tient compte des pertes probables, le bénétice sera au moins de 100000 franes.

Dans l'île de Ré, sur une longueur de près de quatre lieues, plusieurs milliers d'hommes venus de l'intérieur des terres ont pris possession d'une inmense et stérile vasière, 
et l'ont transformée, depuis deux ans seulement, en un riche domaine. Quinze eents pares y sont daus eo moment en pleine activité, èt deux mille autres en voie de construrtion. Ces établissements formeront bientôt une ceinture antour de l'ile. L'industrie a réussi à écouler les vasiòres en pratiquant des empierrements composés de fragments de rochers. Les Ihuitres se développent avec une facilité itonnante au milieu de ees fragments. Les agents do l'administration ont pu en compter, en moyenne, 600 par mètre carré, la plupart ayant déjà une taille marchande. Or, la surface en exploitation étant aujourd hui de 630000 mètres carrés, il en résulte que le nombre d'élìves fixés sur cette plage, jadis inculte et dépeuplée, est déjà de 378 millions: ce qui représente une valeur de 6 ì 8 millions de franes.

L'Océan n'a pas été le seul théâtre des essais de M. Coste. Priss de :800000 Huitres ont été portées dans la rade de Toulon et dans l'étang de Thau. Un fragment de clayonnage pris an milien de l'huitriere artificielle de Toulon, au bout de huit mois, a été tronvé très-riche en coquillages.

La culture des fruits de la mer est une branche d'industrie extrêmement féconde, que tous les gouvernements devraient encourager.

\section{VII}

A l'exemple des Romains, on dépose les IIuîtres dans de grands réservoirs pour les faire grossir et verdir. Cela s'appelle parquer les Iluitres.

A Marennes, ces réservoirs portent le nom de claires. Ce sont comme autant de champs inondés, cà et là, sur les deux rives de l'anse de la Sendre. Ces claires diffèrent des 
viviers et des pares en ce qu'elles ne sont pas submergées à chaquie marée (Coste). Il faut deux ans de séjour pour quime Huitre âgée de six à huit mois atteigne la grandeur et la perfection convenahles. Mais la plupart de celles qu'on livre à la consommation sont loin d'offrir les qualités requises. Placées adultes daus les réservoirs, elles verdissent en quelques jours. (Coste.)

On sait que la coloration des Huîtres vertes n'est pas générale. Elle se montre particulièrement sur les quatre feuillets respiratoires. On en trouve aussi des traces à la face interne de la première paire de palpes labianx, ì la face externe de la seconde, et dans une partie du tube digestif.

On a cru pendant longtemps que la viridité des Huitres ćtait due au sol mème des réservoirs, ou bien à la décomposition des Ulves et des autres hydrophytes, ou bien encore à une maladie du foie, à une sorte de jaunisse (plutòt verdisse) qui teindrait en vert le parenchyme de l'appareil respiratoire. Gaillon a prétendu qu'elle venait d'une espèce d'animalcule infusoire en forme de navette, qui pénétrait lans la substance du Mollusque. Bory de Saint-Vincent : prouvé que l'infusoire en question n'était pas normalement vert, mais coloré, dans certaines circonstances, comme l'Huître, et par la même cause. Suivant ce naturaliste, la source de la viridité est une substance moléculaire (matière verte de Priestley) qui se développe dans toutes les eaux par l'effet de la lumière. Suivant M. Valenciennes, cette coulemr est formée par une production animale distincte de toutes les substances organiques déjà étudiées. M. Berthelot a analysé cette matière, et a reconnu qu'elle présente en effet des caractères particuliers. Elle ne ressemble ni à l'élément colorant de la bile, ni à celui du sang. ni à la plupart des matières colorantes organiques. 
Les molécules vertes dont il s'agit, pénètrent dans les branchies par l'effet du mouvement respiratoire, sy arrêtent, les gorgent, les obstruent et les colorent. En même temps, le pauvre animal, gêné dans une de ses fonctions essentielles, s'infiltre, se dilate, et subit une sorte d'anasarque qui rend son tissu.... plus tendre et plus délicat!

\section{VIII}

En 1828, nos banes d'Huitres ne fournissaient que :2 millions d'individus. Déjà, en 1847, le petit port de Granville, seulement, occupait depuis le mois d'octobre jusqu'au mois d'avril, soixante et douze bateaux qui ne faisaient pas autre chose que pêcher des Huîtres.

Vers 1840, la vente des Huitres d'Arcachon n'atteignait guère qu'un millier de franes. En 1861, la pèche libre, faite en dehors des pares réservés, a valu aux marins 280000 franes. (Mouls.)

Le prix des Huitres était, à Paris, il'y a cent cinquante ans, de 1 franc 50 centimes le mille. Il s'élevait, au commencement de ce siècle, de 12 à 14 francs. Il a été porté plus tard à 20 , à 2.3 et à 30 . Il est aujourd'hui à 40 franes.

En 1861, on a vendu à Paris 503131100 Huîtres au prix moyen de 4 francs 2 centimes le cent; ce qui donne un prix total de 2216270 francs.

Pendant la saison de 1848 à 1849 , on a vendu à Londres 130000 bourriches d'Huitres. A cent Huîtres par bourriche, cela fait 13 millions d'individus.

Un journal racontait, en 1845, qu’à Varsovie, un général s'était fait une belle réputation d'amphitryon, principalement par les Huitres. Il en servait à ses convives des quan- 
tités considérables. Chacune lui revenait à z:3 centimes; ce qui faisait 7 ğ francs le cent et 730 franes le mille. On n'est pas plus magnifique!

N'oublions pas de dire, en terminant ce chapitre, que, pendant son dernier voyage en Zélande, le roi des PaysBas a été reçu, dans un village de la còte, sous un arc de triomphe construit en coquilles d'Huîtres... et sans odeur!

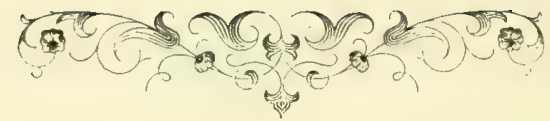




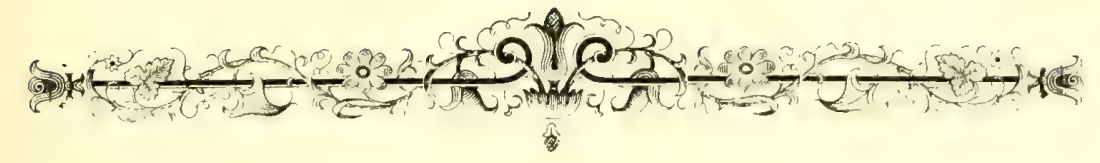

\section{CHAPITRE XXI}

\section{A MOUTLE.}

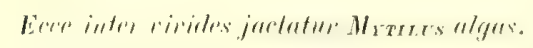

(ANTHOLogie.)

\section{I}

La Moule ${ }^{1}$ n'a pas le goût exquis ni la réputation de l'Huitre. Cette dernière passe, avec raison, pour le coquillage par excellence. C'est le bivalve de l'aristocratic (nobilisstmus cibus).

Toutefois ne disons pas trop de mal de la modeste Noule. Son abondance et son prix la rendent accessible aux classes peu aisées; elle peut done être regardéc, après la Clovisse, comme le bivalve de la pauvreté (vilissimus cibus).

La Moule se fait distinguer, entre tous les coguillages, par le bleu violet de ses battants et par le jaune roux de ses viscères. L'Huitre n'a pas cette parure, ni à l'extérieur, ni à l'intérieur. Elle ne brille pas par sa livrée, quoiqu'elle écrase sa rivale par d’autres qualités, sans doute plus solides.

"Mytilus edulis Limné. 
La Moule est encore caractérisée par sa figure, par son pied et par son byssus.

$1{ }^{\circ}$ Sa figure deltoïde n’est pas sans élégance. Ses valves sont égales entre elles, bombées et à peu près triangulaires. Un des côtés de l'angle aigu forme la charnière, où l'on observe un ligament étroit et allongé. La partie antérieure du Mollusque est logée dans l'angle aigu.

2. Le prétendu pied de notre Mollusque est organisé comme un petit doigt. Il peut atteindre jusqu à ä centimètres de longueur; il est crensé d'un sillon longitndinal. C'est un organe de tact bien plus qu'un instrument de reptation. A ce point de vue, la Moule est plus favorisée que l'Huitre, et si elle a plus de tact, elle est plus intelligente....

Cette différence nous explique peut-être pourquoi l'on dit proverbialement : Bète comme une Huître, tandis qu'on n’a jamais dit: Bêle comme une Moule! (Reveillé-Parise.)

$3^{\circ}$ Le byssus est un assemblage de petits câbles divergents qui amarrent le bivalve d'une manière si solide, qu'il peut braver l'effort de la tempête. On a plus de peine à le détacher qu'à le casser.

La glande qui sécrète le byssus se trouve près de la base du pied. Il en sort une matière d'abord demi-liquide qui remplit le sillon de cet organe, sillon qui se convertit en canal, dans lequel le fil se moule et s'organise.

Quand le Mollusque veut fixer son byssus, il allonge le pied, le porte à droite et à gauche, tâte les objets, appuie sa pointe contre le corps qu'il a choisi, dépose l'extrémité du fil, et, retirant le pied brusquement, il laisse cette extrémité adhérente. Le bivalve répète plusieurs fois ce petit manége, et chaque fois il attache un nouveau fil. Il en fixe ainsi quatre ou cinq par vingt-quatre heures, chacun Jong de plusienrs centimètres et terminé par un empatement. 
Son ancrage est complet quand il en a produit un linisceau. l. byssus de certaines Moules présente jusqu’ì cenl cinquante petits cábles : nos vaisseanx ne sont pas andurrés aussi solidement!

Quand la Moule a tendu un premier cordage, elle le met a l'épreuve pour s'assurer sil est bien attaché. Elle le tire fortement, comme pour le rompre. S'il résiste à cet effort, elle travaille à la production et à la fixation du second fil, qu'elle essaye comme le premier. Décilément la Voule. a plus d'esprit que l'Huitre!

A l'aide de son byssus, notre bivalve se suspend à différentes hauteurs; il touche rarement le sol. Voilà pourquoi sa coquille est toujours bien unie et bien proprette. On no peut pas en dire autant du test de son orgueilleuse rivale, dont les battants, grisatres et raboteux, retiemnent le phus souvent, dans les intervalles de leurs feuillets, de la terre, le la bone et toute sorte d'ordures étraugères. Evidemment, l'habit ne fait pas toujours le moine!

Les Moules sont, comme les Huitres, des Mollusques sociables. On les tronve nombreuses presque partont. Elles aiment le mélange des eaux douces et des eaux salées : il est peu de rochers, à l'embouchure des fleuves, où l'on n'en rencontre quelque florissante colonie. Elles s'attachent tantôt aux branches des Polypiers et aux racines des arbres, tantôt aux bois submergés, aux piquets du rivage et à la carène des bateaux....

\section{I}

On mange la Moule tantôt crue, tantôt cuite. Mais la saveur de ce coquillage ne plait pas à tout le monde; cependant nous avons conmu des gourmets qui l'avaient 
ell grande estime. Louis XVIII aimait passionnóment les Noules : charque semaine, on lui en faisait venir de la Rochelle. Le monarque, dans un jour de belle humem, enseigna, dit-on, à VI. de Talleyrand la recette d'une sauce an poivre de Cayeme, qui plaçait désormais ce bivalve au rang des mets du premier ordre.

Toutefois nous devons convenir que la Moule est moins appétissante que l'lluître. moins excitante ot surtout moins légère.

N'oublions pas unc recommandation gastronomique qui n'est pas sans importance. On doit manger les Moules pendant tous les mois sans $\boldsymbol{r}$, tandis que les amateurs ne prisent les Huitres que dans les mois dont le nom conticnt cette lettre.

Un pharmacien d'Orléans a publié un mémoire sur l'emploi de la Voule dains les affections des voies respiratoires (?)....

Hélas! on adresse à notre coquillage le grave reproche d'ètre malsain, même nuisible à certaines époques de l'année, et malheureusement ces époques ne sont pas exactement connues. La Iloule occasionne alors des nausées, des coliques, un saisissement à la gorge, une éruption cutanée, une sorte d'empoisonnement.... Les médecins sont embarrassés pour expliquer ce genre d'action. Au moven âge, on croyait que les phases de la lune et la malice des sorciers y étaient pour quelque chose. Aujourd'hui, on est plus raisonnable, mais est-on mieux renseigné? On accuse tour à tour : la présence des pyrites cuivreuses dans les parages habités par la Moule; le séjour de ce bivalve contre la coque des navires tapissée de vert-degris; une maladie qui lui serait particulière; la fermentation ou la décomposition de son tissu; certains petits Crabes logés entre ses valves; enfin, le frai des Fitoiles de mer 
(Lamouroux) et cehui des Méduses (Durandean). Ces denx dernicres causes semblent ètre les plus habituclles.

\section{III}

De bonne hemre on a eu l'idée d'élever les Moules. II existe une mytilicullure comme il existe une ostréiculture.

L'éducation de nos bivalves a lieu sur une tres-graude échelle dans diverses localités, particulièement à Lisnandes, à Marsilly et à Charron, dans la baie de l'Aiguillon, près de la Rochelle.

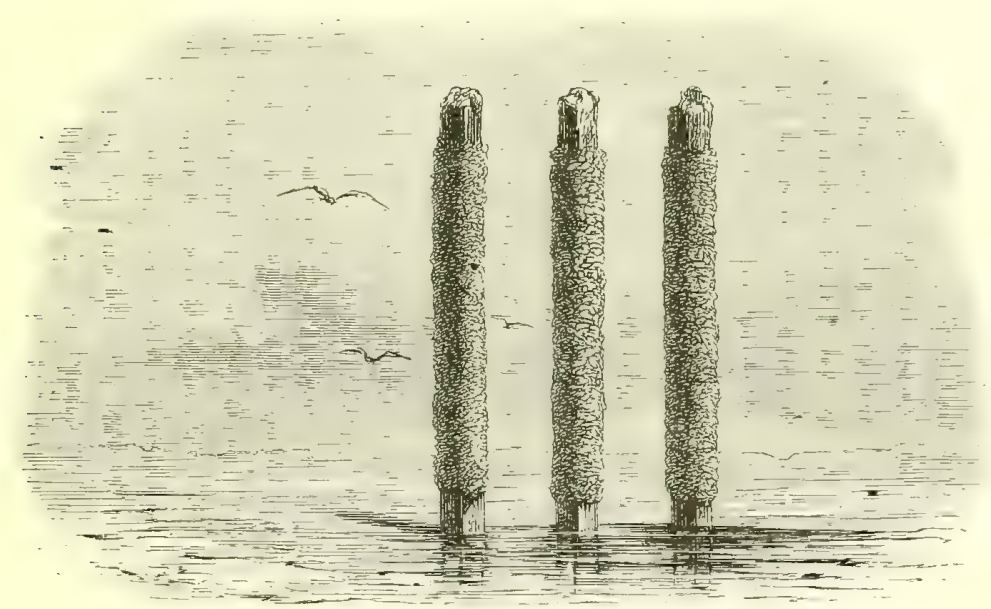

WHE $X$ COLLECTEL RS WI RR.H.

Les premiers pares furent établis, en 1230, par un patron de barque irlandais, nommé Patrice Walton, jeté sur nos côtes à la suite d'un naufrage. La nécessité lui suggéra lidée de tirer parti de ces plages abandonnées, et il fonda la mytiliculture.

Les descendants de Walton habitent encore à Esnandes, entourés de l'estime publifue. Ils continuent avec succès l'industric crééc par leur aiteul. 
Un pratique des pares artificiels, formés de pieux et de palissades réunis par un clayonnage grossier haut de 2 metres et tapissé de Fucus. Ces palissades avancent dans l'Océan quelquefois jusqu'à une lieue; elles dessinent un triangle dont la base est tournée vers le rivage et la pointe vers la mer. A cette pointe, on pratique un passage étroit. Le triangle dont il s'agit est le champ où l'on sème, où l'on éclaircit, où l'on repique, où l'on plante, où l'on récolte les Moules. (Quatrefages.)



CLMUTYSGE CHARGE DE MUTLES,

Ces pares sont désignés sons le nom de bouchots; on appelle boucholeurs les pêcheur's qui les exploitent.

La plupart des boucholeurs possèdent phisieurs bouchots. comme certains propriétaires plusieurs fermes. Quelquesuns, les plus pauvres, n'ont pour tout patrimoine que la moitié, le tiers, le quart, ou mème le cinquième de l'un de ces établissements, qu'ils soignent en commun nvec leurs associés, et dont ils partagent les charges et les bénéfices. (Coste.) 
Un récolte les Moules toute l'année, excepté pendant les grandes chaleurs et à l'époque du frai. On attend que la marée soit basse, mais alors le bouchot n'est plus qu'ume vasière. Pour ne pas s'enfoncer dans le sol, qui est trísmou, le boucholeur fait usage d'une sorte de nacelle, moitic bateau, moitié patin, nommée acon ou pousse-pied. Cet instrument ingénieux est long de 2 mètres et large de ¿0 centimetres. Il se compose de quatre planches minces. Celle du fond, de bois de noyer, se relève en avant et s'appelle sol ou semelle; les trois autres, de sapin, forment les flanes et l'arrière, lequel est coupé carrément.

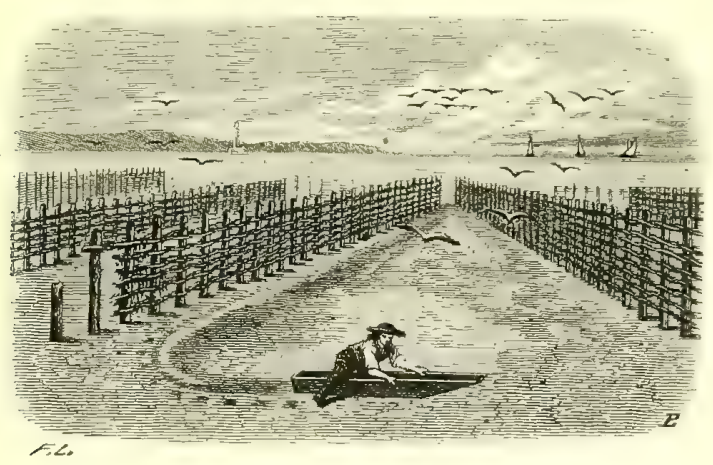

BOUCHOLEUR DAXS SOY ACOY.

(Quand il veut se servir de l'acon, le boucholeur se met à cheval sur l'un des bords, tient ployée sous lui une jambe, se penche en avant, et s'appuie sur les deux mains, qui étreignent les deux côtés de la nacelle. Il pousse avec l'autre jambe enfoncée daus la vase, et glisse avec rapidité sur la surface du bouchot. Le pécheur peut prendre une personne avec lui dans son acon.

C'est de la sorte que les boucholeurs se rendent à leurs bouchots, qu'une longue habitude leur permet de distinguer de ceux de leurs voisins, mème pendant les nuits les 
plus obscures, malgré tons les détours de l'immense labyrinthe que forment sur la vasière les six mille palissades qui la recouvrent aujourd'hui. (Coste.)

D’Orbigny père a pullié en 1847 , sur la inytiliculture, un mémoire très-intéressant. A cette époque, les bouchots étaient disposés sur quatre rangs au plus. En 18:2, M. de Quatrefages a vu sept rangs de bouchots. Au lieu de simples pieux, on employait des poutres énormes, et l'ensemble formait une immense estacade continue de 4 kilomètres de large sur 10 de long.

Il résulte, des recherches faites par d'Orbigny, que, antérieurement à 1834, trois cent quarante bouchots, ayant coùté 700000 francs en nombre rond, et exigeant anmuellement près de 400000 francs de frais d'entretien, y compris l'intérêt du capital engagé, donnaient 124000 franes de revenu net, et entrainaient un mouvement de charrettes, de chevaux ou de barques, repré-

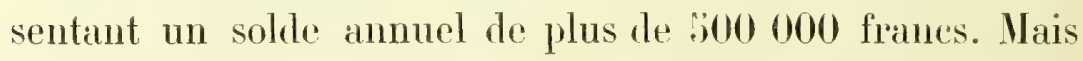
tout grandit vite de nos jours. Au lieu de trois cent quaraute bouchots, il y en a maintenant plus de cinq cents, formés par mille palissades. Chaque bouchot représentant en moyenne une longueur de 4.50 mitres, il s'ensuit que l'ensemble compose un clayonnage de 225000 mìtres de long. (Coste.)

La mytiliculture est done une des brauches les plus fécondes de la culture de la mer!

On devrait élever une statue au batelier Walton!.....

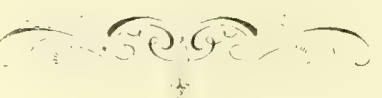




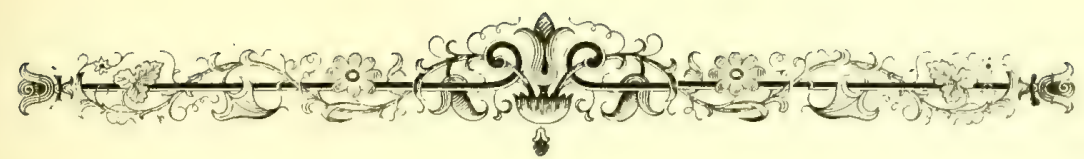

\section{CHAPITRE XXII}

\section{LA NAGRE ET LES PERLES.}

Ainsi la nacre industrieusc

Jette lat perle précieuse.

(A. Chévier.)

La nacre et les perles sont produites principalement par un coquillage bivalve que les conchyliologistes désignent sous le nom de Pintadine mère aux perles.

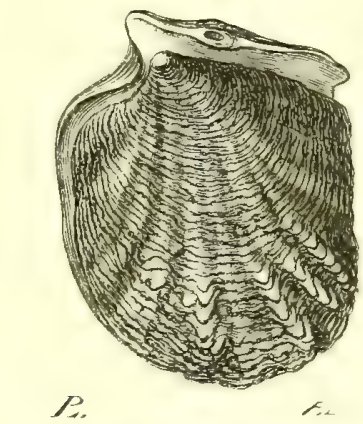

PIXTADIXE MLRE ALX PERLES

(Meleagrina margaritifera Lamarck).

Ce bivalve est amarré au fond de la mer par un byssus très-fort, de couleur brune.

Les battants de sa coquille sont irrégulièrement arrondis. 
Pendant leur jemnesse, ils paraissent en dehors légèrement feuilletés et ornés de bandes verdâtres et blanchâtres, qui partent du sommet en rayonnant et en se divisant en deux ou trois branches peu écartées. Dans leur vieillesse, leur surface devient rude et noirâtre.

Les plus belles coquilles sont âgées de huit à dix ans. Leur taille peut atteindre alors jusqu’à 15 centimètres de diamètre, et une épaisseur de 27 millimètres.

\section{I}

On appelle nacre, la substance très-dure et très-brillante qui forme la partie interne de ces valves. Cette matière est blanche, soyeuse, un peu azurée et plus ou moins irisée.

La plupart des bivalves peuvent fournir de la nacre. Il y en a même qui en donnent de bleuâtre, de bleue et de violette.

L'Oreille de mer Iris ${ }^{1}$ offre une nacre d'un beau vert d'émeraude chatoyant, avec quelques reflets d'un violet pourpre. Certains Turbos présentent leur bouche brillante comme l'argent ${ }^{2}$ qu éclatante comme l'or ${ }^{3}$. Mais ce sont les Pintadines qui donnent la nacre la plus blanche, la plus uniforme et surtout la plus épaisse.

Cette production doit à un jeu de lumière son aspect brillant et irisé.

Les marchands usent avec un instrument, ou dissolvent avec un acide toute la partie extérieure des coquilles bivalves ou univalves, et mettent à nu la couche nacrée.

1 Haliotis Iris Gmelin.

2 Turbo argyrostomus Linné.

3 Turbo chrysostomus Linné. 
Tantôt ils dénudent cette dernière en enticr, tantòt ils la font paraître par portions et par dessins.

\section{III}

Les perles, ces gouttes de rosée solidifée, suivant les Orientaux, sont des sécrétions maladives de l'organe de la nacre. La matière, au lieu de se déposer sur les valves par couches très-minces, se condense, soit contre ces mêmes valves, soit dans l'intérieur des organes, et forme des corps plus ou moins arrondis. Les perles déposées sur les valves sont généralement adhérentes; celles qui naissent dans le manteau ou dans le corps sont toujours libres. Généralement, on trouve dans leur centre un petit corps étranger, qui a servi de noyau à la concrétion. Ce corps peut être un ovule stérile du Mollusque, un auf de poisson, un animalcule arrondi, un grain de sable.... La matière solide est disposée tout autour, par couches minces et concentriques.

Les Chinois et les Indiens ont mis à profit cette observation pour faire produire à divers bivalves, soit des perles, soit des camées artificiels. Ils introduisent dans le manteau du Mollusque, ou bien ils appliquent à la face interue d'une valve des fragments arrondis de verre ou de métal. Dans un cas, ils obtiennent des perles libres, et dans l'autre des perles adhérentes. Voici contre une valve un chapelet tout entier, et sur une autre, une douzaine de jolis camées représentant des Chinois assis. Dans le chapelet sont des grains de quartz attachés par un fil, et dans les camées, des plaques d'étain représentant des figurines.

Une seule Pintadine contient quelquefois plusieurs perles. 
On en cite une qui en renfermait cent cinquante. Cela est-il bien exact?

Les perles sont d'abord très-petites. Elles s'accroissent

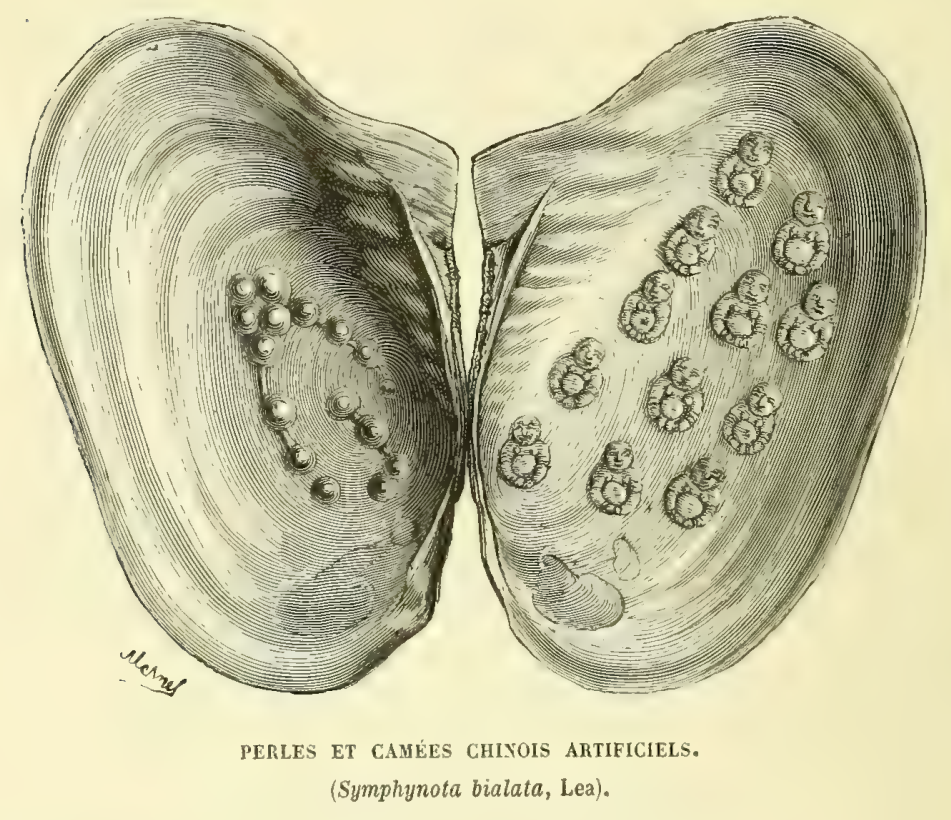

par couches aunuelles. Leur éclat et leur nuance varient comme ceux de la nacre yui les produit : tantôt elles sont diaphanes, soyeuses, lustrées et plus ou moins chatoyantes; tantòt mates, sales, obscures et plus ou moins enfumées.

\section{IV}

Les plus importantes pêcheries de P'intadines sont dans le golfe du Bengale, à Ceylan, et dans la mer des Indes. Avant 1795, ces pêcheries appartenaient aux Hollandais. Pendant la guerre des Indes, les Anglais s'en emparèrent, 
et la possession leur en fut définitivement cédée en 1802, avec celle de Ceylan, par suite du traité d'Amiens.

Avant le commencement de la pêche, le gouvernement ordonne une inspection des côtes. Il fait quelquefois la récolte à ses risques et périls. D'autres fois il s'adresse à des entrepreneurs. La saison de la pêche, en 180/, fut cédée à un capitaliste pour une somme de 3 millions. Afin de ne pas dépeupler toutes les zones à la fois, on ne va, tous les ans, que dans une partie du golfe.

La pêche des Pintadines, dans le golfe de Manaar, à Ceylan, commence en février ou en mars, et dure une trentaine de jours. Elle occupe plus de deux cent cinquante bateaux, qui arrivent des différentes parties de la côte.

Ces bateaux partent de dix heures du soir à minuit. Un coup de canon leur donne le signal. Dès que le jour arrive, les plongeurs se mettent à l'œuvre. Chaque barque est montée par vingt hommes et un nègre; les rameurs sont an nombre de dix. Les plongeurs se partagent en denx groupes de cinq hommes, qui travaillent et se reposent alternativement. Ils descendent jusqu'à la profondeur de 12 mètres, en se servant, pour accélérer leur descente, d'une grosse pierre pyramidale portée par une corde, dont l'autre extrémité vient s'amarrer au bateau.

D'après certains voyageurs, on fait souvent, avec les avirons et d'autres pièces de bois, une espèce d'échafaudage à jour, qui dépasse les deux côtés du bateau, et auquel on suspend la pierre à plonger. Celle-ci a la forme d'un pain de sucre et pése 2:3 kilogrammes. La corde qui la soutient porte, à la partie inférieure, un étrier pour recevoir le pied du plongeur.

Au moment de descendre dans l'eau, chaque homme met son pied droit dans cet étrier, ou bien passe entre les doigts de ce pied la corde à laquelle la pierre est attachée. 
Il place entre ceux du pied gauche le filet qui doit recevoir les Pintadines; puis, saisissant de la main droite une corde d'appel convenablement disposée, et se bouchant les narines de la main gauche, il plonge, se tenant droit ou accroupi sur les talons.

Chaque homme n'a pour vêtement qu'un morceau de calicot qui lui enveloppe les reins. Aussitôt arrivé au fond, il retire son pied de l'étrier ou ses doigts de la corde. On remonte sur-le-champ la pierre, qu'on accroche de nouveau à l'aviron. Alors le plongeur se jette la face contre terre, et ramasse tout ce qu'il peut atteindre. Il met les Pintadines dans son filet. Quand il veut remonter, il secoue fortement la corde d'appel, et on le retire le plus tôt possible.

Il y a toujours, pour une pierre à plonger, deux pêchenrs qui descendent alternativement; l'un se repose et se rafraîchit pendant que l'autre travaille.

Le temps qu'un habile plongeur peut demenrer sous l'eau excède rarement trente secondes. Lorsque les circonstances sont favorables, charque individu peut faire quinze à vingt descentes. Souvent il ne plonge guère que trois ou quatre fois. Ce travail est pénible. Les plongeurs, revenus dans la barque, rendent quelquefois par la bouche, le nez et les oreilles, de l'eau teintée de sang: aussi deviennent-ils rarement vieux.

On pêche habituellement jusqu'à midi. Un second coup de canon donne le signal de la retraite. Les propriétaires attendent leurs canots et surveillent leur déchargement, lequel doit avoir lieu avant la nuit.

En 1797, le produit de la pêche, à Ceylan, fut de 3600000 francs, et, en 1798, de 4800000 francs. A partir de 1802 , la pêcherie était affermée pour la somme de 3 millions; mais, depuis une quinzaine d'années, les banes de Pintadines sont moins productifs. (Lamiral.) 
Les indigènes des côtes du golfe $\dot{d} u$ Bengale, cewx des mers de la Chine, du Japon et de l'archipel Indien, se livrent aussi à la pêche des Pintadines. Le produit de cette industrie est estimé, dans ce pays, à une vingtaine de millions.

Des pêcheries analogues ont lieu sur les côtes opposées à la Perse, sur celles de l'Arabie, jusqu'à Mascate et la mer Rouge.

Dans ces pays, la pêche ne se fait qu'en juillet et août, la mer n'étant pas assez calme dans les autres mois de l'année. Arrivés sur les banes de Pintadines, les pêcheurs rangent leurs barques à quelque distance les unes des autres, et jettent l'ancre à une profondeur de $\breve{3}$ à 6 mètres. Les plongeurs se passent alors sous les aisselles une corde dont l'extrémité communique avec une sonnette placée dans la barque. Ils mettent du coton dans leurs oreilles et pincent leurs narines avec une petite pièce de bois ou de corne. Ils ferment hermétiquement la bouche, attachent une grosse pierre à leurs pieds, et se laissent aller au fond de l'eau. Ils ramassent indistinctement tous les coquillagés qui sont à leur portée, et les jettent dans un sac suspendı an-dessus des hanches. Dès qu'ils ont besoin de reprendre haleine, ils tirent la sonnette, et aussitôt on les aide à remonter.

Sur les banes de l'île de Bahrein, la pêche des perles produit seule environ 6 millions de franes, et, si l'on y ajoute les approvisionnements fournis par les autres pêcheries du voisinage, la somme totale donnée par ces côtes arabes peut s'élever jusqu'à 9 millions. (Wilson.)

Dans les mers du sud de l'Amérique, il existe aussi des pêcheries de même genre. Avant la conquête du Mexique et du Pérou, les pêcheries étaient situées entre 
Acapulco et le golfe de Tehuantepec. Mais, après cette époque, d'autres exploitations furent établies auprès des îles de Cubagua, de Marguerite et de Panama. Les résultats en devinrent si productifs, que des villes populeuses ne tardèrent pas à s'élever dans ces divers lieux. (Lamiral.)

Sous le règne de Charles-Quint, l'Amérique envoyait des perles à l'Espagne pour une valeur annucile de plus de 4 millions de franes. Aujourd'hui, l'importance des pêcheries américaines n'est plus évaluée qu’à 1500000 francs.

Les plongeurs des côtes dont il vient d'être question descendent tout nus dans la mer. Ils y demeurent vingtcinq à trente secondes, pendant lesquelles ils arrachent seulement deux ou trois Pintadines. Ils plongent ainsi douze à quinze fois de suite : ce qui donne, en moyenne, de trente à quarante Pintadines par plongeur.

\section{V}

Les Pintadines, apportées sur le rivage, sont étalées sur des nattes de sparterie. Les Mollusques meurent et ne tardent pas à se putréfier : il faut dix jours pour qu'ils se corrompent. Quand ils sont dans un état convenable de décomposition, on les jette dans de grands réservoirs remplis d'eau de mer; puis on les ouvre, on les lave, et on les livre aux rogueurs.

Les valves foumissent la nacre, et le parenchyme les perles.

On nettoie les valves et on les entasse dans des caisses ou des tonneaux. En enlevant leur surface extérieure, on 
obtient des plaques de nacre plus ou moins épaisses, suivant l'âge du Mollusque.

On distingue, dans le commerce, trois sortes de nacres: la franche argentée, la bälarde blanche, la bätarde noire.

La première se vend par caisses de 125 à 140 kilogrammes. On l'apporte des Indes, de la Chine et du Pérou. Les navires marchands français, hollandais, anglais of américains importent dans nos ports des coquilles en vrac, c'est-à-dire à fond de cale, pour servir de lest.

La seconde nacre est livrée en cafas de 125 kilogrammes, ou par tomneaux. Elle est d'un blane jaunitre et quelquefois verdâtre ou rougeâtre, et plus ou moins irisée.

La troisième est une variété d'un blanc blenâtre tirant sur le noir, avec des reflets ronges, bleus et verts. (Lamiral.)

\section{I}

Les perles forment la partic la plus importante de cette industrie.

Quand elles sont adhérentes aux valves, on les détache arec des tenailles. Mais, habituellement, les rogueurs les cherchent au milieu du parenchyme de l'animal. Puis on fait bouillir ce même parenchyme, et on le tamise pour obtenir les plus petites, ou bien les grosses oubliées dans la première opération.

Quelques mois après qu'on a jeté le Vollusque putréfié, on voit encore de misérables Indiens remuer ces masses corrompues, pour y chercher les petites perles qui ont pu échapper à la sagacité des industriels.

On nomme baroques les pertes allhérentes ì la coquille: 
leur forme est plus ou moins irrégulière; elles se vendent au poids. On appelle vierges ou parangons les perles isolées, formées dans le tissu de l'animal: elles sont globuleuses, ovoïdes ou piriformes; elles se vendent à la pièce.

On nettoie les perles recueillies. On les travaille avec de la poudre de nacre, afin de leur donner de la rondeur et du poli. Enfin, on les fait passer dans divers cribles de cuivre pour les séparer en catégories.

Ces cribles, au nombre de onze, sont faits de manière à pouvoir s'enchàsser les uns dans les autres; chacun est percé d'un nombre de trous qui détermine la grosseur des perles et leur donne leur numéro commercial. Ainsi, le crible $n^{0} 20$ est percé de vingt trous, et les cribles $\mathrm{n}^{\mathrm{os}} \cdot 30,50,80,100,200,600,800,1000$, sont percés d'un nombre de trous égal à ces chiffres. Les perles qui restent au fond des eribles $n^{\text {os }} 20$ à 80 sont comprises sous la dénomination de classe mell, ou perles du premier ordre. Celles qui traversent les cribles $n^{\text {os }} 100$ à 800 sont de la classe vadivoo, ou perles du second ordre. Enfin, celles qui passent au travếs du crible no 1000 appartiennent à la classe nomméẻ tool, ou semence de perles, qui sont celles du troisième ordre. (Lamiral.)

On enfile avec de la soie blanche ou bleue les perles moyennes et les petites; on réunit les rangs par un nœud de ruban bleu ou par une houppe de soie rouge, et on les expédie ainsi par masses de plusieurs rangs, suivant le choix des perles.

Les très-petites perles, dites semence, se vendent à la mesure de capacité ou au poids.

En Amérique, on ouvre les bivalves l'un après l'autre, avec un couteau, et l'on cherche les perles en écrasant le Mollusque entre les doigts. On n'attend pas que son parenchyme ait été ramolli par la putréfaction, et on ne le fait 
pas bouillir. Ce travail est plus long et moins sûr que le procédé des Indes orientales décrit plus haut; mais les Américains prétendent que leur manière d'opérer conserve mieux anx perles leur fraîcheur et leur orient.

\section{VII}

Divers auteurs ont donné la mesure ou le prix de phlısieurs perles célèbres.

Une perle de Panama, en forme de poire et grosse comme un cuf de pigeon, fut présentée, en 1579, à Philippe II, roi d'Espagne. Elle était estimée 100000 franes.

Une dame de Madrid possédait, en 160:\%, une perle américaine du prix de 31000 ducats.

Le pape Léon $\mathrm{X}$ acheta me perle à un joaillier vénitien pour la somme de 350000 franes.

Une autre perle donnée par la république de Venise à Soliman, empereur des Tures, valait 400000 francs.

Jules César offrit à Servilia une perle évaluée à un million de sesterces, environ 1200000 francs de notre monnaie.

On ne connaît pas au juste le volume ni la valeur des deux fameuses perles de Cléopâtre : l'une que cette reine eut le singulier caprice de faire dissoudre dans du vinaigre et de boire (Dieu nous préserve d'une pareille boisson!); l'autre qui fut partagée en deux parties et suspendue aux oreilles de la Vénus du Capitole. Quelques auteurs pensent que la première de ces perles valait 1500000 franes.

Il y a deux siècles, une perle fut achetée à Califa par le voyageur Tavernier, et vendue au schah de Perse pour le prix énorme de 2700000 franes. 
Un prince de Mascate a possédé une perle extrêmement belle, non à cause de sa grosseur, car elle ne pesait que 12 carats $1 / 16^{\circ}$, mais paree (puelle était si claire et si transparente, qu'on voyait le jour à travers. On lui en offrit 2000 tomaris, environ 100000 franes. Il refusa de la céder.

On trouve dans le musée Zozima, à Moscou, une perle presque aussi diaphane. On l'appelle pellegrina. Elle pèse près de 28 carats; sa forme est globuleuse.

On dit que la perle de la conronne de Rodolphe II pesait 30 carats, et qu'elle était grosse comme une poire. Ce volume est plus que douteux.

Le schah de Perse actuel possède un long chapelet dont chaque perle est à peu près de la grosseur d'une noisette. Ce joyau est inappréciable.

En 1855, à l'Exposition universelle de Paris, la reine d'Angleterre nous a fait voir de magnifiques trésors de perles fines, et l'Empereur des Français en a montré une collection de 408 , chacune pesant 16 grammes, d'une forme parfaite et d'une belle ean. Elles valent ensemble plus de 500000 franes.

Les Romains estimaient beaucoup les perles fines; ils ont transmis leur passion aux Orientaux. Ceux-ci attachent une idée de grandeur et de puissance à la possession des perles les plus grosses et les plus éclatantes.

\section{VIII}

Les Pintadines ne sont pas les seuls bivalves de la mer qui puissent donner des perles. Presque tous les Mollusques sont sujets à la maladie qui faconne la nacre en tubérosités arrondies ou ovoüdes. 
M. Lamiral a vu une perle de la grosseur d'um œuf de poule Bantam, parfaitement sphérique et blanche comme du lait, provenant du grand Bénitier.

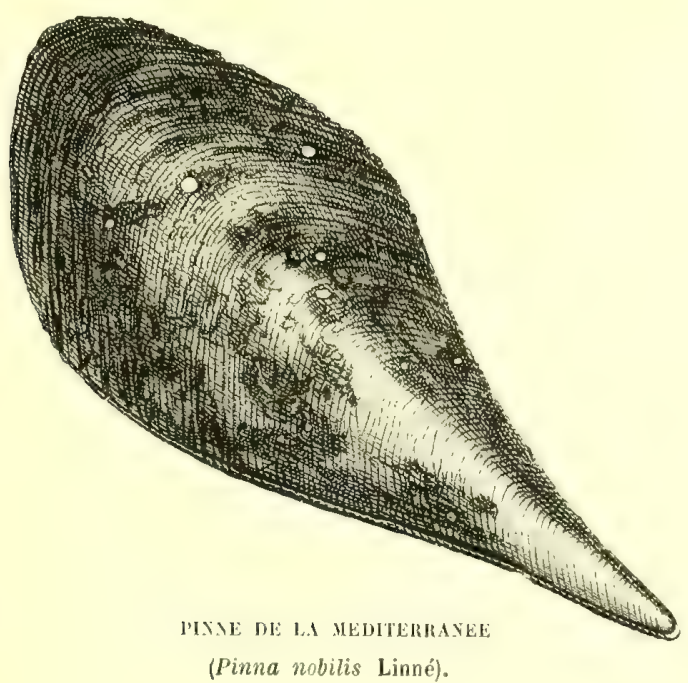

La Pinne marine produit des perles roses. L'Oreille de mer Iris en dome de vertes. D'autres bivalves en fournissent de bleues, de grises, de jaunes et même de noires. Ces dernières sont très-peu communes.

Il y en avait un collier dans le trésor de l'empereur de la Chine. Est-ce le même dont on a fait présent à une auguste souveraine?

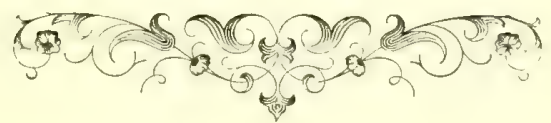





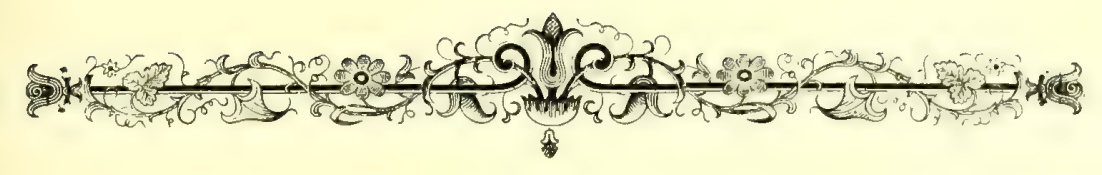

\section{CHAPITRE XXIII}

\section{LES MOLLUSQUES CEPHALES.}

Ame tout aquen poble cimable é banari.

(C. Reybaud.)

Les Mollusques sans tête (Acéphales) nous conduisent naturellement à ceux qui en ont une, les Mollusques Céphalés.

Nous trouvons encore, parmi ces derniers, des especes nues et des espèces testacées.

Les Céphalés nus ${ }^{1}$ varient assez dans leurs formes. Les plus communs sont ovoïdes, plus ou moins allongés, bombés en dessus, plans en dessous, avec une tête antérieure plus ou moins caractérisée, portant plusieurs organes sensitifs, entre autres deux yeux bombés et humides, et presque toujours des cornes ou tentacules, des barbillons ou des panaches.

Un trait distinctif, assez général chez ces animaux, bien

1 Voyez les planches XVII, XVIII et XIX. - Les dessins de ces deux planches nous ont été communiqués par M. Deshayes et par M. de Quatrefages. 
prononcé, surtout chez ceux qui jouissent de la faculté de marcher (ou, pour mieux dire, de ramper), c'est la présence d'une dilatation charmue abdominale, sorte de disque énorme, formé d'un entrelacement inextricable de fibres musculaires, avec lequel le Mollusque exécute une série de petites ondulations successives qui ont été comparées à des vagues en miniature. A cause de ce pied-ventre, Cuvier désigné ces individus sous le nom de Gastéropodes.

Signalons tout d'abord les Aplysies ${ }^{1}$, on Lièvres de mer, petits Mollusques qui ressemblent, jusqu'à un certain point, aux quadrupèdes dont on leur a donné le nom.

Ils vivent parmi les plantes marines. Ils ont un cou plus ou moins long et deux prolongements supérieurs creusés comme des oreilles de Quadrupède.

Leurs dents ne sont pas dans la bouche, mais dans l'estomac. Ce dernier est Quadruple; il se compose d'un jabot énorme, membraneux, d'un gésier musculeux, d'une autre poche accessoire, et d'une quatrième en forme de sac aveugle (Cuvier). Le gésier est armé de plusieurs saillies cartilagineuses, pyramidales, à base rhomboïde, dont les faces irrégulières se réunissent en un sommet partagé en deux ou trois pointes émoussées. Il y en a douze grandes placées en quinconce sur trois rangs, et sept ou huit petites disposées en ligne sur le bord supérieur. Les hauteurs de ces pyramides sont telles, que leurs pointes se touchent au milieu du gésier, et qu'il reste entre elles très-peu d'espace pour le passage des aliments, qu'elles doivent par conséquent triturer avec force (Cuvier). Dans le troisième estomac, il existe une armure tout aussi singulière : ce sont de petits crochets arqués et pointus, dirigés vers le gésier. Cuvier ne peut leur attribuer d'autre desti-

- Aplysia Linné. 

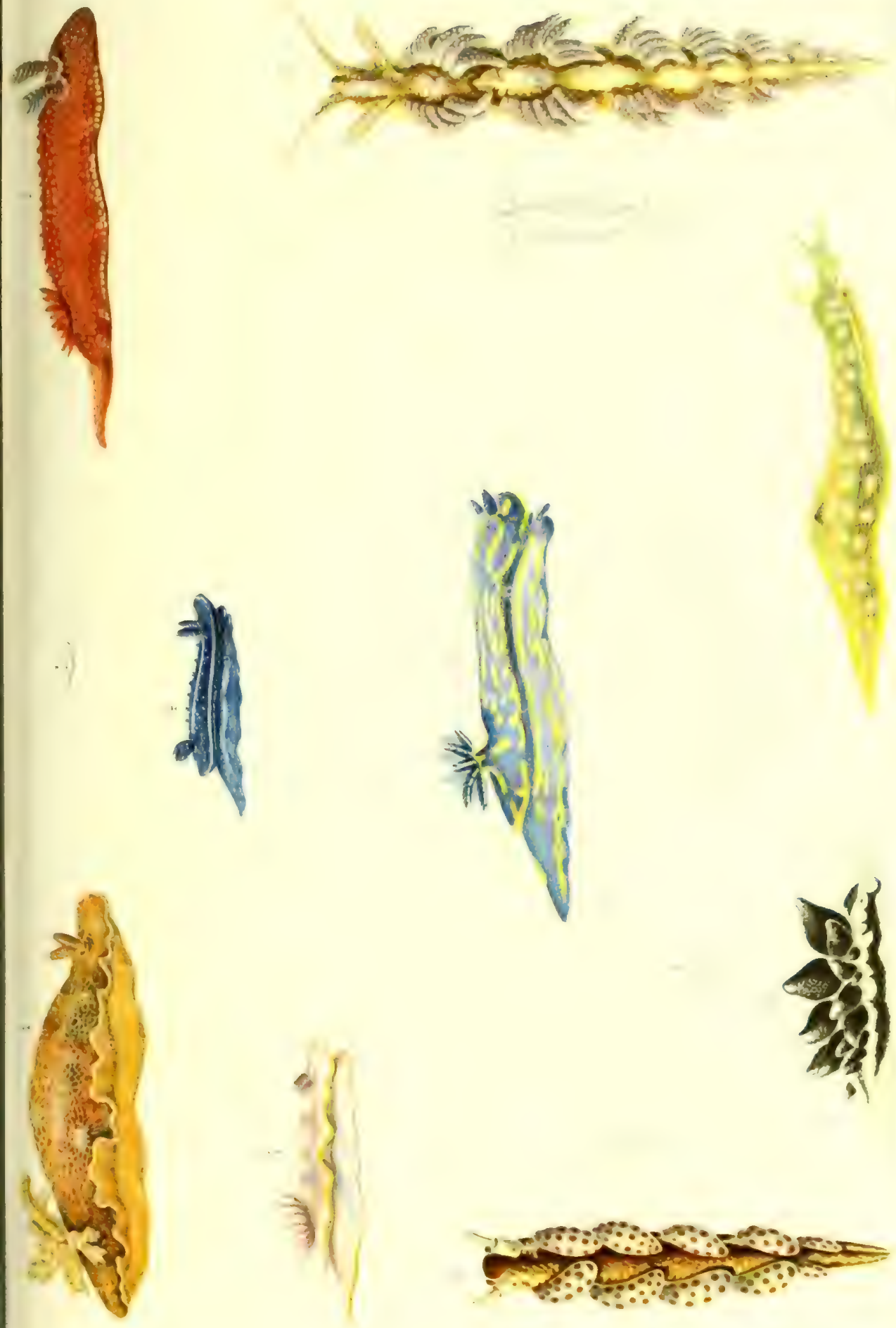

0
2

is

$w$
2
0
0
2
1
-1
0
5
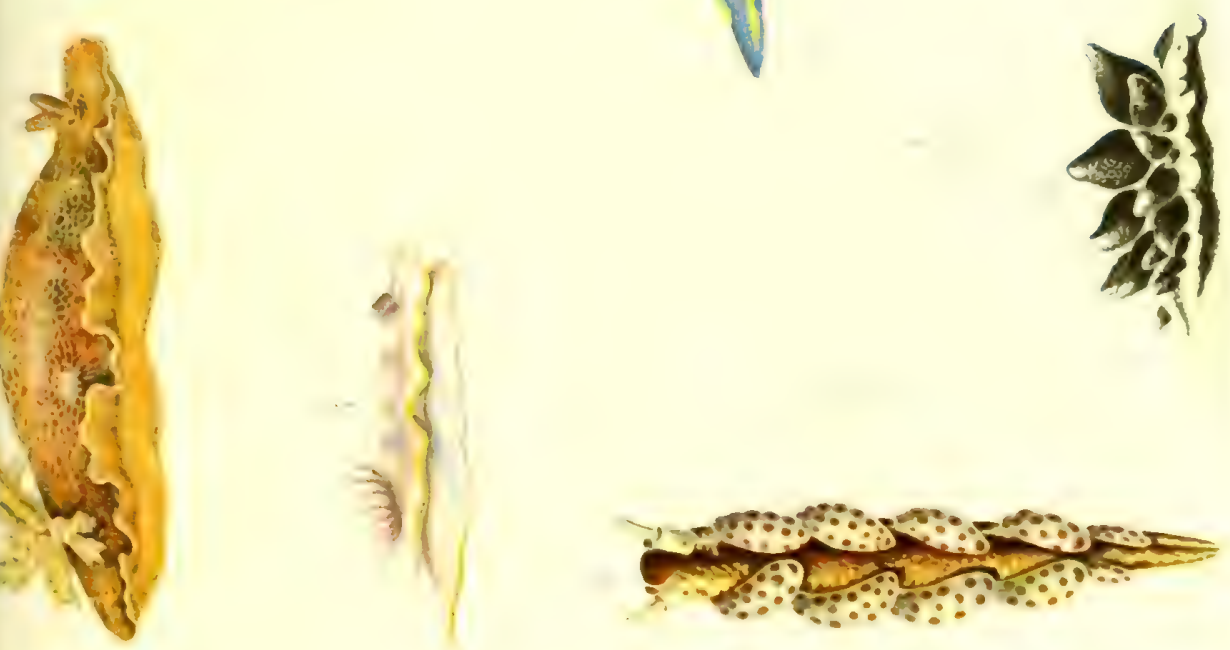

nation que d'arrêter au passage les aliments qui n'auraient pas été suffisamment broyés.

En général, chez les Mollusques, par une merveilleuse compensation, la puissance de l'estomac est toujours en raison inverse de l'insuffisance des dents. Cet organe est d'autant plus faible, que la màchoire est mieux garnic, et d'autant plus énergique, que l'appareil dentaire est plus imparfait. Dans certaines circonstances, comme chez le Lièvre de mer, l'estomac a recu, en supplément d'organisation, des pièces solides, plus ou moins semblables aux dents, qui lui permettent de fonetionmer à la fois et comme estomac et comme bouche.

Les Aplysies exhalent une odeur désagréable ${ }^{1}$; elles sécrètent une humeur limpide particulière, fort âcre dans certaines espèces, qui peut faire enfler les mains de ceux qui les touchent imprudemment. Des bords de leur manteau suinte en abondance une autre liqueur d'un pourpre obscur, dont l'animal colore autour de lui l'eau de mer, quand il aperçoit quelque danger.

Ces Mollusques sont doux et timides.

Les Lièvres de mer étaient regardés par les anciens comme des animaux malfaisants. On leur attribuait une influence magique, par exemple celle d'agir sur le cœur du beau sexe et sur ses déterminations. Apulée fut accusé de sorcellerie pour avoir acheté des Aplysies à des pècheurs. Il venait d'épouser une jeune et riche venve; son principal crime était son mariage, et son principal accusateur le fils de cette veuve!

Les Aplysies ont des organes respiratoires frangés cachés sous leur manteau.

Chez les Tritonies, Céphalés peu différents des Lièvres

1 "Fotidissima ad nauseam usque., (Linné.) 
de mer, ces derniers organes sont à découvert. Ils ressemblent à de petits arbustes.

Le long de nos côtes, nous avons une grande espèce de ce geure, couleur de cuivre, décrite par Cuvier ${ }^{1}$. Dans les eaux de la Sicile, nous en rencontrons une autre encore plus jolie, découverte par M. de Quatrefages. Qu'on se représente une sorte de petite Limace allongée, portant sur ses flancs une rangée de buissons animés, d'une excessive délicatesse. Sa tête est ornée, en avant, d'un voile étoilé de la plus fine gaze, et surmontée de deux grandes cornes transparentes comme du verre, à l'extrémité desquelles s'épanouit un bouquet de branchages roses entremêlés de fleurs violettes.

Tout près des Tritonies viennent se ranger les Scyllées.

Une d'elles, bien connue, la Scyllée pélagique², est commune parmi les Varees de toutes les mers. Son corps est comprimé; le Mollusque embrasse avec son pied étroit, creusé d'un sillon, les tiges des plantes aquatiques. Il a sur le dos plusieurs séries d'organes respiratoires qui s'élèvent comme deux paires de crêtes membraneuses, donnant naissance, à leur face interne, à des pinceaux de filaments. Ses tentacules sont terminés par un creux, d'où sort une petite pointe à surface inégale. La bouche possède une sorte de trompe. Enfin, son estomac présente un anneau charnu, armé de lames cornées, tranchantes comme des couteaux. (Cuvier.)

Förster a décrit, sous le nom de Glauque (Glaucus), un genre de Gastéropodes peu différent des Scyllées. Ce sont de charmants petits Mollusques nageurs, à corps allongé, gélatineux, rétréci d'avant eu arrière, et terminé par une

1 Tritonia Hombergii Cuvier.

2 Scyllaca pelagica Linné. 
queue grêle et pointue, comme une queue de Salamandre (Cuvier). Leur couleur est d'un gris de perle passant au bleu céleste, avec le dos nacré, traversé par deux bandes longitudinales d'un bleu foncé brillant, et le ventre taché de brun. Leur tête est petite; elle agite en avant quatre tentacules courts, coniques, disposés par paires. De chaque côté du corps s'étalent trois ou quatre appendices (nageoires branchiales) opposés, semblables à de grands éventails ovalaires ou arrondis, d'un gris bleu plus ou moins pur, avec une zone plus foncée. Chaque éventail est composé d'unc palette horizontale, bordée de digitations longues, flexueuses et pointues. Les éventails antérieurs sont les plus grands et pourvus d'un pédicule. Les autres diminuent graduellement de taille et manquent de support.

L’animal se tient habituellement renversé sur le dos. Quoique paresseux, il nage avee vitesse; il est aussi distingué dans ses monvements que recherché dans sa parure.

Cuvier a nommé É lides $^{1}$ d'autres Gastéropodes nus, d'unc physionomie tout aussi remarquable. Il les signale comme de petites Limaces sans cuirasse ni manteau. Leur tète porte quatre tentacules, et leur bouche deux petits barbillons. Leurs organes respiratoires consistent en lamelles ou filaments groupés par paquets, toujours des deux côtés du dos. Chez le Dendronote arborescent, les branchies sont au nombre de six ou sept paires; chacune porte quatre ou cinq branches principales, divisées et subdivisées en un grand nombre de ramuscules.

Quand ces Mollusques se reposent, leurs branchies affaissées s'entrecroisent, et leurs grands tentacules sont tordus comme les cornes d'un Bélier. Quand ils marchent, ils

1 Voyez fig. et 7, planche XVII, et les figures de la planche XVIII. 
redressent ces derniers appendices et les brandissent fièrement au-dessus de leur petite tête.

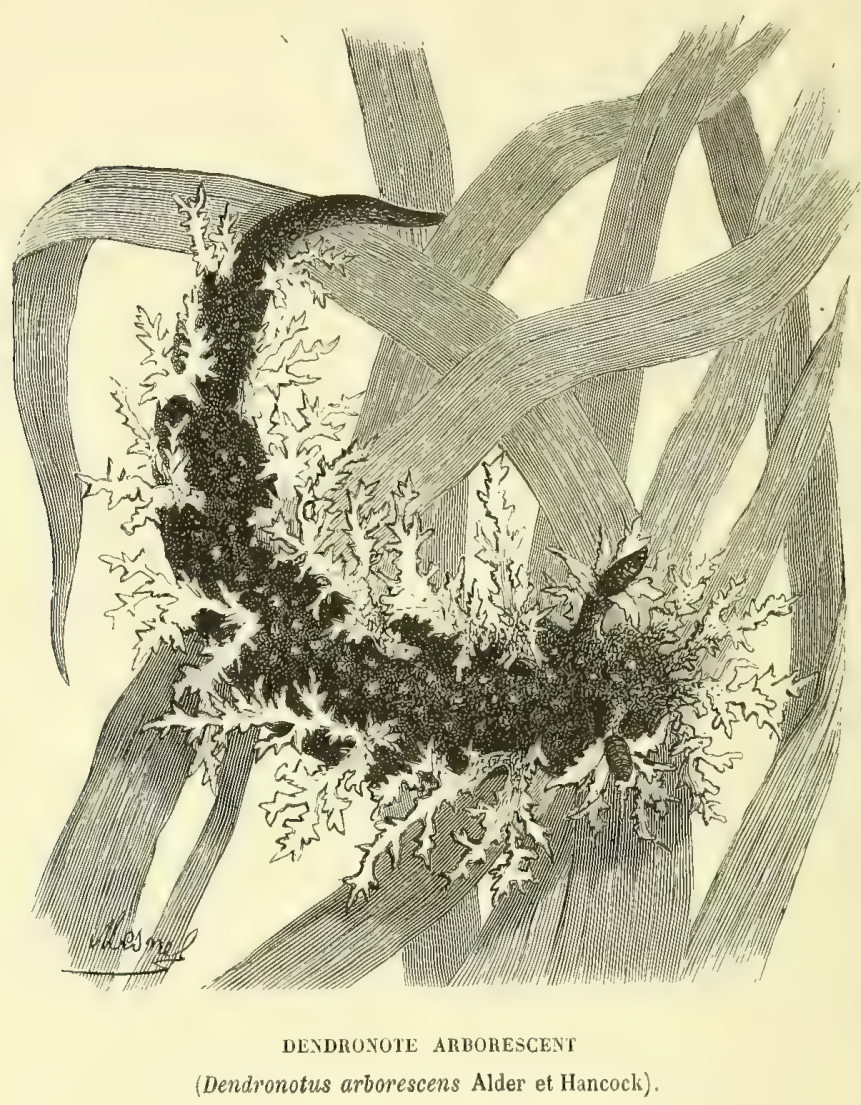

Les Éolides sont des créatures vives, irritables, querelleuses: elles se disputent les proies avec acharnement; elles se mordent et se mutilent. Leurs organes saillants, tentacules ou branchies, se trouvent souvent, après le combat, dans un état déplorable. Il est vrai que tout cela peut repousser. M. Rymer Jones a vu un tentacule tout entier refait à neuf au bout de deux semaines.

Nous avons sous les yeux une petite Élide qui rampe tranquillement sur les parois d'un bocal. Elle a 4 centi- 
mètres de longueur, et un corps demi-transparent, légèrement azuré. Sa tête est à peine renflée et sa queue assez. pointue. Son dos parait jaunâtre et chatoyant. Ses cornes antérieures sont grêles et flexueuses; les postérieures, un peu moins longues et légèrement écartées, droites et roides. Les branchies forment quatre touffes rapprochées de lobes lancéolés-linéaires, un peu aigus, d'un rose vif, passant an pourpre à la partie inférieure, ot devenant couleur de chair pâle vers le sommet. Leur pointe est incolore et transparente.

Il serait difficile de rendre une vilaine Loche plus élégante et plus gracieuse.

Pour terminer dignement ce paragraphe, nous décrirons, d'après M. de Quatrefages, la délicieuse Amphorine d'Albert', découverte par M. Camille Dareste, près de Bréhat, parmi les Goëmons.

L'animal est allongé, avec une tète plus grosse et surtout plus haute que le corps, et la queue très-effilée et trèspointue. Il possède quatre cornes inégales, disposées comme celles des Colimacons; il a deux yeux petits, violets, placés non pas au bout des grandes cornes, mais à leur base et en arrière. Les appendices branchiaux, au nombre de douze et sur deux rangs, ne ressemblent en rien à ceux des autres Céphalés. Ils sont alternativement fusiformes et ovoïdes, les uns petits, les autres grands; les premiers semblables à des urnes lacrymales, et les seconds à des amphores!

Ce Mollusque parait légèrement rugueux et d'un beau blane mat. La partie moyenne de ses cornes est d'un jaune d'or. Un cercle de la même couleur se trouve vers l'extrémité supérieure des branchies, et donne à leur sommet l'apparence d'un couvercle qui fermerait une ouverture à

\footnotetext{
1 Amphorina Alberti Quatrefages (voy. fig. 5 et 5, planche XIX). Cette espice serait, d'apris Alder el Hancock, un jeune de T'Eolis Ferrani.
} 
rebord coloré. Sur la ligne médiane du dos, il existe une série de taches jaunes. L’Amphorine est un vrai bijou de la nature.

\section{II}

Les Céphalés testacés possèdent une coquille d'une seule pièce. C'est pourquoi on les a nommés univalves. Cette coquille présente quelquefois une porte appelée opercule.

Chez les Nérites, la porte se meut sur un petit gond.

La coquille des Céphalés est habituellement tordue en spirale. "Quelle est la loi de cette organisation?") nous demandait un jour un jeune bachelier de la plus hante espérance. Voici notre réponse :

“Quand l'œuf des Mollusques univalves vient d'être pondu, il contient un germe punctiforme à peu près microscopirue ${ }^{1}$. Ce germe n'est autre chose, suivant les savants, que le vitellus, c'est-à-dire le jaune (il ne mérite pas ce dernier nom, attendu qu'il est gris). Tout autour se trouve une certaine quantité de blanc ou albumen, incolore et transparent. Au bout de quelques jours, le jaune se transforme en embryon. Celui-ci se met à tourner lentement sur lui-même; il fait la cabriole. Puis, il change de place et chemine le long de la paroi de son enveloppe protectrice, décrivant une ellipse. Ce double mouvement a été comparé avec raison à celui des corps planétaires. Il est produit par un certain nombre de cils vibratiles extrèmement petits, inégalement placés, qui revêtent l'animal dans les premiers temps de son existence. Ces cils absorbent l'air et la matière nutritive nécessaires au Mollusque; ils servent à sa respiration et à sa nutrition à une époque ou les organes spéciaux de ces deux fonctions n'existent pas

1 Voyez les figures de la planche XVIII. 


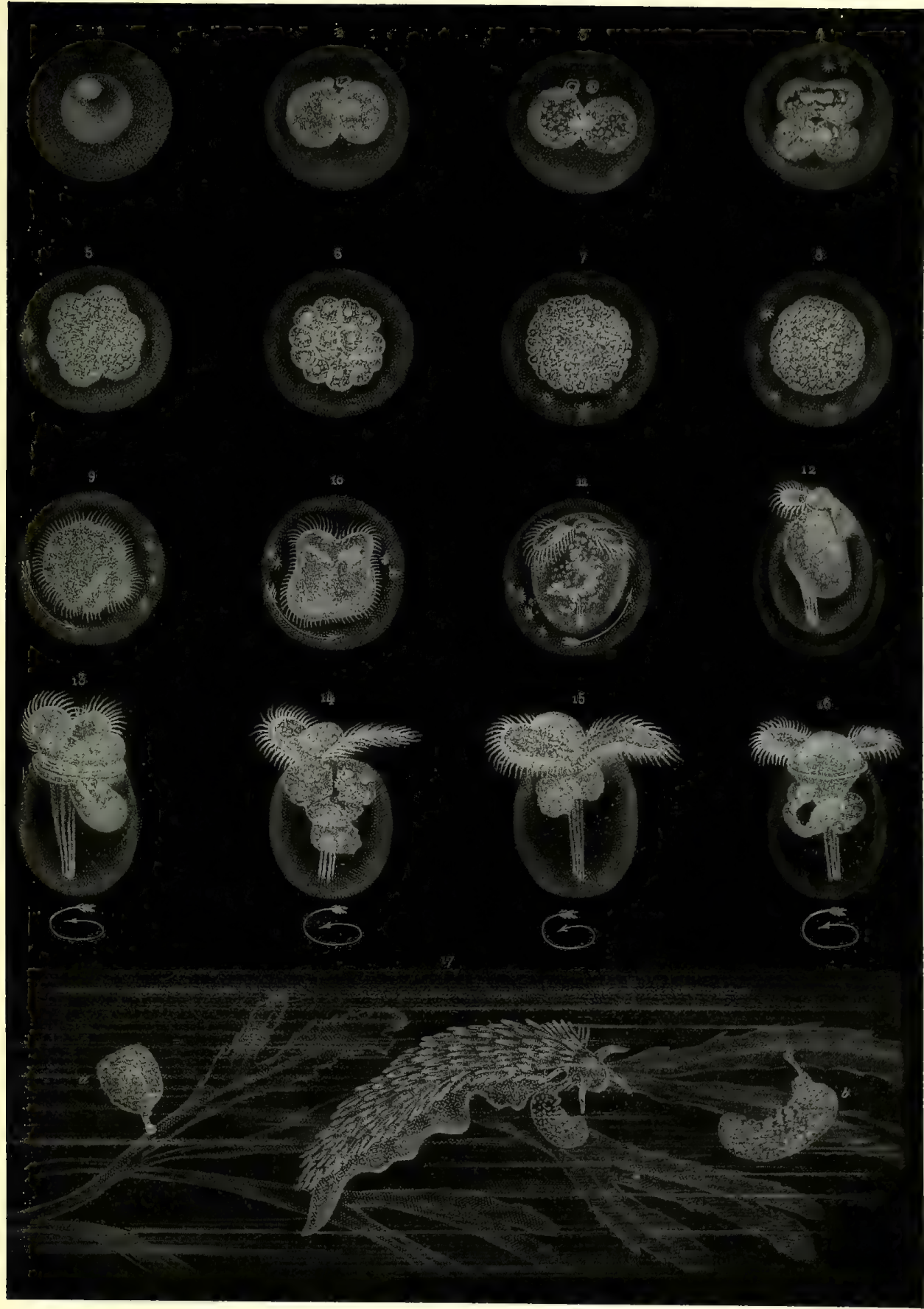

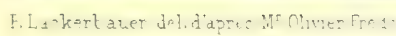

DÉVELOPPEMENT D'UN MOLLUSQUE NU.

1. CEuf fraichement pondu. - 2.3.4.5.6.7.8.9.10,11. Diverses phases de son développement

12. Eclosion du jeune. $-13,14,15,16$. Quatre positions differentes du jeune pendant une révolution.

17. Fionie en pleine ponte. _ a. Paquet d'ouf's enroulé _ $b$. Paquet d'oufs déroulé 

encore. Mais, pour remplir ces denx rôles, il est indispensable qu'ils s'agitent. En s'agitant, ils déterminent des conrants réguliers, et, par suite, le double mouvement do rotation qui vient d'être décrit.

»Quand le Mollusque grossit, les cils s'oblitèrent et disparaissent peu à peu. Ce qui fait que les mouvements se ralentissent insensiblement. Au moment de la naissance, il n'existe de cils que sur l'appareil respiratoire, autour de cet appareil et sur les tentacules. De générales, leurs fonctions sont devenues locales.

"A l'époque où les mouvements rotatoires sont dans leur plus grande activité, l'embryon se développe et s'allonge, et, comme il est très-mou, il se tord forcément en tire-bouchon. L'animal, toumant sur lui-même un peu obliquement, sa torsion devait offrir le même caractère. Remarquez que le pied, la tête et la queue, c'est-à-dire les parties les plus fermes, ne sont jamais en spirale, tandis que le tortillon, qui offre toujours, mème chez les individus adultes et chez les espèces les plus volumineuses, un tissu plus ou moins mou, se trouve l'organe contourné par excellence.

„La coquille, qui s'organise un peu plus tard, se moule sur l'embryon, et adopte la forme spirale qu'il a lui-même revêtue."

Les coquilles spirales peuvent être considérées commo des tubes calcaires qui vont en s'élargissant du sommet à la base, et qui sont plus ou moins enroulés sur eux-mêmes, d'après différents modes.

L'axe réel ou idéal sur lequel le tube opère sa révolution a reçu le nom de columelle. Quand cette columelle est creuse, son ouverture inférieure s'appelle ombilic.

La spire des univalves tourne le plus souvent de droite ì gauche; elle est dextre. Charles Bonnet en a fait la remarque il y a longtemps: "Il existe, dit-il, un plus grand 
nombre de corquilles dont les tours de spirale montent de droite à gauche que de celles dont les tours montent en sens contraire. " - Pourquoi cetle direction dominante? (C'est encore une question de notre bachelier.)

" Le soleil tourne sur lui-même de droite à gauche. Il en est de même des mouvements de rotation et de translation de la terre, des autres planètes de ce monde, de la lune et des autres satellites.... La dextrosité est une loi de la nature!"

L'homme se sert plus habituellement de ses membres droits que de ses membres gauches. La déviation vertébrale des rachitiques est très-souvent tournée du côté droit! Nos escaliers, nos tire-bouchons, nos vis, nos serrures, les roues de nos charrettes, les aiguilles de nos cadrans, les ressorts de nos pendules, les fils de nos bobines.... sont généralement dextres comme nos Colimaçons!

Il existe cependant des coquilles spirales, à la vérité en petit nombre, qui tournent normalement de gauche à droite, c'est-à-dire qui sont sénestres. Elles n'avaient pas échappé à l'attention de Charles Bonnet: ce sont des exceptions.

Quelquefois les Testacés dextres deviennent sénestres par monstruosité. Ils sont alors très-recherchés par les collectionneurs. On sait, pour le dire en passant, que l'homme, dont le foie est à droite et le cœur à gauche, présente dans certains cas, par exception, la situation de ces organes renversée (situs inversus), c'est-à-dire le foie à gauche et le cœur à droite. C'est une anomalie analogue à celle de ces derniers Mollusques.

D'autres fois les Testacés sénestres deviennent dextres. Ce sont des retours à l'ordre habituel.

Plusieurs coquillages ne sont pas tordus en spirale. Par exemple, les Patelles, qui ressemblent ì d'énormes Coche- 
nilles on à de larges éteignoirs. Mais ces espèces, dans leur jeune âge, offraient une torsion manifeste; elles avaient deux tours, trois tours.... Elles rentrent, par conséquent, dans la règle générale.

\section{I}

Certains univalves vivent à la surface de la mer, et flottent nécessairement et graciousement, quelle que soit l'agitation de l'eau.

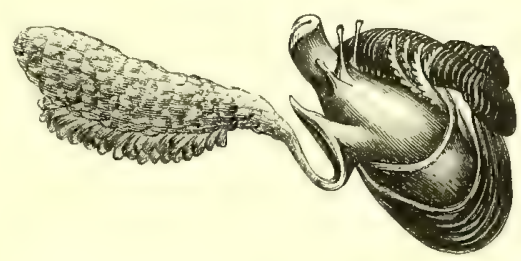

JATTHYE COMHIYE

(Janlhina communis Lamarck).

Le charmant petit coquillage appelé Janthine, protégr" par une tunique mince, fragile, d'un violet tendre, se suspend à une masse spongiense, sorte de tissu hydrostatique composé de petites vessies cartilagineuses semblables à de l'écume de savon consolidée ${ }^{1}$. Ce singulier parachute l'empêche de couler à fond.

A la plus légère alarme, la Janthine répand une liqueur d'un rouge sombre, devient plus lourde que la vague, et descend dans la mer. Bose pense qu'elle vide alors ses vessies, mais cela n'est pas certain.

D'autres Mollusques déploient une sorte de voile produit par le bord dilaté de leur mantean ou par quelque appendice développé en forme de nageoire. Ils voyagent

1 "Spuma cartilaginea, " (FAbics Cotunna.) 
de la sorte, à la surface des flots, entrainés par la lame ou poussés par le vent.

Mais la plupart des espèces ont besoin d'être plus ou moins submergées, quelquefois même à des profondeurs considérables. Les Littorines ne s'éloignent pas des côtes. On a pêché des Fuseaux qui vivaient an-dessous de 2800 mètres.

Les Mollusques testacés habitent, soit parmi les plantes, soit parmi les rochers. Les uns restent collés à la surface des corps solides (on assure que les Patelles opposent à l'isolement une résistance de ij kilogrammes); les autres s'enfoncent dans la vase et s'y creusent des retraites.....

La Natice mille points ${ }^{1}$ coupe le sable avec son pied dilaté en avant et tranchant comme une pelle; elle chemine ainsi horizontalement dans l'épaissem du sol (Deshayes). Son manteau, qui est très-ample, se replie sur sa coquille, protége les cornes, les yeux et l'orifice de la respiration contre les frottements entre deux terres, et rend en même temps la marche plus glissante.

Les univalves marins offrent dans leurs coquilles une immense variété de formes et de couleurs.

Ceux-ci sont enroulés en toupie, en vis, en escalier. Ceux-là sont façonnés en tonne, en bouton, en cadran. Quelques-uns représentent un casque, un turban, une mitre, un bonnet chinois. Certains rappellent une harpe, une olive, un radis, une tarière, une feuille de chicorée, une aile de chauve-souris, un pied de pélican, un casse-tête de sauvage.... Leur surface est lisse, polie, luisante, ou bien mate, rugueuse, et même treillissée. On y voit des plis, des côtes, des lames, des varices élevées, des saillies épineuses et des tubes droits ou infléchis....

1 Natica millepuncta Iamarck. 
Tous ces coquillages, ou presque tous, sont reconverts d'un drap marin, sorte de vêtement épidermique corné,

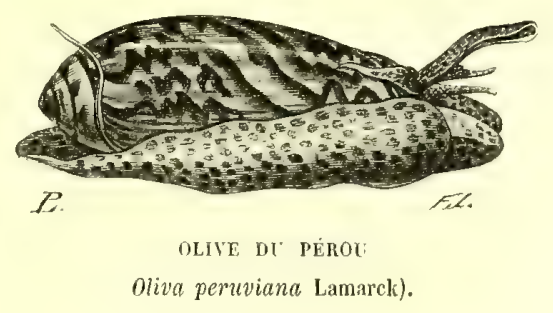

brunâtre, qui masque leur éclat et protége leurs couleurs. Celles-ci paraissent fauves, brunes, blanches, jaunes,

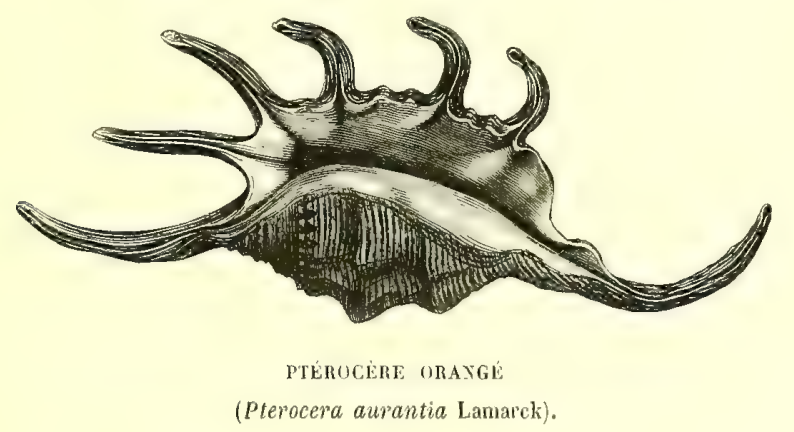

dorées, roses, rouges, bleues, violettes, vertes ${ }^{4}$..... Les brunes sont les plus nombreuses et les vertes les plus rares. Il y a des univalves mouchetés ou tigrés, ou marbrés ou rayés. Quelques-uns présentent les dessins les plus bizarres ou les hiéroglyphes les plus inattendus. D'autres, une broderie fantastique, un air noté, une carte de géographie, le zigzag de la foudre, les sinuosités d'une rivière ou les ramifications d'un arbrisseau. Plusieurs sont peints somptueusement et comme drapés de pourpre et d'or. La belle parure et la grande rareté de certaines espèces de Cônes

Sæpè ego digestos volui numerare colores, Nee potui; numero copia major erat.

(OVIDE.) 
ou de Porcelaines leur donnent un prix très-élevé. Les amateurs les payent $\$ 00,600$ et même 800 franes. On cite un Cône cedonulli qui fut acheté, au commencement dı

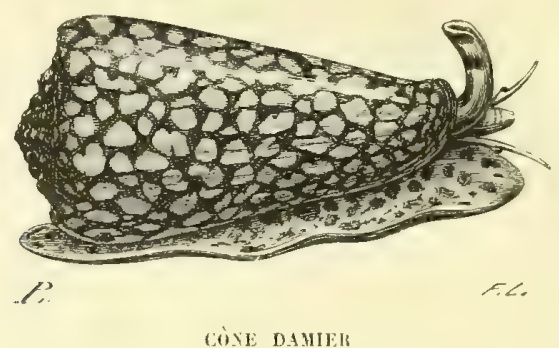

Comus marmoreus Linn(i).

xvine siècle, plus de cinquante louis. Ia Scalaire préciense ${ }^{1}$ s'est vendue jusqu' à 2000 frames. La Porcelaine orange a ité estimée pendant longtemps à un très-haut prix. Les

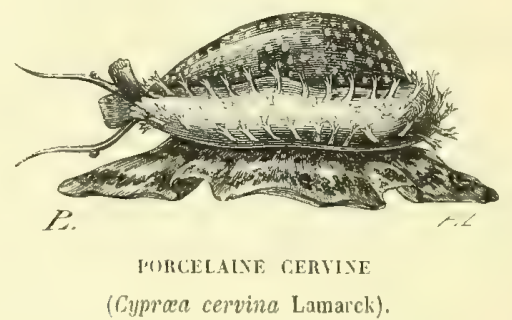

chefs de tribu, daus la Nouvelle-flollande, la portent encore ì leur cou, comme un symbole de leur dignité.

Les savants ont créé, pour les coquillages, une nomenclature régulière, avec des mots souvent prétentieux, généralement tirés du grec ou du latin. Les amateurs et les marchands ne premnent pas autant de peine. Ils choisissent des noms quelquefois bizarres, il est vrai, rui rappellent la forme ou la couleur plus ou moins frappante de chaque espece; ils ont même transporté dans la conchỵliologie les

1 Scalaria pretiosa Lamarck.

${ }^{2}$ Cypráa aurora Solander. 
grades ou les dignités de certaines professions. II y a des Cònes appelés ambassadeurs, gouverneurs, commandanls. capitaines, soldats.... II y en a de nommés vicaires, évêques. archevéques, cardinaux....

\section{IV}

Les Mollusques mivalves ont me maichoire supérienre ou deux màchoires latérales, ou bien trois mâchoires: une en haut et deux sur les còtés. Ces màchoires sont cornées, dures, tranchantes, et plus ou moins courbées en are, avec des còtes saillantes, verticales, en avant, et des denticules pointues, ou des crénelures émoussées sur les bords.

Ces animaux offrent une langue cartilagineuse, recouverte d'une membrane siche, striée, guillochée, garnie de papilles ou de crochets. Cette langue est presque toujours en mouvement; elle lèche, lape, frotte, lime avec beaucoup de force. Le plus souvent elle fait antagonisme à la mâchoire d'en haut, et semble fonctionner comme une màchoire inférieure.

La membrane de la langue est reçue, en arrière de la bouche, dans une poche en forme de talon recourbć (Cuvier), où elle s'enroule sur elle-même (Saint-Simon).

Dans le Vignot commun ${ }^{1}$, elle parait comme un filament blane de 5 centimètres de longuenr, d'ume substance délicate, résistante, diaphane, hérissée de denticules épineuses, qui ont la texture et l'éclat du verre. Ces denticules sont disposées régulièrement sur trois lignes; celles qui constituent la rangée médiane sont à trois pointes, tandis que celles des rangées latérales offrent une dent trifide alternant avec une dent plus grosse, ayant la forme d'une

\footnotetext{
1 Littorina vulgar is sowerby.
} 
moitié de bateau. Toutes se dressent en courbes concaves, et se dirigent dans le même sens (Gosse). Comparées à cet organe, nos râpes et nos limes paraissent de grossiers outils.

Le ruban lingual est quelquefois très-long. Chez le Turbo rugueux ${ }^{1}$, la membrane déroulée présente une étendue qui égale au moins trois fois la longueur de son corps! Quel prodigieux organe! Quel singulier Mollusque! un animal trois fois plus court que sa langue!

A mesure que la partie antérieure de la membrane dont il s'agit s'use par l'exercice et perd ses denticules ou ses crochets, le ruban est poussé en avant par un mécanisme spécial, à peu près comme la lame de fer dans le rabot du menuisier. De telle sorte que la partie agissante est toujours neuve et dans les meilleures conditions pour fonctionner.

Les univalves dépourvus de mâchoire sont en même temps privés de langue. Ils ont alors une trompe musculeuse et mobile. Cette trompe est tantôt charnue, plus ou moins extensible et sans pièces solides; tantòt coriace, avec des denticules ou des saillies capables d'entamer les corps les plus résistants.

Chez la Pourpre teinture ${ }^{2}$, cet organe se retourne comme le doigt d'un gant. Son extrémité offre des espèces de lèvres qui peuvent être séparées ou rapprochées suivant le besoin. En dedans existent des crochets aigus, supportés par deux longs leviers cartilagineux. Ces crochets sont alternativement élevés et abaissés. Par la répétition de ces mouvements, le Mollusque entame et perfore les coquilles les plus dures, comme s'il avait une lime au bout de son museau. M. Rymer Jones a vu, dans l'espace d'une après-

\footnotetext{
1 Turbo rugosus Linné.

2 Purpura lapillus Lamarck.
} 
midi, une Pourpre teinture percer la coquille d'un Pétoncle et en dévorer l'animal.

La nourriture des univalves varie suivant leur organisatiou. Les uns sont herbivores, les autres carnassiers, un certain nombre polyphages.

Les petites espèces mangent des végétaux microscopi_pues ou des animalcules, des graines ou des cufs....

Le Vignot commun, dont nous venons de parler, consomme ces infiniment petites plantules qu'engendrent les milliards de spores impalpables tenues en suspension dans la mer.

Ces plantules et ces spores sont déposées sur les parois des aquariums, où elles se développent avec rapidité. Elles ne tarderaient pas à les recouvrir d'une couche opaque de verdure. Mais on a soin de placer dans ces réservoirs un certain nombre de nos petits Gastéropodes, lesquels arrètent cette intempérance végétale, et entretiennent très-efficacement, à coups de langue, la propreté et la transparence du cristal. (Gosse.)

\section{V}

Les Céphalés possèdent un cerveau nettement caractérisé; mais le noble organe n'est pas placé dans leur tète, il est au-dessus du cou, et fait partie du collier nerveux qui entoure le commencement du tube digestif. Ce collier est ordinairement lâche et mobile; il avance ou recule, suivant les mouvements: d'où il résulte que le cerveau, au gré de l'animal, peut être porté d'arrière en avant, ou d'avant en arrière, entrer dans la tète et se réfugier dans le corps! Habituellement, il repose sur la nuque. Ce qui explique, pour le dire en passant, pourquoi un Escargot ne meurt pas nécessairement quand on lui a coupé la téte. 
Le cerveau est blanchâtre, jaunàtre, jaune olangé, rougeâtre et même noirâtre.

Les Mollusques univalves ont des organes pour voir, pour entendre et pour odorer.

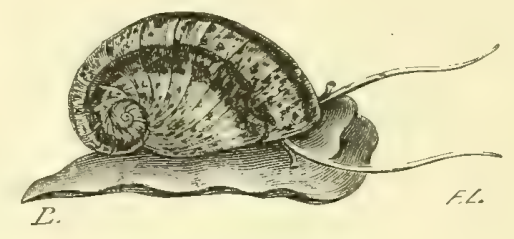

TÉRITE PULIE

(Nerita polita Linné).

Leurs yeux sout placés sur un mamelon, à la base externe ou interne des tentacules. Ils sont simples, myopes, et fonctionnent très-mal au grand jour.

Les organes auditifs sont à la base du cou, en dedans. On n'y voit ni pavillon saillant, ni orifice extérieur. Ce sont des poches membraneuses et transparentes remplies d'uu liquide assez limpide, qui tient en suspension de trèspetites pierres (otolithes) donées d'un monvement ou frémissement particulier. Dans quelques espèces, les poches ont à peine un vingtième de millimètre de diamètre, et contieunent de cinquante à soixante pierres.

Le sens de l'odorat réside à la surface des tentacules. Ceuxci, au nombre de deux, représentent chacun un demi-nez.

Chez l'homme, les cavités nasales se trouvent à l'entrée du canal respiratoire; l'arrivée de l'air amène nécessaircment les molécules odorantes dans leur intérieur. Chez les univalves, oi les demi-nez sont éloignés de l'orifice de la respiration et doués d'une assez grande mobilité, c'est lorgane qui va au-devant des molécules odorantes.

Les tentacules sont recouverts d'un duvet microscopirfuc, a poils très-courts, toujours en mouvement, qui détermine des courants rapides et continus autour de ces organes. 


\section{I}

La plupart des Céphalés sont androgynes, c'est-a-dire à la fois mâle et femelle.

«- Je voudrais bien savoir, nous disait dernièrement une jeune et jolie dame tres-avide d'instruction, si les Mollusques à deux sexes connaissent l'amour?

»- Madame, les Limaçons et les Limaces ont été créés tout exprès pour vous donner une réponse affirmative.

"Épiez ces animaux, d'apparence si apathique, un soir d'été, après une légère pluie, dans une allée de votre jardin ou sur le bord de quelque haie. Vous les verrez s'approcher lentement, se saluer, tourner l'un autour de l'autre; s'approcher davantage, tendre le cou, dresser la tète, se flairce respectneusement; se palper, d'abord avec hésitation, puis avec assurance, puis avec familiarité; se baiser la tète, le front, le mufle, les bords de la bouche....; se lécher bien délicatement, se chatouiller avee tendresse; retirer précipitamment les cornes, comme si le frôlement était trop vif; les allonger de nouveau; enfin les incliner doucement et les laisser pendantes, comme si le plaisir les fatiguait!.... »

“Un jour, M. Bouchard-Chantereaux fut témoin d'un mouvement de colère très-prononcé, chez une Limace agreste $^{1}$ qui avait des prétentions fort amoureuses, et qui, en reucontrant une autre très-froide et très-réservée, lui fit pendant une demi-heure les caresses et les agaceries habituelles, sans ètre payée le moins du monde de retour. Fatiguée de ses avances, elle agita la tête brusquement, mordit au mufle la belle indifférente, et s'éloigna avec dédain. 
Cette Limace pensait, aree paison. que l'amour nexchut pas la dignité! »

“ Les Céphalés de la mer sont organisés comme les Céphalés de la terre, et sommis aux mêmes lois. Ils ont les mœurs des Limaçons et des Limaces; ils aiment! »

Les Mollusques à deux sexes, pourvus d'une tète, peuvent donc éprouver et manifester ce je ne sais quoi dont les effets sont incroyables (suivant la juste remaryue de Pascal); et, si l'amour n'est pas chez eux aussi profond, aussi exquis, aussi durable que chez les Vertébrés supérieurs, comme ces animaux sont à la fois mâle et fenclle, ils le sentent nécessairement de deux manières différentes, ce qui produit un ravissant cumul! "Aimer longlemps, infatigablement, toujours, dit N. Michelet, c'est ce qui rend les faibles forts. "S Sil en est ainsi, aimer double doit être? l'énergie de l'énergie!

Les Mollusques Acéphales, notons-le en passant, ne sont pas favorisés, sans doute, comme leurs frères les Céphalés. Car, malgré l'opinion généralement admise, le véritable amour vient de la têle el non du cœur, parec que c'est dans la tête que se trouve le cerveau. Voilà pourquoi cette admirable sympathie ne parait guere manifeste que chez les animaux qui possèdent une tête.

Toutefois notre proposition n'est rigonreusement exacte que pour les animaux chez lespuels le centre sensitif ost logé dans ladite tète (les intra-Verlébrés); elle ne l'est plus pour ceux où il réside sur le cou (les extra-Verlébrés). Les Limaces et les Limagons sentent l'amour avec la nuque!

Cette noble affection ne se montre done suffisamment développée, chez les Mollusques, que dans les espèces céphalées, c'est-à-dire les plus parfailes, on, si vous l'aimez. mieux, les plus sensibles et les plus locomotiles. Elle offre certainement, chez clles, quelque chose de delicat, pent- 
être mème d'idéal. Mais les pauvres Acéphales ne comprennent pas les tendres sentiments. Est-ce un malheur jour eux? Nous ne le pensons pas; car l'Auteur de toutes choses a donné généreusement à chaque bète tous les sentiments, toutes les sympathies, tous les plaisirs dont elle avait besoin!....

La tendresse sexuelle n'existe pas probablement dans l'Huître et dans la Moule; si elle s'y trouve, elle y est à coup sur bien indéterminće, bien obscure et encore moins morale, s'il est permis de parler ainsi, que dans la Limace et dans le Limaçon.

Linné allait beaucoup trop loin, quand il se laissait entrainer par son imagination sourent si poétique. Il voyait l'amour jusque dans les fleurs. Il a publié un mémoire trèsremarquable sur le mariage des plantes (Sponsalia planlarum), accompagné d'une gravure qui représente deux Mercuriales (mâle et femelle) dont la fécondation est favorisée par le zéphyr. Il a inscrit ces mots, très-significatifs, au-dessns des deux figures : "L'amour unit les plantes" (Amor unit plantas). Linné savait très-bien que la plupart des fleurs sont bisexuées (comme les Limaçons). Il avait vu et voyait tous les jours, daus un OEillet par exemple, les étamines, ou les mâles, entourer les pistils, ou les femelles, se précipiter sur leurs stigmates, les presser, les embrasser, les couvrir de pollen; mais l'immortel naturaliste abusait etrangement de l'analogie, quand il croyait tronver dans la physiologie de cette fleur le sentiment presque divin qui enflamme et ennoblit les animaux supérieurs, voire même les Limaçons et les Limaces!.... Mais revenons à nos Mollusques de la mer.

Les Céphalés de l'Océan pondent des cufs isolés ou agglomérés, sessiles ou pédiculés. Quand ces derniers sont en nombre considérable, ils forment des sphères, des 
rosettes, des étoiles, des coupes, des entomnoirs, des cylindres, des paquets, des grappes, des guirlandes.... Voyez le gracieux ruban des rufs de la Bullée autour d'une branche de Varec ${ }^{4}$.

Les øufs sont blanes, jaumes, oranges, rouges, roses, d'un fauve clair, ou d’un brun foncé. Plusieurs sont entourés d'unc substance gélatincuse (nidamentum) plus ou moins transparente, ou cufermés dans une capsule (oothèque) plus ou moins membraneuse.

Certains Mollusques portent leurs cufs collés au dos de leur coquille et disposés en quinconce. La Janthine suspend les siens, enfermés dans des espèces d'ampoules, à ses vessies matatoires. Ces ampoules, qui ressemblent à des graines de courge, en conticunent plus d'un million. (Yuor.)

\section{VII}

On regarde comme très-voisine des Céphalés une petite tribu de Mollusques qui nagent dans la haute mer à l'aide de deux larges ailes ou nageoires membraneuses sitnées a droite et à gauche de leur tête. Cés expansions sont à la fois des organes de mouvement et des organes de respiration. Les animaux qui les possèdent ont été nommés Pléropodes (pieds-ailes).

On a comparé ces Mollusques à des Papillons qui anraient les ailes étendues. Cette comparaison, il faut l'avouer, n'est pas très-rigoureuse.

Un des plus connus parmi les Ptéropodes, c'est la Clio boréale, jolie petite créature qui se trouve par millions dans les mers du Nord. Les Baleines en consomment des

\footnotetext{
1 Toyez le dessin communiqué par M1. de Quatrefages, planche MII, figr. 7.
} 

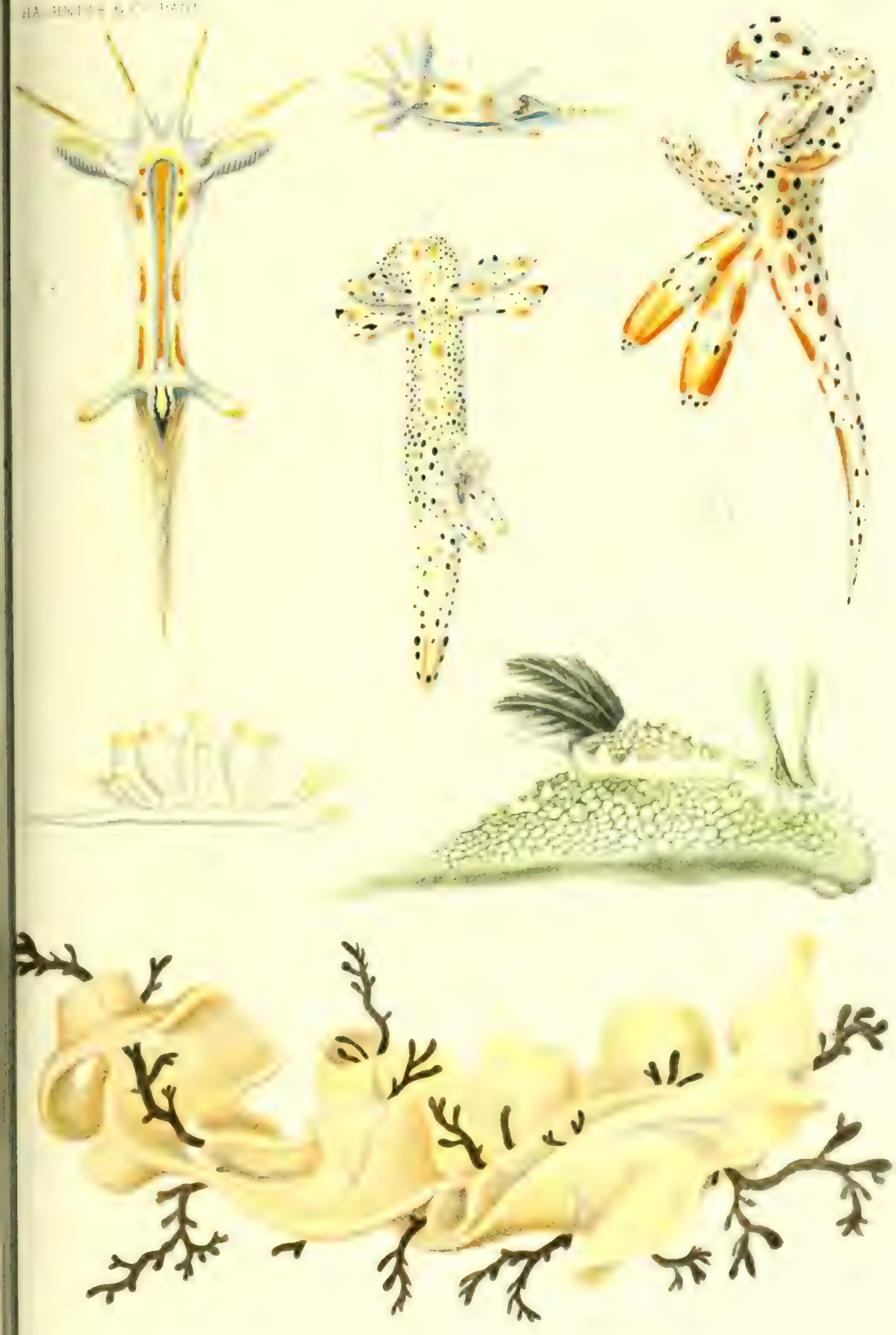

MOLLUSQUES NUS 

quantités prodigienses. C'est pourquoi les matrlots anglais appellent ces bestioles, pâture de la Baleine.

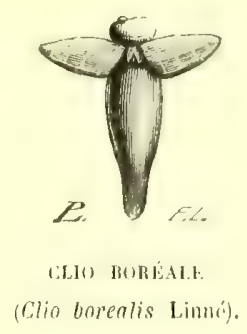

Les voyagemes racontent que ces petits Papillons marins donnent en quelque sorte la vie aux lugubres régions qu’ils habitent, par leur nombre et par leurs évolutions. Les Clios nagent joyeusement, et semblent danser ou gambader en dépit de tout. Par les temps calmes, elles s'élèvent à la surface du liquide; mais à peine ont-elles touché l'air', 'qu'elles replongent aussitôt. Wucliuefois elles jettent leurs ailes ou nageoires autour des hydrophytes et semblent les embrasser étroitement.

Ces gracieuses vagabondes sont blenes, violettes ou purpurines.

Leur tête fournit une nouvelle preuve de la sagesse qui a présidé à leur organisation. Autour de la bouche naissent six tenlacules, dont chacun est couvert d'environ 3000 taches rouges, que l'on voit, an microscope, comme des cylindres transparents. Ces cylindres contiennent environ vingt petits suçoirs qui ont la faculté de se projeter au dehors, et de saisir leur mince proie. II y a done 360000 de ces suçoirs sur la tète d'une Clio. Peut-ètre n'existe-t-il pas, dans toute la nature, un appareil semblable à celui-la pour opérer la préhension! (J. Franklin.)

Les plus chétifs des organes des plus chétifs animaux, examinés de près, excitent d'abord notre étonnement et 
presque aussitôt notre enthonsiasme. On ne sanrait trop le répéter, il n’y a rien de négligé dans la nature!

Un autre Ptéropode tout aussi mignon et tout aussi remarquable que la Clio, c'est l'Hyale tridentée. Cette

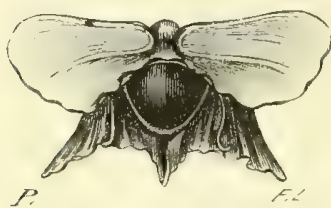

IIYALT: TRIDENTÉT:

(Hyalaca tridentata Iamarek).

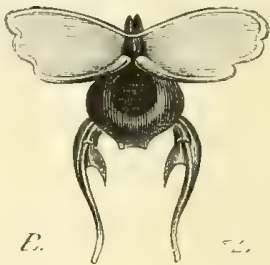

HYALE BORDÉE (Hyalea limbrta d'Orbigny).

espèce manque de tentacules, mais elle a me coquille. Ses nageoires sont très-grandes, jaunâtres, arec une tache d'un beau violet à la base.

Sa coquille est plane en dessus, bombée en dessous et fendue latéralement. La partic supérieure est plus longue que l'inférieure, et la ligne transverse qui les unit présente trois saillies en forme de dents. Cette coquille est demitransparente et d'un jaune d'ambre. Quand l'animal nage, il fait sortir les deux expansions de son manteau par les fentes latérales de son test.

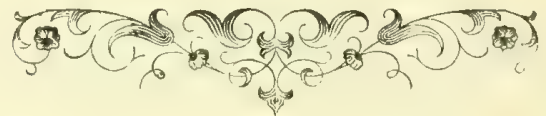




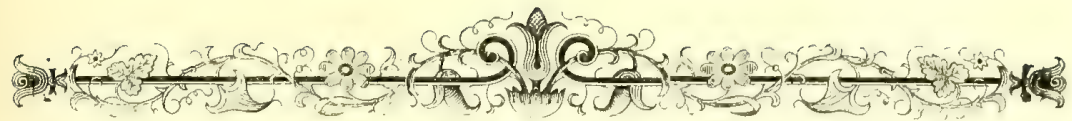

(8)

\title{
CHAPITRE XXIV
}

\section{LA POURPRE DES ANGIENS.}

\author{
"Colores dicti sunt quòd calore ignis vet \\ polis perforiuntur." (GAYYT Isroone.)
}

La pourpre des anciens était une couleur très-belle et très-estimée. Cette conleur fut, dans l'antiquité, l'apanage des seigneurs et des rois. Son nom désignait la puissance ou la royauté. Les grands étaient appelés purpurati, parce qu'ils avaient le droit de porter un habit pourpre. La matière dont il s'agit se vendait, en Asie, au poids de l'argent.

Aujourd'hui, la pourpre est à peu près abandonnée. Les personnes du monde ignorent même généralement la signification exacte que les anciens attribuaient à ce mot, signification un peu différente de celle que nous lui donnons aujourd'hui. Car on n'appelait pas pourpre une teinte rouge, glacée de vermillon, mais une sorte de violet. Dans le principe, c'était même un violet foncé; plus tard, à l'aide de certaines manipulations, on rendit la nuance plus ou moins rouge.

On nommait pourpre dibaphe celle des étoffes teintes deux fois. Cette nuance avait beaucoup de réputation. 
M. Lacaze-Duthiers rapporte que, lorsuruil faisait des recherches à Port-Mahon, en 18:38, son pêcheur Alonzo, en l'attendant daus sa barque, employait somvent ses loisirs

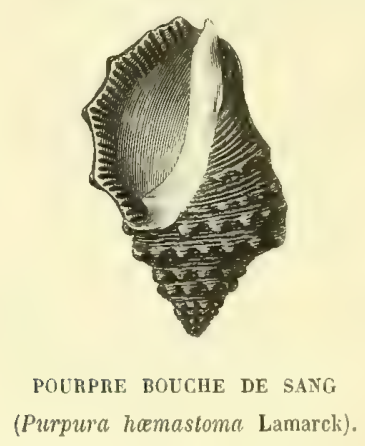

à marquer son linge et ses vêtements : il y dessinait tant bien que mal quelque croix ou quelque petit ange gardien. Il se servait d'une baguette de bois (u'il trempait dans los mucosités du manteau déchiré d'un coquillage nommé dans le pays, Cor de fel. Ce coquillage était la Pourpre bouche de sang des conchyliologistes.

Avec sa baguette, le pêcheur traçait des traits jaunàtres. “ Il n’y paraîtra guère? lui dit M. Lacaze-Duthiers.

" - Cela deviendra colorado, répondit Alonzo, quand le soleil l'aura frappé. »

M. Lacaze-Duthiers pria le pêcheur de faire sous ses yeux, sur le tissu de ses vêtements, quelques-uns des traits ou dessins qu’il savait exécuter. Alonzo obéit. 11. LacazeDuthiers contimua ses explorations. Mais bientôt, c'està-dire au bout de deux minutes, il fut poursuivi par une odeur horriblement fétide. Il vit en même temps les parties marquées sur son linge prendre me coulemr violette d'une vivacité remarquable. 


\section{III}

Les corpuillages qui fournissaient la pourpere anx Grees et anx Romains étaient des Ciastéropodes. Ces copruillages appartenaient au gene Pourpre (Purpura) ot an geme Rocher (Murex).

Parmi les Pourpres, on doit citer la bouche de sang, dont nous venons de parler, et la teinture ${ }^{\text {. }}$

Il est probable que la plupart des espèces du mèmo groupe, sinon toutes, peurent domer cette artmimalu. couleur.

Parmi les Rochers, nous signalerons le fascié , le hérisson $^{3}$ et la petite Massue ou droite épine.

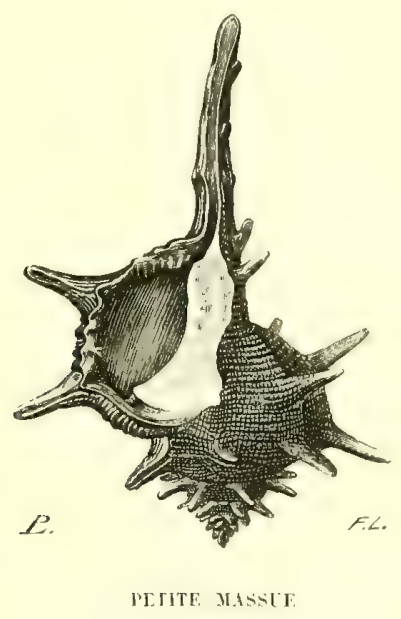

(Murcec brandaris linné).

On a déconvert à Pompéi des tas de coquilles de la première espèce, près de la boutique de plusienrs teinturiers.

1 Purpura lapillus Lamarck.

2 Murex trunculus Linné.

3 Hurex erinaceus I.inné. 
Lesson croyait que la Janthine commune donnait aussi la pourpre des anciens.

Quand on laisse momir les Mollusques producteurs de la pourpre, non-seulement la partie qui renferme cette matière se colore en violet, mais encore les tissus environnants.

Les directeurs des musées ont remarqué que les individus conservés dans l'alcool, ou dans tout autre liquide,

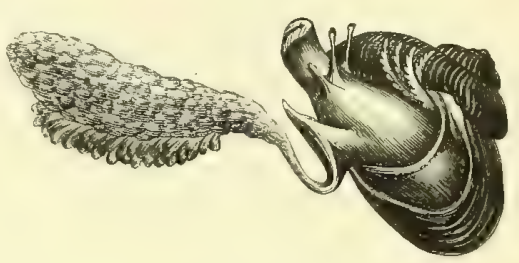

JAYTHIXE COMMTYE

Janflina communis Lamarckl

communiquent la même teinte au milieu dans lequel ils sont plongés.

Jusqu'à ces derniers temps, l'organe purpurifère n'a pas été connu. Quelques naturalistes avaient сru que c'était l'estomac ou le foie, ou le rein, et avaient regardé la pourpre comme le suc gastrique, la bile ou l'urine de l'animal. D'autres, mieux avisés, avaient émis l'idée que la pourpre était produite par un organe spécial. Mais où se trouve cet organe? Quelles sont ses connexions? Quelle est sa forme? Évidemment, on ne l'avait jamais observé, puisque, dans les divers ouvrages de malacologie, on parle d'une veine, d'un réservoir, d'un sac, d'une poche.... C'est à M. Lacaze-Duthiers que la science est redevable de la découverte de cette glande. Il l'a étudiée dans plusieurs espèces, et l'a décrite arec soin. 
Lorgane purpurifère se trouve à la face inférieure du manteau, entre l'intestin et l'appareil respiratoire, plus près de ce dernier que du premier. II a la forme d'une bandelette. Sa couleur est blanchâtre et souvent d'un jaune léger. Cet organe ne varie pas beaucoup dans les divers Mollusques.

\section{IV}

La matière de la pourpre est blanche ou faiblement jaune, parfois un peu grisâtre. Soumise à l'action de la lumière, elle devient d'abord jaune-citron, puis jaune verdâtre, puis verte, puis violette. Cette dernière teinte se fonce de plus en plus. Ces transformations successives sont accompagnées d'une odeur très-vive et très-pénétrante, qu'on a comparée tantôt à celle de la poudre qui vient de prendre feu, ou à celle de l'oignon brûlé, tantôt à celle de l'essence d'ail ou à celle de l'asa foetida. Cette odeur se conserve longtemps, et se manifeste surtont lorsqu'on humecte lẻ tissu, mème un an après sa coloration.

La teinte de la pourpre perd un peu de sa vivacité par le lavage; ensuite elle persiste. C'est pourquoi l'idée de s'en servir pour marquer le linge est une excellente idée.

En recueillant cette matière, M. Lacaze-Duthiers en a répandu plusiemrs fois sur l'ongle de son pouce. Cet ongle s'est bientôt coloré, et il est resté violet pendant plus de cinq semaines.

La substance purpurigène, quand elle n'est pas encore violette, est soluble dans l'eau. Elle devient parfaitement insoluble quand elle a pris cette couleur.

Cette sécrétion, sons l'influence du soleil, est donc insoluble et inaltérable.

Réaumur pensait que l'apparition de la conlenr pourpor 
au bout d'un certain temps était due à l'action de l'air. Un renouvellement de ce fhuide était absolument nécessaire, suivant ce célèbre physicien, pour produire la modification dont il s'agit.

Duhamel a mieux étudié le phénomène. Il a constaté qu'il résultait de l'action des rayons lumineux; mais, an lieu d'y voir une propriété phologénique de la matière sécrétée, il a cru que le soleil déterminait la pourpre comme il produit sur les pêches, les pommes d'api et quantité d'autres fruits, une belle couleur rouge. Il a confondu l'action des rayons solaires sur une substance qui n'est plus soumise à la force vitale, avec son influence sur un tissu régi par cette force.

M. Lacaze-Duthiers fait observer avec beaucoup de justesse, que, sous les climats brûlants et le ciel toujours si lumineux de l'Italie et de la Grèce, la pourpre ne devait pas se faner comme les autres couleurs, surtout comme celles tirées du règne végétal. La Cochenille, dont parle Pline, qui fomrnissait l'écarlate, ne devait point résister à l'action du soleil. La pourpre, au contraire, qui s'est développée directement sous l'influence de la lumière mème, ne peut s'altérer comme les autres couleurs. Évidemment, tout ce qu'aurait pu faire le soleil, et les anciens étaient souvent exposés à ses rayons dans leurs cérémonies publiques, c'eût été de renforcer le ton des étoffes, et l'on doit voir là certainement une des raisons de cette estime de la pourpre entre tontes les couleurs.

La pourpre est done une substance tout à fait photogénique.

M. Lacaze-Duthiers a fait des expériences importantes 
sur la sensibilité de ce produit et sur les avantages 'qu'on pourrait en retirer.

Il conseille de recueillir la matière purpurigène avec ume brosse plate dont on a raccourci les poils. On frotte doncement, et plusieurs fois, l'organe sécréteur. La brosse est bientôt chargée d'une substance visqueuse et filante. « Alors on n'a qu'à barbouiller les tissus que l'on veut imprégnèr, en répétant fréqnemment sur eux un mouvement de moulinet ou de va-et-vient; on arrive ainsi à étendre en couche uniforme la mucosité recueillie, qui fait d'abord un peu de bave ou de mousse, mais qui bientôt ne forme plus qu'un liquide, quoique épais, on toutes les bulles d'air disparaissent progressivement. Pour que le tissu se trouve imprégné à peu près uniformément, on charge le pinceatu une seconde, me troisième, une: quatrième fois, en ayant soin de bien fondre les limites des différeuts points sur lesquels on apporte successivement de la nouvelle matière. ” (Lacaze-Duthiers.)

Il faut un certain temps d'exposition au soleil pour obtenir la coloration de la matière. Ce temps varie suivant la vivacité des rayous lumineux. Dans le midi de l'Espagne, la teinte violette se développe après deux ou trois minutes. Dans d'autres circonstances, une image se dessine au bout de quatre ou cinq. Avec un ciel nuageux, un portrait n'a été fini qu'au bout de trois quarts d'heure. La lumière diffuse, très-faible, demande encore plus de temps.

On doit avoir soin d'humecter la matiere avec quelques gouttes d'eau de mer.

La Pourpre bouche de sang donne un violet léger, quand la substance est peu abondante, et un pourpre plus ou moins foncé, quand elle est considérable.

La Pourpre teinture produit un violet des pius beaux, 
quelquefois avec des reflets blenâtres des plus remarquables.

Le Rocher fascié fournit une teinte bleuàtre. Les dessins obtenus à Mahon étaient, les uns d'un violet bleuàtre, arec des parties tout à fait bleues, les autres d'un violet foncé.

Le Rocher hérisson des côtes de Pornic et de la Rochelle offre constamment du violet. Toutefois, sans savoir pour‘uoi, M. Lacaze-Duthiers a obtenu des teintes plus vineuses. plus bleuâtres ou plus rosées, en opérant daus des conditions qui paraissaient exactement les mèmes.

La petite Massue présente un violet parfois clair et rosé, extrèmement délicat.

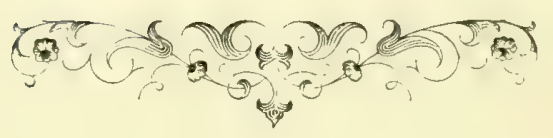




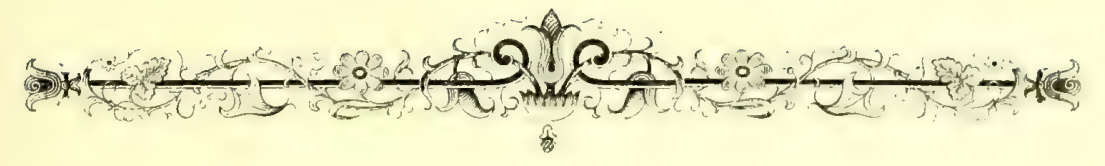

\section{CHAPITRE XXV}

\section{LES CEPHALOPODES.}

\section{- Monsteme hererudem, informe, ingens....}

(VIRGLL.)

Qu'on se figure un sac épais et coriace, ovoïle ou cylindrique, lisse, visqueux, offrant à une extrémité une grosse tète arrondie, avec des yeux latéraux énormes, aplatis, et vers le sommet, une bouche, ou, pour mieux dire, un bec de corne, dur et tranchant comme celui d'un Perroquet; qu'on ajoute autour de ce bec huit ou dix bras vigoureux, dont deux souvent très-longs et conme pédiculés, et l'on aura l'idée de ces Mollusques bizarres et redoutables désignés par Cuvier sous le nom de Céphalopodes'.

On les distingue en trois groupes principaux : $1^{\circ}$ les Sèches, dont le sac est bordé d'une nageoire dans toute sa longueur; 2 les Calmars, qui ont denx nageoires distinctes vers l'extrémité du corps; $3^{\circ}$ les Poulpes, qui n'en possèdent nulle part. Cette division a été indiquée par Aristote. Ce grand naturaliste parait avoir connu l'histoire de ces

1 Voyez la planche $\mathrm{Xx}$. 
animaux, et mème leur anatomie, à un degré vraiment étonnant. (Cuvier.)

Les Céphalopodes oceupent le premier rang parmi les Mollusques. Ce sont les princes de cet embranchement.

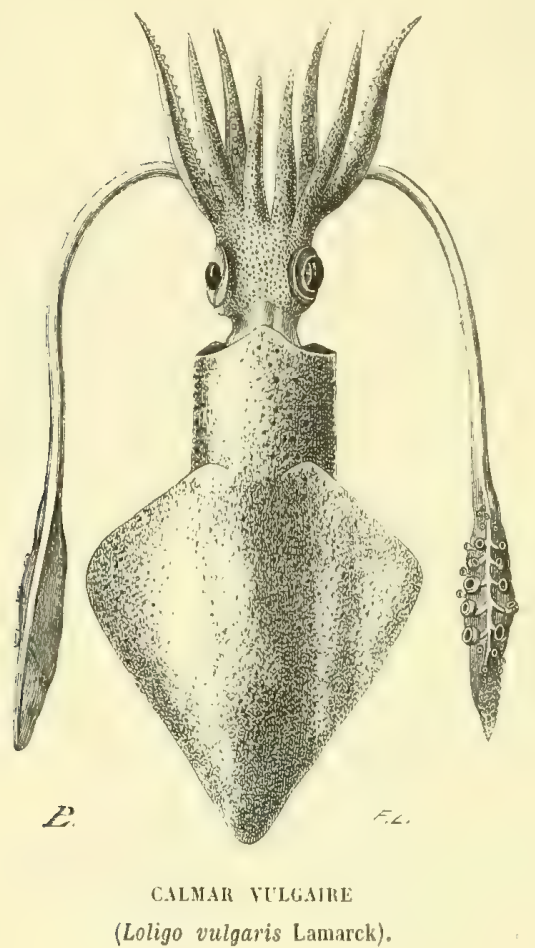

(Loligo vulgaris Lamarck).

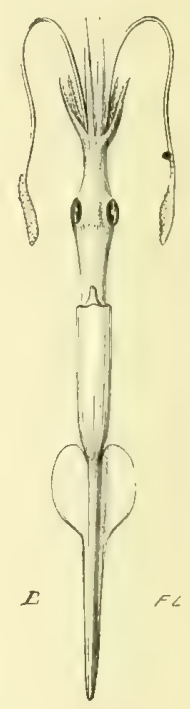

C.ALMARET VERMICLLIIRE (Loligopsis vermicularis Ruppel)

Ces animaux pullulent dans l'ncéan et daus la Méditepranée. Less uns ne s'éloignent pas des côtes, les autres se réfugient dans les caux les plus profondes. Tous se nourrissent de coquillages, de crabes, de poissons....

Ils sont rusés. Ils se blottissent dans des trous, itendant leurs membres au dehors. Ils guettent leur proie comme des voleurs de giaud chemin. Ils la flagellent, l'enlacent, l'étouffent avec leurs bras, la déchirent avee leur beec, et la dévorent sans pitié.

Ils détruisent souvent pour le seul plaisir de détruire. 
Alcide d'Orbigny a vu un de ces animaux, de petite taille, laissé par la marée au milieu d'une troupe de petits Poissons, désappointés comme lui, en faire un massacre épouvantable sans les manger, et cela par délassement.

C'est ainsi que s'entretient le cercle continuel des destructions et des renouvellements, qui sont une des conditions de l'harmonie générale de l'univers.....

Les Céphalopodes expulsent le résidu de leur digestion par un orifice situé en avant du cou, près de la bouche. Singulière place! Leurs organes respiratoires se trouvent dans le sac, et ressemblent à des feuilles de Fougère. Curieuse organisation!

Ils ont trois cours, on, pour mieux dire, un cour divisé en trois parties. (Cuvier.)

Les Céphalopodes sont nocturnes et crépusculaires. Ils se cramponnent aux rochers pendant les tempêtes, avec leurs bras les plus longs, qui fonctionnent comme deux ancres, les autres restant libres et prêts à saisir quelque vietime.

Ces bras sont armés de deux ou trois rangées de ventouses ou suçoils, petites coupes circulaires avec une ouverture au centre, laquelle conduit à une cavité.

A cet orifice s'adapte une sorte de piston. Ces ventouses s'appliquent et adhèrent avec une force surprenante au corps glissant des Poissons, des Mollusques et des autres habitants de la mer. On a calculé que, dans une Sèche, il y a neuf cents de ces ventouses.

Quelquefois les suçoir's des extrémités présentent, au centre de chaque coupe, une griffe acérée et recourbée. On comprend, d'après cette organisation, que la victime la plus lisse et la plus visqueuse ne puisse pas échapper au vorace destructeur.

Dans le Cirroteuthis de Müller, les bras sont réunis par une expansion membraneuse, couleur lilas clair, en forme 
de cloche légèrement lobée, semblable à la corolle d'un Solanum ou d'un Convolvulus.

Les Céphalopodes marchent la tête en bas et le corps presque vertical. Les bras leur servent alors de pieds.

Une espèce de l'océain Pacifique peut faire des bonds considérables. On a vu un de ces Mollusques s'élancer

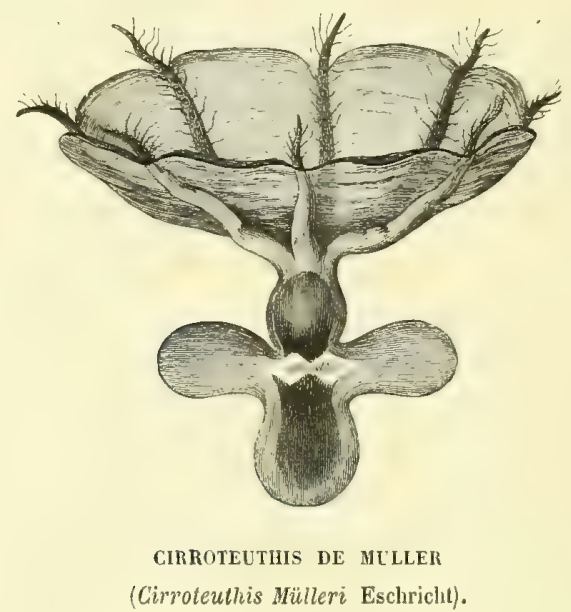

hors de l'eau, et tomber sur le pont d'un navire, où il fut pris (J. Franklin). James Ross rapporte qu'un certain nombre de Sèches bondirent sur son vaisseau, élevé de 16 pieds anglais. On en recueillit plus de cinquante. Quelques-unes passèrent par-dessus le pont et retombèrent dans la mer.

Dans l'intérieur des Céphalopodes se trouve une poche qui renferme une liqueur noire comme de l'encre, brune comme du bistre, ou d'un violet foncé. Cette poche communique avec l'extérieur, au moyen d'un petit canal. Lors‘u'ils sont poursuivis ou menacés, ils lâchent une partie de leur liqueur, qui trouble l'eau, et ils profitent du brouillard artificiel qu'elle a produit pour se sauver au plus vite. 
Un écrivain anglais compare le stratagème de nos Mollusques à la vieille tactique de certains hommes politiques ou théologiens, qui, pour échapper aux raisons qu'on leur oppose, ne trouvent rien de mieux que de répandre du noir dans la discussion. "L'obscurité devient leur force et leur triomphe. Ils troublent la vue des esprits faibles ou

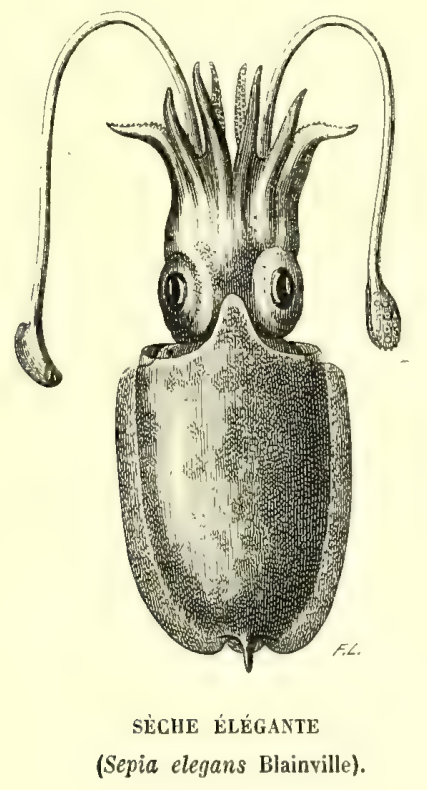

peureux, se dérobent à l'examen, et passent pour invulnérables à travers les siècles, comme les Céphalopodes à travers les eaux noircies de l'Océan. » (J. Franklin.)

Avec l'encre des Sèches, pour le rappeler en passant, on prépare la sépia de Rome, employée dans la peinture à l'aquarelle. Les beaux dessins qui accompagnent une partie des mémoires de l'illustre Cuvier sur l'anatomie des Mollusques ont été exécutés avec l'humeur fournie par plusieurs des individus qu'il disséquait (Duvernoy).

On a prétendu pendant longtemps que les Chinois composaient l'encre de Chine avec la liqueur d'un Céphalo- 


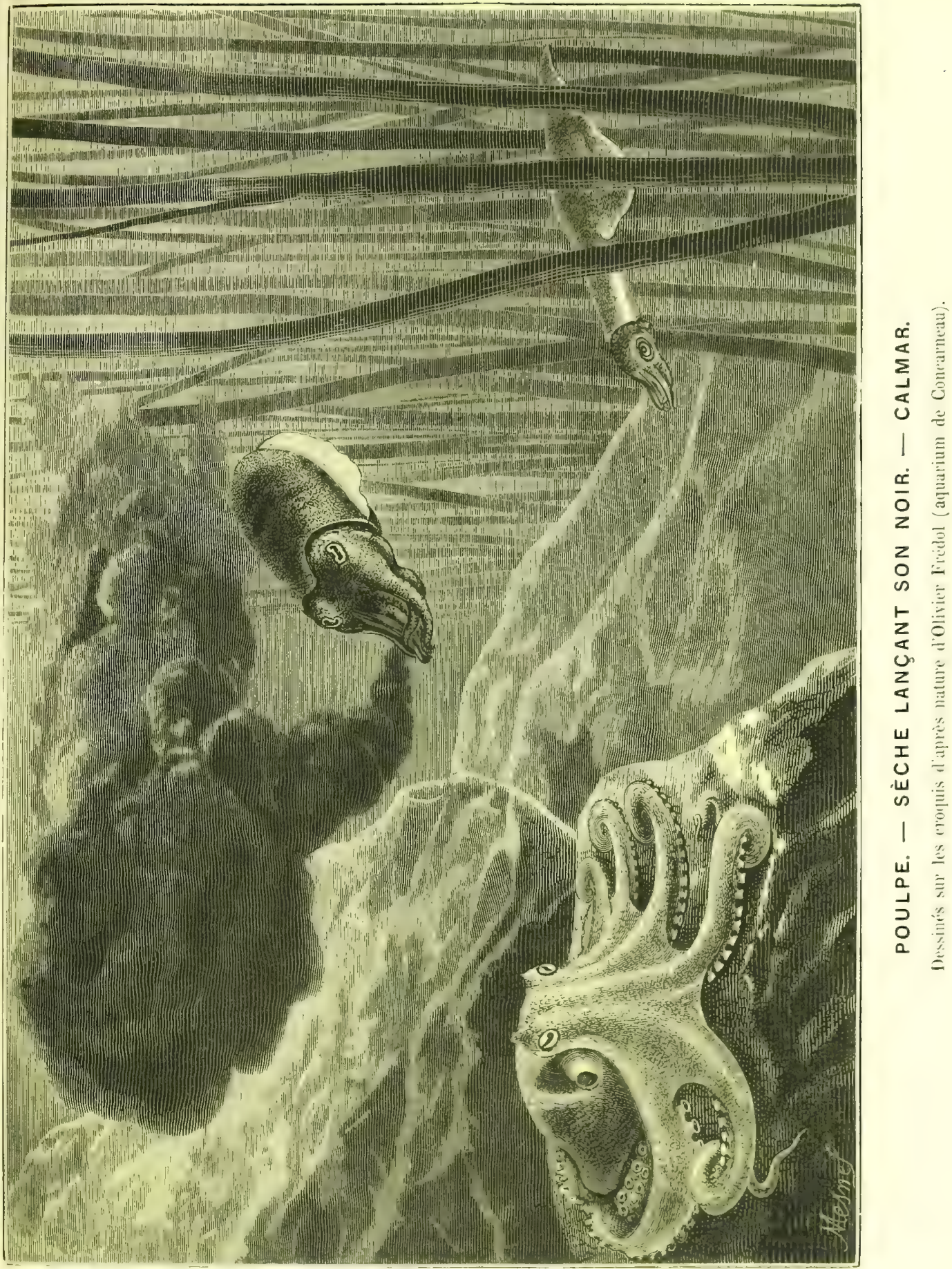



Duthiers en a vu que la sonde avait retirés de plus de 1600 mètres de profondeur.

Plusieurs Sèches jouissent de la merveilleuse faculté de changer de couleur. Elles passent du blane purpurin au gris livide, et du gris livide au brun rougeâtre. Leurs

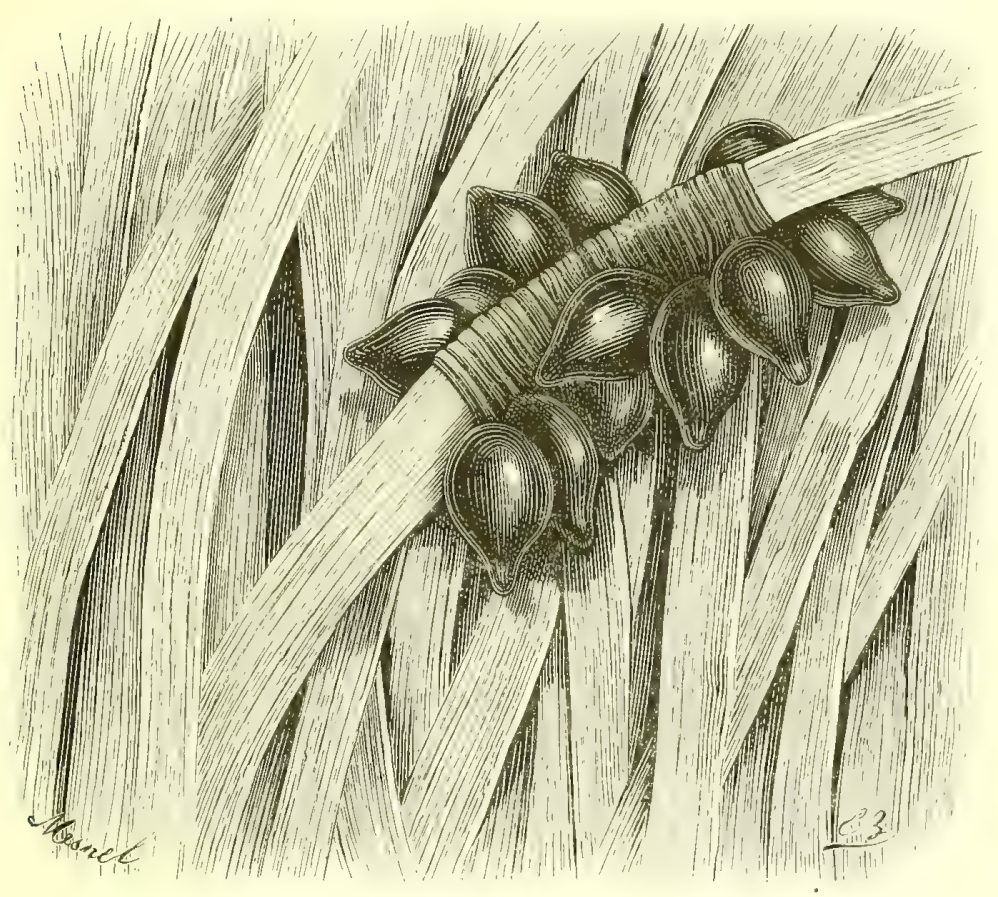

OEves de cÉphalopode (RAISINS de Mer).

teintes disparaissent et reparaissent tour à tour, se mélangent, se confondent ou se séparent de la manière la plus fantastique. Quand l'animal est effrayé ou irrité, ses taches grandissent ou se déplacent avec une rapidité bien supérieure aux changements du Caméléon. Quelques naturalistes supposent que ces curieuses transformations ont pour but d'épouvanter les ennemis.

Quand on entre dans les bas-fonds habités par de grands 
Céphalopodes, par exemple par des Poulpes, il faut se méfier de leur voisinage. Avec leurs bras gluants, ces vilains Mollusques enlacent les membres des nageurs d'une manière si serrée, qu'on a souvent beaucoup de peine à s'en débarrasser.

Le docteur J. Franklin a vu des Sèches se cramponner
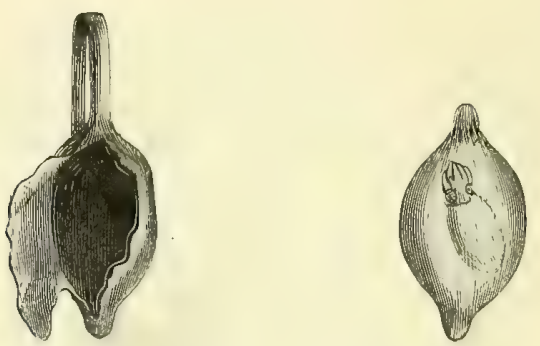

CEUF DE SĖCHE

(Dépourvu de son enveloppe.)

ainsi fort indiscrètement aux jambes des baigneurs.... et des baigneuses. Il se souviendra toujours de la frayeur d'une jeune femme qu'une de ces méchantes bêtes avait saisie un peu plus haut que la jambe.... L'animal ne lâcha prise que lorsqu'on lui eut versé quelques gouttes de vinaigre sur le dos. Il trouva le procédé extrêmement désagréable.

\section{II}

A diverses époques, on a parlé de Calmars ou de Poulpes gigantesques, hors de proportion avec les espèces les plus grosses de nos côtes.

Des naturalistes ou des marins ont signalé des individus d'une taille tellement grande, qu'ils n'ont pas craint de les comparer à des Baleines. 
Pline parle d'un monstre qui avait l'habitude d'aborder' à Castria, sur la côte d'Espagne, pour dévaster les étangs. Il en dévorait tous les poissous. Cet animal pesait 350 kilogrammes. Ses bras et gluants étaient longs de 10 mètres. Sa tête était grosse comme un tonneau; elle offrait la capacité de quinze amphores, et fut envoyée au proconsul L. Lucullus.

Olaüs Magnus raconte les hauts faits d'un Céphalopode colossal, qui avait au moins un mille de longueur, et dont l'apparition au sein des eaux ressemblait plus à une île 'qu'à un animal ${ }^{1}$ (similiorem insula quàm bestice). Ce terrible Mollusque avait été nommé Kraken.

L'évêque de Nidaros découvrit un de ces animaux gigantesques, qui dormait tranquillement au soleil, et le prit pour un immense rocher. Il fit dresser un autel sur son dos, et y célébra la messe. Le Kraken demeura immobile tout le temps de la cérémonie. Mais à peine l'évêque eut-il regagné le rivage, que le monstre replongea dans la mer. (Bartholin.)

Les excréments de cette affreuse bête répandaient un parfum si suave, que les Poissons d'alentour accouraient en toute hâte pour s'en repaitre. Alors l'impitoyable Gargantua ouvrait son effroyable gueule, semblable à un golfe ou à un détroit (instar sinus aut freti), et engloutissait tous les malheureux petits ou grands qui se trouvaient à sa portée. (Bartholin.)

Pontoppidan, évèque de Bergen, regarde comme trèsauthentique l'histoire de ce fameux Kraken. Il assure qu'un régiment pourrait manœuvrer à l'aise sur son dos!

Linné, dans la première édition de son Système de la

1 Des pècheurs de la Manche affirment encore avoir rencontré dans la haute mer des Calmars grands comme des iles. (Lacaze-Duthiers.) 
nature, admet l'existence de ce monstre imaginaire, et le désigne sous le nom de Sepia microcosmus. Plus tard, mieux instruit, il l'effaça de la liste des animaux vivants.

Sonnini n'a pas suivi l'exemple du grand naturaliste suédois. Il a représenté, dans ses Suites à Buffon, ce géant des Céphalopodes étreignant dans ses bras démesurés un vaisseau de haut bord, et cherchant à l'engloutir. Inutile de dire que son dessin n'est pas d'après nalure!

Pernetti parle d'un monstre du même genre et de la même taille, qui réussit à faire sombrer un autre vaisseau.

L'existence du Kraken est regardée comme une fable. La science la repousse comme les récits exagérés, analogues, de Pline et d'Élien. Nous ne sommes plus au temps où l'on croyait à des animaux marins tellement volumineux, qu'il leur eût été impossible de passer par le détroit de Gibrallar!

Cependant il est bien reconnu aujourd'hui qu'il se trouve, dans la Méditerranée et dans l'Océan, des Céphalopodes réellement énormes, non pas, toutefois, de la grandeur d'un vaisseau, d'une Baleine, d'une île...., ou plus larges qu'un détroit...., mais d'une taille assez extraordinaire pour mériter le nom de gigantesques.

Aristote parle d'un grand Calmar (Tềlos) de la Néditerranée, long de cinq coudées $\left(3^{\mathrm{m}}, 10\right)$.

Le fameux plongeur Piscinola, qui descendit dans le détroit de Messine, à la prière de l'empereur Frédéric II, y vit avec effroi d'énormes Poulpes attachés aux rochers, et dont les membres, de plusieurs aunes de long, étaient plus que suffisants pour étouffer un homme. Ce témoignage n'a pas assez fixé l'attention des naturalistes de notre âge.

Nous en dirons autant de l'ex-voto suspendu dans une église de Saint-Malo, lequel représente une embarcation 
arrêtée, sur la côte d'Angole, par les longs bras d'un Céphalopode colossal. C'est très-probablement ce fait, exagéré par l'imagination de Sonnini, qui a servi de modèle ou de prétexte à la figure dont nous avons parlé.

Les naturalistes modernes ont sirnalé, dans nos mers, des Céphalopodes d'une assez belle taille. M. Verany parle d'un Calmar qui avait $1^{\mathrm{m}}, 6535$ de longueur, et qui pesait 12 kilogrammes. On a pêché près de Nice un autre individu qui pesait 15 kilogrammes. On possède au muséc de Trieste le corps d'un animal analogue, trouvé en Dalmatic, sur les bords de la mer.

Un Calmar de très-grande taille $\left(1^{\mathrm{m}}, 820\right)$ a été pris non loin de Cette, il y a une vingtaine d'années; il fait partic en ce moment des collections de la Faculté des sciences de Montpellier'. (P. Gervais.)

Le voyageur Péron a rencontré près de la terre de VanDiemen une Sèche aussi grosse qu'un baril, roulant pesamment sur les vagues, dont les bras avaient jusqu’à $2^{2}$,, 33 de longueur et une vingtaine de centimètres de diamètre à leur base. Ces bras se tordaient comme de hideux Serpents.

Quoy et Gaimard ont recueilli dans l'océan Atlantique, près de l'équateur, pendant un temps parfaitement calme, les débris d'un énorme Mollusque de la même famille, dont ils ont évalué le poids à plus de $\$ 0$ kilogrammes. Il n’y avait que la moitié du corps, sans les bras.

Rang a découvert dans les mèmes eaux un Céphalopode, de couleur rouge, dont le corps offrait le volume d'un tonneau.

Pennant donne les mesures d'une Sèche dont le corps avait 12 pieds anglais de diamètre; ses bras en présentaient 34 .

1 C'est probablement l'Ommastrephes pteropus Steenstrup. 
Swediaur rapporte que des baleiniers ont retiré de la gueule d'un Cachalot des fragments d'une autre Sèche qui avaient 25 pieds de longueur.

On conserve au Collége des chirurgiens de Londres une mandibule de Céphalopode, qui paraît venir des mers du Nord. Elle est plus grande que la main.

II. Steenstrup (de Copenhague) a publié des observations très-intéressantes sur un Céphalopode gigantesque ${ }^{1}$ rejeté en 1853 sur le rivage du Jutland. Le corps de cet animal, dépecé par les pècheurs, fournit la charge de plusieurs brouettes. Son arrière-bouche était grande comme la tète d'un enfant.

Le même naturaliste a fait connaitre un autre Mollusque colossal $^{2}$; qu'on suppose rapporté de Saint-Thomas. Il a montré à I. le professeur Auguste Duméril un tronçon de bras d'une autre espèce, de la grosseur de la cuisse.

Enfin, M. Harting a décrit et figuré diverses parties plus ou moins volumineuses d'un individu du mème groupe, qui se trouvent dans le musée d'Utrecht.

Toutes ces observations s'appliquent évidemment à plusieurs espèces de Céphalopodes voisines des Sèches, des Calmars ou des Poulpes, dont la taille dépasse de beaucoup celle de tous les Invertébrés connus. (II. Edwards.)

\section{III}

Quoi qu'il en soit, voici un exemple anthentique d'un de ces énormes animaux, observé entier et vivant, à quarante lieues N. E. de Ténériffe, par l'ariso à vapeur l'Alecton.

1 Architeuthis dux Steenstrup.

${ }_{2}$ Dosidicus Eschrichtii Steenstrup. 
L'histoire de cette découverte est extraite du rapport officiel du commandant Bouyer, lieutenant de vaissean, et d'une relation de M. Sabin Berthelot, consul de France aux îles Canaries.

Le 30 novembre 1861, l'aviso à vapeur l'Alecton, se rendant à Cayenne, rencontra, entre Madère et les îles Canaries, un Céphalopode monstrueux qui nageait à la surface de l'eau. Cet animal mesurait 5 à 6 mètres de longueur, sans compter les huit bras formidables couverts de ventouses qui couronnaient sa tête. Ses yeux, à fleur de tête, avaient un développement prodigieux, une teinte glauque et une effrayante fixité. Sa bouche, en bec de perroquet, pouvait offrir 50 centimètres d'ouverture. Son corps, fusiforme, mais très-renflé vers le milieu, présentait une énorme masse, dont le poids a été estimé à plus de 2000 kilogrammes. Ses nageoires, situées à l'extrémité postérieure, étaient arrondies en deux lobes charnus d'un très-grand volume.

Ce fut à deux heures de l'après-midi que l'équipage de l'Alecton aperȩut ce terrible Céphalopode.

"Commandant! la vigie signale un débris flottant par bâbord devant.

- C'est rougeâtre, on dirait un bout de mât.

- C'est un paquet d'herbes.

- C'est une barrique.

- C'est un animal, on voit les pattes.

Cependant l'Alecton. approchait du grand Mollusque de toute la vitesse de sa machine. Le commandant fit stoper, et, malgré les dimensions de l'animal, il manœuvra pour s'en emparer. Malheureusement, une forte houle prenait l'Alecton en travers, lui imprimait des roulis désordonnés et gênait ses évolutions; tandis que, de son còté, le Mollusque, quoique toujours à flemr d'ean, se 
déplaçait avec intelligence, et semblait vouloir éviter le navire.

En toute hâte on chargea des fusils; on prépara des harpons et l'on disposa des nœuds coulants. Mais, aux premières balles qu'il reçut, le monstre plongea et passa sous le navire. Il ne tarda pas à reparaître à l'autre bord. Attaqué avec les harpons et blessé par de nouvelles décharges, il disparut deux ou trois fois, et chaque fois il se montrait, quelques instants après, à fleur d'eau. Il agitait ses longs bras dans tous les sens. Mais le navire le suivait toujours, ou bien arrêtait sa marche, selon les mouvements de l'animal. Cette chasse dura plus de trois heures.....

Le commandant de l'Alecton voulait en finir, à tout prix, avec cet ennemi d'un nouveau genre. Néanmoins il n'osa pas risquer la vie de ses marins en faisant armer une embarcation. Il pensa, avec raison, que le monstre aurait pu la faire chavirer, en la saisissant avec un de ses formidables bras. Les harpons qu'on lançait s'enfonçaient dans un tissu mollasse, sans consistance, et en sortaient sans succès. Plusieurs balles (au moins une vingtaine) avaient traversé inutilement divers endroits de son corps. Cependant il en reçut une qui parut le blesser grièvement; car il vomit une grande quantité d'écume et de sang mêlés à des matières gluantes qui répandirent une forte odeur de musc. Ce fut dans cet instant qu'on parvint à le saisir avec un harpon et avee un noud coulant. Mais la corde glissa le long du corps élastique, et ne s'arrêta que vers l'extrémité, à l'endroit des deux nageoires.

On tenta de le hisser à bord. Déjà la plus grande partie du Mollusque se trouvait hor's de l'ean, quand un violent mouvement fit déraper le harpon. L'énorme poids de la masse agit sur le noud coulant, qui pénétra dans les chairs, 
les déchira, et sépara la partie postérieure du reste de l'animal. Alors le monstre, dégagé de cette étreinte, retomba lourdement dans la mer, et disparut.

Le morceau détaché pesait une vingtaine de kilogrammes. On l'a porté à Sainte-Croix de Ténériffe.

11 est probable que ce Mollusque colossal était malade ou épuisé par une lutte récente, soit avec un Céphalopode de sa taille, soit avec quelque autre monstre de la mer. Ou expliquerait ainsi pourquoi il avait quitté les profondeurs de l'Océan et les rochers qui lui servent de repaire, pourquoi il présentait une sorte de lenteur et, pour ainsi dire, de gêne dans ses mouvements, et pourquoi enfin il n'a pas obseurci les flots avec son encre. A en juger par sa taille, il aurait dù làcher au moins un baril de liqueur noire, s'il avait été bien portant et qu'il n'eùt pas épuisé ce moyen de défense dans un récent combat.

II. Berthelot a interrogé de vieux pêcheurs canariens, qui lui ont assuré avoir vu plusieurs fois, vers la haute mer, de grands Céphalopodes rougeàtres, de 2 mètres et plus de longueur, dont ils n'avaient pas osé s'emparer. Aujouĩd'hui, ce n'est pas sans une certaine émotion qu'ils ont appris l'existence, dans leurs parages, d'un voisin aussi redoutable, quoique

\section{..... Il ait perdu la queue à la bataille.}

Très-probablement ce monstre n'est pas le seul de son espèce, ni peut-être de sa taille, aux environs de Ténériffe.

Ce Mollusque est-il un Calmar ou un Céphalopode voisin des Calmars, ainsi que plusieurs journaux ont paru le décider? Si nous en jugeons par la figure que II. S. Berthelot a bien voulu nous communiquer (cette figure a été dessinée, pendant la lutte, par un des officiers de l'Alecton), l'ani- 
mal possède deux nageoires terminales, comme les Calmars; mais il a huit bras égaux entre eux, comme les Poulpes. On sait que les Calmars, comme les Sèches, ont dix bras, dont deux très-longs. Est-ce une espèce intermédiaire entre les Calmars et les Poulpes? Faut-il admettre, avec MII. Crosse et Fischer, que le Mollusque avait probablement perdu ses grands bras dans quelque lutte antérieure?

Les deux savants malacologistes que nous venons de citer, proposent de désigner le nouveau monstre sous le nom de Calmar de Bouyer ${ }^{1}$.

\section{IV}

De mème que les autres Mollusques, les Céphalopodes sont tantòt nus, tantôt pourvus d'une coquille. Les premiers sont plus nombreux que les seconds. C'est l'inverse, comme on l'a déjà vu, chez les Acéphales et les Céphalés.

Les Céphalopodes testacés sont l'Argonaute et le Nautile.

L'Argonaute papyracé ${ }^{2}$ est un mollusque bien connu des anciens, de Pline, par exemple.

L'animal se fait remarquer par ses huit tentacules, assez grands, couverts de deux rangées de suçoirs, dont six étroits, amincis vers l'extrémité et pointus, et deux terminés par une large dilatation membraneuse.

Sa coquille est mince, fragile, roulée en spirale et cannelée onduleusement et symétriquement. Son dernier tour est si grand, proportionnellement, qu'elle a l'air d'une élégante chaloupe dont la spire serait la poupe. (Cuvier.)

1 Loligo Bouyeri Crosse et Fischer.

2 Argonauta Argo Linné. 
Comme le corps de l'Argonaute ne pénètre pas jusqu'au fond de la spire de la coquille, et ru'il n'y adhère point, plusieurs auteurs ont pensé que cette enveloppe n'est pas produite par l'animal, mais qu'il l'habite en parasite après en avoir tıé le propriétaire (Rafinesque). Cependant, comme on a toujours trouvé le Mollusque dans la même coquille et jamais dans une antre, et qu'enfin on a constaté déjà dans l'œuf le rudiment de cette même enveloppe (Poli), il faut rejeter cette opinion.

L'Argonaute se sert de sa coquille comme d'un bateau léger, employant ses tentacules étroits, comme des rames qui frappent l'eau de chaque côté, et, d'après Pline, relevant ses tentacules dilatés, comme des voiles. Cette coquille serait un navire dont le matelot se trouverait à la fois le gouvernail, le mât, les rames et la voile ( $\mathrm{Ch}$. Bonnet). On a peut-être un peu poétisé l'industrie nantique de ce joli navigateur. Cependant il est très-vrai que, pendant les temps calmes, on voit des troupes d'Argonautes flotter et se promener à la surface de la mer.

Au moindre danger, ces Mollusques plient leurs voiles, rentrent leurs bras, contractent leur corps, et descendent dans la mer.

Le Nautile commun est peut-être plus curieux que l'Argonaute papyracé.

Celui-ci ressemble davantage aux Céphalopodes sans coquille. Il a, comme ces derniers, un sac viscéral, des yeux énormes et un bec de perroquet. Mais sa tète, au lieu de porter de grands tentacules, est entourée de plusieurs cercles de petits bras nombreux, fins, contractiles et privés de sucoirs. (Rumph.)

La coquille du Nautile est grande, épaisse, ornée en dehors de bandes et de flammes d'un fauve rougeâtre. Son intérieur parait nacré d'une manière assez brillante. Cette 
coquille est contournée en spirale. Les tours croissent trèsrapidement, de telle sorte que les.derniers enveloppent les premiers. Mais ce qui la distingue essentiellement, e'est sa distribution en chambres symétriques, séparées par des cloisons trausversales et concaves. Ver's le milieu de ces dernières, se trouve un trou assez petit, répondant à un entonnoir étroit, lequel produit un siphon qui va d'une. chambre dans une autre.

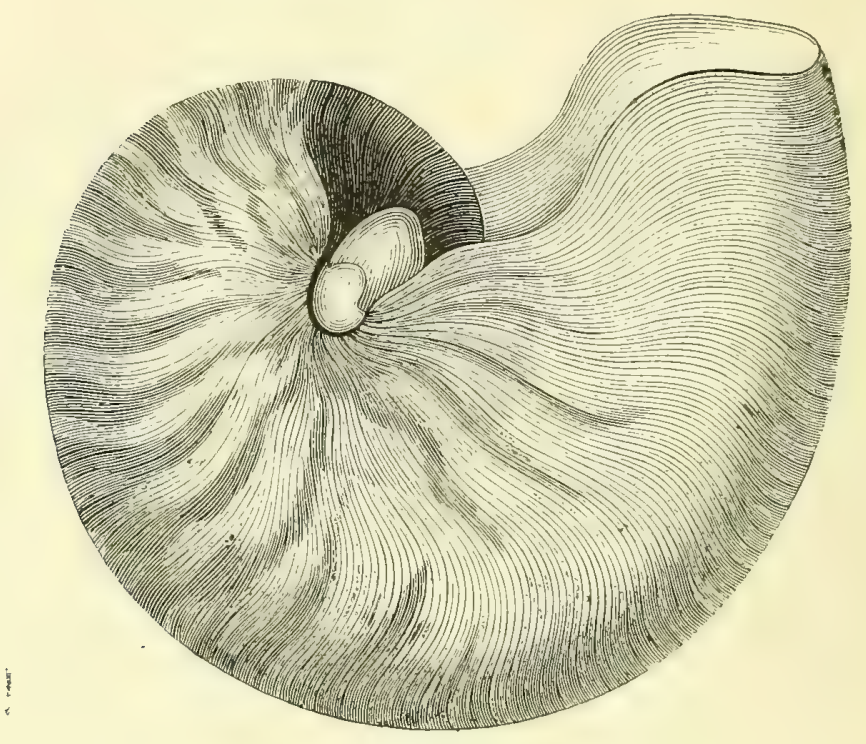

COQUILLE DU NAUTLE COMMUN (Nautilus Pompilius Linné).

L'animal demeure principalement dans la dernière chambre, qui est la plus spacieuse et la seule largement ouverte. Une sorte de cordon, qui parait à la fois un tube et un ligament, nait de sa région dorsale, parcourt tous les siphons, et relie ensemble les différentes parties de son corps logées dans les diverses chambres.

Ce Céphalopode polythalame représente jusqu'à un cer- 
tain point, daus nos mers actuelles, ces coquilles si nombreuses de l'ancien monde, conmues sous le nom de Cornes d'Ammon (Ammonites).

On sait que ces lossiles sont divisés aussi en plusicurs chambres; mais leur derniere loge est relativement petite, et non très-vaste. Leurs cloisons sont anguleuses, tantòt ondulées, tautòt déchiquetées. Certaines ressemblent à des feuilles d'Acanthe. Il existe des Cornes d'Ammon depuis la taille d'une lentille jusqu'à celle d'une roue de carrosse. (Cuvier.)

Quelques naturalistes ont cru que ces dépouilles étaicut des corpuilles intérieures. On trouve encore, anjourd'hui vivant, un petit Céphalopode testacé, appelé Cornet de postillon', qui renferme dans la partie postérieure de son corps une coquille blanche, qu'on ne saurait mieux comparer qu'à un còne très-allongé, tordu sur lui-mème dans un seul plan, et divisé transversalement en une série de cellules par des lames très-concaves.

'Spirula Peronii Lamarck.

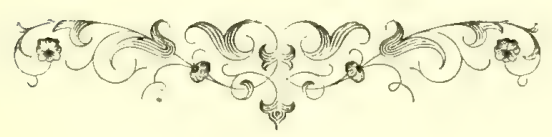





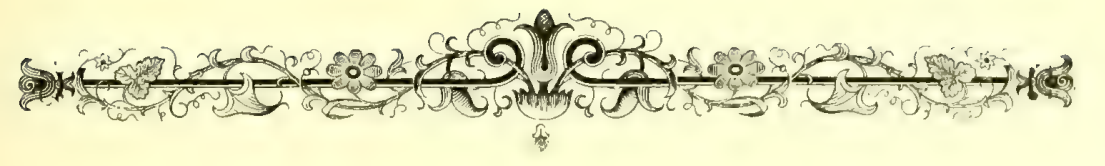

\section{CHAPITRE XXVI}

\section{L'UNITÉ DE COMPOSITION.}

"L'unité dans la variété. "

(LEIBNITZ.)

Les Céphalopodes sont remarquables surtout par la situation de leurs membres au-dessus de la tête. Leur nom signifie littéralement pieds en tête. On appelle Octopodes ceux qui ont huit membres, et Décapodes cenx qui en ont dix. Cette bizarre structure, et le singulier mode de progression qui en est la conséquence, ont frapué tous les naturalistes.

L'étude approfondie des anomalies apparentes de la nature conduit souvent à reconnaître, dans ses prétendues déviations, une confirmation nouvelle de la sagesse de ses lois.

Il y a trente ans, deux ingénicux observateurs, MM. Laurencet et Meyranx, examinant la manière dont sont placés relativement les viscères des Céphalopodes, eurent la pensée de ramener cette classe au type général des Vertébrés. Ils considérèrent ces Mollusques comme des Vertébrés dont le trone serait replié sur lui-mème en arrière, 
à peu près dans la région de l'ombilic, de manière que la nuque touchàt le bassin et que les mains fussent rapprochées des pieds. Cette disposition est exactement celle que prennent les baladins, sur nos places publiques, lorsqu’ils renversent leurs épaules pour marcher à la fois sur les mains et sur les pieds.

Geoffroy Saint-Ililaire, saisissant avidement cette nouvelle vue, annonça, dans un rapport circonstancié, qu elle établissait, entre les Céphalopodes et les animanx supérieurs, une ressemblance jusqu'alors méconnue, et fournissait en mème temps une nouvelle preuve en faveur de la grande loi yu'il avait appelée unité de composition organique.

Cette interprétation détruisait l'opinion émise par Cuvier' daus la plupart de ses ouvrages, sur la grande différence qui sépare les Mollusques des Vertébrés. L'illustre anatomiste réclama avec force, peut-ètre mème avec aigreur, contre les assertions et les conclusions de son savant confrère.

De là cette discussion solennelle qui éclata entre les deux grands naturalistes devant l'Académie des sciences, le 13 février 1830 , discussion qui fixa un moment l'attention de l'Europe tout entière.

Il s'agissait, en définitive, de savoir si la philosophie zoologique, telle que l'a conçue Aristote, telle que l'ont continuée les décourertes de vingt-deux siècles, telle enfin que Cuvier l'avait illustrée par d'admirables dissections, si cette philosophie était insuffisante, et devait céder la place aux doctrines récemment introduites dans l’anatomie comparée, en Allemagne et en France, par plusieurs naturalistes éminents, et en particulier par Geoffroy SaintHilaire.

Guand les discussions scientifiques, disait un éminent 
critique de l'époque, ne roulent que sur des travanx de détail, elles demeurent enfermées dans l'enceinte des Académies. Mais quand elles portent sur les hautes généralités de toute une science; quand de leur choc doit résulter une de ces révolutions qui comptent dans l'histoire du progrès; quand elles sont engagées et soutenues par des hommes dont le nom est européen, alors la curiosité publique s'éveille et s'y attache. Toutes les sciences sont, par' contrecoup, mises en cause, ot ont un intérêt majeur ì leur résultat.

La controverse élevée entre Geoffroy Saint-Hilaire et Cnvier offrit tous ces caractères.

Les questions en litige étaient telles, qu'indépendamment de leur valeur vraiment scientifique, elles devaient saisir l'imagination de tout homme qui pense, et s'emparer fortement de toutes les intelligences pour lesquelles le spectacle de la nature animée est une source féconde d'émotions.

Tous les journaux scientifiques de l'époque, et mème les grandes feuilles quotidiemnes, ourrirent leurs colomnes à l'important débat qui agitait l'Académie.

Un des écrivains les plus puissants et les plus aimés de l'Allemagne, l'illustre Gothe', entreprit de rísnmer of de commenter la célèbre discussion. Il annonça que les sciences naturelles allaient recevoir une nouvelle direction, et que l'esprit humain était sur le point de faire $u n$ trèsgrand pas.....

La sensation profonde que produisit l'aurore de cette transformation scientifique durait encore le lendemain dr cette autre révolution (juillet 1830) qui venait de renverser une ancicnne dynastie. On raconte qu'un voyageur

1 Il avait alors quatre-vingt-trois ans. 
récemment arrivé de France s'étant présenté devant Gœethe, celui-ci lui dit aussitòt: “ Eh bien! que pensez-vous de ce grand événement? le volcan a fait éruption! - C'est une terrible catastrophe, répondit le visiteur; mais que pouvait-on attendre d'un pareil ministère, si ce n'est que tont cela finirait par l'expulsion de la famille royale! - Il s'agit bien de ces gens-là! je vous parle du débal entre Cuvier et Geoffroy Saint-Hilaire!... »'(Sorel.)

Geoffroy Saint-Hilaire posait en principe que la nature a formé tous les ètres vivants d'après un plan unique, le même dans son essence, mais varié dans ses applications. Les formes nombreuses que présentent les espèces d'une même classe d'animaux dérivent les unes des autres. Il a suffi à la puissance créatrice de changer quelques-unes des proportions des organes, pour en étendre ou pour en - restreindre les fonctions, ou pour leur en donner de nouvelles. Les différences viennent d'une autre complication on d'une autre modification.

“Toutes les parties essentielles semblent indiquer, comme disait Buffon, qu'en créant les animaux, l'Étre suprème n'a voulu employer qu'une idée, et la varier en même temps de toutes les manières possibles, afin que l'homme puit admirer à la fois, et la magnificence de l'exécution, et la simplicité du dessin. »

Aver le fil conducteur de la nouvelle méthode, on peut suivre et reconnaitre une partie quelconque de l'organisation à travers ses mille usages et ses mille transformations, et expliquer facilement pourquoi elle est libre dans tel ani- 
mal, soudée dans tel autre, largement développée dans celui-ci et tout à fait atrophiée dans celui-là '.

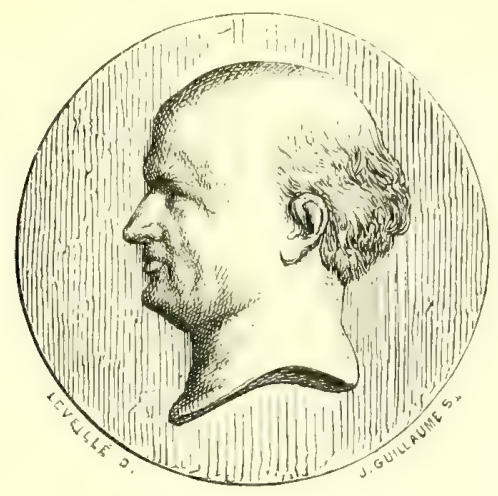

ETIENYE GEOFFROY SAINT-HILAIRE.

Cuvier s'efforçait de démontrer que si, par unité de composition, on entend identité, on dit une chose contraire an plus simple témoignage des sens. Si, par là, on entend ressemblance, analogie, on énonce une proposition vraie dans certaines limites, mais aussi vieille dans son principe que la zoologie elle-mème, et à laquelle les découvertes les phus récentes n'ont fait qu'ajouter, dans certains cas, des traits plus ou moins importants, sans rien altérer dans sa nature.

Geoffroy répondait que l'unité de composition n'était, ni une parfaite identité, ni une simple analogie, mais quelque chose entre-deux; qu'elle s'appliquait aux connexions et non aux formes, aux ensembles et non aux détails; qu'elle s'attachait surtont aux éléments organiques, et présidait au plan général de l'oronanisme, et non à ses arrangements partiels.

1 M. Isidore Geoffroy Saint-Hilaire a résumé les doctrines philosophiques de son illustre père dans un ourrage remarquable, où l'élégance et la variétẻ du style s'allient heureusement avec la justesse ét la profondeur des appréciations. La mort prématurée de ce digne fils a été une perte irréparable pour la science of pour l'amitié. 
Cuvier n'avait-il pas été forcé d'admettre quatre types distincts dans le règne animal? or, les animaux de chacun de ces types, tous les Vertébrés par exemple, offraient-ils entre eux des identités ou des analogies?

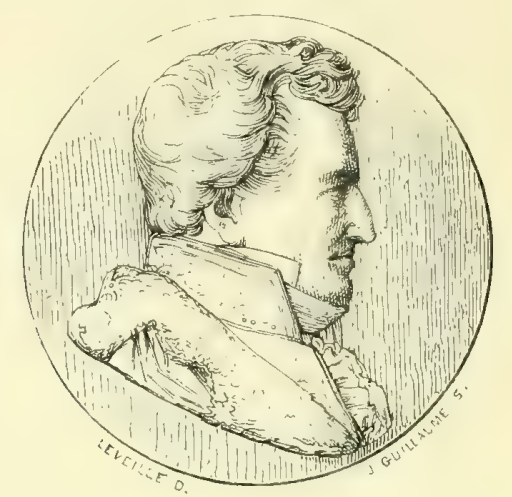

CTYIER.

A la vérité, le grand zoologiste déclarait que la nature a laissé entre ces divers plans des hiatus manifestes, et que les Céphalopodes, par exemple, diffèrent notablement de tous les autres animaux, et ne sont le passage de rien.

Dans ses belles Recherches sur les ossements fossiles, Cuvier, antiquaire d'une nouvelle espèce, n'avait-il pas abandonné plusieurs fois sa méthode rigoureuse d'analỵse, et n'était-il pas arrivé hardiment, par la synthèse philosophique, à des résultats inattendus, féconds, admirables, qui plaidaient éloquemment en faveur de la doctrine de son illustre antagoniste?

\section{III}

Près d'un demi-siècle s'est écoulé depuis cette mémorable discussion. Les prédictions de Gothe se sont réalisies. 
"L'esprit, disait ce profond penseur, gouvernera la matière. On apercevra les grandes maximes de la création; on pénétrera dans l'atelier 'mystérieux de Dieu! Que sont d'ailleurs nos relations avec la nature, si nous nous ocen-

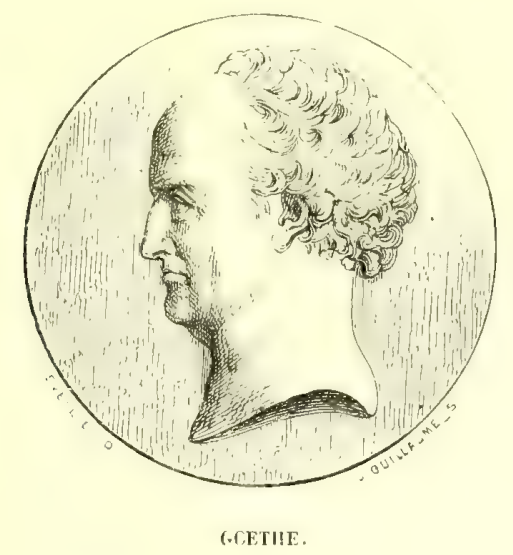

pous simplement des individualités matérielles, et si nous ne sentons pas le sonftle primordial qui donne à charpue partie sa direction, et qui ordonne et sanctionne charpue déviation au moyen d'une loi inhérente? »

Limite de composition et les lois secondaires qui en dérivent se sont introduites peu à peu dans les idées, dans les livres et dans l'enseignement; elles ont produit les résultats les plus féconds et préparé l'heureuse transformation de la science. La nouvelle doctrine n'est autre chose, comme le disait Greoffroy Saint-Ililaire lui-même. que la confirmation du principe de Leibnitz, qui définissait l'mivers: L'unité dans la variété. L'histoire naturelle ainsi comprise est la première des philosophies (Villemain).

Les deux grands hommes qui ont exercé une influence si diverse sur les progrès modernes de la zoologic avaient travaillé ensemble dans leur jeunesse et public plusieurs 
mémoires en commun; mais bientôt la divergence de leurs vues les conduisit à désunir leurs efforts.

Esprit positif, froid et mesuré, Cuvier appliquait principalement son génie à l'observation rigoureuse des faits et aux conséquences immédiates résultant de cette observation. Il proclamait la suprême autorité de l'analyse, et redoutait les conchusions prématurées de la synthèse. II était finaliste exagéré, et par cela même partisan de l'invariabilité absolue des espèces; il ne s'attachait qu'à trouver des caractères distinctifs. Il n'admettait d'autres lois dans les organes que des lois de coexistence et d'harmonie. Enfin, il voyait dans les classifications l'idéal auquel doit tendre l'histoire naturelle, et, dans cet idéal une fois réalisé, la science tout entière.

Penseur enthousiaste ct hardi, Geoffroy Saint-Hilaire donnait une très-grande importance aux rapprochements de la synthèse, et croyait que la science devait être désormais dirigée par le flambeau de la philosophie; il proclamait la variété limitée des espèces, sous l'influence des milieux ambiants; il admettait des harmonies acquises ef non originelles, contingentes et non nécessaires; il embrassait tous les ètres organisés dans une mème loi, et n'accordait aux classifications qu'une valeur très-secondaire.

En résumé, Cuvier défendait la doctrine des différences, et représentait l'école analytique; Geoffroy soutenait la doctrine des ressemblances, et personnifiait l'école synthétique. L'un était l'historien de la nature, l'autre voulait en être l'interprète!

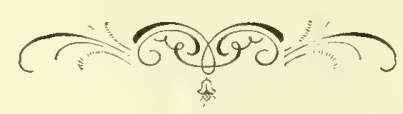




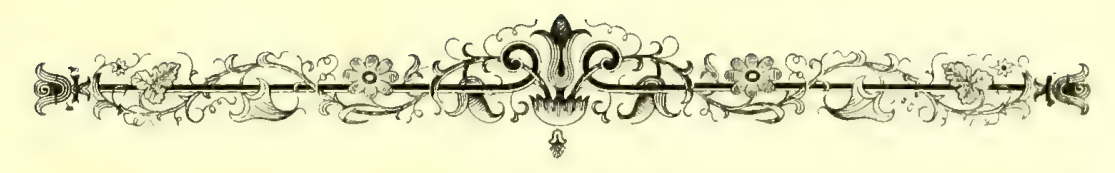

\section{CHAPITRE XXVII}

\section{LES ANNÉLIDES.}

..... Tout ce grand mouvement,

Qu'on jette un peu de sable, il cesse en un moment.

(DELille.)

Voici un groupe d'animaux vermiformes confondus pendant longtemps avec les Vers, à cause de leur physionomie.

Au premier abord, vous allez croire qu'ils sont fort laids et peu intéressants. - Fi done! des animaux qui ressemblent à des vers!

Mais, comme le dit Aristote, la nature ne renferme rien de bas, ni de méprisable. Tout y est sublime, tout y est digne de notre admiration. Vous le verrez bientòt. Les Annélides sont peut-être, parmi les bêtes de la mer, celles qui présentent les formes les plus gracieuses, les appendices les plus élégants et les couleurs les plus brillantes ${ }^{1}$.

Cuvier, un des premiers, étudia ces animaux d'une manière sérieuse. Il les désigna sous le nom de Vers à sang rouge, parce qu'il avait remarqué dans beaucoup d'entre eux le fluide sanguin d'une teinte plus on moins semblable

\footnotetext{
1 Voyez la planche XXI.
} 
à celle qu'il présente chez les animaux supérieurs. Mais, depuis l'illustre zoologiste, on a reconnu dans ces groupes des espèces à sang jaune, et d'autres à sang riolet, à sang blenâtre, et méme à sang rert. Il y en a aussi dont le sang est sans couleur.

Lamarck a proposé, pour ces animaux, le nom d'Annélides (pourquoi pas Annelides? disait Constant Duméril), aujourd'hui généralement adopté. Ce nom est tiré de la strueture particulière du corps, formé comme d'une suite - d'anneaux. Ces anneaux sont au nombre de vingt, de trente, de soixante, de quatre-vingts.... Dans l'Eunice sanguine $^{1}$, il y en a au moins trois cents. Dans la Phyllodoce lamelleuse ${ }^{2}$, on en compte jusqu'à neuf cents (l'animal offre à peine 8 décimètres de longueur).

Ces anneaux sont des rides minces ou épaisses, aplaties ou saillantes, séparées par des étranglements. Chacun ressemble à celui qui le précède et à celui qui le suit. Ceux de la tîte, ou partic céphalique, et ceux de la queue, sont ordinairement un peu modifiés.

Les zoologistes ont donné anx Annélides les désignations les plus euphoniques, empruntées ì la mythologie: Amphitrite, A phrodile, Polynoé, Euphrosine, Alciope, Néréis.... II y a quelque chose de merveilleusement doux dans cette étude de la nature, qui attache un nom ì tous les ètres, une pensée à tous les noms, une affection et des souvenirs à toutes les pensées. (Nodier.)

Le corps des Annélides est nu, ou bien protégé par un vêtement solide.

Les espéces nues sont celles qui ressemblent le plus à des Vers ou à des larves. Quelques-unes se creusent, dans la terre ou dans la vase, des galeries étroites, dans lesquelles

1 Eunice sanguinea Savigny.

2 Phyllodoce laminosa Audouin et M. Edwards. 


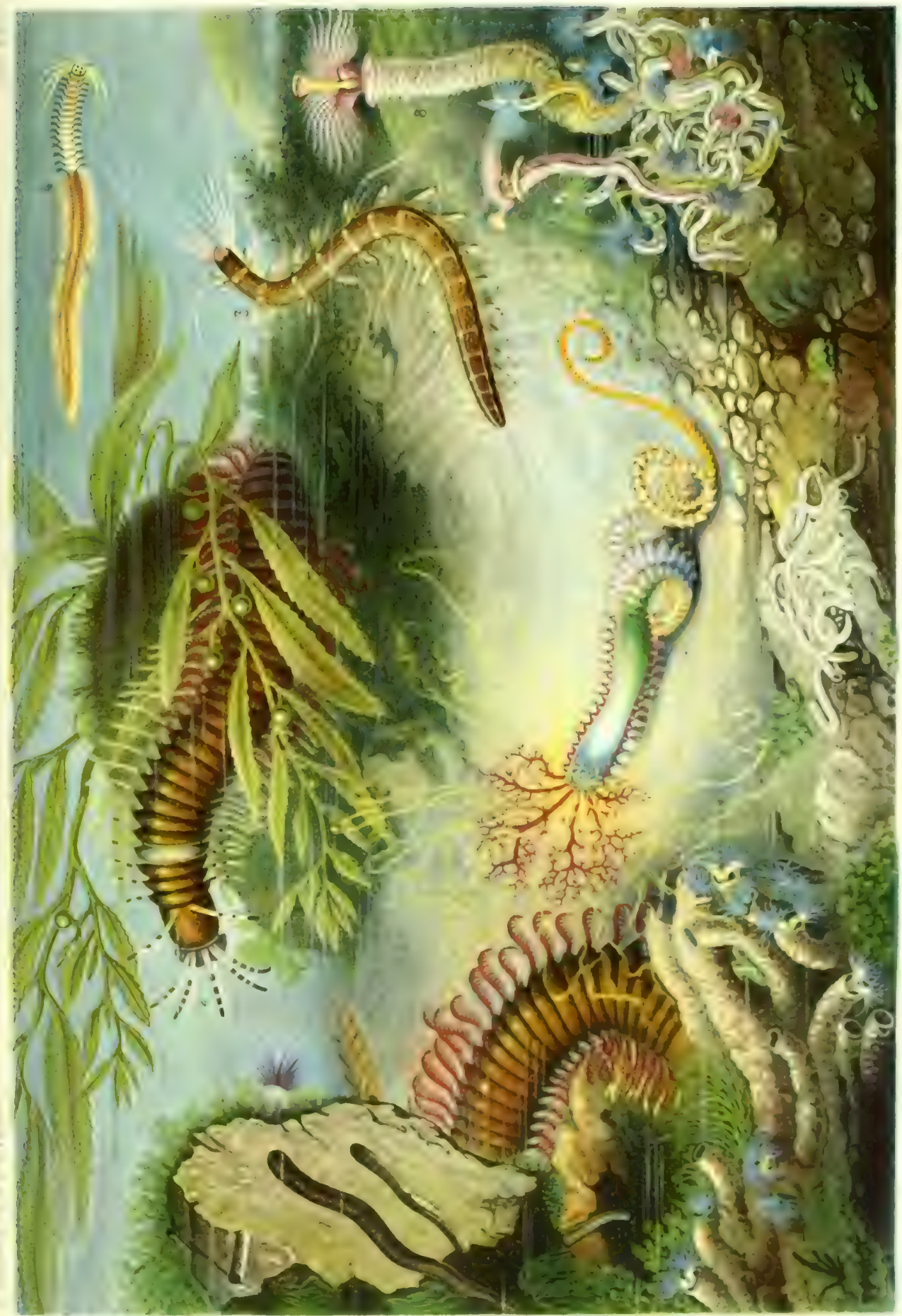



elles se logent. D'autres s'établissent par centaines, par milliers, dans des mottes de sable, qui ressemblent alors à des gàteaux de ruche à miel.

Les espèces à vètement solide possèdent un étui calcaire épais, droit ou flexueux, dans lequel clles peuvent se retirer entièrement, comme dans une coquille.

Cuvier fait remarquer que les Annélides nues ont les organes respiratoires sur la partie moyenne du corps, le long des còtés, et que les Anmélides à vêtement solide offrent ces mèmes organes attachés à la tête ou à la partie antérieure. Ce grand naturaliste nomme les premières Dorsibranches, et les secondes Tubicoles ${ }^{1}$.

Le corps des Annélides est plus ou moins cylindrique, souvent déprimé. Il s'amincit en avant et en arrière. Il est susceptible de contraction et d'extension.

Ces animaux ont des yeux en nombre variable : chez plusieurs, on en compte jusqu'à soixante. M. Ehrenberg a fait connaitre une curieuse espèce qui en porte deux à la tête et deux à la queue. Deux yeux à la queue! On en a décrit une autre, véritable petit Argus, qui a plusieurs yeux sur la tête, deux sur chaque anneau du corps et quatre sur la queue. Quelle richesse d'organes visuels!

Fourier n'a done rien imaginé! L'idée d'un æil au bout d'une quene est, en définitive, une assez pauvre idée. Voyez la nature! Elle en a mis deux dans une bête, et quatre dans une autre!

Plusieurs Annélides possèdent le long du corps deux ou plusieurs rangées de soies courtes ou allongées, molles ou roides. D'autres sont entourées de mille petits filaments gracieusement mobiles, qui deviennent, suivant le besoin, des mains, des pieds on des nageoires....

\footnotetext{
1 Voyez la planche XXIl:
} 
Les Cirratules offrent de longs appendices capillaires qui s'agitent de toutes parts autour d'elles, et qu'elles étendent au loin comme autant de cordages animés. Ce sont à la fois des bras et des branchies, et le sang qui les remplit et les abandonne tour à tour, leur communique une belle teinte d'un rouge cramoisi, ou laisse après lui une couleur d'un jaune d'ambre. Voyez comme elles allongent leur mufle pointu, surmonté d'un double æil en fer à cheval, comme elles se ramassent pour échapper à l'éclat inaccoutumé de la lumière qui les frappe! Les voilà qui forment un peloton plus inextricable cent fois que le nœud tranché par Alexandre. Mais, ici, le câble est vivant; les replis glissent les uns dans les autres, se dénouant et se renouant sans cesse, et toujours renvoyant à votre œil de lumineux reflets. (Quatrefages.)

Les Annélides sont des animaux très-timides, un rien les effraye. Cependant elles sont destinées à vivre de rapine. Les unes se tiennent en embuscade, et attendent au passage les pauvres petites bêtes imprudentes qui s'aventurent dans leurs eaux, les enlacent avec leurs bras ou les saisissent avec leur trompe. Les autres perforent les coquilles les plus dures et dévorent les Mollusques les mieux abrités.

D'un autre côté, ces animaux sont en butte aux attaques d'un grand nombre d'ennemis; ils avaient donc besoin d'être armés d'une manière convenable. La Providence y a sagement et largement pourvu.

Il n'est peut-être pas d'arme blanche, dit un savant naturaliste, inventée par le génie meurtrier de l'homme, dont on ne puisse trouver le modèle dans la tribu des Annélides. Voilà des lames recourbées, dont la pointe présente un double tranchant prolongé, tantôt sur le bord concave, comme dans le yatagan des Arabes, tantôt sur le côté convexe, comme dans le cimeterre oriental. En voici qui rap- 
pellent la latte de nos cuirassiers, le sabre-poignard de nos artilleurs, ou le sabre-baïonnette des chasseurs de Vincennes. Et puis ce sont des harpons, des hameçons, des lames tranchantes de toute forme, légèrement soudées à l'extrémité d'une tige aiguë. Ces pièces mobiles sont destinées à rester dans le corps de l'ennemi, tandis que le manche qui les supporte deviendra une longue pique tout aussi acérée qu'auparavant. Voici encore des poignards droits ou ondulés, des croes tranchants, des flèches barbelées à rebours, pour mieux déchirer la plaie, et qu'une gaine protectrice entoure soigneusement, de peur que leurs fines dentelures ne viennent à s'émousser par le frottement ou à se briser dans quelque choc imprévu. Enfin, si l'ennemi méprise ces premières blessures et ces armes qui l'atteignent de loin, voilà que de chaque pied va sortir un épieu plus court, mais aussi plus fort, plus solide, et que des muscles particuliers mettent en jeu, dès qu'il s'agit de combattre tout à fait corps à corps.... (Quatrefiges.)

En tête des Anuélides dorsibranches, on peut placer les Néréides, avec leurs tentacules en nombre pair attachés aux côtés de l'extrémité céphalique. Leurs branchies forment de petites lames. Chacun de leurs membres offre deux tubercules, deux faisceaux de soies et deux cirres. Lorsque tous ces organes s'unissent pour frapper la vague de concert, l'animal glisse à travers l'eau avec une aisance et une grâce au-dessus de toute expression.

Les Amnélides dorsibranches présentent souvent des couleurs éclatantes. Une des plus riches par sa robe est la 
Nephthys perle', dont le corps est d'un jaune d'orpiment ou d'un rouge orangé, avec une ligne longitudinale plus sombre, courant le long du dos. Toute sa surface est chatoyante. Ses màchoires sont noires et ses yeux bleus.

Une espèce voisine, l'Eunice géante ${ }^{2}$ de la mer des Antilles, peut ètre regardéc comme la plus grande Annélide conmue; elle atteint jusqu'à un mètre et demi de longueur. Elle possede plus de quatre cent einquante articullations. Elle est ornée de teintes irisées resplendissantes, qui rappellent les magnificences du soleil des tropiques. Sa tète est émaillée des plus vives couleurs. Il en sort une trompe énorme, rose, armée de trois paires de màchoires. Autour de la bouche se font remarquer cinq tentacules. Les organes respiratoires, placés sur les deux flanes, paraissent comme des panaches vermillon, surtout lorsqu'ils sont remplis de sang. On peut suivre ce fluide jusque dans le grand raisseau qui parcourt la région dorsale. L'animal posside dix-sept cents organes locomoteurs en forme de larges palettes, d'où sortent des faisceaux de dards qui hui servent de rames, et qui se meuvent tous à la fois avec une rapidité si grande, que l'oil ne peut pas les distinguer dans leur évolution. Quand l'Annélide ondule, qu'elle se tord en spirale, contractant et relâchant alternativement ses anneaux, elle projette par moments des éclats de lumière oi brillent tour it tour les sept couleurs de l'arc-en-ciel.

Dans l'Eunice sanguine, dont nous avous déjà parlé, on compte deux cent quatre-vingts estomacs, trois cents cerveaux (ganglions) et trente mille museles!....

Regardez cette autre Amnélide du même groupe, c’est

- Vephihys margaritacea Sars.

2 Eunice gigantea Cuvier. 
peut-ètre la plus belle des espèces qui vivent sur nos côtes. On l'appelle Chenille de mer (Aphrodite hérissée $)$. Elle est ovoïde, assez pointue aux extrémités et déprimée. Elle a lc dos légèrement convexe et le ventre plat. Il règne en dessus deux rangées longitudinales de larges écailles membraneuses, quelquefois boursouflées, mal à propos désignées sous le nom d'élytres. Ces écailles sont recouvertes par une fourrure épaisse, brune, semblable à de l'étoupe, qui prend naissance principalement sur les côtés. Ce manteau de feutre est perméable à l'eau. Des parties latérales naissent des groupes de fortes épines, qui percent en partie la fourrure, et des faisceaux de soies flexueuses, brillantes de tout l'éclat de l'or, et changeantes en toutes les teintes de l'iris (Cuvier). En effet, on y remarque le jaune, l'orangé, le bleu, le pourpre, l'écarlate, et surtout le vert doré. Ces nuances ont des reflets métalliques, et se jouent de mille manières, produisant les effets les plus merveilleux. L'Aphrodite hérissée ne le cède en beauté ni au plumage des Colibris, ni à ce que les pierres précieuses ont de plus vif. (Cuvier.)

L'animal offre sur les côtés quarante tubercules, d'où sortent des cônes charnus et des aiguilles de trois grosseurs différentes. Il a deux petits tentacules. Son osophage est très-épais, musculeux et susceptible d'être renversé en dehors. Il peut alors servir de trompe. Ses organes respiratoires, au nombre d'une quinzaine, sont placés sur le dos et protégés par les fausses élytres dont nous avons parlé; ils ont la forme de petites crêtes charnues. Pendant qu'ils fonctionnent, les écailles s'élèvent et s'abaissent alternativement.

Les soies de l'Aphrodite sont aussi remarquables par

1 Aphrodite aculeata Baster. 
leur structure que par leur éclat. On peut les regarder comme des harpons dont la pointe serait armée d'une double rangée de fortes barbes; de sorte que, lorsque l'Annélide hérisse ses piquants, l'ennemi le plus courageux hésite à attaquer ce petit Pore-ĺpic si bien défendu. Ces soies rentrent au besoin dans l'intérieur du corps. Chacune possède un fourreau particulier, lisse, corné, composé de deux lames, entre lesquelles l'instrunent est rétracté sans blesser ni même irriter les chairs de l'animal. (Rymer Jones.)

L'Aphrodite est timide et paresseuse. Elle se remue à peine, au moins pendant le jour; clle reste habitucllement dans la même position, blottie sous une pierre ou sous quelque coquille. L'extrémité postérieure de son corps est recourbée, et il sort constamment de l'orifice qui s'y trouve un courant d'eau si rapide, qu'il détermine tout autour un petit tourbillon.

Cependant ces Annélides peuvent nager avec facilité. Elles sortent ordinairement la nuit pour aller chereher leur proie. Elles sont très-voraces et n’épargnent même pas leur propre espèce.

M. Rymer Jones rapporte que deux individus, de taille, inégale et probablement d'âge différent, avaicut été mis dans un aquarium. Après avoì véeu en paix pendant deux ou trois jours, le plus grand essaya de manger son compagnon. Il en avait déjà introduit la moitié dans sa grande et robuste trompe asophagienne. La victime faisait des cfforts désespérés pour se dégager. L'agresseur, après l'avoir retenue pendant quelque temps, fut enfin obligé de rendre gorge. Mais le malheureux patient avait eu, dans le combat, quelques écailles arrachées et les reins cassés. Le lendemain, il n'en restait plus que la moitié, l'autre avait été dévorée. Le vainqueur dardait çà et là sa 
trompe affamée, pour saisir le reste de la pauvre bête qui gisait immobile dans un coin de l'aquarium.....

Les Annélides dorsibranches sont errantes; les tubicoles sout sédentaires.

Celles-ci se font remarquer surtout par l'élégance de leurs organes respiratoires, disposés en aigrettes, en couronnes, en éventails ou en panaches....

L'entrée de leur habitation est ordinairement petite. C'est cependant la seule issue par laquelle nos recluses peuvent jeter un regard sur le monde de la mer, battre l'eau avec leurs branchies, et pourvoir à leurs besoins.

Parmi ces Annélides, citons d'abord les Hermelles ${ }^{4}$.

Il en existe une dans les eaux de la Méditerranée, longue de :3 centimètres, et logée dans un étui de sable. Elle montre de temps en temps sa tête bifurquée, portant une double couronne de soies fortes, aiguës et dentelées, d'un beau jaune d'or. Ces couronnes forment les deux battants d'une porte solide. Ce sont de véritables herses qui ferment hermétiquement l'entrée de l'habitation, lorsque l'Annélide effrayée disparaît comme un éclair dans sa maison de terre.

La moindre brise qui agite le liquide, ou qui fait rider la face de l'eau, suffit pour déterminer le timide animal à se blottir dans sa fortification.

Des bords de la fente céphalique sortent, au nombre de cinquante à soixante, des filaments déliés, d'un violet tendre, sans cesse agités comme de petits Serpents. Ces

1 Voyez la figure 5 de la planche XXI. 
espèces de bras s'allongent ou se raccourcissent alternativement, saisissent la proie au passage et l'amènent dans la bouche. Ce sont eux encore qui ont ramassé un à un, et mis en place, les grains de quartz ou de calcaire qui entrent dans la composition du logement tubulé. Ces grains solides sont reliés ensemble par une sorte de mucosité qui joue le rôle de mortier hydraulique.

Sur les côtés du corps, on aperçoit des mamelons d'ou sortent des faisceaux de lances aiguës et tranchantes, ou de larges éventails dentelés comme des scies en demi-cercle. Ce sont là les pieds de l'Hermelle. Enfin, sur le dos se trouvent des cirres recourbés cil forme de faux, et dont la couleur varie du rouge sombre au vert-pré. (Quatrefages.)

Lorsqu' on drague sur les côtes de la mer, dans une can profonde, on ramène souvent de vieilles coquilles et des tessons de poterie auxquels sont attachées des masses de tubes calcaires, d'un blanc sale, allongés, vermiculés, contournés, entrelacés en tous sens. Ces tubes sont les demeures des Serpules', petits habitants de l'eau salée, dont la brillante parure contraste singulièrement avec la modeste cellule. Ces Annélides vivent dans leur étui comme les Teignes dans leur fourreau. La coupe de cet étui est tantôt ronde, tantôt anguleuse, suivant les espèces. (Cuvier.)

Pour bien voir les Serpules dans un aquarium, il faut user de grandes précautions; car le moindre mouvement suffit pour les faire rentrer dans leur tube.

On apercoit d'abord à l'ouverture une espèce de bouton écarlate, en forme de cône renversé, porté par une longue tige flexible : c'est un tentacule destiné à fermer l'entrée

1 Voyez les figures 6,8 et 9 de la planche XXI. 


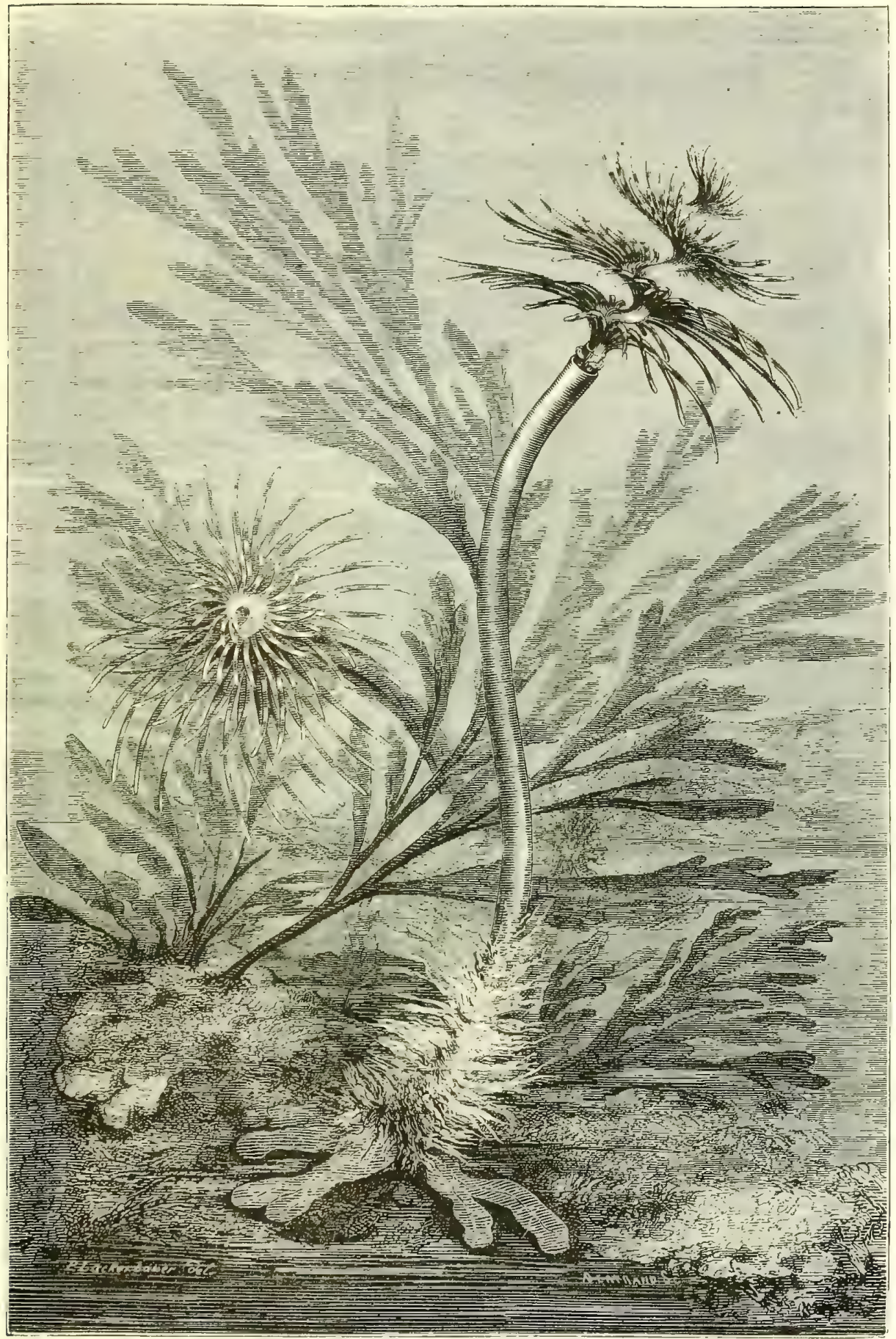

ANNELIDE TUBICOLE

(Sartice trispiras.e).

Dessin de Lackerbauer, d'après nature (aquarium de Concarneau). 

du tuyau, quand l'animal s'y retire tout à fait. Que dites-vous d'une massue servant de porte cochère? L'Annélide possède un autre tentacule à l'état de rudiment. Le bouton est richement nuancé de vermillon et d'orange parfois strié de blanc pur. Son extrémité aplatie est divisée par des sillons qui rayonnent du centre à la circonférence, où ils sont armés de dents microscopiques.

Dans quelques espèces, cette sorte d'opercule se trouve tout à fait plat. Sa surface est tantôt lisse, tantôt hérissée de pointes. Dans la Serpule géante', on y remarque deux petites cornes rameuses comme des bois de cerf. Dans la Serpule étoilée ${ }^{2}$, l'opercule est formé de trois plaques cnfilées; ce qui fait que l'animal ferme sa maison avec trois portes successives.

Quand l'Annélide sort de son fourreau, elle épanouit peu à peu un splendide panache disposé en entonnoir. Ce panache est composé de filaments d'un beau rouge ou d'un bleu clair, ou variés de jaune et de violet. Il parait toujours en mouvement, mais le mouvement est doux et onduleux. Il est tapissé de petits cils vibratiles. Dans plusieurs espèces, l'appareil se roule en spirale au moment où il s'enferme dans le tube.

A proprement parler, les Serpules n'ont pas de tête distincte. La partie antérieure de leur corps représente une sorte de manteau, au-dessous duquel s'ouvre l'estomac. Leur poitrine est composéc de sept segments qui offrent chacun, sur les côtés, une paire de pieds en forme de tubercules, traversés an sommet par un faisceau de soies fines, élastiques et dures qui peuvent sortir de l'organe ou y rentrer à volonté. On compte, par pinceau, vingt à trente

1 Serpula gigantea Pallas.

2 Serpula stellata Grube. 
de ces poils, lesquels, au microscope, offrent l'apparence d'un tuyau jaune, transparent et de consistance cornée, se dilatant à son extrémité en noud armé de quatre pointes. Trois de ces pointes sont ténues; la quatrième se prolonge en lame acérée, très-élastique. Lorsque l'animal veut sortir, il pousse au dehors des pieds les pinceaux du premier segment, dont les pointes pénètrent dans la fine membrane qui tapisse l'intérieur du tube et leur fournit un point d'appui. Les segments postérieurs se contractent, les pinceaux de la dernière paire de pieds s'épanouissent à leur tour et s'arc-boutent de la même manière, tandis que ceux de la première paire rentrent dans le fourreau et permettent au corps de s'allonger. S'agit-il de revenir sur ses pas, la nature y a pourvu par un appareil préhenseur encore plus délicat. Chaque pied est pourvu sur le dos d'une ligne jaunâtre, perpendiculaire à l'axe du corps, ligne imperceptible à l'œil nu, mais qui, sous un grossissement de 300 diamètres, présente l'aspect d'un ruban musculaire érectile, garni sur toute sa longueur de plaques triangulaires parallèles, découpées en sept dents, dont six se recourbent dans un sens, et dont la septième se dirige en sens opposé, en faisant face aux autres. Il existe cent trente-six plaques par ruban; et, comme il y a autant de rubans que de pieds, c'est-à-dire quatorze, on peut évaluer à dix-neuf cents le nombre total de ces petites pièces préhensiles, toutes mues par un muscle distinct. Chaque plaque étant armée de sept dents, l'Annélide dispose donc de treize mille trois cents crochets susceptibles de s'implanter à volonté dans la membrane de son tube. Il n'est pas étonnant qu'avec tant de muscles faisant agir ces myriades de griffes, elle puisse s'eufermer et se cacher avec une telle rapidité. Quel merveilleux appareil moteur prodigué à un si misérable ver! (Gosse.) 
En réalité, tous les mouvements des Serpules se réduisent à élever la partie antérieure ou supérieure de leur corps à une petite distance an-dessus de leur résidence calcaire. L'animal, ainsi qu'on vieut de le voir, grimpe dans son tuyau, à l'aide de ses crochets, comme un petit ramoneur dans une cheminée. (Rymer Jones.)

Une autre Annélide, pourvue de même d'un vêtement calcaire, mais de taille extrêmement petite, habite sur les fucus et les autres hydrophytes, sur les coquillages et sur les rochers. Celle-ci a été nommée Spirorbe nautilö̈de'. Elle sécrète un tuyau plus régulier que celui de la Serpule, enroulé sur lui-mème comme la coquille de plusieurs mollusques fluviatiles désignés sous le nom de Planorbes. Cette jolie petite bête est grosse comme une tête d'épingle; elle adhère fortement aux corps solides par l'un des côtés plats de sa coquille. Elle fait sortir de temps en temps une couronne de six tentacules plumeux et frémissants, au milieu desquels s'ourre sa bouche. Elle épanouit sa comronne et la tourne dans tous les sens avec une harmonie et une gràce parfaites.

Ce paurre animal est sans tête, sans yeux et même sans mâchoire. Il ferme hermétiquement sa maisonnette avec un septième tentacule terminé par une massue, à peu près comme celui de la Serpule.

Les Térébelles² sont aussi des Annélides tubicoles. Elles se font distinguer par leurs nombreux appendices filiformes, susceptibles d'une grande extension, placés autour de la bouche, et par leurs trois paires d'organes respiratoires en forme d'arbuscules et non pas en éventail.

Les tentacules de ces Annélides ressemblent, au premier

1 Spirorbis nautiloides Lamarck.

2 Voyez figure 1, planche XXI. 
abord, à des fils charnus, cylindriques, d'une extrême flexibilité. Mais en y regardant plus attentivement, on reconnait qu'ils sont aplatis et rubanés, et qu'ils offrent une rainure longitudinale pouvant se transformer en pli et saisir alors les corps étrangers qui sont à leur portée.

Dans une espèce, la rainure dont il s'agit est bordée, de chaque côté, par une série de denticules.

Les organes respiratoires des Térébelles sont fort beaux. Ils offrent, dans leurs divisions, une grande profusion d'angles, de courbures et de pointes. Leurs couleurs sont très-variées et très-brillantes.

Le tube protecteur de ces animaux est composé de vase, d'argile, de grains de sable et de fragments de coquilles agglutinés. Il a une forme cylindrique. On remarque, ì son orifice, des bords prolongés en petites branches de même nature, qui servent à loger les tentacules.

Si l'on met dans un aquarium une Térébelle privée do son fourreau, on verra l'Annélide étendre ses fils tentaculaires, balayer le sable, et l'accumuler dans un coin pour en construire une nouvelle habitation. Le petit architecte développe une grande activité dans la mise en cuvre de ces matériaux. Quand le tube est en partie formé, il s'y enferme et y demeure caché tout le long du jour. Vers midi, l'animal manifeste une certaine inquiétude, laquelle angmente au fur ct à mesure que le soir approche. Aussitôt que le soleil est couché, les tentacules sortent de la maisonnette, et se mettent à l'ouvrage. Chacun saisit un grain de sable et le transporte au sommet du tube commencé. Quand un de ces bras, maladroit ou fatigué, laisse échapper sa petite charge, il la cherche jusqu'à ce qu'il l'ait trouvée, et ne l'abandonne plus jusqu'à ce qu'il l'ait portée à sa destination.

Dans certaines espèces, les tentacules semblent s'être 
divisé le travail : les uns sont occupés au choix des matériaux, les autres an transport; certains les alignent et les agglutinent; quelques-uns ramassent soigneusement les débris qui tombent du chantier.

Le travail de construction se continue pendant plusieurs heures, sans relàche, par un véritable procédé de fourmi : il semble marcher avec lenteur. Cependant, le lendemain, on est étonué des progrès qu'a faits le petit édifice. Durant

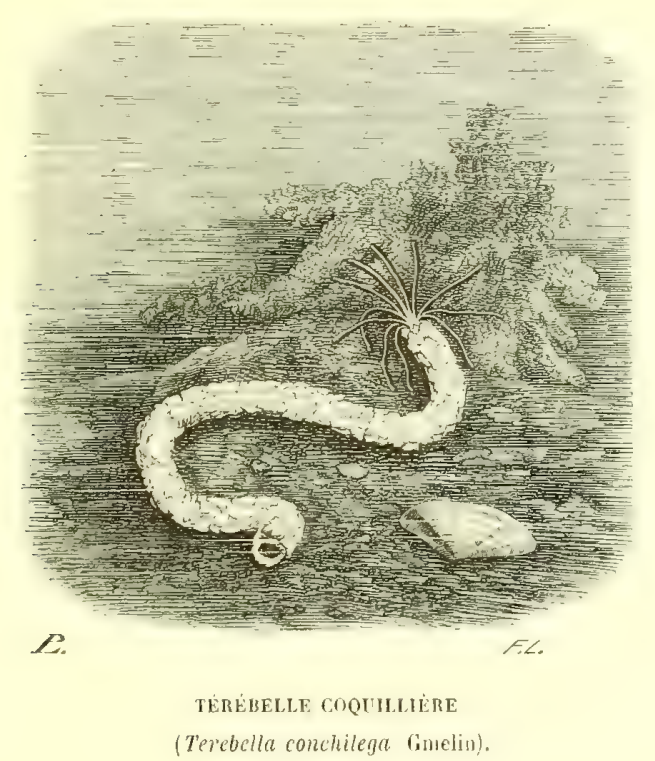

la nuit la tour s'est allongée, et, au milieu des parois nues, on aperçoit maintenant des particules de sable régulièrement et solidement unies ensemble, qui en constituent le revêtement extérieur. L'architecte, satisfait, se repose alors de ses travaux et au milieu de ses travaux. Mais ce repos ne dure que jusqu'au soir. (Rymer Jones.)

L'intérieur du tube est tapissé d'une mince couche de matière semblable à de li soie, laquelle réunit et fortifie les éléments de la maçonnerie, et décore en même temps 
d'une jolie tenture les murs de la chambrette. Cette matière provient d'une humeur gluante sécrétée par la peau de l'Annélide, humeur précieuse qui sert à la fois de ciment et d'ornement.

Quand on arrache brusquement une Térébelle de son tube, on la blesse quelquefois; on entame ses anneaux ou l'on mutile ses tentacules. L'animal paraît peu affecté de ces accidents. Un bras de moins n'est pas un grand malheur pour notre infatigable architecte. Il recommence une nouvelle maison, comme s'il ne lui était rien arrivé!

La Térébelle tisserand' ne se borne pas ì construire une maisonnette tubuleuse avec du sable et de la vase; ello fabrique aussi une sorte de toile d'araignée, me manière de filet pour entourer ses œufs. Cette toile est très-mince, un peu irrégulière, et composée de fils si fins et si transparents, qu'ils sont presque invisibles. C'est mn travail fort compliqué, où se trouvent au moins cinquante fils de la longueur du petit tisserand.

M. de Quatrefages a désigné sous le nom de Térébelle Emmaline 2une nouvelle espèce ravissante, dont il a bien voulu nous communiquer un dessin.

Le corps de cette espèce est allongé, déprimé et comme rubané; il s'amincit fortement en arrière. En dessus, il offre une belle teinte bleu d'azur, qui passe bientôt an vert gai, puis an lilas clair, et enfin au jaune d'ocre. Le dessous est plus ou moins doré. Les articulations, à peine sensibles à la partie antérieure, deviennent de plus en plus marquées dans la róggion caudale. On prendrait cette dernière pour un rameau de Salicorne. Ses bords sont garnis d'une rangée de petits pieds en forme de mamelons; les quinze

- Terebella textrix Dalyell.

2 Terebella Emmalina Quatrefages (voy. la figure 1 de la planche XXI). 
premières paires pourpres et terminées par un pinceau de poils ou de crochets; les autres, jaunâtres et sans armure.

Les six branchies forment en avant et en dessus, à gauche et à droite, deux rangées latérales de panaches d'un beau rouge vermillon, semblables à des arbustes de Corail en miniature. La paire antérieure est la plus grande; la postérieure, la plus petite.

Sur le front naissent de soixante à quatre-vingts tentacules ou cirres trois fois au moins plus longs que l'Annélide, presque aussi minces que des fils d'araignée, demitransparents et jaunâtres. Les uns sont droits, les autres flexueux, quelques-uns tordus en spirale. Tous creusés d'un canal central, en communication avec la cavité abdominale.

Ils divergent, et forment antour de la Térébelle un appareil capillaine de la plus grande délicatesse. Ce n'est pas un réseau, car tous les cirres sont distiucts. C'est presque un nuage, tant ils sont légers et diaphanes! C'est une sorte de soleil filamenteux et contractile qui rappelle l'aigrette soyeuse et tremblante qui couronne les fruits de certaines composées. Ces tentacules servent en même temps à la préhension des aliments et à la locomotion de l'Annélide. Ce sont encore, malgré leur ténuité, des organes d'attaque et de défense; car leur surface est garnie de vésicules urticantes en forme de petites bouteilles à col court, dont l'orifice laisse passer un dard microscopique très-pointu, traversé probablement par un canal qui communique avec une glande venimeuse placée au fond de la bouteille.

Si l'on ajoute, en avant de la partie céphalique d'une Térébelle, des pailles de couleur dorée, disposées sur plusieurs rangs en peignes ou en couronnes, on aura une Amphitrite. 
Celle qu'on désigne sous le nom d'éventail ${ }^{1}$ est bien ceptainement une des plus jolies Annélides de nos mers.

Son tube ressemble à un fourreau de cuir. Il' est étroit et s'élargit graduellement de bas en haut.

L'Annélide étant mise dans de l'eau fraîche, on voit, après quelques moments de repos, s'échapper de son tube plusieurs petites bulles d'air. Bientôt sortent graduellement les pointes d'un pinceau bigarré, qui s'élève peu à peu, jusqu'à ce qu'il forme un merveilleux panache, composé d'une multitude de filaments plumeux d'un carmin vif. Ce panache s'étale et prend la forme de deux éventails demiverticaux, arrondis, concaves, disposés de manière à produire un immense entonnoir. Chaque filament est grêle, pointu et garni sur les còtés de barbes extrêmement fines, arrangées avec une grande symétrie. Ils sont serrés inférieurement et divergent plus ou moins vers la moitié supérieure. Cette dernière moitié est presque toujours d'un rouge pourpre. La base de l'entonnoir plumeux paraît d'un jaune doré, avec cing ou six petites zones transversales et parallèles de ponctuations purpurines.

On remarque au milieu deux antennes triangulaires, pointues, brunes et vertes, et au-dessous deux espèces de lobes charnus qu'on a comparés à deux truelles. Entre ces lobes surgit un organe qui ressemble à une languette.

Le reste du corps est grềle, comme festonné, et peint en jaune, en vert, en rouge et même en brun.

Au plus léger choc, toutes ces brillantes parties s'affaissent, se resserrent ef disparaissent. On ne voit plus qu'un vilain fourreau.

1 Amphitrite ventilabrum Gmelin.

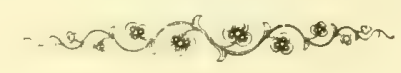




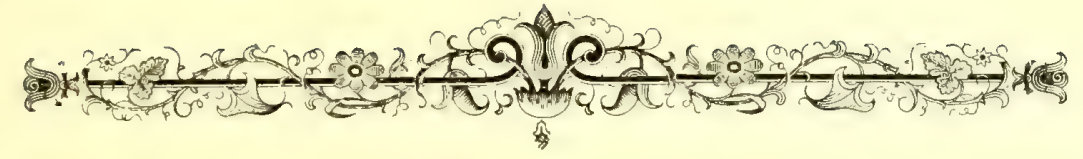

\section{CHAPITRE XXVIII}

\section{LES SANGSUES DE MER.}

"T'u rassasies chinque eréature virante suivant son gout et son désir!"

(D.MID.)

11 existe des Sangsues dans l'Océan comme il en existe dans les marais. Il y a des parasites partout. Mais les suceuses de sang qui vivent dans l'eau salée diffèrent notablement de celles qui serpentent dans l'eau douce.

Et d'abord, au lieu d'une peau mince et délicate, elles ont une enveloppe épaisse et coriace. Elles sont vêtues plus solidement, plus confortablement que les Sangsues ordinaires, sans doute pour mieux résister à la température froide, aux sels pénétrants et aux agitations incessantes du grand milieu qu'elles habitent.

Par suite de l'épaisseur et de la rigidité de leur habillement, ces Annélides n'ont pas les mouvements faciles et gracieux yui caractérisent nos sémillantes Sangsues médicinales. Elles ne peuvent pas se contracter en olive (Rondelet), et leur corps, plus ou moins roide, reste toujours plus ou moins étendu. En second lieu, leur ventouse de 
devant est en forme d'écuelle et non en bec de flùte; elle ressemble, à s'y méprendre, à celle de derrière; elle est seulement plus petite.

Quelle singulière organisation qu'une bête cylindrique, avec une écuelle en guise de tête et une écuelle en guise de queue!

Les Sangsues de mer ont été appelées Albiones et Branchellions. (Ces noms sont bien jolis pour des Sangsues!)

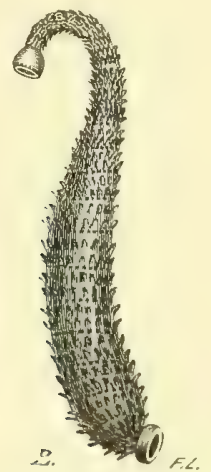

ALBIONE EPINELSE

(Albione muricata Savigny).

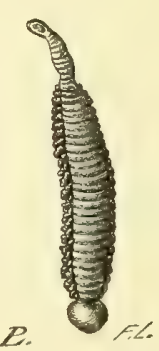

BRAYCHELLIOY DE LA TORPILLE (Branchellion Torpedinis Savigny).

Les premières, nommées aussi Pontobdelles ou Ponbdelles, ont un corps généralement hérissé de verrues plus ou moins épineuses; elles manquent de branchies et respirent par la peau.

Les secondes ont un corps non verruqueux; mais les deux tiers postérieurs de l'animal sont garnis sur les côtés de branchies extérieures, demi-circulaires, onduleuses, semblables à de petites feuilles transversales superposées. Ces branchies composent ainsi deux franges élégantes.

Les Albiones se trouvent principalement sur les Raies, et les Branchellions sur les Torpilles.

Les Sangsues de mer adhèrent fortement à ces poissons 
au moyen de leurs ventouses. Elles ont l'instinct de choisir la racine des nageoires, les bords des yeux, l'orifice des branchies; c'est-à-dire les endroits où la peau est à la fois le plus riche en vaisseaux sanguins, le plus mince et le plus vulnérable.

Ces animaux ne sont pas pourvus, comme les Sangsues médicinales, de trois mâchoires cartilagineuses, robustes, armées d'une soixantaine de dents pointues, en forme de chevrons. On n'y découvre que trois petits tubercules, sans ancune dureté. Comment ces parasites parviennent-ils à diviser les téguments des Raies et des Torpilles? Leur bouche est organisée tout à fait comme une vraie ventouse; elle s'applique contre la peau d'une manière trèssolide, et la déchire par une très-forte aspiration. Cette enveloppe est rompue, déchirée et non sciće; ce qui fait que la blessure doit ètre irrégulière et non trifide.

Les verrues épineuses, et peut-ètre aussi les branchies foliacées, empêchent ces Annélides de glisser sur l'enveloppe rugueuse des Poissons, surtout quand ces derniers s'agitent brusquement. Pendant le jour, elles demeurent immobiles. Le soir, elles sortent de leur apathie, sucent les Raies et les Torpilles, ou bien voyagent sur leur corps.

\section{I}

Les Alliones et les Branchellions aiment le sang rouge. Chacun son gout! Voilà pourquoi ces animaux dédaignent les Mollusques et attaruent les Poissons. Ils prélèrent les Poissons cartilagineux et plats à tous les autres : probablement parce que ces deruiers n'ont pas la peau revêtue de fortes écailles protectrices; peut-être aussi parce qu'ils se tiennent dans les endroits vaseux, presque toujours au fond 
ou près du fond, circonstance favorable aux évolutions, aux mœurs et à la ponte de nos sanguinaires Annélides.

Les animaux parasites, qui se nourrissent exclusivement de sang, enlèvent presque toujours ce fluide à d'autres animaux doués d'une structure plus compliquée que la leur, ou, comme disent les savants, d'un organisme plus parfait. Or, dans une bête quelconque, le sang peut être regardé comme la quintessence de son alimentation. Par conséquent, une très-petite quantité de ce fluide devrait suffire à un animal très-dégradé. Pourquoi done toutes les Sangsues en prennent-elles aussi abondamment?

Personne n'ignore que le Ver à soie mange, dans un repas, une quantité de feuilles plus pesante que son corps (Tyson). On conçoit cette voracité, les feuilles du inûrier étant peu nourrissantes et l'animal devant grandir avec rapidité! Mais le sang de l'homme ou du poisson est un liquide très-nutritif pour des Sangsues, et les Sangsues grossissent lentement! Cette habitude de gloutonnerie tiendrait-elle à ce que nos bêtes sanguivores supportent de longs jeûnes, de très-longs jeûnes, et à ce que chaque repas doit représenter chez clles un certain nombre de repas?

Les Sangsues médicinales absorbent sept fois et demic leur poids de sang humain. Les Sangsues de mer ne prennent que deux fois lemr poids de sang de poisson. A quoi tient cette différence? A une circonstance de structure fondanentale, qui influe sur les appétits des unes et des autres. Les premières possèdent onze paires d'estomacs énormes, d'autant plus vastes, qu'ils sont plus postérieurs, et dont la dernière est à elle seule presque aussi grande que tontes les autres réunies. Les secondes ont un estomac tubuleux, droit, sans poches latérales. Ajoutons à cette différence que les Sangsues médicinales sont revêtues d'une pean mince, facilement dilatable, et que 
les Sangsues marines sont habillées d'un cuir épais trèsrésistant.

Mais le sang du poisson nourrit moins que celui de l'homme. Les Albiones et les Branchellions devraient donc faire de plus gros repas que les Sangsues médicinales? Pourquoi est-ce l'inverse qui a lieu?... Voilà une question physiologique dont nous ignorous la solution. Il s'en présente et s'en présentera souvent de semblables. “Tous ces mystères, dirait Pline, sont impénétrables à la raison humaine, et restent cachés dans la majesté de la nature'. ")

\section{1}

La quantité de sang que font perdre les Sangsues de mer est, en définitive, peu considérable relativement à la corpulence de l'animal sucé. Le plus souvent, ce dernier ne semble pas s'apercevoir de la voracité de son parasite. Il est à peine affaibli, il n'est jamais épuisé. On serait même tenté d'admettre qu'à certaines époques, les très-petites saignées rfu'on lui pratique le rendent plus leste, plus dispos ct lui donnent plus d'appétit!

O bonne, 6 sainte, ó divine saignée!

(J. Du BELLAY.)

On l'a dit avec raison, les parasites s'attaquent moins à l'organisme qu'à ses produits surabondants. (Van Benedeu.)

Ce qui constitue surtout le parasitisme (qu'on nous passe ce mot), c'est le fait remarquable, que l'individu vivant aux dépens d'un autre individu ne fait pas périr ce dernier; à moins de circonstances particulières, lesquelles, par

1 "Omnia incerta ratione, el in natura majestate abdita." (PLINE.) 
bonheur, se rencontrent rarement. S'il n'en était pas ainsi, l'espèce du parasite, ou celle de l'animal qui le nourrit, devrait nécessairement disparaittre, conséquence contraire aux lois essentiellement harmoniques qui régissent l'univers.

\section{IV}

Comme les Sangsues ordinaires, les Albiones et les Branchellions sont à la fois mâle et femelle (androgynes). Dans leurs amours, chaque Annélide est en même temps poursuivante et poursuivie, fécondante et fécondée, et par conséquent père et mère; double devoir qu'elle accomplit saus se donner plus de peine ou de souci que n'en premnent les autres animaux qui sont réduits à un seul rôle!

\section{Toutes choses se meunent en leur fin.}

(RABELaIs.)

Les Albiones se reproduisent par des capsules rarement solitaires, le plus souvent réunies par groupes de vingt,

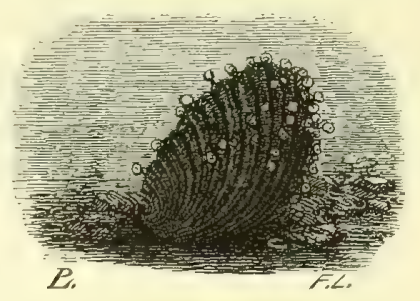

OEUFS D'ALDIONE SUR UXE COQUILLE.

trente, quarante et mème de cinquante. Elles les attachent à l'extérieur ou à l'intérieur de quelque vieille coquille. Chaque capsule est un sphéroïde de millimètres de diamètre, porté par un pédicule très-court, dilaté à sa base en un épatement arrondi qui le fixe solidement au corps 
étranger. Cie sphéroïde est lisse et creusé, au sommet, d'un petit ombilic; il paraît d'abord blanchâtre ou couleur de chair; il brunit peu à peu. Au bout de quatre ou cinq jours, le blanchàtre primitif est devenu brun olivâtre.

Cette capsule globuleuse ne ressemble en rien aux cocons ovoïdes des Sangsues médicinales, ni aux bourses coriaces, plus ou moins aplaties, des animaux voisins.

Au lieu de plusieurs œufs, les capsules dont il s'agit n'en contiennent qu'un seul. La petite Albione éclôt par l'ombilic; elle uaît du sphéroïde par en haut. Chez les Sangsues médicinales, les enfants sortent du cocon par les deux bouts.

Comment se reproduisent les Branchellions? Les savants n'en savent rien.....

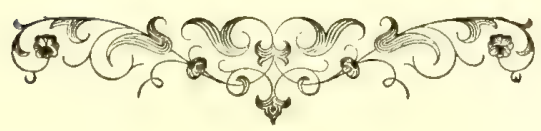





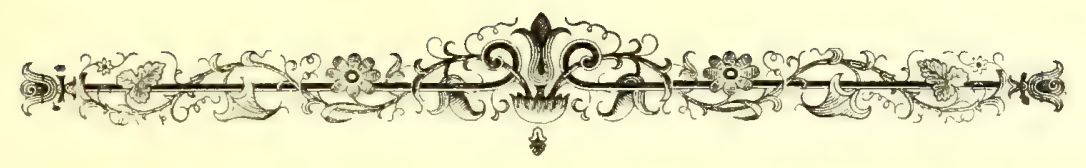

\section{CHAPITRE XXIX}

\section{LES Z0ONITES.}

"Natura non facit saltus."

(LIXNÉ.)

L'étude des Annélides, si ardemment poursuivie depuis le commencement de ce siecle, a déjà rendu de très-grands services à l'anatomie et à la physiologie comparées.

Ces animaux, avec leurs articles placés bout à bout, présentent une organisation des plus curieuses. On trouve généralement, dans ces articles, les mêmes organes régulièrement répétés et symétriquement associés.

Tout le monde connait la Sangsue médicinale'. Cet animal est regardé comme un des types de la classe des Annélides, bien qu'il en soit un des moins brillants.

Cette Sangsue offre un corps vermiforme, atténué antérieurement, composé d'environ quatre-vingt-quinze articles. En avant et en arrière, se trouvent deux ventouses : l'une, dite orale, taillée en bec de flùte; l'autre, dite anale, en forme de soupape.

Si vous examinez la région dorsale d'une Sangsue, vous

IIirudo medicinalis Iinné. 
y observerez six bandes longitudinales parallèles, roussâtres, ornées de taches d'un brun foncé, de forme triangulaire ou carrée. Ces taches se répètent régulièrement de cinq en cinq anneaux.

Dans la Sangsue dragon, les bandes sont interrompues et les taches isolées; ce qui rend la disposition symétrique de ces dernières encore plus apparente.

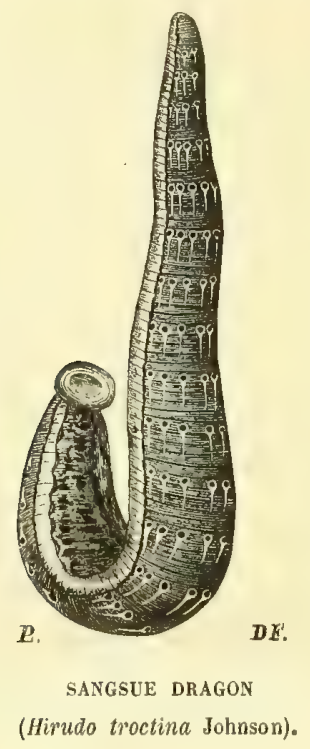

Essuyez une Sangsue, et saupoudrez-la avec de la farine ou de la craie pulvérisée, elle prendra alors une couleur grisâtre; si ensuite vous la distendez et la fixez par le dos, sur une planche, vous distinguerez bientôt, à la partie inférieure du corps, sur les côtés, de petites taches produites par certaines portions de farine ou de craie délayées dans de la mucosité sortie de deux séries d'appareils sécrétoires que l'animal possède dans ses flancs. Une paire de ces petites taches se fait remarquer de cinq en cing anneaux. 
Disséquons maintenant l'animal, et nous serons surpris de voir le rapport qui existe entre la symétrie des parties extérieures et la symétrie des organes intérieurs. Ainsi, pour le système nerveux, la Sangsue nous présente, de cinq en cinq anneaux, à la même distance que les taches dorsales ou que les glandes mucipares, un ganglion nerveux bilobé.

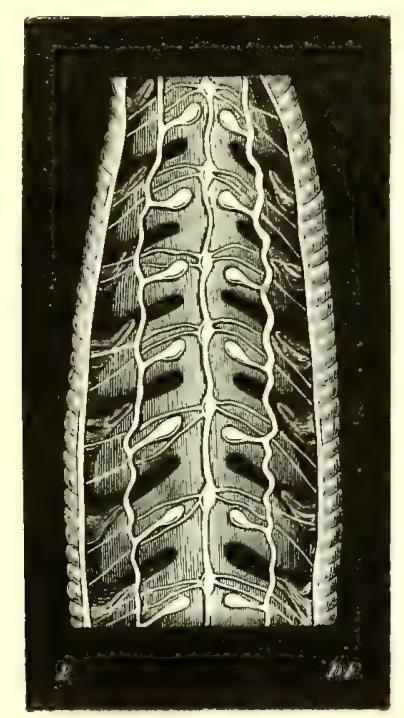

PORTION DE SANGSUE MÉdicINALE (anneaux médians).

L'estomac se compose de onze paires de poches correspondant chacune à un ganglion, et disposées par conséquent de cing en cinq anneaux.

Sur les parties latérales, on remarque de petits canaux allongés, intestiniformes, qui communiquent avec une ampoule membraneuse. Ces appareils sécrètent une partie de la mucosité destinée à lubrifier la Sangsue. Il y en a dixsept paires, que nous trouvons encore à chaque distance de cinq anneaux.

Le système vasculaire nous offre le même genre de répé- 
tition. Il se compose d'un vaisseau dorsal, d'un vaisseall abdominal, et de deux vaisseaux latéraux. Ces derniers fournissent tous, à un même intervalle de cinq anneaux, une branche transversale avec un renflement qui n'est autre chose qu'un petit cœur. (Gratiolet.)

Dans l'enveloppe coriace (dermato-squeletle), nous retronvons, de cinq en cinq anneaux, le même groupe de faisceaux musculaires.

Enfin, si nous considérons l'appareil reprodncteur, nous découvrons encore une répétition des parties et une symétrie du même genre.

Ainsi, la Sangsue nous offre, par chaque fragment de cing anneaux, un système nerveux, un système stomacal, des systèmes glandulaire, vasculaire, musculaire et reproducteur; en un mot, un organisme complet, c'est-à-dire tout ce qui est nécessaire pour constituer un individu. On pourrait la comparer à une série d'animaux symétriquement alignés et soudés!

La Sangsue n'est done pas un être simple, mais un être multiple. Nous en dirons autant du Ver de terre, du Millepieds, du Ténia....

Tous les zoologistes ont constaté depuis longtemps, que certains êtres jouissant de l'animalité, les Polypiers, par exemple, diffèrent des animaux ordinaires en ce que, an lieu d'ìtre isolés, ils sont groupés ensemble et vivent en société ${ }^{\prime}$.

Il y a done, dans la nature, des animaux isolés, ou unitaires, et des animaux composés, ou associés.

Eh bien! entre ces deux sortes d'animaux viennent se ranger, comme intermédiaires, d'autres animaux qui ne présentent, ni l'unité parfaite des premiers, ni la

1 Voyez les chapilres VIII, IX, X, XI, XVIl et XVIII. 
multiplicité manifeste des seconds. La nature ne fait pas de sauts!.....

La Sangsue médicinale est un de ces êtres juste-milieu les mieux caractérisés.

Les autres Amnélides possèdent une organisation identique ou analogue.

On a désigné (1826) ces organismes individuels sous le nom de zoonites.

Les zoonites n'embrassent pas nécessairement un intervalle de cinq anneaux. Il y en a de quatre, de trois, de deux et même d'un seul.

Ces organismes sont sur une seule ligne (unisériés) chez les Annélides et chez tous les animaux dits Articulés ou Annelés; mais, chez d'autres espèces, pour le dire en passant, les zoonites sont mullisériés, c'est-à-dire disposés tantòt suivant deux dimensions, comme chez les Étoiles de mer". tantôt dans tous les sens, comme chez les Pyrosomes ${ }^{2}$. Ces derniers font le passage vers les animaux associés.

On ne doit plus s'étonner de l'erreur dans laquelle sont tombés certains auteurs, en comparant la Sangsue aux Vertébrés. C'est une portion de Sangsue seulement, un zoonite, rqu'il fallait leur comparer.

On s'est souvent demandé pourquoi un quadrupède auquel on compe la tite mourait presque instantanément, tandis qu'une Sangsue, après une semblable mutilation, vit encore plus d'une année. Ce fait est facile à expliquer. Le quadrupède n'a qu'un seul centre sensitif, un cervean, contenu dans la tête. Si vous le retranchez, l'animal doit périr. Chez la Sangsue, il y a plusieurs centres de vie, et vous no faites mourir que l'organisme sur lequel vous agissez.

2 Voyez le chapitre XVIII. 
De nombreuses objections ont été élevées contre la théorie des zoonites.

"Nous reconnaissons volontiers, dans une Sangsue, a-t-on dit, des ressemblances assez fortes entre les organismes de la parlie moyenne; mais nous ne pouvons admettre que l'on compare à ces mêmes organismes ceux des extrémités, qui présentent en avant une ventouse en bec de flùte, les yeux et la bouche, et, en arrière, une ventouse en forme de soucoupe et l'ouverture anale. La théorie de la multiplicité des organes est donc insoutenable. »

On a répondu à cela :

$1^{\circ}$ La ventouse orale et la ventouse anale ont des rapports tellement sensibles, qu'on les a désignées l'une et l'autre sous le même nom, le nom de ventouse.

D'un autre côté, ces deux ventouses se ressemblent si fort, chez les Sangsues de mer, qu'un savant zoologiste, Baster, a pris la première pour la postérieure, et celle-ci pour celle de la bouche!

$2^{\circ}$ Dans un Papillon, on distingue une tête, un corselet et un abdomen, trois parties bien différentes. Or, avant d'être Papillon, l'animal avait été chrysalide; avant d'être chrysalide, il avait été chenille! Eh bien! sous cette dernière forme, il existait sans doute, en germe ou en puissance, une tête, un corselet et un abdomen; mais ces parties offraient alors une même organisation. Dans l'animal adulte, elles ne se ressemblent phus.

$3^{\circ}$ Les Planaires, petits animaux aquatiques, d'eau douce et d'eau salée, voisins des Sangsues, présentent, à la partie moyenne du ventre, une poche munie d'une petite trompe. Voilà tout leur système digestif. C'est avec cette trompe que 
l'animal saisit sa proie et l'introduit dans son estomac. Quand l'aliment est digéré, il rejette les parties excrémentitielles avec le même organe.

Si, à l'aide d'un instrument tranchant, on coupe transversalement une Planaire en deux parties, on formera deux êtres nouveaux. Mais l'estomac étant unique, suivant l'endroit où l'on aura opéré la division, il se trouvera dans l'une ou dans l'autre des deux moitiés. Si vous coupez en avant de la poche digestive, cette poche sera dans la queue; si vous coupez en arrière, elle sera dans la tête. Au bout de quelque temps, apparait sur le milieu de chaque fragment un point blanchâtre qui s'étend, se creuse et donne naissance à un nouvel appareil. L'estomac ancien, quelle que soit la place qu’il occupe, se flétrit et disparaît. (Il y a un moment où les Planaires possèdent deux estomacs, un normal, dans la situation ordinaire, et un autre plus ou moins atrophié, dans la queue ou dans la tête!) Nous pouvons done, suivant le lieu où nous porterons le scalpel, faire naitre l'estomac à l'endroit que nous voudrons! Que résultet-il de là? Que chez certains Invertébrés, il est permis de considérer comme identiques des parlies ou des organes qui, au premier abord, ne se ressemblent pas.

\section{III}

On a recueilli, depuis quelques années, un grand nombre de faits physiologiques qui prouvent que la Sangsue n'a pas seulement une vie générale, une vie d'association, si l'on peut parler ainsi, mais aussi des vies particulières, des vies de zoonites.

Pour l'harmonie générale, la nature a pourvu cette Amnélide de cordons nerveux de commmication qui relient 
entre eux les organismes particuliers. Le premier zoonite, qui offre le centre sensitif le plus développé et qui porte les organes des sens, peut être regardé commè le chef des organismes, le régulateur de l'association, le pilote du vaisseau. Si l'on détruit ce zoonite, les autres continuent de vivre, mais d'une vie obscure et confuse. L'animal ne peut plus pourvoir à sa nourriture, ni à ses principaux besoins.

Voici quelques expériences qui montrent manifestement que les vies des zoonites sont, jusqu'à un certain point, indépendantes les unes des autres.

$1^{\circ}$ Si l'on mouille avec de l'eau salée ou avec un acide affaibli les premiers zoonites d'une Sangsue pleine de sang. les estomaes qui Jeur correspondent se dégorgent, les autres conservent le sang qui les remplit.

2. Si l'on plonge partiellement une Sangsue dans un acide concentré ou dans l'alcool, on ne détruit que la vitalité de la portion plongée.

$3^{\circ}$ Si l'on coupe en deux une Sangsue aux trois quarts gorgée et encore attachée à la peau, la moitié antérieure continue de sucer, et l'on voit le sang couler par son extrémité ouverte.

4. Si, d'une manière quelconque, on fait périr un zoonite de la région moyenne, les parties antérieure et postérieure ne cessent pas de vivre. Seulement, d'un animal multiple, on en a fait deux.

$5^{\circ}$ Si l'on coupe ou si on lie, en avant et en arrière d'un ganglion, les cordons qui l'unissent avec ses deux voisins, le zoonite de ce ganglion conserve sa sensibilité, mais on a donné naissance à un animal isolé, placé entre deux animaux multiples. Les pirûres qu'on fait éprouver à cet animal ne sont senties que par lui seul.

$6^{\circ}$ Enfin, quand on coupe ou qu'on lie le cordon médullaire d’une Sangsue, dams la partie moyeme du corps, on 
produit et l'on isole deux animaux mulliples. Il se crée it l'instant deux volontés bien distinctes, et les phénomènes sensitifs et locomotifs ani se passent dans la moitić antérieure n'ont rien de commun avec ceux de l'autre moitié.

Le docteur Vernière a conservé pendant plus de deux mois une Sangsue soumise à cette opération. Rien n’était plus singulier, dit-il, ‘ue le conflit des deux volontés entrc les deux demi-Sangsues, lorsque la ventouse de chacune se trouvait fixée aux parois du vase. On voyait s'engager une lutte dans laquelle charque moitié se montrait tour à tour contractée ou tiraillée, suivant qu'elle était ou plus forte ou plus faible. Ce combat durait jusqu'à ce que l'une des deux, ınoins solidement attachée ou moins robuste, vint à céder: alors la moitié victorieuse la trainait à sa suite. Mais, à son état de contraction et d'immobilité, il était aisé de voir que c'était à contre-cour, s'il est permis de le dire, que la moitié vaincue se sentait forcée d'obéir à sa compagne.

$7^{\circ}$ Si l'on coupe une Sangsue de manière à isoler plusieurs fragments, chacun vivra, même pendant un temps considérable.

On a conservé des tronçons, sans nourriture, pendant (puatre, six et onze mois. Carena et Rossi assurent en avoir gardé deux ans.

Ces tronçons présentaieut, du reste, des signes notables d'amaigrissement : ils ne mangeaient pas. Tout porte à croire que, si par un procédé quelconque on avait pu les nourrir, en introduisant, par exemple, de temps à autre, 'fuelques gouttes de sang dans leur cavité digestive, leur vic se serait prolongée plus longtemps encore.

Qui sait mème si, dans ce cas, il n'y aurait pas reproduction des organes amputés?

"La théorie, a dit un penseur profond, est le seul chemin qui conduise à Dieu, à travers la nature. Il ne suffit pas de 
voir la création, il faut voir derrière elle le Créateur. Linné, avant de commencer son immortel inventaire des trésors de notre globe, se demande quel est le but suprême de l'histoire naturelle, et se répond solennellement que c'est la glorification du Créateur. Cette belle pensée est aussi forte par sa droiture que par sa piété. Plus nous nous séparons des effets par la vertu du perfectionnement de la science, pour remonter vers les principes, plus nous nous rapprochons de la cause première, et plus sa gloire éclate et nous encourage. Il n'y a, en histoire naturelle, que les points de vue pris dans les lois générales qui aillent vers l'infini. Les quitte-t-on pour descendre vers les détails, ces détails ne trouvent plus d'appui que dans la réalité la plus vulgaire, et la science, humiliée, perd son auréole.» (J. Reynaud.)

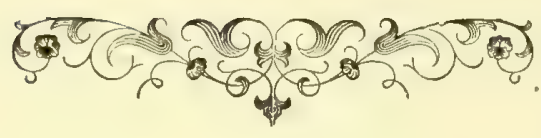




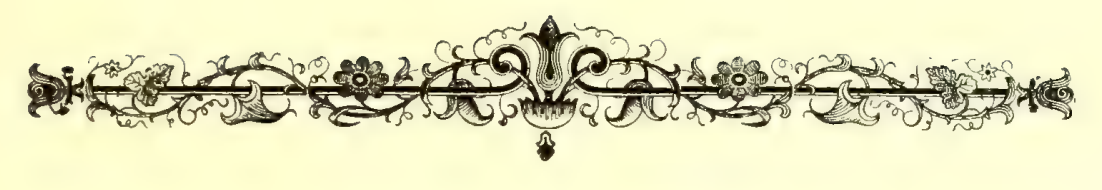

\section{CHAPITRE XXX}

\section{LES CIRRIPÈDES.}

"Les méthodes les plus parfaites sont des espèces de filets scientifiques dont, malgré toutes nos précautions, il s'échappe toujours quelque chose. » (Montbeillard.)

\section{I}

La mer est bien plus riche que les continents en productions singulières, disait Charles Bonnet. Que de bizarres animaux elle fait et défait à chaque instant!

Parmi ses habitants les plus extraordinaires, il faut ranger les Anatifes.

Ces animaux ont une physionomic sui generis. Ils sont enfermés dans une sorte de mitre calcaire comprimée, composée de cinq pièces, deux de chaque côté, et la cinquième sur le bord dorsal. Cette mitre est portée par 1111 pédicule très-gros, qui la fixe à quelque corps solide; pédicule ridé transversalement, tubuleux, flexible, opaque et brunâtre vers le haut, demi-transparent et couleur de chair à sa partie inférieure.

La fixation d'un animal est un indice d'infériorité organique : car la faculté de se mouvoir volontairement constitue un des grands attributs de la sensibilité. Dès qu'un être 
vivant est capable d'éprouver des sympathies et des antipathies, il faut nécessairement qu'il puisse se porter ver's les objets qui lui conviennent et s'éloigner de ceux qui lui déplaisent. Un arbre, qui est insensible, ne se ment pas. Un oiseau, qui sent, est locomotile. Aussi, pour le dire en passant, l'invention des Hamadryades de la Fable était une combinaison tout à fait déraisonnable, nous allions dire absurde.

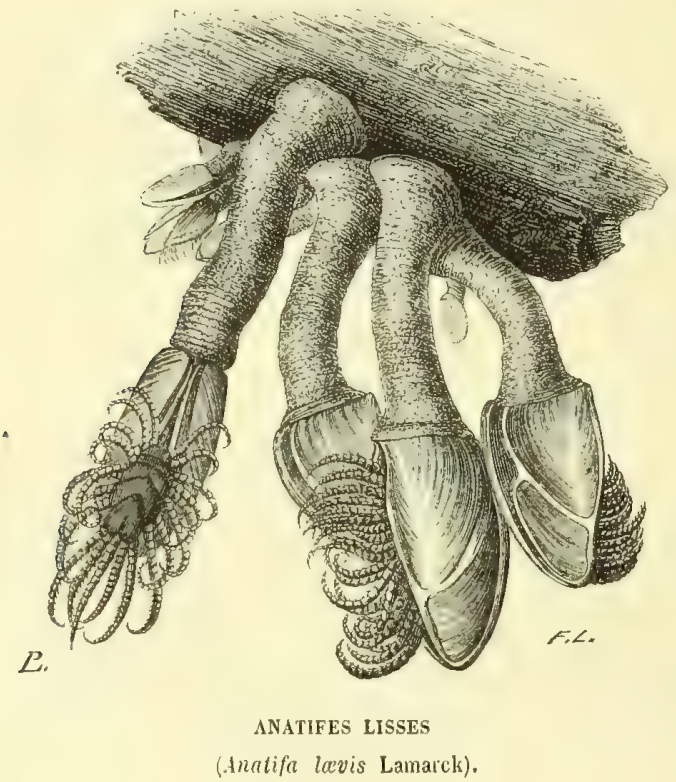

La Providence ne pouvait pas créer des êtres animés seusibles comme des femmes et enracinés comme des arbres: c'eût été le comble de la barbarie (de Candolle).

D'après ce qui précède, il est permis de conclure que plus In animal est sensible, plus il est locomotile; on bien, en retournant la proposition, moins il est locomotile, moins il est sensible, ou, ce qui revient au même, moins compliqué en organisation.

Les Anatifes ne possèdent pas la faculté de se mouvoir. 
On pourrait donc décider à priori que ce sont des animaux à structure dégradée. Cependant, parmi les Invertébrés fixés, on les regarde comme les plus élevés par la structure.

Les Anatifes forment une classe désignée sous les noms de Cirripèdes ou Cirropodes, comme on voudra.

Les naturalistes ont été longtemps en désaccord sur les affinités naturelles de cette classe. Les uns la mettaient parmi les Mollusques, les autres parmi les Articulés. On la place aujourd'hui avec ces derniers, et l'on regarde les Cirripèdes comme intermédiaires entre les Crustacés et les Annélides, ou comme des Crustacés dégradés et sédentaires. (Thompson, Burmeister.)

La Nature s'est toujours jouée et se joucra toujours de nos classifications!

Le pédicule des Cirripèdes peut cependant se mouvoir dans un certain rayon, et porter l'animal en haut, en bas, à droite et à gauche. Ces mouvements sont lents, imparfaits, mais très-certainement volontaires.

Les Anatifes s'attachent aux rochers, aux trones d'arbres baignés par la mel’, aux débris des navires naufragés. On les rencontre assez souvent sur les fragments de bois à moitié pourris, apportés par les marées.

Les pièces calcaires qui protégent les organes s'écartent de temps à autre, et l'Anatife fait sortir des bras ou pieds, appelés cirres; d'où les noms de Cirripèdes et de Cirropodes. Ces bras sont ordinairement au nombre de douze et disposés longitudinalement sur deux rangs, six de chaque còté. Ils sont formés de petites articulations garnies de cils, et semblent plumeux. Dans l'état de repos, ils s'enroulent comme de jeunes feuilles de Fougère ou comme la crosse d'un évêque. Quand l'animal veut s'en servir, il les déploie et les allonge. 
Le nom d'Anatife vient de Anas (canard), et fero (je porte, je produis), parce que l'on a cru pendant longtemps, sur les côtes de l'Ecosse, que cette curieuse bète était une sorte d'ouf pédiculé, qui donnait, an bout d'un certain temps, un oiseau palmipède, de la famille des Canards! Des pêcheurs ont même assuré avoir entendu les eris confus du jeune poussin encore enfermé dans la mitre testacée. D'autres ont raconté avec détail comment l'oiseau prenait naissance. Il montre d'abord les pattes, puis le corps, et puis le bec; il éclôt à reculons et tout nu. Il tombe dans la mer, où il revêt bientôt son plumage, et devient alors, ou une Bernache, ou une Macreuse....

Quelle est la source de cette croyance populaire? On suppose qu'elle vient de la grossière ressemblance qui existe entre les eirres d'apparence plumeuse de l'Anatife et les ailes d'un oiseau!

\section{III}

Les Cirripèdes se nourrissent de bestioles microscopiques. Ils les attirent et les saisissent par un mécanisme trèssimple et très-élégant. Les cirres, placés vers l'orifice de la corpuille, sont presque toujours en action; ils sortent ct rentrent alternativement, et battent l'eau avec rapidité et symétrie. Lorsque ces organes sont tout à fait étendus, leurs tiges flexibles et plumeuses constituent douze jolis appareils collecteurs, qui attirent, balayent, rassemblent et 
poussent dans la bouche les animalcules et les autres parcelles nutritives qui sont à leur portée.

La bouche de l'Anatife est placée, non pas à l'entrée de la coquille, comme les bras, mais dans le fond. Elle présente deux mâchoires latérales.

\section{IV}

Nos pauvres Cirripèdes, fixés par un pédicule, sans tête et sans jambes, semblent, au premier abord, bien déshérités par la Providence. Mais, quand on les examine de près et avec un peu d'attention, on y découvre des instincts qui surprennent, des actes qui confondent et des combinaisons merveilleuses qui redoublent nos sentiments d'admiration pour la puissance créatrice.

Comme les Anatifes ne changent pas de place, il ne devait pas y avoir, chez eux, de mâles et de femelles séparés. Car, s'il y en avait eu, comment ces malheureuses bêtes auraient-elles pu aller les unes vers les autres, se poursuivre, s'atteindre et se choisir? L'amour suppose toujours le mouvement. Voyez comme, aux époques fortunées, tous les animaux de la Nature, daus l'eau comme dans l'air, deviennent agités et remuants!

On comprend pourquoi, chez nos immobiles Cirripèdes, les deux sexes se trouvent associés dans le mème individu, comme ils le sont dans la plupart des fleurs, daus une Rose, par exemple.

Autre merveille! Les nouveau-nés ne ressemblent en aucune manière à leurs parents. Au sortir de l'œuf, ils n'ont pas de pédicule et nagent librement. Ils se meuvent même avec beaucoup d'activité. Et, comme pour se transporter d'un endroit dans un autre, il faut pouvoir se diri- 
ger, la Nature leur a octroyé, avec des nageoires trèsmobiles, un ceil très-gros, placé au milieu du front.

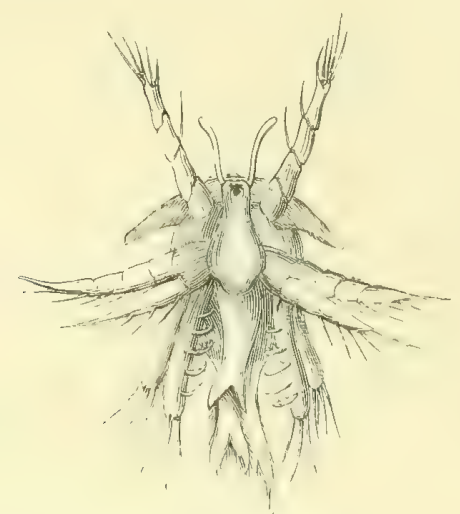

CIRRIPLDE JEUYE ET LIBRE

(Larve du Chthamalus stellatus Darwin).

Ces nageoires et cet æil n'existent plus chez l'adulte. La locomotion et la vision devenaient inutiles dans un animal adhérent.

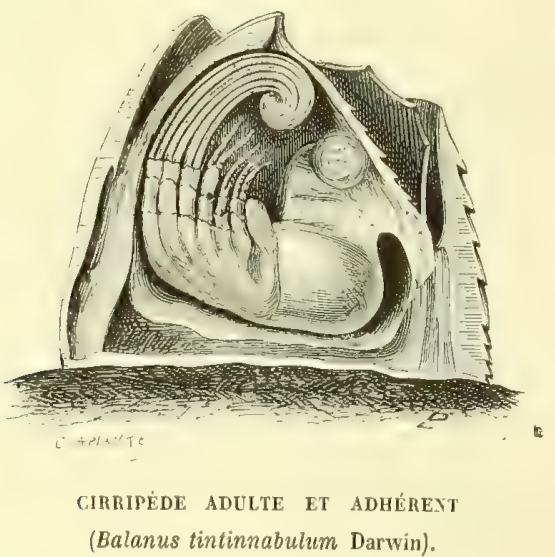

Voilà donc une bête dont la larve est, à certains égards, plus compliquée en organisation que l'animal PARFAIT!

$\mathrm{Si}$ les pauvres Anatifes, esclaves de leur pédicule, avaient des yeux, ils verraient leurs jeunes larves nager 
autour d'eux, bondir et folâtrer.... Que penseraient-ils de cette émancipation si extraordinaire et si complète? Probablement ce que pense une Poule éplorée, enchainée au rivage, quand sa couvée de Canards se précipite dans une pièce d'ean? Heureusement, les Anatifes ne jouissent pas du sens de la vue.... Nais leurs petits, qui ont un œil, que pensent-ils, les vagabonds! de l'immobilité de leur maman?

Un phénomène analogue se rencontre chez d'autres Invertébrés, par exemple chez plusieurs animalcules infusoires. II. Ehrenberg a trouvé, dans les jeunes Eudorines, un wil rouge qui manque chez la mère. Les petits sont ici plus clairvoyants que les parents!

Dans la société des hommes, la loi commune protége toujours les mineurs, c'est-à-dire les plus faibles et les moins expérimentés. Dans l'économie de la Nature, la sagesse iufinie défend les larves encore plus efficacement. Elle leur donne les moyens de résister elles-mêmes à tous les agents de destruction, animés ou inanimés, dont elles sont entourées. Dans son immense bonté, la Providence est pleine de tendresse et de sollicitude pour ses moindres enfants.

Plusieurs savants zoologistes, partant de l'idée que l'Homme représente l'organisme le plus parfait de la Vature, ont considéré les animaux comme des embryons plus ou moins avancés, arrêtés dans leur développement, et jetés avant terme dans ce monde. Suivant eux, la limite d'évolution pour une espèce n'est que le premier, le second, le troisième degré pour une autre espèce....., et l'animal le plus compliqué a passé, pour arriver à la combinaison de ses organes, par une série de variations fœtales qui correspondent aux états définitifs de plusieurs antres animaux moins heureusement organisés.

Cette théorie est séduisante, au premier abord. Mais 
l'exemple des larves qui ont des nageoires et des yeux et qui les perdent en devenant adultes, démontre que, dans la formation des organismes, il y a autre chose que des développements successifs arrêtés à différents degrés.

On peut ajouter que les diverses parties qui entrent dans la composition d'un animal donné ne présentent pas, généralement, entre elles, une complication correspondante. Tel organisme qui se trouve au-rlessus d'un autre par' son appareil respiratoire, est quelquefois au-dessous par son appareil locomoteur; tandis que tel autre, qui ressemble à ce dernier par ces deux ordres d'organes, peut en différer essentiellement par son système nerveux ou par son système digestif.... On rencontre d'ailleurs, dans des espèces plus ou moins simples, des instruments qui n'existent pas même à l'état de rudiment, dans des espèces plus ou moins compliquées!.....

L'harmonic générale des animaux obéit à des lois plus nombreuses et plus difficiles ì formuler que celles qui président à l'embryogénie de tel ou tel individu.....

Tout ce qui précède fait voir que la théorie ancienne, reproduite de nos jours, d'une série linéaire continue des êtres organisés, ou d'une chaîne animale, est une hypothèse inadmissible. La Nature a lié les organismes par un réscau plutôt que par une chaîne. Une carte géographique suffirait à peine pour indiquer les rapports multipliés qui unissent, soit les familles entre elles, soit les genres dans une même famille, soit les espèces dans un même genre.

Mais ne nous perdons pas dans des divagations étrangères au sujet de nos études, et hâtons-nous de revenir aux Anatifes.

Les larves cyclopes de nos animaux ont un corps à peu près triangulaire, couvert d'un large bouclier. Elles présentent en avant deux petites cornes divergentes, et en 
arrière une queue double. Elles possèdent, sur les côtés, six nageoires inégales : les deux antérieures très-grandes et très-simples, les quatre autres très-courtes et bifides. Ces larves grossissent lentement. A une époque déterminée, elles perdent non-seulement leurs nageoires et leur œil, mais encore leurs antennes et leur queue.... Elles se transforment en Anatifes; elles sont alors fixées, pédiculées et mitrées. C'est une autre organisation.

«Chaque animal a ses beautés naturelles. Plus l'Homme les considère, plus elles excitent son admiration, et plus elles le portent à glorifier l'Auteur de la nature. ") (Saint Augustin.)

Les autres Cirripèdes diffèrent plus ou moins des Anatifes. La plupart n'ont pas de pédicules. La mitre, ou le corps qui la représente, est adhérente sans intermédiaire; quelquefois elle s'enfonce profondément dans le tissu.

Le nombre de pièces qui composent la coquille peut ètre au-dessus ou au-dessous de cinq.

Les Glands de mer, ou Balanes, ont un tube calcaire court, à plusieurs pans, dont l'ouverture est fermée plus ou moins par deux ou quatre battants mobiles.

Ces animaux s'attachent à la carapace des Tortues de mer, ou se greffent à la peau des Cétacés. Ils varient suivant les monstres marins sur lesquels ils sont placés. Chaque espèce de Baleine a ses parasites propres, lesquels sont tantôt des Coronules, tantôt des Tubicinelles.

Les Coronules forment des taches circulaires, hexagonales, qui maculent le dos de ces gigantesques animaux.

Sur un petit lambeau de 40 centimètres de long et de 10) de large, détaché de la lèvre d'une Baleine, conservé 
dans le musée de l'École supérieure de pharmacie de Paris, nous avons compté quarante-cinq Coronules, la plupart adultes, symétriquement arrangées comme les pierres d'un pavé.

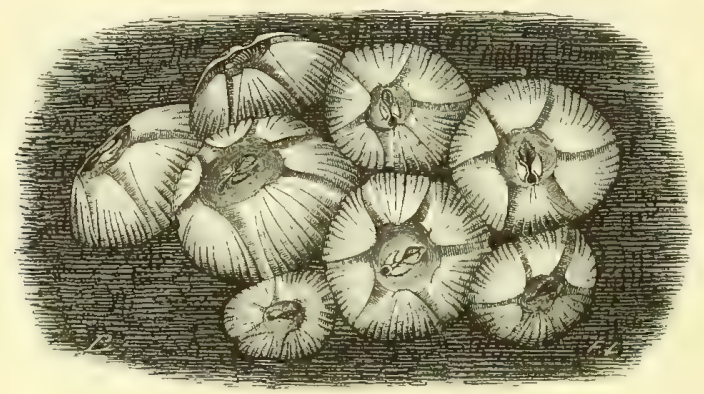

COROSTLE DE LA BALEIYE

(Coronula diadema Lamarck).

Les Tubicinelles sont moins déprimées et plus étroites que les Coronules : elles pénètrent à un décimitre et plus dans l'épaisseur de la peau; elles vivent dans le lard.

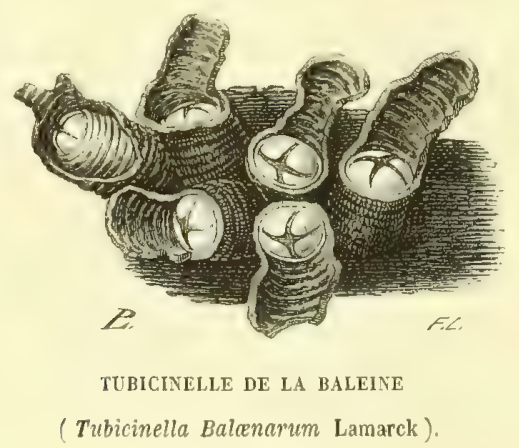

Vous figurez-rous exactement ce que doit être une habitation, une prison, toute une existence dans le lard d'me Baleine?

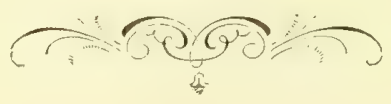




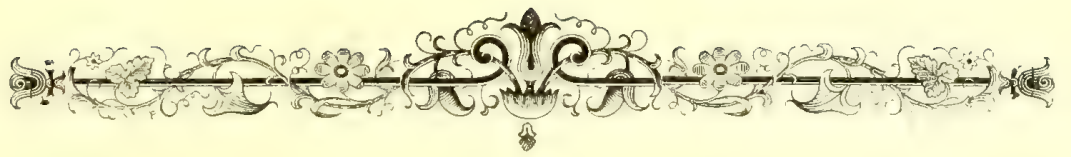

\title{
CHAPITRE XXXI
}

\author{
LES ROTIFERES.
}

" Et quand leurs roues marchoient, ils marchoient; et quand elles s'arrêtoient, ils s'arrêtoicnt: car l'esprit de ces animaux étoit dans leurs roues, b) (Ézéchiec.)

1

Les Rotifères, on Porte-roues, ainsi nommés parce qu'ils semblent avoir denx roues au devant de la bonche, sont

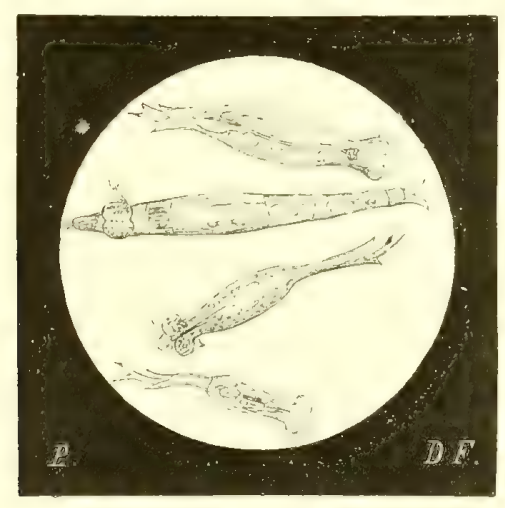

WTRCULAIRES.

des animaleules aquatiques, diaphanes, jaunâtres on rosés, ronsidérés d'aboril romme des Infusoires, et plus tard comme des Annelés. 
On les a comparés aux Crustacés microscopiques.

Ces animaux ont le corps oblong ou ovoïde, contractile, protégé par un petit fourreau solide et transparent.

Dans les espèces dites univalves, ce fourreau est d'mne seule pièce. C'est une sorte de bouclier, de verre mince, qui couvre seulement le dessus de l'animal, ou bien une manière de capsule qui enveloppe tout son corps. Cette singulière carapace est ovalaire, fusiforme, cylindrique ou

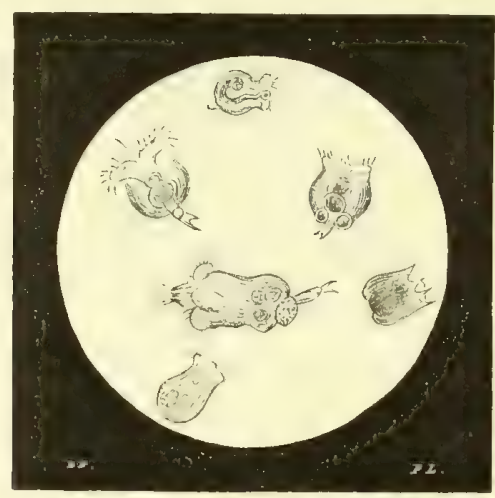

BRACHIOxS.

quadrangulaire, quelquefois dentée en avant, d'autres fois bilobée en arrière.

Dans les espèces dites bivalves, la tunique est de deux pièces, jointes ensemble dans toute la longueur du dos. C'est un paletot-sac qui se ferme par derrière ou par dessus.

L'organe singulier, plus ou moins dilaté, rotiforme (adjectif peut-être trop savant!), qui caractérise surtout nos animalcules, paraît toujours bordé de cils. Il offre souvent une échancrure dans sa partie moyenne, laquelle lui donne la figure d'un 8 couché horizontalement. On croit alor's voir deux roues indépendantes, accolées (Dutrochet). Comme les cils des bords sont vibratiles, et qu'ils décrivent avec 
une rapidité extrême des cercles dans la même direction, les expansions qui les portent prennent l'apparence de deux roues d'engrenage tournant en sens contraire, de dehors en dedans (Dujardin). Dutrochet supposait mal à propos l'existence d'une bordure membraneuse, plissée régulièrement, comme une collerette, et agitée d'un mouvement ondulatoire continu.

Les cils vibratiles précipitent vers la bouche les corpuscules tenus en suspension dans l'eau; ils mettent le Rotifère en rapport constant avec l'air dissous dans le liquide, et contribuent en même temps à sa progression.

La puissance créatrice sait tirer le plus grand parti possible de ses moindres combinaisons. Elle fait souvent beaucoup avec très-peu. Elle remplit trois ou quatre fonctions avec un cil!

Plusieurs Rotifères sont sans queue (Anurées). Certains en ont une toute petite, d'autres une longue; et celle-ci est tantôt simple (Siliquelles), tantôt bifurquée (Furculaires), quelquefois à trois branches et à trois pointes (Ézéchiélines). Dans les Ptérodines, cet organe se termine par une fossette en forme de ventouse. Lorsqu'on voit ces animaux pour la première fois, on croit alorder le domaine du fantastique.

Quand les Rotifères nagent, la queue leur sert de gouvernail. En même temps les lobes ciliés paraissent se mouvoir comme les roues d'un bateau à vapeur.

Plusieurs de ces petites créatures portent sur le front une sorte de prolongement en forme de corne ou de trompe, dont on ignore la fonction. Est-ce une arme offensive on défensive?

La bouche est très-ample et très-contractile. Elle a la forme d'un entonnoir ou d'une cloche. Elle offre deux mâchoires latérales; ce sont de simples tiges cornées et 
coudées, terminées par une ou plusieurs dents; ou bien des ares tendus, dans lesquels les dents sont disposées comme le seraient des flèches prêtes à partir. (Ehrenbergo.)

Leur système digestif est assez compliqué. On y trouve un estomac très-long ou très-large, garui souvent d'appendices latéraux, et un gros intestin dilaté en forme de vessie.....

Les Rotifères ont un cœur toujours en action. On le voit, à travers la carapace, se contracter et se dilater alternativement. Son existence est liée avec une circulation évidente, et, à ce point de vue, les Rotifères sont plus favorisés que les Insectes.

Les anciens naturalistes croyaient que les animaux étaient d'autant plus simples en organisation, qu’ils étaient plus petits. Le microscope a singulièrement modifié leur opinion à cet égard.

Nos animalcules porte-roues n'offrent généralement qu'un seul neil arrondi et mobile, rouge ou rougeâtre, situé au milieu du front (Brachions). Un petit nombre d'espèces, mienx douées, en possèdent deux, trois et même quatre. D'autres n'en ont pas (Lapadelles).

Ce qui est digne de remarque, c'est que cet organe est quelquefois placé sur la nuque et mème sur le dos (Ehrenberh, Nitzsch); de manière que l'animal voit plutôt audessus de lui ou en arrière de lui qu'au devant de lui. Pourquoi cette organisation?

M. Ehrenberg assure avoir constaté dans certaines espèces la présence d'un système nerveux. Un système nerveux dans des bestiolettes qu'un grain de sable peut couvrir!

Les Rotifères sont ovipares. Ils portent leurs œufs suspendus à l'origine de la queue, comme la plupart des Crustacés. 
Spallanzani a donné beaucoup d'importance aux Porteroues. Il a découvert que ces animaux peuvent ètre desséchés, aplatis, collés à une feuille de papier; rester ainsi, pendant un an ou deux, immobiles et dans un état complet de léthargie ou de mort apparente, et puis revenir à la vie. Il suffit de les mouiller pour les ressusciter!

Au contact de l'eau, la petite carcasse se gonfle, remue la quene, tord le ventre, se décolle, agite les cils de sa roue, et se met à nager !..... Heureux Rotifère!

Blainville et Bory de Saint-Vincent ont refusé de croire a l'admirable faculté dont il s'agit. On a protesté, de tous còtés, contre le scepticisme de nos deux savants naturalistes. L'exactitude du sévère Spallanzani pouvait-elle être en défaut? M. Schultze a publié des expériences décisives qui ont confirmé les résultats obtenus par l'illustre physiologiste italien. Il est bien démontré aujourd'hui que cette merveilleuse propriété existe. Mais, pour réussir dans les opérations d'engonrdissement et de réveil, il faut dessécher les petites bètes graduellement, bien graduellement; ne pas trop les comprimer; ne pas les exposer à une température trop élevée, surtout pendant qu'elles sont encore humides; ne pas les garder trop longtemps endormies, et les ranimer avec lenteur et précaution. M. Doyère a fait comnaître les conditions de ce remarquable désengourdissement.

C'est sur le Rotifère commun ${ }^{4}$ qu'on observe le curieux, l'incompréhensible phénomène dont nous venous de parler. Cet animalcule habite dans l'eau douce, ou, pour mieux

1 Rotifer redivious Cuvier. 
dire, au milieu de la mousse humide, sur les murs ot sur les toits. Il est long de trois quarts de millimètre; il a des roues sept ou huit fois plus petites que son corps.

Les Rotifères de la mer périssent sans retour par la dessiccation. Pourquoi la vie est-elle moins tenace dans l'eau salée que dans l'eau douce?

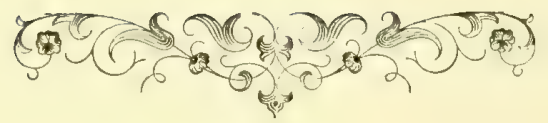




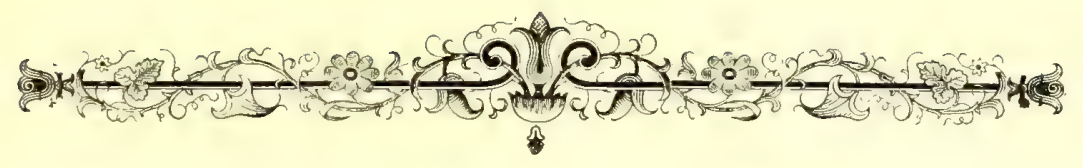

\title{
CHAPITRE XXXII
}

\author{
LES CRUSTACÉS.
}

C'est li Loups famillieux qui tout tue et devore;

Quanque tient devant eulx tout mort, riens n'assavore.

(Girart de Rossillox, 1316.)

Les Crustacés sont les Insectes de la mer; mais ils ont plus de taille, plus de force et plus de voracité que les Insectes ordinaires. An lieu d'une tunique coriace, ils sont revêtus d'une armure calcaire plus ou moins épaisse et plus ou moins dure, sonvent hérissée de poils roides, de tubercules épineux, mème de pointes acérées.

Partont où dans l'Insecte nous trouvons la corne, dans le Crustacé nous rencontrons la pierre. C'est à peu près la même construction, seulement le Constructeur a changé ses matériaux.

Les Crustacés ont presque tous d'énormes pinces crochues et dentelées, dont ils se servent comme de puissantes tenailles ou comme d'eugins de guerre redoutables. On les a comparés à ces lourds chevaliers du moyen àge, audacieux et cruels, bardés d'acier de pied en cap. Visière et corselet, brassards et cuissards, rien n'y manque..... 


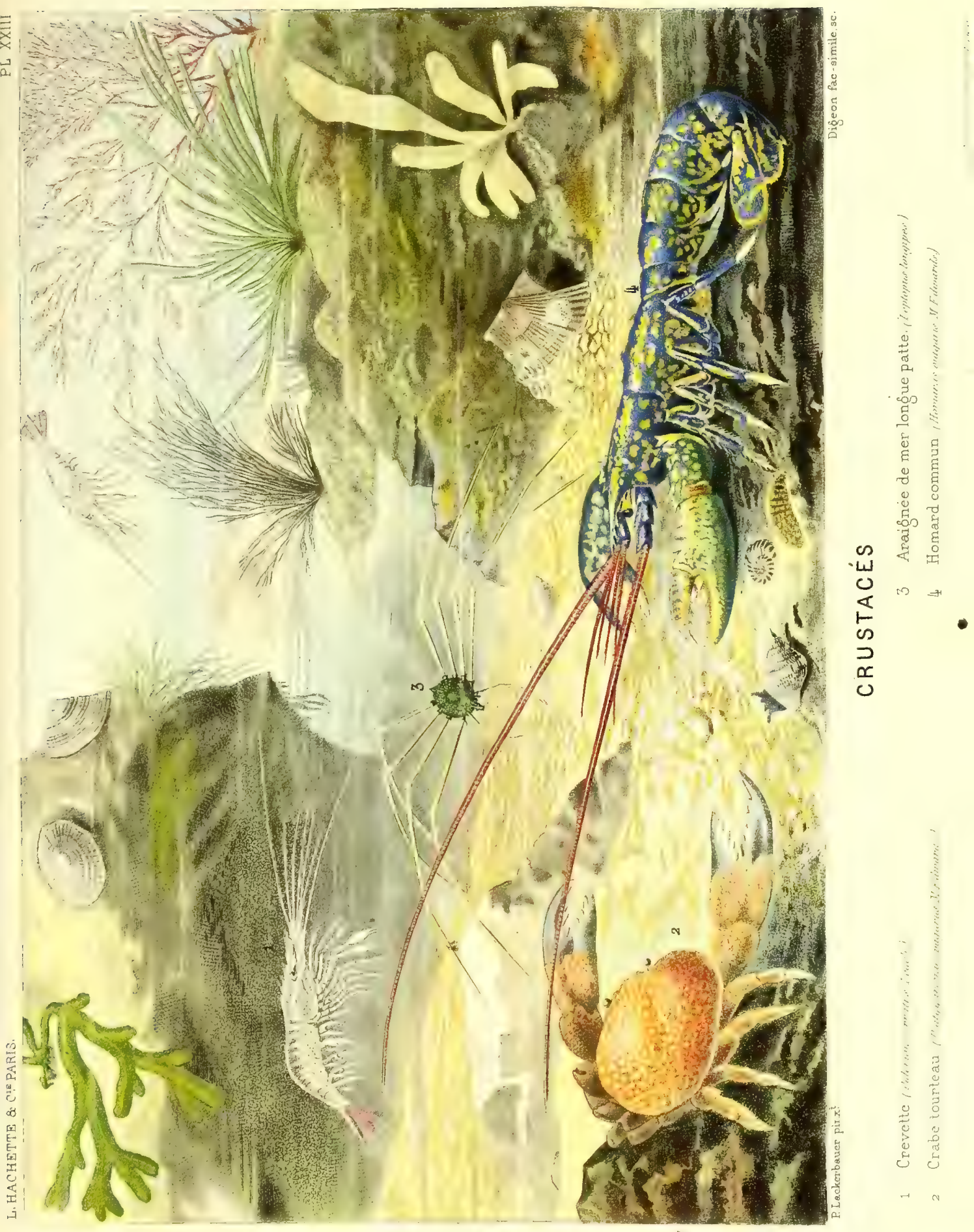



et laisse a découvert une tunique mince, pàle et délicate. Daus cet état, le Crustacé ne mérite plus son nom. Sa peau est devenue presque aussi vulnérable que celle d'un Mollusque. Mais il a l'instinct de sa faiblesse : il se retire prudemment à l'écart; il se cache honteusement dans quelque trou obscur, jusqu'à ce qu'une autre vestiture résistante, appropriée à sa nouvelle taille, lui ait rendu, et son armure de combat, et sa dignité de Crustacé. Malheur à lui si, pendant sa période de faiblesse, il est rencontré par $u 1$ de ses anciens opprimés. Il est à sa merci, et paye alors cherement, comme on dit, ses cruautés d'autrefois.

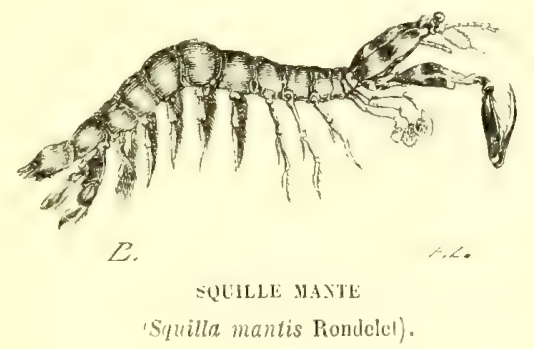

Les Crustacés n’ont pas, comme les animaux supériéurs, unc colonne vertébrale, e'est-à-dire un axe calcaire intérieur, à la fois dur et mobile, portant des appendices de même nature, avec lesquels il forme une charpente solide ou squelette. Mais ils possèdent, ainsi qu'on vient de le voir, une enveloppe pierreuse. L'élément osseux ne s'est point condensé dans le corps, il s'est accumulé à la périphérie. Leur peau tient done la place du srfuelette. Geoffroy SaintHilaire disait que les Crustacés vivent, non pas en dehors de leur colonne osseuse, comme les Mammifères, mais en dedans, comme les Mollusques, et qu'ils sont logés dans leurs vertèbres. Il existe donc des animaux à squelette intérieur, à vérilable squelelle, et des animaux à squelette tégumentaire ou dermato-squelette. 
Les Crustacés ont une armure sombre, bronzce on gris de ler', comme les métaux forgés pour les combats. Quelques-uns sont rouges ou rougeâtres, comme le sang de leurs victimes; quelques autres, d'un jame terreux ou d'un bleu livide, comme la chair qui se corrompt.

Leur croûte calcaire est épaisse et résistante, surtout dans la région dorsale. Leurs membres ont aussi une dureté très-remarquable.

Cependant, chez les petites espèces, on observe souvent un test fort mince et d'une transparence cristalline, qui permet de suive au travers les actes de leur digestion et les mouvements de leur circulation.

Plusieurs Crustacés tout à fait microscopiques contribuent parfois à colorer les eaux de la mer en rouge pourple ou violacé. Telles sont la Grimotée de d'Urville ${ }^{1}$ et la Grimotée sociale ${ }^{2} \ldots$

Chez les Araignées de mer, où le cou n'existe pas, la tète est fondue dans la poitrine (céphalothorax), mais le ventre reste distinct. Le milieu du corps présente un resserrement, une taille quelquefois étroite et gracieuse. Chez les Crustacés, il n’y a plus ni cou ni taille. La tête, la poitrine et le ventre ne forment plus qu'une seule masse, souvent courte, trapue, athlétique et difficile à entamer.

Plusieurs de ces animaux possèdent une queue puissaute, composée d'un certain nombre de palettes ciliées, avec laquelle ils battent l'eau à reculons, et dont ils se servent habilement pour étourdir leurs ennemis. N'oublions pas de dire que la partie appeléc queue, par les gens du monde, est la queue plus le ventre ${ }^{3}$.

1 Grimotea Durvillei Milne Edwards.

2 Grimotea gregaria Leach.

${ }^{3}$ Ce qu'on mange dans une Écrevisse n'est pas sa queue, mais son dos, ou, si l'on veut, son râble. 
En leur qualité d'animanx aquatiques, les Crustacés respirent par des branchies. Chez les grosses espèces, ces branchies sont des lamelles ou des filaments dont les supports sont parcourus par deux canaux : l'un qui amène le sang dans l'économie; l'autre qui le dirige vers le

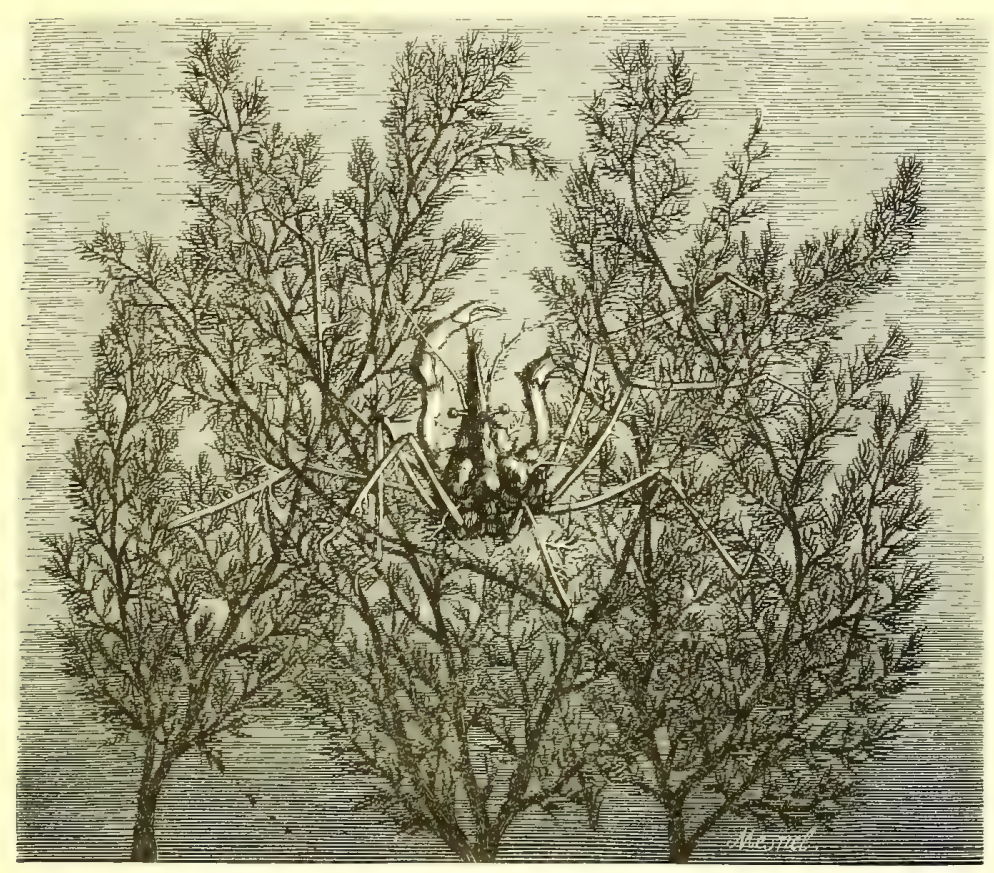

H..1H, I:L HE: MER

l'ist telraodon Inach).

cœur. Cies organes sont enfermés dans le corps. Chez les petites espèces, les brancbies paraissent souvent extérieures et pendent dans l'cau comme des franges. Quelquefois ces mêmes organes servent en mème temps à respirer et à nager. Cie sont des branches-pattes ou des nageoires-branchies. D'autres fois l'animal ne possède pas d'appareil spécial pour la respiration.

Presque tous les Crustacés sont robustes, hardis et destructeurs. Ils forment daus la mer une horde de brigands 
nocturnes, ou de maraudeurs impitoyables, qui ne reculent devant aucun guet-apens. Ils se battent à outrance, nouseulement avec leurs ennemis, mais souvent entre eux, pour une proie ou pour une femelle, quelquefois uniquement pour le plaisir de se battre. Les misérables! Ils luttent audacieusement avec leurs pinces vigoureuses. D'ordinaire la carapace résiste aux coups les plus terribles; mais les pattes, la queue, et surtout les antemues, subissent les plus affreuses mutilations. Ileureusement, fort heureusement pour les vaincus, que les membres emportés repoussent après quelques semaines de repos! C'est pour cela qu'on rencontre maintes fois des Crustacés avec des serres de grosseur très-inégale; la plus petite est celle qui renaît pour remplacer une perte épronvée dans un combat. La Nature n'a pas voulu que les Cirustacés restassent longtemps invalides. Ils revienuent bientôt sur le champ de bataille, tout à fait remis de leurs blessures. On a vu des Homards ${ }^{1}$ qui, dans une rencontre malheureuse, avaicut perdu une jambe malade et débile, reparaitre au bout de quelques mois avec une jambe complète, vigoureuse et d'un excellent service.

0 Nature! comme tu remplis notre âme d'étonnement et de respect!

Daus les ports d'Espagne, quand on a pris une espèce de Crabe appelée Boccace (singulier nom pour 111 Crustacé!), on se contente de lui couper les grosses pinces, regardées comme un excellent manger. On jette ensuite dans la mer le pauvre animal mutilé, pour le repêcher plus tard, quand il aura refail des pinces toutes neuves.

Les Crustacés sont carnivores. Ils mangent avec avidité les autres animaux, soit vivants, soit morts, soit frais, soit

1 Homarus vulgaris Milne Edwards (voy. planche XXIII, fig. 4). 
corrompus. Peu leur importent la qualité et l'état de la victime!

Il est amusant de voir l'adresse et la gravité avec lesquelles le Crabe commun, lorsqu'il s'est emparé d'une malheureuse Moule, tient une valve sonlevée avec une pince et détache l'animal avec l'autre, rapidement et proprement, portant chaque morceau à la bouche, comme on le fait avec la main, jusqu'à ce que la coquille soit entièrement vidée! (Rymer Jones.)

Ce Crustacé ne mord pas directement sur sa proie comme l'Écrevisse. Il est aussi goulu, mais mieux appris.

I. Charles Lespés a surpris, sur la plage de Royan, une troupe de Crabes au moment de leur repas. Ce jour-là ils dinaient en commun, et Dieu sait la joie, comme dit le bon la Fontaine. Ils étaient en rang, tous tournés du même rôté, et presque debout sur leurs huit pattes. Ils saisissaient ì terre de petits objets et les portaient à la bouche prestement et régnlièrement. Chaque main avait son tour. Quand la droite arrivait à l'orifice buccal, la gauche prenait à terre; quand celle-ci à son tour donnait l'aliment, la première ramassait. Il n'y avait pas de temps perdu. Figurez-vous une troupe de zouaves disciplinés, mangeant avee ordre à la gamelle. Ce Crustacé, vous le voyez, a le bonheur d'être ambidextre.

Les Corophies à longues cornes ${ }^{1}$, si remarquables par la gracilité de leur corps, savent très-bien couper le byssus des Moules, pour faire tomber ces bivalves dans la vase et les avoir à leur portée.

Est-il vrai que d'autres Crustacés, grands mangeurs d'Huitres, ont assez de ruse ou d'instinct (comme on voudra) pour attaquer ces Mollusques sans s'exposer au 
danger de leurs battants? Quand le bivalve entr'ourre sa coguille, espece de trappe vivante, pour jouir d'un rayon de soleil ou pour prendre son repas, le malin Crustacé y glisse au plus vite une petite pierre. Cela fait, il dévore à son aise le pauvre coquillage, qui ne peut plus se barricader ${ }^{1}$.

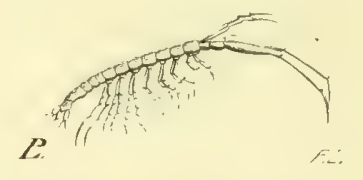

COROPHE A LONGIES CORYES

(Corophium longicorne Latreille).

Les Corophies, dont il vient d'être question, sont extrêmement nombreuses sur les bords de l'Océan, surtout à la fin de l'été et dans l'automne. Elles font la guerre, sans relâche, aux Vers marins. On les voit par myriades s'agiter en tous sens, battre la rase avee leurs longues antennes et la pétrir pour y tronver quelque proie. Rencontrent-elles une Néréide ou une Arénicole, souvent cent fois plus grosse que leur corps, elles se réunissent en troupe pour l'attaquer et pour la dévorer.

Les Corophies rendent cependant d'immenses services aux éducateurs de Moules des environs de la Rochelle. Pendant l'hiver', la vase des bouchots où l'on élève ces bivalves est délayée et très-inégalement amoncelée. Lorsque la saison devient chaude, les parties les plus élevées s'égouttent, se dureissent et rendent la récolte des Mollusques tout ì fait impraticable. II faudrait niveler ces plaines de vase en partie desséchée et en partie demi-liquide, ce qui serait très-difficile et très-coûteux. Eh bien! les Corophies,

${ }^{1}$ L'oiseau appelé Huîtrier (Hamatopus ostralegus Linné) procède ainsi sur nos plages. Mais il possède un bec comprimé, en forme de couteau, merveilleusement disposé pour s’introduire dans la maison du bivalve. 
toutes seules, se chargent de ce soin. Elles démolissent et aplanissent plusieurs lieues carrées couvertes de rugosités et de sillons. Elles délayent la vase, qui est emportée hors des bouchots à chaque marée, et la surface de la vasière se trouve aussi unie et aussi praticable qu'à la fin de l'automne précédent. Il faudrait des milliers d'hommes et peut-ètre tout le cours de l'été pour obtenir ce résultat, exécuté en quelques semaines par un chétif animal.

Nous avons dit que les Crustacés ne se respectaient guère entre eux. Souvent, dans une mème espèce, les gros dévorent les petits. Rara concordia fratrum!

Un jour, M. Rymer Jones avait introduit dans un aquarinm six Crabes tourleaux ${ }^{1}$ de différentes tailles. Un d'eux s'aventura vers le milieu du réservoir, et fut bientôt accosté par un autre un peu plus gros, qui, le prenant avec ses pinces comme il aurait pris un biscuit, se mit à briser sa carapace et à se frayer un chemin jusqu'à sa chair. Il y enfonca ses doigts crochus avec aisance et volupté, paraissant s'inquiéter fort peu des yeux affamés et jaloux d'un autre compagnon, plus fort et tout aussi cruel, qui s'avançait vers lui, contemplant avec délices ce spectacle abominable. Mais, comme l'a dit Horace (et il n’a pas été le premier à le dire), personne n'est heureux de toul point dans ce bas monde ${ }^{2}$. Notre féroce Tourtean continuait paisiblement son repas, lorsque le voisin le saisit exactement comme il avait saisi son frère, le brise et le déchire avee le mème sans-façon, pénétrant jusqu'an milieu de ses entrailles avec la mème sauvagerie.... Et pendant ce temps, la victime, chose singulière! ne se dérangea pas un seul instant; elle continua de dépecer et

1 Platycarcinus pagurus Milne Edwards (voy. planche XXIII, fig. 2).

Xihil est ab omni parte beatum. (Hok.k...) 
de manger le premier Crabe, jusqu'à ce qu'elle fût ellemême entièrement déchirée par son hourrean, présentant un exemple remarquable d'insensibilité, pendant qu'on lıi infligeait eruellement la loi du talion!

Manger les autres et être mangé soi-mìme, est une des grandes lois de la Nature!

"Toutes les espèces de la mer, dit Buffon, sont presque également voraces; elles vivent sur elles-mèmes ou sur les autres, et s'entre-dévorent perpétuellement sans jamais se détruire, parce que la fécondité y est aussi grande que la déprédation, et que presque toute la nomriture, toute la consommation tourne au profit de la reproduction. »

Le lendemain matin de ce tragique spectacle, il ne restait en vie que deux des six Tourteaux du jour précédent, les plus gros at les plus robustes; chacun, blotti dans un angle de l'aquarium, regardait son rival avee une mine concentrée, malicieuse et défiante. M. Rymer Jones ne voulut pas troubler cette féroce méditation ${ }^{1}$.

Dans une autre circonstance, quatre petits Crabes communs se trouvaient dans un mème réservoir. Un d'eux devint aussitôt la proie d'un de ses frères affumés. Peu d'instants après, un second fut saisi par les pinces dı plus gros. On l'en arracha très-difficilement : l'infortuné y laissa plusieurs de ses membres. On le transporta, par. pitié, dans un autre aquarium. A peine en sûreté, il se mit à manger quelques morceaux de Moule avec autant de plaisir et de sang-froid que s'il ne lui était rien arrivé; et cependant il avait subi une effroyable mutilation, puisque, de ses dix pattes, il en avait perdu sept! Il ne lui restait que les deux pinces et la patte droite de derrière. Eheu!.... 
Quatre-vingt-quatorze jours après ce désagrément, le Crabe changea de carapace, et alors les dix pattes se trouvèrent au complet. Toutefois nous devons avouer que les sept nouvelles étaient plus petites que les précédentes, quoique du reste aussi parfaites. (Dalyell.)

L'animal resta probablement un peu boiteux tout lo temps de sa convalescence!.....

Quoique essentiellement carnassiers, les Crustacés mangent quelquefois des végétaux marins, surtout dans les temps de famine. Plusieurs néanmoins semblent préférer les fruits aux matières animales. Tel est le Crabe, si commun dans les îles de la Polynésie, qui se nourrit presque exclusivement de noix de coco. Ce Crabe a des pinces épaisses et fortes; les autres pattes sont relativement étroites et faibles. Au premier abord, il semble impossible qu'il puisse entamer une grosse noix de coco, entourée d'une couche épaisse de filasse et protégée par un noyau très-dur. Mais II. Liesk l'a vu très-souvent faire cette opération. Le Crabe commence par arracher le tissu fibre par fibre à l'extrémité où se trouvent les fossettes du fruit. (Il ne se trompe jamais d'extrémité.) Quand cela est fini, il frappe avec ses grosses pinces sur l'une de ces dernières, jusqu'à ce qu'il ait fait une ouverture. Puis, à l'aide de ses pinces étroites, et tournant sur lui-mème, il extrait la substance blanche de la noix. Cette adroite manœuvre est un exemple bien curieux de l'instinct des Crustacés.

Les Crustacés ont des yeux de deux sortes, des yeux simples et des yeux composés : les premiers, sessiles et immobiles, peu saillants et très-bombés; les seconds, portés par une courte tige calcaire et formés d'une quantité considérable de petits yeux symétriquement agglomérés. La réunion de tontes les cornées microscopiques d'un aeil 
composé ressemble à une calotte chagrinée on taillée à facettes. On dit que dans un oil de Homard se tronvent 2500 petits yeux ${ }^{4}$.

Les yeux simples sont myopes; les yeux composés sont presbytes. Ainsi un Homard peut voir de près ou de loin, ad libitum, bien entendu sans avoir recours à nos instruments d'optique!

Les Crustacés paraissent jouir d'un odorat subtil : ils arrivent de très-loin vers une proie. Si l'on met un petit Poisson mort sous une pierre, on verra bientôt cette dernière entourée d'une multitude d'affamés. On sait avec quelle rapidité affluent vers un morceau de viande, même fraîche, les Écrevisses qui peuplent nos ruisseaux. Si, comme le pensent beaucoup de naturalistes, l'organe de l'odorat réside dans les antennes, la longueur souvent excessive de ces organes chez les Crustacés expliquerait très-bien le développement de ce sens.

Beaucoup de Crustacés ne savent pas nager; ils marchent plus ou moins rapidement au fond de l'eau ou hors de l'eau. Il y en a qui courent obliquement, et qui se servent de leurs pattes aussi habilement dans le recul que dans la progression. On dit que le Cavalier $^{2}$ des côtes de Syrie doit son nom à la rapidité avec laquelle il parcourt de grandes distances. Est-il vrai qu'il va plus vite qu'un cheval?

Les Crustacés qui nagent s'élancent par bonds et par saccades, ou bien glissent mollement et régulièrement, soutenus et poussés par deux rangées de rames parallèles

1 Ce nombre est sans doute considérable, mais il l'est bien davantage dans certains Insectes. On a compté 4000 petits yeux dans la Mouche domestique, 7000 dans le Taon du Bœuf, 8000 dans le Hanneton, 11300 dans le Cossus gate-bois, 25000 dans une Mordelle, et 34650 dans un Papillon. (Blanchard.)

2 Ocypoda cursor Fabricius. 
qui se meurent avec régularité, comme les rames des galères.

La Porcellane large pince ${ }^{1}$ est un mauvais nageur. Elle se contente d'agiter son abdomen, lequel l'aide à descendre obliquement et à reculons jusqu'au fond de l'eau. Elle se fixe sous la première pierre venue et s'y tient blottie pendant des mois entiers. Ses longues antennes, sans cesse en mouvement, l'avertissent de la nature des objets qui s'approchent. Ses pattes-mâchoires sont alternativement et sans relâche projetées en avant et ramenées ensuite vers la bouche. Ces pattes ressemblent à des faucilles. Elles sont formées de cinq articulations bordées intérieurement de soies courbes parallèles, lesquelles, à chaque déploiement de pattes, s'étalent comme les branches d'un éventail, et se rapprochent quand le membre se replie. Examinée au microscope, chaque soie paraît garnie elle-même d'un rang de poils plus courts, implantés perpendiculairement à sa longueur. Dans le mouvement de rétraction, les poils de chaque soie, s'entrecroisant avec ceux qui garnissent les soies latérales, forment un véritable treillis qui doit enfermer et entrainer les animalcules flottants à leur portée; tandis que, au déploiement, les soies s'écartent et laissent s'échapper tout ce que rejette le Crustacé, lequel pent ainsi se procurer sa nourriture sans changer de place. (Gosse.)

Les Chevrettes ou Crevettes ${ }^{2}$ offrent, à l'extrémité de la première paire de pattes, un appendice semblable à un râteau, composé de poils très-courts placés sur le membre à peu près à angle droit. L'animal emploie ce râteau à rassembler les plus petites épluchures, qu'une paire de

1 Porcellana platycheles Latreille.

2 On désigne sous ces noms deux Crustacés, le Palcmon serratus de Leach (roy. planche XXIII, fig. 1) et le Crangon vulgaris de Fabricius. 
secondes pattes porte délicatement à sa bouche. Après quoi le ràteau devicut une brosse dont la Chevrette se sert pour le nettoyage des fausses pattes de son ventre et des lobes de sa queue. Quand il travaille à sa toilette, notre petit Crustacé prend une position grotesque. Son corps s'élève sur les quatre dernières paires de membres; le ventre et la queue se recourbent en avant, de manière que la partie postérieure de la Chevrette se trouve rapprochéc des organes du brossage. (Rymer Jones.)

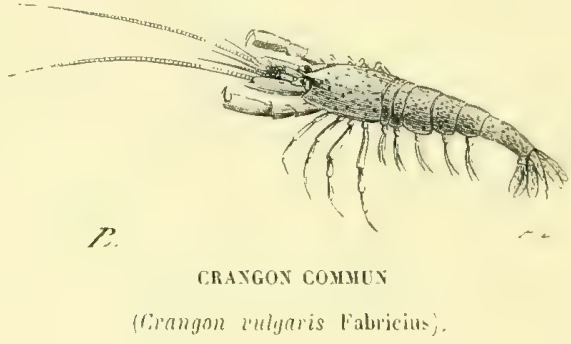

Les Crustacés ont les sexes séparés. Les mâles ressembent plus on moins aux femelles. Cependant, chez certaines espèces parasites des Poissons, on rencontre, entre les deux sexes, des différences très-notables, non-sculement dans la forme, mais surtout dans la taille. Le mâlr est cinquante fois, cent fois, méme mille fois plus petit que sa femelle! Lidemment, dans ce ménage, c'est l'époux qui doit itre dirigé et maitrisé par l'épouse! Cette dernière loge presque toujours son mari... dans une rirle de son dos!

Les fausses pattes des Crustacés sont employées par les femelles à soutenir les œufs qu'elles transportent avec elles.

On a compté dans une Chevrette 6807 œufs, et dans un Crabe 21 699. Dans d'autres espèces, on en a trouvé 29000,30000 et jusqu'a 100000 . Trois ou quatre de ars dernieps Crustaces seraient suffisants pour engendrep 
en six mois une famille égale en nombre à la population du Portugal!

Les œufs des Crustacés sont petits, globuleux ou ovoïdes, jaunàtres on rougeâtres. Ceux des Chevrettes paraissent d'un roux brun; ceux des Langoustes, d'un jaune d'or.

Les aufs de quelques espèces se conservent desséchés pendant un grand nombre d'années, et ne se développent que lorsque les circonstances favorables se présentent.

Quand les æufs sont près d'éclore, ils sont plus gros et plus transparents. A travers leur mince enveloppe, on distingue parfaitement les yeux de l'embryon. Celui-ci ne communique pas avec le jaune par le ventre, comme l'embryon de la l'oule, mais par le dos (Hérold), comme celui du Ver à soie.

Les petits ne ressemblent pas beaucoup aux parents. Ils

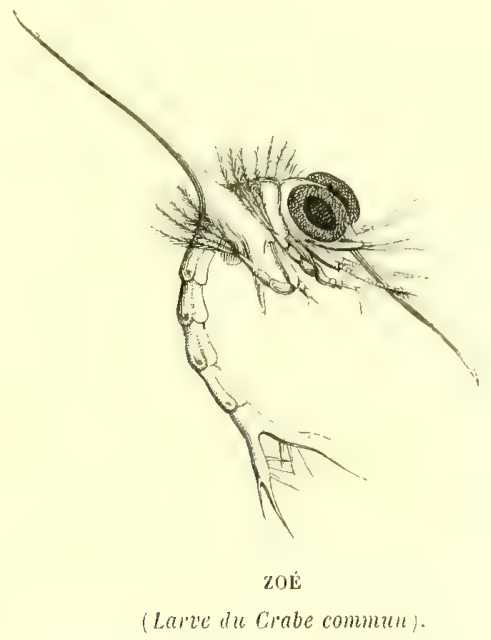

ont sonvent un aspect assez étrange, à tel point que les naturalistes les avaient d'abord pris pour des animaux particuliers, et en avaient fait un genre distinct, sous le nom de Zoé (Thompson). Tous sont plus ou moins arrondis, avec une longue pointe dirigée en avant, arquée comme le 
bec d'uu Ibis, et une autre partant de la nuque, proéminente comme une épine de Groseillier; un ventre singulièrement grêle, une queue fourchue plus on moins ramifiée, et de longues pattes articulées, pourvues chacune A'un long appendice dont l'extrémité digitée est garnie de cils vibratiles propres à la natation. Ces larves ne possèdent pas de pinces; elles nagent avec une très-grande rapidité. On sait que l'animal adulte n'est pas organisé pour la natation. "Rien, en un mot, dit M. de Quatrefages, ne rappelle, chez eux, ce Crabe à corps aplati, verdâtre, qui fuit sans trop de hâte devant le promeneur, et semble, dans sa marche oblique et saccadée, lui adresser le geste bien connu des gamius de Paris! »

A chaque pas, dans l'étude de la Nature, on est terrassé de surprise, comme dit M. Michelet.

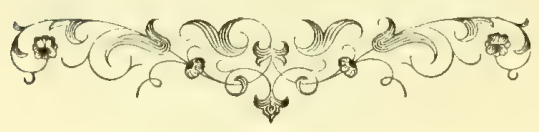




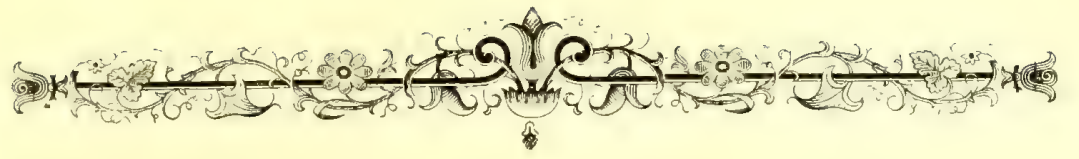

\title{
CHAPITRE XXXIII
}

\author{
LES HOMARDS, LES LANGOUSTES, \\ LES GHEVRETTES.
}

Geants el hains parmi les Ecretisses.

Sur les còtes de l'Océan et de la Méditerranée, certains Crustacés sont l'objet d'une industrie et d'un commerce assez importants. Nous voulons parler des Homards, des Langoustes et des Chevrettes.

Les Homards et les Langoustes peuvent être regardés comme les chefs de file ou les grands seigneurs de la gent crustacée : ce sont d'énormes Écrevisses marines. Les premiers ont des pinces très-grandes et le dos lisse; les secondes, des pinces petites et le dos épineux.

Tihère César fit déchirer le visage d'un pauvre pêcheur avec la cuirasse raboteuse d'une Langouste.

La saison des amours commence en septembre pour les Langoustes, et en octobre pour les Ilomards. (Vous représentez-vous un Homard amoureux?) Elle se prolonge jusqu'au mois de janvier. C'est M. Coste qui nous le dit. Par couséquent, les Langoustes sont plus longtemps amoureuses que les Homards!... Heureuses Langoustes! 
Les femelles des deux espèces pondent des aul's en nombre très-considérable. Les Langoustes sont beaucoup plus fécondes que les Homards (cela devait être!). Les

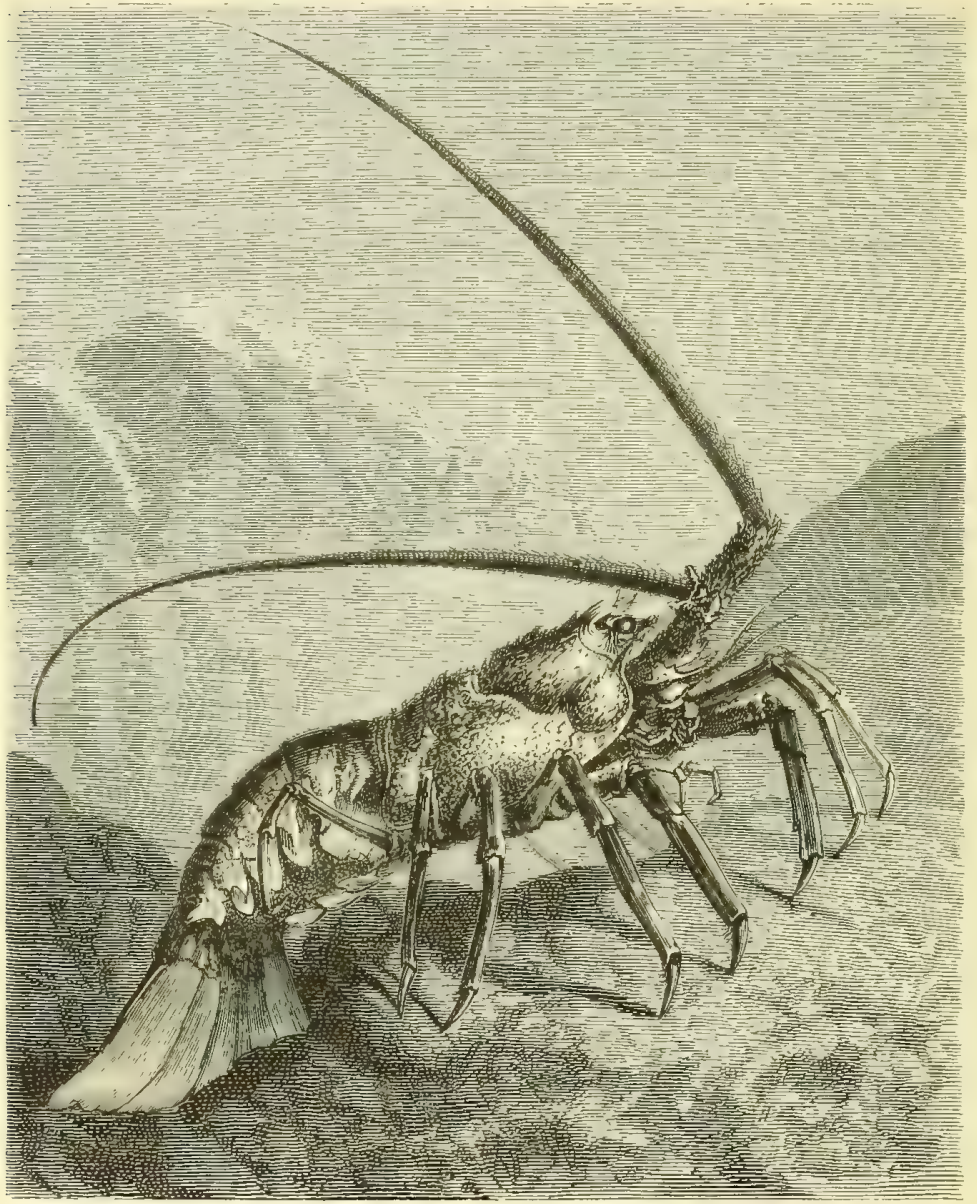

J.A.GULSTE GRALTEE.

Homards produisent 20000 aufs; les Langoustes en domment 100000 et 120000 . (Gerbe.)

Ces oufs sont réunis en paquets et appliqués contre la face ventrale de la queue. Ils sont englués, collés et retenus par une humeur visqueuse particulière. 
Les femelles chargées d'œufs sont dites grainées.

Suivant qu'elles fléchissent ou qu'elles redressent la queue, elles peuvent tenir leur portée dans l'obscurité ou la présenter à la lumière. Tantôt elles laissent leurs reuf's immobiles ou simplement immergés; tantót elles leur font subir des lavages successifs, en agitant doucement les fausses pattes qui les protégent à droite et à gauche. (Coste.)

L'évolution des germes dure six mois. Au moment de l'éclosion, les femelles couveuses étendent la queue. Elles impriment aux ceufs de légères oscillations, pour semer les larves prètes à déchirer leur coque, et se délivrent en un ou deux jours de leur portée entière. (Coste.)

Aussitôt nés, les jeunes Crustacés s'éloignent de leur mère, et montent à la surface de l'eau, pour gagner la haute mer. Ils nagent en tourbillonnant. Nais cette vie pélagienne n'est pas de longue durée; ils la quittent à la quatrième mue, qui survient le trentième ou le quarantième jour, et leur fait perdre les organes transitoires qui servaient à la natation. Alors, ne pouvant plus se soutenir à la surface de la mer, ils tombent au fond, pour y séjourner désormais, et, à partir de ce moment, la marche devient leur mode habituel de locomotion. (Coste.)

Voilà donc des animaux qui courent ou nagent (ce qui revient au même) avant de savoir marcher! L'observation doune souvent les démentis les plus formels aux généralisations les plus accréditées.

A mesure qu'ils grandissent, les jeunes Crustacés se rapprochent des rivages qu'ils avaient momentanément abandonnés. Ils reviennent vers les lieux habités par leurs parents.

Les formes des larves diffèrent tellement de celles des adultes, qu'il serait bien difficile, si l'on n'avait assisté à leur éclosion, de les rapporter à l'espèce dont elles pro- 
viennent. C'est à tel point, que les naturalistes avaient considéré les embryons des Langoustes comme des animaux parfaits, et en avaient constitué un genre distinct, sous le nom de Phyllosome, jusqu an moment ou M. Gierbe est venu les éclairer ${ }^{1}$.
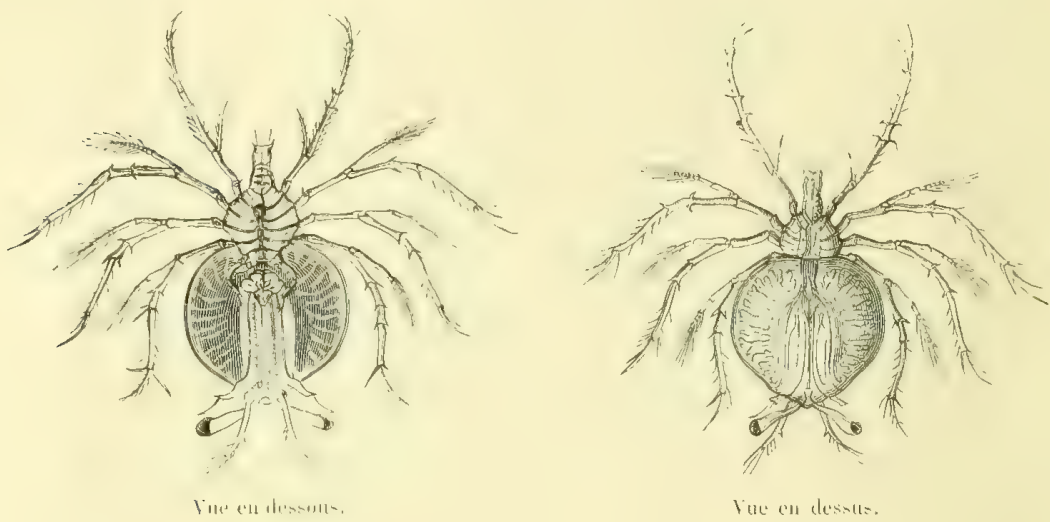

LARVES DE LAYGOUSTE (PHYLLOSOMES),

(D'après les dessins inédits communiqués par M. Gerbe.)

Les embryons des Homards et des Langoustes portent aux pieds des panaches caducs, sortes de rames vibratiles a l'aide desquelles ils se tiennent en suspeusion permanente et se meuvent avec facilité, jusqu'au moment de la quatrième mue.

Les Homards n'atteignent la taille adulte et ne sont aptes à se reproduire qu'à la fin de leur cinquième année.

D'après les observations de .M. Coste, chaque jeune animal perd et refait sa carapace huit à dix fois la première année, de cinq à sept la seconde, trois ou quatre fois la

- Ceci nous rappelle que Linné a décrit comme une Cochenille (Coccus aquaticus) la capsule ovigère... d'une espèce de Sangsue (Nephelis octoculata Savigny). Ce grand homme connut plus tard la vérité, et s'empressa de confesser loyalement sa méprise. "J'ai vu, dit-il, et j'ai été stupéfait" (Vidi et obstupui). 
HOMARDS, LANGOUSTES E'T GHEVRETTES. 451

troisième année, et deux ou trois la quatrième. D'où il résulte que les plus petits Homards servis sur nos tables ont changé en moyenne vingt et une fois de vêtement calcaire, et en sont à leur vingt-deuxième habit !

La taille réglementaire d'un Homard a été fixée à 20 cen-

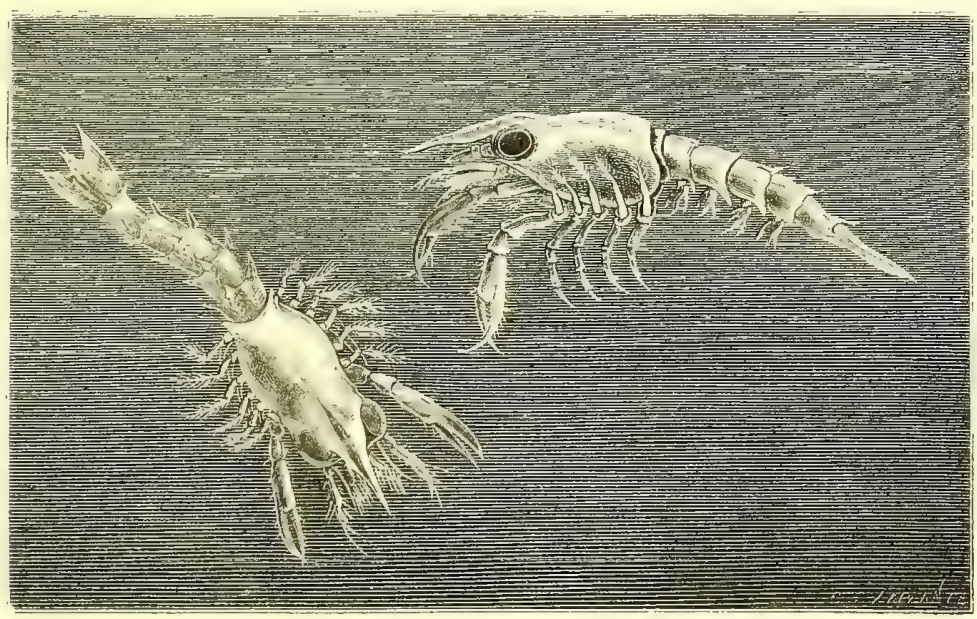

JELXES HOMAIDS $\frac{6}{1}$

(Toisième mue.)

timètres. Tout individu plus court, vendu au marché, est un Homard de contrebande.

Les habitants de Blainville vont s'établir tous les ans à Chausey, pour la pêche des Homards.

On prend ces Crustacés avec des espèces de paniers en forme de cônes tronqués, dont le sommet offre une ouverture disposée de telle sorte que l'animal, une fois entré, ne peut plus sortir. Que de traquenards dans l'industrie!

Le nombre de Homards que chaque famille de pêcheur capture dans une saison peut être évalué à mille ou douze cents. Chausey expédie donc annuellement de huit à neuf mille de ces Crustacés, dont le produit, payé à Coutances, est de 10000 à 12000 francs. Chaque maître pêcheur 
retire à peine 1300 à 1.400 franes de cette campagne, qui dure près de neuf mois. (Quatrefages.)

En Norvége, on prend beaucoup de Homards. On les expédic en Angleterre, à bord de navires dont la cale est divisée en grands compartiments qui communiquent avee la mer. Chaque compartiment peut contenir sept à huit mille individus ${ }^{1}$.

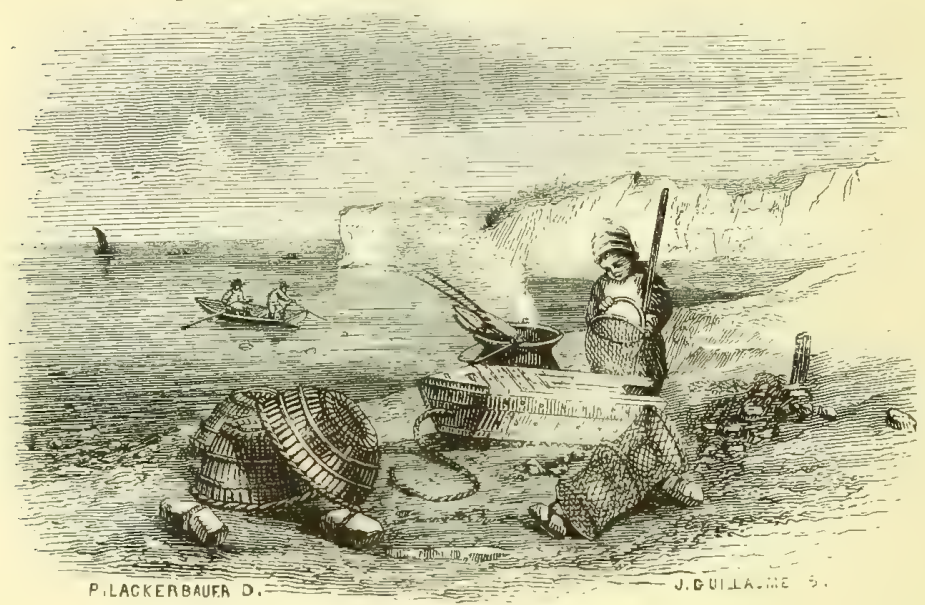

Lvolxs ne: riche.

On peut garder les Homards pendant quelque temps, avec la plus grande facilité. Jadis on les enfermait dans de grandes caisses de bois percées de trons. Aujourd'hui, on les met dans de véritables bassins. M. Richard Scowell possède à Hamble, près de Southampton, un réservoir de briques revêtues d'une couche de ciment, dont l'eau se renouvelle aı moyen d'écluses et de conduites, et dans lequel 50000 Homards peuvent tenir à l'aise et vivre en bonne santé pendant einq à six semaines.

1 L'Angleterre en reçoit annuellement pour une somme de 500000 francs. On en a vu arriver jusqu'à 30000 par jour. 
Quand les réservoirs sont bien installés, il suffit de quelques mètres cubes d'eau pour conserver un grand nombre de Crustacés. Dans les viviers-pares de Concarneau, creusés dans le roc de la falaise, et recevant, avec les marées, l'eau fraiche de la pleine mer, nous avons vu plus de 12000 Langoustes, sans compter un nombre considérable de Homards, entassés dans un éspace de moins de 400 mètres carrés. Par les fortes chaleurs du mois d'août, ces animaux se portaient bien et la mortalité était insignifiante. De temps en temps on leur distribuait les poissons de rebut que laissaient à bon compte les pêcheurs de Sardine de la localité.

Pour empêcher ces animaux de s'entre-détruire, on paralyse les mouvements de leurs pinces au moyen d'une cheville de bois enfoncée dans une de leurs articulations.

Les Langoustes sont les Homards de la Méditerranée; elles passent pour un manger plus délicat et moins indigeste.

Elles sont abondantes, surtout dans le détroit de Bonifacio.

Les Chevrettes sont très-recherchées dans certaines villes. On en fait une assez grande consommation à Paris.

Ces jolis petits Crustacés ressemblent assez aux Écrevisses. Si, comme ces dernières, ils avaient de fortes pinces, ce seraient des miniatures d'Écrevisses.

La pêche des Chevrettes est très-simple. Il suffit d'entrer dans l'eau jusqu'au-dessus du genou, muni d'un filet appelé truble ou havenau, en forme de grande poche, dont le bord est tendu par un demi-cercle de bois et une corde qui fait le diamètre. Un bâton est attaché par l'un de ses bouts au milieu de la corde. Le milieu du demi-cercle y est aussi fixé solidement, et le pêcheur s'en sert pour ratisser les herbiers avec la corde ten- 
due, en tenant l'autre bout du manche appuyé contre la poitrine ${ }^{1}$.

On ne peut exploiter de cette manière que des côtes très-basses, en suivant le mouvement des eaux et par un temps très-calme. Pour rendre la pêche plus fructueuse el mettre à contribution une plus grande étendue de ner. deux pêcheurs prennent un bateau, et disposent trois ou quatre filets de manière qu'ils parcourent le fond comme des trubles de grande dimension. In les jetant et en les retirant de temps en temps, ils font une ample récolte do nos petits Crustacés.

Mais, en général, ce genrè de pêche est confié aux femmes et aux enfants.

A Chausey, la récolte des Chevrettes est abandonnée aux femmes, qui, au nombre de dix environ, se livrent à cette modeste industrie. Armés de leur's bouquetouts, elles parcourent les anfractuosités de l'archipel, fouillent sous les roches et dans les mares, et peuvent, avec de l'activité, en recueillir deux kilogrammes par jour. Mais cette pêche n'est possible que lorsque les marées sont assez fortes. Le produit total de la campagne ne peut guère être évalué au delà de 200 à 300 kilogrammes par personne. C'est done euviron 2500 kilogrammes de Chevrettes que l'on retire tous les ans de Chausey, et dont la plus grande partie s'envoie à Paris. Ce petit commerce rapporte environ 800 francs par personne, à peu près 8000 franes en tout. (Quatrefages.)

Pendant l'hiver, les Chevrettes se retirent dans de plus grands fonds, oì il n'est plus possible de les atteindre aver les havenaux. On se sert alors de casiers de filets, de forme assez semblable à ceux qu'on emploie pour la pêche dı

1 Voyez la planche XXIV. 


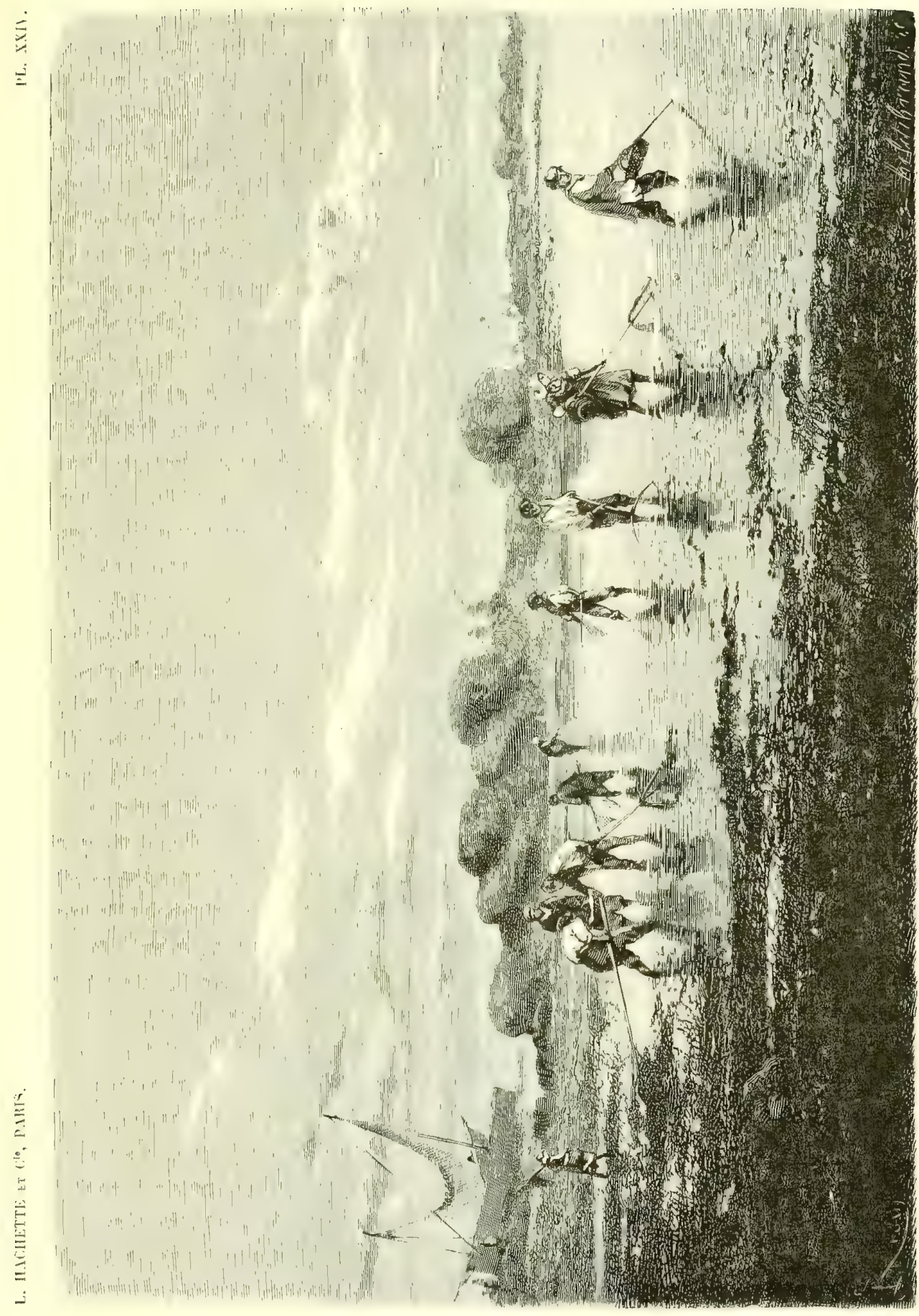

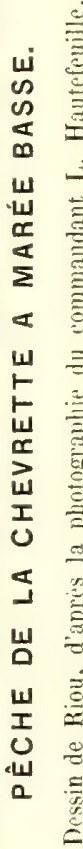



Homard. Dans ces derniers temps, le commandant L. Hautefenille a eu l'heureuse idée de remplacer les filets que l'on devait changer tous les mois, par de la toile métallique galvanisée, dont la durée est de deux à trois ans. Cet excellent engin est déjà très-répandu.

Les Chevrettes se conservent parfaitement, dans des parcs d'une contenance restreinte, pourvu que l'eau de mer soit suffisamment renouvelée. Elles y grossissent même, si on leur donne une nourriture appropriée. L'expérience en a été faite dans les viviers de Concarneau, sur plus de 1500 kilogrammes, représentant une valeur de près de 3000 francs.

A la Rochelle, on a des bassins particuliers pour faire reproduire les Chevrettes.

Les Chevrettes rougissent par la cuisson, mais ne prennent jamais une teinte aussi foncée que les Homards et les Langoustes. Elles sont plutôt d'un rose très-vif que d'un rouge très-brillant. Une variété pêchée dans la Garonne, audessus du bee d'Ambez, ne rougit pas; elle blanchit au contraire, si elle a toujours vécu dans l'eau douce. Mais, après avoir passé quelques jours dans l'eau salée, l'anomalie commence à disparaître.

Les autres Crustacés sont loin d'être recherchés comme les Homards, les Langoustes et les Chevrettes.

Cependant, à Venise, on vend, dit-on, chaque année, pour près de 500000 franes de Crabes ordinaires. Ce chiffre nous paraît bien élevé : à un centime la pièce, il présenterait cinquante millions d'individus.

Dans d'autres pays, on mange les Tourteaux', les $\boldsymbol{E}_{\text {trilles }}^{2}$, les Squinado ${ }^{3}$, les Salicoques ${ }^{4}$, les Caramotes $^{5}$, les Nika ${ }^{6} . .$.

\footnotetext{
- Platycarcinus pagurus Linné.

2 Portunus puber Fabricius.

3 Maia squinado Lamarck.
}

\footnotetext{
4 Palcmon squilla Leach.

5 Paneus caramote Latreille.

6 Nitra edulis Risso.
} 
L'utilité alimentaire des Crustacés et des antres habitants de la mer est reconnue par tout le monde. Aussi nous comprenons parfaitement (et nous approuvons mème) la classification peu savante, mais essentiellement pratique, proposée par le comte Marsigli, pour les animaux de la Yéditcrranée : Animaux que l'on mange; Animaux que lon ne mange pas ${ }^{1}$.

1 Le nombre des Homards et des Crabes consommés à Londres est évalué à deux millions et demi. On porte au même chiffre ceux qu'on mange dans le reste de l'Angleterre. Somme totale, cinq millions!

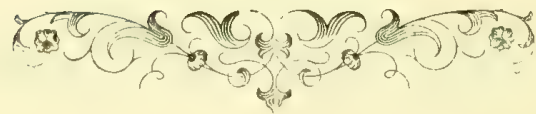




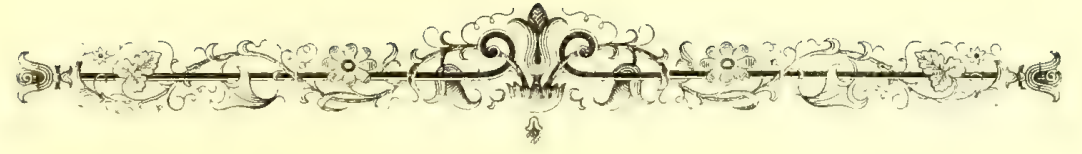

\section{CHAPITRE XXXIV}

\section{LE BERNARII LERIITE.}

Je me loge oi je puis et comme il plait à Dieu.

(BOLleat.)

Le Bernard l'ermite, ou Soldal, est un Crustacé trèsbizarre et très-curienx, qui vit sur les bords de la mer. II mérite bien un chapitre spécial.

Il diffère des Crustacés proprement dits en ce que, au lieu d'avoir le corps protégé par une armure calcaire plus ou moins épaisse et plus ou moins solide, il n'offre de cuirasse qu'en avant, c'est-d̀-dire à la tête et à la poitrine; tout le reste n'est revêtu que d'une peau molle et peu résistante. La partie vulnérable du Bernard est un moreean friand pont ses voraces compatriotes. Mais notre malin Crustacé connait parfaitument la misérable faiblesse de son train postérieur. La prudence lui fait chercher quelque coquille vide, d'une taille en rapport avec la siemne. Quand il n'en trouve pas, il attaque un testacé vivant, le tue sans pitié, le mange sans remords, et s'empare de son logement, sans autre forme de procès. Une fois maitre de la coquille, 
il s'y introduit à reculons; il s'y installe et s'y retranche comme dans un petit fort.

Aux heures des repas (et à celles des amours), le Bernard montre la tête et les pattes, surtont les grosses pinces. II agite an-devant de lui ses deux colnes, qui sont longuelles et menues, suivant les expressions d'Amleroise Paré. Quand

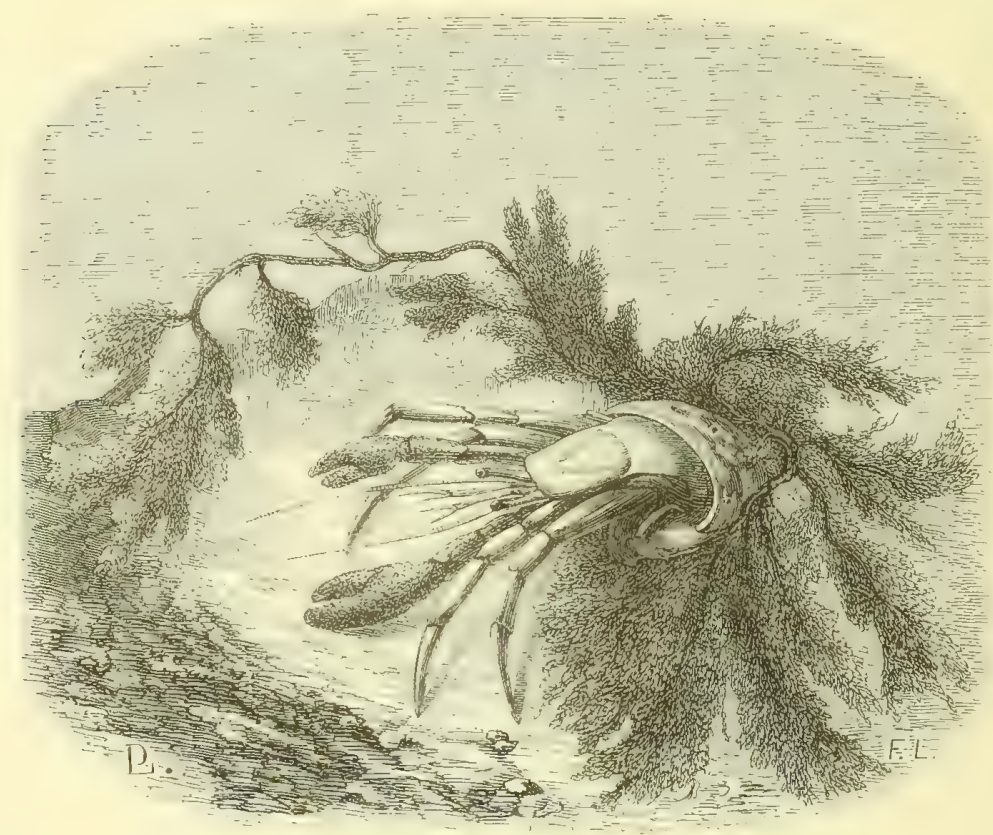

HERYATI L ERMITH

(l'agarus Rornhardus Fabr.)

il marche, il accroche avee ses tenailles les corps qui l'avoisinent, et entraine avec lui son habitation, comme l'Escargot la sienne. Mais les parties de son corps mal défendues restent tonjours enfermées et protégées.

Vovez, à la marée basse, les Bernards disséminés sur les grèves rocailleuses. On croit apercevoir un grand nombre do coupuillages de diverses grandems, qui se meuvent dans 
toutes les directions, avec des allures différentes de celles qui appartiennent à leur race essentiellement lente et mesurée. Si on les touche, ils s'arrêtent lorusquement. On découvre bientôt que chaque maisonnette sert de résidence non pas à un Mollusque, mais à un Crustacé.

Le Bernard vit seul dans sa petite citadelle, comme un cénobite dans sa cellule ou une sentinelle daus sa guérite. Il serait bien difficile qu'il en fùt autrement. C'est pourquoi on l'a surnommé l'ermite ou le soldat.

Quand notre Crustacé grossit et que son habitation d'emprunt devient gênante, il se met en quête d'un autre coquillage un peu plus grand et mieux approprié à sa taille, et il change de maison.

Le Bernard profite souvent, arons-nous dit, des coquilles vides abandonnées. Quand la marée se retire, il n'en manque pas. Il faut le voir, alors, chercher, tourner, retourner, et surtout essayer son nouvean domicile. II fait glisser lestement son abdomen, qui est gros et contourné, tantôt dans une coquille, tantôt dans une autre, regardant avec méfiance autour de lui, et revenant bien vite à son ancien logis, si le nouveau ue Jui parait pas confortable. II en essaye souvent un grand nombre, comme on essaye des rêtements neufs, avant d'en avoir rencontré un qui lui convienne.

Dans ses déménagements successifs, le petit sybarite, tout en se domant un ermitage de phis en plus spacieux, ne manque pas de suivre son goût et son caprice, dans la couleur et dans l'architecture de sa nouvelle habitation.

L'ennui naquit un jour de l'uniformité!

Le rusé compère choisit une maisonnette tantôt grise ou jaune, tantòt rouge ou brune, globuleuso ou cylindrique, en forme de tourelle on de tonnean, sonvent armée de 
dentelures, de créueaux, de lames tranchantes on de prolongements pointus.

Cependant notre Diogène Crustacé préfèro les coquilles en spirale un peu allongée : par exemple, les Cérites, les Buccins et les Rochers....

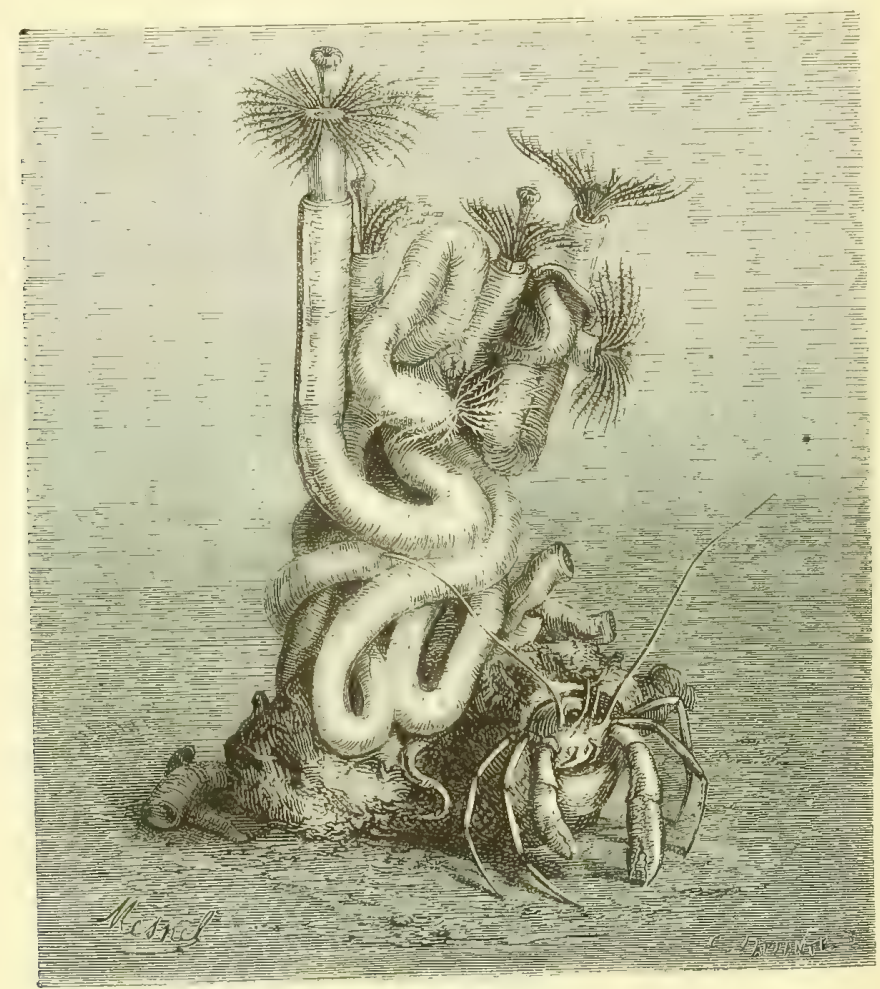

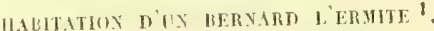

Le Bernard est timide. Au moindre bruit, il se retire dans son gite, et s'y tapit sans mouvement. Il rentre la plus petite de ses pinces et ferme la porte avec la plus grosse Celle-ci offre souvent des poils, des tubereules ou des dents. Notre prudent cénolite se cramponne si fortement au fond

1 Pêché à la drague par lrente brasse's de profondeur, au sud des îles de Glenans. 
de sa retraite, qu'on le mettrait en pièces plutòt que de l'en arracher. Sa queue est transformée en une sorte d'appareil d'adhérence (haftorgan) à l'aide duynel elle le fixe solidement à sa nouvelle habitation.

Ce Crustacé est robuste et vorace. Il mange avec délices les Poissons morts et les débris de Mollusques et de Vers. II attaque aussi les animaux vivants.

Quand on introduit un Bernard dans un aquarium, il l'a bientôt bouleversé et dévasté, avec ses courses désordomnées et avec sa rapacité insatiable.

On réussit quelquefois à conserver en bonne harmonie plusieurs individus dans le même réservoir, mais cela tient plutòt à l'impossibilité où ils se trouvent de s'attaquer entre eux, étaut bien barricadés et bien rusés, qu'à la douceur de leur caractère ou à l'amour de leur prochain.

En effet, ces animaux sont très-querelleurs. Deux Bernards ne peuvent guère se rencontrer sans manifester des sentiments hostiles. Chacun étend ses longues pinces et semble tâter l'autre, comme font les Araignées quand elles cherchent à saisir une mouche du côté le plus vulnérable. En général, ils se contentent de ces preuves de hardiesse mutuelle, et chaque agresseur, trouvant l'ennemi parfaitement fortifié, s'empresse de battre prudemment en retraite. Souvent il y a une véritable passe d'armes: les bras s'écartent, les pinces s'ouvrent et s'agitent d'une manière menaçante; les deux adversaires se culbutent et roulent l'un sur l'autre, mais plus effrayés que meurtris ${ }^{1}$.

M. Gosse a vu, une fois, la lutte se terminer par un dénoûment tragique. Un Bernard s'approcha d'un confrère agréablement logé dans une coquille plus grande que la sienne, le saisit par la tête avec ses puissantes tenaillès,

1 Voyez la planche $\mathrm{XI1}$. 
l'arracha de son asile avee la rapidité de l'éclair, ef s'y logea $110 n$ moins promptement, laissant le malheureux dépossédé se débattre sur le sable, dans les convulsions de l'agonie.

Nos combats, dit Charles Bonnet, n'ont presque jamais lieu pour un objet aussi important! Il s'agissait d'une maison!

Une jolie espèce d'Anémone de mer, l'Anémone parasite, aime à vivre avee le Bernard. Il est des sympathies tout à fait inexplicables! Dans les afuariums, cette Anémone se fixe presque toujours sur la coquille qui sert do demenre-au Crustacé, et l'on peut dire que là où s'établit le Bernard, s'établit aussi l'Anémone.

Ces deux animaux vivent ensemble en parfaite intelligence. Les observations de M. Gosse nous ont appris qu’il y a entre eux une entente cordiale et réciprocité d'affection. Ce savant observatem vit un jour un Bernard qui venait de changer d'habitation, détacher délicatement de sa vieille demeure sa chère compagne l'Anémone, la transporter avec précaution et la placer confortal,lement sur la nouvelle coquille, et puis, avec ses larges pinces, donner à sa bien-aimée phusicurs petites tapes pour qu elle se fixàt plus promptement.

M. A. Lloyd a été témoin plusieurs fois du même phénomène, dans son établissement de Portland-road. Il a même vu un Crustacé renoncer à. changer de domicile, parce qu'il n’avait pu décider son Anémone, qui était souffrante, à déménager avec lui.

Une autre espèce de Bernard a pour compagne l'Anémone manteau. On assure que lorsque le Crabe vient à mourir, son amie inconsolable ne tarde pas à succomber. 

On connait anssi une Annélide, la Néréide à deux lignes, qui forme avec notre Crustacé une association encore plus intime. Elle s'introduit dans la coquille nême qu'il habite et partage son logis. Les pècheur's de Weymouth, qui conmaissent cette particularité, ne manquent pas de briser cette coquille pour en retirer le Ver marin, dont ils font un excellent appàt.

\section{III}

Nous avons rencontré un Bernard, qui probablement n'avait pas trouvé de coquille à sa convenance, blotti dans une vieille Éponge.

Nous en avons découvert un autre installé dans un morceau de pierre ponce.

An Jardin zoologique d'acclimatation, il existait, en juillet 1861, un Bernard qui avait introduit son abdonen dans une Anémone de mer vivante. Il la trainait avec lui, bon gré mal gré, partout où il lui plaisait. L'Anémone, quand elle n'était pas trop seconée, étalait paisiblement les rayons de sa collerette, et semblait presque habituée à l'occupation de sa poche digestive. Cependant elle ne mangeait pas! Les déjections du Bermard lui servaicut-elles d'aliment? Comment l'estomac de l'Anémone n'exeregait-il aucune action dissolvante sur la queve et sur le ventre du Bernard? Toujours des faits qui embardassent la science!

\section{IV}

Un petit animal re la famille de notre Crustacé choisit une pierre plate ef la couche sur son dos, comme un abri solide. Il la retient avee ses deux pattes de derrière. 
La Dromie globuleuse se couvre et se protége avec une valve de coquille. Elle la porte sur elle comme un bouclier.

M. Spencer Bate avait mis dans un verre quelques Puces de mer, avec une petite Ulve verte. Au bout d'une heure ou deux, il vit avec surprise que l'une de ces petites créatures avait enroulé autour d'elle la plante marine, et s'en était fait une sorte de tube protecteur, dans lequel elle vivait commodément et paisiblement, n'en sortant que la tềte et les antennes. Lorsqu'on la tourmentait, elle se retirait bien vite au centre de sa maisonnette, s'y retournait, et sortait alors la tête par l'autre extrémité.

L'Amphithoé rougeâtre ${ }^{1}$ cherche sous les pierres, dans les crevasses des rochers ou entre les tiges des Fucus, des endroits bien abrités, et là elle se construit un petit nid, composé d'une matière soyeuse et de corpuscules étrangers étroitement unis et mastiqués. Examiné au microscope, ce nid présente une grande puantité de fils tris-fins entrelacés et comme tissus d'une manière très-serrée. Cà et là on remarque quelques soies plus fortes, doubles, tordues en spirale. (Spencer Bate.)

\section{V}

Le Pinnothère ${ }^{2}$, joli Crustacé d'un rose vif, de la taille d'un pois, se fait le commensal de quelyue grosse Iluitre. II entre et vit dans la maison du bivalve exactement comme chez lui.

Pline eroyait que ce petit Crabe recommaissait, en hôte généreux, l'hospitalité qu'on lui accorde (à la vérité un peu forcément). L'Huitre, disait-il, est aveugle et pourrait

1 Amphithoe rubricata Leach.

2 Pinnotheres veterum Bosc. 
être surprise par quelque méchant animal. Le Pimnothère, qui a des yeux très-gros et un esprit très-attentif, pince le manteau de sa patronne, toutes les fois qu'un danger la menace. Il oblige ainsi cette dernière à rapprocher ses deux battants et à fermer sa maison ${ }^{1}$.

Plutarque apprécie différemment les services que le Pinnothere rend anx bivalyes. Voici son opinion, exprimée par Montaigne: “Dans la coquille de la Nacre se trouve „le Pinnothere, luy servant d'huissier et de portier, assis

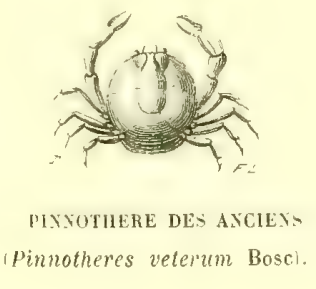

" a l'ouverture de rette coquille qu'il tient continuellement ” entrebaillée, jusqu'à ce qu'il y voye entrer quelque petit " poisson propre à leur prinse. Car, alors, il entre dans la "Nacre, et luy va pinceant la chair vifve, et la contraint " de fermer sa coquille. Lors, eulx deux, ensemble, man"gent la proye enfermée dans leur fort. "

Il est vraiment dommage que ces histoires, tant celle de Pline que celle de Plutarque, soient des histoires faites à plaisir. Il n’y a de vrai que la présence du Pimnothère dans les bivalves, présence déterminée par l'instinct de sa conservation.

Ce petit Crustacé est timide et paresseux; pour se mettre en sủreté, il se loge dans les Huitres, dans les Pinnes², dans les Moules et dans les Modioles....

1 Ostrea in conchis luta fuêre suis. (Ovioe.)

2 Lénom de Pinnothère ou Pinnotère signifie littéralement " pourvoyeur de la Pinne " (venator Pinno) ou "gardien de la Pinne " (custos Pinno). 
Suivant M. W. Thompson, sur dix-huit Moules des còtes de l'Irlande, on a trouvé quatorze Pinnothères femelles. II n'est pas rare de rencontrer, dans le mème bivalve, deux femelles et même trois, un mâle et plusieurs petits. Le Pinnothère, comme on voit, n'est pas égoïste; quand il a découvert une belle et bonne Moule, il ne la prend pas pour lui seul, il s'y établit en famille.

Il n’y a rien d'isolé dans la création. L'animal le plus humble a des rapports intimes, non-seulement avec la mer. avec les nuages, avec l'air, avec le soleil..... mais encore avec les plantes et avec les autres animaux. L'harmonie est la grande loi de la Nature. (Channing.)

Mais qui peut se vanter, dans l'Océan, de n'avoir pas d'ennemi? Le pauvre Pinnothère, quand il change de coquille, s'il ne prend pas bien ses précautions, est bientòt appréhendé au corps par quelque Cinstacé plus gros ef plus robuste, qui le dépèce et le dévore en un clin d'œil.....

\section{1}

Le Bernard et les Crustacés, qui ont besoin d'un abri, terminent nos études sur les Animaux sans vertèbres.

Dans les chapitres suivants, nous traiterons des Vertébrés.

Nous marchons du simple au composé.

lin zoologie, le mot composé peut itre pris dans trois sens différents. Il exprine dabord la réunion en communaté d'un certain nombre d'individus élémentaires, plus ou moins distincts les uns des autres; secondement, la fusion plus ou moins complicte de plusieurs organismes particuliers ou zoonites; troisiènement, la complication phs ou moins grande des individus isolés. 
Les Polypiers sont des réunions d'individus distincts.

Les Crustacés sont des associations de zoonites adhérents.

Les Poissons. sont des individus isolés compliqués.

Les Coraux ont une organisation arborisée. Leurs animalcules sont associés, comme les fleurs dans une plante.

Les Anémones, les Étoiles, les Oursins....., possèdent une organisation rayonnée. Daus un grand nombre, cette structure est à peu près rigoureuse. Leurs parties répétées sont arrangées autour d'un point ou d'un axe commum, dont elles divergent presque géométriquement. Quel- quefois l'ensemble présente en mème temps comme unc moitié droite et une moitié gauche (Dujardin). C'est un passage entre la symétrie rayonnée et la symétrie bilatérale.

Les Annélides, les Crustacés et les autres animaux dits Annelés, possèdent une organisation unisériée. Mais comme chaque zoonite se trouve composé de deux moitiés semblables latéralement accolées, il en résulte que l'ensemble est plutòt bisérié qu'unisérié; en d'autres termes, que ces animaux ont à la fois, et la structure sériée, et la structure bilatérale.

linfun, les Vertébrés, ‘u’on a nommés aussi unitaires, ne présentent plus, dans leur organisme, ni disposition rayonnée, ni groupement sérié; mais ils offrent deux moitiés semblables: une à droite, l'autre à gauche. Leur symétrie est simplement bilatérale.

L'arrangement rayonné est celui des amimaux les plus simples. L'arrangement bilatéral est celui des animaux les plus parfaits.

Dans le règne végétal, pour to dire cu passant, les fleurs offrent aussi, dans la disposition de leurs parties similaires, tantòt le plan rayonné, tautòt le plan bilatéral. 
Il suffit, pour s'en convaincre, de jeter les yeux sur une Renoncule ou sur un OEillet, et sur nne Linaire ou sur une Sauge. Les botanistes, nous en ignorons la raison, npellent régulier ce premicr mode d'arrangement, et irrégulier le second. Dans len's classifications, ils regardent les plantes à fleurs régulières comme plus parfaites que les plantes à fleurs irrégulières. On vient de voir que les flenrs dites irrégulières ne diffèrent des autres que par unt symétrie différente. Si les caractères avaient la mème importance dans les de'ux règnes, les fleurs à symétrie bilalérale seraient plus élevées en organisation que les fleurs à symétrie rayonnée.

Les botanistes et les zoologistes devraient de temps en temps, sortir de leurs études exclusives, regarder un peu ce qui se fait de bon chez le voisin, et se mettre d'accord avec lui. La science y gagnerait.

Lectemr, venillez pardonner les considérations générales yui terminent ce chapitre. Nous venons d'aborder, sans nous en douter, un des sujets les plus importants de la zoologie. Ce n'était peut-être pas la place dans un livre yui n'est pas savant et dont l'auteur ne cherche pas à le paraitre....

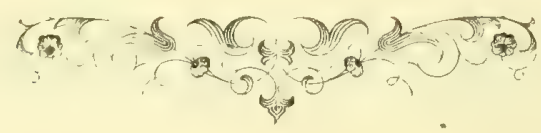




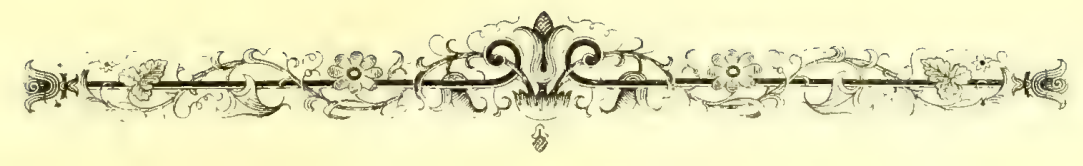

\section{CHAPITRE XXXV}

\section{LES POISSONS.}

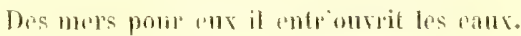

(RACIVE.)

Les Poissons sont les habitants de l'eau par excellence. Ils naissent dans l'eau, vivent dans l'ean et meurent dans l'eau. Quand on les retire de ce milieu, ils succombent à une sorte d'asphyxie. Les Poissons sont les principaux hôtes de l'Océan, e'est-à-dire, les plus nombreux, les plus variés, les plus vifs et les plus brillants....

Dans le premier chapitre de cet ouvrage, nous avons rappelé que les sept dixièmes de la surface de la terre sont baignés par les mers. On serait tenté de croire, disait un homme d'esprit, frappé de cette immense étendne d'eau, ‘ur notre globe a élé créé surtout pour les Poissons!

Les loissons sont en quelque sorte le lien qui unit les Animanx vertélnés aux Animanx sans vertibres. Its ont une organisation plus compliquée que toutes les bètes, petites ou grandes, dont nous avons parlé jusqu'à présent.

Pline n’a signalé que 94 espèces de Poissons; Linné en a caractérisé tant bien que mal 478; les savants d'aujourd'hui en connaissent plus de 13000 , parmi lesquelles le dixième tout au plus appartient à l'ean donce.... 
Les Poissons ne sont pas dispersés çà et là au hasard. Au milieu des mers, comme sur la terre, la distribution des animaux est soumise à des lois. Poussée par son instinct, chaque race choisit les eaux les plus favorables à son organisation. Beaucoup de Poissons occupent des localités déterminées, et ne peuvent point impunément changer d'habitation. Les uns sont répandus dans de vastes espaces, les antres cantonnés, pour ainsi dire, dans des localités restreintes. Il y en a qui vivent tout à fait à la surface des canx, par exemple lo Chauffe-soleil ${ }^{1}$ des Autilles. D'autres. an contraire, ne quittent pas les profondeurs. An nombre de ces deruiers, citons le Chien de mer, nommé Hexanche ${ }^{2}$ at cause des six fenter respiratoires qu’il a sur les cotés; le Malarmat cuirasse ${ }^{3}$, qui ne sort de ses abîmes qu'à l'époque de la ponte; le Télescope ${ }^{k}$, si remarquable par la grosseur de ses yeux, et le Grenadier ${ }^{5}$, si singulier par la carène de ses écailles. Ce dernier, suivant Risso, vit toute l'année à 1200 mètres de profondeur.

Quelques espèces ne quittent que rarement la vase: par exemple, la Clavelade Cla Pastenague $^{7}$ et la Baudroie $^{8}$.

Presque tous les Poissous marins réclament l'eau salée: c'est pourquoi ils se tiemnent éloignés de l'embouchure des grands flewres. 11 en est, an contraire, qui cherchent de préférence les endroits où il se fait un mélange hahituel d'eau douce et d'eau de mer. Le Muge ${ }^{9}$, la Daurade ${ }^{10}$, le Flel $^{11}$.

\footnotetext{
i Glysiphodon saxatile Cuvier et Valenciennes.

2 Hexanchus griseus Rafinesque.

3 Peristedion cataphractes Lacépède.

4 Pomatomus telescopus Risso.

5 Macropus rupestris Bloch.

- Raja clavata Linné.

- Raja pastinaca Linné.

8 Lophius piscatorius Linné, vulgairement Grenouille ou Diable de mer (Rana piscatrix).

${ }^{9}$ Mugil cephalus Linné, vulgairement Mulet de mer.

10 Chrysophrys aurata Cuvier.

11 Pleuronectes flesus Linné, vulgairement Picaud.
} 

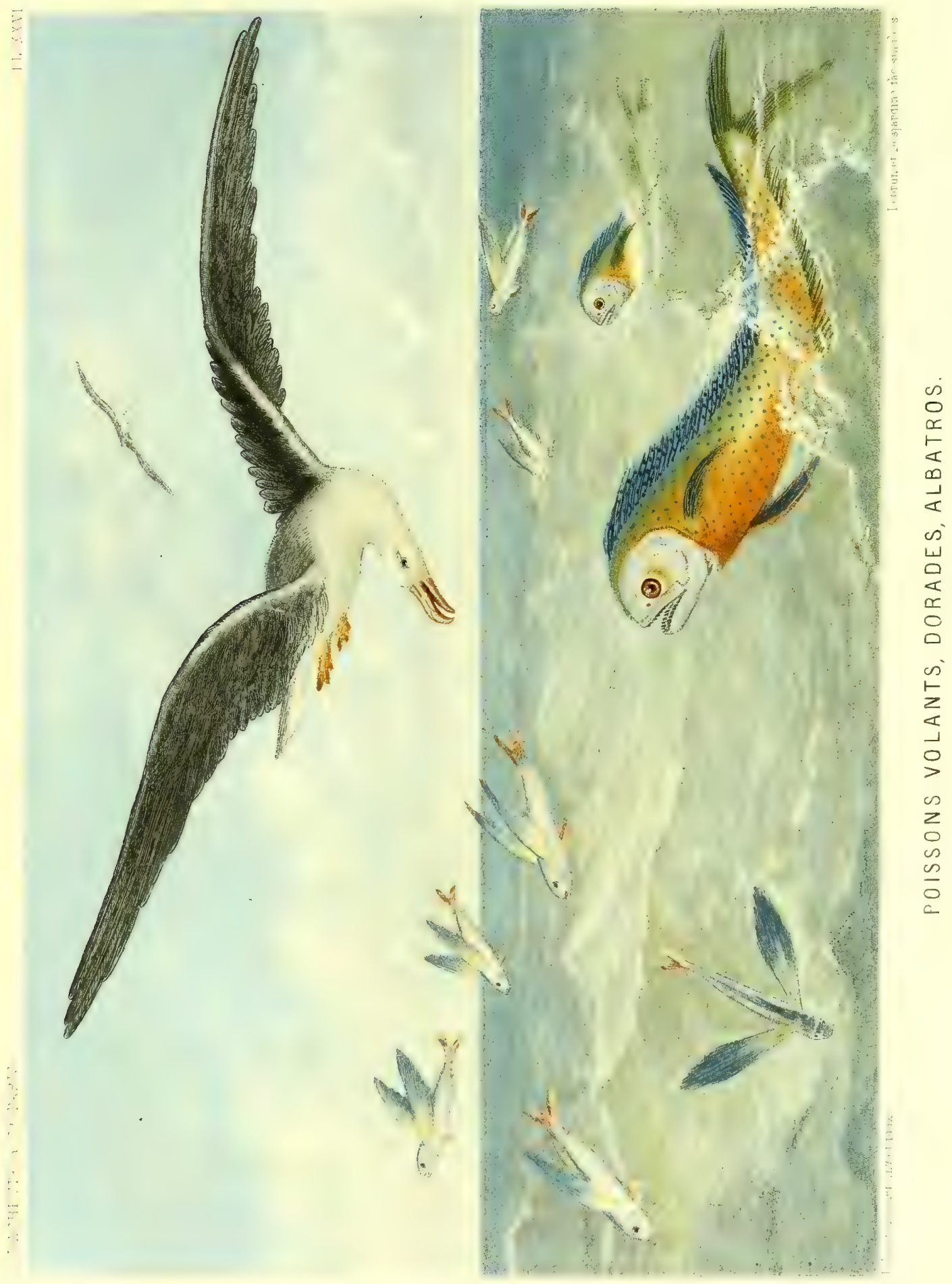

offrent de remarquables exemples de rette nécessité d'un séjour dans un milieu saumàtre.

Certains Poissons vivent à peu près isolés; d'autres se réunissent en troupes innombrables.

Il y en a qui semblent obéir, chaque année, comme les Pigeons et les Grues, a $u n$ instinct d'émigration. Ils se rassemblent par millions, et forment dans ha mer des colonnes épaisses et serrées, longues sonvent de plusieurs lienes.

Les Poissons ont me forme allongée, arnincie en avant

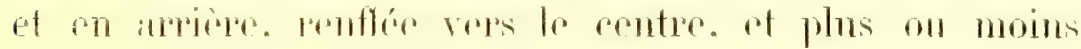

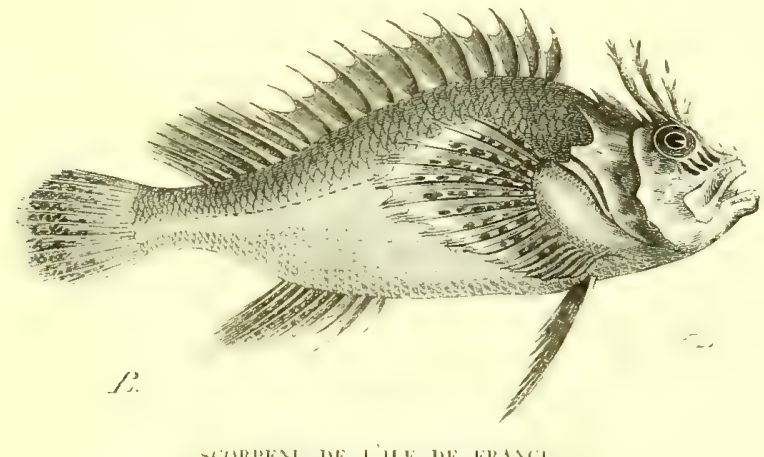

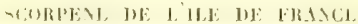

rsconthena nesogallica Cuvicr, Valenciennes.

comprimée. Ils sont admirallement taillés pour l'élément anquel ils appartiennent. Beaucoup ressemblent à des navettes glissantes ou à des fuseaux effilés.

Chez les animaux supérieurs, à organisme très-complexe. la Nature a fort pru modulé les nuances de leur structure intérienre. Il cxistr une parenté bien étroite entre tous les membres de la nombreuse classe des Poissons; leur anatomie varie a peine, quoigue leur physionomie soit souvent très-différente! 
Que ces animaux habitent les profondeurs de la mer, les rochers du rivage ou l'embouchure des cours d'eau; qu’ils soient écailleux ou chaquinés, osseux ou cartilagineux. leur composition organique reste la mème on à peu près la mème, dans ses éléments essentiels. Ils ont tous un fond constant, à travers des milliers de broderies. Ils sont semblables et néanmoins divers. Toujours l'unité et toujours le changement!

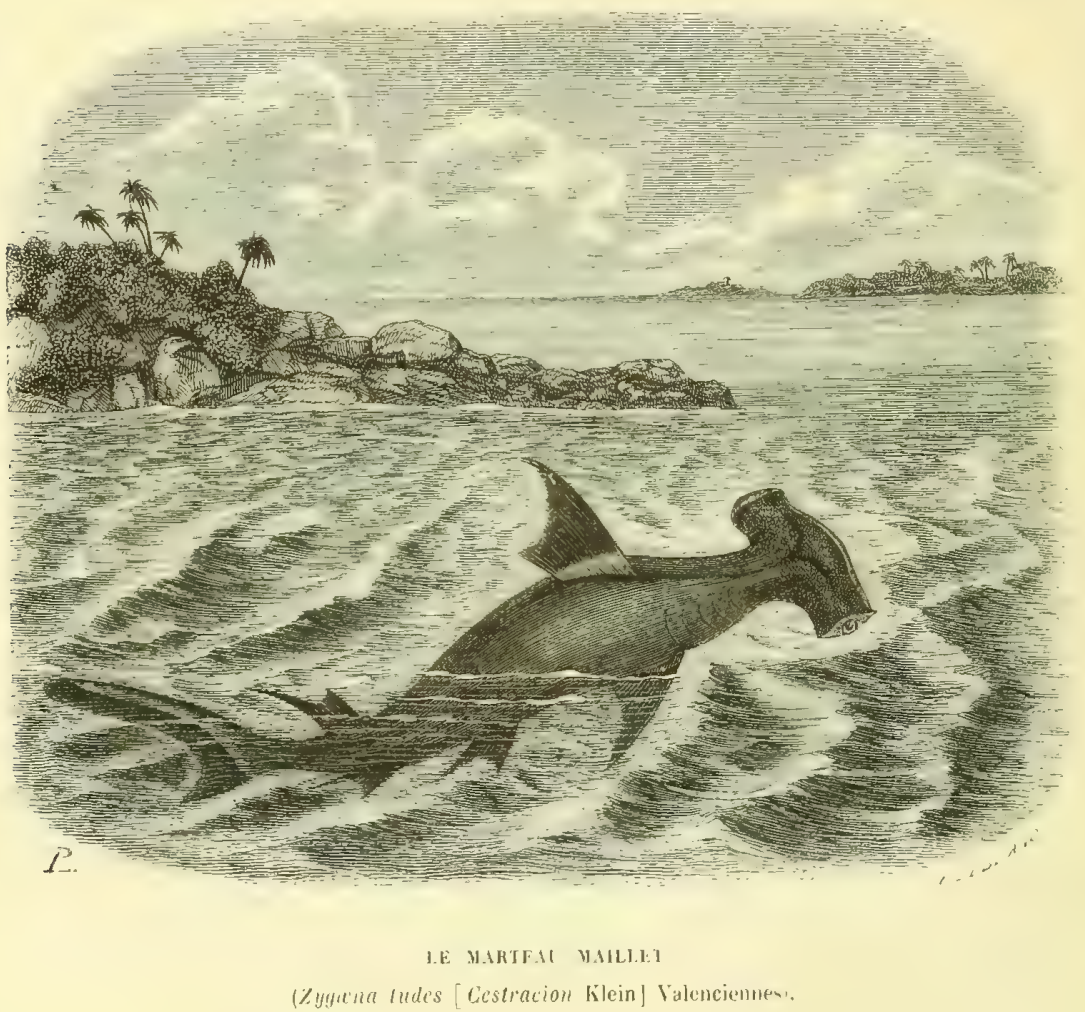

Cependant, dans la classe des Poissons, comme dans les sroupes les plus naturels, on rencontre quelques espèces de forme bizarre, exceptionnelle, et pour ainsi dire anomale. Celui-ci est ventru comme une outre, ou comprimé comme une lame; celui-là ressemble à un marteau. En 
voici un qui parait plus haut que long, avec la bonche an milieu du ventre et des nageoires en croissant. En voilà un autre qui s'allonge en spatule, avec la tête à peine distincte de la queue, et des ouies percées comme les trous d'un flageolet!...

Les Poissons sont couverts d'écailles minces, dures et serrées, nacrées ou colorées, aplaties, carénées ou cise--

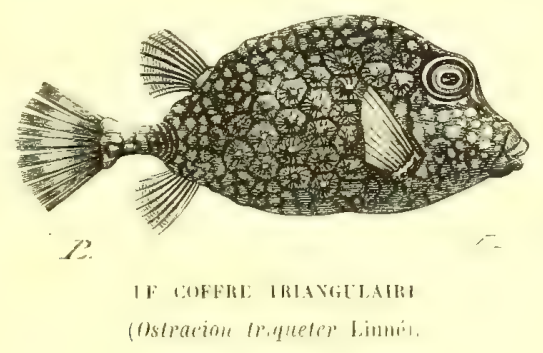

lées, toujours disposées avec symétrie et le plus généralement comme les tuiles, sur un toit. Ces écailles, quelque-

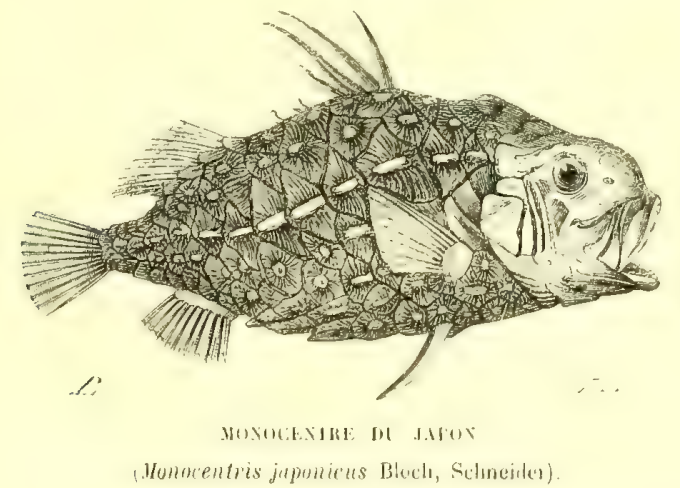

fois très-petites, scmblent ne pas exister dans l'Anguille?. La peau des Poissons est toujours lubrifiée par un enduil visqueux. Leur tissu est pénétré d'une graisse huileuse qui l'empêche d'ètre altéré par l'ean salée.

I Murcena anguilla Tinné. 
Cés animaux présentent les couleurs les phus brillantes et les costumes les plus élégants. Ils ne le cident en rien, pour la beauté de la parure, ni aux Papillons, ni aux Oiseaux, ni aux coquillages si variés de l'Océan.

Les Rougets sont vètus de pourpre. La Coquette ${ }^{1}$ est tachetée de vermillon et de violet. La Jarretière pessembl.

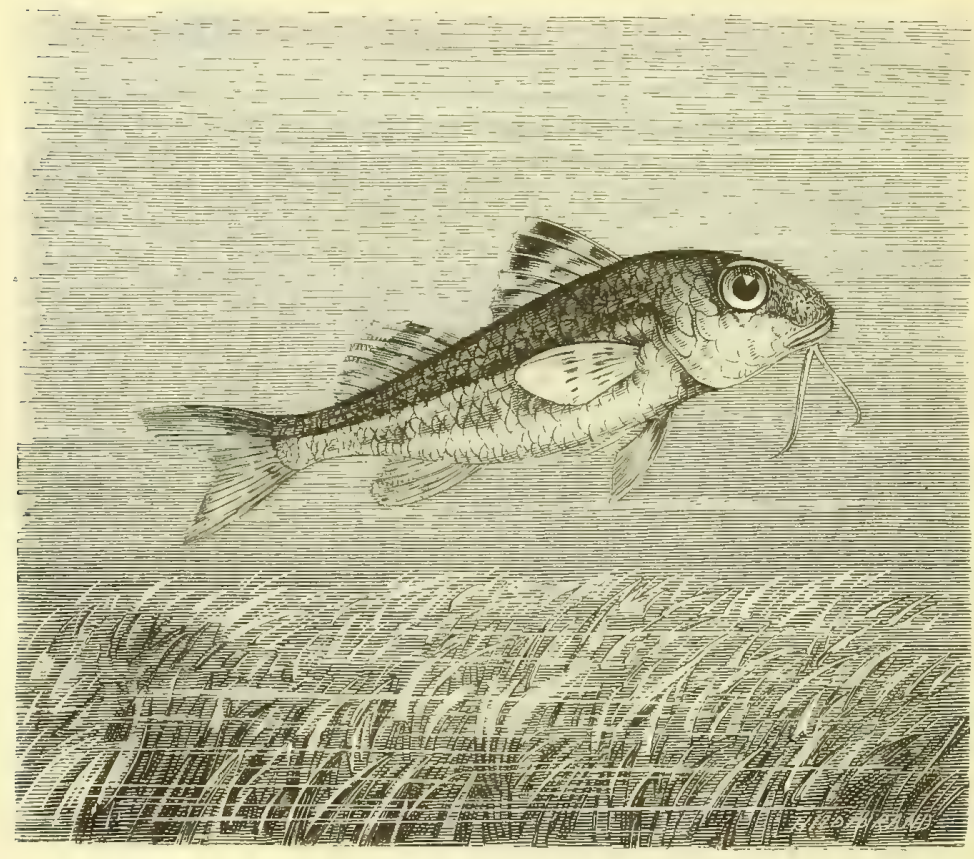

ROUGEI

Mullus bavbutus Linnc,

à un serpent argenté, qui nage par ondulations, réfléchissant des teintes de rose et d'azur. Les Zées sont décorés l'une riche et sompturuse broderie. Les Scares, les Maquereaux, les Daurades, étincellent de l'éclat de J'émeraude, du rubis, de la topaze et du saphir....

1 Holacanthus tricolor Lacépède.

2 Lepidopus argyreus Cuvier. 
Toutes ces couleurs sont souvent distribuces en banderoles flexueuses ou en taches ocellées.

La plupart des teintes, mème les plus vives, paraissent extrêmement fugaces : elles s'affaiblissent quand l'animal devient malade ou vieux; elles se ternissent quand il n'est plus dans son élément; elles se transforment dans l'hiver; elles s'évanouissent au moment de la mort... Les Romains prenaient plaisir à contempler les changements de couleur qu'éprouve le Rouget pendant son agonie (Sénèque).

On assure que certaines espèces phosphorescentes ont été vues distinctement à 7 mètres de profondeur, pendant une mer calme. (Borda.)

Bennet a fait connaitre un Requin remarquable par la phosphorescence d'un vert brillant qui régnait sur toute la partie inférieure de son corps. Un individu porté dans une chambre la remplit de lumière. Le poisson avait un aspect horrible; sa lumière était permanente, mais elle ne paraissait augmenter ni par le mouvement, ni par le frottement. Quand le Requin mourut (ce qui arriva trois heures après sa sortie de l'eau), la lumière du ventre disparut la première, celle des autres parties s'éteignit graduellement; les mâchoires et les nageoires restèrent les dernières phosphorescentes. La seule partie de la surface inférieure du monstre qui ne brilla pas, fut la bande noire de la gorge.

La petitesse des nageoires dans cette espèce est cause qu'elle ne nage pas facilement.

Comme elle vit de rapine et qu'elle est nocturne, Bennet conjecture quavec sa phosphorescence elle fait venir sa proie, comme le pêcheur avec une torche attire le poisson. 


\section{III}

Les Poissons se nourrissent de plantes marines succulentes, de vers, de coquillages et de petits crustacés. Certains mangent d'autres Poissons, et même se dévorent entre eux. Les gros engloutissent les petits, sans respecter

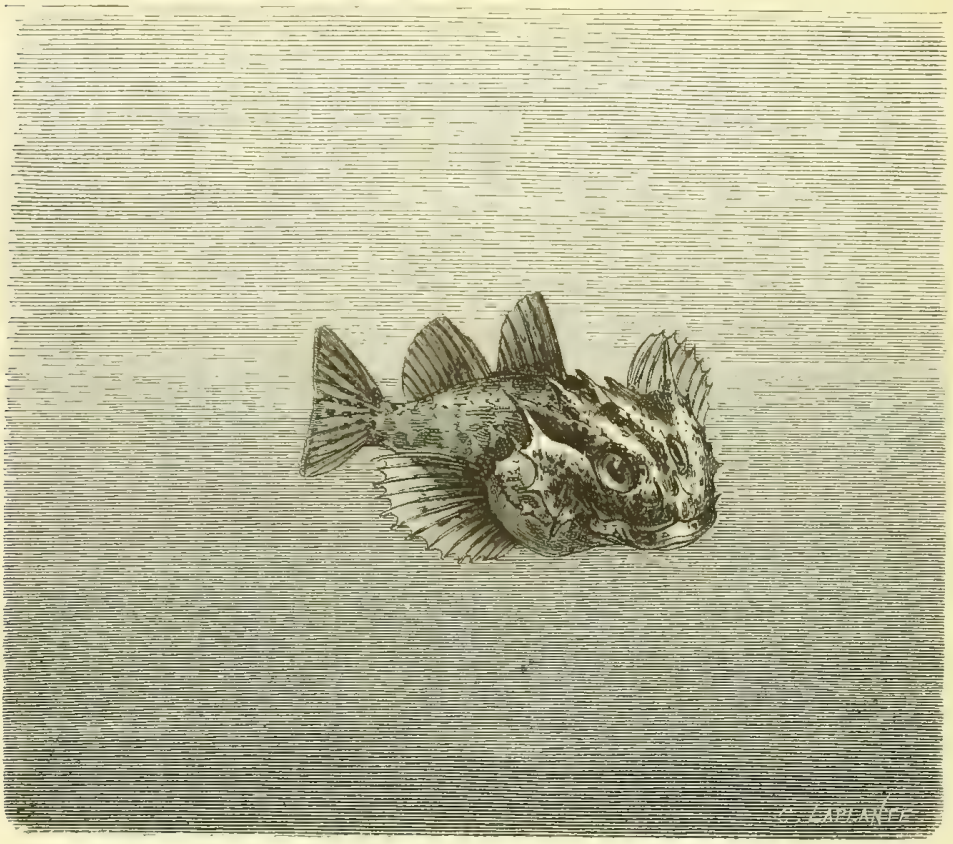

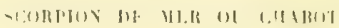

(Collus bubalis Enplupasn.

leur propre espèce, ni même leur famille! En général, ces animaux sont très-voraces; ils avalent les morceaux sans les mâcher, le plus souvent même sans les couper.

Nous avons vu un Chabot qui avait avalé un jeune Rouget une fois et demie plus long que lui. 
Johu Barrow rapporte qu'un Chien de mer harponné près de l'île de Java avait dans son estomac un grand nombre d'ossements, fragments d'une grosse Tortue; une tète de Vache buffle et un Veau.

Brümich, étudiant à Marseillo les Poissons de la Méditerranée, trouva, dans un autre Chien de mer, deux Thons et un matelot tout habillé.

Dans un troisième individu des mèmes parages, l'estomac contenait un soldat avee son sabre.

Müller assure que dans un de ces animaux, du poids de 750 kilogrammes, pris aux environs des îles SainteMarguerite, le tube digestif renfermait un Cheval tout entier! Ce fait est-il bien authentique?

Au combat naval du 12 avril 1782 , le feu ayant pris au vaisseau francais le César, phsicurs matelots qui s'étaient jetés à la mer furent déchirés et dévorés par des Requins rangés entre les deux flottes. Ces monstres marins se disputaient leur proie avec acharnement, sans ètre effrayés par les bordées d'artillerie qui tonnaient des deux côtés. (Ch. Douglas.)

Le père Labat alfirme, de la façon la plus formelle, que les hequins préfèrent la chair des noirs à celle des blancs. ct cela parce qu'elle est plus savomreuse et plus parfumée. II ajoute que les Anglais sont plus prisés des Requins que les Français.

Les Poissons ont des dents non-seulement sur les bords des machoires, mais quelquefois encore sur le palais, dans le gosier et mème sur la langue.

Chez les Mammifères, dit Cuvier, il n'y a que trois os qui puissent porter les dents; chez les Poissons, il y en a huit.

Les dents sont coniques et pointues, ou bieu comprimées et tranchantes, ou bien cucore déprimées et arrondies. 
Cielles de la Raie peprésentent de petites plaques d'ivoire serrées les unes contre les autres, et disposées comme le carrelage d'un pavé. Celles de quelques autres Poissous sont arquées ou recourbées, et ressemblent moins à des dents qu'à des crochets.

Les plus terribles, parmi ces organes, sont peut-être ceux des Loups de mer. Ces dents sont triangulaires, aiguis, tranchantes of quelquefois garnies de denticules sur les bords. Le poisson en possède généralement six rangées. Steller était présent lorsqu'on prit un Loup de mer sur la côte du Kamtchatka. L'animal saisit avec la gueule un levier avec lequel on le frappait, et le brisa comme un morceaul de verre. Schonfeld assure rue ce monstre laisse l'empreinte de ses dents sur les ancres des navires.

Existe-t-il réellement, dans la mer du Sud, des Poissons ¿d dents acérées, qui broutent le Corail comme un monton broute l'herbe?

On connait des Poissons dont les dents nombreuses son! si fines et si rapprochées, qu'en promenant les doigts dessus, on eroit toucher du velours.

Les organes respiratoires ou branchies des Poissons offrent une organisation peu variée. Ce sont généralement des filaments ou petits tubes attachés en séries parallèles it des espices d'ares osseux, comme les brins d'une frange. Chez les Aiguilles de mer ${ }^{1}$ of les Chevaux chenilles ${ }^{2}$, an lieu d'ètre disposés en peigne, ces organes sont groupés en touffes arrondies.

Les orifices des branchies sont les ouies, fermées par les opercules.

Les mouvements habituels de la bouche et des opercules

1 syngnalhus acus.

2 Hippocampus. 
ont donné lieu a l'opinion vulgaine que It Poisson boit constamment de l'eau. De là le proverbe : Altéré comme un Poisson; proverbe absurde, attendu que, lorsque cet animal prend du liquide, il ne boit pas, il respire. (J. Franklin.)

Les brauchies offrent l'admirable propriété de s'enparer d'une quantité d'oxygène d'autant plus considérable, qu'elles fonctionment à une plus grande profondeur. (Biot et Delaroche.)

\section{II}

Les Poissons passent pour muets; cependant plusieurs d'entre eux produisent des sons bien caractérisés. Le Coin-coin' fait entendre un grognement particulier, que II. Valenciennes compare à la voix peu harmonieuse du Canard. La Vieille jette un cri plaintif quand on s'empare d'alle. Les Thons ${ }^{3}$ vagissent comme des cofauts, quand on les tire de l'eau. Le Tambour ${ }^{4}$ fait, en nageant, un bruit étrange qui ressemble au roulement d'une baguette sur nue peau d'âne bien tendue. Ce n'est qu'à l'époque du frai ‘ue ce Poisson se fait entendre; le reste de l'année, il est muet: la basane est détendue.

On a découvert tout récemment en Amérique, dans la baie de Pailou, située au nord de la province d'Esmeraldas, dans la république de l'Équateur, de petits Poissons de couleur blanche, avec quelques taches bleuattres ver's le dos, qui ont non-senlement de la voix, mais une sorte de chant.

II. O. de Thoron longeait un jour une plage, au coucher

"Pristipome anus Valcucienturs.

3 Sromber thynmus Liuné。

2 Ralistes vetula linné.

4 Pogonias chromis Iinne. 


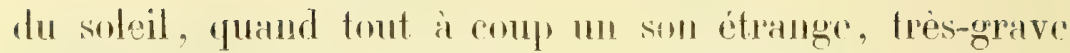
ot tress-prolongé, vint fiapper son oreille. Notre voyagenr crut d'abord an voisinage de quelque insecte de grandeur extraordinaire. Il regarda autour de lui et ne vit rien; il questionna un rameur.

“Monsieur, répondit celui-ci, c’est un Poisson qui chante.

- Comment, un Poisson qui chante!

- Oui, monsieur, un Poisson, un véritable Poisson. Les uns l'appellent Sirène, les autres Musico (musicien). ”

M. de Thoron fit arrêter sa pirogue, pour mieux apprécier le phénomène. Il entendit une multitude de voix qui formaient ensemble un singulier concert.

Ce chant est sonore; il ressemble, à s'y méprendre, aux sons moyens des orgues d'église entendus d'une certaine distance.

Les Poissons chantent sans sortir de l'eau, comme la sirène de M. Cagniard-Latour.... C'est vers le coucher du soleil qu'ils commencent à se faire entendre, et ils contimuent pendant la nuit. La présence des auditeurs n'inlimide nullement ces musiciens d'une nouvelle espèce'. (Thoron.)

Nous ne dirons plus: Muet comme un Poisson!

Les Poissons possèdent des espèces de rames appelées nageoires, qui leur servent à se soutenir dans l'eau et à nager. Le plus grand nombre en ont deux paires : deux devant (pectorales), qui sont les bras, et deux plus ou moins en arriere (abdominales), qui sont les jambes. Quand on redresse l'animal sur sa queue, la seconde paire se trouve placée, le plus généralement, à une certaine dis-

1 Les Nigres croient que ces petits Poissons, quand on les mange, rendent amoureux, au point qu'on aime toujours sans pouvoir jamais guérir. 
tance au-dessous de la première, comme le seraient les jambes postérieures par rapport aux antérieures, chez un Chien roquet qui danse sur ses pattes de derrière. Mais, dans plusieurs espèces, les nageoires abdominales et pectorales sont très-rapprochées, de manière à paraitre les unes au-dessous des autres, quand l'animal est dans sa position habituelle, ou sur le même niveau, quand il est vertical.

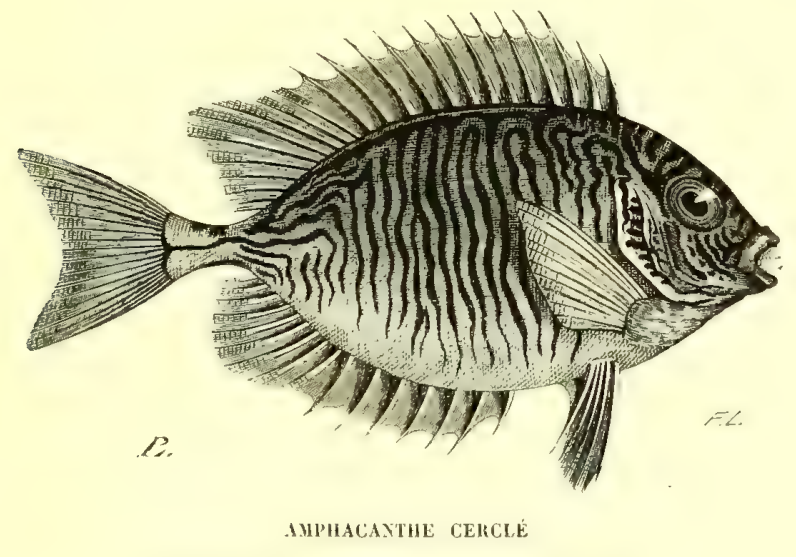

Amphacanthus Wolialus Cuvier el Valenciennes.

Les autres nageoires sont ordinairement impaires : la caudale (c'est-à-dire la queue); l'anale (simple ou double), à la racine de cette dernière, en dessous; et la dorsale (simple, double ou triple), sur le bord supérieur.

Le nombre maximum des nageoires est done de dix : quatre paires et six impaires.

Ces organes ont des rayons plus ou moins nombreux, tantôt durs, tantôt mous, qui représentent les doigts des mains et des pieds.

Les Poissons sont de parfaits nageurs.... Ils savent avancer et reculer sans effort, tourner en tous sens, bondir, s'élancer et s'arrêter brusquement. Les uns, comme de légères bulles d'air, remontent perpendiculairement 
du sein des plantes submergées. Ies autres, comme des corps graves, semblent descendre jusquaux régions les plus profondes. Ceux-ci décrivent une route oblique et tortueuse; cenx-là se balancent mollement a la surface du liquide, comme des navettes d'or et d'argent ou comme des paillons d'acier poli. Tous s'avancent, reviennent, se pressent, se forment en escadrons, s'éparpillent, se réunissent de nouveau, s'égarent, disparaissent, et la trace de feu qu'ils ont laissée scintille encore à nos yeux émerveillés.

L'agitation ef l'inconstance de la mer semblent s'empreindre, sur les ètres qui vivent an milieu de ses ondes, dans la souplesse, la rapidité et la vivacité de leurs allures. Que d'harmonies ravissantes dans le sein de l'Océan!

Quelques Poissons résistent aux vagues les plus fortes; d'autres, au contraire, sont entrainés par les courants les plus légers. On a vu des Bonites ${ }^{1}$ et des Orbes $^{2}$ amenés par le Gulf-stream dans la Nanche, sur la côte du Devonshire.

La queue des Poissons est plus ou moins longue, arrondie, carrée, échancrée on bifide, mais, suivant les espèces, toujours comprimée, c'est-à-dire verticale.

Chez l'Hippocampe, cette nageoire est grèle et susceptible de s'emrouler antour des tiges de Corail ou de Fucus, comme la queue de certains singes autour des branches des forêts. Cette queue est prête à saisir tous les corps ‘u'elle peut embrasser. Lorsque deux Hippocampes se rencontrent étourdiment, ils s'entrelacent souvent l'un l'autre.

Certains Poissons, comme le Grondin, ont des nageoires

1 Thynnus vagans Lesson.

${ }^{2}$ Diodon. 
très-étendues, très-ininces et semblables à des ailes. Ils peuvent même faire de temps en temps des excursions aériennes. Car il existe des Poissons volants, comme il existe des Oiseaux nageurs. Les principaux sont les

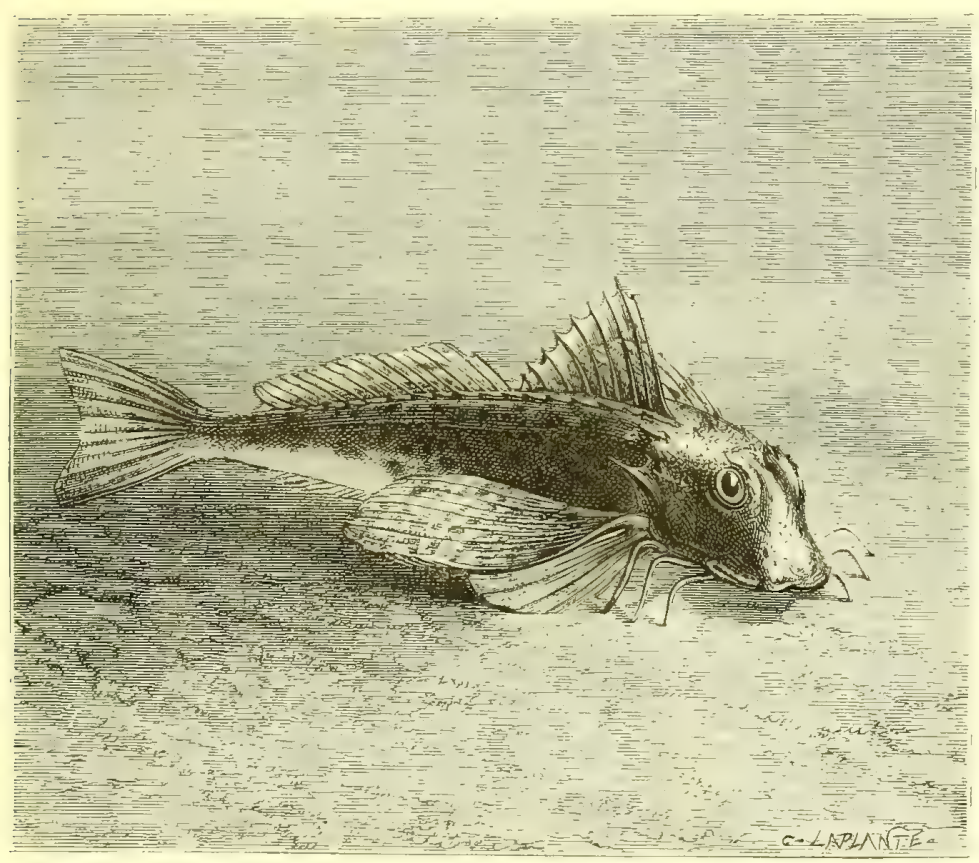

GHOMDIS

(Trigla gurnardus Linne).

Exocets $^{1}$, le Trigle $^{2}$ et la Rascasse ${ }^{3} . .$. C. Ces poissons s'élèvent à un ou deux mètres de hauteur, et parcourent une étendue d'environ 100,150 et même 1000 mètres. Mais bientòt leurs nageoires se dessèchent, perdent leur flexibilité, et l'animal retombe dans la mer. Pauvres Poissons volants! lorsquils sont poursuivis par une Dau-

- Exocetus volitans Iinné, E. evolans Linné, E. exiliens Iinné.

2 Dactylopterus volitans Lacépède.

${ }^{3}$ Pterois volitans Cuvier. 
rade ou par un Dauphin, ils ont beau s'élancer hor's du milieu qu’ils habitent, un Albatros on une Frégate fond sur eux et manque rarement son coup. Danger dans l'eau, danger dans l'air, danger partout : les infortunés échappent difficilement à leur cruelle destinée ${ }^{1}$.

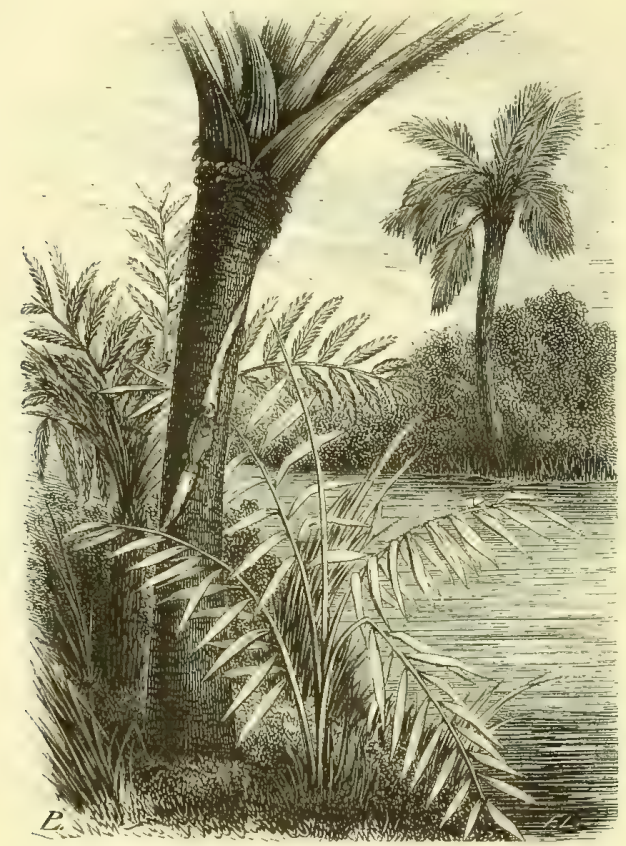

JUISSON SEXYAL SIR I I PALMHER.

Les Trigles milans ${ }^{2}$ offrent l'intérieur de la bouche lumineux. Lorsque, pendant la nuit, une compagnie de ces poissons vole au-dessus de la mer, on croit voir un groupe d'étoiles filantes ${ }^{3}$.

On trouve an Malabar un petit poisson appelé Sennal, qui se donne le plaisir de sortir de l'ean, non pas en

1 Voyez la planche XXVI.

2 Trigla lucerna Linné.

3 Voyez le chapitre V. 
volant, mais en rampant et grimpant le long d'une tige de Palmier. On en a vu s'élever jusqu'à deux mètres de hauteur. Son appareil respiratoire peut retenir une certaine quantité d'eau, et l'animal peut vivre quelque temps dans l'air.

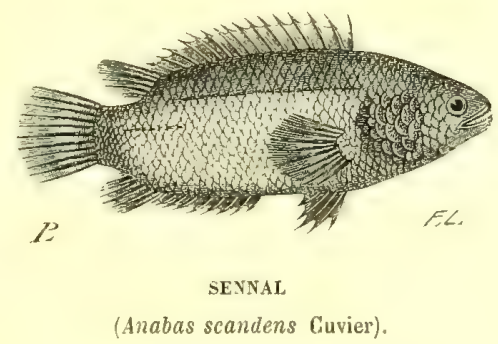

Le Hassar ', de l'Anérique méridionale, quand son marais se dessèche, se met aussitòt en quête pour en avoir un autre. Il fait de longs voyages à terre; il marche toute la nuit. Il se traîne avec ses écailles et ses nageoires. On dit qu'il résiste plusieurs heures au soleil le plus chaud. S'il trouve tous les marais desséchés, il s'enfonce dans la terre humide, comme une Sangsue, et reste enfoui jusqu'au retour de l'ean.

Les Poissons ne manquent pas d'intelligence.

Le Rémore, que les marins français nomment Sucet, porte sur la tête un disque ovale, à bords épais et contractiles et à fond plat, garni de plusieurs rangées de lames transversales, quelquefois denticulées. A l'aide de cette espèce de ventouse, l'animal se fixe aux corps solides sous-marins. II s'attache quelquefois an ventre du Requin,

1 Doras costata Lacépide. 
et se met ainsi sous la protection de ce monstre, qui l'emporte avec lui et malgré lui.

Le Rémore voyage de la sorte rapidement, sans danger et sans fatigue.

Les anciens croyaient que ce bizarre poisson pouvait arrêter dans sa course le plus grand vaisseau ${ }^{1}$. Les rames, les voiles, les flots soulevés par la tempête, rien n'était capable de vaincre la puissance de notre petit animal. Le navire restait toujours à la place où il l'avait fixé. A la bataille d'Actium, le vaisseau d'Antoine fut retenu par cet invisible obstacle, et c'est ainsi qu'Auguste obtint la vic-

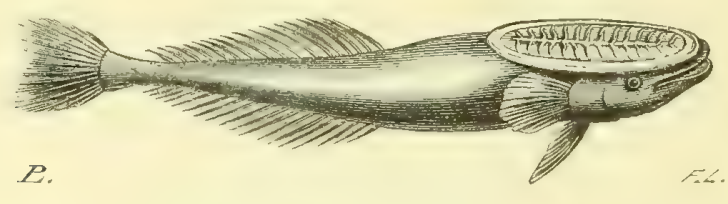

LE REMORE OU SUCET

Evheneis remora Lime

toire et l'empine. Pline rapporte très-sérieusement cette histoire, généralement admise de son temps.

“Que les vents soufflent tant qu'ils voudront, s'écrie le naturaliste romain, que les tempètes exercent leur rage, le petit poisson commande à leur furie et met des bornes à leur puissance ${ }^{2}$.»

Cette fable ridicnle n'était pas la senle, du reste, dont le

1 Ie Rémore, fichant son débile museau

Contre le moitte bord du tempeste vaisseau,

T.'arreste tout d'un coup au milieu d'unc flofte.

(D) B.RTis.)

2 Dy nous en quel endroit, o Rémore, tu caches

L'ancre qui tout d'un coup bride les mouremens

I'nn raisseau combaltu de tous les élémens?

(IDEM.) 
Rémore était l'objet. L'innocente bête passait encore pour entraver le cours de la justice, pour éteindre les feux de l'amour, et pour protéger les femmes dans une situation intéressante....

Les Raies et les Pastenagues se tiennent en embuscade pour saisir les faibles animaux yni nagent sans méfiance au-dessus de leur retraite.

Le Filou' demeure immobile au fond de l'eau; quand il voit un jeune poisson à sa portée, il allonge brusquement le museau, et s'empare aussitôt de l'imprudent.

La Baudroie possède des appendices flexibles, terminés par deux lobes charnus qu'elle laisse flotter, et au moyen desquels elle entraine dans sa bouche béante les poissons inexpérimentés trompés par ce faux appàt. Rondelet rapporte qu'une Baudroie déposée parmi les herbes aquatiques saisit avec les dents la patte d'un jeune Renard, et le retint prisonnier. Que diable ce Renard allait-il faire parmi les herbes aquatiques?

Les Rascasses poursuivent avee audace et déchirent avec acharnement les Morues les plus grosses, même des individus vingt fois plus grands qu'elles. Ce ne sont pas toujours les gros qui mangent les petits!

Le Souffet ${ }^{2}$ de l'Inde, dont le museau est long et tubuleux, quand il découvre une mouche posée sur une des plantes qui croissent dans ses eaux, s'en approche doucement; puis, avec une dextérité surprenante, il lance une goutte d'eau, qui frappe le diptère et le précipite dans la mer.

L'Archer ${ }^{3}$ de Java fait la chasse aux insectes de la même manière, avec la même arresse et le même succès.

\footnotetext{
1 Epibulus insidiator Cuvier.

2 Chelmon longirostris Cuvier.

"Toxotes jaculator Cavior.
} 
La Nature a donné aux Poissons divers moyens pour résister à leurs ennemis. Beaucoup ont le corps cuirassé de plaques osseuses ou garni de crochets pointus. Certains relèvent les piquants de leurs nageoires, et percent vivement la main qui les saisit; d'autres ont le corps tout couvert d'aiguillons, ils s'arrondissent en boule et prennent l'apparence d'un Hérisson contracté.

Ces derniers sont appelés Orbes épineux ${ }^{1}$. Le père Dutertre raconte d'une manière très-naïve comment on les prend aux Antilles : “ La pesche de ce poisson, dit-il, " est un tres-agreable passetemps. (On luy jette la ligne, an " bout de laquelle est attaché un petit ameçon d'acier, cou" vert d'un morceau de cancre de mer, duquel il s'approche " tout incontinent. Mais, voyant la ligne qui tient l'ameçon, " il entre en deffiance et fait mille petites caracolles autour » de luy; il le gouste quelquefois sans le serrer, puis le " lasche tout à coup: il se frotte à l'encontre et le frappe » de sa queuë, comme s'il n'en avoit aucune envie; et s'il " voit que pendant cette ceremonie, ou plustost pendant ") cette singerie, la ligne ne bransle point, il se jette brus" quement dessus, avalle l'amecon et l'appas, et se met en " estat de fuyr. Nais, se sentant arresté par le peschem qui " tire la ligne à soy, il entre en mne telle rage et furie, qu'il ") dresse et herisse toutes ses armes, s'enfle de vent comme » un balon, et bouffe comme un poulet d'Inde qui fait la " roüe. Il se darde en avant, à droite et à gauche, pour " offenser ses ennemis de ses pointes, mais en vain; car, " pendant, s'il faut ainsi dire, qu'il enrage de bon cœur et ") creve de despit, les spectateurs s'eventrent de rire. Enfin, " voyant que toutes ses violences ne luy servent de rien, il » employe les ruses : il besse tout à fait ses pointes, soufle 
" tout son vent dehors, et devient flasque comme un gand ” moïillé: en sorte qu'il semble, qu'au lieu du poisson armé ) qui menaçoit tout le monde de ses pointes, on ayt pris un ") méchant chiffon moüillé. Cependant on le tire à terre, et "alors, connoissant que toute son artifice ne luy a de rien "servy, que tout de bon on a envie d'avoir sa peau, et ") que desjà il touche le roch ou le gravier de la rive, ' il entre en de nouvelles boutades, fait le petit enragé, ") et se démene estrangement. Se voyant à terre, il herisse "tellement ses pointes, qu'il est impossible de le prendre " par aucune partie de son corps, si bien qu'on est contraint " de le porter avec le bout de la ligne un peu loin du " rivage, où il expire un peu de temps après. "

Dans l'Espadon ', la mâchoire supérieure est prolongée en forme d'épée on de broche aplatie, sorte de machine de guerre horizontale, puissante, terrible, avec laquelle lo poisson peut attaquer les plus grands animaux marins. Les coups qu'il porte sous l'eau, contre les navires, sont assez forts pour en percer les bordages. On possède, au Musée royal de Londres, un fragment de carène traversé par l'épée d'un Espadon.

La Scie ${ }^{2}$ offre en avant du museau, non plus un glaive, mais, comme son nom l'indique, une véritable scie. C'est une lame longue (quelquefois de trois mètres), large, extrêmement dure, armée sur les deux bords d'épines osseuses un peu écartées, très-fortes et très-pointues. Ces épines sont implantées dans les alvéoles et ressemblent à des dents, mais elles n'en ont pas la texture. (Les vraies dents de l'animal se trouvent sur ses mâchoires; elles ressemblent à de petits pavés.) Avec ce terrible instrument, lo

\footnotetext{
- Xiphias gladius Cuvier.

2 Pristis antiquorum Latham.
} 
monstre réussit à déchirer le ventre des Baleines ou les flanes des Cachalots... Quelles affreuses blessures!

Le Chirurgien ${ }^{4}$ et le Docteur ${ }^{2}$ présentent aussi une arme dangereuse pour attaquer et se défendre, mais cette arme se trouve à la queue et non à la bouche; elle est petite. C'est une sorte de lancette.

Enfin, plusieurs espèces sont armées d'un appareil arlmirable, avec lequel elles peuvent atteindre au loin, par une puissance invisible, et frapper avec la rapidité de l'éclair. Nous voulons parler des Poissons électriques, dont le phus conmu est la Torpille ${ }^{3}$, poissons qui semblent avoir dérobé au ciel, et transporté sous l'eau, une étincelle du majestueux météore qui éclate dans les airs.

\section{VI}

La Providence semble laisser an hasard, chez les Poissons, la reproduction do l'espece, et pourtant tout est si bien disposé, que le grand but ne manque jamais d'etre atteint.

A l'époque de la reproduction, les femelles s'approchent du rivage et des grèves sablonneuses exposées au soleil. Elles y pondent leurs cufs. Les mâles arrivent peu do temps après et les fécondent.

Pour que le vœu de la Nature s'accomplisse, il n'est pas nécessaire que ces derniers aient aucun rapport direct avec les femelles. Cihez la plupart des espèces, les deux sexes ne se voient pas, peut-ètre même ne se sont-ils jamais vus. Par conséquent, ils ignorent tout à fait les tendres sentiments! A quoi leur servirait l'affection sexuelle? Sous er rapport, les Escargots nous semblent plus heureux ${ }^{4}$.

1 Acanthurus chirurgus Bloch.

2 Acmilhumes caruleus Blo'h.
3 Torpedo Galvanii Hisso.

4 Voyez le chapitre XXIII, \$6. 
Chez les Épinoches ${ }^{1}$, les choses se passent un peu différemment. Quoique ces poissons appartiennent à l'eau douce, nous devons dire quelques mots de leurs allures. Le mâle, revêtu de sa livrée d'amour, construit un nid avec des racines, des herbes et des fibres végétales artistement entrelacées. Ce nid a deux portes. Lorsqu'il est prêt, l'Épinoche appelle une femelle, l'encourage à le suivre. Si elle oppose quelque résistance, il la saisit par une nageoire et l'entraine violemment. Il la fait entrer dans le domicile conjugal, la surveille pendant qu'elle pond, et puis la chasse par la seconde porte. Alors il entre lui-mème dans le nid pour arranger et féconder les œufs, glisse et reglisse par-dessus en frétillant; les quitte pour réparer le dégât fait à la couchette; puis court chercher une autre femelle près de pondre, et répète lc mìme manége jusqu'à ce que le berceau soit suffisamment rempli. Alors il ferme la seconde ouverture et ne laisse qu'une porte. Il demeure en sentinelle près des aufs, pour les défendre contre les autres Einoches. Suspendu verticalement au-dessus du nid, le museau à l'entrée, il agite l'eau sans cesse avec ses nageoires. Il parait content, mais il est trop inquiet pour avoir m bonheur parfait.

Guillaume Pellicier, évèque de Montpellier, avait reconnu, il y a bien longtemps, que les Gobies et les Hippocampes ont aussi l'habitude de construire des nids pour recevoir leurs aufs.

Certains Poissons ne peuvent pas frayer au milieu des eaux salées. Ils se rendent dans les fleuves, ainsi que dans leurs affluents. Ils ont la faculté de nager contre le courant; ils courent en arrière. Les plus célèbres sont les Esturgeons", qui abandoment la mer, et particulieremont

1 Gasterosteus aculeatus I.inn:.

"Acipenser Linnó. 
la mer Caspienne et la mer Noire, où ils vivent en troupes nombreuses, pour gagner les eaux douces du Volga et du Danube; les Aloses $^{1}$, si recherchées pour la table quand on les prend à l'époque de l'émigration, et si peu estimées au contraire au moment de leur retour; et les Saumons, qui remontent les fleuves et les rivières, et vont le plus près possitble des sources, franchissant, à l'aide d'une force musculaire excessive, des obstacles en apparence insuımontables.

Poussés par un instinct analogue à celui qui ramène les

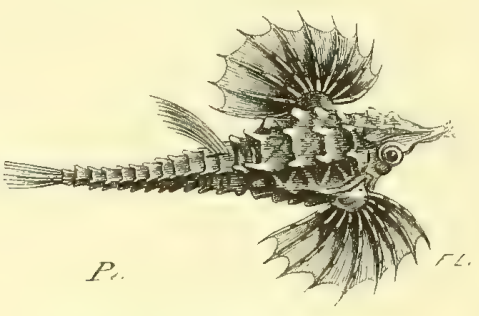

PÉGASE VOLANT

(Pegasus volans Liune, Gmelin).

Ilirondelles à leurs nids, ces poissons reviennent chaque année dans les mêmes eaux, après être retournés à la mer. (A. Duméril.)

Deslandes, commissaire général de la marine, ayant acheté douze Saumons aux pêcheur's de Châteaulin, près de Brest, leur mit un anneau de cuivre à la queue, et leur rendit la liberté. Les années suivantes on en reprit quelques-uns.

Les Poissons sont d'une fécondité excessive. Leur multiplicité dépasserait tout ce qu'on peut imaginer, si mille causes de destruction ne s'y opposaient pas. Un nombre immense de germes périssent avant leur éclosion. Les courants les dispersent, les tempêtes les meurtrissent, le soleil

1 Clupea alosa Linné. 

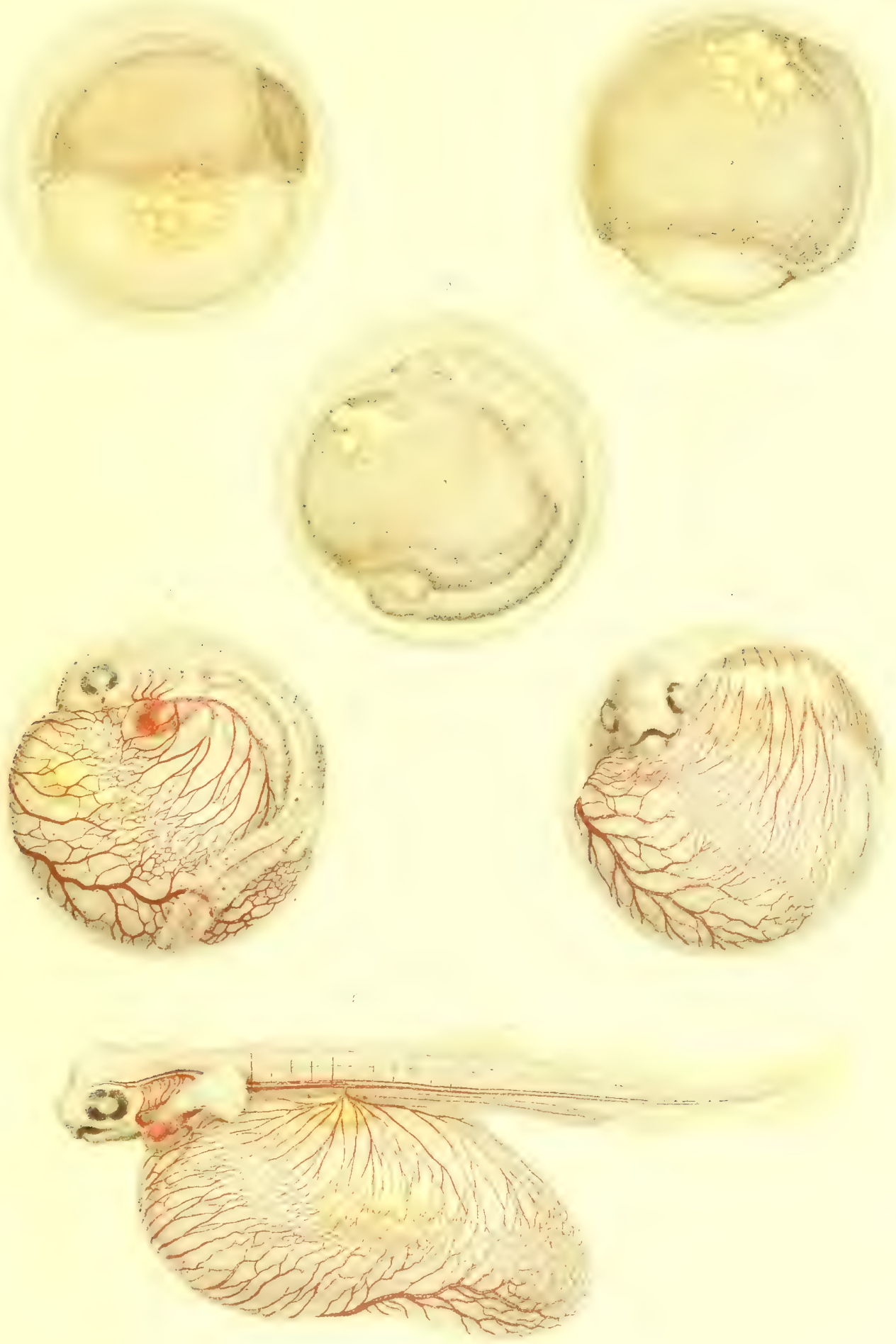

DÉVELOPPEMENT D'UN POISSON

1. Apparition de la tache embryonnaice. 2. Premiors linéaments de l'embryon

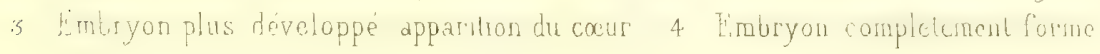
5. Embryon prét à éclore. 6. Embryon éclos. 

les dessèche. A peine un pour cent, parmi ces aufs, produisent-ils une créature vivante. Des milliers de petits sont dévorés; des fuantités considérables d'adultes servent de nourriture à d'antres Poissons, à des Oiseaux, à d'autres animaux marins et à l'Homme lui-même....

On a trouvé par le calcul:

Chez un Rouget ${ }^{1} \ldots \ldots . . . .881586$ œufs.

Chez une Sole ${ }^{2} \ldots \ldots . . . . . . .100362$

Chez un Maquereau ${ }^{3}$. . . . . . . . 546681

Chez une Carpe de 45 centim., 600000 à 700000

Chez un Esturgeon pris à Neuilly. . . . 1467856

Chez une Plie ${ }^{5}$ de 30 centimètres. . . 6000000

Chez un Turbot ${ }^{6}$ de 50 centimètres. . . 9000000

Chez un Muge à grosses lèvres ${ }^{7}$. . . . 13000000

Après la ponte ${ }^{8}$, l'œuf devient plus transparent, et l'ou voit apparaitre sur un point de la surface du globe intérieur, au milieu d'un amas de gouttelettes d'huile, une petite tache circulaire blanchàtre. Chez les Poissons d'été, une heure ou deux suffisent pour que cette tache, qui représente le germe, se réalise; tandis qu'il en faut huit ou dix chez les Salmonidés. Puis on voit ce germe s'affaisser, diminter d'épaisseur, mais en mème temps s'agrandir et se trausformer en membrane. Son extension augmente de plus en plus, envahit le tier's, la moitié, enfin la totalité du globe intérieur de l'ceuf. En même temps l'embryon se manifeste sous la forme d'une ligne blanchâtre occupant un quart de la circonférence de l'ouf. Plus tard, les formes du jeune Poisson se dessinent à travers la membrane externe, et les yeux apparaissent comme des points noiràtres.

1 Mullus barbatus Linné.

2 Solea vulgaris Cuvier.

3 Scomber scombrus Linné.

4 Cyprinus carpio Linné.
5 Platessu vulyaris Cuvier.

6 Rhombus maximus Cuvier.

" Mugil chelo Cuvier.

8 Voyez planche XXVII. 
Enfin, les aenl's ne tardent pas à éclore. Il f'ant me semaine d'incubation dans la Carpe, une vingtaine de jours chez l. Brochet, et deux ou trois mois chez la Truite et le Saumon.

La plupart des Poissons blanes se dispersent presque aussitòt nés. Les Salmonidés portent, au sortir de l'cenf, nuc énorme vésicnle, qui les rend incapables de se soustraire par la fuite à la voracité de leurs enmemis; ils se retirent à l'abri de la vive lumière, et se nourrissent des éléments renfermés dans leur énorme poche abdominale. Vers la cinquième ou sixième semaine, cette poche abdominale a disparu, et le jeune Poisson est semblable à ses parents.

Ordinairement la mère ne prend ancun soin des petits. II y a peu d'exceptions à cette règle.

On cite comme exemple du contraire le Hassar', dont nous avons déjà parlé. Cette espèce construit un berceau qu'on a comparé au nid de la Pie. Il est arrondi, un peu aplati vers les pôles, et disposé de manière que sa partie supérieure arrive jusqu'à la surface de l'eau. L'orifice est petit : il a juste ce qu'il faut pour laisser passer une femelle. Celle-ci veille, avec le soin maternel le plus actif, juscu'à la sortie des petits.

Quand on veut prendre ce poisson, on place un panier devant son nid; on frappe légèrement sur ce dernier. Le Hassar, en colère, hérisse ses piquants et sort à l'iustant de la couchette; il se précipite dans le panier. (R. Schomburgk.)

Le père poisson, qui montre quelquefois tant d'affection pour les ceufs à une époque où ils ne sont pas encore vivifiés, et où, par conséquent, il n'est pour rien dans leur organisation, ne regarde plus ces mêmes aufs, fécondés par lui, quand ils éclosent, et les jeunes poissons, ses propres enfants, quand ils sont nés! O bizarrerie de la pateruité! 
Un assure cependant que l'Épinoche màle, après avoir courageusement protégé son nid et les cuffs de ses fémelles, prend soin des petits qui vienuent d'éclore. Il les défend comme une Poule défend ses poussins, les empêche de sortir du berceau pendant les premiers temps, et leur apporte progressivement une nourriture convenable.

On dit aussi que l'Aiguille de mer mâle ${ }^{1}$ présente sous la queue deux appendices mous, qui peuvent former une poche en se rapprochant. Il enferme dans cette poche les rufs de sa femelle. Ces oufs sont ainsi soumis à une sorte d'incubation. Au mois de juin, les petits éclosent et quittent la bourse; mais ils suivent leur père. Toutes les fois qu'un danger les menace, ils retournent chercher un refige dans la poche protectrice, comme font les jeunes Kanguroos de la Nouvelle-Hollande dans la poche maternelle. Mais, chez notre petit poisson, c'est le mâle qui est la mère.

Il ne faut pas croire, avec Plutarque, que le Requin ne le cède en bonté paternelle à aucune créature vivante. L'illustre historien dit que le père et la mère se disputent le soin d'alimenter leurs tendres nourrissons et de leur apprendre à nager, et quils les regoivent dans leur gueule protectrice, quand il survient quelque ennemi.

Il est heureux que le bon Plutarque ait été plus exact sur les faits et gestes des grands hommes que sur les habitudes des Requins.

\section{VII}

La mer est une abondante source de productions pour les population des còtes. Elles puisent dans son sein les éléments de leurs richesses. La ligne ou la drague, le filet flottant

1 Syngnathus acus Linné, vulgairement Poisson tube. 
ou le chalut', tout est bon pour retirer du sombre abime le corpuillage ou le poisson qui peut être de quelque utilité ou de quelque agrément.

Les gouvernements ont dû mettre un frein à cette sorte de pillage, et protéger les populations contre elles-mêmes. Mais en même temps qu'on réglait les moissons marines, on a cherché à les multiplier par la pisciculture.

Cet art a une origine très-ancienne. Les Chinois le pratiquent depuis un temps immémorial; les Romains le faisaient servir à leur amusement et au luxe de leur table.

(1) retenait prisonniers dans des piscines les poissons qu'amenait la marée montante, ou que les pècheurs rapportaient de leurs courses. On les élevait, on les engraissait comme les bestiaux de nos étables. On obtenait ainsi des élèves excellents et très-recherchés.

Cette sorte de parcage est pratiqué de nos jomrs sur des points nombreux de la côte où la montée du poisson est abondante. Lindustrie du lac Comacehio est l'une des plus considérables.

Iu milieu du $x_{\text {vn }}{ }^{\mathrm{e}}$ siècle, une découverte vint transformer la pisciculture.

On savait que les Truites et les Saumons, quand vient l'époque de la ponte, remontent les ruisseaux qui roulent une eau limpide sur nu fond de gravier; y choisissent une place où ils s'arrètent; écartent les pierres avec leur tête et leur quèue, les rangent de manière à former des espèces de digues qui puissent faire obstacle à la rapidité du courant, ct daus les interstices desquelles leur progéniture se trouve à l'abri. C'est lì, en effet, que la femelle dépose ses oufs. Les uns s'arrêtent sous un caillou, les autres sous un coquillage ou tont autre abri, jusqu'à ce que toutes les 

anfractuosités du lit qui a été préparé pour eux en soient garnies. Dans cette position, le choc continuel de l'eau ne peut les emporter, mais il les conserve dans un état de propreté indispensable à leur développement ultérieur. On savait encore qu'au moment où la femelle vient de pondre, le mâle verse sa laitance sur les oufs, et que cette laitance, entraînée par le liquide qui lui sert de véhicule, passe sur eux comme un nuage bienfaisant, les imprègne, leur communique la propriété de se développer, et se dissipe après avoir troublé la transparence de l'eau. (Coste.)

Le savant naturaliste Jacobi eut l'idée d'imiter dans un ruisseau artificiel ce que tous les jours il voyait se passer normalement dans la nature; il alla plus loin : il comprit toute la portée industrielle de sa découverte, et démontra, par des essais d'une précision et d'un bon sens pratique admirable, l'excellence des résultats.

C'est dans le Hanovre, près de Nortlem, que ces premiers essais furent tentés. Ils devimrent la source d'un commerce important. L'Angleterre accorda une récompense publique à leur auteur.

Dans ces dernières années, à l'occasion d'une réclamation de priorité à l'Académie des sciences, on apprit que, dans une des vallées les plus reculées de la chaine des Vosges, un pècheur de la Bresse, doué d'un remarquable esprit d'observation, et voulant porter remède au dépérissement de son industrie, avait passé plusieurs années de sa vie à refaire laborieusement la série des procédés de la fécondation artificiclle. La nouvelle de cette application laite pour la première fois en lirance avec plein succès eut un grand retentissement.

On se demanda si l'on n'était pas en droit d'espérer le repeuplement des rivières et des lacs, et si l'on ne pourrait point étendre la main sur les champs inexplorés de la mer. 
Un savant que sa position et ses travaux d'embryogénie comparée appelaient, tous les ans, à exposer dans ses cours les principes sur lesquels repose la nouvelle méthode, couconrut puissamment à sou organisation naissante, en lui accordant un bienveillant patronage ef mettant à son service les laboratoipes du Collége de France. Ciest dans ces laboratoires que furent construits et perfectionnés les modèles de tous les appareils de pisciculture cnvoyés par les diffé-

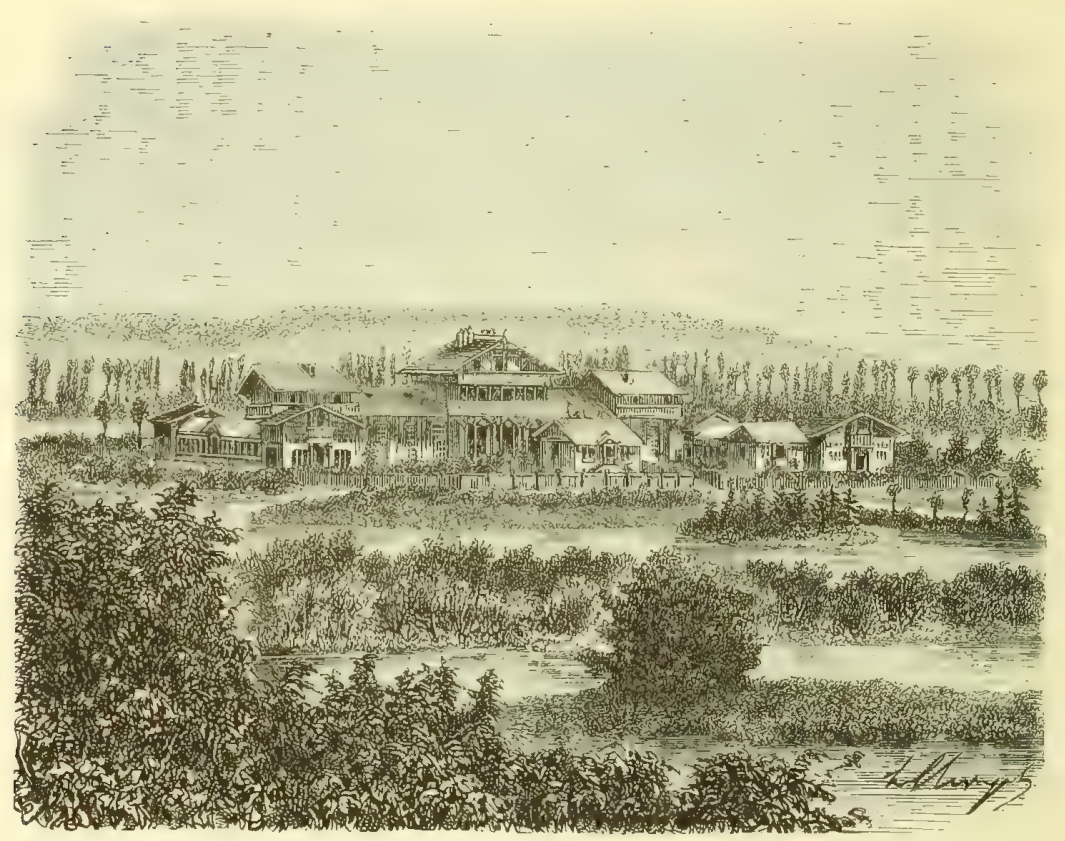

VUE GEXERALE DE L'ÉTABLISSEMENT D'HUNTYGE.

rents pays à lit demiere exposition de Londres (Coumes).

II. Coste fit ressortir de quelle utilité serait pour les populations l'ensemencement des eaux, et éleva la question à la hauteur d'un intérêt public (Coumes).

Sur sa proposition, fut décrétée la création de l'établissement d'lluningue pour la pisciculture d'eau douce, et 
des viviers laboratoires de Concarneau pour l'étude des animaux marius.

L'établissement d'Iluningue est un vaste appareil d'éclosion. Des bâtiments considérables contiennent les auges d'incubation, et les bassins pour recevoir les jeunes nouvellement éclos. Des réservoirs extérieurs sont destinés à la stabulation de l'alevin et à son acclimatement aux intempéries de l'atmosphère.

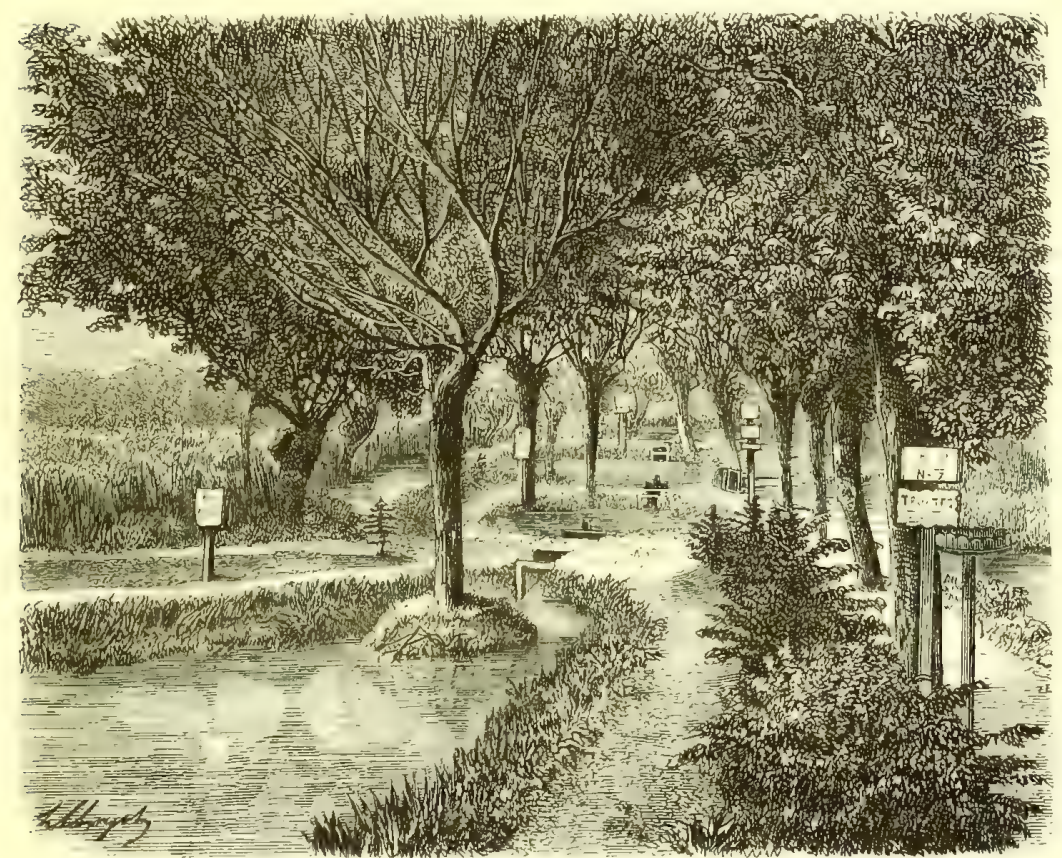

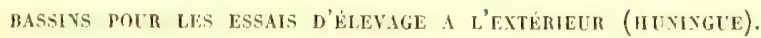

Cet établissement distribue un grand nombre d'oufs et de jeunes dans les lacs et les rivières de la France et des pays voisins. Son utilité est si générule, que sil construction a été suivie de constructions semblables à l'étranger.

Les viviers de Concarneau sont des laboratoires où la science et la pratique se prêtent un mutuel appui dans l'étude des animaux marins. 
Des bassins sont réservés pour les animanx eu expérience; d'autres, plus spacieux, servent au parcage des Crevettes, des Langoustes et des Itomards, qui doment lieu à un commerce considérable. Des aquariums nombreux contiennent une grande variété d'animaux. On voit se développer, dans cette maison transparente, les moindres particularités

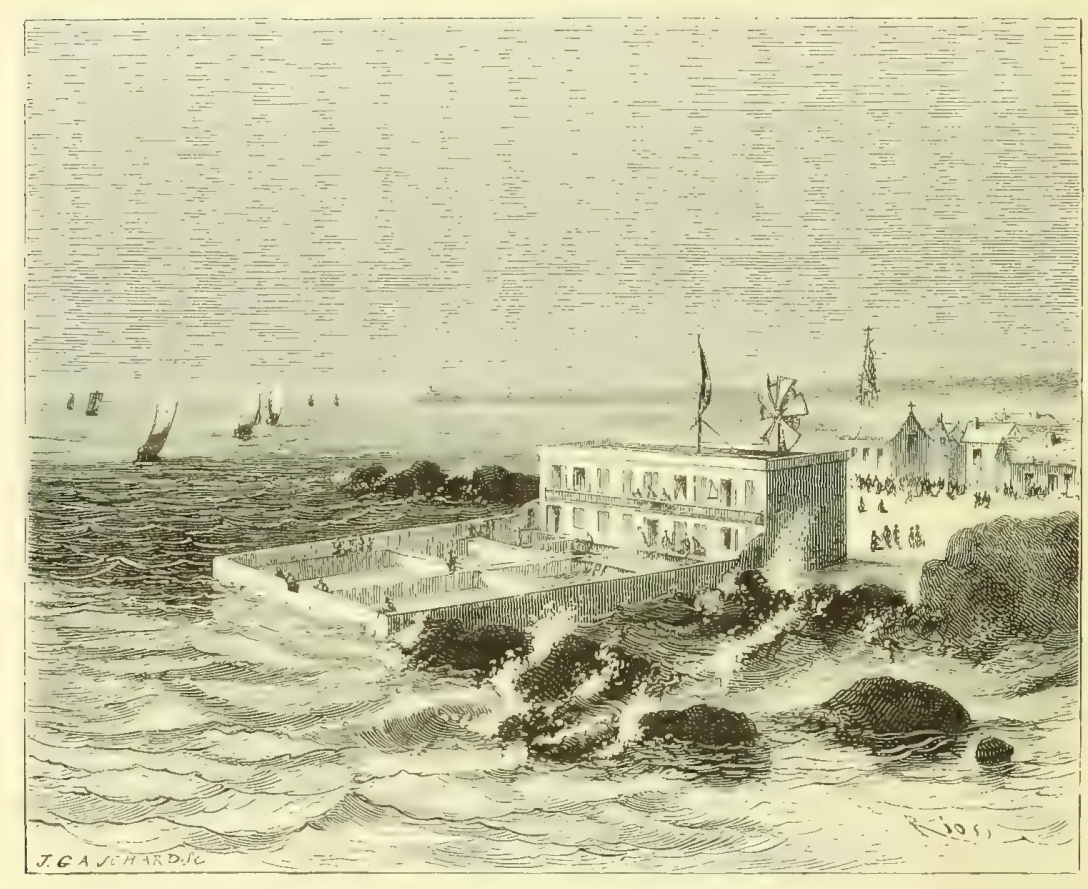

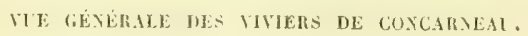

de la vie marine; Lucine elle-même n'a plus de mystère.

On y est témoin de la voracité des Vieilles et des Turbots, des Poulpes et des Sìches. On y voit la délicate opération de la mue des Homards et des Langoustes; l'accouplement des Aplysies, l'incubation des Plies toutes rondes de frai; la ponte pénible du Chat de mer, qui attache ses dix-huit œufs, par leurs longs filaments contournés en vrille, aux Goëmons et aux rochers, où ils seront 
retenus tout le temps que durera le travail enbryonnaire. Enlin, on assiste a l'areonchement laborieux des Syngnathes

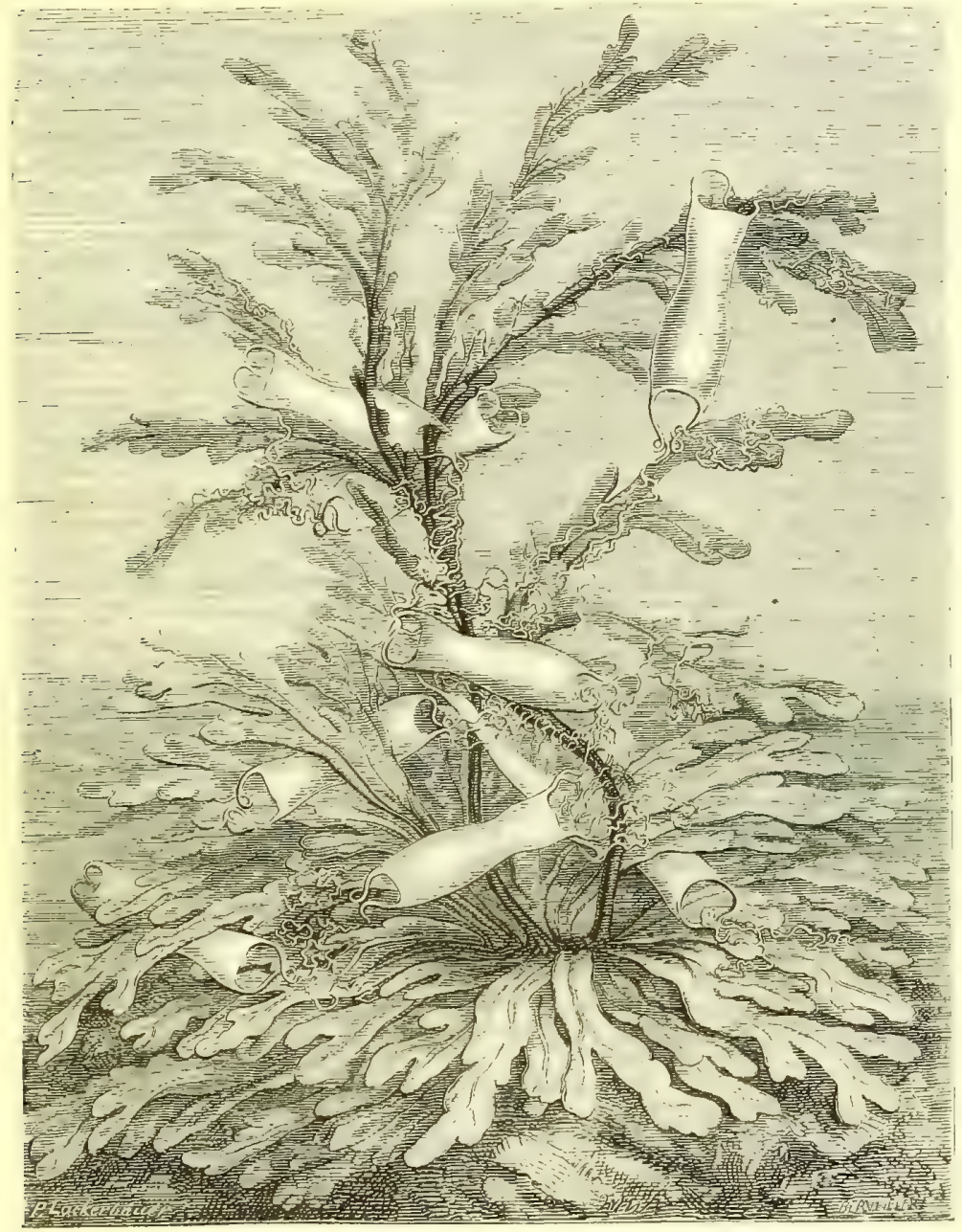

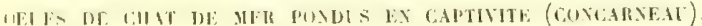

(Ślualus cululus Linné).

et de l'llippocampe. Rien de phus arieux que de voir cette pauvre bète fixée par l'enroulement de sa queue à une branche de Gorgone, tantrit noire, tantôt verte, tantòt pâle de douleme, donner suressivement naissance, par inter- 
valles irréguliers, à plus de cent cinfuante petits, qui, aussitôt nés, se mettent à nager dans toutes les directions, emportés par leur caprice ou leur étourderie, indifférents aux souffrances de leur mère; tandis que le mâle, tournant autour de sa femelle, la caressant, l'entourant de sa queue, imite ses attitudes et ses changements de couleur, comme pour lui témoigner sa sympathie pour tant de souffrances.

Sous la haute direction et la puissante activité de l'inspecteur général des pêches, s'accumulent des matériaux considérables pour l'histoire des animaux et pour le progrès de la pisciculture marine. (L. Soubeiran.)

Ce n'est que par l'observation et l'expérience que l'on peut comnaitre les mours et les habitudes des Poissons, et que la science, mieux informée, fournira les données nécessaires pour concilier les intérêts de la reproduction des eaux avec ceux de la libre pratique, les exigences de l'industrie avec les besoins permanents du repenplement.

On ne verra plus détruire par centaines de millions (Coste) ces tourbillons de jeunes poissons de toute espèce, qui surgissent sur les plages vers le mois d'avril. Ces générations nouvelles descendront dans les vallées sousmarines pour aller s'y transformer en troupeaux de grande taille, ou seront retenues dans des viviers-pares, où on les contraindra suivant qu'on les nourrira en liberté ou en prison cellulaire, à grandir soit en longueur, soit en épaisseur, comme le Beuf et le Mouton que l'art faconne dans nos étables, comme le Turbot que l'on voit engraisser dans les viviers-laboratoires de Concarneau. (Coste.)

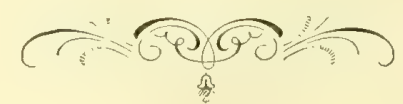




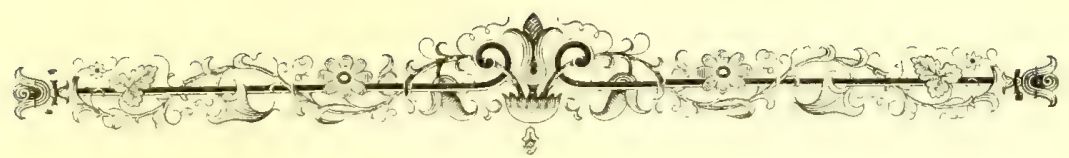

\section{CHAPITRE XXXVI}

\section{LE HARENG。}

\footnotetext{
"Millions de millions, milliards de milliards, qui osera hasarder de deriner le nombre de ces légions?»

(Michelet.)
}

"Moïse était un pêcheur à la ligne. Jésus-Christ a choisi la plupart de ses apôtres parmi de simples pêcheurs, et n'a jamais blâmé leur occupation; tandis qu'il a condammé celle des scribes et des changenrs d'argent. Après sa résurrection, quand il revit plusieurs de ses disciples, il les retrouva pêchant, et se garda bien de les gronder. » (J. Walton.)

La pêche est donc une industrie fort ancienne et fort honorable.

Si Moïse revenait sur la terre, il trouverait le nombre des pêcheurs à la ligne prodigieusement augmenté et leur art singulièrement perfectionné. Nais il verrait, en même temps, d'autres genres de pêche plus ingénieux, plus rapides et surtout plus lucratifs....

On assure que les piecheurs d'Angleterre retirent anmuellement, de l'Océan, une richesse de plus de 60 millions. Noùs n'avons pas de peine à le croire. En 1857, la seule ville do Paris a consommé pour 9169397 francs de marée! 
Parmi les bienfaits alimentaires les plus précieux que nous devons à l'eau salée, on doit ranger les Harengs.

Tout le monde connait ces poissons. Il n'est personne qui n'en ait yu, sinon vivants et dans la mer, du moins desséchés et dans des tonnes, à l'état de momies dorées, enfumées, entassées, symétrisées.

Les Harengs sont des Poissons sociaux et voyageurs, qui se réunissent en bandes nombreuses et serrées, les-

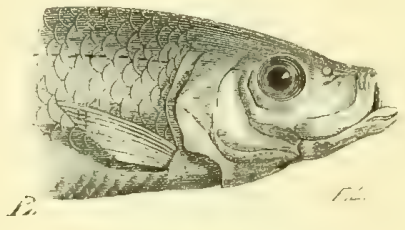

1. II: DE: HARFMG

(Giapea harengus Limi).

quelles présentent jusqu'à 30 kilomitres de longueur ef ๖ ou 6 de largeur !..... Qui pourrait calculer le nombre immense des individus qui composent ces effrayantes masses! Elles émigrent du pôle boréal vers les côtes do la Norvége, de la Ilollande et de l'Angleterre.... Philippe de Maizières écrivait ì Charles VI: "Les Ilarengs font »leur passage de la mer du Nord dans la Baltique de "s septembre en octobre, et tant y en passe, qu'on pourroit ') les tailler avec l'espée. "

Les Ilarengs glissent rapidement à travers les flots. La lumière, décomposée dans leurs écailles, semble se transformer en rubans de nacre ou en navettes de métal, qui contrastent avec l'azur de leur habitation; et leurs lueurs 
phosphorescentes scintillent, ondulent et dansent sur les flots, comme le dit si bien M. Michelet.

Le poids de ces poissons atteint bien rarement deux cents grammes. Ils ont le dos d'un bleu verdàtre, et le reste du corps d'un blanc argenté. Leur mâchoire inférieure est un peu plus courte que la supérieure. L'une et l'autre sont garnies de jolies petites dents; on observe même, sur leur langue, des papilles pointues, assez fortes pour retenir une proie. Ils aiment à lever la tête au-dessus de l'eau, comme pour humer l'air. Les mille mouvements d'une colonne de Harengs imitent le loruit d'une pluie qui tombe à grosses gouttes. (J. Franklin.)

Quelques centaines de Cétacés et plusieurs milliers d'Oiseanx de mer accompagnent ces pauves bêtes et les détruisent par millions. On assure que, dans le voisinag' des Hébrides, les seuls Fous dévorent annuellement plus de cent millions de Harengs. Un autre poisson, appelé Sey ', poursuit nos voyageurs it outrance, se jette au milieu de leurs colonnes, et les disperse, au grand préjudice des pêcheurs.

La mer, comme la terre, est un théâtre éternel de naissances et de destructions. Tout s'y reproduit pour s'y détruire, et s'y détruit pour s'y reconstituer ! (Virey.)

"Les Harengs vont comme un élément aveugle et fatal, et nulle destruction ne les déconrage. Hommes, poissons, tout fond sur eux; ils vont, ils voguent toujours. Il ne faut pas s'en étonner: c'est qu'en naviguant, ils aiment. Plus on en tue, phus its produisent et multiplient chemin faisant. Les colonnes ípaisses, profondes, dans l'électricité commune, flottent livrées uniquement à la grande cuvre du bonheur. Le tout va à l'impulsion du flot, et du flot

1 Merlangus virens Cuvier. 
électrique. Prenez dans la masse, an hasard, vous en trouverez de féconds, vous en trouverez qui le furent, et d'autres qui voudraient l'ètre. Dans ce monde qui ne connait pas l'union fixe, le plaisir est une aventure, l'amour une navigation. Sur toute la route ils épanchent des torrents de fécondité. » (Michelet.)

On a trouvé dans un Hareng 20000 œufs; dans un autre, 36000 ; dans un troisième, 70000 !....

Aussi, malgré les pertes annuelles, si considérables, si effroyables que leur font éprouver les autres hôtes de la mer... et les filets des pêcheurs, on ne s'est jamais aperȩu que leur nombre diminuât. Cette fécondité a bien de quoi calmer les inquiétudes des économistes alarmés sur le sort des générations futures.

\section{II}

En Norvége, à la côte méridionale et occidentale de l'ile de Karnsa, l'avant-garde des llarengs d'hiver se présente vers les premiers jours de janvier. Ces Harengs sont bientôt suivis de phalanges nombreuses et compactes.

Divers auteurs ont prétendu que les migrations régulières des Harengs sont soumises à une discipline rigoureuse, et que leurs nombreuses évolutions étaient dirigées par un ou plusieurs chefs, qu'on a nommés Harengs royaux ou rois. Les IIollandais respectent beaucoup ces prétendus chefs. Ils les épargnent avec soin, quand ils les trouvent dans leurs filets, et les rejettent dans la mer, afin de ne pas détruire les guides de la nation Hareng. Les ichthyologistes n'ont pas confirmé cette discipline; ils ont reconnu seulement que les divers mouvements des bandes voyageuses sont gouvernés par les saisons. 
L'arrivée annuelle de ces poissons dans les diverses régions de l'Océan est ordinairement assez régulière. Cependant elle éprouve, de temps à autre, des vicissitudes qui influent non-seulement sur l'époque de la visite, mais encore.sur la quantité de visiteurs.

On a eu l'idée tout récemment de mettre à profit le télégraphe électrique qui longe la Scandinavie, pour annoncer aux pêcheurs l'avant-garde et le corps d'armée de ces malheureux et bienfaisants poissons.

Le document le plus ancien, relatif à la pêche du Hareng, est daté de 709. Il existe dans les chroniques du monastère d'Evesham.

Les Français s'occupaient déjà de cette pêche dès le $\mathrm{xl}^{\mathrm{e}}$ siècle : on connait une charte authentique de 1030. Il paraît qu'à cette époque, des vaisseaux sortis de Dieppe allaient prendre ce précieux poisson dans la mer du Nord. Nais ces premiers industriels ne furent pas imités par leurs compatriotes.

Dans le $\mathrm{XII}^{\mathrm{e}}$ siècle, la pêche du Hareng commença en Hollande; elle y prit une grande faveur, à tel point que, dans le siècle suivant, les Ilollandais allaient pêcher jusque sur les côtes de la Grande-Bretagne. Ils consacraient au moins deux mille bâtiments à cette exploitation.

Les Anglais suivirent bientôt cet exemple lucratif, et donnèrent à cette industrie un développement considérable. Les Français, de leur côté, ne voulurent pas rester en arrière. Les Danois, les Suédois et les Norvégiens arrivèrent à leur tour.

Parmi ces peuples, les Anglais, les Hollandais et peutêtre les Norvégiens, semblent avoir aujourd'hni le monopole de l'exportation. Les pêcheries françaises, danoises et suédoises n'excèdent guère la consommation de leurs pays respectifs. 
La ruantité de Hapengs récoltée chaque ammée par nos voisins d'outre-Manche est véritablement énorme. Dans le petit port de Yarmouth seulement, on équipe quatrr cents navires de 40 à 70 tonnes, dont les plus grands sont montés par douze hommes. Le revenu est d'environ 17500000 franes. En 185\%, trois de ces navires, appartenant au mème propriétaire, apportèrent 3 \62000 poissons.

Depuis le commencement de ce siècle, les pêcheurs de l'Écosse ont commencé à rivaliser de zèle avec ceux de l'Angleterre. En 1826, les pêcheries écossitises employaient

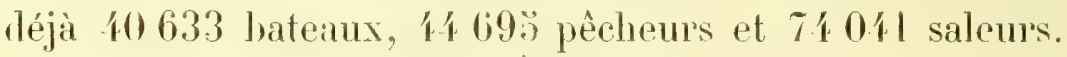

En 1603, la valeur des Harengs exportés par la Hollande s'élevait à près de 50 millions. Lcur pêche occupait 2000 bateaux et 37000 marins. Trois ans plus tard, nous trouvons que les Provinces-Unies envoyaient 3000 baryues i la mer; que 9000 navires transportaient les Harengs dans les autres pays, et que le commerce de ce précieux poisson employait environ 200000 personnes.

Bloch rapporte fue, de son temps, les Hollandais salaient jusqu à 621 millions de ces animaux. Suivant un dicton des Pays-Bas, Amslerdam est fondée sur des têtes de Hareng.

Quoique aujourd'hui tris-active, la pêche hollandaise est loin de la splendeur qu'elle avait il y a deux siècles. En 18:8, elle a employé quatre-vingt-quinze navires; en 18:99, quatre-vingt-dix-sept, et en 1860, quatre-vingtdouze. En 18:38, la Ilollande a importé 16940 tonnes de 1000 pirces; en 18:39, 23198, et en 1860, 27230. Cettr dernière anuée, la pêche a rapporté 1191179 franes, soil 12749 francs par navire.

Le Ilareng, dit Lacépède, est une des productions dont l'emploi décide de la destinée des empires. Aussi, dans le nord de l'Europe, la pêche de ce poisson est-elle appelée la grande péche, tandis que celle dr la Baleine est appelée la petite. 
Quelupefois, chez les peuples où la pieche du Hareng n'est pas habituellement lobjet d'un grand mouvement industriel, il se fait, par exception, des prises extraordinaires.

Cuvier et Valenciennes assurent qu'un pêcheur de Dieppe rapporta, dans une seule nuit, 280000 Harengs, et qu'il en avait rejeté un nombre égal à la mer. Total, 560000 individus.

En 1781, la ville de Gothembourg, en Suede, exporta 136649 barils de Harengs, contenant chacun 1200 poissons. Ce qui donne un chiffre de 163978800 Harengs.

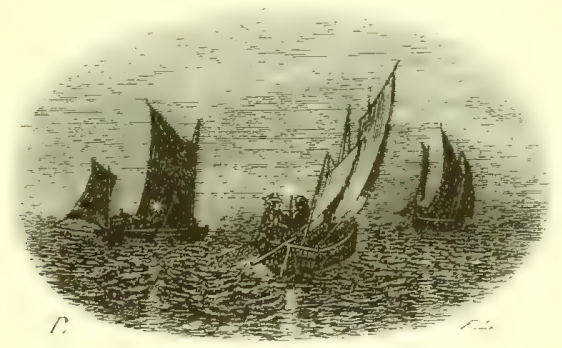

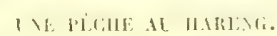

"Les Harengs, dit Duhamel, entrent parfois en si grande quantité dans la Nanche, qu ils ressemblent aux flots d'une mer agitée : c’est ce que les pécheurs nomment des lits ou bouillons de Harengs. Quand les filets doment dans ces bouillons, il arrive qu'ils sont tellement chargés de poisson, qu'ils se rompent et coulent bas. "

Les bâtiments équipés pour la pèche du Hareng sont du port d'une soixantaine de tonneaux. On les charge de petits bateanx, de filets, de sel et de caques.

Comme on pèche pendant la nuit, pour prévenir toute espèce de collision, et peut-être aussi pour attirer le poisson, chaque embarcation porte un ou deux petits fanaux. Au banc de Yarmouth, où plusienrs milliers de bateaux sillonnent la mer à la fois, toutes ces lumières 
qui se meuvent et s'entrecroisent, produisent une scène véritablement féerique. (L. Wraxall.)

Les filets présentent jusqu'à 220 mètres de longucur, et la grandeur des mailles est telle, que le Hareng y est reteun par les ouies et les nageoires pectorales, lor'sque sa tête s'y engage.

Le pauvre poisson s'embarrasse dans l'immense mur perpendiculaire qu'on lui oppose, et reste suspendu, sans pouvoir avancer ni reculer, jusqu'à ce que le pêcheur vienne le détacher et le prendre.

Les caques sont de bois de chêne. Les autres qualités de bois, particulièrement les résineux, communiquent au poisson une odeur et une saveur désagréables.

Les Harengs pêchés sont divisés en trois catégories : les vierges, c'est-à-dire ceux qui n'ont pas encore frayé; les pleins, ceux qui portent de la laite ou des oufs (laités ou œuvés); les vides, ceux qui viennent de se débarrasser de leur laite ou de leurs oufs. Ces derniers sont les moins estimés.

On fait une première salaison à bord des navires, ou bien sur la côte, si elle n'est pas trop éloignée. Plus tard, on les remanie et les sale de nouvean. Enfin, avant de les expédier, les négociants les changent ordinairement de sel, quelquefois même de caque.

Les Harengs saurs sont embrochés, suspendus et exposés à la fumée et à l'air chaud.

Les Norvégiens accourent, de toute la partie méridionale de leur pays, vers les parages fréquentés par les Harengs. Ils préparent des filets de 23 à 30 mètres de longueur sur 7 a 8 de largeur. Chaque bateau porte de quarante à soixante filets.

Lorsque le Hareng pénètre daus l'intérícur des baies, on le barre avec de grands filets de 250 à 300 mètres de 
longueur, sur une largeur de 33 à 40 . On se sert ensuite de filets plus petits pour l'amener à terre.

Dès qu’il est pèché, le Hareng se vend, soit aux petits navires des environs, qui le transportent frais à Bergen et dans le voisinage, soit aux saleurs, qui ont des magasins dans tous les parages où se fait la pêche. (Baars.)

La mi-janvier passée, d'autres masses de Harengs se jettent sur les còtes de Bremanger, de Batalden et de Kinn, à environ dix ou douze lieues au nord de Bergen, où les attendent d'autres milliers de pêcheurs. Ici la pêche se fait presque exclusivement à l'aide de filets ordinaires, les localités se prètant moins au barrage que les parages du sud. A mesure que la saison avance, les masses de Harengs se dirigent un peu vers le sud-est, et, après avoir frayé vers le milieu de mars, elles quittent la còte. (Baars.)

Au mois de février et au commencement de mars, on prend aussi beaucoup de Harengs entre Bremanger et Aalsund.

Le produit de la pêche, au nord de Bergen, se sale sur les lieux mêmes, où se trouvent de grands magasins, ou bien il est transporté dans les environs par de petits navires. On l'évalue à 500000 ou 600000 barils. Chaque baril contient de 450 à 500 poissons. Ce qui fait, par conséfuent, jusqu'à 300 millions d'individus. On assure 'qu’en 1860, le chiffre fut encore plus élevé. Ce sont les Harengs d'hiver.

Cette pêche terminée, les avant-coureurs des Harengs d'été commencent à se montrer dans les environs de Bergen. Cenx-ci sont d'abord petits et maigres; mais an fur et à mesure que la saison avance, on les voit grossir et devenir de meilleure qualité : à la mi-juin, on en trouve de très-beaux. 
La pêche commence à se faire en grand vers le milieu du mois de juillet; elle dure jusqu'au mois de septembre.

Elle s'opère avec de grands filets à barres. Vers la fin, cependant, on emploie quelques filets ordinaires.

Cette pêche donne au moins 40000 barils, ce qui fait jusqu'à 20 millions d'individus. La moitié environ de ces Harengs est consommée dans le pays.

La pêche norvégienne a donné en 1862, dans la saison dite du printemps, 659000 tonmes de Harengs, c'est-ḋ-dire 764440 hectolitres, dont il faut retrancher 23 pour 100 pour la consommation intérieure. Il reste donc, comme objet de commerce avec l'étranger, 494250 tonnes ou эั73 330 hectolitres, représentant sur place une valeur minimum de 8551675 franes, et maximum de 11274600 franes.

Les Ilarengs fournissent une huile qui peut remplacer l'huile de Baleine. Pour préparer cette huile, on fait bouillir le poisson dans l'eau douce pendant cinq ou six heures, en ayant soin de remner constamment. Lorsque le Hareng est réduit en bouillie, on laisse refroidir la masse, puis on recueille l'huile qui surnage. On la clarifie par le filtrage ou par de simples décantations successives, et on la met dans des barils. (La Morinière.)

Le résidu qui reste au fond des chaudières est appelé ıangrum. Les Suédois le regardent comme un excellent engrais.

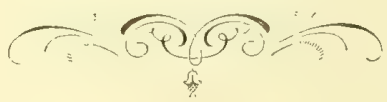




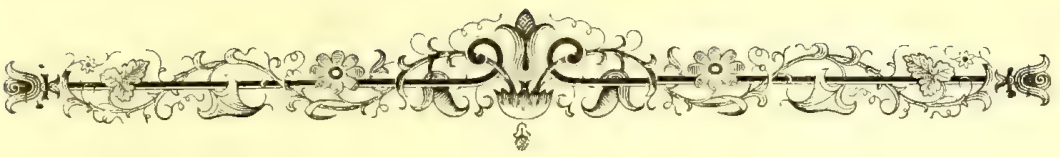

\section{GHAPITRE XXXVII}

\section{LA SARDINE.}

"Est enim divitiarum fructus in copia."

(Gícérox.)

La Sardine ${ }^{1}$ est une très-proche parente du Hareng.

On prétend qu'elle doit son nom à l'île de Sardaigne. Est-ce bien vrai? Ne serait-ce pas plutôt cette belle île qui doit son nom à la Sardine?

Quoi qu’il en soit, ce délicieux habitant de l'eau salée jouissait déjà d'une haute réputation avant que l'Ilomme ait inventé le moyen de le confire. Épicharme en parle dans ses vers comme d'une des friandises servies à Hébé pour son déjeuner de mariage! (J. Franklin.)

La Sardine est un joli petit poisson qui a la tête pointue, les yeux gros et les opercules ciselés. Quand on le retire de la mer, son dos paraît bleu, diapré de teintes plus obscures; ses côtes sont argentines et moirées de vert brillant ou de bleu tendre. Mais il faut la voir, cette élégante nageuse, s'ébattre librement, par un beau soleil de juillet, dans la trausparence d'une mer calme et limpide.

On est émerveillé de la grâce et de la perfection de ses

- Clupea sardina Guvier. 
formes, de la souplesse et de l'agilité de ses mouvements, de l'éclat et de la variété de ses couleurs. Son riche corsage de nacre semble refléter l'azur et l'émeraude....

La fécondité de ce poisson paraît miraculeuse. C'est surtout aux Sardines, dit un auteur moderne, que semblent s'adresser les promesses de la Bible : « Je multiplierai ta race, qui deviendra aussi nombreuse que les grains de sable de la mer et que les étoiles du firmament. » Si la bénédiction se mesure à la fécondité, comme le croyaient les Israélites, ces poissons doivent être spécialement bénis entre tous les animaux.....

Les Sardines habitent l'océan Atlantique boréal, la Baltique et la Méditerranée. Elles se trouvent dans la profondeur des baies, à l'abri des rivages. Elles aiment le remous des courants et les endroits où la mer est peu agitée.

Comme les Harengs, les Sardines se rassemblent par colounes compactes, souvent très-longues et très-larges.

Leurs légions émaillées arrivent en Bretagne vers le mois de mai. Leur présence est indiquée par les bouillonnements de la surface de la mer et par la teinte de l'eau, tantôt bleuâtre, tantòt blanchâtre, ces animaux présentant alternativement au soleil leur dos d'azur ou leur ventre d'argent.

Ces brillants poissons arrivent au printemps dans la Méditerranée. Ils en sortent avant l'hiver (S. Berthelot).

On pêche les Sardines avec des seines et avec d'autres filets traînants. Les seines sont tirées à terre ou relevées à la mer.

Dans la Méditerranée, on a le sardinal, filet à petites 
mailles et d'une seule nappe, qui flotte entre deux eaux, verticalement, en décrivant des courbes à une certaine distance du rivage. On le tend pendant la nuit. L'une de ses extrémités est attachée au bateau, qui dérive arec iui au gré des courants. (S. Berthelot.)

En Bretagne, on emploie aussi des filets flottants. La grandeur de la maille est calculée de telle sorte que le poisson puisse passer la tête.

Pendant la saison des Sardines, il y a, sur les côtes de Bretagne, deux mille à deux mille cinq cents embarcations occupées à cette pêche. Chaque barque ou pesqueresse porte quatre ou cinq hommes : le patron, deux ou trois matelots et un mousse; elle a cinq ou six filets, de la rogue et des paniers.

Les embarcations partent de grand matin. Elles se rendent à trois ou quatre lieues de la côte : elles doivent être sur le lieu de pêche au lever du soleil. Alors on amène les voiles et les mâts, et tandis que les matelots rament lentement, on laisse couler à la mer un filet, qui descend verticalement dans l'eau, soutenu par les liéges qui flottent à la surface. Le patron, debout à l'arrière, jette la rogue par poignées, tantôt d'un côté du filet, tantôt de l'autre, jusqu'à ce que le poisson soit monté des profondeurs. Aussitôt, prenant une écuelle d'eau, il la lance brusquement et bruyamment pour effaroucher et rabattre le poisson sur le filet. La Sardine s'effraye, fuit précipitamment, et engage sa tête dans les mailles, où elle reste prisonnière par les ouies. Le patron reconnaît que les filets sont chargés de poisson lorsque les liéges entrent dans l'eau. Alors on les hale à bord les uns après les autres; on en retire les Sardines, que l'on dépose au fond du bateau ${ }^{1}$.

1 Voyez planche XXIX. 
Lorsque les Sardines sont abondantes, on peut en prendre jusqu'à un tonneau d'un seul coup de filet. Quand la pêche est bonne, chaque embarcation revient avec 23000 à 30000 individus. On assure en avoir vu qui en portaient jusqu'à trente-cinq milliers.

Cette pêche dure cinq ou six mois, pendant lesquels on ne compte gnère que cent journées de travail. Elle produit 7500 millions de Sardines, lesquelles, veudues fraiches, procurent 7500000 francs. Le tiers est la part de l'équipage, ec qui fait, par journée de travail, 2 francs 22 centimes pour le pêcheur et 1 franc 11 centimes pour le mousse.

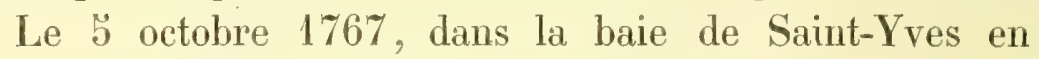
Cornouailles, on a pêché 7000 barriques de Sardines. Chacune en renfermait environ 35000 ; total, 245 millions. (Borlase.)

Les Basques se servent, pour prendre les Sardines, d'un filet fermé comme un sac avec des anneaux de corne.

Les Anglais emploient une grande seine, manœuvréc à contre-courant par trois ou quatre chaloupes montées chacune par six marins. Ils ramènent quelquefois, d'un seul coup de filęt, jusqu'à 40 tonneaux de poisson.

\section{III}

On prépare les Sardines de plusieurs manières. Elles sont salées: en vert, , [uand on les saupoudre seulement de sel blane; en grenier, lorsqu'on en forme des tas avec du sel entre chaque couche; en malestan, quand on les lave dans de l'eau de mer, qu'ou les met en barils par couches saupoudrées de sel, puis, qu'au bout d'un séjour d'un mois, 


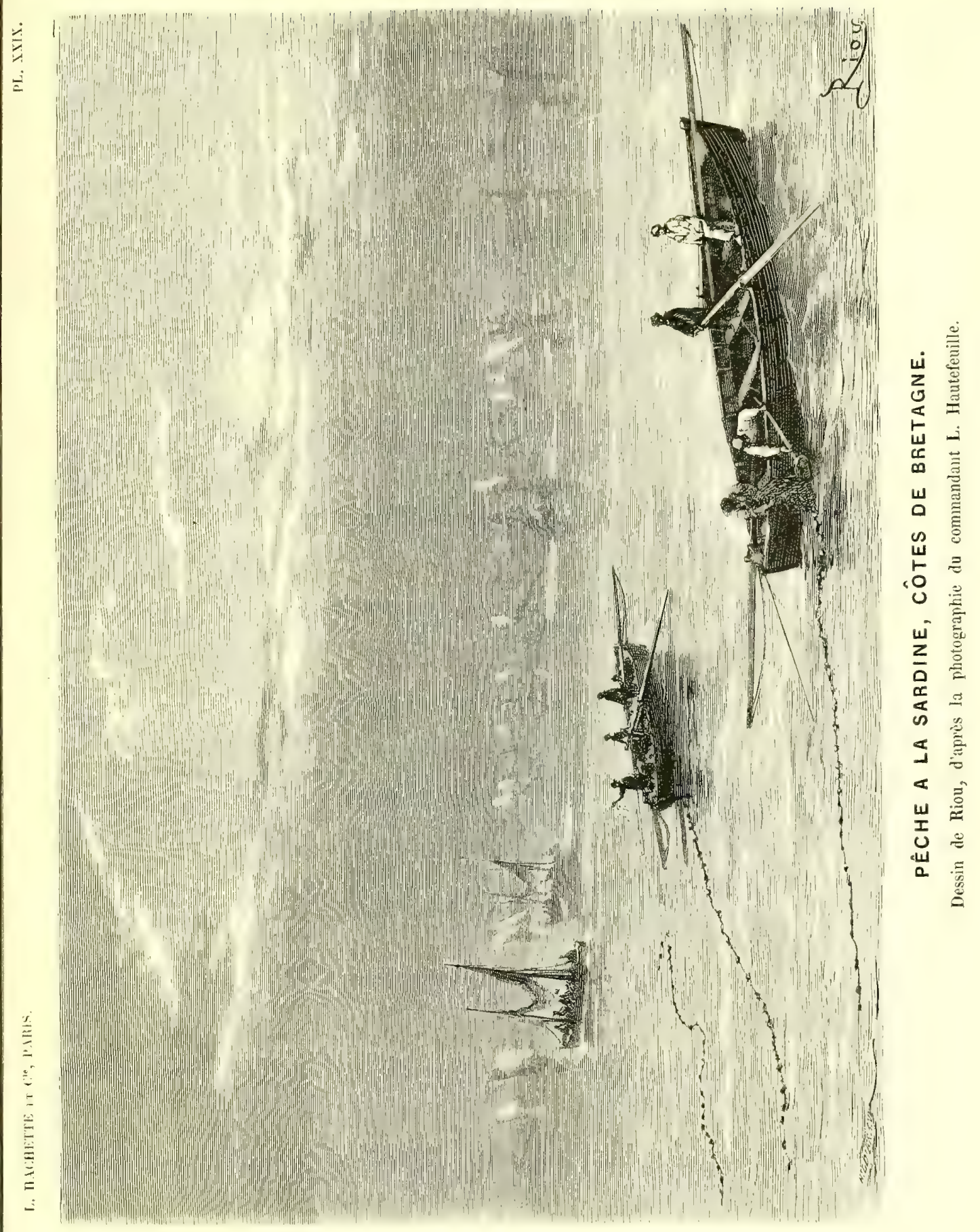



et après les avoir lavées de nouveau dans de la saumure et déposées symétriquement dans de nouvelles barriques, on les presse jusqu'à ce que leur huile et la saumure se soient écoulées.

On les dit anchoisées, lorsqu'on les met en barils, avec du sel mêlé d'ocre rouge pulvérisée.

On les saurit, après les avoir salées, en les suspendant pendant sept ou huit jours dans un licu où l'on allume un feu de copeaux de chêne.

On a réussi à confire les Sardines dans l'huile. Dès qu'elles arrivent de la pêche par paniers de cent à deux cents, des femmes leur tranchent la tête, et du même coup leur enlèvent les entrailles; puis elles jettent les poissons dans de la saumure, où ils restent une heure ou deux, suivant leur grosseur et leur fraîcheur. On les lave ensuite à grande eau, on les étale sur des claies d'osier ou. de fil de fer galvanisé. Pour les faire sécher, on les plonge dans de l'huile en ébullition, où on les laisse cuire quelques minutes. Quand ils sont refroidis, on les met dans de petites boites de fer-blane qu'on remplit d'huile, et dont on soude le couvercle. Enfin, on passe le tout à l'eau bouillante pour bien assurer la conservation (Balestrier). C'est ce qu'on appelle Sardines en boîtes. Il faut que l'huile soit vierge, c'est-à-dire de première qualité. Cette huile se fige totalement en hiver, et ressemble à des flocons de neige safranée.

On conserve aussi les Sardines dans du beurre fondu (Sardines en daube).

Suivant Marco Polo, les habitants de certaines contrées de l'Arabie en font une espèce de gâteau, en les séchant au soleil et en les réduisant en poutre.

Dans d'autres parties de l'Orient, les nègres les font bonillir avec des herbes et du poivre. 
Dans beaucoup de pays, les Sardines sont employées comme assaisonnement.

Ce poisson a une chair très-délicate, mais on n'apprécie bien son goût exquis qu'en le mangeant au moment où il vient d'être pêché. Lorsqu'il est bien frais, sa peau s'enlève facilement par la cuisson, et ses flanes se détachent en entier comme deux filets aplatis.

Les Sardines salées et fumées excitent l'appétit, mais les estomacs débiles s'en accommodent avec peine.

\section{IV}

Nous ne pouvons terminer ce chapitre sans parler de l'Anchois, petit poisson du même genre, si délicat et si précieux dans la science culinaire.

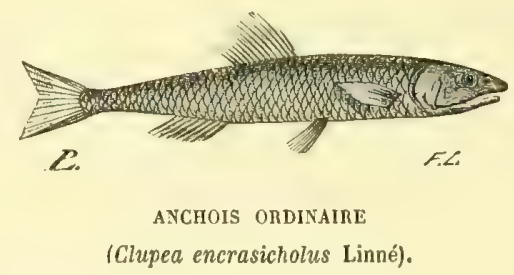

L'Anchois est le compagnon de la Sardine. On le trouve commun dans la Méditerranée et rare dans l'Océan.

Les Anchois de la Provence jouissent d'une excellente réputation.

On pêche habituellement les Anchois à Antibes, à Fréjus et à Saint-Tropez. Les femmes de ce pays ont une habileté très-remarquable pour enlever avec l'ongle, et d'un seul coup, les ouies, le foie et les entrailles. On sale ensuite 
les Anchois. On les met dans des miniatures de barils, et on les apporte à la foire de Beaucaire, d'où ils se répandent dans le monde entier.

II. Sabin Berthelot pense que ces myriades de trèspetits poissons, presque imperceptibles, à chair molle, gélatineuse et transparente, qui pullulent au printemps dans les environs d'Antibes et de Nice, sont peut-être le fretin des Sardines et des Anchois (?).

Les pêcheurs et les cuisiniers du pays les appellent Nonnats ou Non-nats (pas encore nés).

Risso en parle dans son Ichthyologie; il y découvre trois espèces, ni plus ni moins! Trop zélé Risso! Il a décrit plus d'un animal anquel la Nature n'avait jamais songé !.... Voici le signalement qu'il donne à l'une de ces trois miniatures de poissons : "Museau pointu; tête rougeâtre, aplatie; prunelles d'un noir de jais. Un manteau blanc s'étend sur tout son corps, et n'est relevé que par six taches rondes d'un noir d'ébène, qui descendent jusqu'à... " (Le reste est trop shocking!) Il nomme cette espèce Stolephorus Risso. Et pour qu'on ne suppose pas qu'il s'est dédié ledit poisson à lui-même, par amour-propre (le public est si malin!), notre prudent naturaliste s'empresse d'ajouter sentimentalement : "Je l'ai consacré comme un monument de la piété filiale aux mánes de mon père... La teinte de son corps est l'image de sa candeur, comme celle des taches noires est celle de mes regrets!... »

Quoi qu'il en soit, les Nonnats se plaisent dans les fonds sablonneux, à l'embouchure des rivières, et pénètrent mème dans les étangs salés en communication avec la mer. 
A Nice, ils habitent de préférence les fonds de galets, et s'introduisent dans les vides que ces pierres roulées laissent entre elles.

La pêche de ces petits poissons est souvent si abondante, qu'ils ne se vendent que 30 centimes le demi-kilogramme. On en fait d'excellentes fritures et de délicieux ragoûts au lait (S. Berthelot).

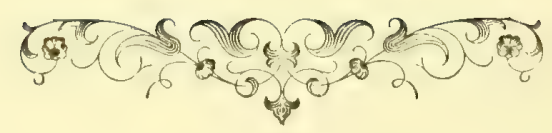




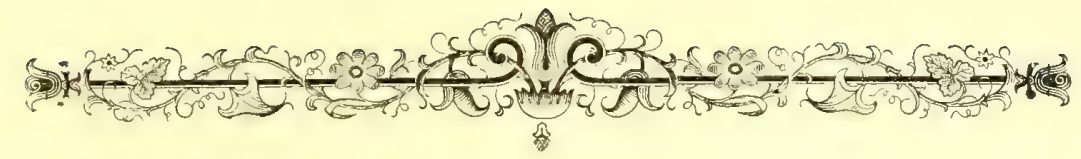

\section{CHAPITRE XXXVIII}

\section{LA MORUE.}

Mar cuajado de peces.

(Viera.)

\section{I}

Les Harengs et les Sardines peuvent ètre classés parmi les petits habitants de la mer, mais ils compensent l'exiguité de leur taille par la richesse de leur nombre et par l'étendue de leurs phalanges.

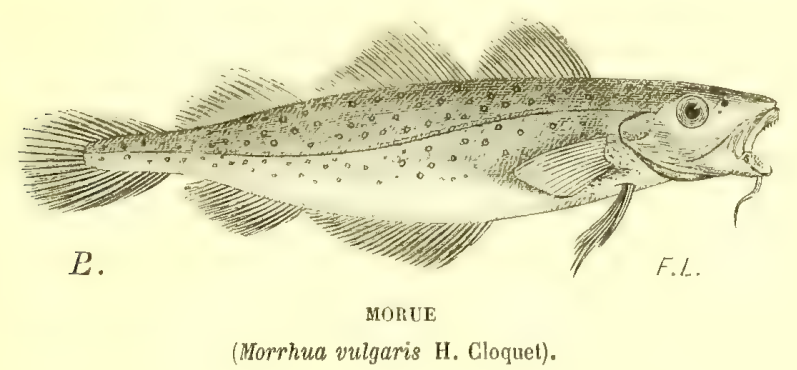

Les Morues sont à la fois de gros poissons et des poissons nombreux.

Elles fréquentent principalement les mers du Nord. Chaque année, vers le milieu de janvier, on voit arriver des masses considérables de Morues qui viennent du grand 
Océan et pénètrent à l'entrée de l'archipel de Lofoden. Ces pauvres bêtes accourent pour frayer, et ne prévoient guère le sort cruel qui les attend.

D'un autre côté, un nombre vraiment incalculable de ces poissons se rassemble périodiquement sur la montagne sous-marine américaine, appelée banc de Terre-Neuve. Les Morues occupent, assure-t-on, un espace long de deux cents lieues et large de soixante.

Les Morues sont en forme de fuseau; leur corps est arqué comme les bâtiments bons marcheurs. Les habitants des villes, qui n'ont jamais vu ces poissons que chez les marchands de comestibles, les croient aplatis comme des Soles. Ils ignorent qu'avant de les sécher, on leur coupe la tète, on les ouvre et on les étale. Les Morues vivantes ont la peau d'un gris jaunâtre, le dos tacheté de brun et le ventre blanchâtre. Elles offrent une ligne longitudinale claire de chaque côté. Leur longueur moyenne est de 80 centimètres, et leur poids de 12 kilogrammes.

De leur mâchoire inférieure descend un petit barbillon. - Ce poisson est vorace. Il se nourrit surtout de Harengs.

La Morue appartient à la famille des Gadoüdes, tribu gloutonne s'il en fut, qui, de ses yeux écartés, ne voit guère, n'en mange que mieux, et qui n'est, pour ainsi dire, qu'estomac. (Michelet.)

La fécondité de ce poisson a toujours été citée comme exemple. Leuwenhoeck a calculé qu'une seule femelle peut porter environ 9384000 œufs. Un autre observateur en a compté 11 millions.....

Supposez, dans le banc de Terre-Neuve seulement, cent millions de Morues femelles, et calculez le nombre effrayant de germes qu'elles produiront, même en n'admettant qu'une ponte par individu! 0 intarissable et merveilleuse puissance créatrice!... Le chanoine canarien Viera pourrait 
bien dire, dans son style si expressif et si poétique, en parlant de la fécondité des Morues, que la mer est caillée de poissons ${ }^{1}$.

On a réussi à élever des Morues dans des étangs en communication avec la mer. Le docteur Jonathan Franklin rapporte qu'il a visité, il y a quelques années, un de ces étangs, sur la côte ouest de l'Écosse. Les Morues s'approchaient familièrement pour happer des Moules qu'on leur présentait débarrassées de leur coquille. Elles se poussaient, se bousculaient les unes les autres, comme font les volailles dans une basse-cour, à la vue de la fermière qui leur apporte à manger. Elles venaient prendre les Moules jusque dans la main. La femme du gardien mit un de ces poissons, des plus grands, sur ses genoux, le caressa, le flatta, disant: Pauvre ami! pauvre ami! absolument comme si c'eùt été un enfant. Elle lui ouvrit la bouche, et y introduisit une Moule, que le poisson avala en donnant des signes qu'il la trouvait bonne. Puis, elle le remit dans l'eau.

\section{II}

La pêche de la Morue forme la source principale des richesses de Granville, Saint-Malo, Saint-Brieue, dans les départements de la Nanche, de l'llle-et-Vilaine et des Côtes-du-Nord.

Les Anglais et les Américains se livrent à cette lucrative industrie avec la mème ardeur que les Français.

1 Mar cuajado de peces (Viera). - Cuajar (coagulare) signifie littéralement "épaissir, figer, cailler". 
C'est principalement sur le banc de Terre-Neuve qu'on va chercher ce précieux poisson.

La Morue y arrive au printemps.

La quantité des poissons qui s'y rassemblent est vraiment phénoménale. Il y a plus de trois siècles que toutes les nations du monde s'y donnent rendez-vous, y viennent prendre des chargements considérables, et l'on n'y a pas encore constaté de diminution sensible.

En 1578, la France avait, sur le bane de Terre-Neuve, 150 navires; l'Espagne, 123 ; le Portugal, 50 , et l'Angleterre, 40.

Pendant la moitié du Xrrme siècle, la pêche fut exploitée par les Français, les Anglais et les Américains.

Le relevé de neuf années, commençant avec 1823 et finissant avec 1831, nous a appris que la France avait envoyé à Terre-Neuve 341 navires jaugeant 36680 tonneaux, montés par 7083 matelots. Ces navires ont exporté 25718466 kilogrammes de poisson, dont 897 4 238 salé, 16744228 de Morue verte, et 1217008 d'huile. En estimant à 20 franes le quintal métrique de poisson, et à 100 francs celui de l'huile, nous trouvons un chiffre de 6360746 francs par année moyenne.

On assure que l'Angleterre emploie annuellement près de 2000 navires et environ 30000 marins à la pêche de la Morue.

On dit que les Américains mettent en mouvement, pour la même industrie, 3000 navires et 45000 marins.

On a calculé que les navires anglais et américains rapportent chacun, en moyenne, 40000 poissons:

La Hollande n'est pas en arrière des antres nations. Elle a exporté, en 18:6, 1 172.203 kilogrammes de ce poisson préparé de différentes manières; en 18:57, 1297666 kilogrammes; en 1858, 1702431 , et en 1859, 1507788. 
Sur les côtes de la Norvége, depuis la frontière de la Russie jusqu'au cap Lindesness, la pèche de la Morue forme la source d'une industrie et d'un commerce extrêmement considérables. Elle dure environ trois mois. On évalue à plus de 20 millions le nombre de Morues qu'elle procure à la consommation.

Dans ce pays, cette pêche occupe plus de 20000 pêcheurs, montés sur au moins 5000 bateaux. Elle se fait à une distance de deux lieues norvégiennes (15 au degré) de la terre, dans une profondeur de 100 à 160 mètres.

D'après le rapport officiel fait au roi de Suède par l'inspecteur en chef de la pèche à Lofoden, on a mis en mer, en 1856, 4623 bateaux, et en 1860, 5675. Cette dernière année, on a employé 3453 appareils de profondeur, 7775 pêcheurs à la ligne, et 13038 pêcheurs au filet.

Suivant le même rapport, on a salé, cette même année, à l'est de Lofoden, 10080000 Morues fendues, et à l'ouest, 2640000. On estime les poissons ronds, e'est-à-dire les Morues non fendues, à 9000000 . Si l'on ajoute à ces chiffres les Nlorues consommées pendant la pêche, on arrivera au total de 24 millions.

Les cufs obtenus en 1860 ont rempli 16000 tomneaux, et l'huile, 40000.

Les côtes de l'Islande sont aussi très-riches en Morues.

La France a fourni pour la pêche de ce poisson : en 1860 , 210 bâtiments et 3273 hommes; en 1861, 222 bâtiments et 3602 hommes, et en 1862,232 bâtiments et 3741 hommes. Le port de Dunkerque seul a donné, cette dernière année, 134 navires et 2157 marins. 


\section{III}

On prend les Morues, soit avec des filets, soit avec des lignes.

Le filet employé à Terre-Neuve est une seine, grand filet rectangulaire garni de plomb au bord inférieur. et de liége au bord supérieur. On en fixe une extrémité près de la côte, et, avec un bateau, on va porter l'autre extrémité en pleine mer, ayant soin de décrire une courbe, laquelle enferme le poisson dans un enclos circulaire. En tirant sur les deux extrémités, des hommes entrainent tout le poisson. Un seul coup en donne quelquefois la charge de plusieurs bateaux. On conçoit que ce genre de pêche ne peut se pratiquer que le long d'une côte.

En Norvége, chaque bateau porte ordinairement soixante filets de 40 mètres de longueur sur 7 mètres de profondeur. Ces filets sont mis à la mer le soir, et n'en sont retirés que le matin. On en dispose à la fois vingt à trente, noués les uns aux autres. Sur le halin ou haussière, et à 2 mètres l'une de l'autre, sont fixées des pierres qui tiennent les filets en place. En outre, des bonées, formées de sphères de verre, de liége ou de bois, maintiennent la partie supérieure des filets à une distance déterminée de la surface de la mer. A chaque bout, se trouve un petit baril portant le nom du propriétaire. (Baars.)

Tout le monde connait l'organisation des lignes. On les tend le jour et la nuit, par dix ou douze à la fois.

Chaque bateau norvégien en porte une vingtaine, armées chacune de deux cents hameçons.

On se sert, pour appât, de Harengs salés, et quand ils manquent, de rogues de Morue, ou même de petits morceaux de ce poisson. 
A Terre-Neuve, chaque pêcheur est muni de deux lignes, qu'il tient à droite et à gauche du bateau. 11 arrive souvent que pendant qu'il en retire une, un poisson mord à l'autre, et ainsi de suite. On a vu des pêcheurs habiles prendre chacun jusqu'à quatre cents Morues dans un jour, ce qui est un terrible travail pour leurs bras. Ces lignes sont appelées lignes de main. On nomme lignes de fond, celles qui consistent en cordes très-fortes, sur lesquelles on fixe un certain nombre de lignes partielles armées chacune d'un hameçon. A l'une des extrémités de la corde est attachée une petite ancre à plusieurs pattes (grappin), qui l'entraine au fond de l'eau, et l'on fixe une autre ancre à l'autre bout. Chacune de ces ancres tient à un petit câble (orin) amarré à une bouée de liége. On peut disposer ainsi deux à trois mille hameçons.

\section{V}

Dès que les pêcheurs sont revenus à terre, ils enlèvent aux Morues la rogue, le foie, la tête et les entrailles.

Les rogues sont salées dans des barils percés de trous, par où s'écoule la saumure.

Les foies sont mis dans des barils de chêne. Ils se liquéfient en se décomposant. On soumet leur résidu à l'action du feu et on le comprime. Les premières huiles sont dites blanches ou blondes, et les dernières brunes ou noires. Ce sont les premières surtout dont on se sert en médecine. les dernières sont employées principalement par les corroyeurs. Depuis quelques années, on prépare l'huile de Morue en plaçant les foies frais, coupés par morceaux, dans de grandes cornues hors du contact de l'air, et en les faisant distiller au bain-marie. 
La tête et les entrailles sont séchées, pour être vendues plus tard à la grande fabrique de guano de poisson établie à Lofoden.

Les corps des Morues sont suspendus et abandonnés à l'action des vents secs, qui les transforment en slockfisch.

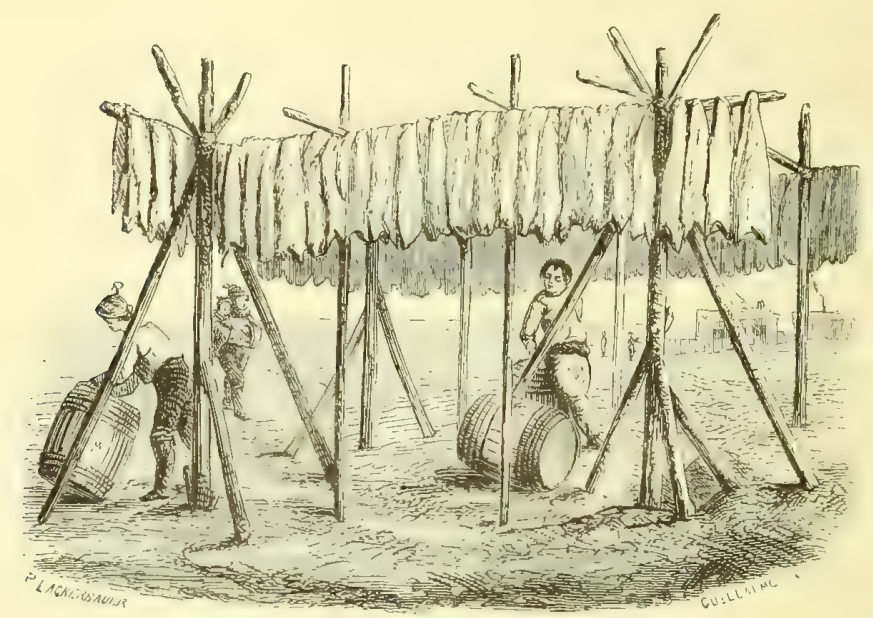

PRÉPARATION DES MORUES A TERRE-NEUVE.

D'autres fois, après avoir fendu l'animal et enlevé presque toute l'arête, on le lave, on le sale; on le met en presse, on retire les parties liquides, puis on le sèche au soleil. C'est là ce qui constitue le klipfisch.

La préparation de l'huile de foie et celle du klipfisch ont lieu ordinairement après la pêche, lorsque les bateaux sont rentrés.

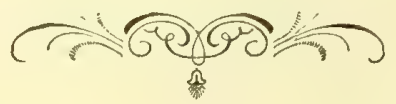




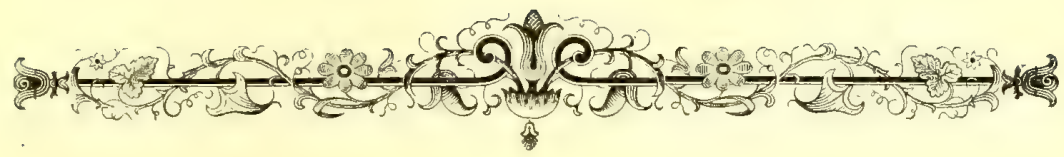

\section{CHAPITRE XXXIX}

\section{LE THON.}

Ye pourraiton pas pècher sans massacrer?

\section{1}

Le Thon est encore plus grand que la Morue. C'est un des princes de la nombreuse classe des Poissons. Il pèse habituellement de 25 à 100 kilogrammes.

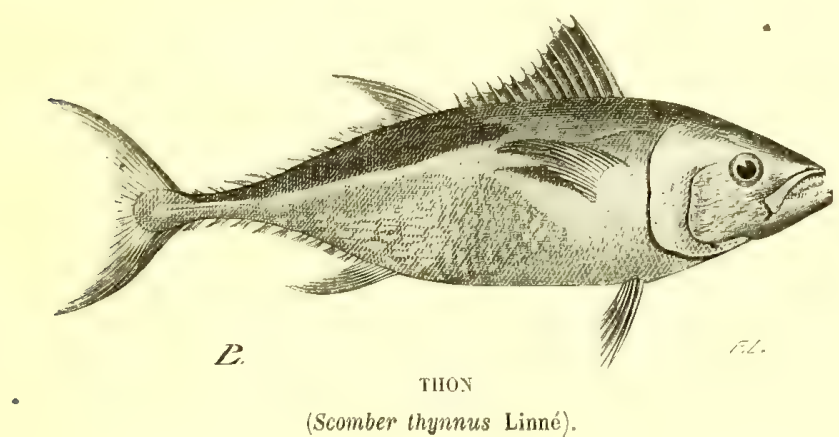

Le Thon est très-commun dans la Méditerranée. Son dos est d'um bleu noir, et son ventre d'un blanc argenté; ses rayous dorsaux sont dorés, et ses nageoires anales présentent de six à huit zigzags irisés.

Son corps, robuste, lisse et fusiforme, semble moulé pour 
la course. Les rayons épineux de ses nageoires, principalement ceux de la dorsale et de l'anale, dénotent, à première vue, leur action puissante dans les fonctions qu'ils ont à remplir. Le grand aileron du centre de la nageoire du dos est armé d'un premier rayon qui, au besoin, peut servir de défense; une rangée d'autres petits ailerons, trèscourts et lobés à leur extrémité, s'étend jusqu'à la naissance de la queue, et ces mêmes organes se montrent aussi vers la nageoire anale, non moins robuste que celle du dos. Tout ce système de natation est en parfaite halmonie : pectorales vigoureuses, caudale des plus fourchues. (S. Berthelot.)

Comme presque toutes les espèces de sa famille, le Thon a l'habitude de s'élancer hors de l'eau d'une manière particulière, en sautant par bonds rapides. Quand ces animaux sont réunis en troupe, ils nagent généralement en formant une sorte de triangle.

Ces poissons ne manquent ni d'instinct, ni d'une certaine sagacité. Ce sont des touristes enragés, comme les Harengs et les Morues. Les anciens, qui avaient remarqué la régularité de leurs marches et de leur's contre-marches, les regardaient comme très-habiles en stratégie; ils assuraient même qu'ils étaient bons géomètres. Montaigne a répété et commenté cette singulière assertion. Évidemment, l'auteur des $\boldsymbol{E s s a i s ~ c o n n a i s s a i t ~ m i e u x ~ l e ~ c o u r ~ d e ~ l ' H o m m e ~}$ que l'intelligence des Poissons.

On pêche le Thon de plusieurs manières différentes.

Les Basques emploient le grand couple, et les Provençaux la courantille. 
Un appelle grand couple, un ensemble de lignes gigantesrques, qui portent des centaines d'appàts trainés par des barques montées par huit ou dix hommes.

La courantille est une espèce de seine, de 500 à 700 mètres de longueur, que l'on promène sur un espace de deux à trois lieues.

Un certain nombre de bateaux dirigés par un chef se disposent en demi-cercle, et réunissent leurs filets de manièrr.



a former unc sorte de cloture. Ils cutourent les Thons of les serrent pêle-mêle les uns contre les autres. On les cntraine peu à peu vers le rivage. Lorsqu' on s'approche de la terre, les pêcheurs jettent un large filet terminé par une poche longue et conique. Les Thons se précipitent dans cette poche. On tue les plus gros a coups de perche ot de crochet, et l'on saisit vivants les plus petits.

\section{1}

Nais la plus curieuse des pèches qu'on ait imaginée est bien certainement celle a la madrague', si connue des Marseillais.

\footnotetext{
1 Appelée tonnara en Italie, et pig's catcher en Amérique.
} 
La madrague est un véritable parc, avec des allées de chasse aboutissant à un vaste labyrinthe composé de chambres qui s'ouvrent les unes dans les autres. Ces chambres conduisent toutes à une chambre principale, appelée chambre de mort ou corpou, situéc à l'extrémité de la construction.

Les murs de ce pare ont quelquefois plusieurs lieues de développenent. Aussi, pon transporter une madrague, faut-il souvent un navire ou un bateau à vapeur.

A l'aide de pierres attachées à la partie inférieure de ces filets et de bouées fixées à leur bord supérieur, on les fait plonger dans la mer et on les maintient verticaux. On amarre solidement l'édifice avec des ancres, de manière qu'il puisse résister pendant toute la belle saison aux plus violents orages. Ce filet gigantesque est plus perfide ot plus meurtrier que la toile d'araignée la plus savante. On le tend ordinairement à l'entrée de quelque baie.

"Le Thon arrive sans défiance, jouant à fleur d'eau; il va devant lui, sans quitter la paroi, qu'il côtoie, soit parce 'pu'il espère en voir bientôt la fin, soit parce que cela lui plait de heurter son museau sur cette surface résistante où il trouve probalblement de petits poissons qui lui servent de pâture; soit encore parce que c'est le propre des Poissons en général, voire même de tous les animaux, d'avancer coûte que coûte, tant qu'ils peuvent, sans réfléchir à leur retraite. » (E. Carrey.)

Le Thon suit, suit toujours les allées de l'engin destructeur. Quelefuefois les pêcheurs le poursuivent et le poussent de chambre en chambre. Le poisson passe des unes dans les autres, par des portes qui se referment derrière lui. Il arrive ainsi jusru’à la chambre de mort. Celle-ci forme une prison spacieuse, où les captifs peuvent vivre plu- 
sieurs jours, mème plusieurs semaines. Là le Thon est pris sans salut possible, à moins de sauter par-dessus les bords; ce qu'il pourrait facilement exécuter, mais l'idée ne lui en vient jamais.

Ce filet-vivier possède un plancher mobile, formé par un petit filet horizontal, attaché à des cordages disposés de manière que, à un instant donné, on peut exhausser le plancher et le rapprocher de la surface de la mer.

Lorsqu'on a réussi à rassembler dans la chambre de mort un certain nombre de poissons, on élève peu à peu le plancher dont il vient d'être question. Généralement, on y travaille toute la nuit. On rend ainsi de moins en moins profonde l'enceinte où sont accumulés ces paurres animaux.

Bientôt on voit les Thons s'agiter, nager, bondir dans tous les sens, passer les uns sur les autres, se précipiter contre les murailles des filets, les éviter, y revenir et s'en éloigner encore.

Au milieu de la chambre de mort se trouve une petite yole qui porte le chef principal de la pêche.

A mesure que le plancher s'élève et que les Thons deviennent apparents, la yole court sur eux, les effraye, les poursuit, et les oblige à s'élancer vers les bords du parc.

Là se trouvent tout autour un certain nombre d'embarcations montées par des pècheurs expérimentés, qui harponnent les poissons, ou les tuent toutes les fois qu'ils s'approchent. Ils les manquent rarement.

Le massacre est bientôt général.

Les Thons, harponnés et retirés de l'eau, se tordent avec force, donnent de vigoureux comps de quene et vagissent comme des enfants. 
Les blessés fuient l'ennemi et plongent au plus vite, mais ils rencontrent l'inévitable plancher qui les arrête. Ils vont, ils viennent, effarés, épouvantés et désorientés, rougissant la mer de leur sang. Ils ne tardent pas à se heurter contre un autre filet et contre une autre embarcation. On leur jette un nouveau harpon, plus adroit ou plus heureux que le premier, et, cette fois, les malheureuses bêtes, solidement accrochées et promptement hissées, sont jetées au milieu des morts et des mourants, que les pêcheurs acharnés entassent dans leurs barques.

Quand les Thons sont très-nombreux et qu'on peut les approcher, les pêcheurs leur plongent hardiment la main dans la gueule, et passent une corde dans une ouie; ils tendent cette corde à un camarade, qui hale la victime sur le pont du bateau.

Il faut souvent deux ou trois hommes pour enlever un Thon ainsi saisi et enfilé.

Lorsque, par hasard, un d'eux se débat trop vivement aux mains de ses bourreaux, un pècheur lui arrache brutalement, avec le doigt, quelque chose au fond de la bouche. Aussitôt le sang coule à flots, par jets, et presque en même temps la victime, épuisée, se laisse hisser sans mouvement.

En 1861, dans la baie de Porto-Ferrajo, on a pris à la madrague cent soixante Thons gros et petits, depuis des Thons bébés d'un kilogramme environ jusqu'à des Thons vieillards de 120 et même de 150 kilogrammes.... En estimant chaque poisson, en moyenne, à 25 kilogrammes, cette pêche a donné environ 4000 kilogrammes de Thou! (E. Carrey.)

Lorsque Lonis XIII visita sa bonne ville de Marseille, on organisa en son honneur une grande pêche à la madrague. Ce massacre officiel enchanta tellement le 
monarque, peu sensible et peu facile à divertir, comme chacun sait, qu'on l'entendit dire plusieurs fois que c'était la plus agréable journée de son voyage. Heureux roi!... et pauvres Thons!!

Ne pourrait-on pas pêcher sans massacrer?

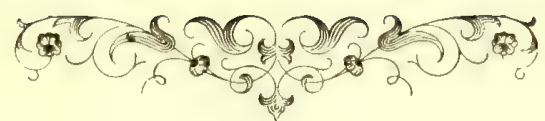





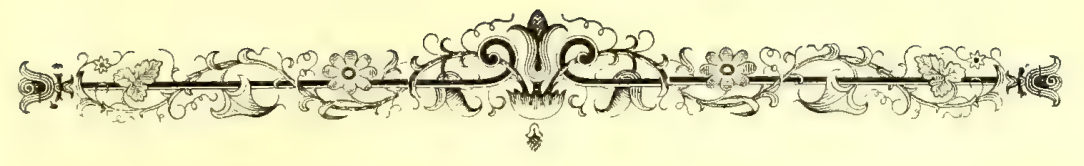

\title{
CHAPITRE XL
}

\section{LES TORTUES DE MER.}

\author{
"Esse et in piscatu voluptatem maxime \\ Testitudinum, w \\ (Plixe.)
}

Les Reptiles sont rares dans la mer; mais ceux, en petit nombre, qu'elle nourrit, se font remarquer par leur organisation, par leurs mœurs et par leur utilité. Nous voulons parler des Tortues. Aristote désignait ces animaux sons le nom de Thalassites.

Comme les Tortues terrestres, les Tortues marines sont revêtues d'une cuirasse osseuse et écailleuse très-dure et très-solide, fortifiée par huit paires de côtes.

Cette cuirasse forme en dessus une carapace plus ou moins bombée, et en dessous, un plastron plus ou moins aplati.

La carapace et le plastron composent une sorte de boîte protectrice, dans laquelle le reptile tient son corps à l'abri, et retire, au besoin, son cou et sa queue. Chez les Tortues 
de terre, dont la tête et les pattes sont proportionnellement moins grandes, l'animal peut encore les rentrer et les loger dans son armure ${ }^{1}$.

Si l'on n'avait jamais vu de Tortue, soit de terre, soit de mer, et qu'on rencontrât pour la premic̀re fois une de ces bizarres organisations, ne serait-on pas bien étonné?

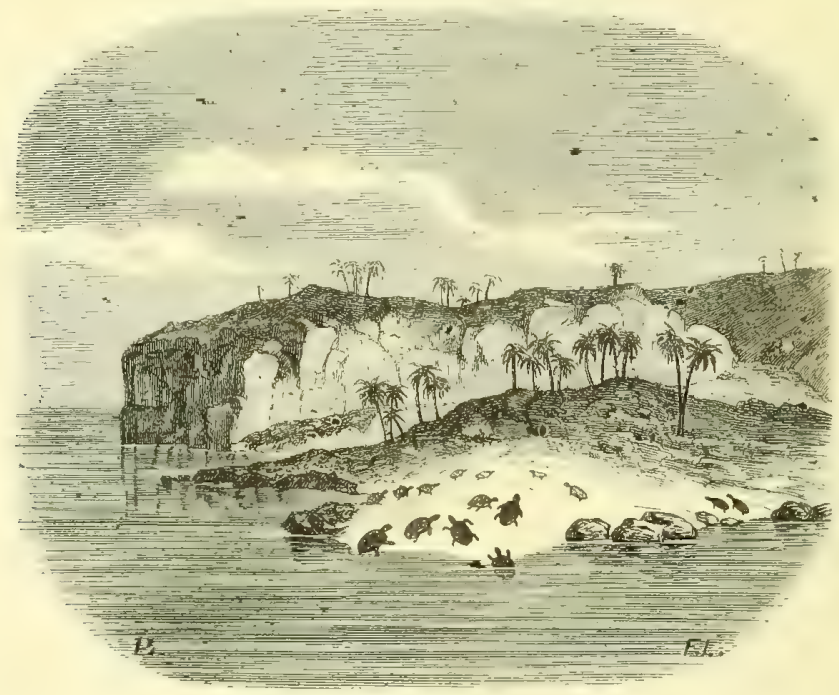

TORTUES.

Un montagnard du centre de la France trouva un jour, à la fête de son village, un marchand algérien qui étalait devant lui une cinquantaine de Tortues communes.

“Et combien vendez-vous ces drôles de petites bêtes?

- Trente sous, monsir, sans marchander.

- Trente sous! c'est bien cher pour une espèce de grenouille!.... Et combien en voulez-vous sans la boîte? » 
On connait trois espèces principales de Tortues de mer: la Caouane, la franche et le Caret.

La Tortue caouane est assez commune dans la Méditerranée, la mer Rouge, l'archipel de Madagascar et les Maldives.

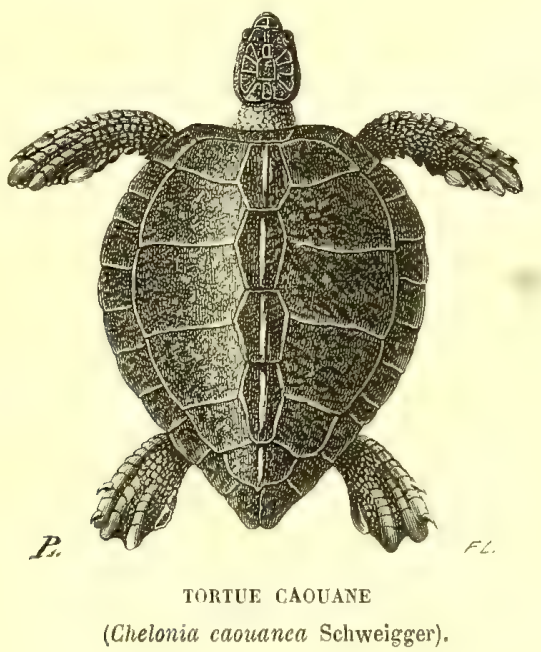

C'est la reine des Tortues de mer. Il y en a une trèsbelle dans les galeries du Muséum d'histoire naturelle, rapportée de Rio-Janeiro par Delalande. Cette espèce peut arriver à environ 126 centimètres de grand diamètre et dépasser le poids de 200 kilogrammes.

Sa carapace est couverte de plaques cornées, grandes, minces, transparentes, et d'un brum moucheté de blanc et de jaune vif.

La Tortue franche ou Midas' se trouve dans l'océan

\footnotetext{
'Chelonia Midas Schweigger; vulgairement aussi, Tortue verte, Tortue commune.
} 
Atlantique. On la rencontre quelquefois à Madire et anx îles Canaries.

Elle a de 150 à 160 centimètres de grand diamètre; elle pèse généralement une centaine de kilogrammes.

Sa carapace offre des places marron glacées de verdâtre, veinées longitudinalement de nuances phus claires. Son plastron est d'un jaune-serin verdâtre.

Pline assure qu'il en existe dans la mer des Indes, qui sont si grandes, que leur carapace sert de nacelle aux habitants des îles de la mer Rouge, et qu'une seule suffit pour couvrir une maison. La véracité du naturaliste romain est quelquefois un peu suspecte....

Quelques voyageurs prétendent qu'on rencontre, aux Antilles, des Tortues de mer sur le dos desquelles quatorzc hommes peuvent se tenir debout à la fois (?).

Dampierre cite un individu très-grand dont la déponille formait un petit bateau. Un enfant de neuf à dix ans, le fils du capitaine Rocky, s'y embarqua pour aller, à un quart de mille de distance, gagner le navire de son père.

En 1752, la mer jeta dans le port de Dieppe une Tortur franche qui avait 2 mètres de long et 130 cenitimètres de large, et qui pesait 450 kilogrammes.

En 1754, on en prit une autre dans le pertuis d'Antioche, à la hauteur de l'ỉle de Ré, qui offrait à yeu près le même poids. Elle mesurait 2 mìtres 60 centimètres depuis le musean jusqu'à la queue. La carapace seule avait plus d'un metre et demi de longuem. Quand on lui coupa la tête, elle répandit huit litres de sang. On en retira 50 kilogrammes de graisse. Son foie se trouva, dit-on, assez volumineux pour donner à diner à plus de cent personnes (?).

La Tortue caret se trouve dans l'océan des Indes et dans l'Océan américain. 
Cette espèce a 73 centimètres de grand diamètre. Elle est, par conséquent, moins grosse que la précédente.

Sa carapace est marbrée de brun sur un fond fauve et jaune.

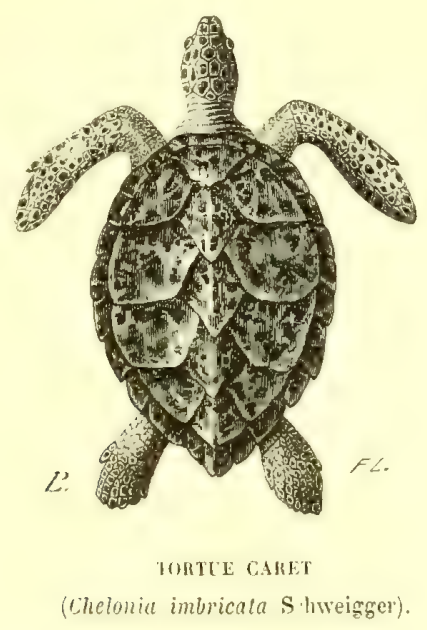

Dans ces trois Tortues, la carapace est écalleuse; mais il en existe une quatrième, qui ne présente autour de cette armure qu'une simple peau coriace, avec trois arètes saillantes dirigées longitudinalement : c'est le Luth ${ }^{1}$, espèce assez rare, qui habite la Méditerranée et l'océan Atlantique.

Elle offre environ 2 mètres de longueur.

Rondelet parle d'un Luth long de cinq coudées, qui avait été pêché à Frontignan.

Amoreux en a décrit un autre pris dans le port de Cette.

Delafond en signale un troisième, capturé à l'embouchure de la Loire en 1726.

Borlase en a figuré un quatrième, harpomé sur les côtes de Cornonailles en $17 \%$ iti. 


\section{III}

Les Tortues de mer ont des mâchoires sans dents. Leurs gencives sont cornées, dures, à bords tranchants comme le bec d'un oiseau de proic. Elles coupent les Zostères, les Ulves, les Varees, dont ces animaux font leur principale nourriture.

La Caouane est simplement herbivore, tandis que la Tortue franche mange non-seulement des matières végétales, mais encore des Zoophytes et des Sèches.

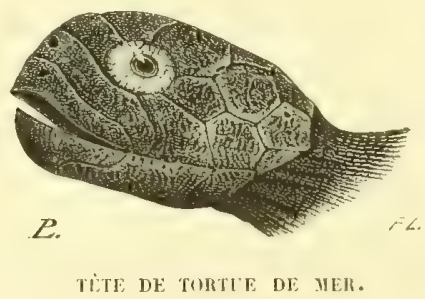

Les Tortues de mer passent pour des animaux lourds, timides et assez doux. Leurs nembres sont transformés en rames aplaties, légèrement courbées d'avant en arrière. Les antérieurs dépassent du tiers les postérieurs.

Les Tortues marines nagent et plongent avec la plus grande facilité; elles peuvent rester longtemps sous l'eau. L'orifice externe de leur canal nasal est surmonté d'une masse charnue, dans l'épaisseur de laquelle on distingue le jeu d'une soupape que l'animal soulève lorsqu'il est dans l'air, et qu'il ferme hermétiquement lorsqu'il s'enfonce dans l'eau (Duméril). Leur marche est assez pénible. Le missionnaire Labat s'est fait plus d'une fois porter par cette lourde et un peu cahotante voiture.

Dans les parages tranquilles, on aperçoit de temps en 
temps, à la surface de la mer, à sept ou huit cents lieues de terre, des Tortues qui flottent dans une immobilité absolue. Elles dorment.

Ces reptiles n'ont pas d'armes pour se défendre, mais leur carapace les protége jusqu'à un certain point. Ils ont, du reste, la vie très-dure. On en a vu, la tête coupée et le cour arraché, remuer encore les nageoires, et donner des signes de souffrance.

Les Tortues de mer sont ovipares. A l'époque de la ponte, les femelles se rendent à terre après le coucher du soleil, pour déposer leurs œufs. Elles crensent un trou sur le rivage, écartant très-habilement le sable avec leurs pieds postérieurs, qui fonctionnent alors comme de larges pelles. Ce trou peut avoir une soixantaine de centimètres de profondeur. Le prince Maximilien de Neuwied rapporte avoir vu une Tortue franche, sur la côte du Brésil, qui creusait ainsi la grève. On s'approcha doucement; elle ne se dérangea pas. Il fallut quatre hommes pour la soulever. Bientôt elle se mit à pondre. Un soldat recueillit une centaine d'œufs dans l'espace de dix minutes. Cette espèce peut, du reste, en déposer jusqu'à cent cinquante.

On dit que les Luths en produisent de deux cents à deux cent soixante.

Après avoir pondu, la mère recouvre ses œufs avec le sable amoncelé derrière elle, et nivelle si parfaitement la surface du sol, que peu de persomnes recomnaitraient qu'on a remué quelque chose en cet endroit. Cette opération terminée, l'animal retourne à la mer.

Les cuf's sont arrondis, un peu déprimés et revêtus d'une coque coriace. La chaleur du soleil suffit pour les faire éclore.

Les jeunes Tortues naissent au bout de trois semaines. Au sortir de l'cuf, elles sont grosses comme de petites 
Cirenouilles, presune anssi molles, et blanchitres. Elles se dirigent aussitòt vers la mer. Les vagues les reçoivent aprelipuefois avee de rudes caresses, et les rejettent de leur sein.

Pendant son séjour aux Florides, plusieurs pêcheurs assurèrent au célèbre naturaliste Audubon, que toute Tortue prise à la place mème où elle dépose ses œufs, et transportée à une distance de plus de cent milles, si on lui rend ensuite la liberté, regagne le lieu où elle a coutume de pondre, soit immédiatement, soit dans la saison suivante.

\section{IV}

On emploie diflérents procédés pour prendre les Tortues.

Dans certains parages, on profite de l'époque où les femelles se rendent à terre pendant la nuit pour déposer leurs aufs. On va les ehercher principalement dans les iles désertes. On recomnait leur passage aux traces qu'elles laissent sur le sable. On les guette, on leur coupe la retraite, et on les renverse sur le dos, soit avec les mains, soit arec des leviers. Ces animaux, ainsi retournés, cherchent quelfue point d'appui; ils ne peuvent se redresser, et on les retrouve, le lendemain, à la même place et dans la même situation.

Il existe entre Vera-Ciruz et Tampico un petit ilot désert, grand tout an plus comme la place de la Concorde, appelé isla de los Lobos (ile des Loups), on ne sait pourqnoi, attendu ifue, bien certainement, jamais Loup, ni camassier semblable au Loup, n'y a posé le pied.

Les Tortues ont pris cet ilot en affection; elles y tronvent 
un asile paisible, entouré de grands récifs et bien défendu contre leurs ennemis, et, de plus, des plages de sable en pente douce, excellentes pour leurs œufs.

En 1862, vers dix heures du soir, l'équipage d'un navire français surprit dans l'ile de los Lobos, à la faveur de la nuit, une énorme Tortue femelle qui rampait sur le rivage. Elle avait une tète grosse comme celle d'un enfant et un bec quatre fois plus grand que celui d'un perroquet. Elle paraissait chercher un endroit pour pondre. Six hommes s'attachèrent à sa carapace et firent de vains efforts pour la retenir ; ils ralentissaient sa marche, mais ils ne l'arrêtaient pas : elle les entrainait vers la mer. D'autres matelots arrivèrent à temps, et l'on réussit à la renverser sur le dos.

Dans cet état, on lui amarra un petit mât entre les nageoires, et on l'emporta au vaisseau. Le monstre pesait 130 kilogrammes. Il fournit à manger à tout l'équipage. 11 avait trois cent quarante-sept oufs dans le corps. (De Jonquières.)

Les Carets, qui ont le dos plus bombé que les Tortues franches et les mouvements plus vifs, pourraient se déretourner. A cause de cela, on les charge d'une pierre, ou bien on les tue sur place.

Une sconde manière de prendre ces reptiles consiste à tendre, le soir, un grand filet de cordes à mailles làches, appelé folle, qui leur barre le passage lorsqu'elles se rendent a terre pour y pondre. Elles engagent la tête ou les nageoixes dans les mailles, et s'entortillent de telle sorte, qu'elles ne peuvent plus venir respirer à la surface de l'eau, et qu'elles finissent par se noyer. Il faut avoir la précaution de teindre ce filet: quand il est grisâtre ou blanchâtre, les Tortues s'en défient et rebroussent chemin.

Certains pêcheurs font la chasse aux Tortues lorsqu'elles viennent eu pleine mer, à la surface de l'eau, pour res- 
pirer. Ils leur lancent un harpon, espece de javelot à pointe triangulaire comme celle d'une flèche acérée et tranchante, portant un anneau auquel une corde est attachée. On se sert aussi d'une varre, autre harpon à pointe sans crochet. Il faut de l'adresse pour faire pénétrer cet instrument. Quand il est entré dans l'écaille de la Tortue, c'est comme un clou enfoncé dans une planche, et qui ne peut en être arraché sans de grands efforts. Dès que l'animal se sent blessé, il plonge et entraìne le trait avec lui. On lâche d'abord une certaine longueur de corde, puis on attire la Tortue sur le bord de l'embarcation.

Dans les mers du Sud, des plongeurs habiles et exercés profitent du moment où les Tortues sont endormies à la surface de la mer, s'en approchent doucement, et lorsqu'ils sont à portée, ils percent l'animal. Si la Tortue n’est pas très-grande, ils la saisissent sans la harponner.

Les Tortues sont souvent d'une force extraordinaire, à cause de leur taille, et peuvent entrainer le canot à une grande distance et mème le faire chavirer.

Plusieurs auteurs ont rapporté un fait curieux qui s'est passé à la Martinique, en 1696. Un Indien esclave, étant seul à pêcher dans un petit canot, aperçut une Tortue qui dormait sur l'eau. II s'en approche doucement, et lui passe autour d'une patte un nœud coulant, ayant d'avance fixé l'autre bout de la corde a l'avant du canot. La Tortue s'éveille, et se met ì fuir, comme si elle ne traînait rien après elle. L'Indien ne s'épouvante pas de se voir emporté avec tant de vitesse. II se tenait à l'arrière, et gouvernait aree sa pagaie pour parer les lames, espérant que la Tótue se lasserait enfin ou qu'elle étoufferait. Mais il eut le malheur de chavirer, et de perdre dans cet accident sa pagaie, son coutean, ses lignes et ses instruments de pêche. Quoiqu'il fùt habile nageu' et marin expérimenté, il ne parvint 
qu'arec beaucoup de peine à retrouver son canot. Comme il ne pouvait plus gouverner, le même accident lui arriva neuf ou dix fois, et à chacune, pendant qu'il travaillait, la Tortue se reposait, reprenait des forces, et recommençait ensuite une nouvelle course aussi rapide que la première. Elle le traîna ainsi un jour et deux nuits, sans qu'il lui füt possible de détacher ou de couper la corde. La bête se lassa enfin, et le bonheur voulut qu'elle échouât sur un haut-fond, où l'Indien acheva de la tuer, étant lui-même demi-mort de faim, de soif et de fatigue.

Sur les côtes de Cuba et de Mozambique, les pêcheurs se servent, pour prendre les Tortues de mer, de certains poissons vivants, dressés, pour ainsi dire, à cette chasse. Ces poissons, voisins du Rémore, sont plus grands et plus longs. On les appelle Poissons pécheurs ou Sucets. Les Espagnols les nomment Revés (reversi), parce que, au premier abord, on est tenté de prendre leur dos pour leur ventre.

Ces poissons portent au sommet de la tête une plaque ovale, à rebords charnus, offrant intérieurement une vingtaine de lamelles parallèles, formant deux séries garnies sur leur bord de petits crochets qui ressemblent aux pointes d'uue carde. Les pècheurs tiennent phusieurs Sucets dans des baquets pleins d'eau, et chaque nacelle a son barquet particulier. Quand on voit de loin quelque Tortue endormic, ou s'en approche sans bruit, puis on jette à la mer un de ces poissons. Aussitòt que celui-ci aperçoit le reptile, il se précipite sous lui, et s'y cramponne fortement avec sa dilatation céphalique.

Le Revé, dit Colomb, se laisserait mettre en pièces plutôt que de lâcher le corps auquel il adhère.

Ce poisson étant attaché à une longue corde tressée avec de l'écorce de palmier, au moyen d'un anneau dont sa 
quene est garnie, les pècheurs tirent cette corde et amènent dans leur barque et le poisson et la Tortue.

Quand cette dernière est prise, on détache le Sucet en lui imprimant un mouvement d'arrière en avant, lequel fait renverser à l'instant tous les crochets.

En général, la pêche des Tortues de mer est faite sans discernement et sans frein; d'où il résulte comme conséquence inévitable, qu'au bout d'un temps peu éloigné, ces précieux animaux deviendront rares.

11 existe, il est vrai, dans plusieurs pays, des parcs à Tortues, donnant lieu à un commerce considérable. Ces pares sont approvisionnés par la priche vulgaire, mais on ne s'y ocempe guère de la multiplication de l'espèce. On assure cependant que, dans l'ile de l'Ascension, on respecte les œufs et l'on protége les jeunes sujets jusqu'à ce que leur carapace ait assez de dureté pour défendre suffisamment l'animal.

M. Salles, capitaine au long cours, a proposé de multiplier les Tortues de mer dans la Néditerranée. La Société zoologique d'acclimatation s'est empressée d'approuver et d'encontager les conclusions de son mémoire. Le succès est d'autaut plus certain, qu'il s'agit non pas d'introduire une nouvelle espèce dans les localités qui en étaient privées jusqu'à ce jour, mais seulement de repeupler des régions aujourd'hui très-appauvries et où les Tortues se trouvaient autrefois en nombre considérable.

Les Tortues de mel constituent un mets abondant, sain ct mutritif. On peut faire cuir la chair dans sa propre carapace. Cette casserole naturelle est un moven expéditif dont se servent les sauvages. 
Les Inglais aiment beaucoup la chair de la Tortue franche; ils la trouvent supérieure à celle du Bœuf: La graisse de cette Tortue est d'un vert assez foncé, et si abondante, qu il n'est pas rare d'en extraire jusqu'à vingt-huit litres d'un seul individu.

On sait que la soupe à la Tortue jouit d'une certaine réputation chez nos voisins d'outre-Nanche. C'est l'amiral Anson qui apporta en 1732 la première Tortue qui fut mangée à Londres.

La chair du Caret passe pour très-médiocre, mais les œuf's sont fort délicats. Les paquebots apportent régulièrement en Anglelerre des quantités considérables de Tortues de mer. Malheureusement, le prix de plus en plus élevé de ces animaux ne permet pas de les servir sur toutes les tables. C'est pour cela sans doute que, dans la fameuse sonpe à la Tortue, on substitue sonvent à la chair du précieux animal de petits cubes de tête de veau!

Les Tortues de mer fournissent à l'industrie les matériaux d'une foule de jolis petits meubles.

Carvilius Pollio, d'apris Pline, homme extravagant, mais inventif, parait être le premier qui tailla et faconna les plaques des Tortues. Il en orna des armoires et des bois de lit.

Les patriciens, sous le règne d'Iuguste, en décoraient les portes et les colonnes de leurs palais.

Les Romains faisaient venir les plaques de l'Égypte. Lorsque Jules Césir s'empara d'Alexandrie, il tronva dans les magasins une si grande quantité d'écailles, qu'il s'en servit pour embellir son entrée triomphale.

L'écaille des Tortues est douce au toucher et riante à l'ail, comme disent les marchands, mais en mème temps assez fragile.

Le Caret est l'espèce dont les plaques sont les plus estimées. 
On distingue dans le commerce quatre variétés de cette écaille. La meilleure est celle qui vient des mers de la Chine et des Philippines. Ces plarues sont noires, avec des jaspures d'un jaune clair, bien transparentes et parfaitement détachées. Le Caret des îles Seychelles (qui arrive par Bourbon) a des plaques plus épaisses, d'une couleur vineuse, avec des taches d'un janne noins clair, moins transparent et moins tranché. Le Caret de l'Inde, appolé souvent écaille d'Egyple, paree qu’il est expédié par la voie d'Mexandrie, offre une teinte brune mancée de rouge, avee des taches d'un rouge brun et d'un jaune-citron.

Les plaques de la Caouane sont les moins recherchées: elles se rapprochent de l'apparence de la corne. Elles sont de couleur brun noirâtre ou brun rougeâtre, avec de grandes taches transparentes d'un bane sale, et de plus petites opaques ou d'un blane mat.

La Tortue franche a des jlarpues minces, flexibles, élastiques, transparentes, d'un janne pâle, marquetées de jaune rougeâtre et de noir.

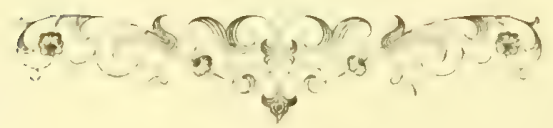




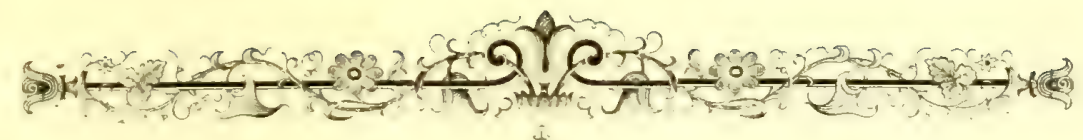

is

\section{CHAPITRE XLI}

\section{LES OISEAUX DE MER.}

Voulez-rous aimer, rous aimez.

In lieu vous déplait-il, vous allez dans un autre.

DESUU[CIIERES.)

Les Oiseaux sont fils de l'air, comme les Poissons fils de l'eau. Mais, parmi eux, une tribu considérable réclame ces deux éléments.

Ceux-ci, dits aquatiques, habitent en familles nombreuses nu milicu de la mer et sur ses rives, sur les lacs et sur les fleuves.

Les Oiseaux qui fréquentent, soit exchusivement, soit ordinairement, l'eau salée, sont appelés marins ou pélagiens. Ils composent, suivant Charles Bonaparte, lit quatorzième partie de tous les Oiseaux du globe ${ }^{1}$.

Les ()iseamx arguatiques offrent géméralement des pattes avec les doights réunis par des membranes, ce qui les a fait nommer Palmés on Palmipèdes. Cette structure existe chez presque toutes les espèces marines.

\footnotetext{
T.e nombre de loutes les espèces du globe pst de 9400 .
} 
Les pieds palmés forment comme deux petites rames légères, admirables pour naviguer.

Ordinairement, les membranes unissent seulement les trois doigts antérieurs, celui de derrière restant libre; d'où il résulte une palette triangulaire à trois nervures (Canards, Pétrels). Mlais, dans quelques espèces (Cormorans, Pélicans), les doigts de devant et le postérieur sont tous unis.
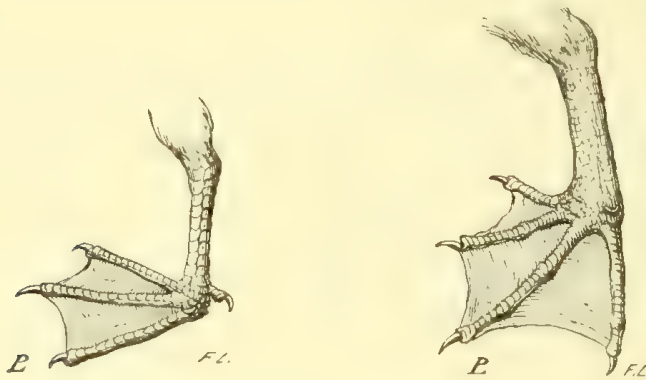

PATTES D'OISEAIX PAIMPEDES.

Ils composent ainsi une rame beancoup plus grande que celle des Palmipides proprement dits; laquelle n'est plus triangulaire, mais en forme de trapèze.

Les rames des Oiseaux sont d'autant plus commodes, qu'il n'est pas besoin, comme pour les rames ordinaires, de les sortir de l'ean ì chaque coup; il suffit que les doigts se rapprochent pour que la patte puisse, prestue sans effort, être ramenée en avant. Là les doigts s'écartent de nouveau, la membrane s'étend, et la palctte se reforme pour frapper le liquide une seconde fois.

Les Oiseanx manins pourraient ìtre rangés géographiquement en quatre groupes :

$1^{\circ}$ Les Voiliers (on Longipennes), tels que les Albatros et 






les Pétrels, qui fréquentent la hante mer. On les rencontre a des distances inouies de toute terre; ils s'approchent rarement du rivage.

2 Les Marilimes ordinaires, tels que les Moueltes et les Fous, qui s'arancent assez loin du rivage, mais qui reviennent, chaque soir, vers les îles ou vers la terre ferme.

$3^{\circ}$ Les Riverains, tels que les Canards et les Harles, qui s'écartent très-peu des còtes, et semblent mème préférer à la mer les étangs, les marais et les embouchures des cours d'eau.

$4^{\circ}$ Les Nageurs, tels que les Pingouins et les Manchots, qui se tiennent aussi à une faible distance du rivage. Ceux-ci sont privés de la faculté de voler, mais ils nagent et plongent d'une manière merveilleuse.

\section{1}

Nous ne connaissons pas d'Oiseaux qui représentent mieux la grande tribu des P'almipètes que les Goëlands.

Parmi ceux-ci, on pourrait regarder comme type principal le Goëland argenté", si commun dans les mers du Nord.

Ce bel Oiseau est de la taille d'une Corneille, mais il a des ailes phus longues et phus effilées. Son corps parait bien pris, ni trop massif, ni trop élancé. Il porte un manteau uniforme, d'un cendré clair, légèrement blenâtre. Les extrémités de ses ailes sont de velours noir, avec des pointes d'un blanc de neige. Sa tête présente des yenx d'un jaune pâle (ce qui ne les empèche pas d'être expressifs), et un bec robuste couleur d'ocre, avec une tache de corail à

1 Larus argentatus Brünnich (voy, la planche XVIII). 
l'angle inférieur. Les pieds sont couleur de chair un peu grisâtre.

Ce Goëland est déliant et farouche, cependint on l'a pprivoise aver facilité. Il tient la tite hante, un peu ramenée

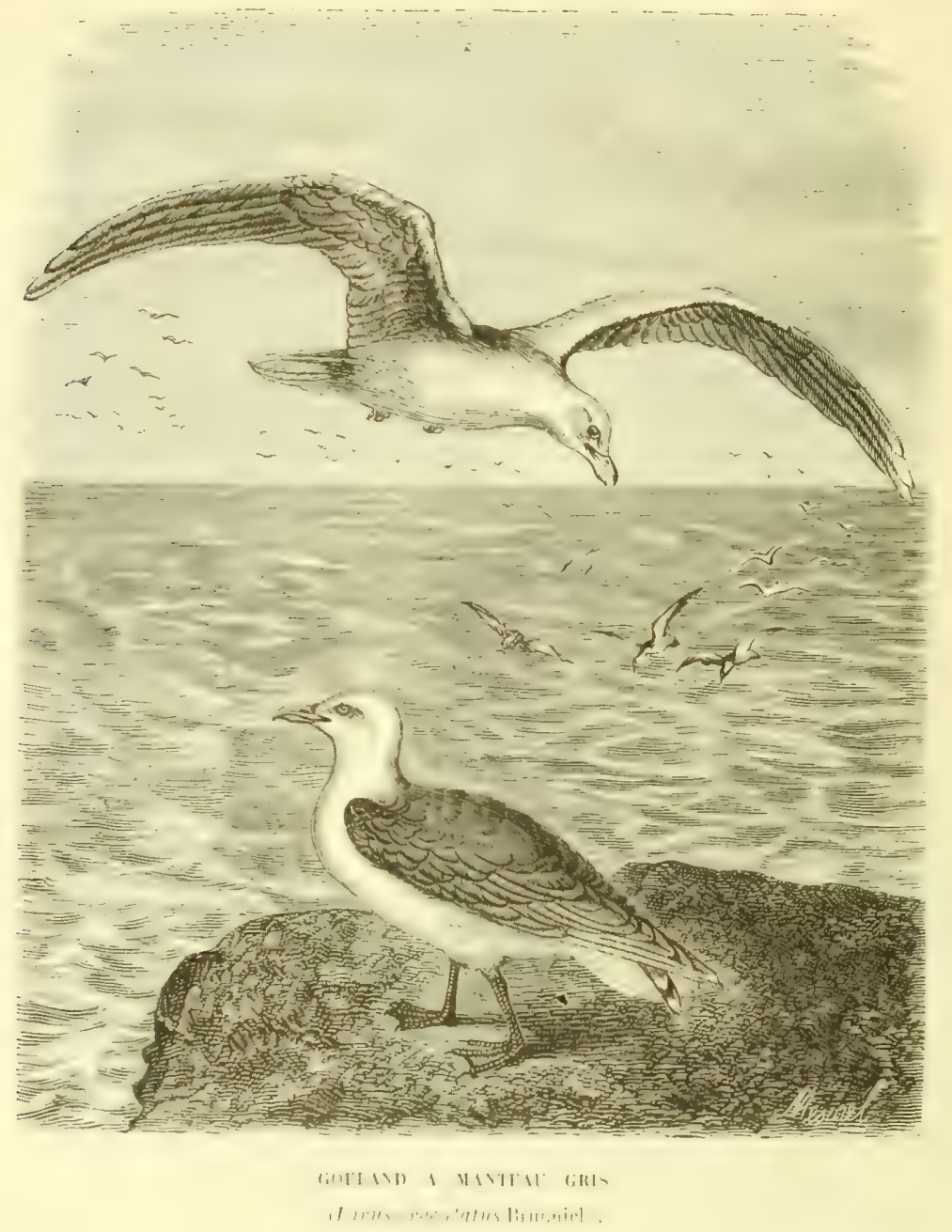

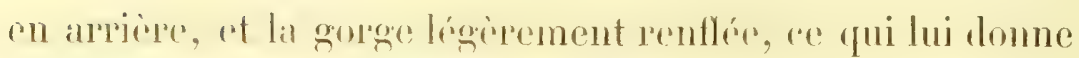
111 air a'mportance, moins caractérisé, tontefois, que celui des Cimiuds. Tantit il se couche doucement et paresseusement sum le salble. an solpil, les veux demi-fermés on fixés 
sur la mer, dans la situation d'une Poule sur ses øufs, ou bien les ailes à moitié ourertes, écartées, pendantes, comme une Perdrix sur ses poussins; tantit il se redresse sur un pied, cachant l'autre dans son duvet, et demeure des heures entières immobile, muet, méditatif, semblable à un Échassier à pattes courtes qui digère son repas.

Quand le Goüland argenté marche, il a de l'assurance et de la dignité; mais il ne se dandine pas. Il court assez vite. Lorsqu il nage, il fend l'eau avec lenteur. Il plonge rarement et péniblement : on voit qu'il n'a pas l'habitude d'aller chercher sa proie au fond de l'eau.

Son vol est ferme et soutenu; il le dirige en ligne droite par des battements d'ailes émergiques et fréquents, avec des balaneements légers et onduleux yui ajoutent à sa grâce sans rien ôter à sa rapidité.

\section{I}

Les Oiseanx palmipèdes aiment en général les grands balancements de la mer et le fracas des tempêtes. Ils semblent plus rares dans les beaux temps ou plus difficiles i approcher. On dirait que l'agitation des vagues est nécessaire pour leur fournir phus aisément les Mollusques et les Poissons qui font leur nourriture, et que, dans les grandes perturbations de l'atmosphère, ils ont un plaisir instinctit particulier ì lutter contre les ouragans of it se joucr des flots en courroux. (Lesson.)

Les ailes blanches des Mouettes et des Ilirondelles de mer, quand ces oiseaux se jouent au milieu d'une tourmente, produisent $m$ admirable contraste aver les nuages noirs qui obscurcissent l'horizon. 
Les (liseaux marins varient beaneoup pour la taille. Le plus grand est l'Albatros, surnommó Monton du Cap ou Vaisseau de guerre, qui offere une enveroure de 4 mitres

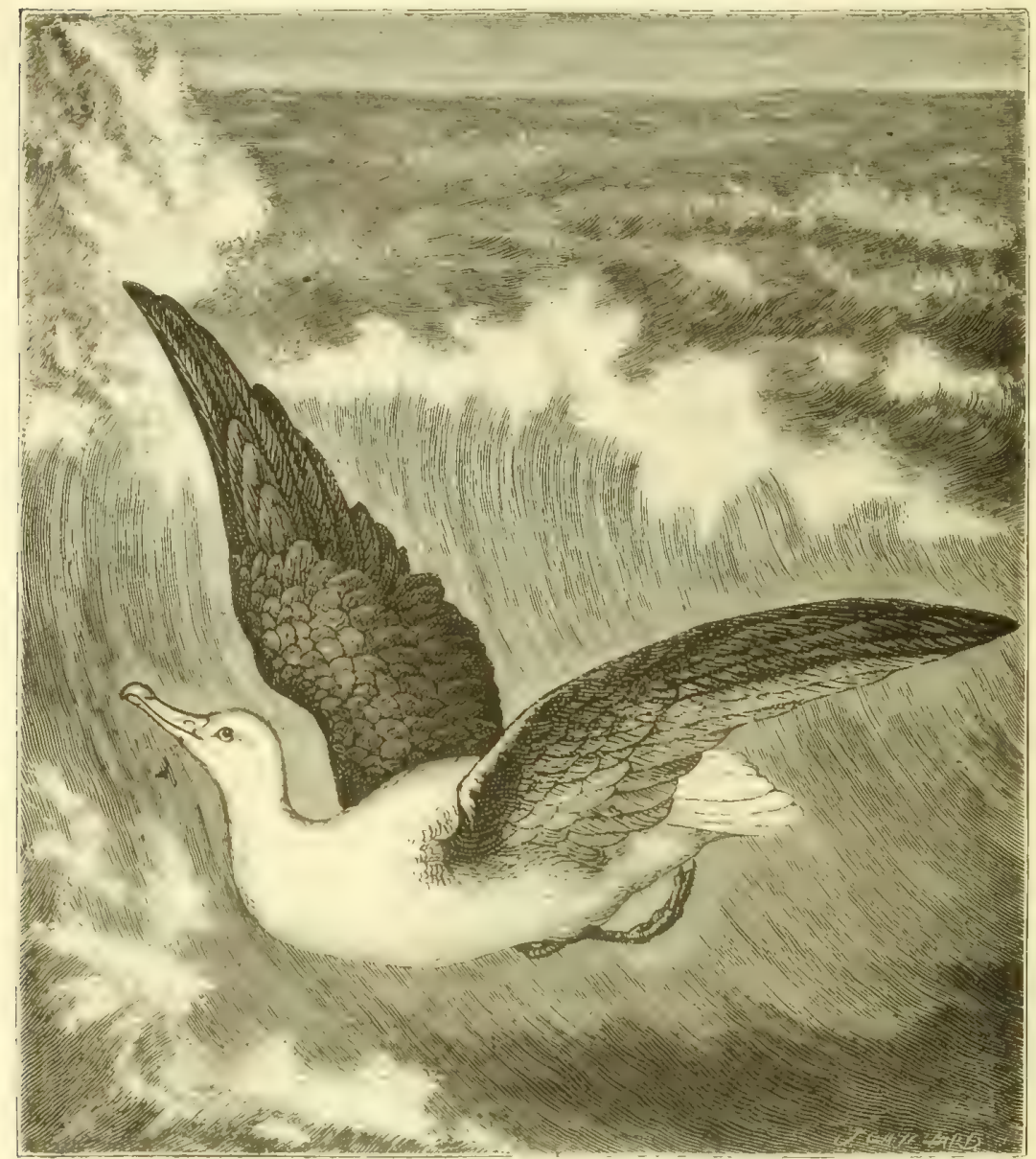

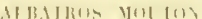

(Diomedea exulans linné)

environ. Le plus pelit est l'Oiseau de tempête, qui atteint à peine la taillo du Moinean. L'Nllbatros est le géant des Palmipèdes, l'Oiseau de tempête en est le nain.

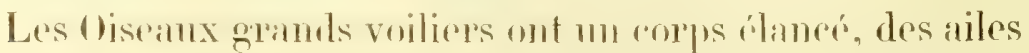


cllilées et une longue queue. Ils sont organisés pour le vol de lougue haleine. Mais les nageurs présentent un corps trapu, des ailes réduites à des moignons et nne queue rudi-

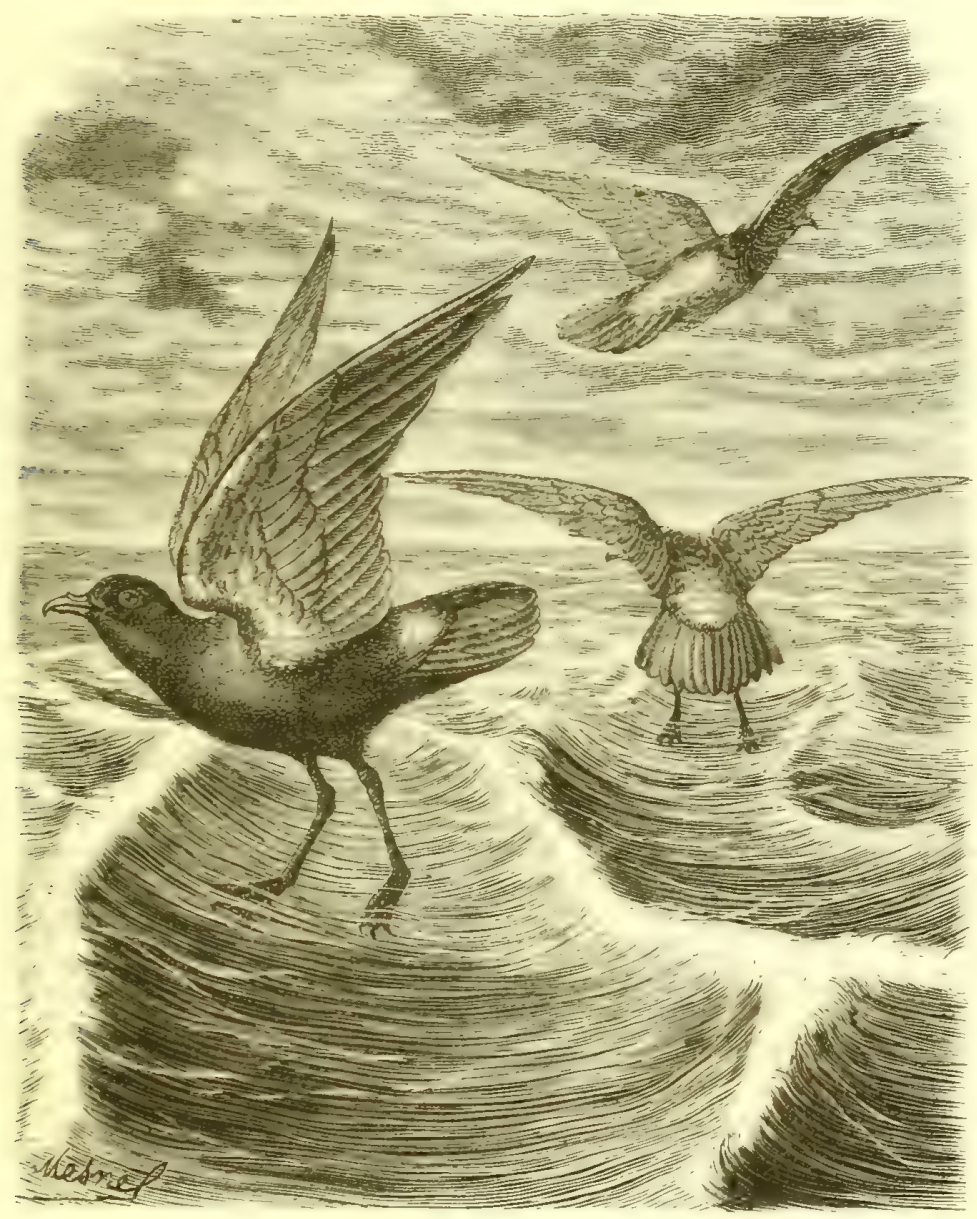

HSI M HE TIUITI

(Thalusidroma pelagica Tenuminch).

mentaine. Tous portent 1 m plumage serre, gami de duvet et enduit d'une humeur huileuse qui le protége contre l'eau. 
Les Palmiperdes se nomrissent de substances rigétiles, de Mollusques et de Poissons.

Nos pêcheurs se réjonissent à la vue du Stercoraire parasite'; il leur décile les gramdes colonnes de Ilarengs, qu'il accompagne ou qu'il poursuit.

Les Goülands et les Pétrels se préeipitent sur les Cachalots et sur les Dauphins ćchoués, of lemr arrichent des lambeaux de chair huilcuse.

Les Albatros, ces vautours de l'Océan, sentent une Baleine morte d'une distance vraiment considérable.

Les Canards ont le bec garni sur les bords de cannelures paralleles, admirablement disposíes pour permettre a loisean, lorspu il barbote, de cribler les matieres dont il reut faire son lepas. Ce bee est aplati comme une pelle, arec unr mandibule infóricure en forme de cuiller. II semble frapper l'eau.

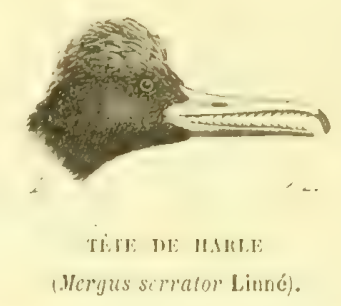

Les Ilarles, intrépides prehenrs, cousins germains des Canards, présentent à la marege de leurs mandibules des dentelures tres-pointues, a l'aide destuelles ils retiennent solidement les patures poissons. Ces dentelures sont dirigées d'arant en arrière, de manière que la proie ne peut

1 Lestris parasitica Boje. 
pas séchapper de la pince vivante qui la retient, mais peut ètre dirigée facilement vers le gosier.

Les froïlands ont l'extrémití du bec contróe en crochet. Ils frappent ef happonnent aree cette arme toujours aiguise les animanx marins les plus glissants. lls s'élancent le plus sourent entre deux vagues arec la rapidité d'une fleche, of reparaissent an bout d'um instant, tenant au bec quelque animal.

Les Ilirondelles de mer fuligineuses ${ }^{1}$ ne plongent jamais la tite en bas at rerticalement, comme les autres piscivores, mais passent an-dessus des animaux marins en déclivant une courbe et les enlevant avec dextérité. On les voit planer dans le sillage de quelque Marsonin, tandis que ce

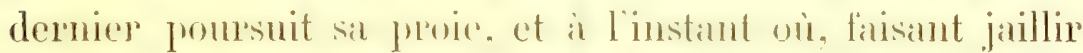
les ourles, le Cétacé amene a la surface lo foretin épouranté, l'oisean se précipitr dans l'an bonillonnante ef cmporte en passant un ou deux petits poissons. (Audubon.)

Le Bec-en-ciseaux posside des mandibules comprimées et tranchantes, disposées comme les branches d'une paire

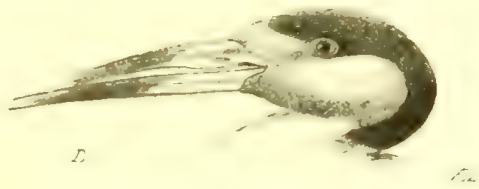

THTE DE BEC-EY-CINAIX

(Rlyuchoys nigna Limuir.

de ciscaux. L'oiseau rase la surface de la mer, et coupe en deux la proie rqu'il peut atteindre.

Les Pélicans offrent au-dessous du bee un sac de peau singulierement extensilule. Ils le remplissent de poissons, qu'ils apportent à leurs petits.

II. Nordmann raconte, dans sa Faune de la mer Noire,

1 Haliplana fuliginosa Wagler. 
fue les l'élicans, très-nombreux dans l'Urient, lont souvent des pêches en commun sur les lates qui avoisinent rette mer.

"C'est ordinairement, dit-il, dans les heures de la matinée ou le soir que ces oiséaux se réminssent dans ce but, procédant d'après un plan systématique qui est apparemment le résultat d'une espèce de convention. Après

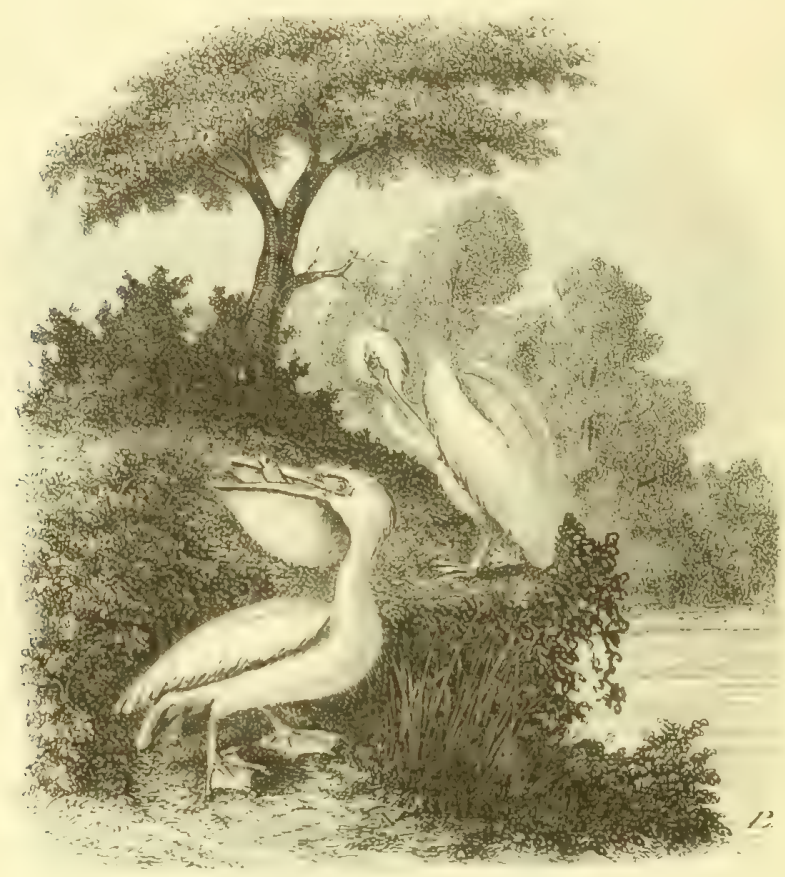

Pl.1.11, IS 131.19

I'clecanus onocrolalus limu:

avoir choisi un condroit convenable, ume baic on l'eau soit basse of le foud lisse, ils se plitcent tout antour, en formant un grand croissint ou $11 \mathrm{n}$ fer it cheval. I a distance d'un oiseatu à $u 11$ antre semble itre mosurée; elle équivaut a son envergore (3 a r mitres). Fin battant fréquemment la surface de leau aree leur's ailes déployées et en plongeant de temps en temps aree la moitié du corps, le cou tendu en avant, les Pélicans s’approchent lentement du 
lirage, justua a ce que les poissons réunis de la sorte se trouvent enfermés dans un espace étroit. Alors commence le repas commun.

"Outre les quarante-neuf Pélicans dont la compagnie. se composait ce jour-là, il s'était rassemblé sur les tas d'ulves, de conferves et de coquilles rejetées par les vagues ct amoncelées sur le rivage, des centaines de Monettes, d'llirondelles de mer, de Choucas, qui se préparaient à happer les poissons chassés hors de l'eau et à partager cutre cux les restes du repas. Enfin, plusieurs Grèbes, de la petite et de la moyenne espèce, nageant dans l'espace circonscrit par le demi-cercle, tant que cet espace fut encore assez grand, prirent, eux aussi, leur part du festin, co plongeant fréguemment après les poissons effrayés et étourdis.

"Q Quand tous furent rassasiés, la compagnie entiere se rassembla sur le rivage pour attendre le commencement de la digestion. Les Pélicans lustraicut Jem plumage, recourbaient le cou pou le laisser reposer sur le dos, et liaisaient ainsi, à côté des petites et fréles Mouettes, l'effet de colosses informes. Leur tronpe se composait d'oiseaux de différents âges; il y en avait de tout blanes, de higarrés et de gris. De temps an temps quelqu'un de ces niseanx vidait sa poche birn garnie, en étendait le contenu devant lui, et se plaisait i le contempler. Les poissons "fui se débattaient encore avaient bientòt la tête écrascé d'un coup de bec. ")

Les Cormorans ont une gibecière du mime genre que celle des l'élicaus, mais beaucoup moins développée. Les Chinois élèvent ces animaux et les emploient comme pècheurs. Ils leur passent au cou un amneau étroit pour les empècher d'avaler les proies quils ont saisies. Mais 


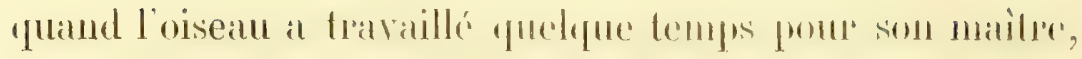
celui-ci enleve le collier, of permet an Cormoran de pêcher pour son propre compte.

- Certains Oiseaux de mer, yui ne prosident ni bee tranchant, ni gibecière gutturale, et qui se nomrissent de coquillages opereulés et solidement barricadés, ont l'instinct de les porter dans les hauteurs de l'atmosphère, et de les lasser tomber sur un rocher pour briser leur enveloppe.

Les Pétrels, qui ne mallgent guère que des poissons, sont tellement huilenx, que les hahitunts des iles feroü tuent ces oiseaux, leur passent une mèche à travers le corps, l'allument, et se servent du Palmipède comme d'unc lampe.

Du reste, beancoup doiseanx piscivores sont chargés d'une graisse pen consistanle: pulils doivent a leur genre de nourriture. A cause de cette circonstance, certains d'entre eux ont été nomnés Pingouins, mot dérivé du latin pinguis (gras, huileux).

Sur les côtes de la Patagonic, où les Manchots sont abondants, on prend ces viscanx, on les écorche, et l'on fait de l'huile aree lan pean. Cefte anveloplpe, doublée d'une conche de graisse plus on moins forte, est soumise à l'action d'une presse, qui ne laisse d'autre résidu que le derme et le duvet. On retire un demi-litre d'huile de charque animal. Il fiut 2000 ) Vanchots pour remplir un tonneau.

Quand on saisit nn Fulmar ${ }^{1}$, il ronit une huite couleur d'ambre, qui est reczardéc par les habitants de Saint-Kilda comme un bon remède dans plusicurs maladies extériemes,

1 Procellaria glacialis Limm. 
surtont dans te phumatisne. On lnule anssi cette huile. La meillene est produite par les rieux oiseaux.

In surprend les fulmars pendant la muit. On leur presse le bec, et on leur fait rendre environ deux cuillerées d'huile. (L. Wraxall.)

Ce sont les diseaux marins qui prodnisent eette matiere préciense appelée guano, ou, pour mieux dire, huanu, si recherchée par les agriculteurs.

Le guano ${ }^{1}$ est un amas d'excréments déposés au sein de la mer, sur des rochers ou sur des îles. On a calculé yu un Palmiperle de taille morenne en fournit à peu près 23 grammes par jour. Or, sur certains rochers, on trouve des conches de guano offrant justgu'a 30 metres d'épaisseur. Il a done fallu des centaines d'amnées et des milliers d'oiseaux pour former ces dépòts. (Boussingault.)

L'ile de Cincha, près du Pérou, à 100 milles au sud de Calao, est un des endroits les plus riches en guano. Les conches supérieures de cette matière sont d'un brun grisitre, et les conches intérienres couleur de rouille. La dureté du guano est d'antant phos grande, quil est situé plus profondément.

Les Oiseaux producteurs du guano sont surtout le Fon varié2, le Goëland modeste ${ }^{3}$ : l'Anhinga ${ }^{4}$, le Bec-en-

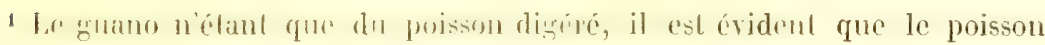
nalurel doit constituer aussi un engrais d'une grande valeur. Dans les localités maritimes où l'on se lirre aux grandes pêches du Hareng, de la Sardine, de la Morue, on utilise les poissons avariés ou les débris inutiles, pour composer un fumicr appelé engrais-poisson, lequel remplacera peut-ĉtre, un jour, le guano, dont les couches sont loin d'être inépuisables.

$\Lambda$ cet effet, on fait cuirc le poisson; on le presse, on le dessèche, on le réduit en poudre. Cet engrais étant à un point de décomposition moins avancé que le guano, agit moins rapidement que ce dernier. Il en a toutefois les principales propriétés.

2 Dysporus variegatus Ch. Bonaparie.

3 Blasipus Bridgesii Ch. Bonaparte.

4 Plotus anhinga Linné. 
ciseaux, le Pélican thagus, le Cormoran de Ciaimard', et le Cormoran de Bougainville 2 .

\section{1}

La voix des Oiseaux marins n'est jamais douce et harmonieuse comme cello de plusieurs oiseaus terrestres.

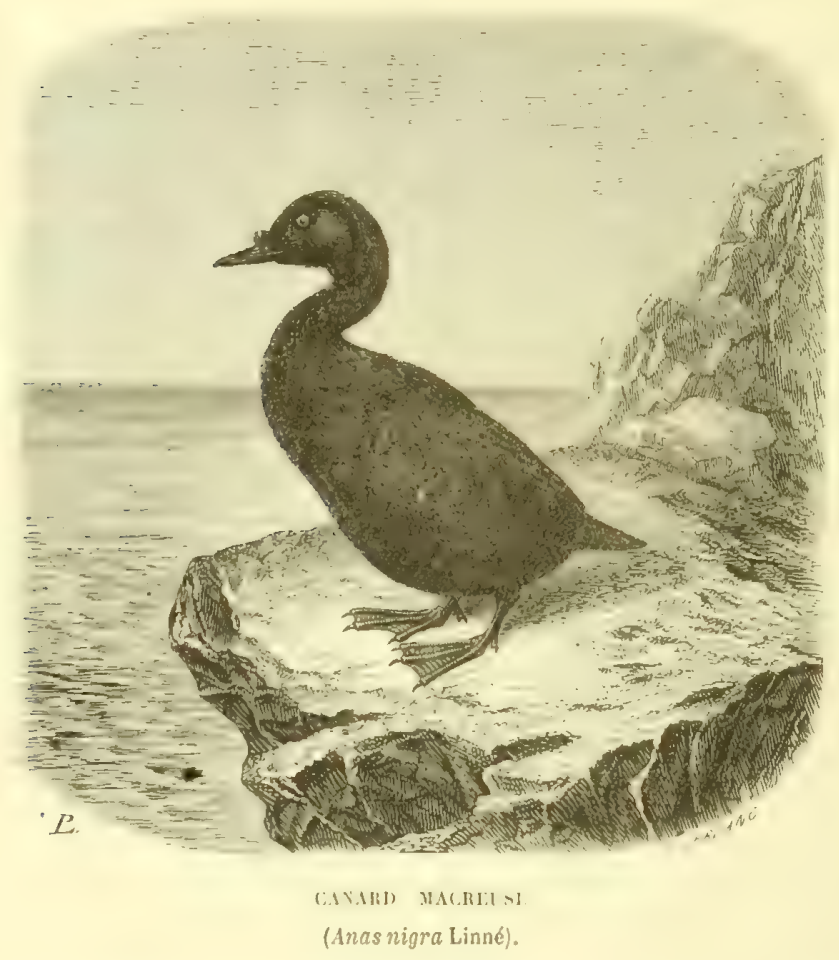

Elle est nasillare ot retentissinte, el tient souvent du raugue ou du lugubre. Cependant les Goülands el les Monettes jettent des rris aigus qui dominent le bruit de

- Stictocarbo Gaimardi Ch. Bonaparte.

${ }^{2}$ Hypoleucus Bougainvillei Lesson. 
lir tempite. Cortains Camards rendent une clangueur percante comme celle du clairon.

Quelipus Palmipedes, wont la trachée est grande et recourbere, imitent plus axactement le son de la trompette.

Il y a des bisanux péligiems qui semblent pleurer comme de petits unfants, ou licaner comme de ricilles femmes.

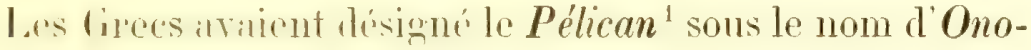
crolale (cri de l'âne), parce que cet oiseau semble braire.

Les Pingouins ont un croassement tout aussi grave

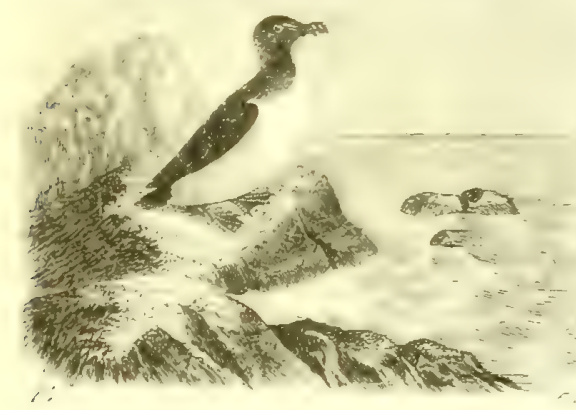

prigorin Conmex

Illea torila I innil.

ct tout aussi désagréable. Lesson dit que, dans l'île de Falkliml. Ir soir, an antrel du soleil, tous les Pingouins poussaient ensemble, à gorge déployée, un immense cri, qui retentissait an loin comme les clameurs d'une armée en révolte.

Un observallum tris-oliginal, habitant d'un port de mer, a étudié pendant huit ans la langne du Pierre-garin ${ }^{2}$.

1 Pelecanus onocrotulus Linné.

2 Sterna hirundo Linné. 
Il en a composé le dictionnaire, preniunt pour modìle le travail de Dupont de Nemours sur la langue du Corbean. Il a distingué cinfuante mots exprimant chacun, suivant lui, une idée particuliere: Ici... là... en avanı... en arrière... à droile... à gauche... plus vite... plus lentement... halle... garde à vous... nourriture... danger... Je lamme... moi de même... méchant... marions-nous... quel bonheur... un mid... nos aufs... couvons... nos petits... Maman... papa... jai faim... Tais-toi...

Voici le commencement de cer dictionnaire: Kia, kié, lii,

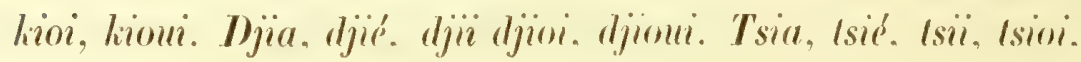
tsioui....

\section{VII}

Les Oiseanx pélagiens onl sonvent des pattes courtes, attaches phus on moins an arriepe: ils matrehent aver manvaise gratere of en se balanganl: plusieurs semblent boiteux.

Les Vagenus se tiomnent redressés sur lenes pattes de derriere of presque renticaux. Les Manchols, vus de loin sur la plage. semblent assis sur lemerompion : on dirail des enfants de charul en camail (Pernetty). D'antes se trainent péniblement sur le sable, lampant persque a plat ventre. Ils se servent quelquefois de leurs ailerons en guise de pattes, ce qui les comvortit momentanément en quadrupèdes.

Quelques espèces aiment ì s'arêter sur les vagues. Le Pétrel damier, ainsi nommó it cause de son dos bigaré de blane et de noir, se repose habituellement dans le sillage des navires, ou le remous hui apporte de nombreux petits mollusques. Le nom de Pßrel, qui signifie pelil Pierre. 
firit allusion an mirade de saint Pierre marchant sur les milix.

Les Palmipèdes sarent nager avec antant d'élégance que de facilité.

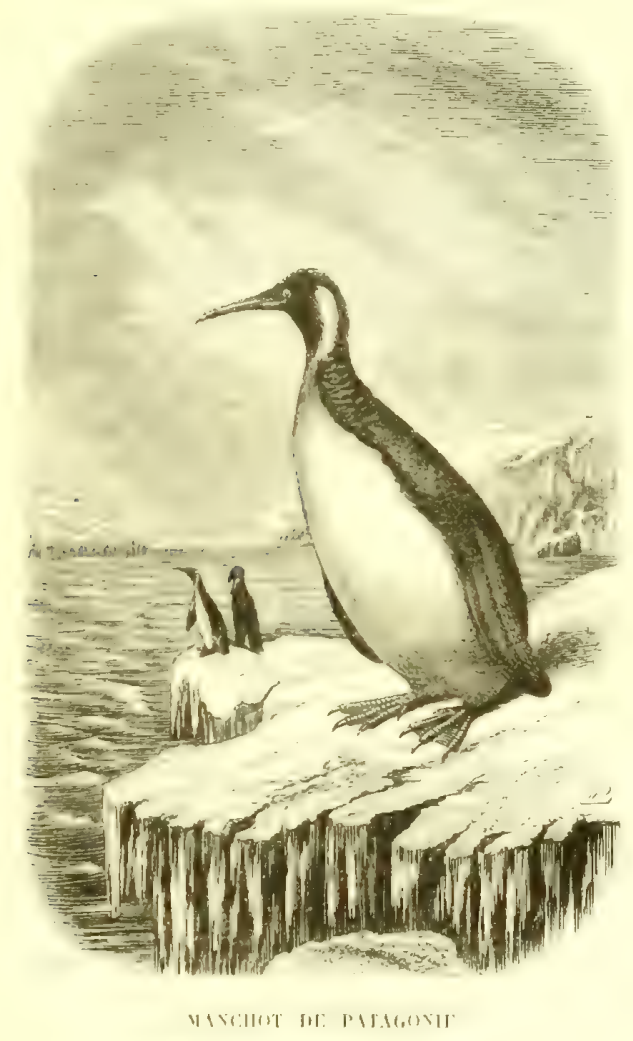

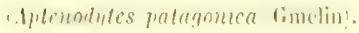

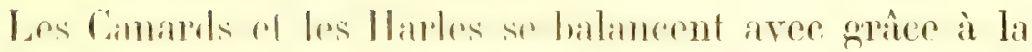
surface des eaux, et se jonent avec tranquillité au milieu des flots les plus mapides. Ces oiseaux ont le corps taillé comme la carène d'un navire; leurs pattes, comme on l'a ru plus haut, sorront de rambers ot leurs ailes demi-díployées représentent les voiles de ce petit vaisseau vivant.

Les espèces privées de la faculté de voler sont les plus habiles daus l'art de nager ot de plonger. Leurs ailes, 
plus ou moins courtes, fonctionnent comme des nageoires, de manière que l'oiseau possède quatre rames, deux en avant et deux en arrière, exactement comme 111 poisson.

Suivant leurs besoins, ces oiseaux s'élèvent ou s'enfoncent dans le liquide. Ils voguent généralement la tête en l'air. Les Pingouins s'élancent par bonds, à la manière des Bonites.

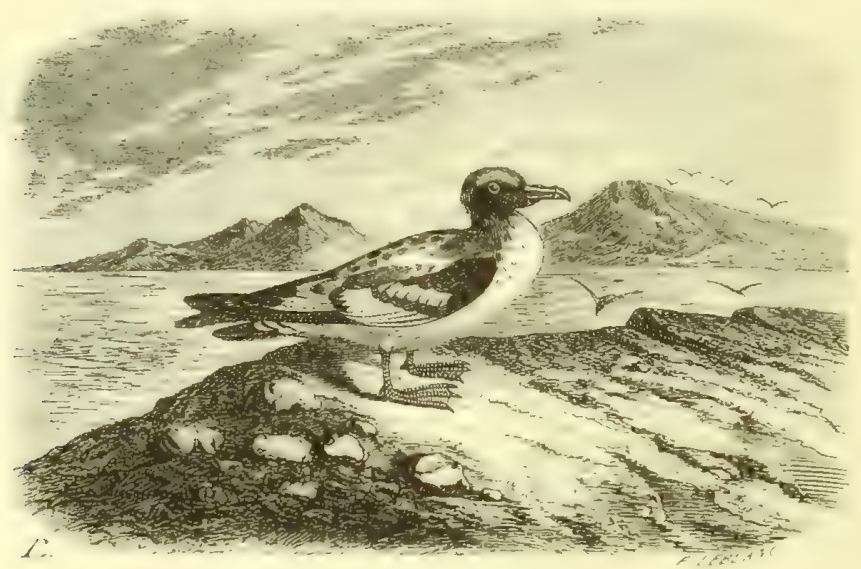

PLTRET. DIUIF

(Procellaria capensis l.ahlian).

Mais le rol constitue la fonction principale des ()iseaux. L'atmosphère est pour eux ce que l'ucéan est pour les Poissons. La natation et le vol, dit Lacépède, ne sont, pour ainsi dire, que le même acte exécuté dans des fluides différents. L'Oiseau nage daus l'atmosphère et le Poisson vole dans l'eau (Virey).

Ce sont surtout les Longipennes et les Maritimes ordinaires qui excellent à voler.

Les Hrondelles de mer, agiles et vagabondes, légères comme le vent, savent planer, cingler, plonger dans l'air, selon la proie qui les attire, l'ennemi qui les poursuit ou la gaieté qui les emporte (Buffon). Rivales des llirondelles 
domestiques. elles pareourent comme elles les régions de latmosphire, et dans tous les sens, comme pour en jouir dans tous les détails. Toujours maitresses de leur vol, elles semblent décrire au milieu des airs un dédale mobile et fugitif, dont les routes se croisent. s'entrelacent, se heurtent, se roulent, montent, descendent, se perdent et reparaissent pom se croiser et se rebroniller de nouveau. (Montheillard.)

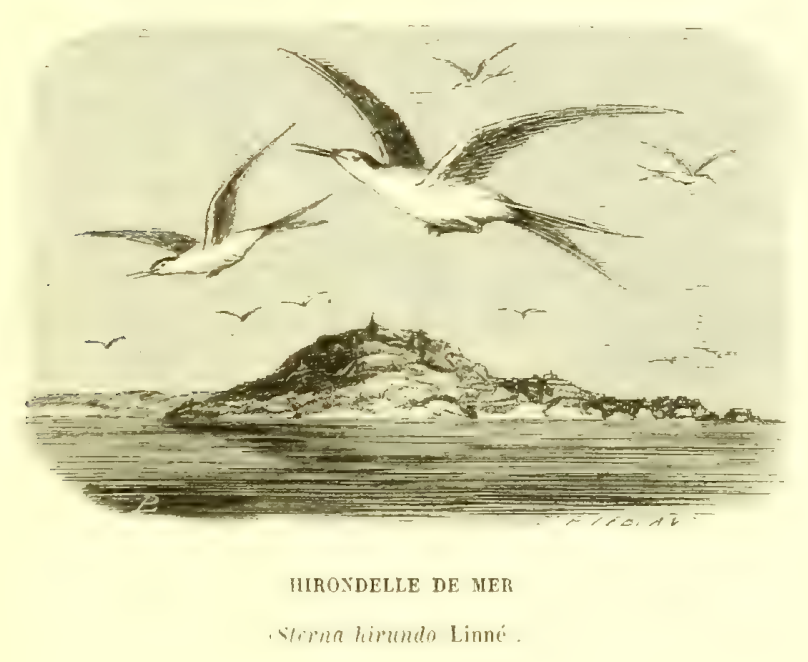

Les Frégales ${ }^{1}$ sont peut-être, de tous les oiseaux, ceux dont le vol est le plus puissant et le plus fier. Elles se tiement dams les régions les plus délées de l'atmosphère; ellesse précipitent comme une fleche et se balancent comme nur nacelle, tantót résistant à la puissance du vent le plus violent, et tantôt se laissant emporter par la plus légère brise.

Elles pêchent mal, mais elles remplacent la maladresse par l'audace. Elles suivent et persécutent les Mouettes qui ont pris quelpue animal, lem font rendre gorge, et sai-

- Tachypetes aquila Vieillot. 
sissent prestement la proie dans sal chute, arant qu'elle soit arrivée à l'eaı.

Audubon observa 'un jour une frégate gui venait d'enlever un assez gros poisson à une lliromble de mer. Loiseau emportait sa vietime en travers du bee. Il la jetil en J'air, pour l'avaler la tite la premiere. Il la reprit comme elle tombait, mais par la quene. Il la likha mo seconde lois, et la rattrapa encore par la quene. Le poids de la tête en était la cause. La frégate recommencal une troisieme fois. Le poisson fut enfin reegu comme il fallait, la tète con bas, et avalé sur-le-champ.

Les Albatros ou les Frégates yui ont saisi daus l'air un malheureux Poisson volant, regagnent aussitot les hantes régions de l'atmosphèe. Mais, souvent, plusicurs maraudeurs de leur esperee, qui les gueftaient, les suirent an milieu des nuages, s'en approchent. les harrilent. C'est

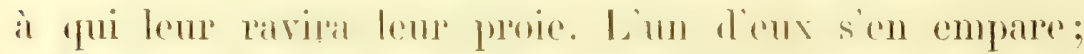
un autre la dejat reprise, mais la bande entiere est a ses trousses. L infortuné proisson, ballotté de bee r'n bee, meurtri, momant, finit par fomber of par disparaitre sous les flots. Comel désilpointement jour tous ces rentres allamés! (Iurbubon.)

Le Stercoraire parasite, vai forbun do l'air, fait aussi la chasse aux especes plus petites el phus finbles que hui. lemr donne des comps de bere, les foree it romir mone partie de leur repas, et se précipite sur cette proie dégon̂tante.

Le vol des Phaétons, on Pailles-en-queue, est rahne, paisible ef composio de battrments d'ailes frépuents, parfois interrompus par des sortes dr a dutes ou dos monvements brusques. (Lesson.)

Ces oiseaux défient la furie des orages; au milieu des

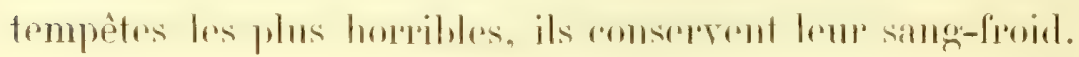


Trampuilles et contents, its ślevent arec la lame, of redescendent avec elle dans l'abime.

Les Phaétons voyagent à plus de cinq cents lienes en mer. el puvent rexagner, chaque soir, les iles on les récifs

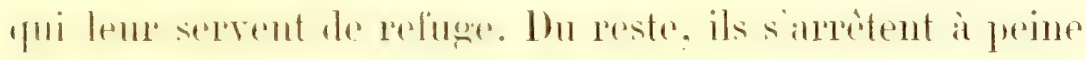

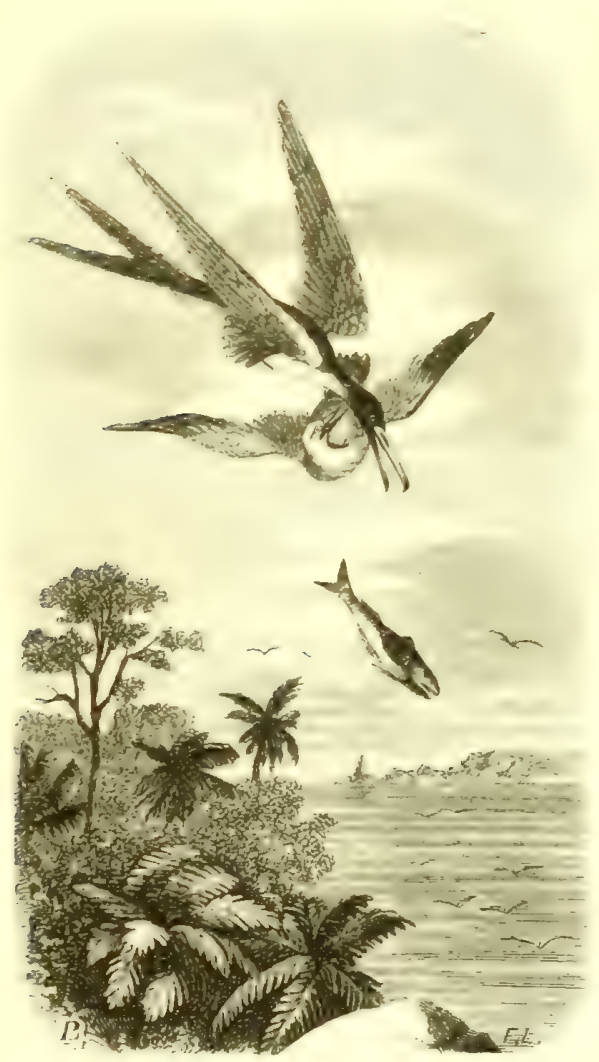

DTERCORAIIE PARASITE EN CHASSF

le temps nécessaire pour dormir. Ils semblent faits pour voler, woler, tonjomis voler.....

Les Oiscaux de mer sont en général pour les navigateurs les indices de la terre. Les vieux matelots interprètent leur apparition ot se trompent rarement. Le Pétrel damier lem 
ammonec le voisinage du calp de lionne-lisprérince; le Pailleentqueue leur apprend qüils sont sous les tropiques; les Frégates, les Nonettes of les Ilirondelles de mer leur pré-

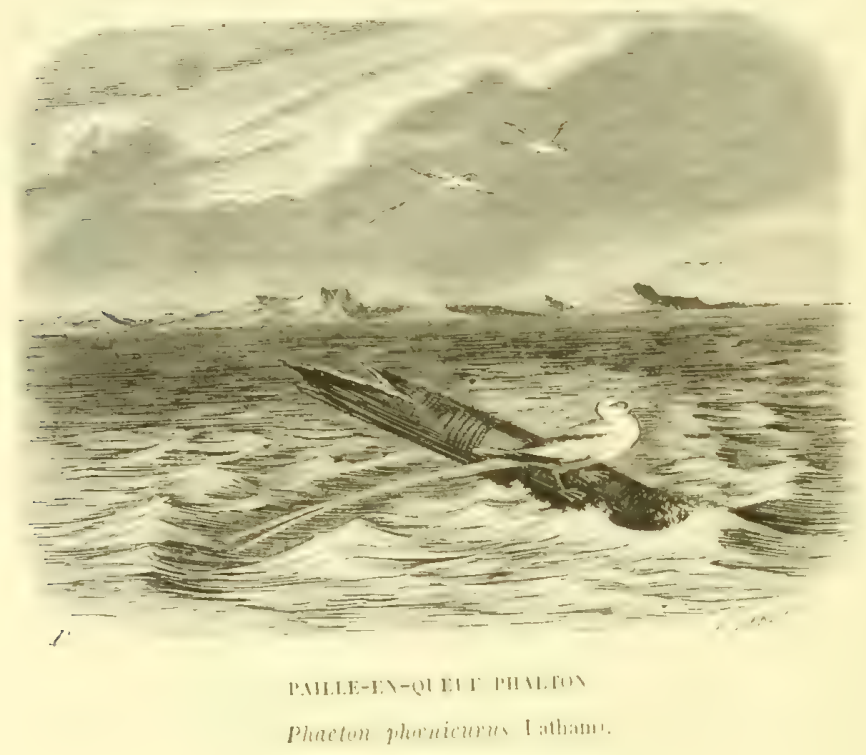

disent, par la direction et la hanteur de leur vol, le lrem

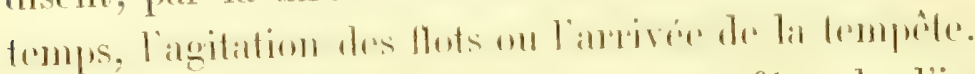

Le livre de la Nature est mne source féconde d'instruc(ion!!

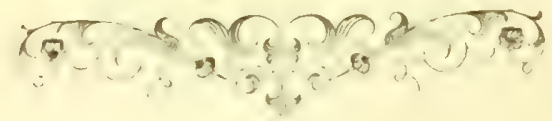




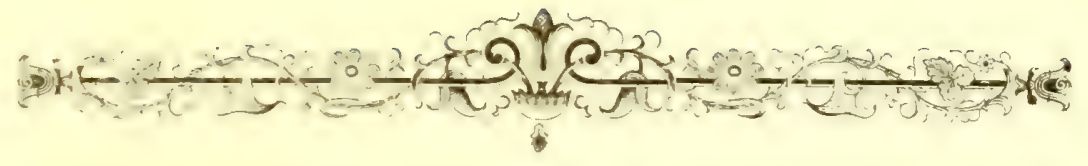

\section{C.HAPITRE XLII}

\section{LES NIDS ET LES OEUFS.}

"Le Passedeau a bicu frouvé sa matison, et l'Hirondelle son nid, où elle a mis ses fulil., Uariv.)

Dans la saison des amours, les Oiseaux marims abandoment les vagues et les eaux, et gagnent les rives et les grives.

Beancoup d'espèces se rassemblent en grandes troupes sur des rochers stériles ou dans des iles désertes. Faber croit que ces oiseaux obéissent à un instinct particulier de sociabilité. Boje pense qu'ils sont attirés par l'abondance de la nourriture. Ces deux raisons peuvent être également conlonmes a la répitr. Maris, pobablement anssi, il en existe d'autres: par exemple, la disposition des récifs, dont les

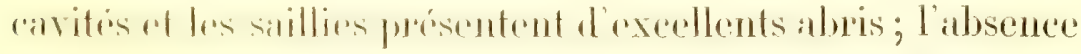
des animaux carnassiers, l'éloignement de l'Homme; en deux mots, la solitude et la tranquillité. 
Ciraba ficit observer que les Pahmipiedes choisissent tonjours, pour nicher, les rochers tommis a l'omest et an mordouest, et qu’ils dédaignent les autres expositions.

Parmi les îlos les plus frépuenties par les discaus nicheurs, il faut placer en premiere ligne le petit archipel des Feroë, entre l'Islande et les îles Shetland. Ced arehipel est formé par vingt-cint gramds rochers à biseaux (Vögelberg).

Ces écueils ont été sourent décrits. Il y en a un, surtout, qui mérite une attention particulière.

Qu'on imagine un rocher noir, composé d'assises horizontales, sélevant verticalement ì 1000 ou 800 metress au-dessus de la mer, qui mugit of brise it ses pieds. L'eau s'élance souvent, pendaut les tenpêtes, à plus de 30 mètres de hauteur, of retombe an cascinde le long de la paroi verticale. Mars, far un temps calme, clle ondule doucement,

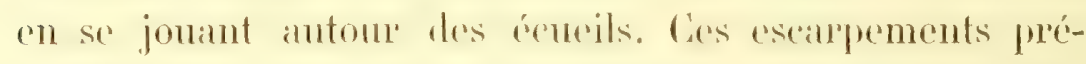
sentent alop's laspeed le plus singuliex' des milliers dojseamx sont rangés sur les complohess a coté les uns des antres; les femelles sur leurs nids, les miles pres d'elles ou volant à une farible distance. Une salle de spectacle, un cirque, $u$ amphithéatre pemplis de spectateurs, ne doment qu'une fable idée du nombre prodigieux d'animaux qui

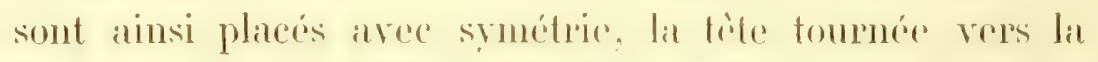
mer. Larrivée de lillomme ne les frouble mullement, et le bruit d'un coup de fusil ne fait envoler quu les mâles, les femelles restent sur leur's auls. Elles ne les quittent mème que lorsquion sapproche d'elles, ef la plupart se laissent prendre sur leur couvée.

Les différentes espèces d'oiseaux établies sur ces rochers ne sont pas éparpillées au hasard. Chacune semble avoir son campement particulier. 


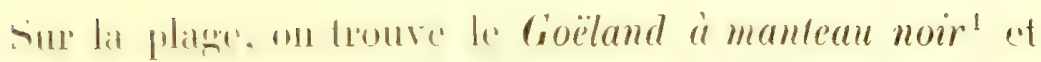
le Perroquet de mer?

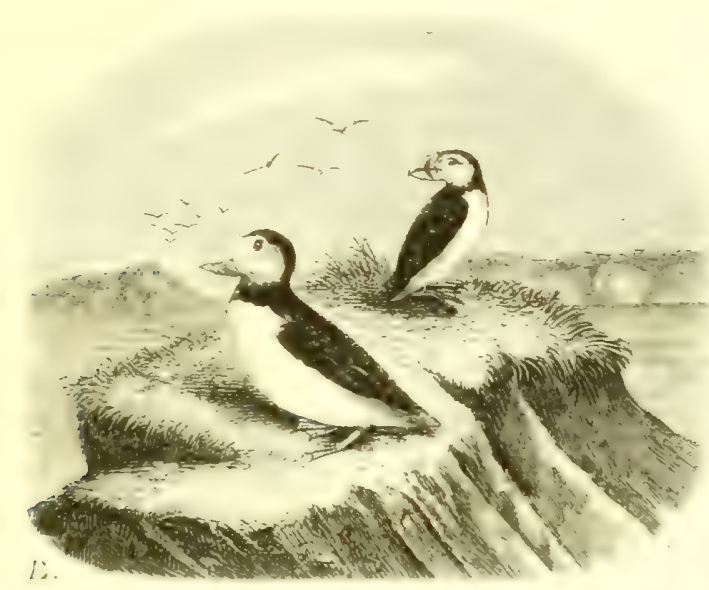

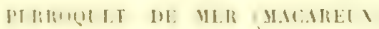

yemon fraterculn Temminek).

In second ring, dims les amdroits converts de plantes, parait lia Wouelle argenlée?.

tu-dessus, sur les rochers les plus découverts, sommeillent les stupides Cormorans".

Von loin de là, sur les falaises baignées par la mer,

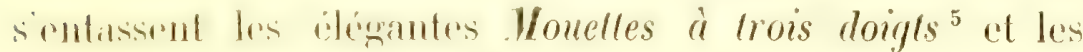
Guillemots à miroir blanc ${ }^{6}$.

Tout à côté, parmi les Varees amoncelés, se redressent les Guillemols ì capuchom ${ }^{i}$ at les ineptes Pingomins".

Tous ces oiseaux vivent en bonne intelligence. Souvent des fomelles diespeces differentes sont assises, coite a còte, sur leurs oufs, et l'on croirait, en voyant les mouvements

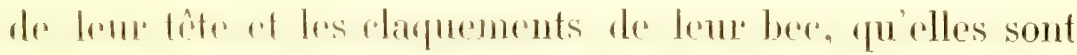

\footnotetext{
1 Jarus marinus Linur.

2 Vulgairement, Macareux moine.

s Lurus triduclylus Latham.

3 Larus argentatus Brünnich.

${ }^{6}$ Uria grylle Latham.

7 Uria troile Latham.

\& Phalacrocorax carbo Ch. Bonaparte. 8 Alca torda Linné.
} 
cngagées dans une conversation animée, pour faire divepsion aux ennuis d'une incubation un peu trop longue.

On peut indiquer encore, comme rendez-vous général des Oiseaux marins, les îles Hébrides, et particulièrement celle de Saint-Kilda.

Cette dernière offre cinf milles environ de tour. Elle sort presque perpendiculairement du sein des flots, et forme à son extrémité orientale, qui s'élève à plus de 440 mètres, le promontoire le plus haut des îles Britanniques.

En approchant de l'île de Saint-Kilda, on aperçoit un spectacle presque impossible à décrire. Les rocs sont cachés par des myriades d'Oiseaux aquatiques occupés à couver.

D'énormes essaims de Fous ${ }^{1}$ blanchissent les sommets sur lesquels ils reposent. Ces plateaux ou ces pics semblent de loin couverts de neige. Les Mouelles à trois doigts et les Mouettes à pieds bleus ${ }^{2}$ ont envahi chaque crête un peu

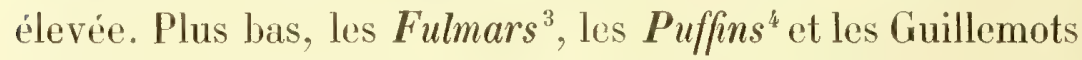
ont pris possession de tous les talus, de toutes les pentes, de tous les endroits où il existe un peu d'herbe. Au bord de la mer, à l'entrée des excavations, perchent des Cormorans, droits et immobiles, comme des sentinelles avancées. (L. Wraxall.)

Tout autour, au sein des eaux, des milliers de nageurs de toute espèce plongent, barbotent, se poursuivent, se becquètent ou se battent. D'autres remplissent l'air de leurs cris rauques ou aigus, allant de la mer à leurs nids ou de leurs nids à la mer; appelant leurs femelles, tournoyant au-dessus d'elles, caressant leurs petits, jouant avec leurs frères, et manifestant, d'une manière bruyante et naïve. leurs craintes, leurs besoins, leur joie ou leur bonheur....

1 Sula alba Meyer.

2 Larus canus Linné. 
Lorsqu'un fragment de rocher se détache et roule du haut de l'ile daus les tlots, il devient le signal d'un tumulte extraordinaire. La frayeur' s'empare de toute la colonic. Le bloc écrase de malheureux Fulmars accroupis sur leur conchette, ef entraine, en bondissant an milieu d'un fracas épouvantable, les herbes et le sable, les cufs ot les poussins. Des nuées d'oiseaux épouvantés s'enfuient sur son passage. Nais bientot ils reviennent a leurs nids, et tout reprend le calme habituel. (L. W raxall.)

Lin Ilollande, d'imnombrables troupes de Mouettes et d'llirondelles de mer nichent, toutes les années, daus l'ile d'Eierland (pays des œufs), et dans les autres îles septentrionales du Texel. Il en est de mème dans celles du Slesvig et du Jutland.

Dans la saison de la poute, les Palmipèdes arrivent par milliers. Beaucoup d'Echassiers se mèlent à leurs troupes.

Les ouf's sont pondus par des Cioëlands, des Monettes, des llirondelles de mer, des Guillemots, des P'ingouins, des Canards, et aussi par des Huitriers, des Pluviers, des bal'ges, des Vammeanx....

\section{II}

Les Viseaux marins placent leur nid, soit dans un simple cnfoncement, derrière deux ou trois galets, soit parmi les luerbes, entre les jones on sous quelque arbrisseau, soit encore dans les creux des rochers.

La Monette tridactyle a l'instinct de s'établir dans les lieux les plus inacessibles; anssi est-elle rarement troublée par les ramasseurs d'eufs.

Les Pingouins et les Manchots se creusent daus le sable uII trou horizontal. Les Macareux s'emparent des terriers 
de's lapius; ils aiment it nicher en societé al a rouver les uns pres des autres. L'endroit qu ils ont choisi est quolquefois tellement miné, qu'en posant le pried dessus, on s'enfonce justu'an genou. Les Tadornes ${ }^{1}$ ont anssi l'habitude de nicher dans des sontertains. Ies anciens domnatient it ces oiseanx le nom d'Oies-renards.

Naumamn a vo, daus la petite île de Sylt, un tress-grand nombre de Tambroses rémis par grompes datns des excatrations artificielles. Il a compte jusqu ì treize nids dans un

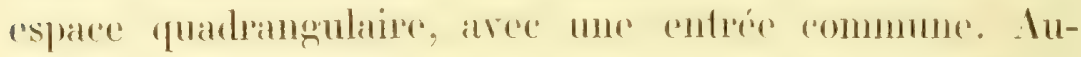
dessus de chargue nid était wn tron comvent d'me touffe de gazon. Quand on soulevait cette touffe, on voyait un Tadorne acemonp. Champe habitant du village possédait plusieurs de ces sonterpanins, dion il retirait par jour, pendant trois semaines, de vingt il terente reufs. Il an laissait six à chaque nid pour l'incubation.

Dans le voisinage du cap de Bonne-Espérance, les

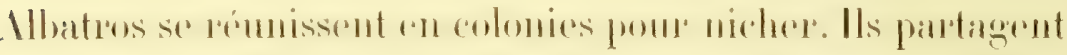

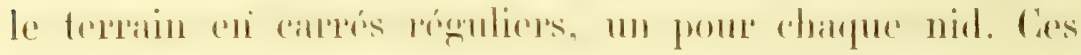

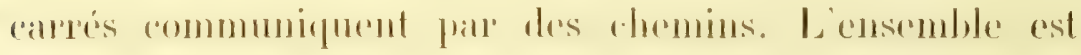
défendu par une chaussée de pierres.

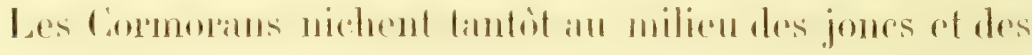
roseaux, tantòt sur les trones des vieux saules ou sur des

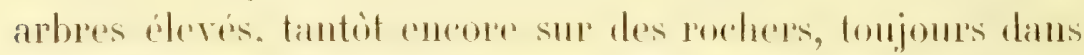

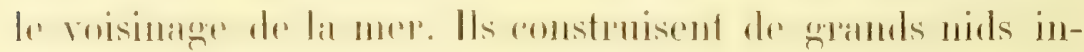

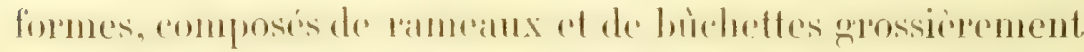

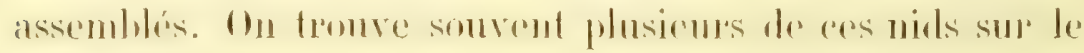
mène allore.

Au commencement de ce siècle, les Cormorans étaient assez rates sur les bords de la mer Baltique. Vers 1810 , phusieurs couples vinrent nicher dans la proximité de l'ile de

1 Anas tadorna Linné. 
Fionie, parmi les rocher's du rivage ef daus les forèts. Leur nombre augmenta peu i peu. An printemps de 1812, quatre paires de ces oiseanx se rendirent dans la terre de Veudorf. presis de la ville de Leutjenbourg, et śétablirent dans tun bois roisin de la mex. sur de grands hètres qui, depuis phusiemes anmies. servalent de retraite à me multiturle de

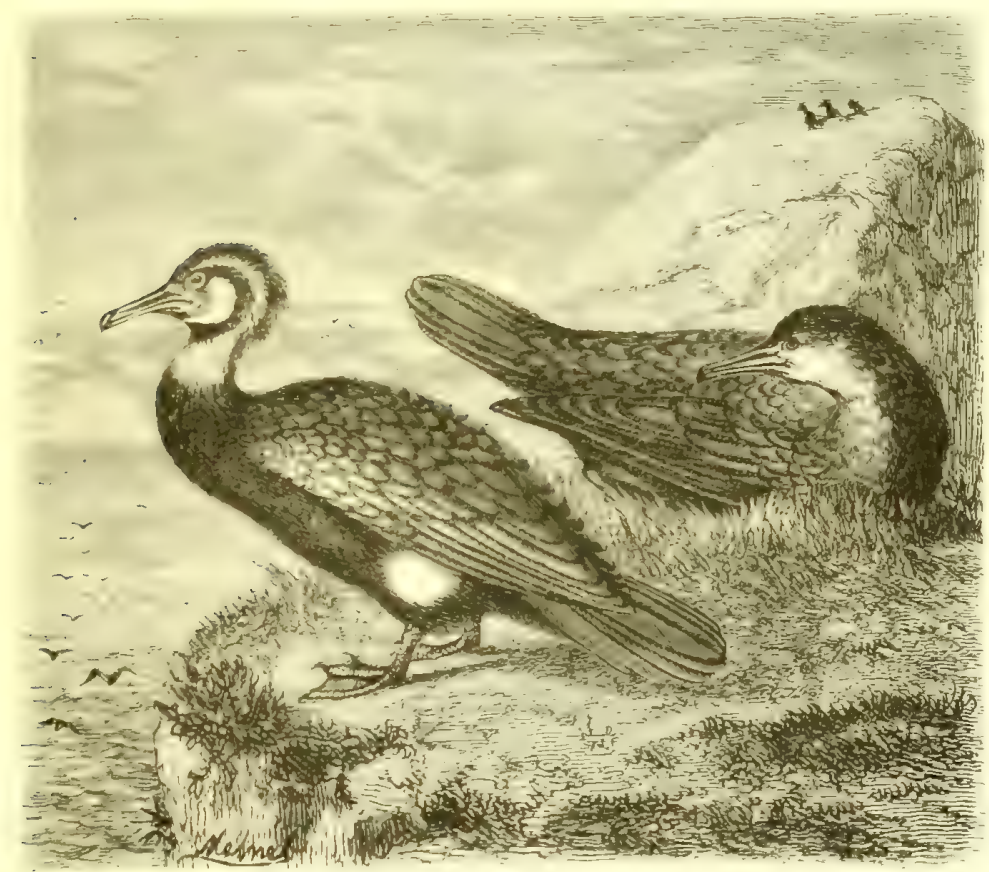

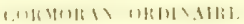

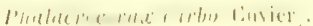

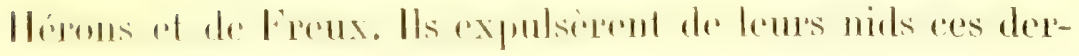
niers oiseaux, firent deux pontes, l'me en mai et l'autre en juillet, et quitterent la contrée en automne. Leur nomber stevait alos's à une trentaine. Pendant le printemps de 1813 et les années suivantes, ils revinrent régulierenuent. Bientirl on calcula qu il y avait 7000 couples de nicheurs. Au mois de juin 1815, on voyait des cinquantaines de nids sur certains arbes, et les innombrables vols 
des Cormorans, mèlés avee les Ilérons, lemplissaient l'air

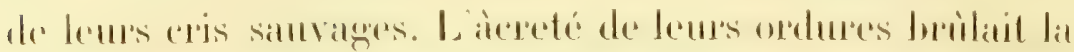
lonille des antores, de les débris des poissons corrompus dond

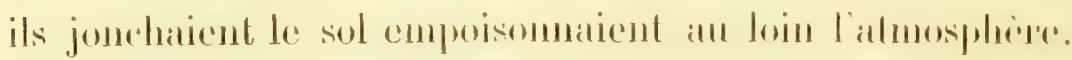

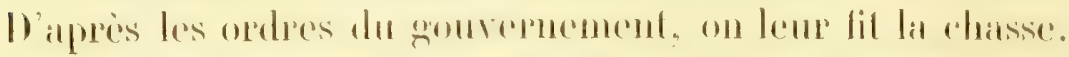

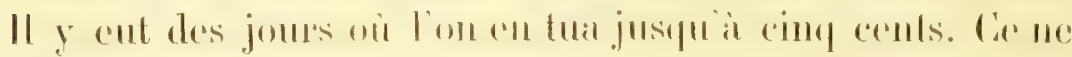

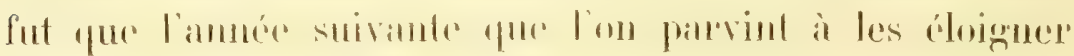
de la contrée. (Boje.)

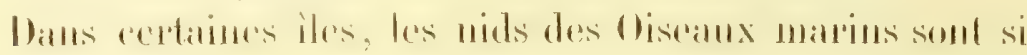
l'approchés, qu'on ne saurait fare un pas sans écraser des

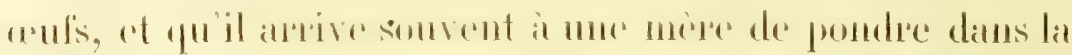
couchette d'une autre mère. (Schinz.)

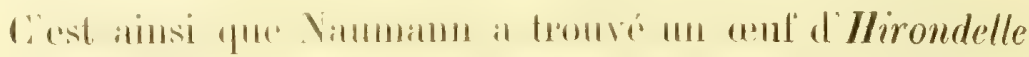
de mer à longue quene daus le nid d' un IluÂtrier", ot aillems's, un ouf de ce dernice oiscan dans le nid d'un Goöland. Cependant chafue comveuse recomait ses propres oufs et ne sy trompe jamais. (ie que nous croirions impossible, si

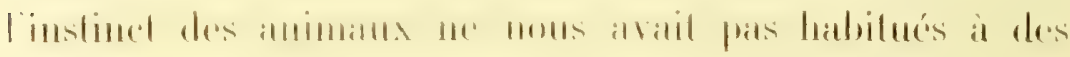
minacles.

\section{| II}

La plupart des oufs, chez les Viseaux marins, ont un

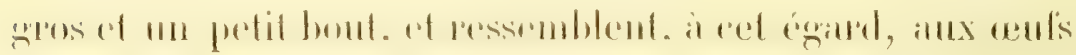
de la Poule. Cenx des Cormorans sont plus allongés et

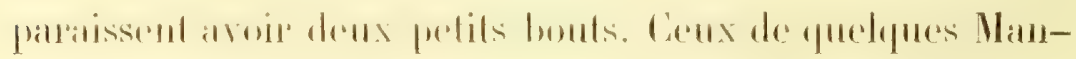
chots sont loul a liait momels.

Les oufs des Cormorans sont assez petits relativement a la taille de l'oisean. Ceux des Guillemots sont au contraire

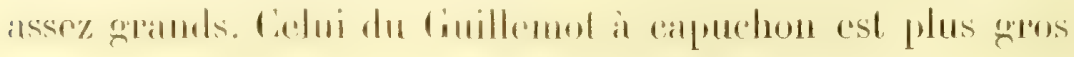




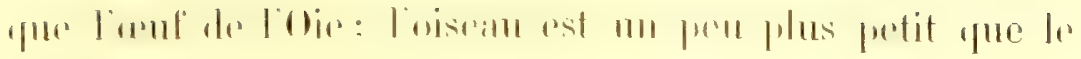
Pigeon ramier.

I. Pingouin brachyplère. on grand Pingonim. est l'oisenu

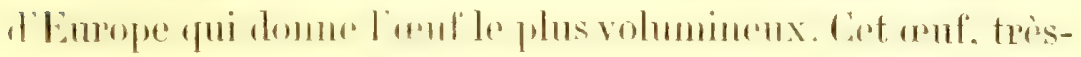
rorherché par les amateurs, devient charue jour phus raro.

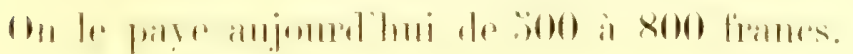

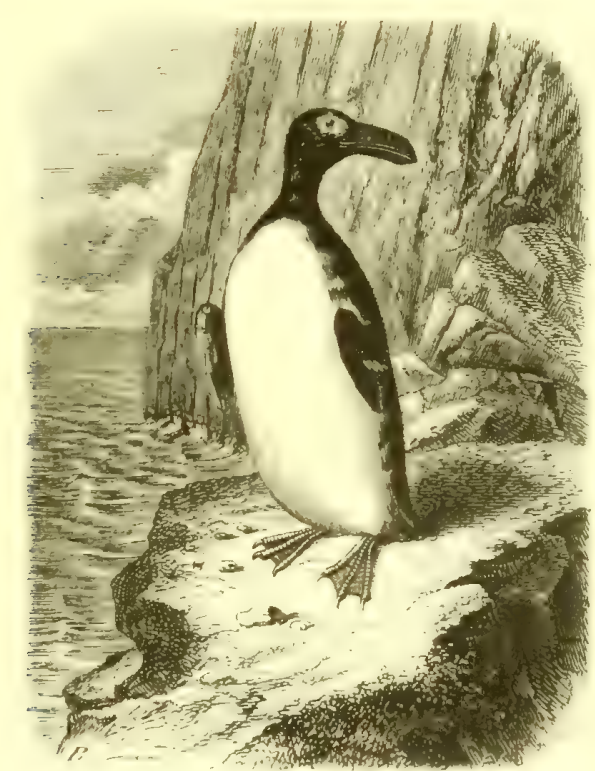

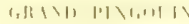

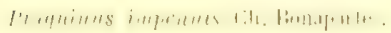

Les Pótrels ont les oufs blancs; cenx des Ilaules sont jannâlres, et ceux des Canards verdatres. Les Göbumls et les Vomettes en pondent d'olivâtres, avec des marbrures brunes gímínlement plus nombreuses et plus fortes vers le gros lmill.

Le grand Pingouin, dont nous venons de parler, dome III ceuf' d'm blane isabelle, avec des rains et des taches pen nombrenses, qui rappellent, dit Temminck, les formes sin-

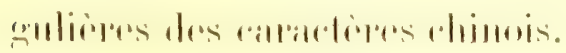


Le Guillemot bridét produit un œuf plus remarquable encore par les traits ou les zigzags nombreux qui décorent sil copuille.

Les Plongeons sont les oismax commus qui offrent les oufs les plus foncés en couleur. Ces reufs sont couleur

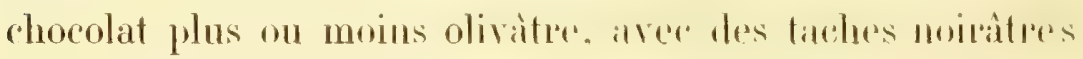
plus ou moins irrégulières.

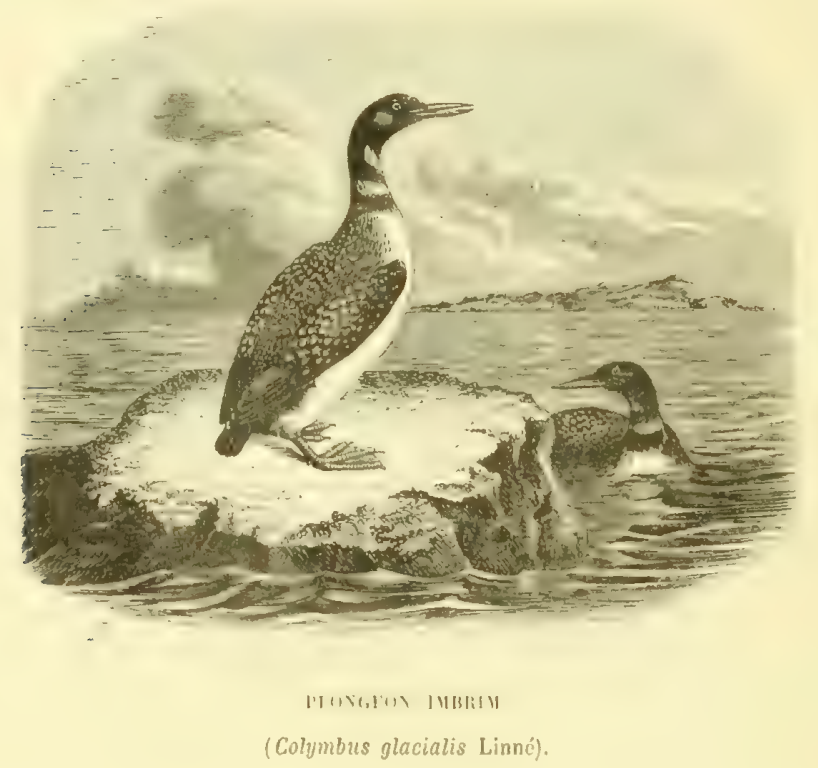

Les aenfs des Commorms of des fous sont revêtus d'un enduit crétacé. blanc. qu on enlive farilement avee l'ongle. Cet enduit est tellement friahle stre l'eeuf' du Flamant², que si lon promene sat ropue sur la manche d'un habit noir, on la blanchit ronme si on liarait frottée avee un morcean de plàtre.

1 Uria rhingvia Brünnich.

2 Phopnicopterus ruber Linné. 


\section{IV}

Guand le nid d'un Oiscau est préparé, la jeune mère doit Arr bien surprise. après les douleurs de l'enfantement, de trourer sur sa couchette, au lieu d'um poussin délicat qui lui ressemble, un sphérö̈lo inanimé, qui ne dil rien; elle a mis au monde une espece de boule, blanche comme de la craie, quelquefois d'un bleu clair de turquoise, ou d'un rouge vineux d’acajou. pointillée, maculée, veinée comme du marbere ou de l'agate!.... Ln reuf n'est pas un Oiseau. pas plus quine graine n est un arbre: cest quelyue chose d'antérienr, quel,fur chose qui contient les rudiments d'un animal, mais qui 11 est pas encore 111 animal, quelque chose yui ressemble plus à mue prorluction mincirale qu’à un germe organisé.

L'instinct de la mère vient en aide à son inexpérience. Elle sattache it ce colps incete arec une passion que nous ne comprenous pas of que mous ne pouvons pas complendre. Est-ce de l'amour matermel? Certainement non! C'est un sentiment voism, tres-voisin, préliminaire, si l'on veut; mas ì comp siur hien diffirent. L'amom matermel n'existe pas encore; il ne viendra que phus tard, il viendra quand les petits seront éclos....

Cet attachement pou les reufs pousse les Oiseaux ì s'accroupir sur ces bizarres produits et à les échauffer.... Ils pressent ces cailloux contre leur cœur (Michelet).

Les parents qui couvent pour la promiere fois savent-ils fuels seront les resultats de lenr incubation? L'instinct est encore ici leur directeur et leur mobile. Anssi voit-on souveut des femelles ot même des mâles (ce qui ast plus étonnant), fuaud ils comrent, oublier lo boire et le manger. Tant est grand l'amour de l'ouf. 


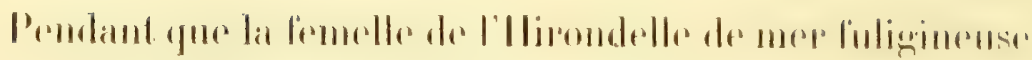
rouve, son mâle arrive de temps en temps et vient se reposer pres du nid. La il dégorge suelque petit poisson is portée de sa compague. Il regarde ensuite cotte dermière.

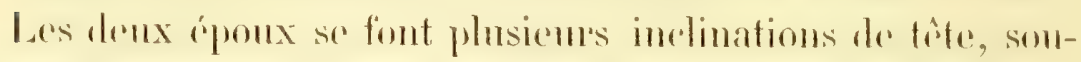
rent singulieres, par lespuelles tris-probablement ils se témoignent liun i l'antre leme temder afleretion of leme doux contentement. (Audibon.)

Le développement de l'euf n'est plus un mystère. Si l'on brise délicatement la corpue d'un certain nombre d'ouls aux différentes époques de l'incubation, on peut assister aux diverses phases de l'évolution du nouvel être.

Au moment de l'incubation, on voit sous la coquille pro-

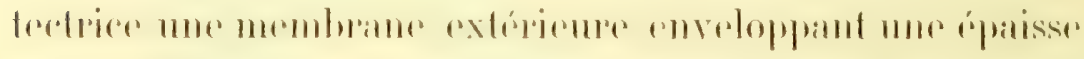

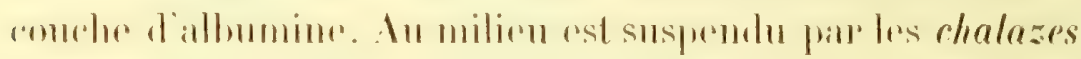
le jame ou vitellus. A la partie supérieure du jaume se trouve le germe; il est blanchatre et composé de deux fenillets: le supérieur deviendra les organes de la vie animale; l'inférieur produira ceux de la vie végétative:

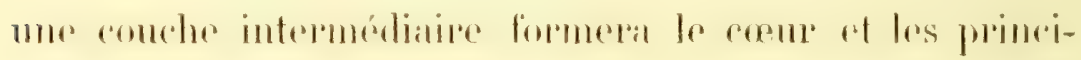
panx vaisseaux.

Plus tard, le eentere du germe est divisé par une ligne médiane transparente on denx moitiés latérales symétriques. Co sont lit les premiers lineaments de l'embryon. Puis les

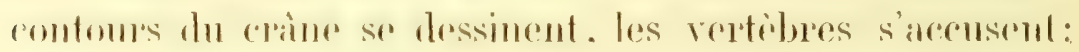

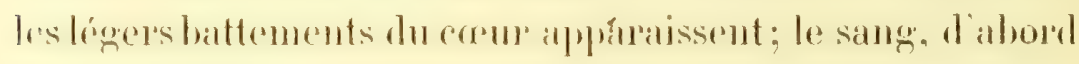
clair et transparent, se colore; et la respiration, devenue

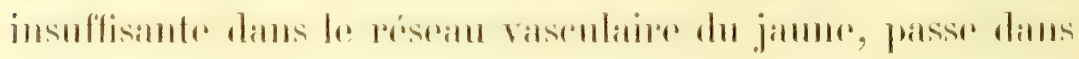
nim poumon transitoire qui se déploie sous la coque.

L'animal croit alors rapidement. Les tiges des plumes 

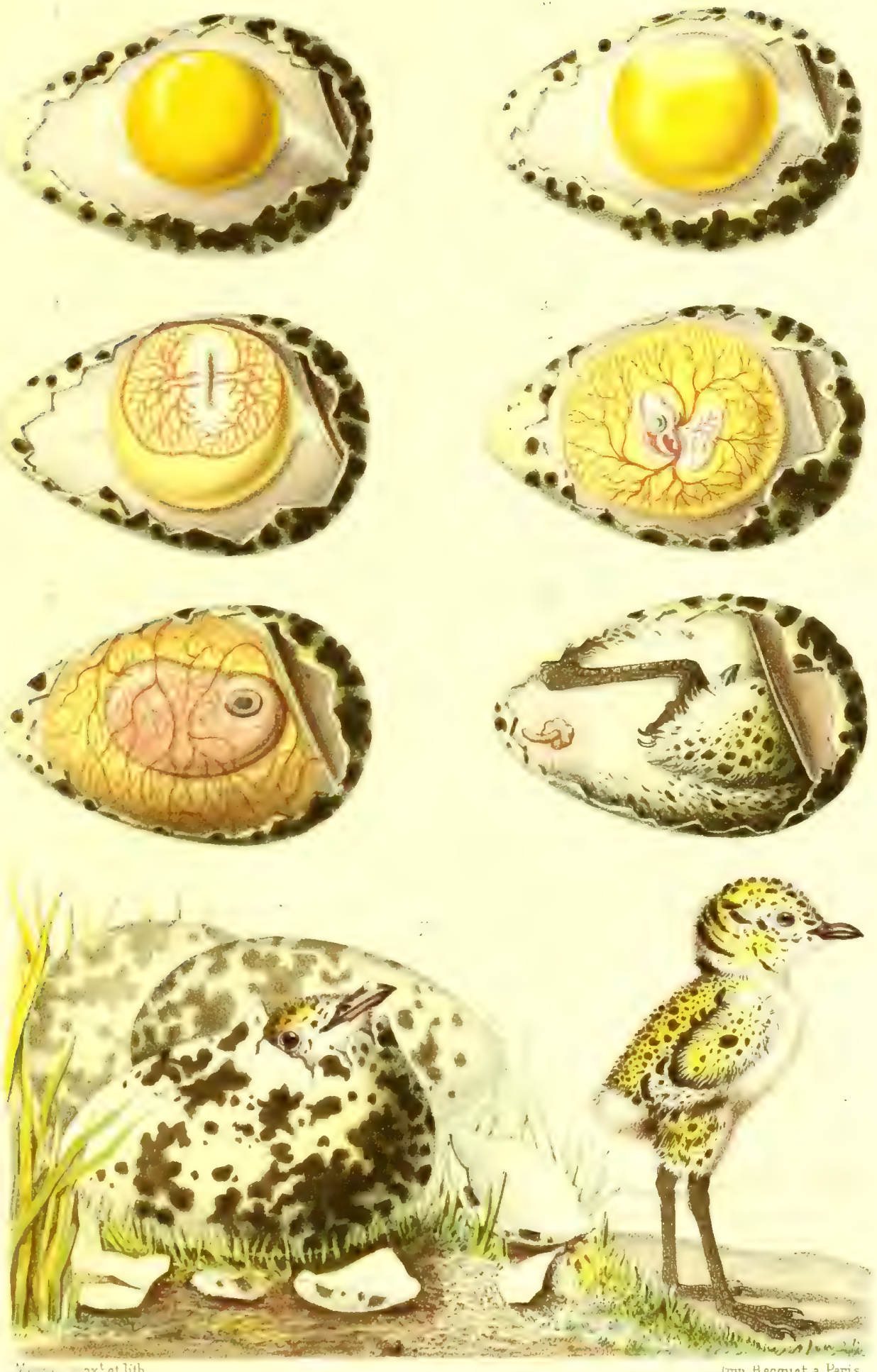

DÉVELOPPEMENT D'UN OISEAU 



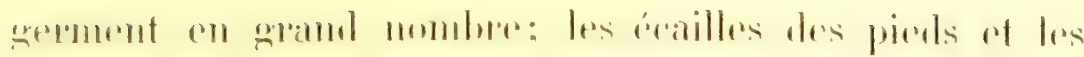

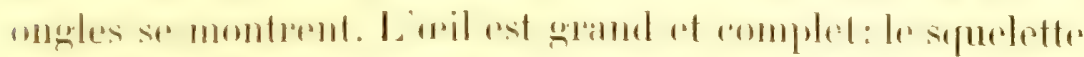

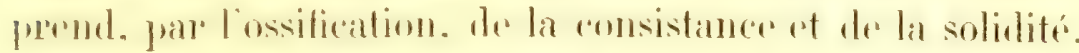

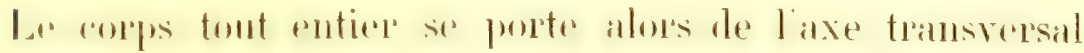
he l'ouf dans son axe longitudinal, la tìte repliée contre la poitrine et cachée sous l'aile.

L'oiseau, ainsi constitué, déchire la membrane de la soupe, pénetre dans la chambre à air; et, plus à l'aise

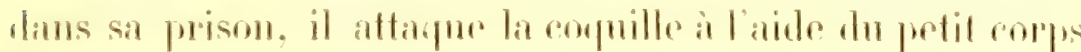

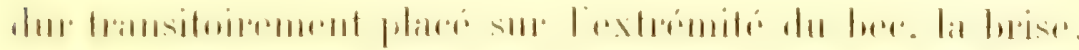
of mait enfin an monle extérienr'.

\section{1}

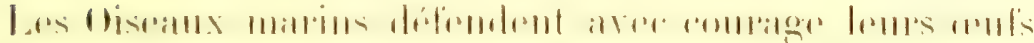
et leurs portils.

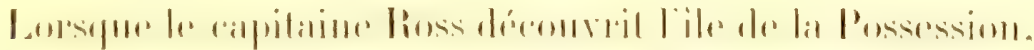
il y tronva une quantité prodigiense de Pingonins: on en voyait justuan sommet des collines. Ces oiseanx s'avalurerent vers le rivage en colonnes serrées, ef attanpuiront havliment, ì coups de bee, les Anglais gui voulaient ocenper lemp pays au nom de Victoria. Mommenr an combege et an patriotisme des Pingonins!

Lat femelle du Canard sameage. phand relle se perme it som nid, s'abat an moins à cent pas de l'endroit ou il se tronve. Une fois à terre, elle se dirige vers sa couchette obliquement ef tortueusement, ayant toujours l'ail aux agnets. pour observer s'il n'y a point d'emnemi qui la regarde.

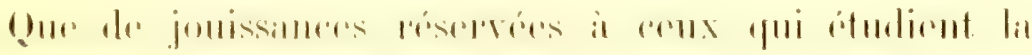
Villine!

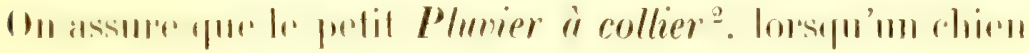

1 Vis? la plawrelu 1111.

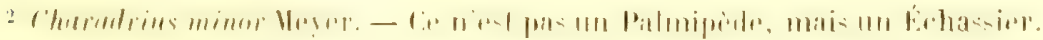


on 1 enfant s'approchent de son nid, n'attemd pas leur inrivée, mais s'avance résolument; fuis, tout à coup, prend son rol arec un grand eri, comme sil était suppris sur ses oufs. (II en est sourent éloigné d'une trentaine de pas.) Alors il volete, il laisse fomber une aile, il comt, il trainr ume patte, il fait le boitemx, jusqu'à ce quil ait combuit le chien ou l'enfant a une gramble distance de sa rouvée et détourne ainsi le danger.

\section{III}

La récolte des oufs forme, dans beaucoup de pays, une branche d'industrie considérable.

Les paurres habitants des îles Feroë se nourrissent de cenx de prestue tous les Palmipèdes qui frépuentent leurs pariges. Ils mangent anssi lespoussins, ot mime les parents, quand ils peuvent les saisir.

Au pereil de leme vie, ils se suspendent it me corde, ou bien ils grimpent anx parois verticales des rochers, en marchant le long des étroites cornichess sur lespuelles couvent ces oiseanx. Li le moinde limux pas est mone mort

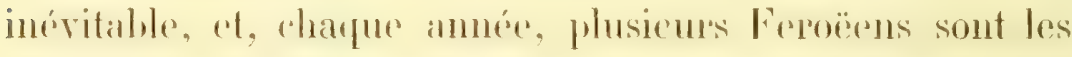
victimes de cette chasse périlleuse.

lne poursuite sans dangere est redle qui se fait en canot.

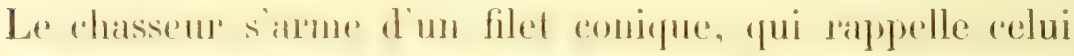
aree lopuel on prend les papilloms; mais il est tissu d'un fil de laine, et par eonserpuent plus fort. Comme ces oiseaux ne sont mullement simvages, on s'approche d'eux, on abat le filet sm leur teite. qui sengage daus les mailles, ef l'on sen empare lincilenent. De centte maniere, on se rend maitre des oiseanx qui volent ì la surface de la mes ou qui pêchent sur les rochers à fleur d'eau. 
Iais le plus grand nombre se troure sur les escarpements des falaises. Pour les atteindre, quatre chasseurs se réunissent. Linn. armé d'une perche terminée par une petite planche horizontale, pousse liantre jusqu à ce quil soit au niveau d'une corniche: celui-ri, it son tour, hisse son camarade avec une corde. La ils saisissent les oiseaux sur leurs cruts on les attrapent an rol avere lo filet. lls les tuent is mesure, of les jettont a leurs camarades qui maintiennent la barpur antedesous du pocher. Ils voyagent ainsi de cor-

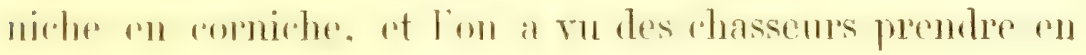
quelques heures des centaines d'oiseaux.

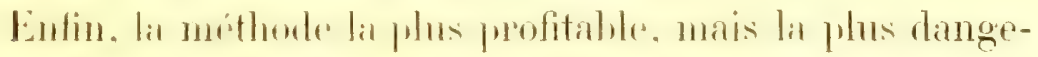

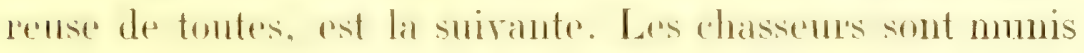

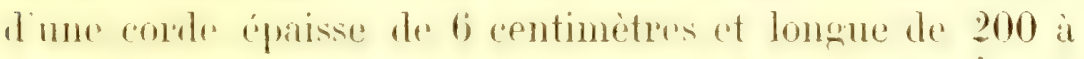
400 mitres, latpuelle prote une espere de siege. On place nue poutre sur le bord du rochere, afin que le cable ne se roupe pas "nl laguant sur la pierre. Six hommes descendent lo promene droiseatux (fuglemand). Cului-ci tient it la main

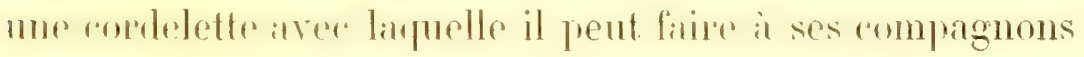

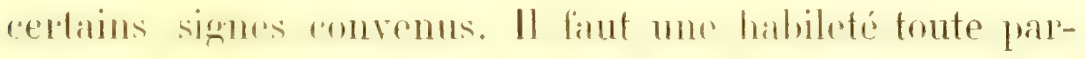
ticulière pour empêcher le câble de se tordre, sans quoi le malheurenx tourne sur lui-meme, et se brise contre

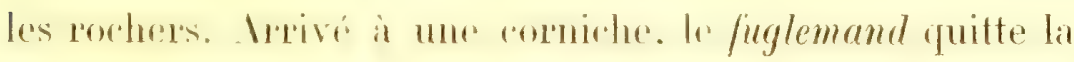

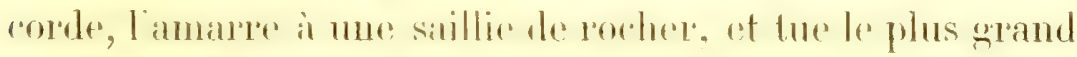
nomber doiseanx possible. en les perenant ì la main on en les attrapant avere son filet. Aperenit-il une circerne ou une "orniche qu il ne puisse atteindre, et on perehent beaucoup de Palmipedes, alors il s'assoit de nouveau sur la planchette, et imprime a la corde des monvenents d'oseillation qui alteigment fuelupufois 30 metres, ot le lancent it la partie du rocher qu'il veut explorer. (Mag. pillor.)

()n assure que sur un senl petit écueil des îles Feroë, on prend annuellement jusqu'à 2400 Perroquets de mer. 


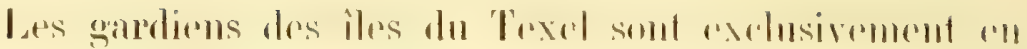

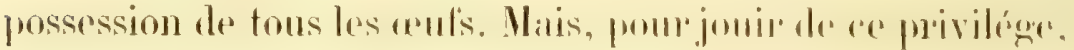
ils payent une somme considérable au gouvernement.

On prétend que les æufs du seul Gö̈land argenté, re-

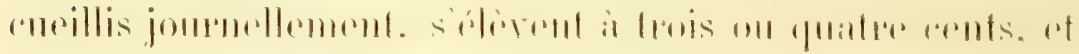

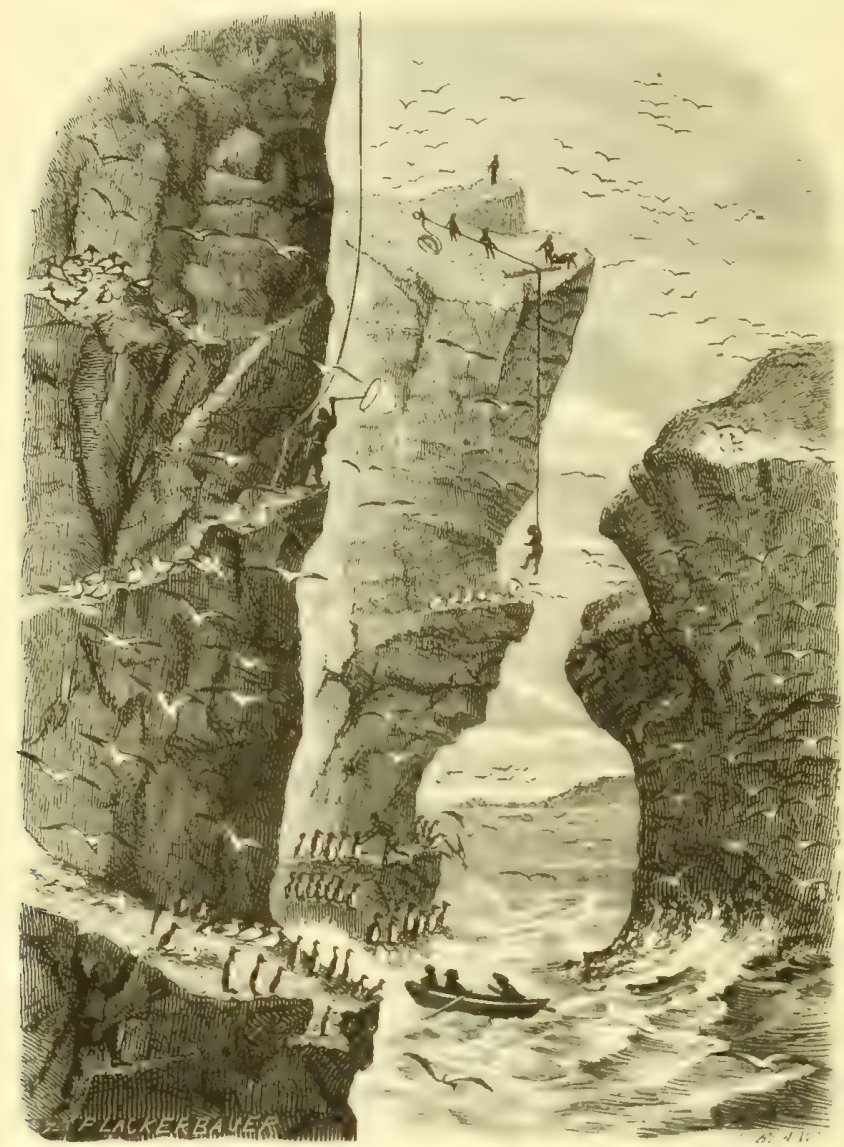

$|m, 1| B \mid m,$.

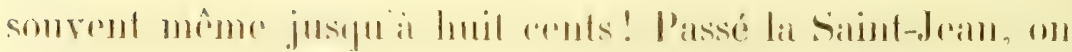
n'onlève plus les œufs, et on laisse ces oiseanx conver en paix ceux qu'ils pondent après cette époque. (Schimz.)

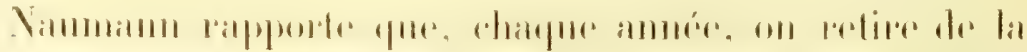

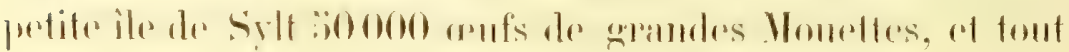




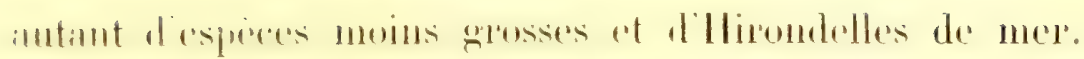

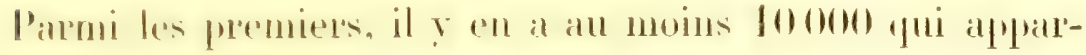

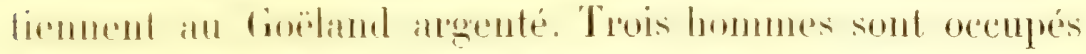

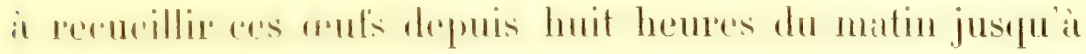

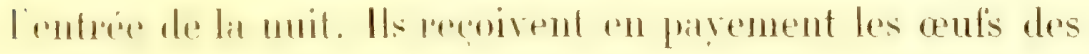
petites especes

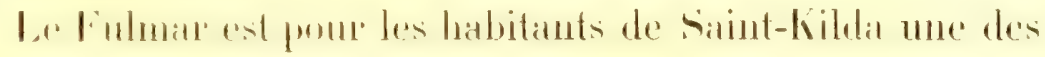
productions les plus précieuses de leur ile.

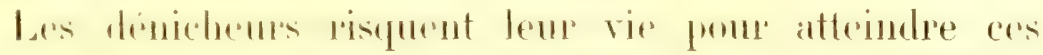
oiseaux. Ils sont ordinarement par deux. L'un, solidement attaché sous les bras arec nne grosse corde, est des-

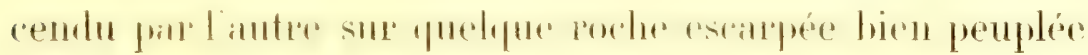

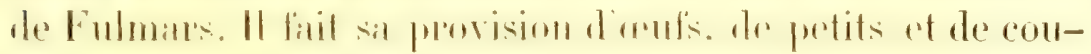
veuses; puis, il est hissé par son compagnon. L'habileté de ces hommes est tres-grande; la moindre surface leur suffit pour se truir. On les voit, déjà ohargés de butin, se trainer sur les genoux et sur les mains, et marcher sur les saillies les plus élroites et les moins avancées. Lai force de celui qui tient la corde est telle, que si le denichenr fait un faux pas et tombe dans l'espace, il supporte le choc et sauve le malhemenx. (I. M I'axall.;

On dit que dans les Mebrides on tue anmuchlement plus de $20(1)(0)$ Fous.

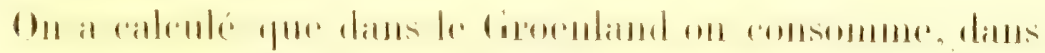
le mime espace de temps, 2000000 outs d'oiseaux agualiiplitis.

Indubon a vu des chereheurs dianlis espagnols, venus lle la Havame dams l'íle aux Oiseaux (golfe du Mexigue), cmporter me cangaison d'environ huit tomues d'anfs de denx espreces d'Hirombles de mer. II leur demanda quel

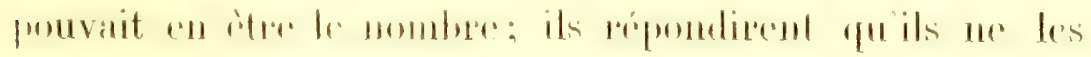
comptaient jamais, meine en les vendant, et fu'ils les

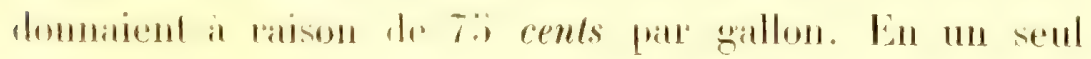


marché, ils se faisaient quelquelois 200 dollars, et il ne leur fallait qu'une semaine pour aller et revenir compléter un nouveau chargement. D'autres chercheurs, yui arrivent de la Clef de l'ouest, vendent leurs oufs 12 cents et demi la douzaine.

\section{VIII}

Disons, en terminant, quelques mots sur le fameux Canard eider ${ }^{1}$.

Cette remaryuable espèce a près de deux fois la taille du Canard ordinaire. Son cou est comparativement court; ses jambes sont un peu hautes.

Ce Canard pond principalement en Islande. Il est protégé par les lois. Tout homme qui se permet de le tuer à l'époque de sa reproduction, est condamné à une amende qui s'élève jusqu'à 30 dollars. On sauvegarde ainsi une des industries les plus lucratives que puissent fournir les Oiseaux de mer: nous voulons parler de l'exploitation of de la vente de ce moelleux duvet connu sous le nom d'édredon.

Mackensie rapporte, dans sun Voyage on lslande, que lorsque son bateau approcha de cette île, il traversa de véritables troupeaux de ce précieux Canard. Les Eiders ne prenaient pas la peine de se déranger sur son passage: ils semblaient comprendre qu'ils étaient protégés par le gouvernement! Entre le rivage et la maison du bailli, le terrain était littéralement couvert d'oiseaux, si serrés, que les visiteurs étnient obligés de mareher avec heaucoup de précaution pour ne pas les blesser. On royait des Eiders occupés à couver, sur les murs des jardins, sur les toits des maisons, dans leur intérieur, et même dans l'église.

1 Anas mollissima Linné. 
(Uuand on les approchait, ils ne changeaient pas de place; ils se laissaient toucher, et frappaient légèrement avec le bec la main des étrangers.

Les nids des Eiders sont arrondis et peu profonds; ils sont construits avec des bûchettes sèches entrelacées avec soin, de la mousse et des plantes marines. L'oiseau y dépose cinq ou six cufs, rarement sept ou huit. Audubon en a compté une fois jusqu' dix. Ces reufs sont plus gros que ceux dı Canard ordinaire, lisses et d'un gris olivâtre clair. Ils passent pour un mets très-délicat.

Chaque nid est tapissé de duvet, que l'oiseau arrache de sa poitrine. Les oufs y sont profondément enfoncés. Autour de la couchette on voit une quantité de plumes suffisante pour couvrir les æufs, quand la mère, à marée basse, va chercher sa nourriture.

«On ne peut contempler, sans être attendri, cette bonté divine qui donne l'industrie au faible et la prévoyance à l'insonciant!n

On enlève le duvet à deux époques différentes. Mais la pauvre femelle est quelquefois obligée de fournir à une troisième récolte. Elle se plume et se rephme, pour tenir son nid convenablement chaud.

Lorsqu'elle a épuisé sa provision de duvet brunâtre, le mâle arrive et lui vient en aide. Il sacrifie, à son tour, son édredon blane de neige et rosé.

Chaque nid peut fournir environ 125 grammes de beau duvet.

\section{II}

Quand on réfléchit aux rassemblements considérables d'Oiseaux marins qui habitent et qui nichent sur les côtes de toutes les îles de l'Europe septentrionale, on est vrai- 
ment pénétré diadmiration. Les grèves les plus arides, less rochers les plus escarpés, les crevasses les plus inaccessibles, tont est emahi et souvent encombré par des nids et par des couveurs.

Souvent chaque femelle ne pond qu'un cuf, et cet ouf est placé dans un endroit tel, qu'on a peine à comprendre comment l'incubation peut avoir lieu.

Les Aigles de mer, les Faucons, les Mouettes, sucent les oufs ou emportent les petits.

Le Stercoraire parasite ${ }^{1}$ nourrit sa couvée avec de jeumes Fous, des l'ingonins et des Fulmars qu'il arrache a leurs parents.

Les grands Poissons happent aussi plus d'un pauvre oiseau, gros ou petit....

Des centaines d'individus meurent de froid pendant lhiver.

Des nichées entières sont surprises par les marées, ou balayées par les ouragans.

Et combien en périt-il sacrifiés pour nos besoins et pour nos plaisirs? (L. Wraxall.)

Malgré ces causes de pertes, le nombre des Oiseaux marins se maintient constamment le même, et les déserts de l'Océan sont tonjours animés par leur présence et embellis par leurs amours !...

'Lastris paresilica Boje.

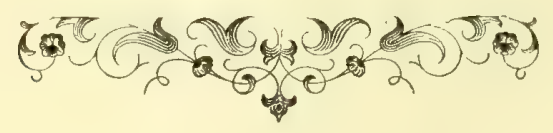




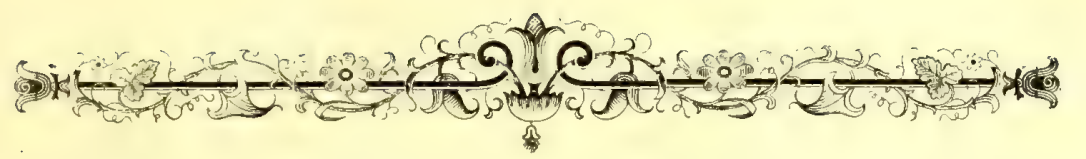

\title{
CHAPITRE XLIII
}

\author{
LES CÉTACES.
}

"Ce sont des quadrupides estropies."

(UN VIEIL AUTEUR.)

\section{1}

Chez les animaux très-simples en structure, le tissu est homogène, et remplit toutes les fonctions par toutes ses parties. A la vérité, ces fonctions se trouvent singulièrement bornées et réduites généralement au nécessaire ou à l'indispensable.

A mesure que les animaux se compliquent, des organes plus ou moins distincts apparaissent, et les fonctions se localisent. Chaque partie est alor's chargée d'un rôle spécial.

La division du travail est, sans contredit, une des lois les plus importantes et les plus curieuses de la Nature. (Milne Edwards.)

Cette division est d'autant plus grande, que l'animal est plus parfait. (Quand elle augmente, les organes et les fonctions deviennent plus nombreux.

Chez les animaux les plus voisins de l'Homme, l'instrument de chaque fonction est tantôt simple, tantôt double; 
mais, dans le premier cas, formé de moitiés semblables, cohérentes. Voilà le maximum de la perfection organique.

Les organes essentiels d'un Vertébré (cerveau, cœur) sont ceux qui, par soudure, acquièrent l'unité.

Les autres organes (oreilles, mains) conservent la dualité.

Chez les Annelés, presque tous les organes sont multiples. Certaines espèces ont 10 mâchoires, d'autres 60 tentacules, d'autres 200 dents; celles-ci 300 pattes, celles-là $3000,15000,30000$ petits yeux $\ldots . .$.

Le plus souvent, ce sont les organismes tout entiers (zoonites) qui se répètent. On en compte une vingtaine daus une Sangsue; il y en a au moins 2000 dans un Ténia'. Cependant l'animal s'éloigne beaucoup d'un Vertébré, et par sa constitution, et par son intelligence.

Il est autrement compliqué; car sa complication résulte, non de la perfection de ses organes, mais du nombre de ses organismes. Chaque zoonite, pris séparément, diffère notablement de l'admirable ensemble d'un Mammifère ou d'un Oiseau, et la réunion de ces zoonites, quoique formant un tout supérieur à celui d'un zoonite isolé, se trouve encore bien au-dessous de l'organisme d'un Vertébré quelconque.

Chez les animaux les plus inféricurs, ce ne sont plus les organes ou les organismes qui se répètent, mais les individus eux-mêmes tout entiers. Ils s'associent et forment un être collectif, un animal composé.

Dans la division du travail, il y a donc quatre modes à considérer :

$1^{\circ}$ Plusieurs individus pour une association.

$2^{\circ}$ Plusieurs ensembles d'organes (zoonites) pour un individu.

I Voyez le chapitre XXIX. 
3 . Plusieurs instruments pour une même fonction.

$\mathfrak{1}^{\circ}$ Des instruments spéciaux (doubles) pour des fonctions spéciales.

Une notion même légère des grandes choses a son prix (Leibnitz); c'est pourquoi on nous pardonnera le caractère un peu sérieux (nous allions dire un peu savant) de cette introduction. Arrivons maintenant aux Mammifères.

\section{1}

Les Mammifères, ou, comme on les appelait anciennement, les Quadrupèdes vivipares, sont les Vertébrés les plus rapprochés de l'Homme. Ceux qui vivent dans la mer constituent trois sections d'animaux assez différentes, et par leur structure, et par leurs mœurs :

1"Les Mammifères dont les membres antérieurs, plus ou moins incomplets, sont trausformés en rames ou nageoires, et qui manquent de membres postérieurs : on les appelle Cétacés.

$2^{\circ}$ Ceux qui ont quatre membres tous convertis en rames ou nageoires : ce sont les Phoques et les Morses.

$3^{\circ}$ Ceux qui ont quatre membres plus ou moins semblables à ceux des Quadrupèdes ordinaires: ce sont les Loutres de mer et les Ours blancs.

Les premiers et les seconds peuvent être regardés comme les Mammifères marins proprement dits.

Les Cétacés sont les moins parfaits en organisation.

\section{III}

Les Cétacés sont des Mammifères marins essentiellement aquatiques. La plupart ne viennent jamais à terre. En 
général, ils se tiennent toujours dans l'cau; mais comme ils respirent par des poumons, ils sont forcés de monter à sa surface pour prendre de l'air.

Lorsque, par suite de quelque gros temps, les grandes espèces se sont échouées, il leur est ordinairement impossible de se remettre à flot.

La tête des Cétacés se joint à leur trone par un cou si court et si gros, qu'on n'aperçoit en cet endroit aucun rétrécissement. Leur tronc se termine par une queue épaisse et charnue. Cette queue est déprimée ou horizontale, et non verticale ou comprimée, comme celle des Poissons. A cause de cette structure, on leur avait donné anciennement le nom de Plagiures (Pisces plagiuri). Ils frappent l'eau de haut en bas et non de droite à gauche.

Un vieux marin, qui avait toujours une histoire prête, disait un jour à un jeune novice, à propos d'un Marsouin ${ }^{1}$ qu'on venait de harponner : “ Vois-tu, mon petit, le Marsouin, c'est comme le Dauphin ${ }^{2}$, deux cousins germains qui naviguent depuis le commencement du monde. Dans le principe, ils avaient la queue en iravers; aussi filaient-ils si vite, si vite, qu’ils dépassaient les chevaux du père Tropique. Ca le vexa, le bonhomme. C'est pourquoi il leur tordit la queue pour leur ralentir le pas! »(S. Berthelot.)

Les Cétacés ont au-dessus de la tête un ou deux orifices appelés évents, qui communiquent avec le fond de la bouche, au moyen desquels l'animal expulse, sous forme de jet de vapeur, l'air humide qu'il a pris pendant sa respiration. Cet appareil leur a valu le nom de Souffleurs.

Les meilleurs plongeurs que l'on connaisse ne peuvent rester sous l'eau qu'un petit nombre de minutes. Les Cétacés demeurent submergés des demi-heures entières,

1 Voyez le chapitre XLV.

2 Ibidem. 
sans paraitre souffrir le moins du monde. Un de nos plus savants anatomistes, le professeur Breschet, a découvert, en disséquant un de ces animaux qu'il possédait, le long de la colonne vertébrale, un réseau considérable de grosses veines, lequel n'existe pas chez les autres Mammifères. Ce réseau lui a paru destiné à servir de refuge au sang durant le temps que l'amphibie reste plongé sous l'eau. Il forme comme un réservoir où se rend le trop-plein de la tête et des organes importants. Aussitôt que le Cétacé retourne à l'air, et que le jeu de la respiration se rétablit, le sang s'échappe de ce réseau et se précipite dans les poumons.

Les Cétacés vivent par troupes souvent nombreuses. Il en existe une centaine d'espèces.

Les uns sont carnassiers, les autres herbivores. Ces derniers sortent parfois sur le rivage, y rampent à l'aide de leurs nageoires, et y paissent comme des Ruminants. Ils font ainsi exception à la règle générale.

Plusieurs espèces, quand elles allaitent leur petit, dressent leur corps verticalement, et tiennent toute sa partic supérieure hors de l'eau. Elles embrassent leur nourrisson avec les nageoires, comme une femme tient son enfant avec ses bras. En apercevant de loin ces femelles dans cette posture et dans cette occupation, on a pu leur trouver une certaine ressemblance avec l'espèce humaine, et de là les noms de Femmes marines, de Nymphes marines, de Sirènes.....

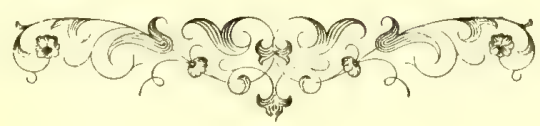





\section{GHAPITRE XLIV}

\section{LES CACHALOTS.}

Grosse tête et petit cerveau.

Les Cachalots sont des Cétacés de grande taille, caractérisés par la grosseur de leurs dents inféricures. Un Cachalot ordinaire mesure 23 mètres; sa tête plus de 10 mètres (L. Hautefeuille).

Phisieurs zoologistes pensent qu'il en existe au moins dix espèces; d'autres n'en reconnaissent que trois; quelques-uns n'en admettent qu'une seule. Les grandes bêtes ne sont guère mieux connues que les petites.

Le Cachalot grosse tête, appelé aussi et plus pompeusement, macrocéphale ${ }^{1}$, se rencontre dans presque toutes les mers.

Anderson en a mesuré un qui avait à peu près 70 pieds anglais de longueur.

'Physeter macrocephalus Linné (Sperma ceti Whale des Anglais, Pottfisch des Allemands). 
Cet animal est d'un noir bleuâtre, plus foncé sur le dos. Sa mâchoire d'en haut est sans dents, ou n'en offre que de rudimentaires cachées sous les gencives. La màchoire d'en bas est plus courte d'un mètre et plus étroite; elle semble hors de proportion avec cette dernière. Nous parlerons tout à l'heure des grosses dents qu'elle présente.

L'évent est unique. Les yeux sont placés sur des éminences.

La nageoire dorsale est réduite à une saillie calleuse. La queue est bilobée.

L'ensemble de l'animal est épais, lourd et disgracieux. Dans sa physionomie sans élégance, il y a moins du Poisson que du Têtard.

Le Cachalot grosse tête nage ordinairement à fleur d'eau, montrant le dos et l'éminence charnue qui entoure l'évent. Il vient donner l'essor aux humides bouffées de son organe, comme un bourgeois hollandais vient fumer sa pipe au soleil (Melville). Sa progression n'est pas rapide. Dans les bas-fonds, on le voit quelquefois dresser verticalement hors de la mer toute la partie supéricure de son corps.

Quand les Cachalots voyagent, le plus grand et le plus fort marche toujours à la tête de la phalange. C'est lui qui donne ordinairement le signal du combat.

En 174, un individu énorme échoua vers l'embouchure de l'Adour, près de Bayonne.

En 1769, un autre fut jeté sur la côte, à peu de distance de Saint-Valery, dans la baie de la Somme.

En 1784, trente-deux Cachalots échouèrent dans la baic d'Audierne, sur le rivage de la commune de Primelin, en basse Bretagne.

Le squelette conservé dans une des cours du Muséum de Paris a été acheté à Londres en 1821. 
Tout récemment (novembre 1862) un petit Cachalot a été tronvé par les douaniers dans les récifs du Darmon (Var). Sa longueur est de $12^{\text {m }}, 70$, et sa cipconférence de 8 mètres.

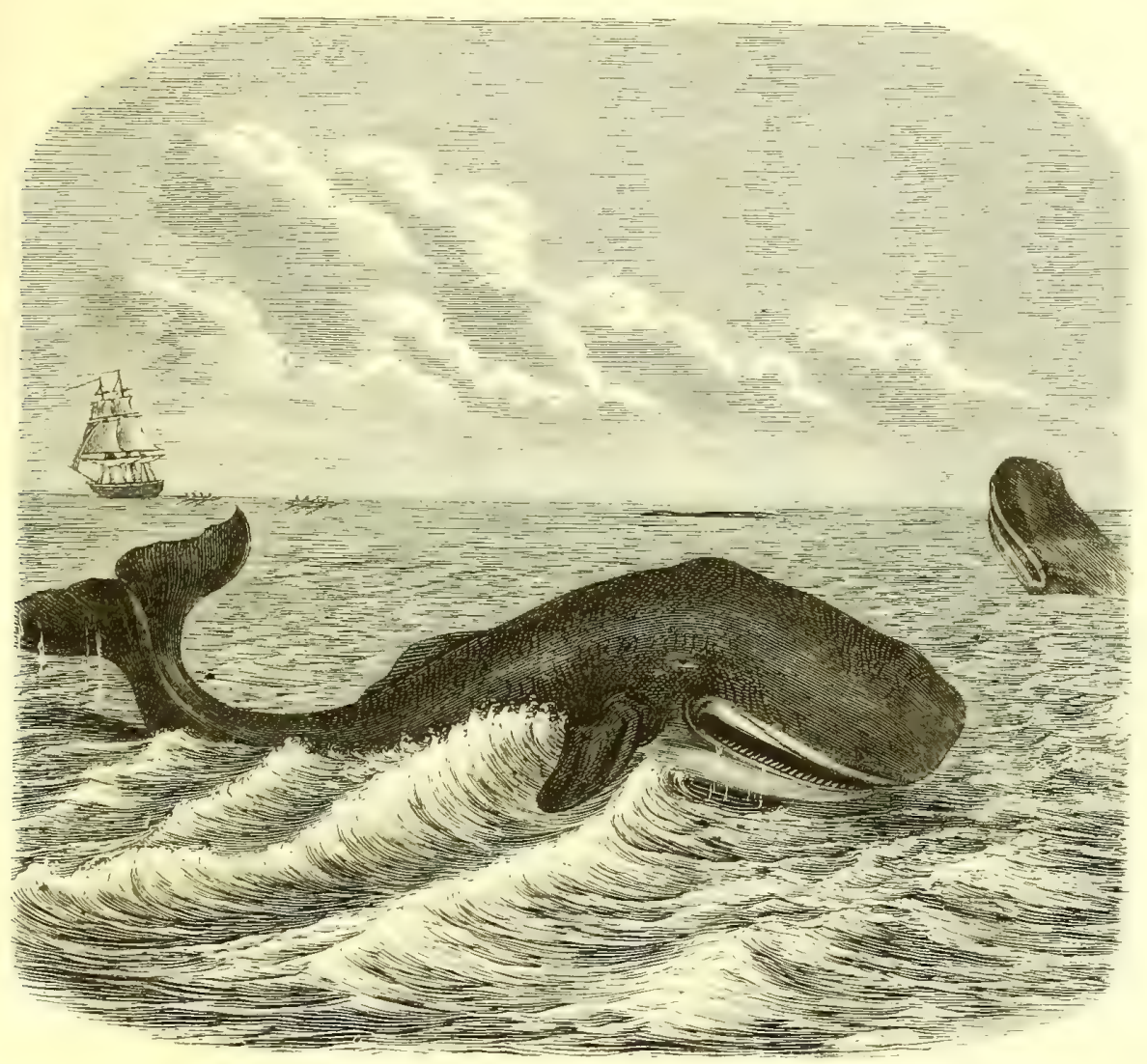

CACHALOT GROSSE TÉTE

(Physeter macrocephalus Linné).

Sa gueule, ouverte, peut recevoir un homme debout et l'avaler sans lui faire subir la moindre pression. On estime son poids à 40000 kilogrammes. Il a été acheté par M. Bienvenu, ex-maître de port, pour la somme de cinquante francs. Le squelette a été vendu pour le musée de Draguignan. 
La pêche des Cachalots est l'objet d'une industric considérable.

Nous devons au commandant L. Hautefeuille quelques détails sur cette pêche intéressante et lucrative.

Chaque capitaine possède à son bord deux hommes en observation au sommet des mâts, et quatre ou cinq canots aigus aux deux extrémités (baleinières). Aussitôt qu'un malheureux Cachalot a été signalé, les canots sont détachés, chacun monté par quatre rameurs intrépides, par un officier qui dirige l'embarcation à l'aide d'un aviron de queue, et par un harponneur expérimenté, ordinairement vieux loup de mer, doué de sang-froid, d'un coup d'cil juste et d'un poignet vigoureux.

Dès que l'animal se sent harponné, il s'élance rapidement vers le fond de la mer. Après quelques minutes, il reparait à la surface pour respirer. La colonne d'air. et d'ean jetée par son évent est parfois ensanglantée. Il replonge, mais auparavant un second et même un troisième harpon ont été lancés d'une autre chaloupe.

Quelquefois les pècheurs emploient un harpon particulier, renfermé dans un appareil semblable à un grand tromblon de cuivre. Au moyen d'un puissant ressort, cet instrument part comme une flèche, et va s'implanter dans la peau du Cétacé. Récemment encore on a imaginé un troisième et plus terrible moyen de destruction : e'est une sorte de pétard qui éclate quand il a pénétré dans les chairs. Tous ces nouveaux systèmes sont généralement peu employés. 
Cependant l'animal, épuisé, remonte à la surface, où ses apparitions deviennent plus fréquentes. C'est à peine s'il peut plonger encore à quelques brasses et retarder sa mort de quelques instants.

A ce moment, les chaloupes, réunies en cercle, le cernent et l'achèvent à coups de lance: mais, souvent, il arrive que le Cachalot se défend et vend chèrement sa vie. Malheur alors à l’imprudent canot qui s'est un peu trop avancé! D'un coup de sa queue puissante, le monstre balaye tout ce qui se trouve à sa portée.

Le Cachalot mort ou mourant, les embarcations le traînent à la remorque. Le navire aborde l'animal et le retient fixé à l'avant par la queue.

L'équipage dîne joyeusement. Il procède ensuite au dépècement, opération toujours accompagnée de rasades de genièvre et de chansons.

D'abord on enleve tout autour du corps de larges bandes de graisse destinées à la cuisson dans de grandes cuves de cuivre. On épuise l'huile et la graisse dans le corps, surtout dans la tète, où on la recueille quelquefois avec des seaux

L'huile de la région céphalique est la plus épaisse, et clle forme à elle seule le tiers an moins de la masse totale.

Lorsque le corps est entièrement épuisé, on le sépare de son chef, et l'on abandonne la carcasse aux Oiseaux et aux Requins.

La tête seule est hissée sur le pont, où l'on achève de la déponiller. Cette opération est possible sur des individus de taille moyenne.

Le dépècement, la cuisson et la préparation demandent quarante-huit heures, et occupent de vingt à trente hommes.

Une fois épurée, l'huile est mise dans des tonnes.

Un Cachalot peut fournir, suivant sa taille, de quatre- 
vingts à cent cinquante tonnes d'huile. Un individu long de 18 mètres, et pesant 60000 kilogrammes, en rend de quatre-vingt-quinze à cent barils. Rarement on en trouve qui en donnent davantage.

La pêche d'un trois mâts est d'environ cinquante individus. Il peut les avoir pèchés dans l'espace variable d'un à trois ans.

Cette pèche est faite de nos jours principalement par les Américains, quelques Anglais, et peu de Franģais et de Portugais. (L. Hautefeuille.)

Les Cachalots fournissent à l'industrie et aux arts, nonseulement de l'huile, mais encore de l'ivoire, du blanc de baleine et de l'ambre gris.

L'ivoire se retire de leurs dents. Il est d'assez mauvaise qualité.

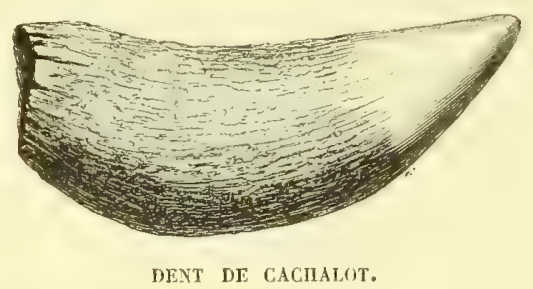

La mâchoire inférieure porte de chaque côté de vingt à vingt-cinq grosses dents ${ }^{1}$. Ces dents sont cylindriques et coniques au sommet, à peine recourbées d'avant en arrière, légèrement comprimées inférieurement et un peu pointues. Nous en avons une sous les yeux qui présente

1 "Dentes 46 inferioris maxilloe." (Linné.) 
20 centimètres de hauteur: nous en avons vu une autre qui pesait plus d'un kilogramme.

Le blanc de baleine se trouve au milieu des grandes carités de la partie supérieure du crâne, au-dessus du cerveau. Ce dernier est petit, relativement an volume de la tète. Camper a trouvé que, sur une tête de 6 mètres de longuenr, la cavité crànienne n'avait que 32 centimètres.

Pendant la vie de l'animal, le blanc de baleine est dissous dans un liquide huileux. Il se fige après la mort. On l'obtient pur en l'exprimant dans un sac de laine. On le fait bouillir ensuite dans une lessive alcaline, pour le débarrasser de la partie huileuse restante. On le lave et on le fond.

Dans un Cachalot des Moluques, long de 19 mètres et demi, M. Quoy a calculé qu’il y avait vingt-quatre barils de blanc de baleine, contenant chacun 12:5 kilogrammes. Par conséquent, cet animal en a fourni 3000 kilogrammes.

Cette matière est solide, blanche, brillante, comme nacrée, un peu transparente et très-douce au toucher. Elle se casse facilement et par écailles.

C'est un des éléments de la pommade anglaise, le coldcream, recommandée pour adoucir la peau.

L'ambre gris n'est autre chose qu'une sorte de calcul intestinal, ou plutôt une partie des aliments des Cachalots, très-incomplétement et très-imparfaitement digérés.

Cette matière, si recherchée dans la parfumerie et si estiméc par beaucoup de belles dames, cette matière présente, comme on voit, une nature très-peu noble et une source tres-peu respectable. L'inconvenance de son origine I'en rend que plus étomnante la suavité de son odeur!

L'ambre, qui se forme dans le corps du Cachalot, est rendu.... avec les excréments.

Plusieurs zoologistes pensent que tous les Cachalots 
rejettent normalement cette substance. D'autres supposent qu'elle est le résultat de certaines maladies, et par conséquent un produit accidentel.

On trouve l'ambre gris, tantôt flottant sur la mer ou déposé sur la plage, parmi les déjections des Cétacés, tantôt dans les intestins mèmes de ces animaux.

C'est sur les côtes du Japon, des îles Moluques, de l'Inde, de Madagascar et du Brésil, qu'on récolte habituellement cette substance.

La nourriture prise par les Cachalots semble influer sur la production de l'ambre. Il parait que ce sont les Poulpes musqués, nommés Élédones, les Sèches et plusieurs autres Mollusques, mème des Poissons odorants, mal digérés et accumulés, qui donnent naissance à cette matière. On sait que, parmi les animaux marins, il en est un certain nombre qui exhalent une odeur de muse plus ou moins forte.

Lorsque les pêcheurs américains découvrent des morceaux d'ambre gris dans un parage, ils en concluent aussitòt qu'il doit être fréquenté par quelque Cachalot.

L'ambre gris est une matière solide, assez dure, grasse, cireuse, plus légère que l'eau. Sa couleur est d'un gris noirâtre un peu cendré, 'quelquefois jaunâtre on brunâtre, souvent masquée par une efflorescence blanche qui se forme à sa surface et qui pénètre mème un peu dans son intérieur. Cette matière offre une odeur douce, suave, susceptible d'une grande expansion.

L'ambre gris est en masses irrégulières, composées tantôt de couches concentriques, comme superposées, tantôt de petits grains inégaux plus ou moins arrondis. On trouve quelquefois, dans son intérieur, des débris de mollusques et de poissons, tels que des mandibules, des écailles, des arêtes. 
Ces masses pèsent habituellement de 50 à 500 grammes. On en trouve, cependant, de 5 à 10 kilogrammes. Le Cachalot échoué en 1741, près de Bayonne, avait dans ses intestins un morceau d'ambre du poids de $\mathrm{s}^{\mathrm{kil},}, 30$. Un baleinier en retira 20 kilogrammes des entrailles d'un individu, et 52 de celles d'un autre. La Compagnie des Indes en avait une masse, en 169:, du poids de 73 kilogrammes. Valmont de Bomare en vit un bloc, en 1721, de 100 kilogrammes. On a parlé d'un autre de 293 kilogrammes, ce qui parait bien extraordinaire.

On prétend que les Renards sont très-friands de l'ambre gris, qu'ils viennent chercher sur les côtes de la mer. Ils le mangent et le rendent tel qu'ils l'ont avalé, quant à son parfum, mais altéré dans sa couleur. C'est au résultat de ce goùt qu'on attribue l'existence de quelques morceaux d'ambre blanchâtre, qu'on trouve à une certaine distance le l'Océan, dans les Landes aquitaniques, et que les habitants du pays appellent ambre renardé (Bory)? Cette seconde qualité de matière parfumée aurait done traversé le tube digestif de deux Mammifères différents, et aurait toujours conservé son excellente odeur.

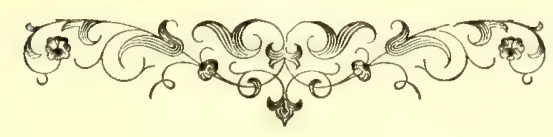





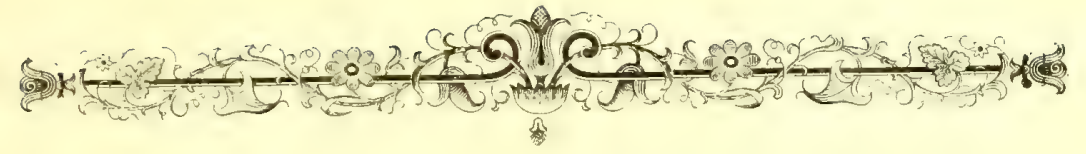

\section{CHAPITRE XLV}

\section{LES DAUPHINS.}

"Velocissimum omnium animalium non solum marinorum est DELPHINUS, ocyor volucre, ocyor telo." (PLine.)

Les Dauphins sont des Cétacés souvent petits, élancés et gracieux. Il y en a cependant d'une taille colossale.

On les rencontre dans toutes les mers.

Le plus commun est le Delphis', que les pêcheurs nomment Oie de mer et Bec-d Oie, à cause de son museau effilé et pointu, structure rui le distingue du Marsouin ${ }^{2}$, autre espèce à museau court et tronqué.

Le Delphis offre dans son palais un double sillon recouvert par la peau. Il a quarante-cinq paires de dents à chaque mâchoire.

Sur une tête qui fait partie du musée de l'École de pharmacie de Paris, nous avous compté l04 dents à la mâchoire

- Delphinus delphis Linné.

${ }^{2}$ Delphinus phocana Linné. 
supréreure (32 de chaque côté), et 98 à la mâchoire inl'éricure (49 de chaque côté); en tout, 202. Ces dents sont très-petites, très-égales, très-blanches, pointues ef légèrement courbées.

Les Dauphins ne manquent pas d'intelligence. Mais les écrivains grees et les écrivains romains ont singulièrement cxagéré leurs différentes aptitudes. Ils ont prétendu qu’ils étaient sensibles à la musique et qu'ils pouvaient rendre à l'Homme des services signalés....

Pline rapporte très-sérieusement que, de son temps, sur la còte de Varbonne, des Dauphins aidaient les pêcheurs ì prendre des poissons, et qu'on les récompensait de leurs peines, nou-seulement par une portion de la pêche, mais encore par du pain trempé dans du vin.

On a été jusqu'à dire que des Dauphins avaient porté des hommes sur leur dos. On a parlé d'un individu trèsapprivoisé, qui, n'ayant plus revu l'enfant qu'il affectionnait, mourut bientòt de chagrin!

Le' Dauphins fendent les vagues plus rapidement qu'un oiseau qui traverse les airs (ocyor volucre). Avant-coureurs d'un vent frais, ils accourent du bout de l'horizon, et bondissent sur la lame comme pour saluer le navire. Aussi les marins regardent-ils leur arrivée comme un heureux présage (S. Berthelot). Des troupes vagabondes suivent les vaisseaux pendant des journées enticres, les dépassent en sautant, les croisent en se poursuivant, plongent sous leur quille, disparaissent, et reviennent pour recommencer leur premier jeu. Ces troupes sout composées de cinq ou six individus, rarement d'un plus grand nombre. Cependant on en a vu formées d'une vingtaine. Les Dauphins chassent en meute dans l'eau, comme les Loups sur la terre. (Audubon.)

Les Dauphins sont l'amour et l'orgueil des ondes, suivant 
les belles expressions d'Oppien. Ces animanx se témoignent les uns am autres une sympathie vraiment remarruable, et bien plus réelle que leur affection prétendue pour l'espèce humaine. Du moment que l'un d'eux est pris, tous ceux de la troupe s'approchent et l'entourent, jusqu'à ce qu'on l'ait enlevé sur le pont. Alors ils s'éloignent ensemble, et aucun ne veut plus mordre, quelque chose qu'on lui jette. Cependant cela n'a lieu que lorspu'il s'agit de gros individus rusés et méfiants, qui se tiemnent à part des jeunes, comme on l'observe dans plusieurs espèces d'oiseaux. Au contraire, si vous avez affaire à une troupe de jeunes, ils resteront tous sous l'avant du vaisseau, et continueront de mordre, l'un après l'autre, comme empressés de voir par eux-mèmes ce qu'est devenu le camarade, et de cette manière ils sont tous capturés (Audubon).

La plus grande espece connue est l'Orque on Epaulard ${ }^{1}$.

On en prit un dans la Tamise, en 1787, long de 8 metres, et un autre dans la Loire, en 1793, long de 6. On assure qu'il peut atteindre jusqu'à 10 mètres.

Deux individus, un jeune et une femelle, ont échoué, en 1844, près d'Ostende.

Ce beau Dauphin a le dessus du corps noir, et le dessous blanc. Il offre une tache blanchatre, en forme de croissant, a la prartie supérieure des yeux. Ses dents sont coniques et un peu crochues.

Il passe pour le plus redoutable des Cétacés qui visitent nos parages. Il atturue les Mammifires de la mer, même les plus grands; il ose poursuivere la Baleine.

Une troupe d'Épaulards harcèlent le roi des Cétacés, jusqu'à ce qu'il ouvre la gueule, et alors ils lui dévorent la langue (Cuvier). Rien n'est intéressant comme d'entendre

1 Delphinus orca Linné. 
les récits des pêcheurs du Groenlaud et du Spitzberg, sur la férocité et la gloutonnerie de ces dangereux animaux.

Le $1^{\text {er }}$ août 1862, un beau mâle est venu se perdre sur la côte du Jutland. La nouvelle en a été dommée immédiatement au professeur Eschricht, à Copenhague, leruel s'est rendu sur les lieux. Ce savant zoologiste a voulu savoir, avant tout, de quoi le monstre s'était nourri pendant les dernières heures. Il a retiré de son estomac treize Marsouins et quinze Phoques!

La pêche du Dauphin est une des occupations les plus importantes et les plus fructueuses des habitants des îles Feroë.

L'espèce principale qu'on rencontre autour de ces îles est l'Épaulard à tête ronde', remarquable par la saillic excessive de son front, qui représcnte un casque antique. Ce Dauphin vit en troupes nombreuses, conduites par un grand individu.

Lemaout, pharmacien à Saint-Brieuc, en a observé soixante et dix jetés sur la côte, près de Paimpol. Lin 1806. il en échoua quatre-vingt-douze dans la baie de Scapay, à Pomona, l'une des Orcades. L'année précédente on en avait poussé jusqu'à trois cent dix sur le rivage de Shetland. Scoresloy en a vu jusqu'à mille réunis en une seule troupe. (Des Moulins.)

“ Dès qu'un pêcheur des îles Feroë a reconnu en pleine mer la présence d'une bande de Dauphins, il la signale 
aussitôt aux habitants de la côte, en arborant un pavillon particulier. Ceux-ci s'en vont sur la montagne, allument un feu de gazon, et bientôt ce signal télégraphique annonce à toutes les îles la joyeuse nouvelle. Les tourbillons de fumée flottent dans les airs, les feux éclatent de sommet en sommet; leur nombre et lem position indiquent aux habitants des côtes éloignées l'endroit où se trouvent les Dauphins.

» A l'instant, le pêcheur détache sa barque du rivage. Ses parents, ses voisins, accourent à la hâte se joindre à lui. Des femmes leur préparent des provisions, et ils s'élancent gaiement sur les flots. A Thorshavn, la capitale des îles Feroë, il y a, ce jour-là, un mouvement dont on ne saurait se faire une idée. Des femmes, des enfants, vont tout effarés à travers la ville, en criant : Gryndabud! Gryndabud! (Nouvelle du Dauphin!) A ce cri de bénédiction, toutes les portes s'ouvrent, toutes les familles sont en rumeur. C'est à qui ira le plus vite à son bateau, à qui sera le plus tôt prêt pour fendre la lame avec l'aviron ou à déployer la voile. Le gouverneur et le landfogde accourent aussi, et se mettent à la tête de la caravane, avec leur chaloupe conduite par dix chasseurs en uniforme, et portant au haut du mât la banderole danoise.

„Quand tous les pêcheurs sont réunis à l'endroit désigné, ils se rangent en ordre de bataille, s'avancent, selon la position des lieux, en colonne serrée, ou forment un grand demi-cercle. Ils enlacent dans cette barrière les Dauphins étonnés, les poursuivent, les chassent jusqu’à ce qu’ils les amènent au fond d'une baie. Là le cercle se resserre, les Dauphins sont pris entre les bateaux et la terre, arrètés d'un côté par des mains armées de lances ou de pieux, et de l'autre par la grève, où le moindre mouvement imprudent les fait échoner....

"Bientôt il se fait un carnage horrible. Les pêcheurs 
frappent, égorgent, massacrent. Le sang ruisselle, la mer devient tonte rouge; et ceux des Dauphins qui pourraient encore s'échapper, perdent dans la vague ensanglantée leur agilité distinctive, et tombent comme les autres sous le fer acéré. Souvent on compte les victimes par centaines.

"Quand le carnage est fini, on traîne les Dauphins sur le sable. Le sysselmand apprécie la valeur de chaque Cétacé, leur grave une marque sur le dos, et le gonverneur en fait le partage. D'abord on prend, à titre de dime, une part pour le roi, pour l'kglise, pour les prêtres, une autre pour les fonctionnaires, une troisième pour les paurres, une quatrième pour ceux qui sont associés à la pêche, tant par barque et tant par homme. Celui qui a déconvert le troupeau a droit de choisir le plus gros de tous les Danphins. Ceux qui ont été blessés ou qui ont souffert quelque avarie dans l'expédition ont une part supplémentaire. Enfin, on en réserve encore une part pour les propriétaires du sol où la pêche s'est faite, et celle-ci est presque toute dévolue au roi, qui est le plus grand proprićtaire du pays.

» Quand le partage est tẹminć, les animaux sont dépecés. On en retire la peau, qui sert à fabriquer des comroies; la chair et le lard, qui forment une des meilleures provisions de la famille feroëenne. Avec la graisse on fait de l'huile, et la vessie desséchée sert de vase pour la contenir. Les entrailles sont portées par chaque bateau en pleine mer, afin de ne pas infecter la côte.

" Un Dauphin de moyenne grandeur donne ordinairement une tonne d'huile, qui se vend, à Thorshavn, de 30 à 40 franes. La chair et le laud ont à peu près la même valeur. " (Mag. pittor.)

Audubon rapporte que, pendant un long calme, des troupes de superbes Dauphins glissaient près des flanes de son vaisseau, étincelant comme de l'or bruni à travers la 
lumière et semblables en éclat aux météores de la nuit. Le capitaine et les matelots les surprenaient habilement avec Thameçon, ou les perçaient avec un instrument à cinq pointes, appelé pique.

Quand il a senti l'hamecon, le Dauphin se débat violemment et s'élance avec impétuosité jusqu'au bout de la ligne. Alors, se trouvant soudain arrèté, il saute souvent tout droit hors de l'eau, et parvient quelquefois à se détacher. Quand il est bien pris, le pècheur expérimenté le laisse l'abord faire ses évolutions; bientôt l'animal s'apaise, et on le hisse sur le pont. Quelques personnes préfèrent le tirer tout de suite, mais rarement elles réussissent; car ses brusques secousses, lorsqu'il se sent hors de son élément, suffisent en général pour le dégager. (Audubon.)

\section{III}

Les Dauphins nous rappellent naturellement lo Narwal, ou Licorne de mer', grosse espèce des mers aretiques, agile ot audaciense, armée d'un instrument de combat très-puissant et très-redoutable.

Le Narwal est long de 6 à 9 mètres. Il porte au devant de la gueule une sorte de grande hallebarde, de longue épée d'ivoire, horizontale, étroite, pointue, cannelée, comme tordue en spirale. Cette énorme dent sort d'un alvéole commun à la partie extérieure de l'os maxillaire et à l'os incisif de l'un des côtés. Elle dépasse quelquefois du 2 mètres l'extrémité du musean.

1 Honodon monoceros Linné. 
C'est cette défense qu'on appelait autrefois corne de

\section{Licorne.}

On en conserve deux dans le musée de la Faculté de médecine de Paris, dont la plus grande offre 2 "' 25 de longueur et une circonférence, à la base, de 48 centimètres. Ces deux dents faisaient anciennement partie du trésor de l'abbaye de Saint-Denis. Dans quel but des cornes de Licorne étaient-elles conservées par des abbés?

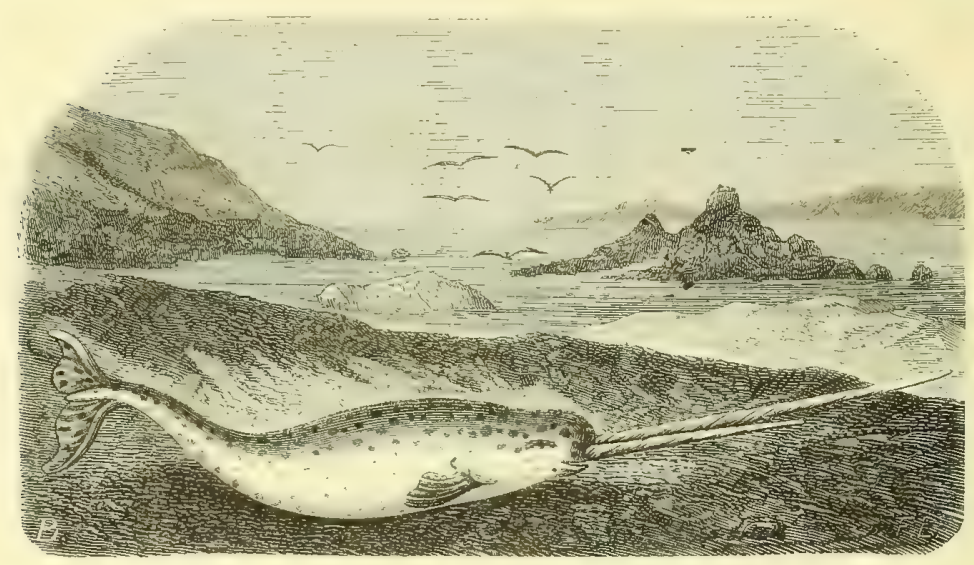

NARWAL

(Monodon monoceros Linné).

La dent correspondante, c'est-à-dire celle de l'autre côté, est habituellement très-peu développée, et reste cachée dans l'os de la mâchoire.

Le Narwal est un Cétacé d'un blanc grisâtre, avec des taches blanches qui semblent pénétrer dans la peau.

Dans l'estomac d'un individu, on a trouvé un bras de Sèche et des morceaux de Carrelet.

Pendant son voyage au Groenland, Scoresby rencontra un jour un grand nombre de Narwals qui nageaient près du vaisseau, en bandes de quinze à vingt. La plus grande 
partie étaient des mâles. Ils paraissaient fort gais, élevaient leurs défenses au-dessus de l'eau, et les croisaient comme pour faire des armes. Ils produisaient un bruit tout à fait extraordinaire et qui ressemblait au glouglou que fait l'eau dans la gorge.... La plupart suivaient le navire et semblaient attirés par la curiosité. Comme l'eau était transparente, on put très-nettement les voir descendre jusqu'à la quille, et s'amuser avec le gouvernail....

Il n'est guère possible de reconnaître le Narwal dans le passage où Pline a décrit la Licorne. Il donne à cet animal la tête du Cerf, les pieds de l'Éléphant et la queue du Sanglier. Ce qui ne l'empêche pas, dit-il, de ressembler à un Cheval. Sa corne est noire et nait au milieu du front!!

\section{IV.}

On mange les différentes espèces de Dauphins. Que ne mange-t-on pas? Les plus petites passent pour les plus délicates. Les Saxons et les Anglais, an moyen âge, estimaient beaucoup la chair des Marsouins.

En 1426, on acheta plusieurs de ces animaux pour la table de Henri III. L'évêque de Swinfield, qui vivait à cette époque, s'en régalait toutes les fois qu'il en trouvait l'occasion.

On servit des Marsouins dans un somptueux bạnquet offert à Richard II, à Durham-House. On dit qu'à l'installation solennelle de l'archevêque Nevill, quatre Cétacés de cette espèce figurèrent honorablement.

En 1491, les baillis d'Yarmouth firent présent à lord Oxford d'un beau Marsouin, qu'ils accompagnèrent d'une adresse dans laquelle ils disaient qu'ils lui envoyaient ce 
présent parce qu'ils pensaient que rien ne pouvait être plus agréable à Sa Seigneurie. (Révoil.)

On servit, au repas de noce de Ilenri V, plusieurs plats de haut goùt, préparés avec la chair de ce Dauphin. Au festin du couronnement de Itenri VII, parurent encore des Marsouins; il y en avait de rôtis, de bouillis, en pâtés et en puddings.

La reine Élisabeth elle-mème, qui avait le goût trèsraffiné, aimait la chair de Marsouin.

On vendit de ces animaux sur les marchés d'Angleterre jusqu'en 1 รัฐว̆, '́poque où ils cessèrent d'ètre recherchés.

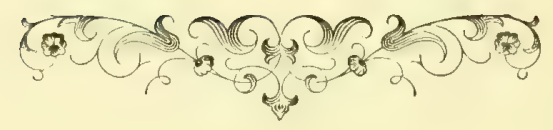




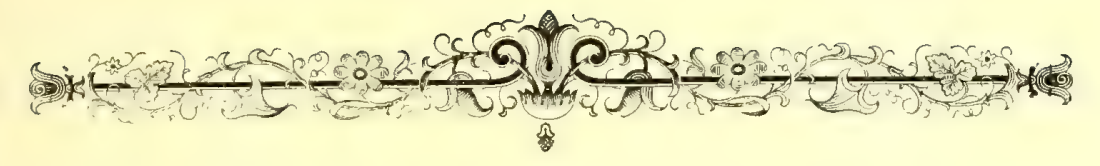

\section{CHAPITRE XLVI}

\section{LA BALEINE.}

"Maximun omnium animalium."

(LINYE.)

Les Baleines sont les plus grands animaux de la mer, et en même temps les plus grands animaux connus.

La Baleine franche ${ }^{1}$, on Nordcaper, a fixé de très-bonne heure l'attention des marins et des naturalistes.

On a fait observer que cette bète gigantesque devait être nécessairement aquatique. Si elle avait été terrestre, quelles jambes auraient pu la soutenir? Si elle avait été aérienne, quelles ailes auraient pu la soulever? Ia Providence a done bien fait de placer les Baleines dans l'eau. Elle leur a donné en même temps la forme d'un poisson, pour s'y mouvoir avec plus de facilité.

Les dimensions de la Baleine sont telles qu'on peut saisir sans peine leur rapport avec les plus grandes mesures terrestres. Des auteurs ont prétendn que des individus très-

- Balcena mysticefus linné. 
âgés ont offert une longucur égale à la cent millième partie du quart du méridien (?).

Lacépède affirme qu'une Baleine dressée contre une des tours de Notre-Dame la dépasserait d'un tiers (?).

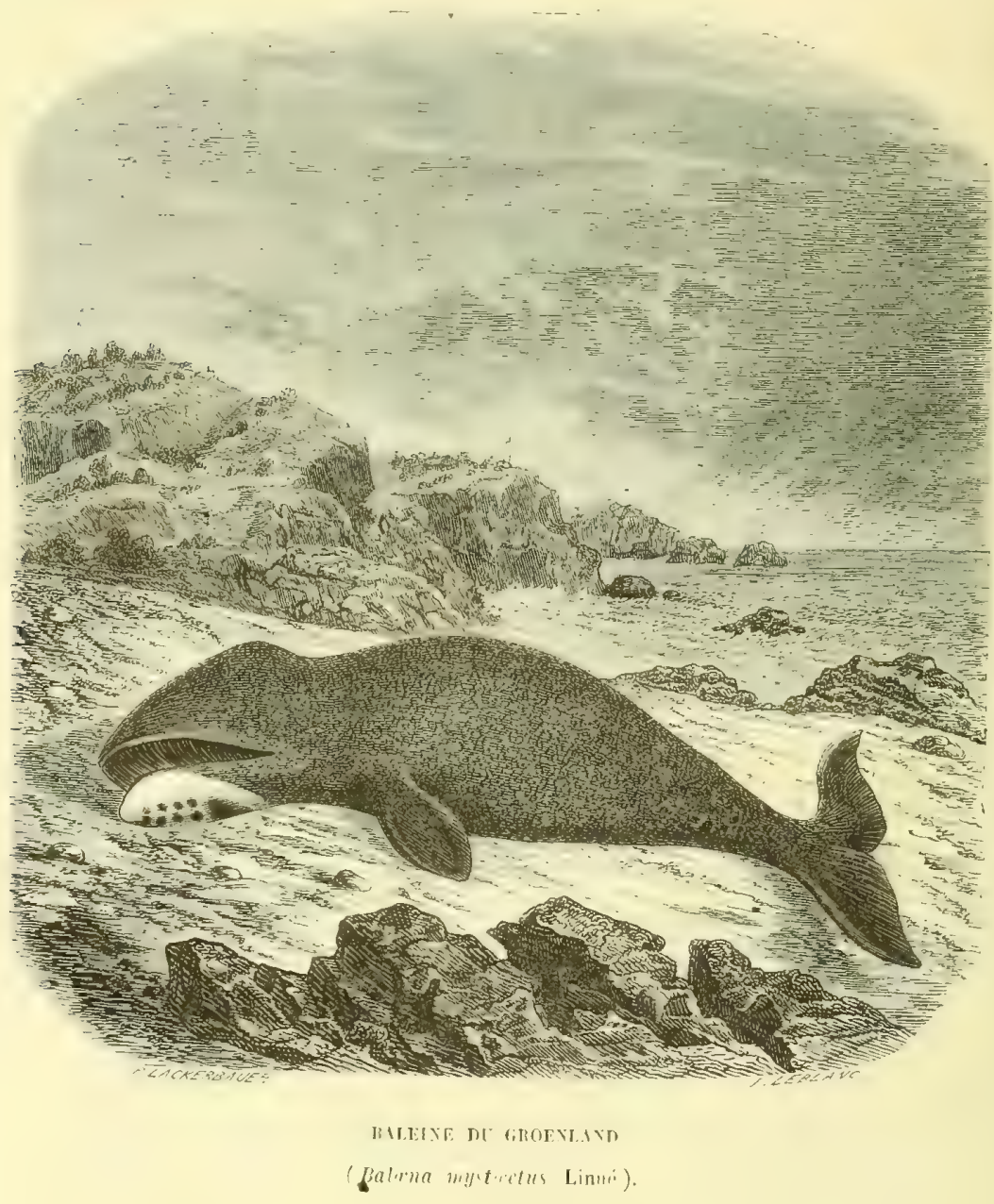

En réduisant les exagérations des marins.... ou des naturalistes, on peut dire que les plus grosses Baleines présentent de 25 à 30 et pent-itre 3:3 mètres de longueur. Tout récemment (avril 1863), la plage de Dunkerque a été 
visitée par un de ces énormes Cétacés, jeté à la côte par un violent coup de vent de sud-est. Il avait 30 mètres de longueur et 20 mètres de circonférence. L'agonie du pauvre Léviathan a duré près de deux heures après son échouement; dans ses dernicrs débats, il faisait voler le sable à 100 metres de la plage. Puis, un effroyable sifflement annonca que la nature était enfin vaincue. (Mémorial d'Amiens.)

Les auteurs prétendent que le poids de cet animal peut atteindre 250000 kilogrammes (?). Une Baleine de 20 mètres, mesurée par Scoresby, n'en pesait que 70000.

Le corps de la Baleine franche est un cylindre colossal et irrégulier, dont le petit diancitre égale à peu près la troisième partie du plus grand.

Ce corps “ n'ha ny poil, ny escailles, mais est couvert d'un cuir uny, noir, dur et espez, soubz lequel y a du lard environ l'espesseur d'un grand pied. ” (Belon.)

La peau de ce géant de la mer offre cependant quelques poils, surtout chez les jeunes sujets.

Sa tête égale en grosseur presque le tiers du volune total; elle a une forme arquée. On voit de loin cette tète colossále s'élever au-dessus de la mer, comme un monticule d'un brun noir.

Sa gueule est d'une grandeur prodigiẻuse, d'une capacité si grande, que dans celle d'un individu de 24 mètres de longuenr, pris en 1726 au cap Thurdel, dans la baie de la Somme, deux hommes pouvaient entrer sans se baisser. (Duhamel.)

Sa mâchoire supérieure porte environ sept cents lames verticales, de nature cornée, à borls frangés, qui pendent des deux côtés. Ces lames, connues dans la science sous le 
nom de fanons, et dans le commerce sous celur de baleines, sont longues de 4 à 5 mètres.

Sa langue est monstrueuse. On assure qu'elle atteint jusqu'à 8 mètres de longueur et jusqu'à 4 de largeur. Elle fournit à elle seule cing ou six barils d'huile. A proprement parler, ce n'est plus une vraie langue, mais un gros matelas épais, mou, tout rembourré de graisse, étalé sur le plancher buccal. Ce matelas est collé dans toute son étendue, et par conséquent immobile. On a de la peine à concevoir une langue qui ne peut pas sortir de la bouche!

La Baleine se nourrit de Méduses, de Mollusques et d'autres petits animaux marins. Ces pauvres bêtes sont entraînées avec la masse d'eau qui les coutient. Le monstre nage à la surface de la mer, la gueule onverte. Il n'a qu'à fermer les mâchoires pour retenir des populations entières. L'eau, tamisée à travers les filets des fanons (véritable forêt de fibres rapprochées), y laisse les mallseureux petits animaux. Chaque repas en détruit plusieurs milliers.

Les gros mangent les petits. C'est la Nature qui le veut. Lt, quelquefois, comme daus le cas actuel, les très-gros mangent les très-petits. Car les bestioles englouties par le colosse des colosses n'ont guère, en moyenne, que 2 ou 3 centimètres de longueur.... Mais le nombre des individus avalés compense, et bien au delà, l'exiguïté de leur taille. On a vu ailleurs que ces petits habitants de l'eau salée se multiplient par millions. Si leur destruction ne portait pas remède à leur fécondité, il arriverait qu'en fort peu de générations, ils encombreraient l'Ucéan et finiraient par le corrompre ou par le solidifier!

Quelle étrange chose que de voir le Gargantua de l'animalité poursuivre de chétives bestioles gluantes et transparentes, presque sans forme et sans consistance, et sonvent à peine perceptibles! 
On assure cependant que la Baleine mange de temps à autre quelques poissons, même des poissons assez gros. Dans l'estomac d'une Baleine on a trouvé un Thon tout entier (Breschet).

Les Baleines vivent comme les Poissons et respirent comme les Quadrupèdes. On dit que le souffle de ces animanx exhale une odeur insupportable, putride et presque cadavéreuse. Est-il vrai qu'on les entend ronfler de loin '? Ce doit être un bien épouvantable ronflement!

Il existe, dans le musée de la Faculté de médecine, de Paris, une tranche verticale du plus grand vaisseau d'une Baleine (l'aorte). Un enfant pourrait passer au travers de cet anneau, lequel offre un diamètre de 36 centimètres et dout les parois ont une épaisseur de 4 centimètres.

Quelle énorme colonne de sang indiquée par cet anneau!

\section{III}

Le poids du cerveau d'une Baleine représente à peine la vingt-cinq millième partie du poids total du Cétacé.

Quoique doué d'une force prodigieuse, cet animal est trèstimide. Quand on le poursuit, il cherche habituellement à fuir et non à se défendre.

Il a des ennemis qui le tourmentent et dont il ne sait pas toujours se défendre ou s'éloigner. Les Espadons le percent, les Scies lui font d'affreuses déchirures; les Marsouins lui arrachent de gros morceaux de chair.

Le diainètre de l'œil d'une Baleine égale la cent quatrevingt-douzième partie de sa longueur totale. Le professeur Carus compare le volume entier du globe oculaire à une

\footnotetext{
I "Balcence stertere audiuntur." (Pline.)
} 
orange, et le docteur Gros, à la tête d'un enfant nouveau-né.

La pupille est transversalement ovale, comme celle des Ruminants.

Quoique ces immenses Mammifères-Poissons manquent de pieds, ils nagent cependant avec une extrême vitesse. Ils se jouent avec les montagnes d'eau soulevées par les tempêtes. Ils se servent admirablement de leurs deux bras, qui forment deux nageoires gigantesques, et surtout de leur queue colossale, composée de deux lobes d'une étendue et d'une force prodigieuses. Aussi, lorsque les baleiniers veulent ralentir la course d'un individu harponné, c'est à cette dernière partie qu'ils adressent leurs coups. Avec une pelle triangulaire bien tranchante, ils pratiquent quelquefois plus de cinquante vigoureuses entailles à la naissance de la queue, et diminuent de moitié la puissance de l'animal fuyant.

Quand une Baleine frappe l'eau avec sa queue, elle produit un clapotement.

On dit qu'une Baleine parcourt, en moyenne, dix milles par heure; mais lorsqu'elle est blessée ou poursuivie, elle s'élance bien plus rapidement. Quelquefois elle s'élève audessus de l'eau et se laisse retomber. Elle produit alors une tempête en miniature, qui se fait sentir assez loin.

\section{IV}

Les Baleines sont sensibles à l'amour. Le mâle accompagne presque toujours sa femelle.

En 1723, on rencontra deux époux Baleines qui traversaient l'Océan. C'était peut-être un voyage de noces! On les attaqua, on les blessa. Un des deux ayant cessé de vivre, 
l'autre se jeta sur son corps bien-aimé avec d'effroyables mugissements (Duhamel).

A l'embouchure de l'Elbe, la mème année, huit femelles échouèrent. Près de leurs cadavres on vit bientôt arriver leurs huit mâles.

Le mâle suit toujours la femelle blessée et reste avec elle. La femelle ne montre, ni la même tendresse, ni la même sollicitude (L. Hautefenille).

Comme tous les Mammifères, les Baleines nourrissent leur petit avec leur lait. Combien donnent-elles de litres de la précieuse nourriture à chaque tetée?

La mère témoigne pour son nourrisson d'un attachement très-ardent et très-courageux.

Quand un Baleineau a été harponné, on peut être certain que la mère ne tardera pas à venir à son secours. Elle le joint à la surface de l'eau quand il y monte pour respirer; elie semble l'exciter à fuir; souvent elle passe sous lui, le charge sur son dos et l'emporte, tandis que le petit, glissant et parfois chavirant sous l'action de la lame, cherche à se maintenir avec ses deux nageoires. Il est très-rare qu' elle l'abandonne, tant qu'il est vivant.

"Dans ces moments, on peut la blesser facilement; car" elle oublie entièrement le soin de sa propre sûreté, pour ne s'occuper que de la conservation de son petit. Elle se lance au milieu des ennemis, méprise les périls; mème après avoir été frappée plusieurs fois, elle reste auprès de son nourrisson, si elle ne peut pas l'entrainer avec elle. Dans son angoisse maternelle, elle court çà et là, bat la mer avec violence, et l'irrégularité de ses mouvements est un indice certain de la vivacité de sa douleur. " (Scoresby.) 
(On appelle fausses Baleines, ou Rorquals, les espèces qui portent une nageoire sur le dos et de larges rides sous le ventre. Leur corps est moins massif que celui de la Baleine; ils nagent avec plus de rapidité, et quand ils plongent, ils restent plus longtemps sous l'eau. Aussi les pècheurs leur donnent-ils rarement la chasse.

Les Rorquals sont encore plus grands que les Baleines. Scoresly parle d'un individu qui avait 120 pieds anglais de longueur!

Ces animaux sont les vrais géants de la création!

En 1828, la mer jeta sur la plage de Saint-Cyprien, dans les Pyrénées-(Trientales, un très-beau Rorqual, qui a été décrit par M. Companyo.

\section{I}

Parmi les grandes pèches qui ont lieu dans les différentes mers, celle de la Baleine, ou du Rorqual, est, saus contredit, la plus renommée, la plus difficile et la plus périlleuse ${ }^{4}$.

0n prenait autrefois de grands Cétacés dans les régions tempérées de l'Europe, soit dans l'Océan, soit dans la Méditerranée.

Divers actes nous apprennent que, jusqu'au $\mathrm{xII}^{\mathrm{e}}$ siècle, ces animaux, assez nombreux dans le golfe de Gascogne, y étaient l'ohjet d'une pêche régulière. Anjourd'bui, ces énormes Mammifères sont devenus de plus en plus rares,

1 Voyez planche XXXII. 
et leur apparition dans ces mêmes eaux est considérée comme un véritable phénomène.

Cuvier croyait que la Baleine du golfe de Gascogne était la mème que la Baleine du cercle polaire. Le professeur Eschricht, de Copenhague, nous a appris que ce sont deux espèces différentes.

Les premiers baleiniers paraissent done avoir été des Basques. Vimrent ensuite les Asturiens, puis les Anglais, et puis les Hollandais.

Le théàtre des pèches, transporté du Midi dans le Nord, a bien souvent changé de parages.

Anciennement, la còte orientale du Groenland passait pour une des meilleures stations. Dans ce moment, cette partie de la mer est complétement déserte. Depuis quelque temps, les Esquimaux ne comptent presque plus sur ce colosse de la mer, qui n'apparait qu'aux environs de Holsteinborg, et encore très-rarement.

Les pêcheurs anglais en ont entièrement dépeuplé la baie de Baffin.

Il y a trente ans, cent navires, appartenant à diverses nations, se livraient à la pêche de la Baleine dans le détroit de Davis. Aujourd'hui, il en vient tout au plus cinc ou six, et encore n'arrivent-ils qu'avec l'espoir d'un butin fort problématique (Ch. Edmond).

La pêche est descendue successivement des Açores au Brésil, du Brésil aux côtes sud d'Afrique, de là au Chili et à la Terre de Feu, puis à la Nouvelle-Ilollande et à la Nouvelle-Zélande. Elle se fait, de nos jours, dans les mers du Japon et sur les côtes du Kamtchatka.

Les bâtiments employés à la pèche de la Baleine sont en général du port de 330 à 430 tonneaux, et portent de trente à quarante-cinq hommes d'équipage. Chaque canot, ou baleinière, est pourvu d'un harponneur placé à l'avant, 
d'un chel qui tient l'aviron de queve, et de quatre rameurs. Il a quatre harpons et deux lances.

Le harpon est long d'environ un mètre. Sa tige est de fer. Son extrémité antérieure porte une dilatation deltoïde, pointue, à deux branches divergentes aiguës, offrant intérieurement comme un petit crochet. Du côté opposé est unc douille également de fer, dans laquelle entre le manche qui sert à lancer l'instrument. Ce manche est une sorte de bàton d'environ un mètre et demi. An-dessus de la douille se trouve fixée une boucle de chanvre natté, qui reçoit l'extrémité de la ligne. On appelle ainsi une corde longue de 300 brasses et épaisse de 2 centimètres.

La lance est une tige de fer longue de 3 à 1 mètres, y compris la hampe, qui en offre à peu près 2 et demi. Eille présente à son extrémité une dilatation ovalaire ou elliptique, aplatie, à bords très-tranchants.

Lor'sque le bàtiment est arrivé dans les parages fréquentés

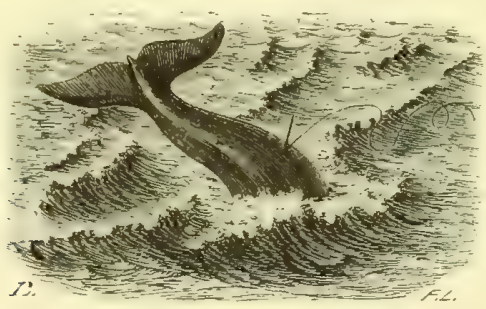

BALEINE HARPONYÉE.

par les Baleines, deux matelots se mettent en vigie au haut du grand màt et du mât de misaine. Aussitòt que l'un apercoit un de ces animaux, il donne le signal. On met les camots à la mer; on s'approche doncement de la Baleine, sans l'effrayer. Le canot qui, le premier, se trouve à distance convenable, commence l'attaque. L'homme placé à l'avant lance son harpon. Il le fait avec adresse et avec 
toute la force dont il est capable. Le géant des ondes, se sentant blessé, donne d'ordinaire un violent coup de quene, et plonge en même temps. Il déroule et entraîne la ligne qui porte le harpon. La baleinière est entrainée à la remorque avec une vitesse effrayante; elle creuse un profond sillon, et soulève devant elle deux grosses lames qui cachent l'horizon anx yeux des matelots.

Les canots ont soin de ne pas se tenir dans la direction de la partie postérieure du Cétacé. Ce voisinage, on le comprend, serait fatal à l'embarcation. Quand la Baleine plonge, sa queue s'élève, se balance quelques instants dans l'air et retombe à plat. Son poids seul peut écraser un canot. Qu'on suppose maintenant le monstre blessé et irrité, et l'on verra combien ses chocs peuvent être redoutables.

La ligne est emportée avec une si grande force et une telle rapidité, qu'elle enflammerait les bords du canot, si l'on n'avait pas le soin de les mouiller de temps en temps.

Si, par malheur, cette corde est arrètée par un nœud ou par tout autre obstacle, l'embarcation est presque toujours submergée.

Au bout d'un certain temps, dix à quinze minutes, la Baleine reparait à la surface de la mer, quelquefois à une grande distance de l'endroit où elle avait plongé.

Au moment de son apparition, il peut arriver aux canots un accident terrible, quoique très-rare. C'est le cas où ils sont pris par-dessous et chavirés.

“Dans l'année 1802, dit Scoresby, le capitaine Lyons, faisant la pêche sur les còtes du Labrador, aperent asse\% près de son bâtiment une grande Baleine. Il envoya aussitôt quatre canots à sa poursuite. Deux de ces canots abordèrent l'animal en mème temps, et plantèrent leur harpon. La Baleine frappée plongea, mais revint bientôt à la surface, et, ressortant dans la direction du troisième canot, qui 
avait cherché à prendre l'avance, elle le lança en l'air comme une hombe. Le canot fut porté à plus de 5 mètres, et, s'étant retourné par l'effet du choc, il retomba la quille en haut. Les hommes s'accrochèrent à un autre canot qui était à portée; un seul fut noyé. »

Quand la Baleine est revenue sur l'ean, on la frappe avec un second et même un troisième harpon. Puis on l'attarque à coups de lance.

Dès que le monstre a cessé de vivre, on le traîne vers le bâtiment, on l'amarre le long du bord, et l'on procède au dépeçage.

On enlève d'abord les parties grasses de la tête, les lippes, la gorge avec la langue, l'os de la mâchoire supérieure et les fanons; puis on trace une bande de lard d'environ $1^{\mathrm{m}}, 50$ de largeur, que l'on détache et que l'on hisse au moyen de palans, en déroulant la Baleine ${ }^{1}$. (On peut se représenter l'opération en pelant une poire en spirale, du gros bout vers la queue.)

Lorsque la bande est hissée jusqu'au haut, on fait, à l'aide d'un conteau à deux mains, une incision longitudinale dans la bande; on y introduit l'estrope dı second palan que l'on fixe au moyen d'un morceau de bois en travers. On coupe alors la bande un peu au-dessus de l'incision, et l'on continue à hisser. Le morceau ainsi obtenu est descendı dans l'entrepont, où il sera coupé en petits morceaux pour être fondu.

Pour dépecer la bande de lard, deux officiers baleiniers se placent en dehor's du navire, sur de petits échafauds. Celui qui se trouve sur l'avant trace la bande sur le corps de la Baleine; celui de l'arrière aide au décollement des chairs. (L. Hautefeuille.) 


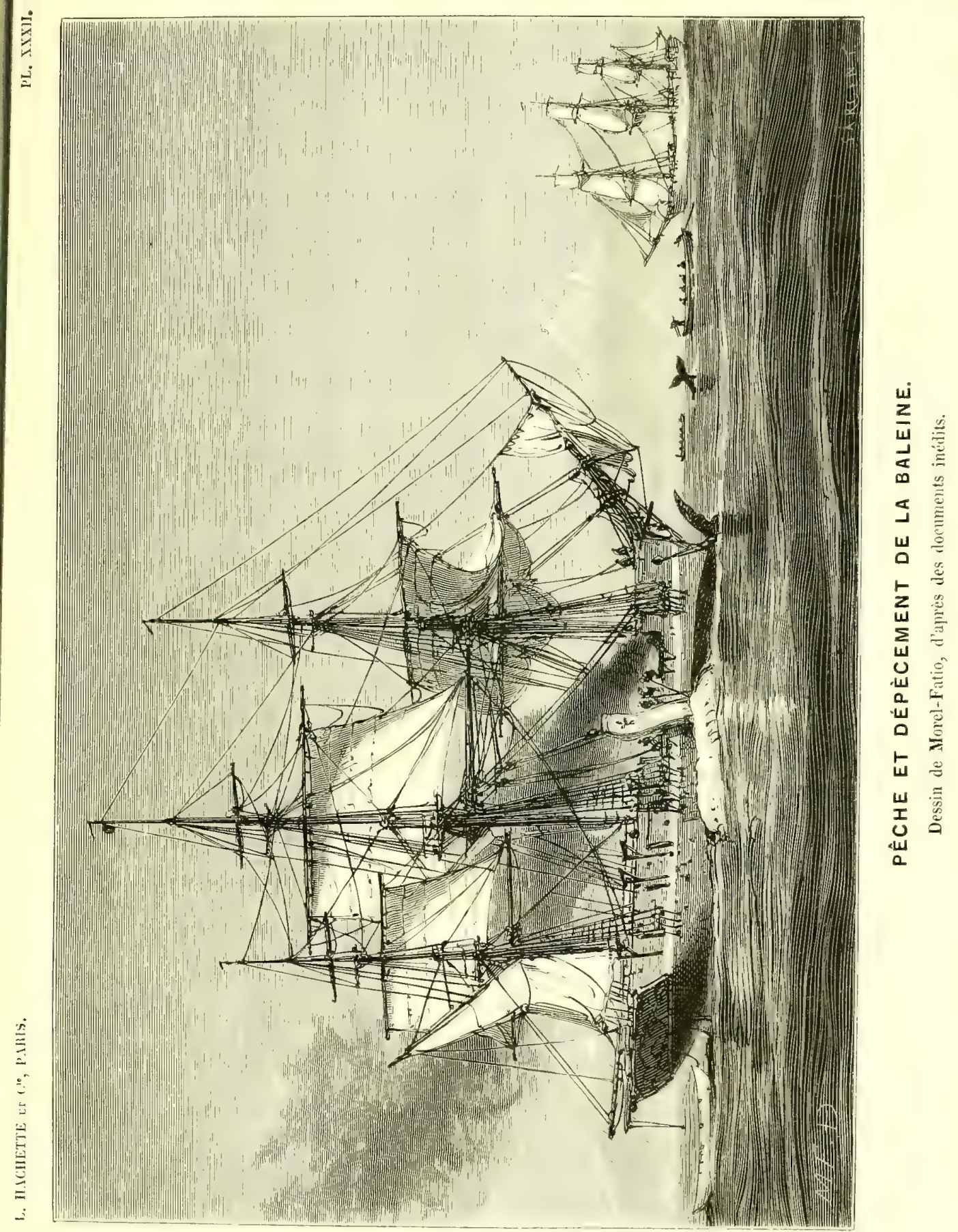



Puis, on abandonne sa chair aux Oiseaux aquatiques, aux Phoques et aux Ours.

La pèche de la Baleine peut offrir des dangers encore plus grands que ceux qui viennent d'être signalés.

On rapporte qu'un navire américain, l'Essex, se trourant, le 13 novembre 1820, dans la mer du Sud, aperçut un certain nombre de Baleines, vers lesquelles il se dirigea. Arrivé au milieu de ces animaux, il mit, suivant la coutume, les canots à lit mer. La petite flottille s'avançait rapidement, et le navire la suivait de près. Tont à coup la plus grosse Baleine se détacha du groupe (qui semblait former une famille), et, dédaignant les embarcations, s'élança droit sur le vaisseau, qu'elle prit sans doute, et non sans raison, pour le chef de ses ennemis. Du premier choc, elle fracassa une partie de la fausse quille, et elle s'efforça ensuite de saisir le navire en divers endroits avec ses gigantesques màchoires. Elle ne put y réussir; elle s'éloigna d'environ 200 mètres, et revint frapper de toute sa force contre la proue du bâtiment. Le navire recula avee une vitesse de quatre nœuds par seconde. Il en résulta une vague très-haute. La mer entra dans l'Essex par les fenêtres de l'arrière, en remplit la coque, et le fit coucher de côté. Vainement les canots anivèrent pour sauver le navire, il n'était plus temps. Toul ce qu'on put faire, fut, en enfonçant le pont, d'extraire une petite quantité de pain et d'eau, que l'on déposa dans les cmbarcations (?).

\section{VII}

Dans les mers du Nord, la prise d'une Baleine est une bonne fortune.

Quand les Espuimaux apercoivent un de ces monstres, 
ils revêtent à l'instant leurs plus beaux habits. C'est peutetre la seule occasion où hômmes et femmes se nettoient et fassent toilette! On assure qu'ils prennent garde surtout de ne pas mettre un vêtement qui ait été en contact avec un cadavre humain. S’ils négligeaient cette précaution, la Baleine prendrait la fuite aussitòt, quand même elle aurait dans le corps plusieurs harpons. Cette assertion est-elle bien exacte?

Quoi qu'il en soit, les dispositions convenables une fois prises, toute une flottille s'élance à la mer. On harponne l'animal, on le crible à coups de javelots, on l'épuise, on le tue....

La Baleine est ensuite trainée jusqu’à la còte, et dépecée, le corps étant moitié dans l'eau.

Les gens qui ont assisté en simples spectateurs à la lutte participent an partage tout aussi bien que ceux qui y ont pris part. Hommes, femmes, enfants, tous se précipitent sur le Cétacé. C'est à qui pratiquera la plus profonde entaille, à qui emportera le plus gros morceau. Pendant quelques jours, la Baleine devient ainsi un garde-manger général, où chacun vient prendre sa pitance quotidienne. (Ch. Edmond.)

\section{VIII}

Linné dit que l'huile fournie par une seule Baleine est souvent si abondante, qu'elle peut suffire ì la charge d'un vaisseau. Cette quantité est évaluée à 12 tonneaux.

La pêche de ce précieux Cétacé dans les mers polaires a donné : en 1859, 2078 barils d'huile; en 1860, 1909, et en 1861, 1710. Sur ces derniers 1710 barils, 1013 appar- 
tenaient aux navires de Dundee, et 697 seulement aux autres ports. (Revue marit.)

En 1861, une transformation s'est opérée dans le matéric| des armements pour la pêche de la Baleine. Les bâtiments à hélice ont été substitués aux bâtiments à voiles, et les résultats de la deuxième saison ont été assez encourageants pour engager les armateurs à persévérer dans leurs tentatives. Par suite même de ces succès, un grand nombre de navires à voiles, surtout à Peterhead, ont été vendus, et l'on semble reconnaître aujourd'hui que la question est résolue, et que l'avenir appartient désormais aux navires pourvus d'un moteur à hélice. (Revue marit.)

On voit que les mers polaires ne sont pas inaccessibles aux progrès.

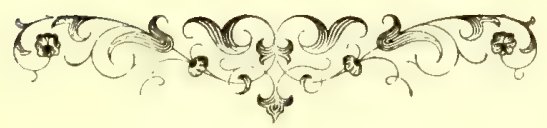





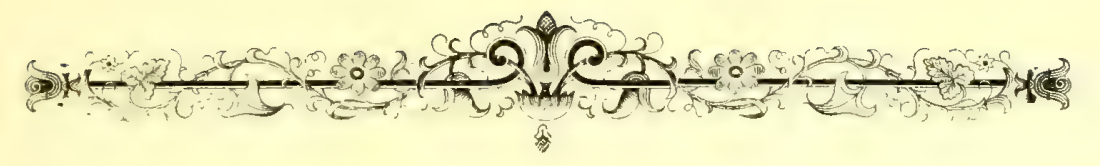

\section{CHAPITRE XLVII}

\section{LES PHOQUES.}

Era gros coma un azer, et era pélos coma

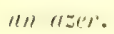

(Petit Tifalames de Moxtpelier, 1383.)

Les Phoques sont moins marins que les Baleines.

Ils viennent de temps en temps à terre.

Ils possèdent quatre nageoires, et ont le corps velu, pélos.... Ils s'éloignent moins des Quadrupèdes....

Par leurs formes et par leurs habitudes, les Phoques ont donné naissance aux fables des Tritons et des hommes marins. Celle qui fait garder par Protéc les troupeaux de Neptune repose plus particulierement sur l'observation imparfaite de ces Mammifères pisciformes, dont les bandes nombreuses se jouent gaiement à la surface des vagues, viennent ramper sur les plages dísertes, ou s'arrêter sur les roches à fleur d'eau pour y recevoir l'action bienfaisante des rayons du soleil (P. Gervais). 
Le Phoque commun est assez abondant sur nos côtes. (1) en trouve beaucoup dans la mer Adriatique, dans les eanx de l'Archipel et dans certains parages de l'Afrique. On en rencontre aussi dans l'Océan. Il en vient exclusivement des troupes assez nombreuses dans la baie de la Somme. Les pêcheurs ont donné à cet animal les noms de Loup marin et de Veau marin.

Le Phoque a le corps allongé, vêtu d'une fourrure serrée et soyeuse. Sa tête ressemble à celle d'un Chien auquel on aurait coupé les oreilles. Il a de fortes moustaches, comme un Chat, et deux beaux yeux vert de mer, veloutés et limpides comme les yeux d'un enfant.

Sa vue est perçante et son ouie fine. Ses narines sont munies d'une sorte de petite porte (valvule), que l'animal ouvre et ferme à volonté, et qui empêche l'eau de pénétrer dans son nez.

Deux paires de nageoires fort longues lui tiement lien de mains et de pieds. Celles de derrière, unies à la queue, forment, à droite et à gauche de cette dernière, comme deux grandes oreillettes.

Le régime du Phoque est principalement animal; il consiste en Mollusques nus, en Crabes et en Poissons. Ce gracieux Mammifère mange aussi des végétaux, surtout des fruits. Il s'accontume parfaitement au pain monillé.

Le Phorque est timide et sanvage. Il a une physionomie très-douce et un regard très-expressif.

Il ne manque pas d'intelligence, et il est susceptible

"Phoca vitulina linné. 
d'apprivoisement, mème d'une certaine éducation. On montre de temps en temps, dans les ménageries, de malheureux Phoques emprisomés dans une cuve, mal nourris, chétifs, malades, dont on vante les hautes qualités; qualités qui se réduisent, le plus souvent, à reconnaitre la voix du cornac, et à venir prendre familièrement un poisson ou un morceau de pain qu'on leur présente.

Le cri de ce Mammifère est doux et flûté, et rappelle certains mots usités dans toutes les langues, en particulier les syllabes pa-pa, ma-ma. D'où les charlatans s'empressent de conclure que ces animaux peuvent apprendre à parler... Ne croyez pas que les Phoques soient capables, comme on l'a dit, de prononcer les mots gâteau, café, manger, merci, et encore moins les phrases: Vive le roi, Bonjour monsieur, Je suis Francais...

En les tenant dans une quantité d'eau suffisante pour leur permettre de nager, et en les nourrissant avec du poisson frais, on peut les conserver pendant plusieurs années.

Quelques naturalistes modernes ont pensé rqu'il ne serait pas impossible à l'Homme d'assujettir complétement à sa puissance ces fugitifs habitants de la mer. On peut s'étonner, dit Frédéric Cuvier, que les peuples pêcheurs n'aient pas dressé les Phoques à la pêche, comme les peuples chasseurs ont dressé le Chien à la chasse. M. Babinet a insisté, tout récemment, sur les services nombreux que ces Mammifères pourraient nous rendre, si nous les élevions auprès de nous. Il voudrait en voir jusque dans nos eaux douces!

Il existe, depnis plusieurs années, deux Phoques au Jardin zoologique d'Amsterdam. Ils vivent dans un grand parc d'eau salée. On assure qu'ils s'y sont reproduits par deux fois. Non-seulement ils distinguent la voix des gar- 
diens qui les soignent, mais encore ils saisissent an loin le bruit des pas du directeur. Ils jettent de petits cris dès qu'ils l'entendent, et se précipitent au-devant de lui.

Un vieillard, accompagné d'une petite fille et d'un griffon de la Havane gros comme le poing, venait souvent visiter nos deux Phoques et leur apporter des friandises. Ceux-ci sortaient de l'eau, rampaient devant le chien et la petite fille, leurs amis, et venaient s'ébattre sur le sable avec eux. On se roulait, on se faisait des niches, on partageait fraternellement les fruits on les gàteaux que contenait le panier de la petite fille.... Or, un jour, au milieu de ces jeux, le chien manque son élan, passe par-dessus la tête d'un Phoque, et tombe dans le bassin. Le pauvre roquet se démène un instant, et disparaît.... Aussitôt les deux Phoques jettent un cri, rampent au plus vite jusqu’à l'eau et s'y précipitent. En un clin d'veil le mâle reparait, tenant délicatement dans sa gueule le griffon sans mouvement. Il le dépose aux pieds de la petite fille. (H. Berthoud.)

Le Phoque nage très-bien et plonge encore mieux. Il peut retenir sa respiration pendant un temps assez long. Il montre dans ses évolutions une prestesse et une élégance remarquables.

Il vient de temps en temps se coucher et se reposer sur le sable du rivage, ayant soin de ne pas s'éloigner de plus de $\ddot{\text { à }} 6$ mètres. $A$ la moindre alerte, il se précipite dans l'eau et regagne la haute mer.

Son allure, sur terre, est lente et disgracieuse; il se traine plutôt qu'il ne marche. Il avance au moyen de sauts petits et fréquents, produits par les contractions de tout son corps, ses nageoires antérieures appliquées contre les flanes. 


\section{III}

Chaque Phoque se retire avec sa famille sur un quartier de rocher, qui devient comme son domicile et sa propriété exclusive. L'intrusion d'un étranger amène aussitôt un combat terrible. Ordinairement chaque famille vii à une certaine distance des familles voisines.

Le mâle rassemble d'ordinaire un sérail de femelles, pour lesquelles il a beaucoup, d'affection et dont il défend l'approche aux autres mâles. Il en a jusqu'à cinquante.

A l'époque des amours, les mâles se battent entre eux avec fureur.

Lorsqu'ils sont vieux, leurs femelles les abandonnent saus pitié.

Quand les femelles vont faire leurs petits, le mâle les conduit sur le rivage, à une place tapissée de plantes marines. Les mères y déposent leurs nourrissons, pour lesquels elles montrent un attachement très-vif.

Les petits aiment à jouer et à folâtrer les uns avec les autres. Quand ils ont atteint l'àge de cing ou six mois, le père, kes jugeant assez forts pour vivre par eux-mèmes, les chasse et les force à s'établir ailleurs.

\section{IV}

Les Phoques de la Somme sont l'objet d'une chasse remplie d'attraits pour les amateurs, laquelle donne lieu à une branche d'industrie maritime qui n'est pas sans importance. M. Ch. de Rylé a publié des détails fort intéressants sur cette chasse. 
La saison la plus favorable est le mois de juin, époque où les femelles viennent de mettre bas, et sont accompagnées de leurs petits. Ces derniers, moins rusés que leurs parents, se laissent plus aisément surprendre. Les Phoques adultes, de leur côté, se résignent difficilement à abandonner leurs nourrissons. On a done plus de chance de les tirer à belle portée.

Il y a deux manières de chasser les Phoques, sur terre, et dans l'eau.

Pour les tirer sur terre, il faut profiter du moment où ces animaux se trouvent à une certaine distance du rivage : ce qui n'est pas facile. Les chasseurs se placent dans un canot et suivent les courants. Ils tirent sur les individus qu'ils surprennent sur les rives. Ils emploient des armes à longue portée et de grande précision. Car l'animal, épouvanté à la vue de l'embarcation qui s'avance, cherche à fuir rapidement, et il faut quelquefois le tirer à 200 ou 300 mètres de distance.

D'autres fois, le chasseur débarque sans bruit, laissant au matelot qui l'accompague la garde du canot. Il se trainc sur le sable, en rampant comme le sauvage qui veut surprendre un ennemi. Il parcourt souvent, de cette manière, un kilomètre et plus, poussant sa carabine devant lui. II s'arrête par intervalles, pour domner à la proie qu'il ambitionue le temps de se rassurer, si elle paraît inquiète, et dissimule en un mot sa présence, autant que possible, jusqu'au moment où, jugeant le Phoque à portée, il fait feu. 11. de Rylé a bien décrit les ruses et la patience qu'il faut avoir dans cette circonstance.

La chasse dans l'eau est plus simple, mais moins certaine. On tire le Phoque au moment où il se montre à la surface de la mer. Il faut savoir que l'animal sort seulement la tête, la laisse voir tout au plus une minute, et plonge immédiate- 
ment. Quand on est assez adroit pour le toucher, on court risque de le perdre. Si le Phoque n'est que blessé, il regagne la pleine mer; s'il est tué roide, il coule au fond de l'eau, et ce n'est pas sans peine qu'on réussit à le pècher.

On a distingué dans les Phoques deux groupes différents :

Les Otaries, qui présentent une oreille externe et des incisives de forme particulière: on rencontre ces espèces dans l'océan Pacifique ${ }^{1}$;

Les Phoques proprement dits, qui sont dépourvus d'oreille externe, et dont les incisives sont pointues. Dans le Groenland, il en existe plusieurs espèces différentes du Phoque commun : ce sont le Phoque de Gmelin ou capuchonné $^{2}$, celui de Müller ${ }^{3}$, et celui de Schreber ${ }^{4}$.

La chasse de ces animaux se fait en pleine mer et avec le harpon.

Ce harpon est long de 2 mètres, et terminé par une pointe de fer mobile, encastrée dans un os, retemue par une courroie et pouvant se détacher au moment où elle pénètre daus la chair de l'animal. Une vessie qui flotte au bout de la ligne indique l'endroit où le Phoque blessé a plongé sous l'eau. Le harpon glisse sur une navette de bois excessivement

I Voyez la planche XXXIII, dessinée d'après un vélin du Muséum d'histoire naturelle, et libéralement communiquée par M. Milne Edwards.

2 Phoca cristata Gmelin.

3 Phoca groenlandica Müller.

4 Phoca hispida Schreber. 
polie: ce qui lui donne plus de force et lui fait suivre plus sûrement la direction voulue.

Les autres projectiles sont confectionnés de la même manière, et on les lance par le même procédé.

Aussitôt que le Phoque, forcé de venir à la surface de l'eau pour respirer', a révélé sa présence, l'Esquimau cherche à le surprendre, en se tenant sous le vent et en tournant le dos au soleil, afin de n’être ni vu ni entendu. Il se penche sur son kayack, de façon que la vague dérobe le plus possible sa figure. Arrivé à une trentaine de mètres, il prend la pagaie de la main gauche, ajuste son harpon sur la navette et le lance avec vigueur. Si le coup a porté juste, le fer se détache de la lance et dévide la ligne roulée en spirale sur l'avant du kayack. La vessie qui termine la ligne est jetée instantanément dans l'eau.

Le Phoque, atteint, plonge avec une extrême rapidité. Nous avous déjà signalé, chez les Cachalots et les Baleines, ce besoin impérieux de s'enfoncer dans l'eau, que manifestent tous les Mammifères marins qui ont été frappés.

Le pêcheur dome ensuite un tour de pagaie, et ramasse son harpon qui flotte.

Il arrive, parfois, que le Phoque entraine avec lui la vessie; mais, forcé de respirer, il reparaît bientôt à la surface de la mer, et il n'y a pas à craindre qu'on ne le retrouve plus.

L'Esquiman pousse au monstre, et lui fait avec sa lance de plofondes blessures. II l'achève enfin à coups de javelots. Quand l'animal est mort, il bouche ses plaies avec de petits tampons de bois, empèchant ainsi la déperdition du sang. Il le gonfle ensuite, en soufflant entre la chair et la peau, et l'amarre à la gauche de son kayack.

Cette chasse n'est pas sans danger. Quelquefois la ligne, en se dévidant, s'enroule autour du bras ou du cou du 



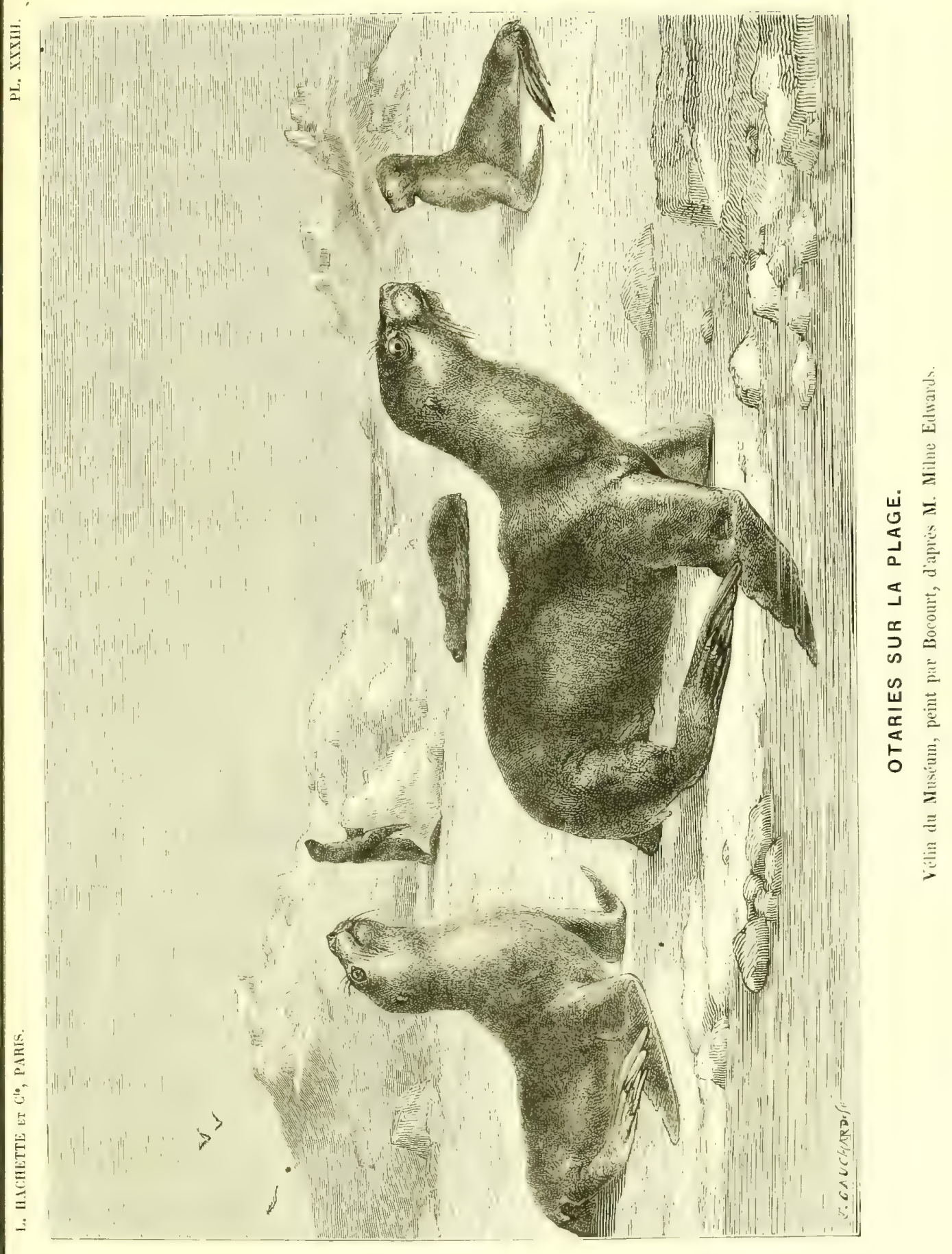



pêcheur. D'autres fois, dans les ébats de l'agonie, le Phoque se jette du côté opposé du kayack, l'entraine, le renverse, et l'homme est bientòt noyé. Ou bien encore, quand la chasse est finie, le Phoque, qui n'est pas mort, se jette furieux sur l'Esquimau, et le mord aux bras et au visage.

Cet animal est surtout terrible quand il défend son petil. Il se précipite alors sur le kayack et en arrache des lambeaux. La vague remplit l'embarcation, et le pêcheur, sans aucune chance de salut, est submergé avec elle.

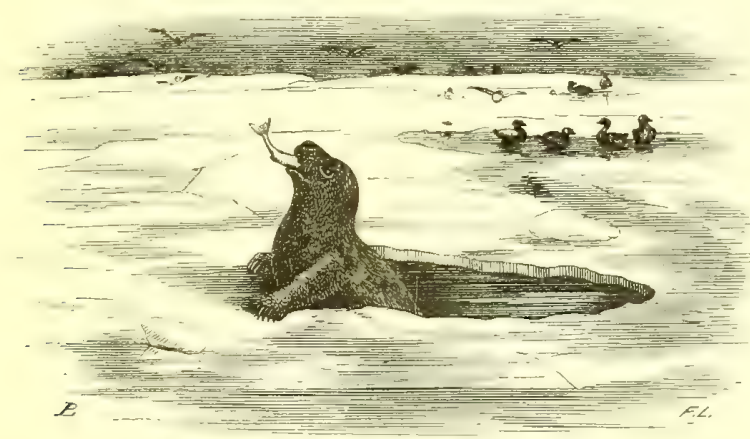

PIIOQL'E

(Phoca vitulina Linné).

La pêche au Phoque se fait, en hiver, dans le même pays, d'une façon bien différente. On a remarqué que cet animal se pratique alors dans la glace des ouvertures par lesquelles il vient respirer l'air. L'Esquimau le guette, et quand la victime a fait son apparition, il se glisse sur le ventre en imitant son cri. Le Phoque le prend pour un frère, le laisse approcher, et ne recomnait son erreur que lorsqu'il a reçu le coup mortel. (Ch. Edmond.) 


\section{I}

La peau des Phoques est assez estimée. Les Esquimaux l'emploient dans la construction de leurs bateaux, de leurs kayacks et de leurs tentes. Ils en font aussi des courroies, des vêtements et des chaussures.

On retire de ces animaux une huile recherchée pour les chariots et pour léclairage....., et même pour fabriquer l'huile de foie de morue.

Les Lssuimaux mangent la chair des Phoques. Ils préparent avec leur sang un potage épais et substantiel. Ils composent avec ses intestins une sorte de fil. Ils confectionnent avec sa vessie les rideaux de leurs tentes, leurs chemises et les petits ballons attachés a leurs instruments de pêche. lls façomment avec leurs os la pointe de presque tous leurs instruments....

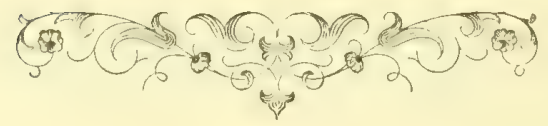




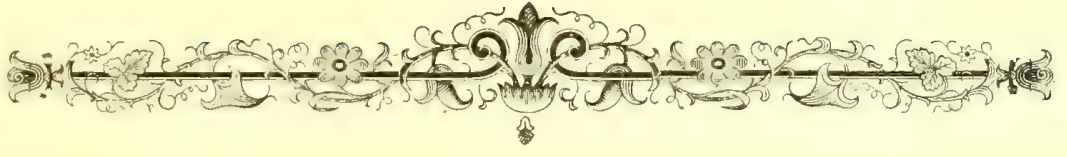

\section{CHAPITRE XLVIII}

\section{LE MORSE.}

"Deus itù artifex in magnis, ut minor non sit in parvis."

(Saint Augustin.)

\section{I}

Existe-t-il dans la mer un Cheval marin, une Vache marine, un Éléphant marin?

En aucune manière. Mais on y trouve un Mammifère de forte taille, le Morse ${ }^{1}$, auquel on a donné mal à propos chacun de ces trois noms.

Le Morse vit dans les régions arctiques, au milieu des glaces. On le rencontre surtout dans le détroit de Beering.

Le Morse est plus gros et plus laid que le Phoque.

On en trouve qui ont jusqu'à 7 mètres de longueur. On peut donc le regarder comme une des grandes bêtes de la mer.

Sa peau est épaisse, rugueuse, garnie de poils ras, peu

1 Trichechus rosmarus Linné (voy. la planche XXXIV). 
nombreux et de couleur fauve roussâtre. Elle recouvre une forte couche de graisse.

Les yeux du Morse sont petits. Sa lèvre est hérissée de quelques poils jaunes, demi-transparents, épais comme des pailles.

De son museau, court et large, sortent deux grosses dents d'ivoire, allongées, un peu verdâtres, qui forment des défenses très-dures et très-fortes. Ces dents sont recourbées en arrière, comme les deux fers d'une pioche.

A cause de ces défenses, les marins appellent quelquefois le Morse, la béte à grandes dents.

L'animal emploie ces énormes crochets, soit à se cramponner aux corps solides, soit à détacher les herbes de la mer, soit encore à racler le sol submergé pour mettre à nu les petits animaux dont il fait sa nourriture.

Le Morse possède aussi des dents molaires; et, chose digne de remarque, celles d'en haut s'emboitent dans celles d'en bas, comme un pilon dans son mortier. (F. Cuvier.)

Notre Mammifère, comme on le voit, n'offre rien qui permette de l'assimiler sérieusement au Cheval, à la Vache ou bien à l'Éléphant.

Quand le temps est beau, on voit quelquefois des centaines de Morses qui se jouent, en faisant retentir l'air de leurs mugissements, lesquels ressemblent aux beuglements du taureau; d'antres sont paresseusement couchés au soleil. Quand ils dorment, il y a toujours une sentinelle vigilante, l'œil ouvert, le cou tendu, qui avertit la troupe s'il survient quelque danger.

On a élevé plusieurs fois des Morses dans le nord de l'Europe. On leur donnait de la bouillie d'avoine ou de millet.

Il y a plusieurs années, on a réussi à en conduire un jusqu’à Londres; mais il n’y a vécu que quelques jours. 
On le nourrissait avec des Crabes; ce qui lui convenait mieux que l'avoine ou le millet.

On a montré, pendant quelque temps, en Angleterre, un antre individu âgé de trois mois. 11 se mettait en colère toutes les fois qu'on voulait le toucher; il entrait même en fureur. La seule chose que l'éducation avait pu obtenir de lui, était de suivre son maitre en grondant, quand celui-ci lui offrait à manger. (E. Worst.)

On s'accorde à dire que le Morse a moins d'intelligence et de douceur que le Phoque. Cependant il n'est pas féroce, il n'attaque pas l'Homme, mais il se défend avec un indomptable courage. Quand on le poursuit au large, il faut prendre beaucoup de précautions; car il arrive souvent que toute une troupe de Morses se jette audacieusement sur les embarcations, les entoure et cherche à les submerger.

\section{1}

Le capitaine Buchanan soutint un jour un combat, un véritable combat, contre des Morses. C'était en 1818, dans les parages du Spitzberg.

L'équipage avait aperçu, le soir, un grand nombre de ces animaux qui se dirigeaient vers un plateau de glace. Des embarcations furent aussitôt équipées pour les poursuivre. Le premier troupeau prit la fuite; mais le second se groupa sur le plateau avec une telle impétuosité, qu'il dérangea le plan de bataille des marins, et les empêcha d'intercepter leur marche. Les Morses étaient nombreux, et le combat s'annonçait avec des apparences très-sérieuses. Aux premiers coups de feu, ils s'élancèrent contre les marins, grognant, beuglant avec colère, saisissant les bords 
des embarcations avec leurs longues dents ou les frappant avec leur tète. Dans cette lutte violente, et périlleuse pour l'équipage, les Morses étaient conduits ot comme commandés par un individu, un mâle, plus grand et plus terrible que ses frères. Ce fut sur celui-ci, principalement, que les matelots dirigèrent leurs coups. Mais il recevait les atteintes de leurs massues sans fléchir, et les lances, malheureusement peu aiguisées, ne pouvaient pénétrer dans sa rude cuirasse. Le troupeau était si nombreux, et ses attaques étaient si vives et si réitérées, que les matelots n'avaient pas le temps de charger leurs grosses carabines. Par bonheur, le commis aux vivres avait son fusil prêt; il visa adroitement le chef Morse et lui envoya ses balles dans les entrailles. L'animal tomba sur le dos, au milieu de ses compagnons. Ceux-ci abandonnèrent à l'instant même le champ de bataille, se rassemblèrent autour de leur général, et le soutinrent à la surface de l'eau avec leurs formidables dents. Probablement ils agissaient ainsi par une sagacité naturelle, pour l'empêcher de suffoquer. (Buchanan.)

On raconte que des pêcheurs, ayant découvert, également au Spitzberg, un petit Morse dans une caverne an bord de la mer, s'en emparèrent et le mirent dans un bateau. Le père et la mère, furieux de ne plus trouver leur nourrisson, poursuivirent l'embarcation, et l'un d'eux, l'ayant accrochée avec ses défenses, la fit tellement pencher, qu'un des pècheurs glissa dans la mer. L'autre Morse se jeta sur lui avec achamement, et il fut impossible aux autres pêcheurs de sauver le malheureux.

Dans une autre circonstance, tonjours au Spitzberg, une chaloupe attaqua un mâle et une femelle. Cette dernière fut blessée pendant qu'elle allaitait son petit, attaché à sa poitrine. Le mâle, pour se venger, donna une forte secousse au bateau. La femelle serra étroitement son nourrisson 

sous sa nageoire gauche, et se dirigea, malgré ses blessures, vers un plateau de glace. (Elle avait trois lances enfoncées dans la poitrine.) Arrivée là, elle y déposa son petit. Mais, celui-ci, à l'instant même, s'en revint vers l'embarcation avec mne telle rage, qu'il l'eùt certainement fait chavirer,

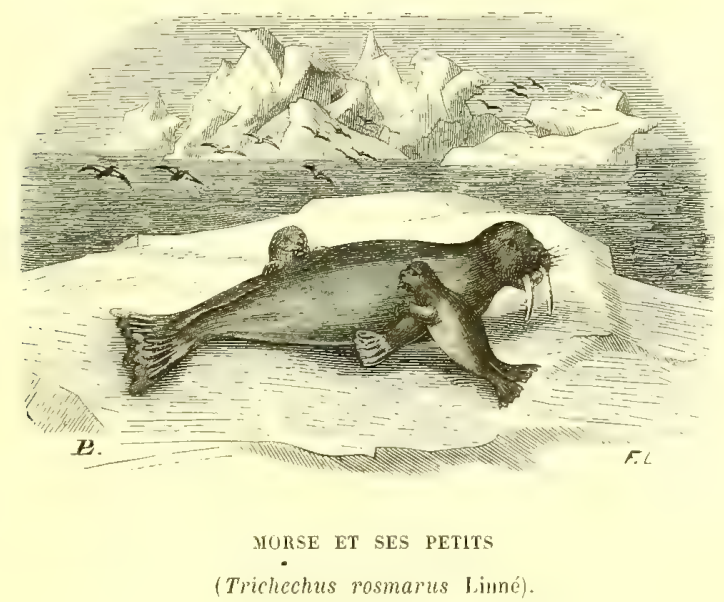

s'il en avait eu la force. Il reçut une blessure à la tête, et retourna vers sa mère, qui se traînait péniblement de glaçon en glaçon. Le mâle, redoutant une nouvelle attaque, prit sa malheureuse compagne avec les dents, et l'entraina dans l'eau jusqu'à ce qu'elle fùt hors d'atteinte. (Buchanan.)

\section{III}

La chasse au Morse est facile et productive.

Généralement, ces pauvres bêtes se laissent tuer sans montrer beancoup de ruse à fuir les assaillants. Un bateau pêcheur en prend d'ordinaire deux à trois cents par saison. En 1608, l'équipage de Welden en tua plus de 
mille sur les côtes de l'île Cherry. Au rapport de Gmelin, les Anglais en prirent, en 1705 et 1706 , sept à huit cents dans six heures; en 1708, neuf cents dans sept heures, et en 1710, huit cents dans une semaine. On assure que, chaque année, dans les mers du Nord, on en détruit près de trois à quatre mille.

Quand un Morse, surpris à terre, se sent blessé, il entre dans une colère effrayante. Il brise les armes du chasseur imprudent, ou bien les lui arrache. S’il ne peut pas atteindre l'ennemi, il frappe le sol de côté et d'autre avec ses défenses. Poussé à bout et comme enragé, il met sa tête entre ses nageoires, et, profitant de la pente du rivage, il se laisse rouler dans la mer. Si on l'attaque dans l'ean, il se défend avec fureur.

\section{V}

Comme les Phoques, les Morses fournissent une certaine quantité d'huile.

On tire parti de leur peau pour faire des soupentes. Cette peau était anciennement précieuse pour la navigation : on la coupait en lanières que l'on tordait, et l'on obtenait ainsi des câbles d'une très-grande résistance.

Les dents de Morse sont préférables à l'ivoire, parce qu'elles sont plus dures et moins sujettes à jaunir. Malheureusement, elles n'ont pas le volume des défenses de l'Éléphant; cependant on en trouve qui offrent plus de 80 centimètres de longueur, et près de 33 de circonférence à leur sortie de l'alvéole. L'ivoire des Morses est compacte, susceptible d'un beau poli, mais sans stries. De petits grains ronds, placés pêle-mêle comme les cailloux dans un pou- 
dingue, forment la partie moyenne de la défense (Cuvier). Ces dents sont utilisées de différentes manières. Les prisonniers russes, en Sibérie, les travaillent très-adroitement, ¿ peu près comme les forçats de Toulon cisèlent les noix de coco. Ils en fabriquent des coffrets, des boites, des étuis, res chaînes et d'autres petits bijonx élégants, vrais chefsd'œurre d'art et de patience.

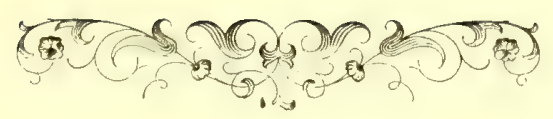





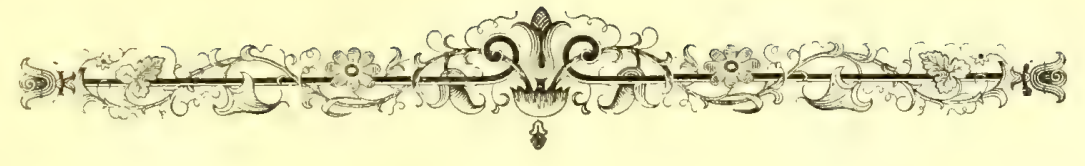

\section{GHAPITRE XLIX}

\section{LA LOUTRE DE MER.}

"Vestus d'habits moult somptueusement,
tres-bien fourrés....."
(S.ILYT-GeLAIs.)

Les Mammifères marins, nous l'avons dit dans les cbapitres précédents, ne sont pas organisés comme les Mammifères terrestres. Leur corps est plus ou moins pisciforme, et leurs membres ressemblent plus ou moins à des nageoires.

Voici maintenant un petit quadrupède qui diffère à peine, par sa structure, de ceux qui vivent sur la terre, et qui est néanmoins un animal exclusivement marin. C'est peut-être le seul qui existe (?).....

Tout le monde connait la Loutre ordinaire ${ }^{1}$, petit Mammifère carnassier à pieds palmés et onguiculés, et à queue longue presque arrondie.

1 Lutra vulgaris Erxleben. 
La Loulre de mer, ou Enhydre, présente une taille un peu plus grande. Elle peut atteindre jusqu'à un mètre et demi de longueur.

Sa tête est médiocre, arrondie, et ressemble un peu à celle du Chat. Elle porte des oreilles courtes, des yeux presque circulaires et noirs, et des moustaches blanches, longues et pendantes. Sa queue est proportionnellement moins développée que dans la Loutre ordinaire. Ses pattes sont plus petites et plus adaptées à la vie aquatique. Les posté-

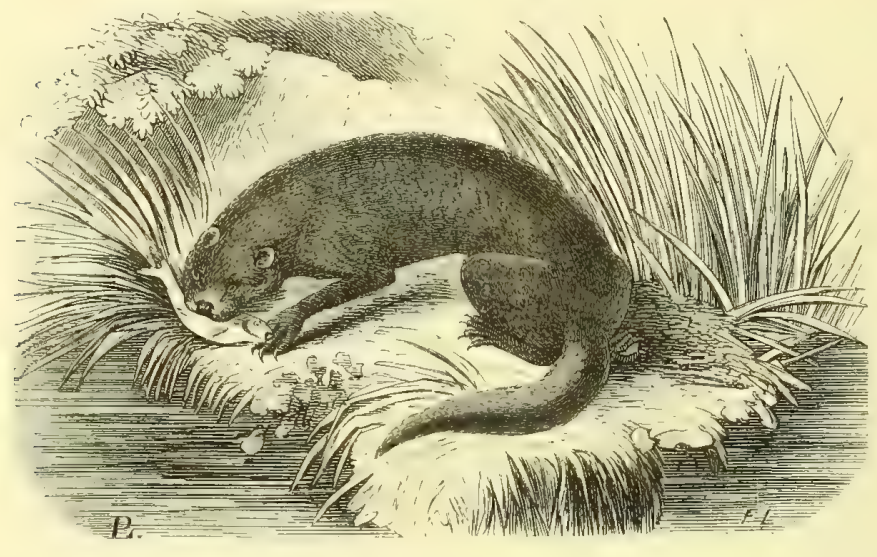

LOUTRE DE MER

(Enhydris marina Fleming).

rieures ressemblent moins à des pieds qu'à des nageoires.

Cependant ces organes diffèrent notablement des nageoires des Morses et des Phoques; et, quoique leurs doigts, réunis par des membranes, composent de véritables palettes destinées à frapper l'eau, l'animal, en définitive, est plutôt organisé comme un Mammifère terrestre que comme un Mammifère marin.

Ce petit quadrupède habite dans une grande partie de l'océan Pacifique boréal, entre le $50^{\circ}$ et le $56^{e}$ degré de 
latitude nord. On le rencontre jusque dans les parages du Japon.

On le voit souvent couché sur des îles flottantes de Néréocystés, se réchauffant aux rayons du soleil, ou guettant quelque proie. C'est pourquoi, dans certains pays, les végétaux dont il s'agit sont désignés sous le nom de Choux aux Loutres

Ce Mammifère se nourrit de Poissons, de Crustacés, de coquillages, et, au besoin, de plantes marines.

Il plonge comme les Morses et les Phoques, mais il ne reste pas aussi longtemps sous l'eau.

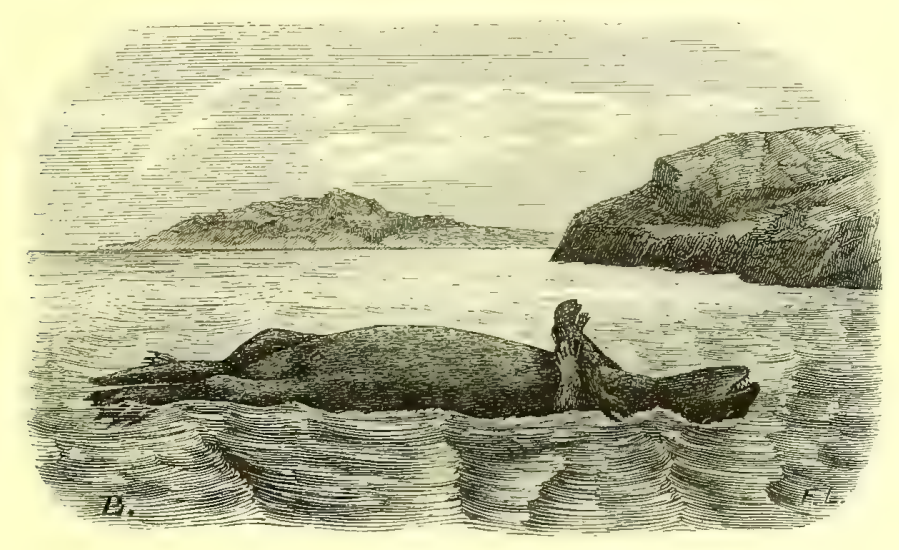

LOUTRE FEMELLE ET SON PETIT.

Il est d'un brun marron eni dessus, et d'un brunâtre argenté en dessous.

La Loutre de mer vit par couples. ILa femelle ne met bas qu'un seul petit. Elle s'en sépare rarement et s'occupe de son éducation avec beaucoup de tendresse. Souvent on voit à côté de la mère, non-seulement le nourrisson de l'année, mais encore celui de l'année précédente. Elle joue avec eux sur la glace ou dans les flots. Elle les jette dans la mer, et leur apprend à nager et à plonger. Quand elle dort à la 
surface de l'eau, le ventre en l'air, et qu'elle s'abandomne au gré des vagues, elle tient son petit au-dessus d'elle, entre ses pattes de devant. Steller a représenté une mère dans cette position. Les chasseurs surprennent souvent ces pauvres bêtes ainsi endormies, et réussissent presque toujours à les tuer.

Quand on enlève ses petits à une Loutre de mer, elle pousse des cris plaintifs; elle suit même le ravisseur de loin, appelant ses nourrissons d'une manière suppliante : ceux-ci lui répondent par des vagissements.

Steller découvrit une fois une Loutre couchée sur la glace; son petit dormait entre ses pattes. Notre savant naturaliste s'approcha doucement. La mère, vigilante, ouvrit les yeux, reconnut le danger, éveilla son nourrisson et l'excita à fuir. Mais l'innocent préférait le sommeil. La Loutre le saisit vigoureusement, et l'entraina malgré lui vers la mer.

Le pelage de cet animal est très-serré, très-moelleux et très-lustré. On le recherche comme fourrure précieuse, - et l'on a bien raison, car c'est une des plus belles qui existent.

On appelle bobry les mâles adultes, matka les femelles, koschloki les petits d'un an, et medwieki les petits de quelques mois.

Les navires russes ou les navires américains qui chassent les Loutres de mer, ou qui en font le commerce, les vendent principalement en Chine, où leurs peaux sont employées comme ornement et comme signe distinctif par les hauts fonctionnaires. On en apporte rarement en Europe. Cepen- 
dant beaucoup de seigneurs russes estiment cette remarquable fourrure presque autant que les mandarins chinois.

Suivant leur degré de conservation et la finesse ou le lustre de leur poil, ces peaux valent, en Chine, de 800 à 1500 francs pièce. Nais on constate d'année en année que le nombre des Loutres diminue dans les parages où on les prenait autrefois assez facilement; aussi leur prix tend-il considérablement à augmenter (P. Gervais).

On assure que, dans ces derniers temps, plusieurs fourrures ont été vendues, à Saint-Pétersbourg, jusqu'à 2000 franes (Nordmann).

Du temps de Steller, l'équipage d'un seul navire pouvait tuer jusqu'à 800 individus dans une seule eampagne. Aujourd'hui, les pêcheurs d'Enhydres ne sont pas aussi favorisés. Ils ont beaucoup de peine à s'en procurer quelques couples. Dans beaucoup de parages, et particulièrement sur les côtes du Japon, les Loutres de mer ne paraissent plus en quelque sorte qu'accidentellement.

Il faudrait réglementer la chasse de ce précieux Mammifère et le ménager un peu, pour empècher que, dans un avenir peu éloigné, son espèce n’ait complétement disparu.

La Loutre de mer présente un intérêt historique : c'est, en grande partie, en la poursuivant, que les Russes sont arrivés d'abord jusqu'au Kamtchatka, et plus tard jusqu'en Amérique.

L'Enhydre est rare dans les musées, on en comprend la raison. Le cabinet de Munich possède un squelette de cet animal, qui lui a été donné par le duc de Leuchtenberg. Le Muséum d'histoire naturelle de Paris s'est enrichi, en 1853, de deux squelettes, un mâle et une femelle, qui lui ont été envoyés par le professeur Nordmann. 


\section{III}

Les Loutres mâles ont des mamelles..... à la vérité trèsimparfaites. Il en est de même, du reste, chez tous les Mammifères. Nous nous sommes bien souvent demandé le cui bono de ces mamelles.

Les organes des animaux ont généralement des fonctions déterminées. L'aile sert au vol, l'œil à la vue, l'oreille à l'audition.....

Dans certaines circonstances, des arrêts ou des excès de développement modifient la constitution des parties, et l'ensemble peut remplir un usage différent. C'est ainsi que l'aile du Manchot devient nageoire, tandis que la nageoire de l'Exocet devient aile....

Habituellement, l'organe modifié conserve l'ancien usage, en même temps qu'il s'applique au nouveau. Le nez du Tapir et celui de l'Éléphant sont toujours affectés à l'olfaction, quoiqu'ils soient devenus boutoir et trompe, c'est-àdire appendice pour creuser et membre pour saisir....

Mais quand l'arrêt de développement est arrivé de trop bonne heure, l'organe n'apparaît plus que comme un rudiment. Dans cet état, à quoi sert-il? Peut-il servir à quelque chose?

Quelles sont les fonctions des yeux atrophiés ou couverts par la peau chez la Taupe? Quelles sont celles des tubercules oculaires chez les Sangsues, ou des points oculiformes chez les Planariés?

Pourquoi existe-t-il des mamelles rabougries chez le mâle de la Loutre de mer, et chez ceux des autres quadrupèdes?

Étienne Geoffroy Saint-Hilaire regardait ces dévelop- 
pements incomplets comme des éléments du plan primitif de l'organisme, et par conséquent comme des indices de la symétrie générale conservés dans les symétries particulières.

Plusieurs éminents zoologistes ont voulu voir, dans ces rudiments, des tendances de la Nature vers un but déterminé, c'est-à-dire des ébauches abandonnées ou des efforts non réussis.

Cette explication est-elle préférable à celle de Geoffroy Saint-Hilaire?

La nature active, en d'autres termes la puissance créatrice ne ressemble en rien à la puissance humaine, qui essaye, qui prend de la peine, et qui n'aboutit pas toujours. Dieu n'a jamais eu besoin de tentatives ni d'efforts, même pour ses combinaisons les plas transcendantes ou pour ses organismes les plus ingénieux! Il a toujours fait ce qu'il a voulu et dans le temps qu'il a voulu, appareils très-compliqués ou très-simples, ensembles d'organes, portions d'organes, et, si l'on veut, semblants d'organes!.....

Le mot tendance renferme cependant une idée philosophique; il serait parfait si les animaux étaient la création des hommes. Comment faut-il le remplacer, les animaux étant la création de Dieu?

A quoi servent donc les mamelles chez les mâles? Nous l'ignorons complétement, et nous avouons franchement notre ignorance.

Dieu seul pourrait nous l'apprendre, car Dieu sait beaucoup de choses, comme disait Abd-el-Kader!

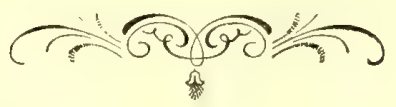





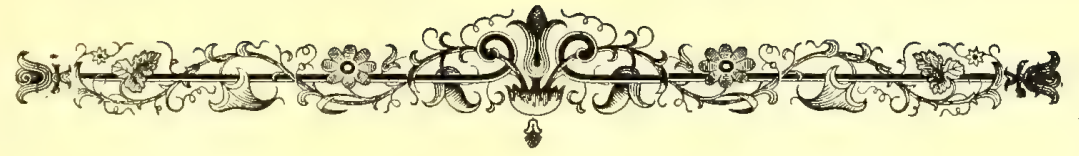

\section{CHAPITRE L}

\section{L'OURS BLANC.}

Il couche sur la neige, et soupe quand il tue.

(A. de Musset, )

On l'a déjà vu, les mers du Nord ne sont pas déshéritées de la vie; elles ont aussi leurs habitants, même leurs populations insonciantes et joyeuses, sur les amas de neige ou sur les bancs de glace, au milieu des eaux les plus froides ou des brouillards les plus épais.

L'Ours blanc ou polaire ${ }^{1}$ est comme le souverain de ces populations. Il règne en despote cruel sur les animaux du pôle arctique. Il habite toutes les mers; il fréquente toutes les côtes. 11 aime le froid comme les autres aiment le chaud.

Il $\mathrm{y}$ en avait anciennement un très-grand nombre dans l'île Cherry, appelée d'abord Beeren eiland, c'est-à-dire ile des Ours.

1 Thalarctos maritimus Gray. 
L'Ours blanc est un véritable quadrupède terrestre. Mais il diffère de son homonyme l'Ours des Alpes, par sa taille plus grande et plus élancée, par ses membres plus élevés, pourvus de pieds plus robustes, par son cou plus long, et par sa tête plus étroite et plus fixe.

11 peut acquérir de grandes dimensions. Certains individus n'ont pas moins de 2 mètres de longueur (P. Gervais).

En 1596, le voyageur Guillaume Barentz en tua deux dont il conserva les peaux. L'une était longue de 3 mètres et demi, et l'autre d'environ 4 mètrès.

On assure que les plus gros individus pèsent quelquefois jusqu'à כૅ00 kilogrammes.

L'Ours polaire est vêtu d'une fourrure blanche trèslégèrement jaunâtre, à tissu soyeux et serré. Les pêcheurs norvégiens l'appellent pittoresquement le gros homme en pelisse. On conçoit comment, avec cet excellent habit, il peut résister aux grands abaissements de température, si communs dans son pays.

Ses yeux offrent une teinte foncée. 11 a le bout du museau, l'intérieur de la gueule et les ongles noirs.

L'Ours blane se nourrit de Phoques, de Poissons et de plusieurs autres animaux marins. On dit qu'il attaque les jeunes Baleines. Il mange aussi des substances végétales, surtout pendant l'été. Il peut supporter de très-longues abstinences.

Il suit les Phoques à la piste. Pour les saisir, il s'accroupit sur les pattes de devant, avance peu à peu et sans secousse avec celles de derrière, confondu par sa couleur avec la neige et les glaçons, et c'est seulement à quelques mètres qu'il s'élance sur l'animal qu'il veut saisir.

Quand le dégel commence, il se forme, dans les régions septentrionales, des ruisseaux qui glissent silencieusement sur la neige, comme des rubans argentés posés sur du 


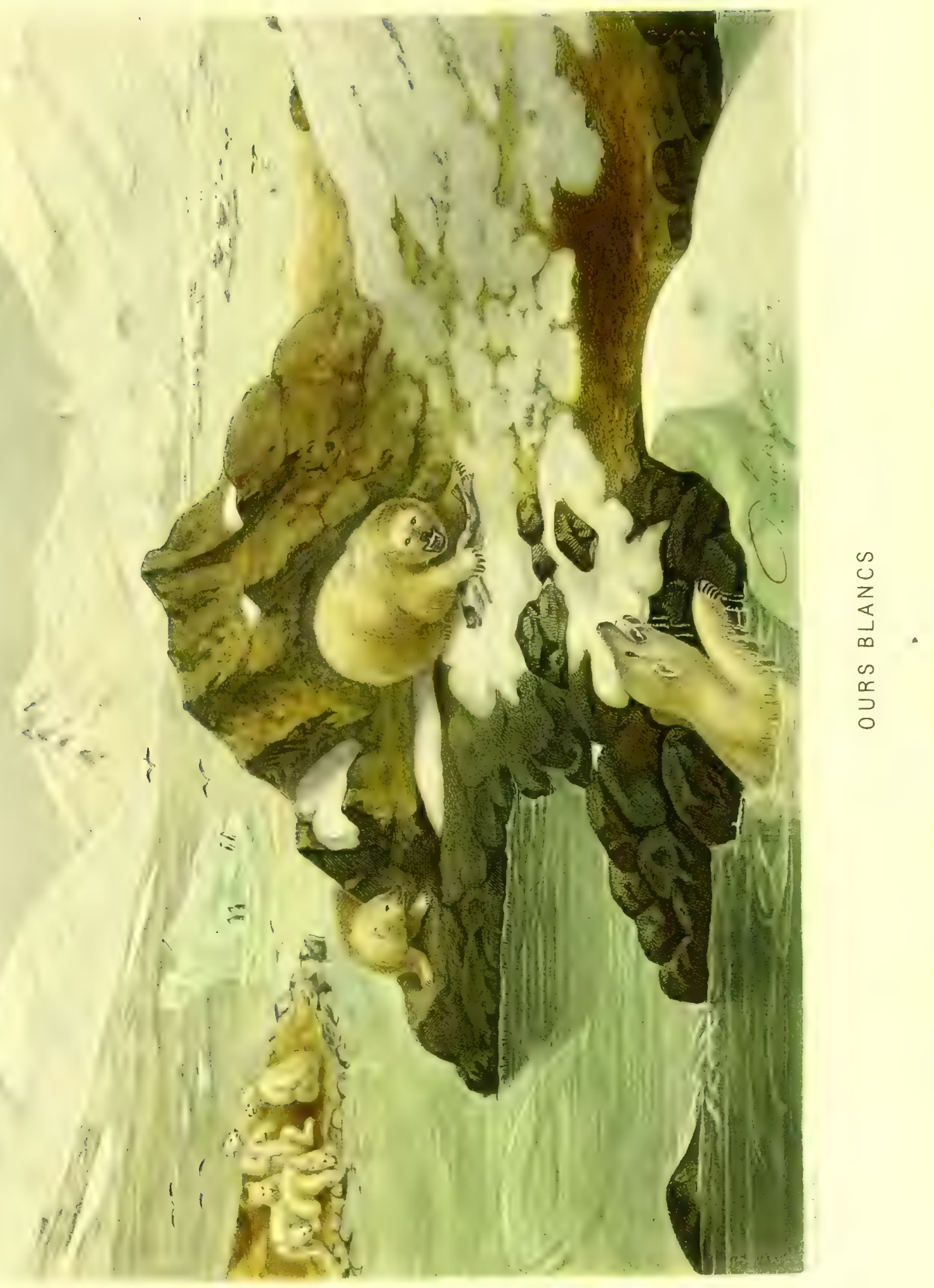



velours blanc. Nos féroces quadrupèdes viennent se désaltérer dans ces petits ruisseaux.

L'Ours blane a les doigts unis à leur origine par de fortes membranes. C'est encore un caractère qui le distingue de l'Ours brun. Du reste, comme ce dernier, il marche sur la plante des pieds, et peut au besoin se tenir debout sur ses membres postérieurs.

Il nage rapidement et plonge avec facilité. Mais il ne passe pas toute l'année au sein de la mer; pendant la belle saison, il vient à terre, et se rend dans les bois. Il court sur le terrain comme les quadrupèdes ordinaires. Il peut faire jusqu'à trois milles par heure. Pendant l'hiver, quand les neiges recouvrent le sol, il retourne à l'Océan, accompagné de ses petits. Lorsque le froid augmente, on voit les Ours blancs rôder sur la glace, grimper sur les blocs, et plonger dans l'eau qui n'est pas encore gelée. Ils se réunissent, à cette époque, en nombre plus ou moins considérable. Ce sont, du reste, les seuls Mammifères du même groupe chez lesquels on observe des dispositions pour la sociabilité (P. Gervais). Ce qui est d'autant plus remarquable, qu'ils sont extrêmement cruels, et que les animaux d'un naturel semblable vivent généralement plus ou moins isolés.

Quelques Ours blanes, placés sur des glaçons flottants comme sur des radeaux, se laissent entrainer et emporter d'un pays dans un autre. C'est ainsi qu'on a vu des individus en quelque sorte échoués sur les côtes de l'Islande et de la Norvége. On assure même que d'autres ont traversé, accidentellement, le détroit de Beering, et qu’on en a rencontré jusque dans l'archipel du Japon (Siebold).

Parfois, emportés vers la haute mer par les glaces, ils ne peuvent plus regagner la terre, ni quitter leur îlot; alors ils meurent de faim, ou se dévorent les uns les autres.

Cet animal est plus terrible que l'Ours des Alpes. La force 
de sa mâchoire est telle, qu'on l'a vu couper en deux une lame de fer de 10 millimètres d'épaisseur. (Scoresby.)

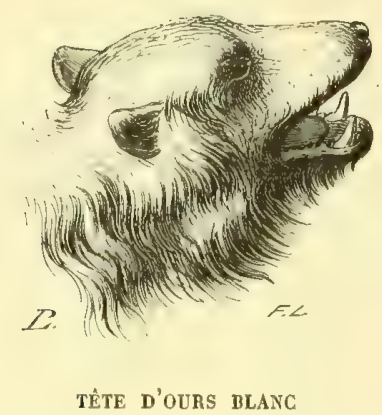

(Thalarctos maritimus Gray).

Lorsqu'un Ours blane débarque dans une île peu habitée, il en attaque les troupeaux et leurs propriétaires avec fureur. Il égorge et dévore tous les malheureux qui tombent sous ses griffes. Il dévaste même les cimetières : les cadavres conservés par le froid lui fournissent une nourriture abondante.

Rien n'est sûr en son passage, Ce qu'il trouve, il le ravage.

(MalHerbe.)

A l'apparition d'un Ours en Islande, les insulaires alarmés se rassemblent pour combattre le redoutable carnassier et pour sauver le bétail. Ce sont les côtes du Groenland qui sont le plus exposées aux invasions de ces déprédateurs. Le capitaine Scoresby en vit dans ces parages un si grand nombre, qu'il compare leurs réunions à des troupeaux de moutons. 


\section{II}

Il y a quelques années, trois jeunes chasseurs passant enlsemble l'hiver au Labrador laissèrent leur cabane pour aller visiter des piéges tendus dans la forêt. A leur retour, ils furent étonnés de trouver leur porte arrachée et jetée sur la neige. Ils crurent d'abord que quelque voisin, mauvais plaisant, avait voulu leur jouer un tour pendant leur absence. Tout avait été bouleversé : le poêle et son tuyau étaient par terre, l'armoire vidée, la provision de lard pillée; le sac de farine avait disparu; il manquait encore une tasse de fer-blanc, un paletot et une paire de bottes.... Il y avait eu vol avec effraction. Nos trois jeunes gens se mettent en quête du voleur ou des voleurs.... On cherche, et l'on découvre que tout le dégât avait été causé par deux Ours blancs. A peu de distance de la cabane était le sac vidé et déchiré; un peu plus loin gisait la tasse, portant l'empreinte de fortes dents... Quant au paletot, à la paire de bottes, les gaillards les avaient emportés! (Ferland.)

\section{I}

En général, les Ours blanes n'attaquent pas l'Homme, à moins qu'ils ne soient affamés; ils évitent même ordinairement sa rencontre. Mais, lorsqu'on les provoque et qu'on les met dans la nécessité de se défendre, le combat n'est pas sans danger pour les assaillants. A cause de cela, les Ours sont très-redoutés par les petites embarcations qui cherchent 
à leur donner lá chasse. On assure, toutefois, que ces animaux sont moins courageux qu'on ne serait tenté de le croire, et qu'ils désertent vite le champ de bataille lorsqu'ils se sentent blessés.

Un baleinier se trouvait bloqué par les glaces dans le détroit de Davis, sur les côtes du Labrador. Un Ours blanc s'approcha du navire à la distance de quelques mètres. Un matelot fut tenté de s'en emparer tout seul, pendant que ses compagnons étaient encore à table. Il descendit sur la glace, armé d'une pique; il courut sur l'animal. Celui-ci ne recula point, désarma son faible adversaire, le saisit par le milieu du dos avec les dents, et l'entraina si rapidement, qu'il fut impossible de lui porter secours.

Un autre baleinier arrêté sur les côtes du Groenland était amarré à un bloc de glace. Il découvrit an loin un Ours énorme occupé à guetter des Phoques. Un matelot, dont le courage était exalté par une forte dose de rhum, forma le projetd'aller attaquer le redoutable animal. Aucune remontrance ne put calmer son ardeur belliqueuse. Il part sans autre arme qu'un harpon, traverse les neiges, et, après une course d'une demi-heure, harassé et commençant à reprendre son sang-froid, il se trouve devant l'ennemi, lequel, à sa grande surprise, n'est nullement intimidé, et l'attend de pied ferme. L'effet du rhum s'affaiblissait, et l'Ours était si grand, et son regard annonçait tant d'assurance!..... Le matelot fut sur le point de renoncer à l'offensive. Il s'arrête, préparant son arme. L'Ours ne bougeait point. Le marin essaye de se douner du courage, excité surtout par la crainte des railleries dont ses camarades ne manqueraient pas de l'accabler. Mais, tandis qu'il songeait aux moyens de commencer le combat, l'Ours, moins préoccupé que son adversaire, se met en mouvernent, et semble vouloir attaquer le premier. Cette fois, la valeur 
du matelot s'évanouit, et la honte d'une retraite ne peut le retenir : il prend la fuite. L'Ours le poursuit. Accoutumé anx courses sur la neige et sur la glace, l'animal gagnait continuellement du terrain sur l'imprudent matelot, et la terreur de celui-ci était an comble. L'arme qu'il portait encore n'était qu'un poids inutile, un embarras de plus; il la jette afin de courir plus lestement. L'Ours apercoit cet objet, le flaire, le soumet à l'épreuve de ses pattes et de ses dents, et, en perdant ainsi quelques minutes, il donne au fuyard un répit dont il profite de son mieux. Enfin, l'Ours abandonne le harpon et reprend sa course. Le matelot, se sentant près d'ètre atteint, cherche encore quelque autre moyen de distraire et d'arrêter son terrible ennemi, il lui jette une de ses mitaines. Ce fut assez pour occuper pendant quelques minutes l'insouciant et curieux animal, et ce retard vint très à propos, car les forces du pauvre matelot étaient presque épuisées. L'Ours ayant laissé l'objet de sa distraction pour continuer sa poursuite, le fugitif fit le sacrifice de son autre mitaine; il en vint ensuite à son chapeau.

L'équipage, qui assistait de loin à cette comédie, vit enfin qu'elle devenait trop sérieuse, que l'irritation du carnassier se montrait de plus en plus menaçante, et que le malheureux matelot allait succomber. Une troupe vint arrêter l'impétuosité de la poursuite et protéger le pauvre fuyard aussi tremblant qu'épuisé de fatigue. A l'aspect de ses nouveaux et nombreux adversaires, l'Ours fit d'abord mine de se battre; mais, ayant été blessé, il reconnut habilement qu'une honorable retraite était le seul parti convenable. Il mit bientôt entre les poursuivants et lui un espace de neiges et de glaces raboteuses que les matelots n'osèrent pas franchir. (Mag. pittor.) 


\section{IV}

Au mois de septembre 1596 , un vaisseau hollandais commandé par Guillaume Barentz, arrivé au delà de la Nouvelle-Zemble, fut surpris pendant la nuit dans un port de glaces, et tellement enfermé de toutes parts, qu'aucun effort humain n'aurait pu le dégager. Barentz fut done réduit à la triste perspective d'hiverner dans cette région d'horreur'.

Le vaisseau, assiégé et tourmenté par les mouvements des glaçons, craquait en plusieurs endroits. On prit la résolution de traîner le canot à terre, et l'on y transporta le biscuit, le vin, les armes, de la poudre et du plomb. On dressa une tente près du canot; plus tard, on construisit une hutte.... Le 15 septembre, pendant qu'on travaillait, un matelot vit venir trois Ours d'inégale grosseur. Le plus petit demeura derrière un gros glaçon; les autres continuèrent d'avancer. L'un d'eux plongea la tête dans un cuvier où l'on avait mis de la viande à tremper. L'équipage tira, et l'animal tomba mort. L'autre Ours s'arrêta, comme ébahi, regarda fièrement son compagnon, le flaira, et, comme s'il eût reconnu le péril, il retourna sur ses traces. D'après l'ordre de Barentz, on ouvrit l'Ours mort, on lui ôta les entrailles, et on le plaça sur ses quatre jambes, pour le laisser geler dans cette posture, et le porter en Hollande, si l'on parvenait à dégager le vaisseau.

Le 23, on eut le malheur de perdre le charpentier; il fut enterré dans une fente de la montagne : on n'avait pu ouvrir la terre pour y creuser une fosse.....

L'équipage ne consistait plus qu'en seize hommes. 
Le 27, il gela si fort, que si quelqu'un mettait un clou dans sa bouche, comme il arrive souvent pendant le travail, il ne pouvait le tirer sans emporter la peau.....

Le 23 octobre, comme on était occupé à transporter les agrès sur des traineaux, Barentz vit derrière le vaisseau trois Ours qui s'avançaient. Il fit de grands cris, auxquels se joignirent ceux des matelots qui étaient avec lui. Mais les trois animaux n'en furent pas effrayés. Alors on résolut de se défendre. On trouva heureusement deux hallebardes; Barentz en prit une, et Girard de Veer l'autre. Les matelots coururent au vaisseau; mais, en passant sur la glace, un d'entre eux tomba dans une crevasse. Cet accident fit trembler pour lui; on ne douta point qu'il ne fût le premier dévoré. Cependant les Ours suivaient ceux qui couraient vers le vaisseau. D'un autre côté, Barentz et de Veer en firent le tour pour entrer par derrière. Le matelot tombé se releva de sa chute, et eut le bonheur de rejoindre l'équipage. Tout le monde était dans le navire.

Les Ours, furieux, cherchaient à monter sur le pont. On les arrêta d'abord avec des pièces de bois et divers ustensiles qu'on se hâta de leur lancer à la tête, et sur lesquels ils se précipitaient chaque fois, comme les chiens après les pierres qu'on leur jette. Il n'y avait point à bord d'autres armes que les deux hallebardes dont il vient d'être question. On voulut allumer du feu, brûler quelques poignées de poudre. Mais, dans la confusion, rien de ce qu'on entreprenait ne pouvait s'exécuter.

Cependant, les Ours revenant à l'assaut avec la même furie, on commençait à manquer d'ustensiles et de bois pour les amuser. Les Hollandais ne durent leur salut qu'au plus heureux des hasards. Barentz, réduit à l'extrémité, agissant par désespoir plutôt que par prudence, lança sa hallebarde contre le plus grand de ces animaux. L'Ours fut 
atteint sur le museau et si fortement blessé, qu'il jeta un grand cri et fit retraite tout de suite.

Les deux antres le suivirent, quoique d'un pas assez lent.....

Les Ours ne reparurent qu'avec le retour du soleil.

Le 6 avril, il en descendit un jusqu'à la porte de la hutte. Elle était ouverte. On se hâta de la fermer et de la soutenir. L'Ours s'en alla.

Cependant il revint deux heures après, et monta sur la hutte, où il fit un bruit effroyable. Il essaya de renverser la cheminée. On le crut plus d'une fois maitre de ce passage. Il déchira la voile dont elle était entourée. Enfin, il ne s'éloigna qu'après avoir fait un ravage extraordinaire.

Le mois suivant, pendant qu'on mettait la chaloupe en état de partir, parut un Ours énorme. Les pauvres marins rentrèrent aussitôt dans la hutte, et les plus habiles tireurs se distribuèrent les trois portes, attendant l'animal de pied ferme; un autre monta sur la cheminée avec son fusil. L'Ours marcha fièrement sur la hutte. Un coup de mousquet le renversa; on acheva aisément de le tuer. On trouva dans son ventre des morceaux entiers de Chien marin, avec la peau et le poil.

Le 30, les matelots, travaillant au radoub du vaisseau, furent surpris par un Ours, qui vint hardiment à eux. Tous prirent la fuite vers la hutte. L'animal les suivit, mais une salve de trois coups de fusil, qui portèrent tous, l'étendit mort sur la neige. Cette victoire coûta cher aux pauvres marins; car, avant dépecé la terrible bête, et en ayant fait cuire le foie, quils mangèrent avec plaisir, ils en furent tous malades. Trois, entre autres, parurent comme morts pendant quelques heures. (G. de Veer.)

Dans le voyage au Spitzberg de Manby, le capitaine 
Lewis, accompagné de cinq hommes, voulut attaquer un Ours blanc. A quarante pas environ de l'animal, quatre matelots firent feu en même temps et blessèrent le quadrupède. L'Ours, furieux, courut sur les assaillants, la gueule onverte. Comme il s'en approchait avec des hurlements épouvantables, le matelot et le capitaine, qui n'avaient pas tiré, firent feu et lui brisèrent l'épaule.

Avant qu'on eût eu le temps de recharger, l'Ours était tout près des chasseurs. Ceux-ci se sauvèrent vers le rivage. L'animal courait toujours, quoique boiteux. Il était sur le point de les atteindre, quand deux d'entre eux se jetèrent dans le bateau; les autres se cachèrent derrière des blocs de glace, et firent feu aussitôt qu'ils purent. Les nouvelles blessures de l'animal ne firent qu'augmenter sa rage. Enfin, il s'approcha de si près, que les marins sautèrent dans la mer, d'un roc perpendiculaire assez élevé. L'Ours sauta après eux, et il avait presque saisi un de ces pauvres matelots, lorsque, fort heureusement, les forces lui manquèrent, et il rendit le dernier soupir.

Quand on eut porté son corps sur le rivage, on constata qu'il avait reçu huit balles.

\section{V}

Le cri de l'Ours blanc ressemble plutôt, assure-t-on, à l'aboiement d'un chien enroué qu'au murmure grave des autres espèces. (Boitard.)

Ce quadrupède a de l'intelligence et de la sagacité.

Un Phoque reposait sur la glace, près d'un trou qui devait assurer sa fuite, en cas de péril. Un Ours, qui l'épiait, s'approche en silence et à couvert, aussi près qu'il pent. Il 
plonge alors dans la mer, gagne sous les flots le trou de la retraite, s'élance par ce trou, et saisit le malheureux Phoque.

Le capitaine d'un vaisseau baleinier voulait avoir une peau d'Ours blanc bien entière, et, par conséquent, il fallait prendre l'animal sans le tuer avec une arme à feu. Il imagina d'étendre sur la neige une corde avec un nœud coulant dans lequel il mit un appât. Un Ours qui rôdait sur les glaces des envirous fut attiré; il saisit l'insidieuse pâture, serra la corde, et l'une de ses pattes s'y trouva prise. Il parvint à se dégager à l'aide de l'autre patte, et emporta la provision pour la manger en lieu sûr.

On rétablit le piége. L’Ours revint, et, conservant le souvenir de ce qui lui était arrivé, il écarta prudemment la corde et saisit la proie.

Dans une troisième épreuve, la corde fut recouverte de neige et parfaitement cachée. On ne fut pas plus heureux.

Pour dernière tentative, on plaça l'appât au fond d'un trou assez profond, pour que l'Ours ne pût le prendre qu'en y plongeant la tête. On arrangea le nœud coulant autour de l'ouverture, toujours masquée par de la neige. Le succès semblait certain. Vain espoir! L'animal méfiant commenesa par enlever délicatement la neige, découvrit la corde, l'écarta prudemment, enleva l'appât, et disparut. (Mag. pittor.)

Scoresby prétend que, lorsqu'un Ours frappé réussit à fuir, il se retire derrière quelque éminence, et là, en sûreté, comme s'il avait connaissance de l'effet styptique du froid, il applique de la neige sur sa blessure avec la patte. 


\section{VI}

La femelle met bas au mois de mars. Elle fait habituellement un ou deux petits, rarement trois.

Les jeunes Ours blancs sont proportionnellement d'une petitesse remarquable.

L'attachement des femelles pour leurs petits leur inspire quelquefois un courage bien digne d'admiration.

Voici ce qui a été observé par la frégate sur laquelle le fameux Nelson commença sa carrière navale. Cette frégate se trouvait en 1773 dans les régions polaires. A l'aube du jour, on signala, du haut des hunes, trois Ours blanes qui marchaient sur la glace avec une grande vitesse, et qui se dirigeaient vers le vaisseau. On reconnut que c'était une femelle accompagnée de deux Oursons déjà presque aussi forts que leur mère. Tous les trois coururent vers un foyer où l'on avait jeté les restes d'un Morse. Ils en tirèrent les chairs que le feu n'avait pas encore consumées. La mère fit la distribution, donnant à ses petits la plus grosse part.

Les chasseurs embusqués saisirent ce moment pour faire feu sur les deux Oursons, qui restèrent sur la place. Ils tirèrent ensuite sur la mère, qu'ils atteignirent aussi, mais qui ne fut point abattue. Son désespoir eût ému les cours les moins accessibles à la compassion. Sans faire attention aux blessures dont elle était couverte, ni au sang qu'elle répandait, elle ne s'occupait que de ses deux petits, les appelait par des cris lamentables, plaçait devant eux la part de nourriture qu'elle s'était réservée et la leur dépeçait. Comme ils restaient immobiles, ses gémissements devinrent 
encore plus touchants. Elle essaya de relever les pauvres créatures, et, reconnaissant l'impuissance de ses efforts, elle s'écarta de quelques pas et renonvela ses appels. Retournant auprès des deux morts, elle lécha leurs blessures, et ne les quitta que lorsqu' elle fut bien convaincue qu'ils avaient perdu la vie.

Alors des hurlements épouvantables dirigés vers le vaisseau accusèrent les meurtriers, qui leur répondirent par une nouvelle décharge. La malheureuse mère vint expirer auprès de ses petits, léchant leurs blessures jusqu'au dernier moment.

\section{VII}

Les Our's blanes s'habituent facilement à nos ménageries.

Comme ils souffrent presque toujours de la chaleur, on leur jette de temps en temps mon seau d'eau fraiche sur le corps. On a soin d'entretenir près d'eux un bassin d'eau froide, daus lequel ils vont se mouiller le museau, se désaltérer ou se plonger.

Ceux du Jardin des plantes de Paris attirent constamment, devant leur fosse, un nombre considérable de curieux.

Ces animaux ont souvent une apparence haletante, comme les chiens dans l'été, lorsqu'ils viemnent de courir. Ils exécutent avec leur tète, leur cou et leur train de devant une sorte de balancement continuel qui captive d'abord l'attention par sa singularité, mais qui la fatigue bientôt par sa monotonie.

Dans la servitude, ces Ours ne se montrent susceptibles 
d'aucune éducation et d'aucun attachement. Ils conservent toujours leur sauvagerie brutale et stupide. (Boitard.)

Il paraît que cette espèce était connue des anciens. Cuvier pense que c'est un Ours blanc que Ptolémée Philadelphe fit venir à Alexandrie, et dont parlent Callixène le Rhodien et Athénée.

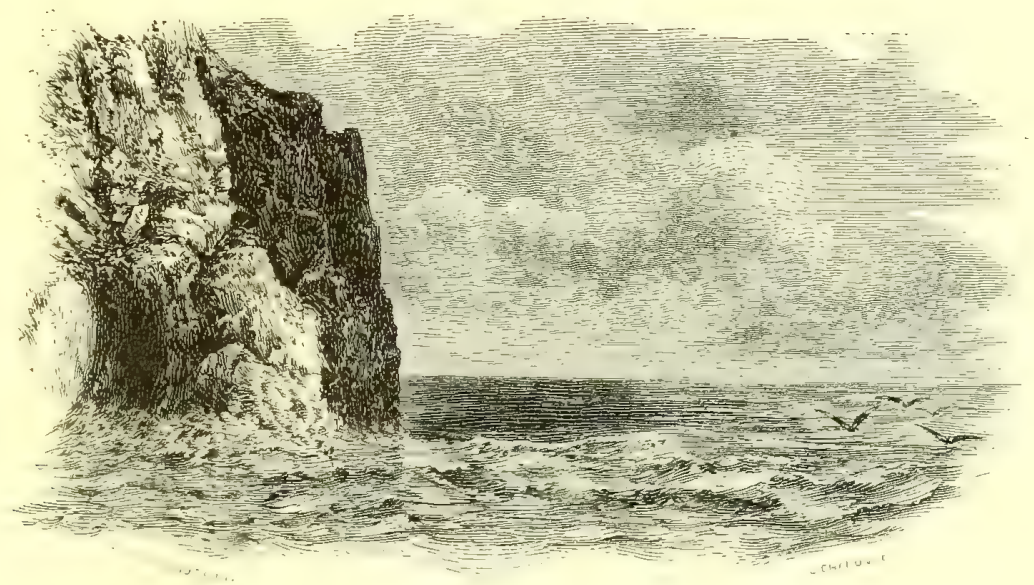





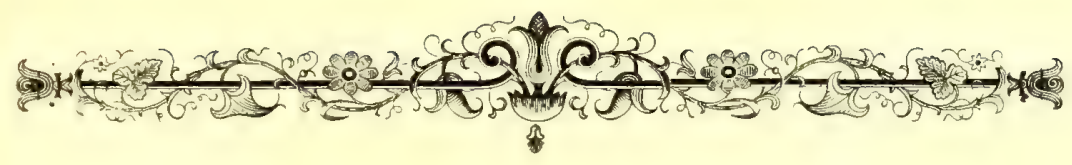

\section{TABLE DES CHAPITRES}

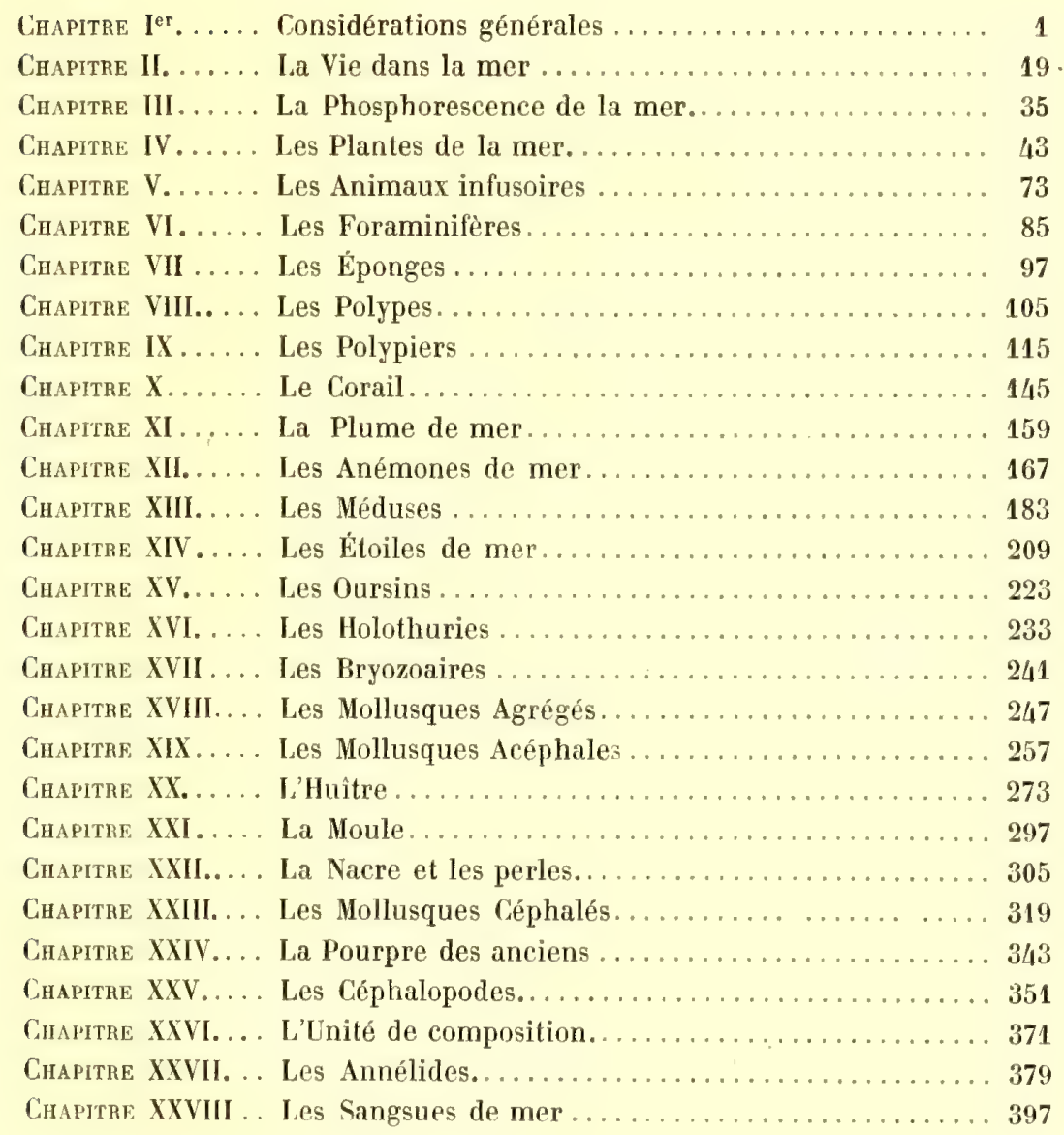


Chapttre XXIX... Les Zoonites...................... 405

Chaptre XXX.... Les Cimpip̀des .................... 415

ChaptTre XXXI... Les Rotifères...................... 425

Chapitre XXXII ... Les Crustacés ...................... 431

Chaprtre XXXIII .. Les Homards, les Iangoustes, les Chevrettes...... 447

Chapitre XXXIV .. Le Bernard l'ermite................... 457

Chapitre XXXV ... Les Poissons ....................... 469

Chapitre XXXVI . Le Hareng. ...................... 503

Chaptre XXXViI. . La Sardine ........................ 513

Chaptre XXXVIII. La Morue.......................... 521

Chapttre XXXIX . Le Thon........................... 529

Chapitre XL..... Les Tortues de mer....................... 537

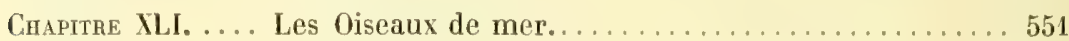

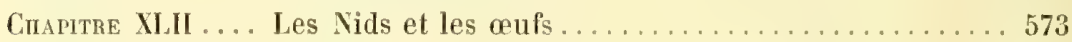

Cijaptrke Xlit.... Les Cétacés............................ 593

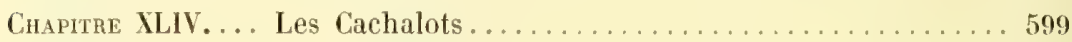

Cuapitre XLV . . . Les Dauphins ... . . . . . . . . . . . . . . . . . . 609

Cunpitre XlVl... La Baleine..........................619

C.haptre Xl.Vil ... Les Phoques........................... 635

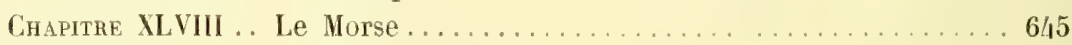

Chapitre XliX... La Loutre de mer..................... 653

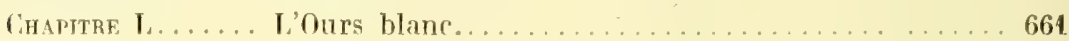

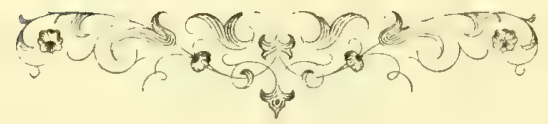




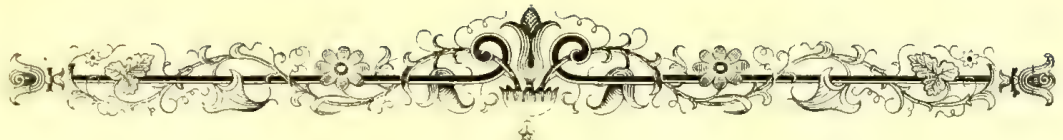

c.

\section{TABLE DES PLANGHES}

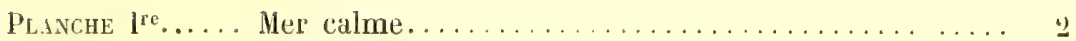

Playche II . . . Brisants.......................... 10

Planche III...... Flore de la mer ....................... 36

Planche IV..... Algues marines...................... 50

Planche V ...... Développement des Algues.................... 68

Planche V bis... Développement d'un Infusoire................ 82

Planche VI. ..... Radiolaires ......................... 94

Planche VII. ... Anthozoanthe parasite ................. 115

Planche VIII . . Corail . . . . . . . . . . . . . . . . . . . . . . 144

Planche IX..... Développement du Corail.................. 150

Planche $X \ldots \ldots$ Anémones de mer. ..................... 168

Planche XI...... Développement de la Méduse ................... 192

Pi.anche XII. . . Galéolaire orangée....................... 204

PLANche XIII .... Apolémie contournée................ Frontispice. 206

Planche XIV . . . Synapte de Duvernoy ...................... 238

Planche XV.... Animaux-mousse ....................... 242

Planche XVI ... Lima tenera .......................... 262

Planche XVII.... Mollusques nus.......................... 320

Planche XVIII... Développement d'un Mollusque............... 326

Planche XIX .... Mollusques nus........................ 340

Planche XX .... Céphalopodes ...................... 356

Ptanche XXI . . Annélides. . . . . . . . . . . . . . . . . . . . . 380

PLANche XXII.... Sabelle unispirale .................... 388

Puanche XXIII... Crustacés......................... 432

Planche XXIV... Pêche à la chevrette..................... 454

Planche XXV.... Combats de Bernards l'ermite................ 462

Planche XXVI... Poissons volants..................... 470 
PLANChe XXVII... Développement d'un poisson............... 492

Planche XXVIII. . Pêche de nuit (aviso le Sylphe relevant le chalut).... 496

PlaAnche XXIX ... Pêche à la Sardine..................... 516

PLanche XXX ... Goëlands argentés . . . . . . . . . . . . . . . 552

Planche XXXI ... Développement d'un oiseau................. 584

Péanche XXXII... Pêche à la Baleine.....................6 630

Planche XXXIII. . Otaries sur la plage..................... 642

Planche XXXIV.. Morses................................. 648

Planche XXXV... Ours blancs............................ 662

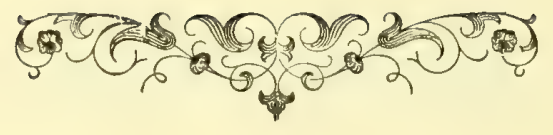




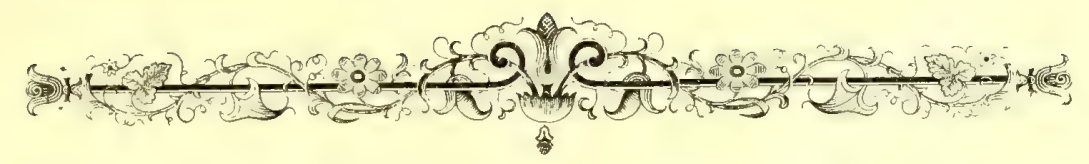

\title{
TABLE DES FIGURES
}

\author{
INTERCALÉES DANS LE TEXTÉ.
}

Acétabule marine.......... 59 Astéric vue en dessous et en

Acon ou pousse-pied. ........ 303 dessus............... 212

Agare de crmelin .......... 56 Astérie équestre.......... 243

Agalhistègues............ $87 \quad$ - mutilée.............216

Alariée............... 57 - violette........... 210

Albatros................ 556 Astrée................ 130

Albione épineuse........... 398 Astrophyte verruqueux........ 219

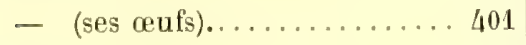

Baleine du Groenland.........6 620

Alcyonide............... 134 Baleine harponnée......... 628

Amibe protée............. 91 Bec-en-ciseaux (tête)......... 559

Amphacanthe cerclé.........4 481 Bernard l'ermite ..........458

Anatifes lisses............446 - (une habitation de)......460

Anchois ordinaire .........4 418 Béroé globuleux........... 196

Anémones de mer.......... 168 Botrylle doré ............ 251

- (leur naissance)........ 176 Brachions .............. 426

- de Couch............. 169 Branchellion de la Torpille..... 398

- cillet.............. 169 Cachalot grosse tête.......... 601

Anthéridies, leur insertion et leur $\quad-$ (dent de)...........604

émission............. 66 Callithamne granifère ....... 55

Autipathe .............. 125 Calmar commun ........... 352

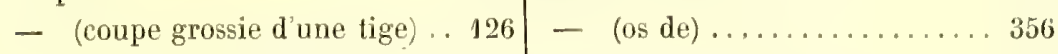

- grossi pour montrer les spi- Calmaret vermiculaire ........ 352

nules ............ 127 Campanulaire dichotome...... 120

- (polype grossi) ......... 126 Caryophyllie de Smith........ 130

Aquarium ............. 30 Caulerpe à f'euilles d'If....... 49

Araignée de mer.........4 435 Céphalopode ( $\propto u f s) \ldots . . . .457$

Ascidies sociales.......... 249 Chabot .............. 476

Aspect des glaces au pole...... 17 Chat de mer (ses ouls)........ 561 
Cirripède adulte............ 120

- jeune.

Cirroteuthis de Müller 354

Cladostèphe verticillée........ 48

chio boréale................. 341

Coffre triangulaire ........ 473

Concarneau (vue générale) ..... 500

Conceptacles à sporanges....... 65

- à anthéridies............ 60

cone damier.................. 332

Corail musique ........... 435

- rouge................ 145

- (son polype)............ 149

- (coupe du polypier)....... 153

- (décortication de la tige)... 148

Cormorans ordinaires......... 579

Coronule de la Baleine........ 424

Corophie à longues cornes ..... 438

Cothurnie d'eau douce........ 76

Coupe d'Isis................ 152

Crabe en pleine mue........ 432

- commun ............. 445

Delessérie rouge ........... 49

Dendronote arborescent....... 22/4

Diphye................. 204

Discorbine................. 89

Dragueurs................ 27

Echinoderme (larve).......... 220

Linallostègues.............. 87

Engins de pêche............ 432

Entomostègues............. 88

Éponge gant de Neptune....... 101

- sur une Algue ........... 99

- usuelle, très-grossie....... 102

Étoiles de mer.............. 209

Filets de pêche............ 25

Flustre foliacée ............ 245

Furculaires ............... 425

Geoffroy Saint-Hilaire (Étienne). . 375

Gérardie (polype de la)........ 428

- (coupe d'un polype)....... 128

Goëland à manteau gris........ 554

Gothe ................... 377

Gorgonide...............136

Grondin................. 483
Hareng (tête)................ 558

Hélicostègues .............. 88

Hirondelle de mer Pierre-garin. . 569

Holothurie élégante ......... 234

- tubuleuse ............. 233

- (pêche malaise) ......... 236

Homards (jeunes)............ 451

Huîtres. ................. 281

- banc artificiel........... 288

— jeunes ................ 283

- jeunes dans les fascines ... 289

Huningue (vue générale)....... 498

- (bassin d'élevage)......... 499

Hyale bordée ............. 342

- tridentée............ 342

Hydroméduse . . . . . . . . . . . . . 199

Iles à coraux..... . . . . . . . . . 143

Infusoires divers ........... 75

- (leur propagation)........ 81

- (leurs parasites)......... 82

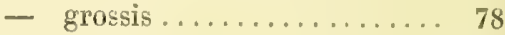

Janthine commune ....... 329-3/46

Lagoncule rampante.......... 242

Laminaires ................. 55

Langouste grainée......... 448

- (larves).............. 450

Laurencie pinnatifide......... 48

Lieberkuhnia de Wagener...... 92

Lizzia de Kolliker... . . . . . . . . . . 187

Loutre de mer............ 652

- femelle et son petit....... 655

Lucernaire campanule......... 181

Hacareux moine............ 575

Nacreuse................ 564

Madréporaires................ 129

Manchot de Patagonie......... 567

Harteau maillet............. 472

Méandrine.............. 13!

Méduse croisée.............. 183

- de Gaudichaud.......... 184

- aux beaux cheveux....... 185

- (leur naissance) ...... . . . 191

- (larves)............... 192

Microscope................ 73

- solaire .............. 74 
Miliole . . . . . . . . ....... 89 Pinne de la Méditerranée...... 317

Modiole lithophage ......... 262 Pinnothère des anciens ...... 465

- lithophages dans le rocher.. 265 Pintadine mère perle .......... 305

Monades............... 76 Plocamie plumeuse......... 50

Monocentre $d u$ Japon........ 473 Plongeon imbrim .......... 382

Morse et ses petits.........649 Plume de mer épineuse...... 160

Morue...............522 - (ses polypes) ......... 161

- (préparationà Terre-Neuve). 528 Plumes de mer (allégories) ..... 162

Moules (clayonnage chargé de)... 302 Polypes................. 105

- (pieux collecteurs du frai).. 301 - groupés ............110

Narwal............................. 107

Nautile commun (coquille) ..... 368 Polypier Actiniaire......... 117

Néréocystée ............... 58

Nérite polie............... 336

Noctiluque miliaire.......... 37

Octospore, son émission........ 66

Oiseau de tempete........... 557

Olive du Pérou.............. 331

Ombellulaire du Groenland...... 163

Ours blanc (tête)............. 664

Oursin livide............... 230

- (appareil buccal) ......... 228

- dans le rocher .......... 230

- grimpant contre les parois

d'un aquarium........... 226

- mamelonné............. 224

Padine paon ............. 40

Paille-en-queue phaéton ....... 572

Palmipède (pattes) .......... 552

Paramécies.................. 79

Pégase volant ............... 492

Pélican blane............... 590

Pentacrine d'Europe..........221

Perles et camées chinois artificiels. 308

Perroquet de mer (Macareux).... 575

Pelite Massue ............... 345

Pétrel damier............... 568

Pholade dans la pierre........ 204

Phoque ................. 643

Phosphorescence (allégorie)....

Physalie de l'océan Atlantique austral.

Physophore hydrostatique...... 205

Pingouin commun........... 565

- brachyptère.

- Bryozoaire.

139

- Hydraire.......... 146,140

Porcelaine cervine........... 332

Poritide............. 132, 133

Pourpre bouche de sang ....... 344

Ptérocère orangé............ 331

Radiolaire monozoa.......... 92

- polyzoa............... 93

Rémore ou Sucet........... 482

Rouget.............. 474

Salpe solitaire............ 255

Salpes phosphorescentes (chaînes de)................... 253

Sangsue dragon ............. 406

- médicinale (anatomie) ..... 507

Scorpène de l'île de France..... 471

Sèche élégante............... 355

- (œufs de)......... 337, 358

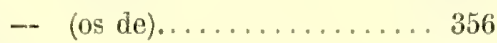

Sennal ................... 485

- sur un Palmier......... 484

Sertulaire........... 121, 138

- argentée............. 122

Spicules du Corail........... 147

- de Synapte............ 238

Squille mante............. 433

Stercoraire parasite.......... 571

Stichostègues............. 87

Taret commun.............. 269

Telline élégante............ 262

Térébelle coquillière ......... 393

565 Thalassiophyllum perforé...... 47

581 Thon.................. 530 
Thon (pêche du) .......... 531 |Varec vésiculeux ..........6 69

Tortues de mer............. 358 - porte-baies.......... 51

Tortue caouane ............ 359 Vélelle................ 198

_ caret............... 541 Virgulaire admirable ......... 463

- de $\operatorname{mer}($ tête).......... 542 Vogelberg.............. 588

Trichodesmie d'Ehrenberg..... 46 Volvoces................80

Tubicinelle de la Baleine..... 424 Zoanthe des Moluques........ 124

Tubulaire chalumeau........ 119 Zoć ................446

Tuile recouverte d'Huîtres ..... 292 Zoospores.............. 62

Vlve ................ 52 - (leur émission)........ 63

Vagues creuses............ 11 - (leur développement).... 64

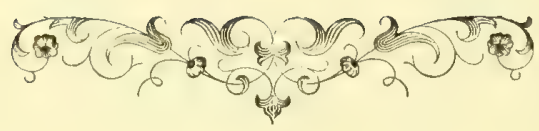




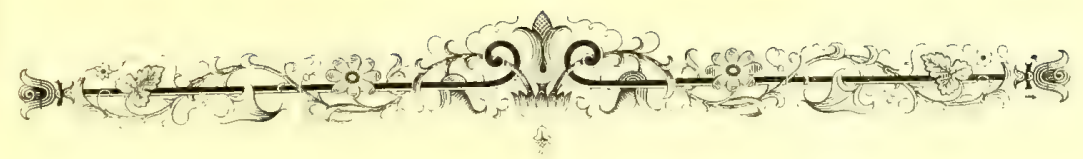

\section{TABLE ALPHABÉTIOUE}

Acétabule, 58 .

Actinies, 123.

Agare de Gmelin, 56.

Agaric androsacé, 59.

Aiguille de mer, 478, 495.

Aliriée, 57.

Albatros, 556.

Albione épineuse, 398.

Alcyonaires, 123.

Alcyonide, 134.

Algues, 44.

Alose, 492.

Amphacanthe cerclé, 481 .

Amphithoé rougeatre, 464 .

Amphorine d'Albert, pl. XIX, fig. 5, 325.

Anacharis du Canada, 53.

Anatifes, 415.

- lisses, 416.

Anchois, 518.

Anémones de mer, 168.

- Anthée, 180.

- crassicorne, 174, 180.

Anémone de Couch, 169.

- déchirée, 177.

- equina, 176.

- œillet, 169, 178, 180.

— pâquerette, 176.

- parasite, 462.

- rousse, 174, 180.

Anguille, 473.

Anhinga, 563.

Animaux-mousse, 241.

Annélides, 378.

- dorsibranches, 381, 383.

- tubicoles, 381, 387.

Anthéridie, 61, 66.

Anthérozoïdes, 64, 66 .

Anthozoanthe parasite, 137.

Antipathes, 123, 125.

Aphrodite hérissée, 385.

Aplysie, 320.

Aquarium, 28.

Araignée de mer, 434.

Archer, 487.

Arches, 261, 267.

Argonaute papyracé, 356. 
Ascidies sociales, 2/49.

- laineuse, 266.

- solitaire, 258.

Asteria rubens, 216.

Astérie, 39, 210.

Astrées, 130.

Astropecten spinulosus, 214.

Astrophytes, 218.

Aurélie phosphorique, 39.

P

Balanes, 423.

Baleine, 619 .

- du Groenland, 620.

- fausse, 626.

- franche, 619.

Baudroie, 470, 487.

Bebryce tendre, 135.

Bec-en-ciseaux, 559, 564.

Bénitier, 267.

-. (grand), 317.

Bernard l'ermite, 457.

Biphores, 253.

Bonite, 482 .

Botrylle doré, 251.

Brachions, 426 .

Branchellions, 398 .

Bryopsis, 63.

Bryozoaires, 241.

Bullée, 340.

(i)

Cachalot, 599 .

— grosse tête, 599 .

- macrocéphale, 599.

Callithamne granifere, 55.

Calmars, 351, 352.

- de Bouyer, 366.

- (os de), 356.
Calmaret vermiculaire, 352 .

Camées chinois, 308.

Cames, 261.

Campanulaire, 118, 120, 140 .

- dichotome, 120.

Canard eider, 590.

- macreuse, 564.

- sauvage, 585.

Carpe, 493.

Caryophyllie de Smith, 130.

Caulerpe à feuilles de Vigne, 54.

- il feuilles d'If, 49.

Céphalopodes, 351.

- (œufs de), 357.

Cétacés, 593.

Chabot, 476 .

Chat de mer, 501.

Chauffe-soleil, 470.

Chenille de mer, 385.

Cheval marin, 645.

Chevaux chenilles, 478.

Chevrettes, 4/3, 447.

Chien de mer, 470, /77.

Cirratules, 382.

Cirripèdes, 415.

- (jeunes), 420 .

- (adultes), 420 .

Cirroteuthis de Müller, 353, 354.

Cladostèphe verticillée, 48 .

Clavelade, 470.

Clio boréale, 340 .

Coffre triangulaire, 473.

Coin-coin, 479.

Concarneau, 500.

Conceptacle, 64, 65, 66.

Cone damier, 332.

- cedonulli, 332.

Coquette, 474.

Corail, 145, 147.

- musique, 135.

- (spicules), 147. 
Cormorans, 575, 579.

- de Bougainville, 464.

- de Gaimard, 464.

Cornes d'Ammon, 369.

Cornet de postillon, 369 .

Cioronules, 423.

- de la Baleine, 424.

Corophie à longues cornes, 437.

Cothurnie, 76.

Crabe Boccace, 436.

- caramote, 455.

- commun, 432 .

— étrille, 455 .

- nika, 455 .

- squinado, 455 .

- tourteau, 439, 455 .

Crustacés, 431.

Culcite discoilde, 218.

I)

Dattes de mer, 203.

Dauphin, 609.

Daurade, 470, 474.

Delessérie rouge, 49.

Dendronote arborescent, 323, 324 .

Dromie globuleuse, 463 .

E

Echinodermes, 224.

- (larves), 220.

Éléphant marin, 645 .

Éolides, 323.

Eolis Ferrani, 325.

Épaulard, 611.

- à tête ronde, 612.

Épinoche, 491.

Epispore, 67.

Eschares, 244.
Espadon, 489.

Esturgeon, 491, 493.

Étoiles de mer, 210.

- équestre, 213.

- rougentre, 211.

- violette, 210.

Eunice géante, 384.

- sanguine, $380,384$.

Exanche, 470 .

Exocet, 483.

\section{$\mathrm{F}$}

Filou, 487.

Flamant, 682.

Flet, 470 .

Flustre, 244.

- foliacée, 245.

Fou, 576 .

- varié, 568.

Frégate, 569.

Fucus vésiculeux, $65,66,67$.

Fulmar, 562, 576, 689.

Furculaires, 425.

Fuseau, 330.

\section{G}

Galatée striée, 229.

Gastéropodes, 320.

Gérardie, 127, 128.

- de Lamarck, 118.

Gland de mer, 423.

Glauque, 322 .

Gobies, 491.

Goëlands, 553.

- argenté, 554, 688, 689 .

- i manteau noir, 575 .

- modeste, 563.

Goëmons, 69 
Ciorgonides, 136.

- (spicules), 136.

Grenadier, 470.

Grimotée de Durville, 434.

- sociale, 434.

Grondin, 483.

Guillemot à capuchon, 575 .

- à miroir blanc, 575 .

- bridé, 582.

\section{H}

Haligenia, 62, 64.

Hareng, 503.

Harle, 558.

Hassar, 485, 494.

Hérisson de mer, 224.

Hermelles, 387.

Hippocampe, 482, 491.

Hirondelle de mer, 568,680 .

- à longue queue, 580 .

- fuligineuse, 559.

- Pierre-garin, 565.

Holothurie, 233.

- élégante, 234.

- frondeuse, 235.

- guam, 237.

- trépang, 236.

- tubuleuse, 233.

- (pêche), 237.

- (spicules), 238.

Homards, 436, 447.

- jeunes, 451.

Huître, 261, 273.

- commune, 284.

- de Cancale, 284.

- de Marennes, 284.

- d'Ostende, 284.

- en crête, 284.

- jeunes, 283.
Huître lamelleuse, 284.

- pelocestiou, 284.

- pied-de-cheval, 284.

- plissée, 284.

- rosacée, 284.

- verte, 294.

Huîtrier, 438, 580.

Huningue, 498.

Hyale bordée, 342 .

- tridentée, 342.

Hydre verte, 108.

Infusoires, 73.

lles à coraux, 143 .

Isis, 137, 151.

Janthine, 304 .

- commune, 329, 346.

Jarretière, 474.

L

Lagoncule rampante, 242.

Laitue de mer, 53.

laminaires, 55 .

Laminaria digitata, 36.

- saccharina, 36.

Langouste, 447.

- jeune, 450.

Lanterne d'Aristote, 227.

Lapadelles, 428.

Laurencie pinnatifide, 48.

Lessonia, 62.

Lessonia fuscescens, pl. IV, fig. 7, 36.

- ovata, pl. IV, fig. 8, 36.

Licorne de mer, 615.

Lièvre de mer, 320. 
Limace, 373.

- agreste, 337.

Lime, 263.

Littorine, 330.

Lizzia de Kölliker, 187.

Loup de mer, 478.

- marin, 636.

Loutre de mer, 653.

- enhydre, 654.

Lucernaire campanule, 181.

Luidies, 211.

- ciliaire, 215.

\section{M}

Macareux moine, $575,577$.

Macrocystis Humboldtii, pl.IV, fig. 6,36 .

- luxurians, pl. IV, fig. 9, 36.

Hadrépores, 129.

Nalarmat cuirassé, 470.

Manches de couteau, 263.

Manchot, 562, 566.

- de Patagonie, 567.

Maquereau, 474, 493.

Marsouin, 609.

Marteau maillet, 473.

Méandrines, 131.

Méduses, 39, 183.

- aux beaux cheveux, 185.

- brune tachetée, 187.

- croisée, 183.

- de Gaudichaud, 184.

- (larves), 192.

Mélite, 151.

Mer de lait, 37.

- de neige, 37.

Modiole, 265.

- lithophage, 262.

Mollusques, 39.

- Acéphales, 257.
Mollusques Agrégés, 247.

Monade, 77.

Monocentre du Japon, 473.

Morse, 645.

Morue, 521.

Mouette argentée, 575.

- à pieds bleus, 576 .

- à trois doigts, 575, 576.

Moules, 265, 297.

Muge, 470.

- à grosses lèvres, 493.

Myrionema, 62.

Mytiliculture, 301.

\section{$\mathrm{N}$}

Nacre, 305.

Narwal, 615, 616.

Natice mille points, 330 .

Nautile, 366.

- commun, 367.

Nephthys, 384.

Néréides, 39.

- à deux lignes, 462.

Néréocystées, 57.

Nérites, 326.

- polie, 336.

Noctiluque miliaire, 37.

Nonnats, 519.

Nordcaper, 620.

0

Océanie, 190.

Octospore, 65,67 .

OFufs de Bulla cornea, pl. XIX, fig. 7, 340 .

Oie de mer, 609.

Oiseaux de mer, 551.

- (développement), pl. XXXI, 584. 
Oiseaux de lempête, 556 .

- maritimes ordinaires, 553.

- nageurs, 563.

- riverains, 553.

- voiliers, 552.

Olive du Pérou, 331.

Ombellulaire, 163.

Ophidiaster miliaris, 217.

Ophiures, 218.

Orbe, 482.

- arbre épineux, 488.

Oreille de mer iris, 306,317 .

Orque, 611.

Oscillatoire, 41.

Ostiole, 65 .

Ostréiculture, 287, 289.

Otaries, pl. XXXIII, 642.

Ours blanc, 661, pl. XXXV, 662.

- polaire, 661.

Oursin, 223.

- comestible, 223, 231.

- granuleux, 231.

- livide, 226, 231.

- mamelonné, 224.

- melon, 231.

Oxybate de Brandes, 218.

\section{$\mathrm{P}$}

Padine paon, 36, 49.

Paille-en-queue, 570, 572.

Patelle, 328, 330.

Palmier marin, 220.

Palmipèdes, 551.

Pandore, 261.

Paramécie, 79.

Pastenague, 470, 487.

Pégase volant, 492.

Pèlerines, 261, 263.

Pélican, 559, 565.
Pélican blane, 560 .

- thagus, 564.

Pennatule épineuse, 160.

- (ses polypes), 161.

Pentacrine d'Europe, 221.

Périspore, 67.

Perles, 305, 307.

- chinoises, 308.

Perroquet de mer, 575.

Pétoncle, 267.

Pétrel, 556, 562.

- damier, 566, 568.

Pétricole, 263.

Phaéton, 570.

Phanérobranche à chevrons, pl. XIX, fig. 2, 340 .

- doriforme, pl. XIX, fig. 1, 340.

Phéosporées, 62.

Pholade, 263, 264.

- datte, 40 .

Phoque, 635.

- capuchonné, 641.

- commun, 636.

- de Gmelin, 641.

- de Müller, 641.

- de Schreber, 641.

- otarie, 641 .

Phosphorescence, 36 .

Phyllangia americana, pl. X, fig. 3, 168.

Phyllodoce lamelleuse, 380 .

Phyllosome, 450 .

Pingouin, 562, 565, 575 .

- commun, 565.

- brachyptère, 581.

- (grand), 581.

Pinne, 265, 267.

- marine, 217.

Pinnothère, 464.

Pisciculture, 495.

Plagiure, 596.

Planaire, 410. 
Planorbe, 391.

Plie, 493.

Plocamie plumeuse, 50 .

Plongeon imbrim, 582.

Plume de mer, 159.

Pluvier à collier, 585.

Poissons, 469.

- (développement), pl. XXVII, 492. Poisson chirurgien, 490.

- docteur, 490 .

- rolants, pl. XXVI, 470 .

Polycère, pl. XIX, fig. 3, 340.

- p1. XIX, fig. 4, 340.

- pI. XIX, fig. 6, 340.

Polypes, 107.

- d'eau douce, 108.

- de la mer, 113.

Polypiers, 43, 115.

- Actiniaires, 118, 123.

- Alcyonaires, 134.

- Hydraires, 118.

Pontobdelle, 398.

Porcelaine, 332.

- cervine, 332.

- orange, 332.

Porcellane large pince, 443.

Poritide, 132.

Porpite, 191.

Poulpe, 351.

Pourpre, 343.

- bouche de sang, 344, 349 .

- teinture, 334, 345, 349 .

Ptérocère orangée, 331.

Ptéropodes, 340.

Puffin, 576.

Pyrosome, 252.

li

Raie, 478, 487.

Rascasse, 483, 487 .
Rémore, 485.

Requin, 475, 495.

Revés, 547.

Rocher, 345.

- droile épine, 345 .

- fascié, 345, 350 .

- hérisson, 345, 350 .

- petite massue, 345, 350 .

Rorqual, 626.

Rotifères, 425.

- commun, 429.

Rouget, 474, 493.

\section{$S$}

Sabelle fasciculaire, pl. XXI, fig. 7, 386.

- perforante, pl. XXI, fig. 8, 386.

- triangulaire, pl. XXI, fig. $9,386$.

- unispirale, pl. XXII, 388.

Sagartia coccinea, pl. X, fig. 2, 168.

- chrysosplenium, pl. X, fig. 17, 168.

- rosea, pl. X, fig. 7 et 13, 168.

- sphyrodeta, pl. X, fig. 8 et $9,168$.

_ venusta, pl. X, fig. 14, 168.

_ viduata, pl. X, fig. 6, 168.

Salicoques, 455 .

Salpe, 253.

Sangsues de mer, 397.

- (anatomie), 407.

-. dragon, 406.

Sardine, 543.

- (pêche de la), pl. XXIX, 548.

Sargasses, 52.

Saumon, 492.

Saxicave, 263.

Scalaire précieuse, 332.

Scie, 489.

Scorpène de l'île de France, 471.

scyllée, 322. 
Scyllée pélagique, 322.

Seches, 351.

- élégante, 355 .

- (œufs), 358.

- (os), 366 .

Sennal, 483.

- sur un palmier, 484.

Serpules, 388.

- étoilée, 389.

- géante, 389 .

Sertulaires, 121.

- argentée, 123.

Sertularia falcata, 123.

Sertularien, 138.

Sey, 505 .

Sole, 493.

Solen, 263.

Soufflet, 487.

Souffleur, 596.

Sphærozoum ovodimare, 93.

- italicum, pl. VI, fig. 6, 94.

Spirorbe nautiloïde, 391.

Sporanges, 64.

Spores, 61, 64.

Stercoraire parasite, $558,570,592$.

Stolephorus Risso, 519.

Stylifère, 225.

Sucet, 486, 488, 547.

Synapte de Duvernoy, 238.

Syncorines, 140.

\section{'}

Tadorne, 578.

Tænia, 408.

Tambour, 479 .

Taret, 268.

- commun, 259.

Télescope, 470.

Telline, 261, 267.

- élégante, 262.
Térébelles, 391.

- Amphitrite, 395.

- Amphitrite éventail, 396.

- coquillière, 393.

- Emmaline, 394, pl. XXI, fig. 1,386.

- tisserand, 394.

Térébratule tête de serpent, pl. VIII, fig. 8,144 .

Tête de Méduse, 220.

Tétraspore, 61.

Thalassiophyllum, 47.

Thécidie de la Méditerranée, pl. VIII, fig. 7, 144 .

Thon, 479, 520 .

Torpille, 490 .

Tortue de mer, 537.

- Caouane, 539, 541 .

- caret, 539.

- franche, 539.

- Midas, 539.

Trichodesmie rouge, 45 .

- d'Ehrenberg, 45.

Tridacne, 261.

- gigantesque, 266.

Trigle, 483.

- milan, 484.

Tritonie, 321.

Tubicinelles, 423 .

- de la Baleine, 424 .

Tubiporides, 135.

Tubulaires, 118, 119.

- chalumeau, 118.

- rameuse, 119.

Turbo rugueux, 334.

Turbot, 306, 493, 502.

Tu rris négligée, 186.

\section{$\mathrm{U}$}

Ulve, 52.

Unité de composition, 372. 
Varec à siliques, 70 .

- dentelé, 70.

- porte-baies, 51.

- porte-poire, 56.

- turbiné, 54.

Veau marin, 636.

Vénus, 261.

Virgulaire, 163.

Volvoce, 80.

Zées, 474.

Zoanthaires, 123.

Zoanthes, 123.

- des Moluques, 123.

Zoé, 445.

Zoonites, 406.

Vermilies sociales, pl. XXI, fig. 6, 386 .

Vieille, 479.

Zoospores, 61, 62, 63 .

Zostéracées, 71.

Zostères marines, 71.

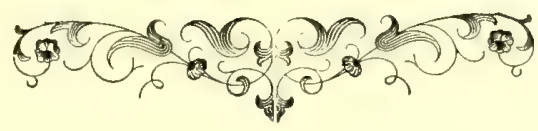

Paris. - Imprimerie de E. MARtinet, rue Mignon, 2 




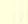




